Schriften zur Göttinger Universitätsgeschichte Band 1

Detlef Busse

\title{
Engagement oder Rückzug?
}

Göttinger Naturwissenschaften im Ersten Weltkrieg

Der Königliche Kurator Aer

Georg August-Universitāt.

- $\overline{25} 1 \%$.

Var Mimifter hor prillepue

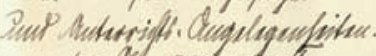

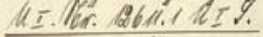

2)

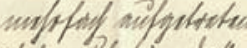

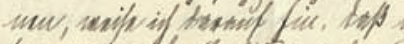

leppuither ti:

Amolie nitpinnfumo fortue.

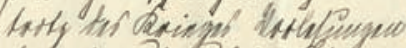

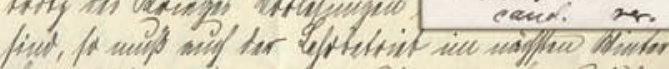

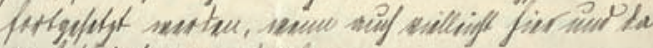

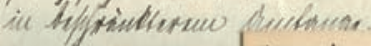

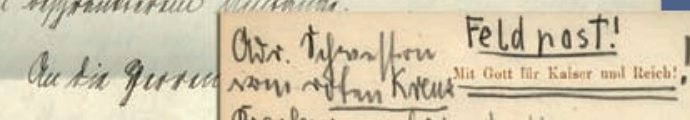

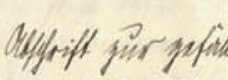

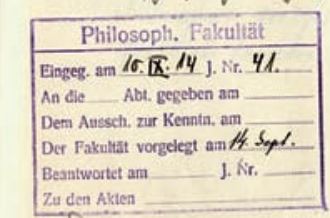
Srestan inforing du die

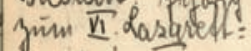

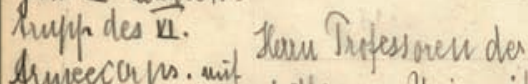

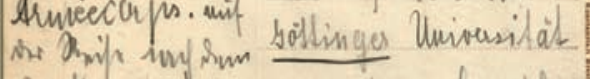
hosflum.

Zu den Akten

6 com

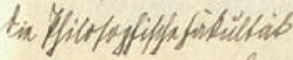

(ini. 

This work is licensed under the Creative Commons License 2.0 "by-nc-nd", allowing you to download, distribute and print the document in a few copies for private or educational use, given that the document stays unchanged and the creator is mentioned. Commercial use is not covered by the licence. 
Erschienen als Band 1 in der Reihe „Schriften zur Göttinger Universitätsgeschichte“ im Universitätsverlag Göttingen 2008 


\section{Detlef Busse}

\section{Engagement oder Rückzug?}

Göttinger Naturwissenschaften im Ersten Weltkrieg

Schriften zur Göttinger

Universitätsgeschichte

Band 1

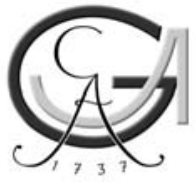

Universitätsverlag Göttingen

2008 


\section{Bibliographische Information der Deutschen Nationalbibliothek}

Die Deutsche Nationalbibliothek verzeichnet diese Publikation in der Deutschen Nationalbibliographie; detaillierte bibliographische Daten sind im Internet über $<$ http://dnb.ddb.de> abrufbar.

\section{Herausgeber der Reihe}

Prof. Dr. Hermann Wellenreuther

Prof. Dr. Nicolaas Rupke

Institut für Wissenschaftsgeschichte der Georg-August-Universität Göttingen

Dieses Buch ist auch als freie Onlineversion über die Homepage des Verlags sowie über den OPAC der Niedersächsischen Staats- und Universitätsbibliothek (http://www.sub.uni-goettingen.de) erreichbar und darf gelesen, heruntergeladen sowie als Privatkopie ausgedruckt werden. Es gelten die Lizenzbestimmungen der

Onlineversion. Es ist nicht gestattet, Kopien oder gedruckte Fassungen der freien Onlineversion zu veräußern.

Satz und Layout: Detlef Busse

Titelabbildung: Schreiben des Kurators der Universität an die Philosophische Fakultät vom 10. September 1914: Abschrift eines Erlasses des Kultusministers vom 9. September 1914. Universitätsarchiv Göttingen, Signatur: UAG.Phil.Fak.II.96 10.09.1914.

Feldpostkarte von Krankenschwestern eines Lazaretttrupps. Universitätsarchiv Göttingen, Signatur: UAG.Sek.38.1 24.8.1914.

Fotografie des Zoologiestudenten Richard Bielert.

Handschriftenabteilung der Niedersächsischen Staats- und Universitätsbibliothek Göttingen, Signatur: SUB.Gött.HSD.Cod. Ms. Ehlers 137 Nr. 4, B1.5

(C) 2008 Universitätsverlag Göttingen

http://univerlag.uni-goettingen.de

ISBN: 978-3-940344-20-5

ISSN: $1866-5144$ 


\section{Schriften zur Göttinger Universitätsgeschichte}

Im Zusammenhang mit den Feierlichkeiten zum 250sten Jahrestag der Gründung der Georgia Augusta Universität wurde im Jahr 1987 auf Anregung des damaligen Präsidenten der Universität, Prof. Dr. Norbert Kamp, und mit finanzieller Unterstützung der Universität vom Vandenhoeck \& Ruprecht Verlag die Reihe „Göttinger Universitätsschriften“ gegründet. Die Mehrzahl der Studien, die im Zusammenhang mit dem Jubiläum entstanden, erschienen in dieser Reihe; so mancher Göttinger Kollege und an Universitätsgeschichte interessierte Bürger wird sie in seinem Bücherschrank stehen haben.

Die Reihe war wichtig und nützlich. „War“, denn sie wurde am 7. Juli 2001 vom Verlag eingestellt, als die Universität die finanzielle Förderung der Reihe beendete. Seitdem erscheinen Veröffentlichungen zur Göttinger Universitätsgeschichte wieder an unterschiedlichen Orten, was nicht zuletzt dem Bild von der Georgia Augusta als einem für die Wissenschafts- und Universitätsgeschichte wichtigen Forschungsgegenstand abträglich ist. Dies ist sicherlich kein besonders glücklicher Zustand für eine Hochschule, die in ihrem Archiv und in der Handschriftenabteilung ihrer Bibliothek über reiches Material zu ihrer Geschichte, ihren Forschungsaktivitäten und zu den Verknüpfungen mit der städtischen ebenso wie allgemein der deutschen Geschichte verfügt. 
Die Herausgeber haben sich deshalb entschlossen, die Gelegenheit der Veröffentlichung einer Dissertation zur Geschichte der Universität während des Ersten Weltkrieges zu nutzen und eine neue Reihe zur Göttinger Universitätsgeschichte ins Leben zu rufen. Sie soll nicht nur Arbeiten, die in Göttingen entstehen, sondern auch solchen, die an anderen Orten zur Göttinger Universitätsgeschichte geschrieben wurden, eine Heimstatt bieten.

Dabei verstehen wir den Begriff „Universitätsgeschichte“ nicht eng, sondern weit: Arbeiten zu Forschungstrends in naturwissenschaftlichen wie geistes- und sozialwissenschaftlichen Bereichen wollen wir darunter ebenso verstehen wie Untersuchungen kultur- und mentalitätsgeschichtlicher Fragen vom 18. bis zum 21. Jahrhundert. Die Reihe soll natürlich auch Quelleneditionen aufnehmen. Bei den eingereichten Manuskripten, gleichgültig, ob es sich um Dissertationen, Habilitationen oder andere handelt, ist nur eines wichtig: hervorragende Qualität. Jedes Manuskript wird in der Regel von auswärtigen Gutachtern gewürdigt. Die letzte Entscheidung über die Veröffentlichung liegt jedoch bei den beiden Herausgebern.

Das Selbstverständnis einer Universität manifestiert sich auch und vor allem in den Reflexionen über sich selbst und in der Beschäftigung ihrer Angehörigen mit ihrer Universität; das Bild der Universität wird zugleich wesentlich geprägt durch kritische Analyse ihrer Leistungen in der Vergangenheit zu Wissenschaften, aber auch ihrer Beiträge zu den Entwicklungen der Gesellschaft und des Staates. Wie dies in ertragreicher, anregender und kritischer Weise geschehen kann, zeigt der erste Band dieser Reihe. Als Herausgeber der Reihe wünschen wir uns aus allen Bereichen der Universität viele solcher Arbeiten. Dem Göttinger Universitätsverlag sind wir dankbar dafür, dass er unsere Anregung zur Gründung der Reihe bereitwillig aufgegriffen hat und fördert. 


\section{Inhalt}

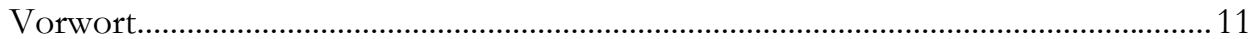

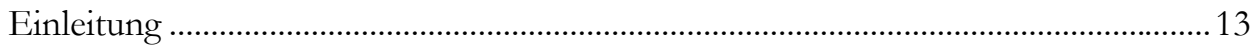

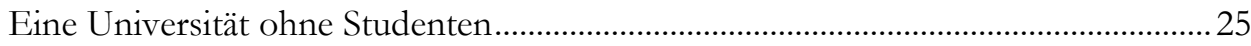

Die Veränderung der Studierendenzahlen ...........................................................2 27

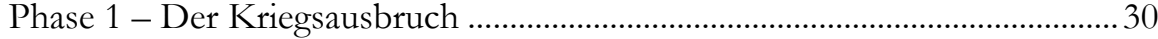

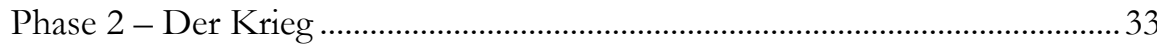

Phase 3 - Das Kriegsende .................................................................................... 36

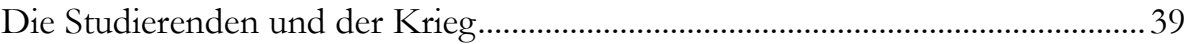

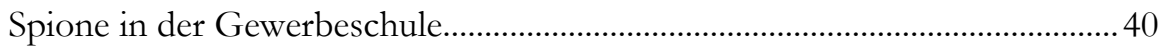

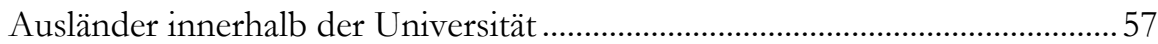

Neue Chancen für Studentinnen ........................................................................

Hilfen für Studierende mit und ohne Uniform ...................................................... 84

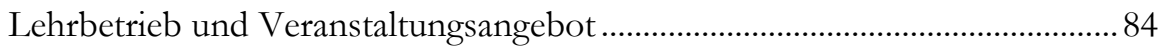

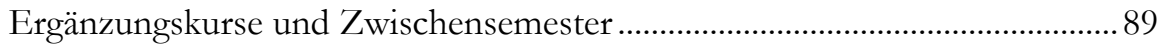

Feldpost und Liebesgaben...............................................................................111

Zwischen Sparzwang und neuen Chancen - die finanzielle Situation.......................129

Universitätsinstitute und Seminare........................................................................130

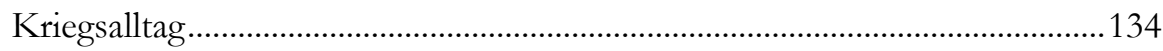

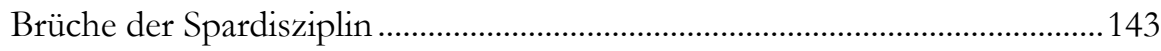

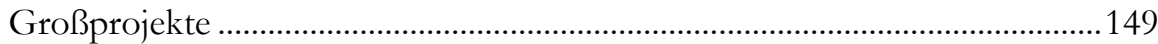

Zusammenfassung ........................................................................................152

Die Modellversuchsanstalt Ludwig Prandtls ........................................................155

Die Entwicklung bis zum Ersten Weltkrieg ....................................................... 155

Neue Möglichkeiten durch den Krieg .............................................................163

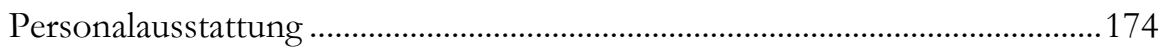

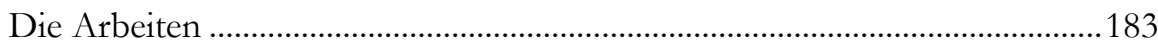

Kriegsende und Bewertung des Gesamtbilds..................................................194 
Schweigen und Forschen - die Rolle der Dozenten ................................................205

Professoren im Kriegseinsatz ...............................................................................209

Rückwirkungen auf das Kollegium ..............................................................226

Göttinger Naturwissenschaftler im internationalen Propaganda-Krieg.............237

Politische Stellungnahmen und ihre Folgen .......................................................243

Das Klima außerhalb der Universität...................................................................260

Spenden sammeln und Streife gehen ..............................................................226

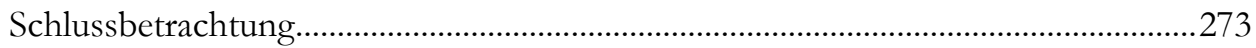

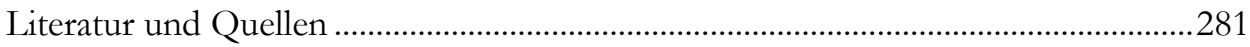

Ungedruckte Quellen..........................................................................................28

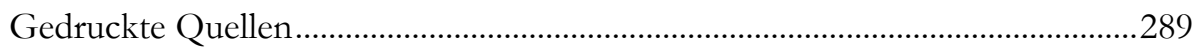

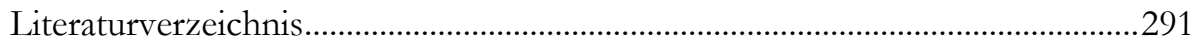

\section{Abbildungen}

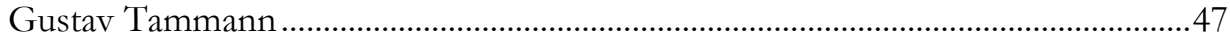

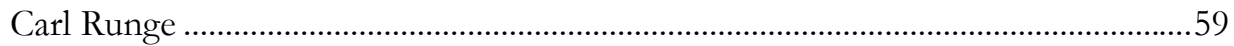

Emmy Noether …………………………………………………………..... 82

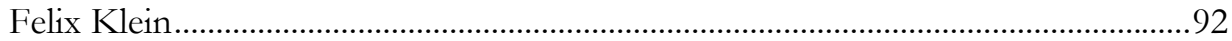

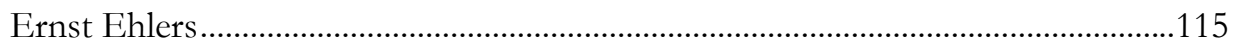

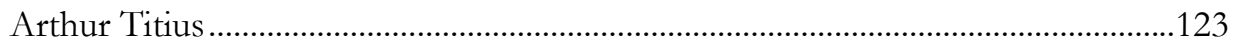

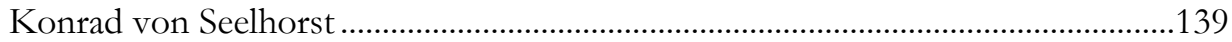

Ludwig Prandtl...................................................................................................159

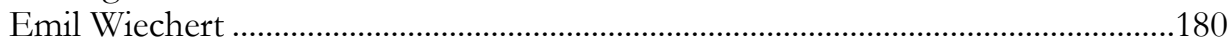

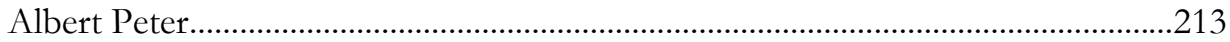

Johannes Hartmann................................................................................................22

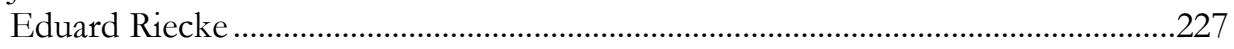

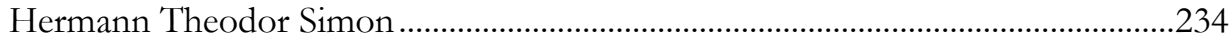

Robert von Hippel..............................................................................................24

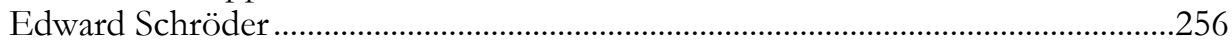

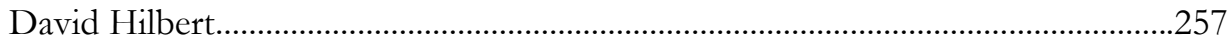




\section{Statistiken}

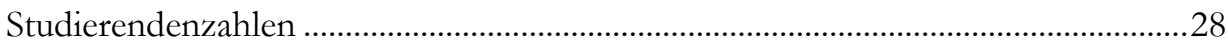

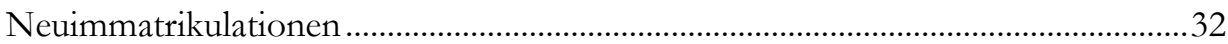

Prozentuale Verteilung männlicher und weiblicher Studierender ............................35

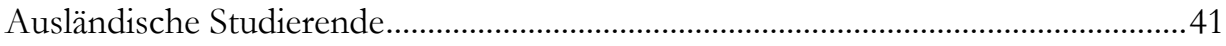

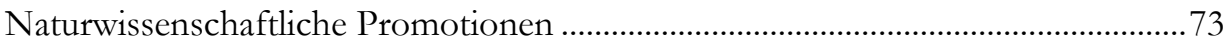

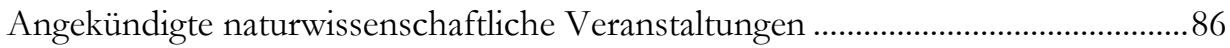

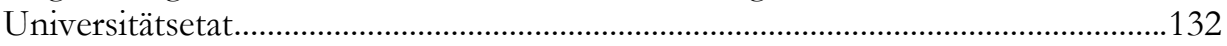

Naturwissenschaftliche Dozenten im Militärdienst .............................................210

Prozentuale Verteilung der sich in Göttingen oder Militärdienst befindenden

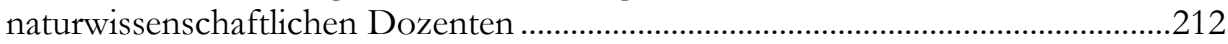





\section{Vorwort}

Die vorliegende Arbeit wurde im Wintersemester 2004/2005 von der Philosophischen Fakultät der Georg-August-Universität Göttingen unter dem Titel Eine Universität im Kriegszustand: Göttinger Naturwissenschaften im Ersten Weltkrieg als Dissertation angenommen. Für den Druck wurde die Arbeit in geringem Umfang überarbeitet und ergänzt.

An erster Stelle gilt mein besonderer Dank Prof. Dr. Hermann Wellenreuther als dem Betreuer und Erstgutachter meines Dissertationsprojekts. Er hat meine Arbeit von den Anfängen bis zur Drucklegung mit Engagement begleitet, gefördert und durch zahlreiche Anregungen und konstruktive Kritik auf einem guten Weg gehalten. Prof. Dr. Nicolaas Rupke bin ich für die Erstellung des Zweitgutachtens zu Dank verpflichtet. Darüberhinaus danke ich Professor Wellenreuther und Professor Rupke für die Aufnahme meiner Arbeit als ersten Band in die neugeschaffene Schriftenreihe Scbriften zur Göttinger Universitätsgeschichte.

Der Leiter des Universitätsarchivs Göttingen, Dr. Ulrich Hunger, hat mir, im Rahmen meiner Tätigkeit als Hilfskraft in seinem Archiv, immer freien Zugang zu den Quellen gewährt und mir in vielen Gesprächen wertvolle Hinweise gegeben, wofür ich ihm sehr dankbar bin. Dem Deutschen Zentrum für Luft- und Raumfahrt danke ich für die Erlaubnis, sein Göttinger Archiv benutzen zu dürfen. Außerdem danke ich allen Mitarbeitern und Mitarbeiterinnen der Bibliotheken und Archive, die ich im Rahmen meiner Recherchen besucht habe. 
Ferner danke ich allen Teilnehmern des Examens- und DoktorandenKolloquiums Prof. Dr. Wellenreuthers. In ihrem Kreis wurden meine Thesen in angenehmer und fruchtbarer Diskussion auf die Probe gestellt. Insbesondere danke ich Dr. Frauke Geyken und Dr. Claus Heinrich Gattermann, mit denen ich den regelmäßigen Erfahrungsaustausch sehr genossen habe. Dr. Sabine Heerwart und meiner Schwester Ellen Busse danke ich für die Stunden, die sie mit Durchsicht und Korrektur dieser Arbeit verbracht haben, an deren Gelingen sie großen Anteil haben.

Zuletzt möchte ich meiner Familie danken. Meine Eltern Edith und Albert Busse haben die Entstehung dieser Arbeit in jeder Hinsicht unterstützt und gefördert. Meinem Vater war es nicht mehr vergönnt, den Abschluss der Drucklegung zu erleben. Meinem Sohn Jakob und meiner Frau Barbara, die gleichzeitig meine erste und strengste Korrekturleserin war, gebührt besonderer Dank für die unendliche Geduld, die sie mit mir hatten und die Zeit, in der sie meine Aufmerksamkeit mit dieser Arbeit teilen mussten.

Hardegsen, im Januar 2008 


\section{Einleitung}

Ich habe diese Acte angelegt, damit unsere Acten nicht wieder so dürtiges Material haben wie 1866 u. 1870. Ich bin überzengt, dass diese Acten später einmal historisches Interesse haben werden. Gassmann Universitätssekretär. ${ }^{1}$

Diese kurze Notiz, die der Universitätssekretär Gassmann 1914 auf den Einband der von ihm angelegten Akte Weltkrieg 1914 niederschrieb, war eine der wichtigsten Anregungen für diese Untersuchung. Aus heutiger Perspektive, 90 Jahre nach Ausbruch des Ersten Weltkrieges, wird deutlich, dass hier ein einfacher Verwaltungsbeamter ahnte, dass ihm persönlich und seinem alltäglichen Leben dramatische Einschnitte bevorstanden. Ein wichtiger Teil seines Alltags war die GeorgAugust-Universität Göttingen.

Gassmann wünschte sich Unterlagen, Dokumente und Zeugnisse über diesen Krieg, der gerade begann und er bedauerte, dass solche Aufzeichnungen über die für das damalige deutsche Selbstverständnis so wichtigen Kriege der Jahre 1866 und 1870 nicht vorlagen. ${ }^{2}$ Wenn er die Worte „unsere Acten“ gebraucht, so dachte er dabei nicht an sich persönlich, nicht an seine Kollegen und auch nicht an das Universitätssekretariat. Er meinte vielmehr die Universität als Ganzes und er war sich sicher, dass es unbedingt zu dokumentieren galt, wie ein großer Krieg,

UAG.Sek.38.1 Notiz auf dem Einband der Akte „Weltkrieg 1914“ des Universitätssekretariats.

2 Einen guten Eindruck vermittelt: Ulrich, Bernd; Vogel, Jakob; Ziemann, Benjamin (Hrsg.): Untertan in Uniform. Militär und Militarismus im Kaiserreich 1871-1914. Quellen und Dokumente. Frankfurt a.M. 2001. 
so wie er ihn kommen sah, diese betraf und wie sie auf ihn reagierte. Ausdrücklich spricht Gassmann vom „historischen Interesse“, weil er fest damit rechnete, dass einmal die Frage gestellt werden musste, wie die Universität Göttingen den Ersten Weltkrieg erlebte, wie sie daran teilnahm und wie er sie veränderte. Dies soll Gegenstand dieser Arbeit sein. Es wird das Bild einer Institution in der Zeit zwischen August 1914 und November 1918 nachgezeichnet werden.

Eine Grundvoraussetzung dafür ist, sich darüber klar zu werden, was die Universität zu dieser Zeit eigentlich war, oder besser: welches Gebilde Gassmann vor Augen hatte, wenn er das Wort „unsere“ gebraucht. Der Universitätssekretär war Mitglied einer Korporation und als solche soll die Universität in dieser Arbeit verstanden werden. Die Hauptbestandteile dieser Korporation bildeten zunächst die Studierenden und die Dozenten, also die Gemeinschaft von Lehrenden und Lernenden. Diese Gemeinschaft ist jedoch nicht ohne einen dritten Bestandteil, nämlich die Universitätsverwaltung denkbar, der auch der Universitätssekretär Gassmann angehörte. Diese Verwaltung regelte das Miteinander der Lehrenden und Lernenden, sie stellte die dafür notwendige Infrastruktur in Form der Universitätsgebäude und der übrigen Einrichtungen zur Verfügung und war vor allem für die Beschaffung und die Verteilung aller finanziellen Mittel zuständig. Analog zu den drei Hauptbestandteilen der Korporation Universität wird diese Arbeit aufgebaut sein: Den Studierenden, den Dozenten und der administrativen Ebene der Universität wird jeweils ein Abschnitt gewidmet werden.

Jeder dieser drei Bestandteile der Universität stand in seinem eigenen Kontext und war somit in ganz unterschiedlicher Art und Weise vom Krieg betroffen. Dieser Tatsache soll hier durch die getrennte Betrachtung Rechnung getragen werden, allerdings stets unter der gemeinsamen zentralen Fragestellung, welche Auswirkungen der Erste Weltkrieg durch sein Einwirken auf die einzelnen Bestandteile auf die Korporation Universität als Ganzes hatte.

Dadurch, dass die Studierenden sich im Normalfall im wehrfähigen Alter befanden und damit die Hauptlast des Kriegsdienstes zu tragen hatten, muss sich in ihrem Fall die Betrachtung zunächst darauf konzentrieren, die durch den Krieg hervorgerufenen quantitativen Veränderungen festzustellen. In einem weiteren Schritt soll dann die Frage gestellt werden, wie sowohl die noch in Göttingen anwesenden Studierenden als auch ihre im Kriegsdienst stehenden Kommilitonen den Krieg erlebten und welche Bedeutung die Universität gerade für letztere trotz des Kriegsalltags behielt. Die Rückwirkungen des Krieges auf die Universität sollen außerdem anhand der Gruppen der Studentinnen und der ausländischen Studierenden betrachtet werden.

Die sich hieran anschließende Betrachtung der Universitätsverwaltung wird sich zunächst auf eine Analyse der Veränderung der finanziellen Ausstattung von Instituten und Seminaren stützen. Besonderes Augenmerk wird hierbei auf einer möglichen Diskrepanz zwischen rüstungsrelevanten und nicht rüstungsrelevanten Fächern liegen, um feststellen zu können, ob und in welchem Umfang kriegstech- 
nische Forschung innerhalb der Universität betrieben wurde. In diesem Kontext wird außerdem eine ausführliche Beschäftigung mit der aerodynamischen Modellversuchsanstalt, dem späteren Kaiser-Wilhelm-Institut für Strömungsforschung stehen, die zwar nicht Teil der Universität war, aber doch räumlich und personell eng mit ihr verknüpft.

Den wichtigsten Faktor bei der Untersuchung der Gruppe der Hochschullehrer werden deren interne Konflikte darstellen. Mit Hilfe einer Analyse dieser Konflikte soll der Frage nachgegangen werden, ob der Krieg das Klima innerhalb des Kollegiums der Universität veränderte oder beschädigte und wie auf etwaige Brüche reagiert wurde. Ferner wird gezeigt werden, in welchem Maße Dozenten sich auch außerhalb der Universität einsetzten und welchen Reaktionen sie sich dort ausgesetzt sahen.

Die für diese Arbeit relevante Forschungsliteratur untergliedert sich zunächst in zwei Bereiche: Dem des Ersten Weltkrieges allgemein und dem Bereich, der sich im weitesten Sinne mit den Universitäten beschäftigt. Insbesondere der Erste Weltkrieg steht in jüngster Zeit, etwa seit der zweiten Hälfte der 1990er Jahre, wieder verstärkt im Mittelpunkt des Interesses. Als große Gesamtdarstellung ist hier beispielsweise Michael Salewskis Der Erste Weltkrieg zu nennen, ${ }^{3}$ aber auch das gleichnamige, bereits 1984 von Wolfgang Michalka herausgegebene Sammelwerk ist immer noch aktuell. ${ }^{4}$ Eine Sonderstellung nimmt jedoch die 2003 erschienene Enzyklopädie Erster Weltkrieg 5 ein, die in zahlreichen Beiträgen den aktuellen Stand der Forschung zusammenfasst und zu allen wichtigen Schlagwörtern des Ersten Weltkrieges detailliert Stellung nimmt.

Einen besonders großen Raum unter den aktuellen Untersuchungen nimmt indes die Frage nach der Wahrnehmung des Weltkrieges durch die Öffentlichkeit und seiner Wirkung auf diese innerhalb der Kriegführenden Nationen ein. ${ }^{6}$ Vor allem die über Jahre gültigen Thesen einer ungeteilten Kriegsbegeisterung im August 1914 wurden von der neueren Forschung hinterfragt und relativiert. ${ }^{7}$ Gerade der Vergleich Deutschlands mit seinen Kriegsgegnern eröffnet hier zahl-

Salewski, Michael: Der Erste Weltkrieg. Paderborn 2003.

4 Michalka, Wolfgang (Hrsg.): Der Erste Weltkrieg: Wirkung, Wahrnehmung, Analyse. München 1994. (= Serie Piper; 1927).

5 Hirschfeld, Gerhard; Krumeich, Gerd; Renz, Irina (Hrsg.): Enzyklopädie Erster Weltkrieg. Paderborn u.a. 2003. Historiographischer Überblick und Literaturauswahl: Hirschfeld, Gerhard; Krumeich, Gerd: Die Geschichtsschreibung zum Ersten Weltkrieg. In: Hirschfeld, Krumeich, Renz (Hrsg.): Enzyklopädie. 2003. S. 304-315.

6 Chickering, Roger: Imperial Germany and the Great War, 1914-1918. Cambridge 1998. (= New Approaches to European History).

7 Verhey, Jeffrey: Der „Geist von 1914“ und die Erfindung der Volksgemeinschaft. Aus dem Engl. von Jürgen Bauer. Hamburg 2000. 
reiche neue Aspekte, wie Thomas Raithel ${ }^{8}$ dies für Frankreich und Sven Oliver Müller ${ }^{9}$ für Großbritannien zeigen.

Betrachtet man hochschulgeschichtliche Arbeiten, muss zunächst festgestellt werden, dass in den frühen Werken aus der Zeit des Nationalsozialismus erwartungsgemäß keine wissenschaftlich kritische Auseinandersetzung mit dem Ersten Weltkrieg stattfindet. Die Arbeit Walter Grüners über die Universität Jena im Ersten Weltkrieg ${ }^{10}$ oder der entsprechende Beitrag Karl Brandis im Göttinger Kriegsgedenkbuch ${ }^{11}$ sind aus heutiger Perspektive eher als Quelle für die Rezeption und Instrumentalisierung des August 1914 oder des Langemarck-Mythos einzuordnen.

Erst seit den 1970er Jahren ist eine Zunahme universitätsgeschichtlicher Forschungen zu beobachten. Bei genauerer Durchsicht überrascht allerdings, dass eine eingehende Beschäftigung mit der Bedeutung des Ersten Weltkrieges für die Hochschulen und Universitäten bisher häufig unterblieb. Zu den wenigen Ausnahmen gehört hier die informative aber sehr kurz gefasste Darstellung Andreas Anderhubs über die Universität Gießen im Ersten Weltkrieg. ${ }^{12}$ Meist wird sich im Rahmen der Betrachtung größerer Zeiträume der Geschichte einer Universität auf die Schilderung kriegsspezifischer Teilaspekte beschränkt, wie etwa Sylvia Paletschek dies in ihrer Arbeit über die Universität Tübingen im Kaiserreich tut. ${ }^{13}$ Bettina Gundler wählt das Jahr 1914 als Ausgangspunkt ihrer Arbeit über die Technische Hochschule Braunschweig, in der sie unter anderem auf die Beziehungen zwischen den Technischen Hochschulen und der Rüstungsindustrie- und Forschung im Ersten Weltkrieg eingeht. ${ }^{14}$ Hans Liermann schildert die Geschichte der Universität Erlangen im Kriegsjahrzehnt, widmet dem Krieg aber lediglich 14 Seiten. ${ }^{15}$ Einen deutlich größeren Untersuchungszeitraum deckt Peter Moraw im

8 Raithel, Thomas: Das „Wunder“ der inneren Einheit: Studien zur deutschen und französischen Öffentlichkeit bei Beginn des Ersten Weltkriegs. Bonn 1996. (= Pariser Historische Studien; 45).

9 Müller, Sven Oliver: Die Nation als Waffe und Vorstellung: Nationalismus in Deutschland und Großbritannien im Ersten Weltkrieg. Göttingen 2002. (= Kritische Studien zur Geschichtswissenschaft; 158).

10 Grüner, Walter: Die Universität Jena während des Weltkrieges und der Revolution bis zum Sommer 1920. Ein Beitrag zur allgemeinen Geschichte der Universität. Jena 1934.

11 Brandi, Karl: Die Universität im Kriege. In: Saathoff, Albrecht (Hrsg.): Göttinger Kriegsgedenkbuch 1914-1918. Göttingen 1935. S. 145-152.

12 Anderhub, Andreas: Das Antoniterkreuz in Eisen. Zur Geschichte der Universität Gießen während des Ersten Weltkrieges. Gießen 1979.

13 Paletschek, Sylvia: Die permanente Erfindung einer Tradition. Die Universität Tübingen im Kaiserreich und in der Weimarer Republik. Stuttgart 2001.

14 Gundler, Bettina: Technische Bildung, Hochschule, Staat und Wirtschaft: Entwicklungslinien des Technischen Hochschulwesens 1914-1930. Das Beispiel der TH Braunschweig. Hildesheim 1991. (= Veröffentlichungen der Technischen Universität Carolo-Wilhelmina zu Braunschweig; 3).

15 Liermann, Hans: Die Friedrich-Alexander-Universität Erlangen 1910-1920. Neustadt a.d. Aisch 1977. (=Schriften des Zentralinstituts für Fränkische Landeskunde und allgemeine Regionalforschung an der Universität Erlangen-Nürnberg; 16). 
Rahmen seiner Kleinen Geschichte der Universität Gießen 1607-1982 ab, in der sechs Seiten dem Ersten Weltkrieg vorbehalten sind. ${ }^{16}$

Bis heute stellt einzig die Arbeit Andrea Wettmanns über die Universität Marburg hier eine Ausnahme dar. ${ }^{17}$ Die ausführliche und detailreiche Darstellung der Heimatfront Universität an der Philipps-Universität steht auf einer breiten Quellenbasis und gliedert sich in zwei Hauptbestandteile: Der Analyse der Marburger Verhältnisse stellt Wettmann eine sorgfältige Darstellung der preußischen Hochschulverwaltung und Bildungspolitik voran. Diese, selbstverständlich auch für die ebenfalls preußische Universität Göttingen einschlägige Darstellung, zählt zu den großen Verdiensten von Wettmanns Arbeit. Andere Monographien, die sich mit einzelnen Hochschulen in der Zeit des Ersten Weltkrieges befassen, fehlen bisher.

Bis zu Wettmanns Arbeit stand fast ausschließlich die Gruppe der Hochschullehrer im Fokus historischer Beschäftigung mit dem Thema Universität. Fritz Ringer prägte für sie bereits 1969 das Schlagwort der „deutschen Mandarine“.18 Maßgebend sind hier aber nach wie vor die Arbeiten Klaus Schwabes, insbesondere der ebenfalls 1969 erschienene Band Wissenschaft und Kriegsmoral, ${ }^{19}$ der die Rolle der deutschen Professoren im Ersten Weltkrieg beleuchtet, und der fast zwanzig Jahre später von Schwabe herausgegebene Sammelband Deutsche Hochschullehrer als Elite, der den Zeitraum von 1815 bis 1945 abdeckt. ${ }^{20}$ Diesen Arbeiten folgten weitere Untersuchungen die sich auf eine intensive Beschäftigung mit der Teilnahme der deutschen Professoren am internationalen Propagandakrieg, dem so genannten Krieg der Geister, der die Kämpfe auf den Schlachtfeldern begleitete, beschränkten. ${ }^{21}$

16 Moraw, Peter: Kleine Geschichte der Universität Gießen 1607-1982. Gießen 1982.

17 Wettmann, Andrea: Heimatfront Universität. Preußische Hochschulpolitik und die Universität Marburg im Ersten Weltkrieg. Köln 2000. (= Abhandlungen zum Studenten- und Hochschulwesen; 9).

18 Ringer, Fritz: The decline of the German mandarins: the German academic community 18901933. Cambridge 1969. In deutscher Übersetzung: Ringer, Fritz: Die Gelehrten: der Niedergang der deutschen Mandarine 1890-1933. Stuttgart 1983. Siehe auch: Ringer, Fritz: Das gesellschaftliche Profil der deutschen Hochschullehrerschaft 1871-1933. In: Schwabe, Klaus (Hrsg.): Deutsche Hochschullehrer als Elite: 1815-1945. Boppard am Rhein 1988. (=Deutsche Führungsschichten in der Neuzeit; 17. Büdinger Forschungen zur Sozialgeschichte, 1983) S. 93-104.

19 Schwabe, Klaus (Hrsg.): Wissenschaft und Kriegsmoral: die deutschen Hochschullehrer und die politischen Grundfragen des 1. Weltkriegs. Göttingen u.a. 1969.

20 Schwabe (Hrsg.): Deutsche Hochschullehrer. 1988.

21 Brocke, Bernhard vom: „Wissenschaft und Militarismus“. Der Aufruf der 93 „An die Kulturwelt!“ und der Zusammenbruch der internationalen Gelehrtenwelt im Ersten Weltkrieg. In: Calder, William M. (Hrsg.): Wilamowitz nach 50 Jahren. Festschrift Ulrich von WilamowitzMöllendorf. Darmstadt 1985. S. 649-719. Flasch, Kurt: Die geistige Mobilmachung: die deutschen Intellektuellen und der Erste Weltkrieg. Ein Versuch. Berlin 2000. Mommsen, Wolfgang J. (Hrsg.): Kultur und Krieg: Die Rolle der Intellektuellen, Kuenstler und Schriftsteller im Ersten Weltkrieg. München 1996. (= Schriften des Historischen Kollegs: Kolloquien; 34). UngernSternberg, Jürgen; Ungern-Sternberg, Wolfgang: Der Aufruf ,An die Kulturwelt!'. Das Manifest der 93 und die Anfänge der Kriegspropaganda im Ersten Weltkrieg. Stuttgart 1996. (= Historische Mitteilungen: Beiheft 18). 
Für den Bereich der Studierenden, ihrer Lebens- und Studienbedingungen, ihrer sozialen Zusammensetzung und dem Verbindungswesen ist besonders auf die Arbeiten Konrad H. Jarauschs zu verweisen, der 1984 seine Gesamtdarstellung Deutsche Studenten 1800-1970 veröffentlichte. ${ }^{22}$ Darüber hinaus existieren mit den Untersuchungen Sigrid Bias-Engels ${ }^{23}$ und Manfred Studiers ${ }^{24}$ Werke, die einen Einblick in das studentische Leben dieser Zeit ermöglichen, aber gerade im Hinblick auf den Ersten Weltkrieg viele Fragen offen lassen. Dieses ist der Arbeit Daniela Siebes hingegen nicht vorzuwerfen, die sich mit den ausländischen Studierenden an der Universität Gießen beschäftigt, von denen es ihr gelingt, ein detailliertes Bild zu zeichnen. ${ }^{25}$

So wichtig die genannten Arbeiten zu den Studierenden und den Dozenten auch sind, tragen sie doch den Mangel der fehlenden Verknüpfung dieser Gruppen untereinander und mit der Universität als Institution in sich; ihnen ist gemein, dass sie weitgehend personenfokussiert geschrieben sind. Die Institution Universität bleibt vielfach ganz unberücksichtigt oder tritt deutlich hinter einzelne Personen, meist Professoren, zurück. Man kann sich Andrea Wettmann nur anschlieBen, wenn sie die bisherige Beschäftigung mit dem Thema Universität als eine Beschränkung auf die „Untersuchung von Teilpopulationen der Universität, also [...] der Gelehrten- und Studentengeschichte“ beschreibt und beklagt, „dass sich die deutsche Universitätsgeschichtsschreibung allgemein schwer damit tut, Universitäts- als Institutionengeschichte zu betreiben." 26

Diese Verengung des Blickwinkels ist auch für die Beschäftigung mit der Universität auf internationaler, europäischer Ebene charakteristisch. In besonderem Maße steht hier der Zusammenbruch der internationalen Gelehrtenrepublik und dessen Auswirkungen auf die Hochschulen der deutschen Kriegsgegner im Mittelpunkt des Interesses, während die Rückwirkungen des ersten Weltkriegs auf Studierende, Forschung und Lehre kaum thematisiert werden. Eindrucksvolles Beispiel hierfür ist der jüngst erschienene, von Walter Rüegg herausgegebene

22 Jarausch, Konrad H. (Hrsg.): The Transformation of Higher Learning 1860-1930. Expansion, Diversification, Social Opening, and Professionalization in England, Germany, Russia, and the United States. Stuttgart 1983. Jarausch, Konrad H.: Students, Society, and Politics in Imperial Germany. The Rise of Academic Illiberalism. Princeton 1982. Jarausch, Konrad H.: Deutsche Studenten. 1800-1970. Frankfurt a.M. 1984. (= Neue Historische Bibliothek, Edition Suhrkamp 1258, Neue Folge 258).

23 Bias-Engels, Sigrid: Zwischen Wandervogel und Wissenschaft: zur Geschichte von Jugendbewegung und Studentenschaft 1896-1920. Köln 1988. (= Edition Archiv der Deutschen Jugendbewegung; 4).

24 Studier, Manfred: Der Corpsstudent als Idealbild der Wilhelminischen Ära: Untersuchungen zum Zeitgeist 1888 bis 1914. Schernfeld 1990.

25 Siebe, Daniela: Ausländische Studenten in Gießen (1900-1949). Akzeptanz, Umwerbung und Ausgrenzung. Gießen 2000.

26 Wettmann: Heimatfront. 2000. S. 11-12. 
dritte Band der History of the University in Europe. ${ }^{27}$ Nicht nur das Kapitel The Mathematical and the Exact Sciences ${ }^{28}$ streift den Ersten Weltkrieg nur in wenigen Zeilen, sondern sogar die Kapitel Student Movements ${ }^{29}$ und Teachers ${ }^{30}$ klammern ihn weitgehend aus. Lediglich Notker Hammerstein widmet sich in dem von ihm verfassten Schlussabschnitt ${ }^{31}$ dem Verhältnis zwischen Krieg und Universitäten. Allerdings beschränkt auch er sich fast vollständig auf den Krieg der Geister und den aus ihm resultierenden Zusammenbruch der internationalen Gelehrtenrepublik. Dieser Zusammenbruch ist auch einer der Hauptuntersuchungsgegenstände des Beitrags J. M. Winters Oxford and the First World War zum achten Band der großen History of the University of Oxford, für den Gleiches gilt. ${ }^{32}$

Die vorliegende Arbeit soll durch die ausdrückliche Einbeziehung aller die Institution Universität konstituierenden Gruppen diesem Defizit entgegenwirken. Besonderes Schwergewicht wird in dieser Untersuchung auf die naturwissenschaftlichen Fächer gelegt werden. ${ }^{33}$ Die Universität Göttingen hatte bereits seit den 1880er Jahren einen intensiven Ausbau zu einem bedeutenden und international anerkannten Zentrum der Mathematik und der Naturwissenschaften erfahren. Die Georgia Augusta war, in Anknüpfung an eine bis in die Jahre ihrer Gründung zurückreichende Tradition fortschrittlicher naturwissenschaftlicher Forschung, ${ }^{34}$ dazu auserwählt worden, in Preußen einen naturwissenschaftlichen Schwerpunkt zu bilden. Dies war Teil einer Initiative des preußischen Kultusministeriums, zum Zweck einer effektiveren Wissenschaftsförderung fachspezifische

27 Rüegg, Walter (Hrsg.): A History of the University in Europe. Volume III: Universities in the nineteenth and early twentieth Centuries (1800-1945). Cambridge 2004.

28 Bockstaele, Paul: The Mathematical and the Exact Sciences. In: Rüegg (Hrsg.): A History. 2004. S. 493-518.

29 Gevers, Lieve; Vos, Louis: Student Movements. In: Rüegg (Hrsg.): A History. 2004. S. 269-362.

30 Klinge, Matti: Teachers. In: Rüegg (Hrsg.): A History. 2004. S. 123-162.

31 Hammerstein, Notker: Epilogue: Universities and War in the twentieth Century. In: Rüegg (Hrsg.): A History. 2004. S. 637-672.

32 Winter, J. M.: Oxford and the First World War. In: Harrison, Brian (Hrsg.): The History of the University of Oxford. Volume VIII. The Twentieth Century. Oxford 1994. S. 3-25. Zwar berücksichtigt Winter auch die Studierendenzahlen und das Leben an der Universität während des Krieges. Sein kurzer Beitrag wirkt jedoch gerade im Vergleich zum beeindruckenden Umfang der History of the University of Oxford zu wenig ausführlich. In den zahlreichen folgenden Kapiteln wird der Krieg nahezu vollständig ausgeblendet.

33 Als Naturwissenschaften sollen hier die Fächer bezeichnet werden, die bis einschließlich Sommersemester 1922 die mathematisch-naturwissenschaftliche Abteilung der philosophischen Fakultät bildeten und danach als mathematisch-naturwissenschaftliche Fakultät selbstständig wurden. Hierzu gehörten Mathematik, Chemie, Physik, Zoologie und Botanik, außerdem Geographie und Geologie. Anders als heute gehörten aber auch die Psychologie und die Ethnologie zu den Naturwissenschaften. Die bedeutendste Abweichung zum heutigen Zustand stellt jedoch der stetig wachsende agrarwissenschaftliche Bereich dar, der besonders seit Beginn des 20. Jahrhunderts eine immer bedeutendere Rolle spielte.

34 Die Reihe berühmter Göttinger Naturwissenschaftler ist lang und beginnt mit dem Physiker Georg Christoph Lichtenberg. Unter anderem lehrten in Göttingen der Chemiker Friedrich Wöhler, der Physiker Wilhelm Weber und der Mathematiker Karl Friedrich Gauß. 
Zentren zu bilden. Der bedeutendste Protagonist bei der Errichtung dieses Systems war der Ministerialdirigent im preußischen Kultusministerium Friedrich Theodor Althoff. Er setzte sich auch für die Berufung des Mathematikers Felix Klein nach Göttingen ein, der hier 1896 seine Arbeit aufnahm. Felix Klein war es, der durch sein enormes wissenschaftsorganisatorisches Talent und seine zahlreichen Kontakte weit über die Grenzen seines Fachgebiets hinaus den geplanten Ausbau vor Ort vollendete. Dabei beschritt Klein teilweise völlig neue Wege. Er förderte die so genannten angewandten Wissenschaften und setzte sich für einen engeren Kontakt zwischen Universität und technischer Hochschule ein. Nicht zuletzt betrat er auch durch seine Bemühungen, finanzielle Unterstützung aus Industrie und Wirtschaft zu gewinnen, sehr erfolgreich Neuland. Es folgten zahlreiche Institutsneugründungen und Neueinrichtungen von Lehrstühlen. ${ }^{35}$ Dieser Ausbau erreichte gegen Ende der 1920er und Anfang der 1930er Jahre, noch nach dem Tod Felix Kleins, seinen Höhepunkt, ehe er 1933, unter anderem durch die Einführung des so genannten Berufsbeamtengesetzes durch die Nationalsozialisten, jäh beendet wurde. Es wurden zahlreiche jüdische Professoren gezwungen, die Universität zu verlassen. Unter ihnen befanden sich viele der namhaftesten Wissenschaftler Göttingens. ${ }^{36}$

35 Diese erstaunliche Entwicklung kann hier nur stark verkürzt wiedergegeben werden, wird jedoch in einer Reihe von Veröffentlichungen ausführlich dargestellt: Tobies, Renate: Wissenschaftliche Schwerpunktbildung: Der Ausbau Göttingens zum Zentrum der Mathematik und Naturwissenschaften. In: Brocke, Bernhard vom (Hrsg.): Wissenschaftsgeschichte und Wissenschaftspolitik im Industriezeitalter: Das ,System Althoff in historischer Perspektive. Hildesheim 1991. (= Geschichte von Bildung und Wissenschaft: Reihe B, Sammelwerke; 5. Edition Bildung und Wissenschaft.) S. 87-108. Brocke, Bernhard vom: Hochschul- und Wissenschaftspolitik in Preußen und im Deutschen Kaiserreich. 1882-1907. In: Baumgart, Peter (Hrsg.): Bildungspolitik in Preußen zur Zeit des Kaiserreichs. Stuttgart 1980. (= Schriftenreihe, herausgegeben von der Arbeitsgemeinschaft zur Preußischen Geschichte e.V.; 1) S. 9-118. Manegold, Karl Heinz: Felix Klein als Wissenschaftsorganisator. Ein Beitrag zum Verhältnis von Naturwissenschaft und Technik im 19. Jahrhundert. In: Technikgeschichte, 35. Jg. (1968), H. 3, S. 177-204. Manegold, Karl Heinz: Universität, Technische Hochschule und Industrie. Ein Beitrag zur Emanzipation der Technik im 19. Jahrhundert unter besonderer Berücksichtigung der Bestrebungen Felix Kleins. Berlin 1970. Baumgarten, Marita: Die Geistes- und Naturwissenschaften an der Universität Göttingen 1866-1914: Die Universität unter preußischer Führung. In: Strobel, Karl (Hrsg.): Die deutsche Universität im 20. Jahrhundert: die Entwicklung einer Institution zwischen Tradition, Autonomie, historischen und sozialen Rahmenbedingungen. Beiträge eines universitätsund bildungsgeschichtlichen Kolloquiums am 15. und 16. Januar 1993 in München. München 1993. (=Abhandlungen zum Studenten- und Hochschulwesen; 5 Veröffentlichungen des Historischen Corpsmuseum München; Bd. 1) S. 30-68. Baumgarten, Marita: Professoren und Universitäten im 19. Jahrhundert. Zur Sozialgeschichte deutscher Geistes- und Naturwissenschaftler. Göttingen 1997.

36 „Von den 53 in der Zeit des Nationalsozialismus aus rassischen oder politischen Gründen entlassenen Professoren stammten 24 aus der Mathematisch-Naturwissenschaftlichen Fakultät: Paul Bernays, Felix Bernstein, Max Born, Richard Courant, Heinrich Düker, James Franck, Viktor Moritz Goldschmidt, Walter Heitler, Paul Hertz, Arthur von Hippel, Kurt Heinrich Hohenemser, Heinrich Kuhn, Spiro Kyropoulos, Edmund Landau, Hans Lewy, Otto Neugebauer, Wilhelm Neuhaus, Emmy Noether, Lothar Nordheim, Willy Prager, Carl Ludwig Siegel, Hertha 
Die hier untersuchte Zeit des Ersten Weltkrieges liegt also inmitten dieses Ausbaus der Göttinger Universität. Daher bieten sich gerade die Naturwissenschaften zur Betrachtung der Folgen des Ersten Weltkrieges für die Universität besonders an. Es ist anzunehmen, dass deren Auswirkungen in einer Phase größter finanzieller und organisatorischer Aktivitäten besonders deutlich werden. Aber noch ein weiteres Argument spricht für eine weitgehende Beschränkung auf die naturwissenschaftlichen Fächer innerhalb dieser Arbeit: ${ }^{37}$ Sie bedeutet eine bewusste Hinwendung zu einer Gruppe, die in der bisherigen Forschung weitgehend vernachlässigt wurde. Wirft man beispielsweise einen Blick in das Personenregister von Schwabes Wissenschaft und Kriegsmoral, so erhält man einen guten Eindruck davon, wie wenig Naturwissenschaftler bisher berücksichtigt wurden. ${ }^{38}$ In dem von Wolfgang Mommsen herausgegeben Sammelwerk Kultur und Krieg treten sie überhaupt nicht in Erscheinung. ${ }^{39}$ Dies ist jedoch gewiss nicht als Versäumnis der Autoren zu bewerten. Es spiegelt vielmehr, entsprechend der jeweiligen Fragestellungen, die tatsächliche Beteiligung naturwissenschaftlicher Hochschullehrer wider. Diese traten nicht in gleichem Maße wie ihre Kollegen aus den theologischen, juristischen und philosophischen Fakultäten öffentlich in Erscheinung, was selbstverständlich auch Rückwirkungen auf eine naturwissenschaftlich dominierte Universität wie Göttingen haben musste. So war hier etwa der Anteil der aktiven Teilnahme am internationalen Propagandakrieg relativ gering, wie Cordula Tollmien in ihrem Aufsatz Der Krieg der Geister in der Provinz zeigt. ${ }^{40}$ Lothar Burchardt bietet für diesen Befund eine erstaunlich einfache Erklärung: Er glaubt, eine

Sponer, Hans von Wartenberg, Hermann Weyl.“ Vorwort des Bearbeiters Martin Fimpel. In: Hunger, Ulrich; Wellenreuther, Herrmann (Hrsg.): Spezialinventar zur Geschichte der Mathematik und Naturwissenschaften an der Universität Göttingen von 1880-1933. Ein Führer zu den archivalischen Quellen. Göttingen 2002. (= Schriften des Universitätsarchivs Göttingen Bd. 1). S. 13-19, Fußnote 2.

37 Weitgehende Beschränkung bedeutet, dass die für diese Arbeit verwendeten Quellen nach dem Kriterium ausgewählt wurden, dass naturwissenschaftliche Dozenten oder Institute entweder aktiv an einem Vorgang beteiligt sein mussten oder direkt von ihm betroffen waren, um in dieser Arbeit berücksichtigt zu werden. Gerade für den Bereich der Studierenden war eine solch strikte Trennung jedoch oft nicht möglich und erschien auch nicht sinnvoll.

38 Schwabe: Wissenschaft. 1969. S. $291 \mathrm{ff}$. Lothar Burchardt setzt dieses Bild in Zahlen um: „Schwabe führt in seiner Bibliographie 121 Professoren-Autoren mit insgesamt 336 Veröffentlichungen [...] auf. Nur vier von ihnen waren Naturwissenschaftler [...] Nur 1,7\% der Verfasser waren also amtierende naturwissenschaftliche Ordinarien, und aus ihrer Feder stammten ganze $0,6 \%$ der einschlägigen Veröffentlichungen. "Burchardt, Lothar: Naturwissenschaftliche Universitätslehrer im Kaiserreich. In: Schwabe (Hrsg.): Deutsche Hochschullehrer. 1988. S. 151-214. S. 212.

39 Mommsen (Hrsg.): Kultur. 1996.

40 Tollmien, Cordula: Der „Krieg der Geister“ in der Provinz - das Beispiel der Universität Göttingen 1914-1919. In: Göttinger Jahrbuch, Jg. 1993, H. 41, S. 137-210. Tollmien stellt fest, dass in Göttingen weder Beiträge verfasst wurden, noch ein wichtiger Protagonist der Auseinandersetzungen aus Göttingen kam (S. 137). 
„Mischung von Zufriedenheit, Mangel an politische[m] Sendungsbewusstsein und Zeitknappheit" 41 zu erkennen.

Diese Aussage Burchardts wird selbstverständlich zu überprüfen sein. Trotz allem sollte die offensichtliche Zurückhaltung naturwissenschaftlicher Professoren im öffentlichen Auftreten während des Ersten Weltkrieges kein Hinderungsgrund dafür sein, sich gerade mit ihnen zu beschäftigen. Angesichts der für die vorliegende Arbeit gewählten Fragestellung ist das Gegenteil der Fall. Eine Konzentration auf die wenigen politisch und öffentlich besonders aktiven Dozenten, wie von Schwabe praktiziert, kann nur wenig aussagekräftig sein im Hinblick auf das Kriegserlebnis einer ganzen Institution, zumal politisches Handeln meist ausschließlich nach außen gerichtet war und kaum Rückwirkungen auf die Universität selber hatte. Gerade letztere soll aber in dieser Arbeit im Zentrum des Erkenntnisinteresses stehen.

Als Hauptquelle bieten sich zu diesem Zweck die Akten der Universitätsbehörden im Universitätsarchiv Göttingen an, die in den verschiedenen Beständen einen guten Einblick in die Arbeit des Universitätskurators, des Prorektors beziehungsweise des Rektors ${ }^{42}$ - und der Fakultäten und damit in den gesamten Bereich der Universitätsverwaltung gewähren. Diese wurde repräsentiert durch den Kurator als obersten Verwaltungsbeamten, der eine Vermittlungsfunktion zwischen dem Kultusministerium in Berlin und der Universität einnahm. Der Universitätskurator war als Vertreter des Ministeriums vor Ort sowohl für die Universitätsangehörigen als auch für das Ministerium selbst die zentrale Anlaufstelle in allen wichtigen Fragen, wie etwa bei Berufungen oder der Vergabe von Finanzmitteln. Die akademische Selbstverwaltung, repräsentiert durch den Prorektor als Vorsitzenden des Senats, der sich wiederum aus den Ordinarien der Universität zusammensetzte, und die Fakultäten unter dem Vorsitz der jeweiligen Dekane, war gerade unter dem massiven Einfluss Friedrich Althoffs stark zurückgedrängt worden. ${ }^{43} \mathrm{Da}$ weder der Prorektor noch die Dekane über finanzielle Mittel verfügten, stellte das Kuratorium in dieser Frage die entscheidende Instanz dar. Der Universitätskurator hatte die Oberaufsicht über alle finanziellen Angelegenheiten der Universität. ${ }^{44}$

Die Verwaltungsakten der Universitätsbehörden können jedoch keine Informationen über inoffizielle, das heißt außeruniversitäre Aktivitäten von Universitätsangehörigen oder private Meinungsäußerungen wiedergeben. Diese fanden nur dann Aufnahme in die Verwaltungsakten, wenn sie die Universität als solche berührten, etwa wenn ein Disziplinarverfahren eingeleitet wurde. Derartige In-

41 Burchardt: Naturwissenschaftliche Universitätslehrer. 1988. S. 213.

42 Seit der 1916 in Kraft getretenen neuen Universitätsverfassung lautete die neue Amtsbezeichnung Rektor. Gundelach, Ernst: Die Verfassung der Göttinger Universität in drei Jahrhunderten. Göttingen 1955. S. 124.

43 Gundelach, Ernst: Die Verfassung. 1955. S. 131.

44 Für nähere Details zur Universitätsverfassung siehe: Gundelach, Ernst: Die Verfassung. 1955. S. 118-131. 
formationen wurden unter Verwendung der verschiedenen Briefnachlässe Göttinger Professoren, die sich in der Handschriftenabteilung der Niedersächsischen Staats- und Universitätsbibliothek Göttingen befinden, ergänzt. ${ }^{45}$

Darüber hinaus gaben die Akten des Stadtarchivs Göttingen, besonders die Akten der örtlichen Polizei, einen Einblick in das lokale Umfeld der Universität. Die Archivalien der Deutschen Gesellschaft für Luft- und Raumfahrtforschung lieferten reiche Informationen zu Ludwig Prandtls Aerodynamischer Modellversuchsanstalt.

Deutlich schwächer stellt sich die Quellenlage für den Bereich der Studierenden dar. Da hier die genannten Verwaltungsakten nicht ausreichten, wurden mit den Burschenschaftlichen Blättern und der Deutschen Korpszeitung (Academische Monatshefte) die Kriegsjahrgänge der wichtigsten überregionalen Verbindungszeitungen in die Untersuchung einbezogen.

Die Frage des Untersuchungszeitraums wird durch das Thema dieser Arbeit weitgehend beantwortet. Um Vergleichsmaßstäbe zu erhalten, werden die Untersuchungen, wo dies erforderlich erscheint, auf das gesamte Kriegsjahrzehnt ausgedehnt. Wirkliche Vergleichsmaßstäbe stellen jedoch nur die Vorkriegsjahre dar. Eine weitere Ausdehnung des Untersuchungszeitraums deutlich über das Kriegsende hinaus ist wenig sachdienlich, da durch Revolution, Wirtschaftskrisen und Inflation keine einheitliche Grundlage für aussagekräftige Vergleiche gegeben ist. Die Betrachtung der ersten Nachkriegsmonate ist allerdings für die Ermittlung der direkten Kriegsfolgen unverzichtbar.

45 Die Auswahl der in dieser Arbeit verwendeten Quellen erfolgte durch die verschiedenen Findmittel des Universitätsarchivs Göttingen und der Handschriftenabteilung der Niedersächsischen Staats- und Universitätsbibliothek Göttingen. Hunger; Wellenreuther (Hrsg.): Spezialinventar. Göttingen 2002. 



\section{Eine Universität ohne Studenten}

Die Studierenden waren zweifellos, schon aufgrund ihres recht jungen Lebensalters, die Gruppe innerhalb der Universität, die am stärksten und unmittelbarsten unter der unmenschlichen Kriegsführung des Ersten Weltkrieges zu leiden hatte, aber sie waren auch ein Teil der Bevölkerung, der durch seinen hohen Anteil an Kriegsfreiwilligen ganz wesentlich das Bild des Ersten Weltkrieges mit geprägt hat. Auch zehn Jahre nach Ende des Krieges durfte der Langemarck-Mythos, ${ }^{46}$ damaliges Synonym für die studentische Opferbereitschaft, in der Rede des Rektors der Göttinger Universität aus Anlass der Enthüllung des universitätseigenen Kriegerdenkmals nicht fehlen:

[...] und der Tag von Langemark, wo unsere jungen Freiwilligen, voll des warmen Blutes und des heißesten Lebens, Deutscbland im Herzen und das Deutschlandlied auf den Lippen, einem übermäcbtigen Feind entgegenziehen, bis die Kugel ibren Scblachtgesang verstummen läßt. ${ }^{47}$

46 Zum Langemarck-Mythos siehe: Hüppauf, Bernd: Schlachtenmythen und die Konstruktion des „Neuen Menschen“. In: Hirschfeld, Gerhard (Hrsg.): „Keiner fühlt sich hier mehr als Mensch ...“: Erlebnis und Wirkung des Ersten Weltkriegs. Essen 1993. (=Schriften der Bibliothek für Zeitgeschichte; N.F. 1) S. 43-84. Hüppauf, Bernd: Langemarck-Mythos. In: Hirschfeld; Krumeich; Renz (Hrsg.): Enzyklopädie. 2003. S. 671-672.

47 Universität Göttingen (Hrsg.): Dem Andenken ihrer im Weltkriege Gefallenen. Gewidmet zum 1. März 1925 von der Georg-August-Universität Göttingen. München 1925. S. 24. 
Abseits solcher Mythen zeigt eine nüchterne Aufstellung der Studierendenzahlen des Kriegsjahrzehnts sehr deutlich, wie stark die Korporation Universität durch den Krieg erschüttert wurde. Diese Statistik soll hier als Ausgangspunkt für weitere Betrachtungen genutzt werden, da sie bereits Indizien für alle wichtigen Faktoren der Auswirkungen des Krieges auf die Universität in sich birgt. Diese Faktoren sollen hier zunächst in einem ersten Abschnitt in chronologischer Reihenfolge nur skizziert werden, um sie dann im Folgenden detaillierter behandeln zu können.

Während der erste Teil der hier anzustellenden Betrachtungen auf rein quantitativer Ebene stattfinden soll, müssen die weiterführenden Untersuchungen des zweiten Teils auf eine möglichst breite Quellenbasis gestellt werden. Dies ist gerade im Falle der Studierenden um so wichtiger, da es nicht möglich sein wird, ein einzelnes, ihnen gerecht werdendes Gesamtbild zu zeichnen. Dies liegt nicht nur an der individuellen Verschiedenartigkeit studentischer Gruppen, sondern vielmehr daran, dass man sich den Studierenden auf zwei unterschiedlichen Ebenen nähern muss. Der Studierende als Teil der Korporation Universität stellte etwas Anderes dar als der Studierende als Teil des studentischen Lebens innerhalb und außerhalb der Universität.

Diese zwei Ebenen existierten natürlich nicht nur parallel, sondern hatten unzählige Berührungspunkte und beeinflussten sich gegenseitig - sie waren eng miteinander verzahnt. Die größte Schwierigkeit bei dieser Betrachtung ist die Verschiedenartigkeit der überlieferten Quellen. Während für den Bereich der Universität hauptsächlich quantitative Daten in Form von Verwaltungsakten zur Verfügung stehen, ${ }^{48}$ existieren persönlichere Aussagen, die auf tatsächliche Stimmungen und Meinungen schließen lassen, im Wesentlichen nur aus dem Bereich der Studierenden selbst. ${ }^{49}$ Hier soll versucht werden, das Ineinandergreifen der verschiedenen Ebenen nachzuzeichnen und zu untersuchen, in wie weit der Krieg in dieses Zusammenspiel eingriff, es störte oder sogar nachhaltig veränderte.

Wenn man davon ausgeht, dass das Zusammenspiel der Bestandteile der Korporation durch den Krieg verändert wurde, muss die übergeordnete Frage, die es in diesem Zusammenhang zu beantworten gilt, lauten: Welchen Stellenwert be-

48 Hierzu sei angemerkt, dass die Akten der Universitätsbehörden fast keine Rückschlüsse auf einzelne Studierende zulassen. Diese treten nur dann in Erscheinung, wenn außergewöhnliche Ereignisse eintreten, etwa aus disziplinarischer Sicht. Welche Vorlesungen ein bestimmter Studierender gehört hat, lässt sich heute nicht mehr nachweisen. Auch im Hinblick auf Prüfungen werden einzelne Studierende erst wieder bei einer Promotion greifbar.

49 Die Quellenlage in diesem Bereich wird es außerdem notwendig machen, sich zumindest zeitweise von der Konzentration auf die Naturwissenschaften zu entfernen, da oft nicht nachzuvollziehen ist, für welche Fächer ein Studierender eingeschrieben gewesen ist. Dies allerdings nicht etwa, weil die Matrikel der Universitäten diese Informationen nicht geben könnten, sondern weil die vorhandenen Daten zu einer eindeutigen Identifizierung nicht ausreichen. Außerdem würde eine Konzentration auf die Naturwissenschaften in diesem konkreten Bereich gar nicht sinnvoll erscheinen: Der Studierende dieser Zeit war sowohl in der Sicht Dritter, als auch in der Sicht anderer Studierender, etwa innerhalb der Studentischen Verbindungen, Student und nicht Student eines bestimmten Faches. 
hielt die Universität für ihre Mitglieder noch angesichts der durch den Krieg geänderten Rahmenbedingungen? Welche Bedeutung hatte für einen Kriegsfreiwilligen die Zugehörigkeit zu seiner Universität und welche Verbindungen hielt die Institution Universität zu den Studierenden im Kriegsdienst aufrecht?

\section{Die Veränderung der Studierendenzahlen}

Bereits ein Blick auf die Studierendenzahlen des Kriegsjahrzehnts verdeutlicht, wie dramatisch der Einschnitt im August 1914 tatsächlich war. ${ }^{50}$ Zur Erläuterung muss erwähnt werden, dass in dieser Darstellung alle Studierenden, die sich im Kriegsdienst befanden, hell markiert sind. Die einzelnen Kurven sind gestapelt, so dass die absolut höchste Kurve die Gesamtzahl der Studierenden zeigt. Die obere Kurve der dunklen Grautöne markiert die Anzahl der tatsächlich in Göttingen anwesenden Studierenden.

50 In die Gruppe der Studierenden sollen hier auch die jungen Wissenschaftler, gemeint sind vor allem die Assistenten, einbezogen werden. Der Grund dafür liegt darin, dass die Assistenten und später auch Assistentinnen zwar eigentlich keine Studierenden mehr waren, aber noch weniger den Dozenten zugerechnet werden können. In dem hier verwendeten Untersuchungszeitraum war die Promotion der gängige Abschluss für angehende Wissenschaftler; das Lehramtsexamen stand hinter diesem eindeutig zurück. Kurz vor, während oder meist nach der Promotion übernahm ein Teil dieser Studierenden eine Assistentenstelle. Diese Möglichkeit zur wissenschaftlichen Arbeit in einem Universitätsinstitut, verbunden mit dem Abhalten kleinerer Veranstaltungen, war anscheinend sehr begehrt und bei weitem nicht in ausreichender Zahl vorhanden, um jedem Interessenten eine Stelle gewähren zu können, obwohl jedes Institut mehrere dieser Stellen anzubieten hatte und die Fluktuation bei ihrer Besetzung recht hoch war. Diese Stellen waren offensichtlich die einzige Möglichkeit für einen Naturwissenschaftler, sich zu habilitieren, da er im Gegensatz zu seinen geisteswissenschaftlichen Kollegen auf die Arbeitsmöglichkeiten eines Laboratoriums angewiesen war. Siehe hierzu auch: Burchardt, Lothar: Naturwissenschaftliche Universitätslehrer. 1988. S. 163. 


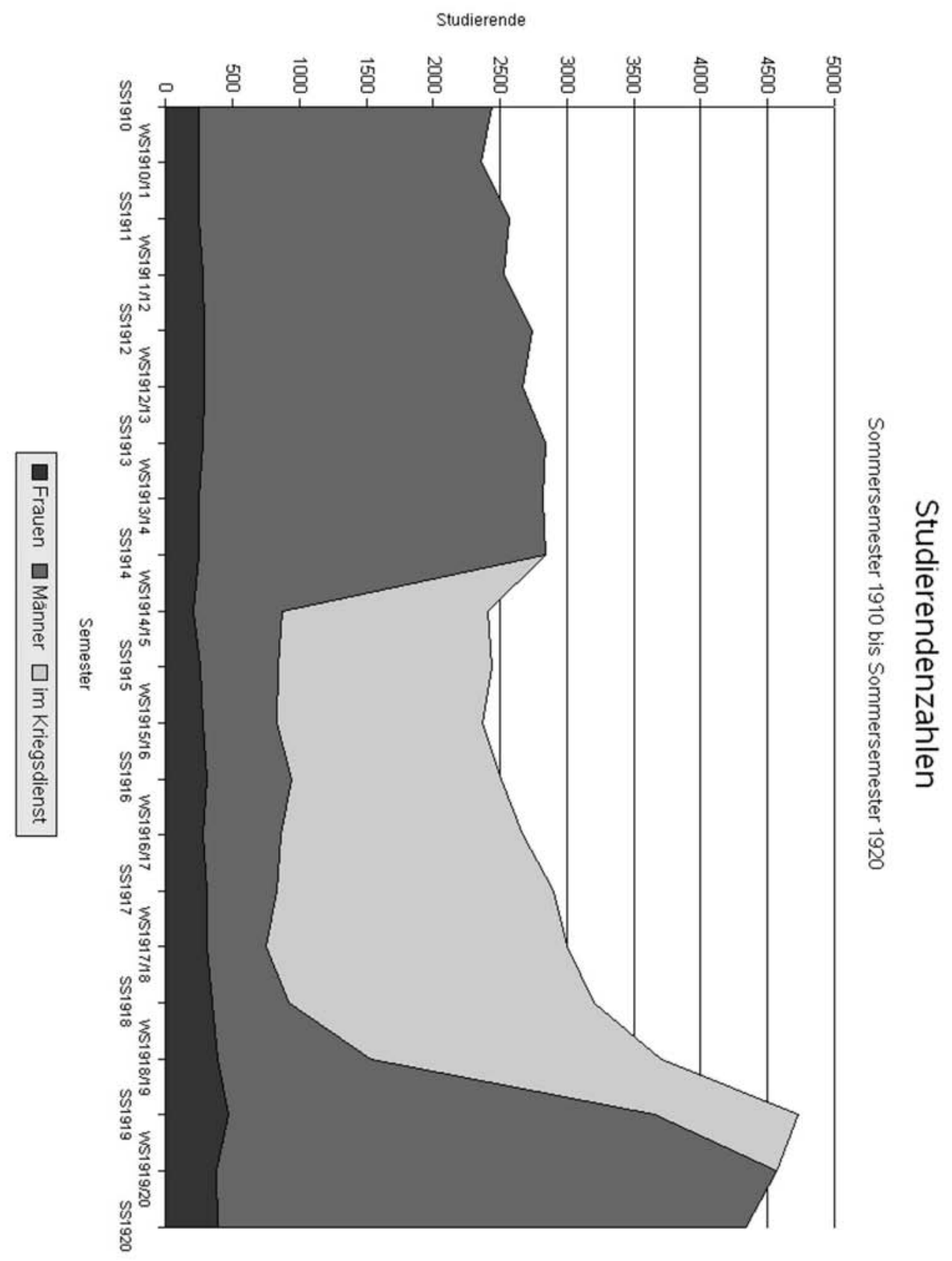

Statistik 1: Daten aus: Universität Göttingen (Hrsg.): Amtliches Verzeichnis des Personals und der Studierenden der königl. Georg-August-Universität zu Göttingen. Göttingen 1910 bis 1920. (Daten jeweils aus der im Folgesemester erscheinenden „Endgültigen Feststellung“). 
Eine relativ exakte Erfassung der sich im Kriegsdienst befindenden Studierenden ist deshalb möglich, weil diese weiterhin immatrikuliert blieben und nur als beurlaubt galten. Unter Kriegsdienst darf man in diesem Zusammenhang nicht nur den Kampfeinsatz an der Front verstehen, sondern auch verschiedene andere Tätigkeiten in Militär oder Wirtschaft. Viele derjenigen, die nicht als Soldaten dienten, waren so genannte Kriegsdiensthelfer. Es handelte sich dabei in der Regel um nicht zum Kampfeinsatz fähige, meist wegen gesundheitlicher Einschränkungen oder von vornherein, zum Teil gerade wegen ihrer Verwendung als Kriegsdiensthelfer, als unabkömmlich deklarierte Männer. Sie wurden im Rahmen des Gesetzes über den Vaterländischen Hilfsdienst vom Dezember 1916 und des so genannten Hindenburg-Programmes zumeist in kriegswichtigen industriellen Unternehmen, in wenigen Fällen aber auch zur Forschung auf militärischem Gebiet eingesetzt. ${ }^{51}$ Aus den Reihen der Universität waren für diese Aufgaben vor allem Assistenten oder Studierende höherer Semester fachlich geeignet. Sie wurden hauptsächlich zu präzisen Kontroll- und Meßarbeiten eingesetzt, mit zunehmender Kriegsdauer aber auch zur Aufsicht ungelernter Hilfsarbeiter, die immer häufiger qualifizierte Fachkräfte in der Industrie ersetzten. Die Fachkräfte waren zwar zunächst als unabkömmlich eingestuft worden, später aber wurden sie doch zum Militärdienst eingezogen. ${ }^{52}$

Ein geringer Teil der Studierenden, die in Statistik 1 hell markiert sind, zum größten Teil Studentinnen, befand sich im freiwilligen Einsatz als Krankenschwestern beim Roten Kreuz oder ähnlichen Hilfsorganisationen. Verglichen mit den Kriegsdiensthelfern und vor allem den Soldaten, ist ihr Anteil eher zu vernachlässigen. ${ }^{53}$

Generell kann man die Entwicklung der Studierendenzahlen während des Krieges in drei Phasen unterteilen. Die erste Phase stellt hierbei der Kriegsausbruch dar mit einem dramatischen Einbruch der Zahl der aktiven Studierenden und einem immer noch deutlichen Absinken der Zahl der immatrikulierten Studierenden. Die zweite und zeitlich längste Phase bildet die eigentliche Kriegszeit vom Sommersemester 1915 bis zum Sommersemester 1918. Charakteristisch ist für sie ein gemäßigtes Absinken der Zahl der aktiven Studierenden - mit Aus-

51 Als Beispiel für eine Verwendung in der rüstungsrelevanten Forschung kann etwa die Göttinger Modellversuchsanstalt Ludwig Prandtls genannt werden, auf welche in dieser Arbeit noch eingegangen werden wird. Auch in Instituten der Universität versuchten Direktoren von der Industrie Themen zur Bearbeitung zu erhalten, die es ihren Mitarbeitern ermöglichten, ihre Dienstpflicht im Rahmen ihrer regulären Tätigkeit gerecht zu werden. Siehe oben.

52 Es bestand seit dem Dezember 1916 zwar eine allgemeine Dienstpflicht, allerdings aus verschiedenen innenpolitischen Erwägungen mit einem gewissen Maß an Wahlfreiheit. Siehe hierzu: Ullmann, Hans-Peter: Kriegswirtschaft. In: Hirschfeld, Krumeich, Renz (Hrsg.): Enzyklopädie. 2003. S. 220-232. Und: Wettmann: Heimatfront. 2000. S. 99ff. Die diesbezüglichen Vorgänge der Assistenten und des übrigen Universitätspersonals sind vollständig überliefert: UAG.Kur.3441-3448.

53 Leider existiert für diesen Bereich keinerlei Zahlenmaterial. In den Veröffentlichungen der studentischen Verbindungen finden sich jedoch immer wieder Hinweise auf solche Tätigkeiten. 
Eine Universität ohne Studenten

nahme des Sommersemesters 1916 - bei einem gleichzeitigen stetigen Ansteigen der Zahl der Immatrikulierten. Die dritte und letzte Phase stellt dann das Kriegsende dar mit einem enormen Anstieg der Gesamtzahl der Studierenden.

Phase 1 - Der Kriegsausbruch

Die Statistik zeigt, dass die Universität Göttingen im Kriegsjahrzehnt bis zum Sommer 1914 einen stetigen Anstieg der Studierendenzahlen zu verzeichnen hatte. ${ }^{54}$ Zwischen Sommersemester 1914 und Wintersemester 1914/15 erfolgte dann der Einbruch. Dieser ist selbstverständlich zu erwarten gewesen, verdient aber in seiner enormen Größe trotzdem Beachtung. Bereits im ersten Kriegssemester, dem Wintersemester 1914/15, befanden sich circa $62 \%$, also fast zwei Drittel aller Studierenden im Kriegsdienst. Im Wintersemester 1917/18 erreichte diese Zahl einen Höhepunkt mit 75\%.55

Neben diesem ersten dramatischen Rückgang der Studierendenzahlen ist ein Minus von 273 Studierenden festzustellen. Dies ist wohl dadurch zu erklären, dass einige Studenten, die eventuell schon länger mit ihrer Situation oder ihrem Studium unzufrieden waren, den Krieg als Gelegenheit nutzten, ihr Studium abzubrechen, ohne gesellschaftliches Ansehen zu verlieren.56 Dies ist zwar Spekulation, aber es ist auffällig, dass sich zu Beginn des Ersten Weltkrieges im Vergleich zum Rest des Jahrzehnts die Eintragungen „Ohne Abmeldung weggegangen“ oder

54 Damit bewegte sich Göttingen exakt im Rahmen der deutschlandweiten Entwicklung der Studierendenzahlen. Jarausch spricht für die Zeit seit 1871 sogar von einer „Frequenzexplosion“. Siehe hierzu: Jarausch: Students. 1982. S. 23ff. Und: Jarausch: Deutsche Studenten. 1984. S. $71 \mathrm{ff}$.

55 Die Zahlen der Universität Göttingen sind denen anderer deutscher Universitäten sehr ähnlich: Andrea Wettmann setzt für ganz Preußen den Tiefpunkt der Entwicklung im Wintersemester 1917/18 an. Zu diesem Zeitpunkt besuchten nur 28\% aller Eingeschriebenen Universitätsveranstaltungen: Wettmann: Heimatfront. 2000. S. 123. In Marburg selbst waren im ersten Kriegssemester von 2078 Studierenden 629 anwesend, davon 151 Frauen: Wettmann: Heimatfront. 2000. S. 225. Der Tiefststand wurde im Wintersemester 1915/16 mit lediglich 526 immatrikulierten erreicht: Wettmann: Heimatfront. 2000. S. 379. Moraw gibt für die Universität Gießen einen Wert von konstant 75\% der Studierenden an, die keine Vorlesungen besuchen konnten: Moraw: Kleine Geschichte. 1982. S. 196.

Auch international zeigte sich ein ähnliches Bild: In Oxford etwa traten im ersten Kriegssemester die meisten, der aus den Ferien zurückkehrenden Studenten, umgehend in das Militär ein. 1915 hatte sich die Zahl der aktiven Studierenden bereits halbiert, war 1916 um 72 Prozent gefallen, bis 1918 nur noch 12 Prozent der Vorkriegszahlen erreicht wurden. Winter: Oxford. 1994. S. 9.

56 Zumindest versuchte man, allen Studierenden, die trotz des drohenden Krieges ihr Studium weiter fortsetzen wollten, dies zu ermöglichen, wie ein Anschlag von Ende Juli 1914 beweist. (Zitiert nach einem Aktenvermerk des Universitätssekretärs Gassmann vom 30.7.1914.) „Am 30. Juli bereits erließ der Prorektor, um den Studenten die Möglichkeit zu geben, der drohenden Kriegsgefahr wegen nach Hause zu reisen folgenden Anschlag: Angesichts der zahlreichen bei mir einlaufenden Gesuche um die Erlaubnis zum vorzeitigen Abtestieren genehmige ich hiermit, daß in allen erforderlichen Fällen das Signieren der abtestierpflichtigen Vorlesungen und Übungen ausnahmsweise von morgen Freitag dem 31. Juli an erfolge.“ UAG.Sek.38.1 30.7.1914. 
„Sonstige Gründe“ häuften. In den letzten zehn Vorkriegssemestern meldeten sich im Durchschnitt nur 114 Studierende nicht zurück. Besonders die Kategorie „Sonstige Gründe“ findet sich in den früheren Jahren fast überhaupt nicht. ${ }^{57}$ Dass dies im Sommer 1914 überhaupt möglich wurde, lag wohl an den dramatischen Verhältnissen bei Kriegsausbruch, auf die hier später noch eingegangen werden wird.

Ein weiterer wichtiger Faktor, der zu den starken Veränderungen bei Ausbruch des Krieges beitrug, war die Zahl der Neuimmatrikulationen. Da der Ausbruch des Krieges in die Semesterferien fiel, konnten noch im letzten Friedenssemester, dem Sommersemester 1914, in weitgehend normalem Umfang Studienabschlüsse erworben werden; diese wurden dann aber im folgenden ersten Kriegssemester nicht mehr durch die Neuimmatrikulationen kompensiert.

Verglichen mit dem Wintersemester 1913/14 (667 Studenten) immatrikulierten sich im Wintersemester 1914/15 (204) zwei Drittel männliche Studierende weniger. Bei ihren Kommilitoninnen blieben die Zahlen jedoch weitgehend konstant. 55 anstatt 60 neuer Studentinnen entspricht einem Minus von weniger als $10 \%$.

57 Zunächst wirken diese Zahlen noch dramatischer: 116 männliche Studenten waren zu Unrecht exmatrikuliert worden, da die Universität offensichtlich erst zu spät erfahren hatte, dass sie sich im Kriegsdienst befanden. Im folgenden Semester tauchen sie wieder mit einem kurzen Vermerk unter der Spalte der Neuimmatrikulationen auf. Dieser Fehler ist auch in allen anderen Statistiken in dieser Arbeit berücksichtigt und korrigiert worden. Daten aus: Universität Göttingen (Hrsg.): Amtliches Verzeichnis des Personals und der Studierenden der königl. GeorgAugust-Universität zu Göttingen. Göttingen 1910 bis 1920. (Daten jeweils aus der im Folgesemester erscheinenden „Endgültigen Feststellung“). 
Studierende

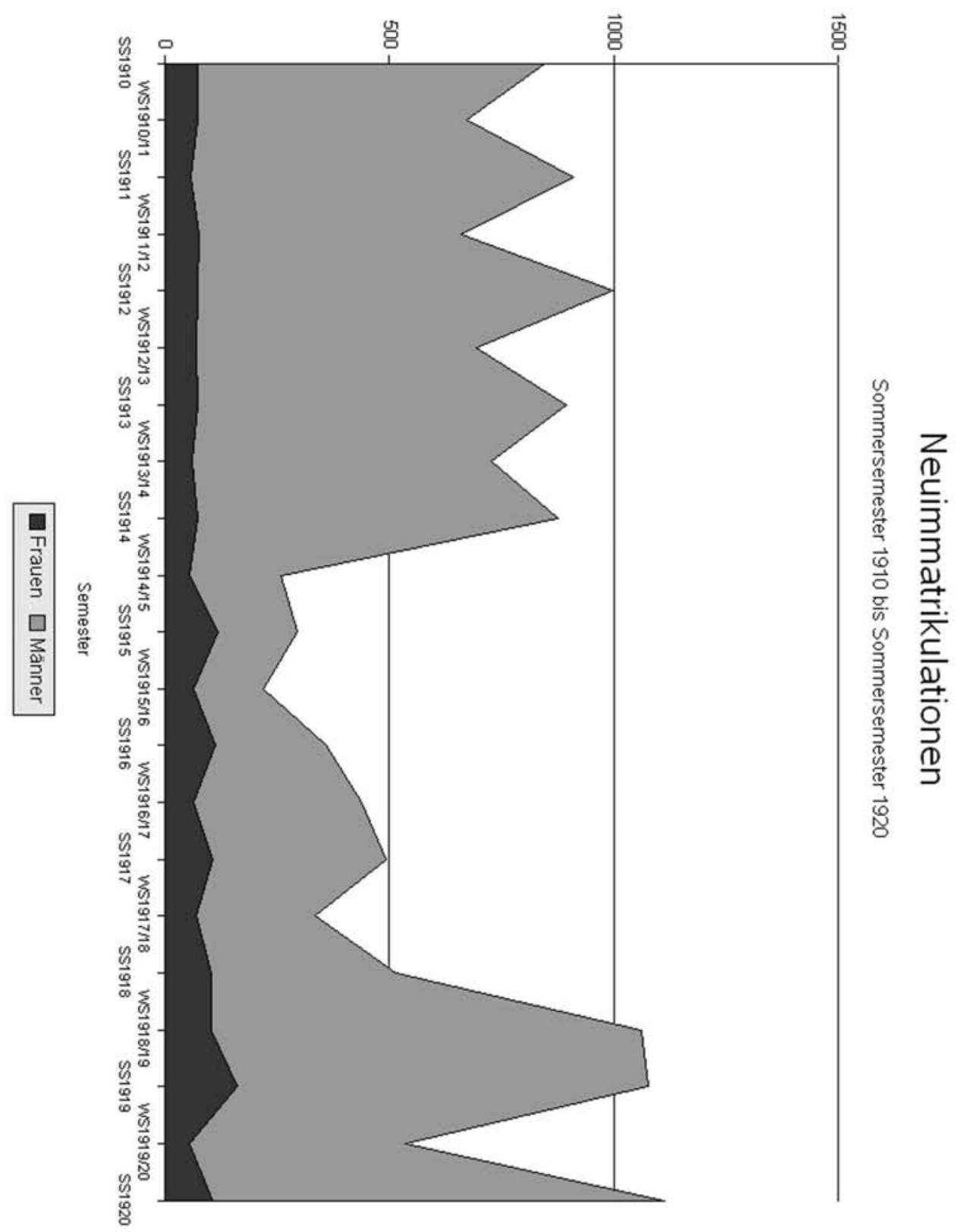

Statistik 2: Daten aus: Universität Göttingen (Hrsg.): Amtliches Verzeichnis des Personals und der Studierenden der königl. Georg-August-Universität zu Göttingen. Göttingen 1910 bis 1920. (Daten jeweils aus der im Folgesemester erscheinenden „Endgültigen Feststellung“). 
Ebenfalls für den Einbruch der Studierendenzahlen verantwortlich war das Ausbleiben der ausländischen Studierenden. Wenn auch, nach absoluten Zahlen beurteilt, ihr Anteil recht gering war, so war doch die relative Bedeutung für die Zahl der nicht-deutschen Studierenden enorm: Von 167 ausländischen Studierenden vor Ausbruch des Krieges waren zu Beginn des Wintersemesters 1914/15 gerade noch 30 eingeschrieben - immerhin ein Rückgang um 82\%. Auf die genauen Umstände und die weitere Entwicklung soll später noch eingegangen werden. Festzuhalten für die Phase des Kriegsausbruchs bleibt, dass die Zahl der tatsächlich in Göttingen anwesenden Studierenden in einem Maße einbrach, dass es beinahe verwundert, dass die Universität überhaupt ihre Arbeit im Herbst 1914 wieder aufnahm. Von 2836 Studierenden waren innerhalb weniger Wochen 873, also nur noch $30 \%$, geblieben. Dies war die erste und unmittelbarste Kriegsfolge für die Georgia Augusta.

Phase 2 - Der Krieg

Verglichen mit den dramatischen Veränderungen bei Ausbruch des Krieges wirken die Entwicklungen der Studierendenzahlen während der eigentlichen Kriegszeit geradezu unspektakulär. Vom Sommersemester 1915 bis zum Sommersemester 1918 stagnierte zunächst die Gesamtzahl der immatrikulierten Studierenden aus den zuvor erwähnten Gründen, begann dann aber, seit dem Wintersemester 1915/16, kontinuierlich von 2378 auf 3200 Studierende zu steigen. Die Zahl der aktiven Studierenden sank, abgesehen von einem kurzen Zwischenhoch im Sommersemester 1916, von 839 im Sommersemester 1915 auf 754 im Wintersemester 1917/18.

Dieses Absinken der Zahl der aktiven Studierenden wurde ausschließlich durch die ausbleibenden männlichen Studierenden verursacht. Ihre Zahl sank ab dem Sommersemester 1916 sogar nochmals um 30\%, nämlich von 636 auf den Tiefststand von 446 im Wintersemester 1917/18. Die unmenschliche Kriegsführung, die Abnutzungsschlachten, für die Namen wie Marne, Verdun, Somme oder die Michael-Offensiven stehen, liefern hierfür die Erklärung. Immer weiter steigende Mannschaftsforderungen führten auch noch zur Einziehung des letzten einsatzfähigen Mannes bei gleichzeitiger Herabsetzung der Tauglichkeitsgrenzen. Deutschland setzte im Ersten Weltkrieg insgesamt über 13 Millionen Männer ein, womit es gut $80 \%$ seiner Ressourcen ausschöpfte. Davon fielen über 2 Millionen, was $8 \%$ aller deutschen Männer wehrfähigen Alters entsprach. Die Zahl der Verwundeten lag noch um ein Vielfaches höher. ${ }^{58}$

58 Zur Ereignisgeschichte des Ersten Weltkrieges und zur Dokumentation der Kampfhandlungen existiert zahlreiche Literatur (Siehe oben.). Exemplarisch seien hier nochmals die jüngsten Veröffentlichungen genannt: Salewski: Der Erste Weltkrieg. 2003. Zahlen aus: Overmans, Rüdiger: Kriegsverluste. In: Hirschfeld, Krumeich, Renz, (Hrsg.): Enzyklopädie. 2003. S. 664-665. 
Die Zahl der Neuimmatrikulationen konnte dem Absinken der Studierendenzahlen nur begrenzt entgegenwirken. Ihre Zahl stieg zwar leicht an, zeigte sich aber uneinheitlich und erreichte selbst bei ihrem Höchststand im Sommersemester 1917 mit 492 Neuimmatrikulationen nur etwas mehr als die Hälfte eines Sommersemesters zu Friedenszeiten. Letztendlich konnten sich die geringen Zuwächse durch die neuen Studierenden aber nicht effektiv gegen das weitere Absinken der Zahlen der aktiven Studierenden auswirken. Dies lag meist daran, dass sich offensichtlich zahlreiche junge Männer noch immatrikulierten, kurz bevor sie zum Militärdienst eingezogen wurden. Folglich sank zwar die Zahl der aktiven Studierenden weiter, die Gesamtzahl der Studierenden stieg aber während des Krieges kontinuierlich an - auch wenn viele von ihnen bis zum Kriegsende noch keine Veranstaltung besucht hatten.

Erwähnenswert bei der Betrachtung der Neuimmatrikulationen ist außerdem die Rolle der Studentinnen. ${ }^{59}$ Zunächst begann ihre Zahl nur in den Sommersemestern, dann aber ganz generell, deutlich zu steigen. Bewegte sich die Quote der Studieneinsteigerinnen seit Anfang des Jahrzehnts immer konstant zwischen 60 und 70 pro Semester, so immatrikulierten sich während des Krieges in keinem Sommersemester weniger als 100 neue Studentinnen. Dies steuerte dem Einbrechen der Zahl der aktiven Studierenden zumindest entgegen, auch wenn es diesem keine Wendung geben konnte.

Trotzdem zeigte die Entwicklung Wirkung: Im Sommersemester 1918 studierten 344 Frauen und damit fast 39\% mehr als im Sommersemester 1914. Den absoluten Zahlen nach betrachtet wirkt diese Entwicklung weit weniger dramatisch. Betrachtet man die Statistik der Studierendenzahlen nur im Hinblick auf die Studentinnen, so erkennt man über das gesamte Kriegsjahrzehnt hinweg einen kontinuierlichen Anstieg ohne wirkliche Extreme. Tatsächlich bewegte sich ihr Anteil an der Gesamtzahl der Studierenden immer um 10\%, denn der Zuwachs an Studentinnen erfolgte stets weitgehend parallel zum allgemeinen Anstieg der Studierendenzahlen. Der Krieg veränderte jedoch dieses Kräfteverhältnis, das sich scheinbar recht stabil bei $10 \mathrm{zu} 1$ eingependelt hatte, grundlegend.

59 Zu den Anfängen des Frauenstudiums siehe: Tollmien, Cordula: Die Universität Göttingen im Kaiserreich. In: Thadden, Rudolf von; Trittel, Günther (Hrsg.): Göttingen. Geschichte einer Universitätsstadt. Bd. 3. Von der preußischen Mittelstadt zur südniedersächsischen Großstadt 1866-1989. Göttingen 1999. S. 357-393. S. 377ff. Zu den Veränderungen durch den Krieg siehe: Wettmann: Heimatfront. 2000. S. 124-126. 


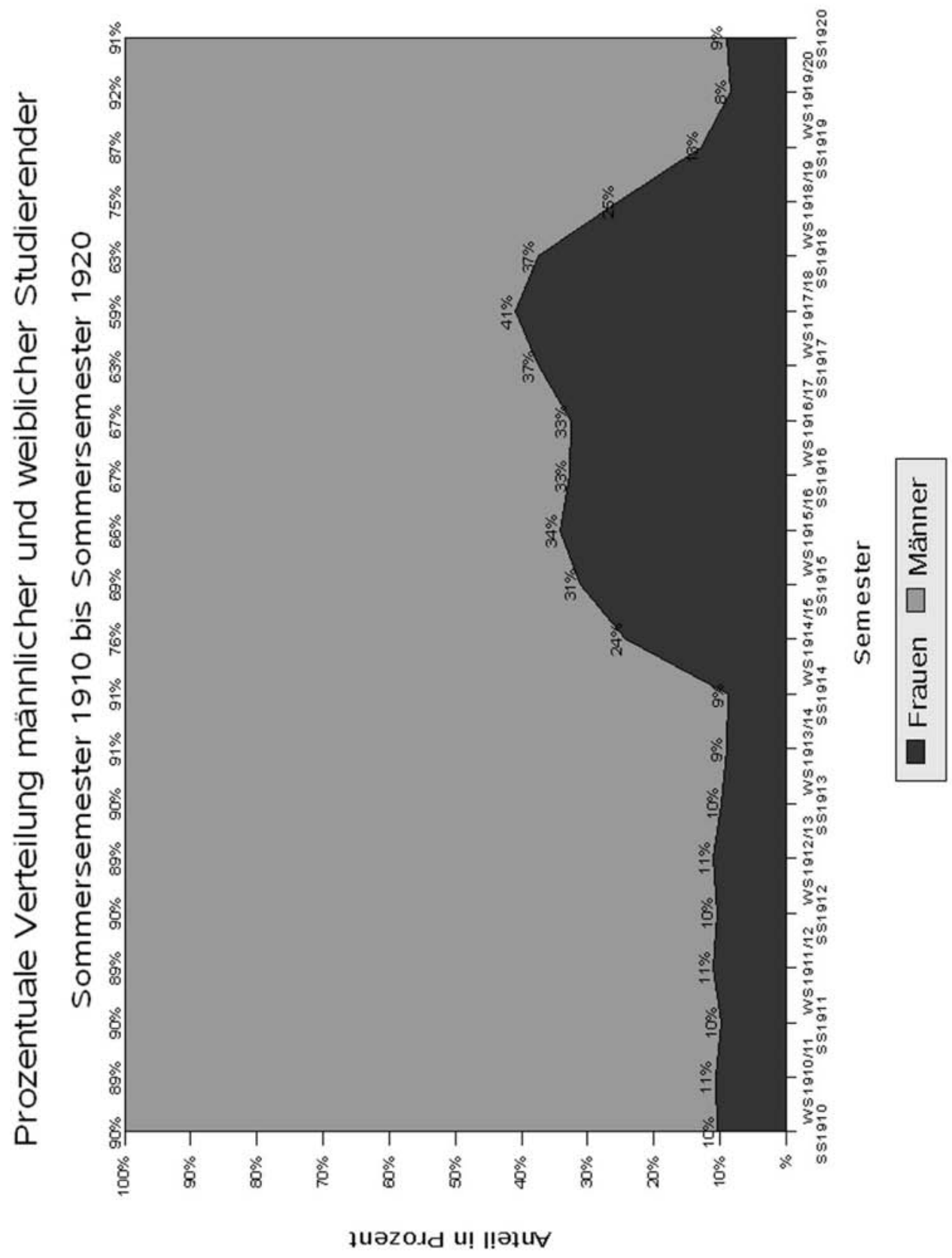

Statistik 3: Daten aus: Universität Göttingen (Hrsg.): Amtliches Verzeichnis des Personals und der Studierenden der königl. Georg-August-Universität zu Göttingen. Göttingen 1910 bis 1920. (Daten jeweils aus der im Folgesemester erscheinenden "Endgültigen Feststellung “). 
Es fällt auf, dass auf dem Höhepunkt der Entwicklung im Wintersemester 1917/18, als sich 75\% aller Studierenden im Kriegsdienst befanden, die Frauen einen Anteil an den aktiven Studierenden von beachtlichen 41\% erreichten. Dabei ist es durchaus möglich, dass der tatsächliche Anteil weiblicher Studierender in den Hörsälen noch deutlich höher war. ${ }^{60}$ Leider lässt sich dies nicht nachweisen und war sicher auch von Fach zu Fach unterschiedlich. Sicher ist aber, dass das Militär keine Rücksicht auf Semesterbeginn oder -ende nahm. Die Zahl der in Göttingen anwesenden männlichen Studierenden dürfte von daher immer einer gewissen Fluktuation unterlegen haben. Auch ist es überaus fraglich, wann ein junger Mann, der bereits am Krieg teilgenommen hatte, dann aber als untauglich eingestuft wurde, tatsächlich wieder am Universitätsbetrieb teilnehmen konnte. Die Verhältnisse wurden vom Professor für Physik und damaligen Rektor der Universität, Hermann Theodor Simon, in der so genannten Weibnachtsgabe der Georgia Augusta an ihre Studenten im Feld vom Jahr 1917 geschildert. Er beschreibt dort in seinem Geleitwort unter anderem die aktuellen Studierendenzahlen: „In unseren Hörsälen ist noch viel fleißiges Leben, freilich sind wohl 75 von Hundert Frauen dort heute die Regel. O academia!‘61

\section{Phase 3 - Das Kriegsende}

Den beschriebenen Einbruch der Studierendenzahlen zu Beginn des Krieges und deren doch weitgehende Stagnation auf niedrigem Niveau während des Krieges kann man nur bedingt als überraschend ansehen. Trotzdem ist eine eingehende Beschäftigung mit den Zahlen wichtig, da sie das tatsächliche Ausmaß der Veränderungen deutlich macht. Überraschend ist jedoch, dass sich die sowohl quantitativ stärksten, als auch die für den Universitätsbetrieb kritischsten Auswirkungen erst bei Ende des Krieges zeigten. Mit Ende des Krieges schnellten die Studierendenzahlen dramatisch in die Höhe und erreichten Ausmaße, die die Universität bis aufs Äußerste belasteten. Das militärische Ende des Krieges fiel in das Wintersemester 1918/19; der endgültige Waffenstillstand war am 11. November 1918. Die Demobilisierung dauerte noch bis ins Sommersemester 1919, so dass im Wintersemester 1919/20 nach langer Zeit kein Student mehr für den Kriegsdienst beurlaubt war.

Bereits im letzten Kriegssemester stieg die Zahl der aktiven männlichen Studierenden wieder: Mit 1148 Studenten, die nicht beurlaubt waren, verdoppelte sich

60 Noch stärker veränderten sich die Verhältnisse an der Universität Marburg. Hier betrug der Anteil der Frauen an den anwesenden Studierenden im Sommer 1914 8\%, stieg bereits 1915 auf fast 40\% und überschritt 1918 sogar die 50\%. Wettmann: Heimatfront. 2000. S. 383.

Ähnlich Zahlen existieren auch für Oxford: Winter: Oxford. 1994. S. 12ff. Und: Howarth, Janet: Women. In: Harrison (Hrsg:): The History. 1994. S. 345-375.

61 Auf die Weihnachtsgaben wird später ausführlich eingegangen werden. Universität Göttingen (Hrsg.): Stimmen aus zwei Jahrhunderten der Georgia Augusta, Weihnachtsgabe 1917 für ihre Angehörigen im Felde. Göttingen 1917. 
ihre Zahl nahezu. Die Zahl der weiblichen Studierenden veränderte sich dagegen kaum. Aber nicht nur Studenten kehrten aus dem Feld zurück, sondern auch Abiturienten, die nun an die Hochschulen drängten. Auch zahlreiche Verwundete wurden nun aus den Lazaretten entlassen. Zum ersten Mal seit dem Wintersemester 1915/16 sank die Zahl der Beurlaubten wieder, wenn auch nur um 112 Studierende von 2282 auf 2170. Die Gesamtzahl der Immatrikulierten stieg bereits auf 3703, was einem Plus von 30\% gegenüber dem letzten Friedenssemester entspricht. Im folgenden Sommersemester 1919 verstärkte sich diese Entwicklung nochmals und erreichte mit 4731 Immatrikulierten ihren Höchststand. Damit waren zwei Drittel Studierende mehr immatrikuliert als vor Ausbruch des Krieges, worunter sich allerdings noch Beurlaubte befanden - zum Teil in Lazaretten und zum Teil in Gefangenschaft. Außerdem kannte man zu diesem Zeitpunkt noch immer nicht die endgültige Zahl der Gefallenen und führte die Studierenden, von deren Schicksal man noch keine Nachricht erhalten hatte, weiter in den Statistiken.

Das erste wirkliche Nachkriegssemester war das Wintersemester 1919/20, in dem kein Studierender mehr beurlaubt war. Hier kann man nun wieder von weitgehend gesicherten Zahlen ausgehen, auch wenn man natürlich bedenken muss, dass nicht jeder, der nun eingeschrieben war, tatsächlich schon physisch und psychisch in der Lage war, sein Studium wieder aufzunehmen. ${ }^{62}$ Insgesamt waren nun 4189 Studenten und 383 Studentinnen an der Georgia Augusta eingeschrieben. Das waren 61\% mehr als vor dem Krieg, was die Universität selbstverständlich an ihre Kapazitätsgrenzen brachte. Obwohl dies schon schwer wog, wirkt diese Entwicklung noch viel dramatischer, wenn man die Kürze des Zeitraums bedenkt, in der sie sich vollzog. Innerhalb von nur zwei Jahren markierte die Anzahl der aktiven Studierenden einen absoluten Tiefststand, um dann förmlich auf einen absoluten Höchststand zu schnellen. Vergleicht man das Wintersemester 1917/18 mit dem von 1919/20, so erkennt man einen weit stärkeren Anstieg als nur von $61 \%$. Innerhalb weniger Semester trat sogar eine Versechsfachung der Zahlen ein: von 754 aktiven Studierenden (1917/18) auf 4572 (1919/20).

Von den 748 Gefallenen, die die Georgia Augusta zu beklagen hatte, waren 726 Studenten. ${ }^{63}$ Zwischen 1532 und 2282 Studierende waren zum Kriegsdienst beurlaubt worden. Wie viele es absolut waren, lässt sich leider kaum ermitteln. Demnach fielen zwischen $32 \%$ und $47 \%$ aller in den Militärdienst eingetretenen Studenten oder 28\% aller männlichen Studierenden des letzten Vorkriegssemesters - also fast jeder Dritte. Diese Quoten lagen deutlich über denen für die gesamten deutschen Streitkräfte. Hier fielen 15\% aller eingesetzten Soldaten und

62 Es dauerte bis in die 1920er Jahre, bevor man die endgültige Zahl der Gefallenen kannte. Siehe hierzu: Universität Göttingen (Hrsg.): Dem Andenken ihrer im Weltkriege Gefallenen. Gewidmet zum 1. März 1925 von der Georg-August-Universität Göttingen. München 1925.

63 Zahlen nach: Universität Göttingen (Hrsg.): Dem Andenken ihrer im Weltkriege Gefallenen. Gewidmet zum 1. März 1925 von der Georg-August-Universität Göttingen. München 1925. 
$12 \%$ aller wehrfähigen Männer. ${ }^{64}$ In dieser Hinsicht stellte Göttingen keinen Einzelfall dar: „Ein großer Teil einer ganzen Akademikergeneration verblutete in den Schützengräben [...]“",65 wie Jarausch es formuliert. Sowohl in den übrigen deutschen Universitäten als auch in denen der Kriegsgegner war das Bild dem in Göttingen ähnlich. ${ }^{66}$

64 Zahlen aus: Overmans, Rüdiger: Kriegsverluste. In: Hirschfeld, Krumeich, Renz (Hrsg.): Enzyklopädie. 2003. S. 664-665.

65 Jarausch: Deutsche Studenten. 1984. S. 109.

66 Siehe hierzu: Weber, Thomas: Studenten. In: Hirschfeld; Krumeich; Renz (Hrsg.): Enzyklopädie. 2003. S. 910-912. Auch von den Marburger Studierenden fiel circa ein Drittel. Wettmann: Heimatfront. 2000. S. 399. Deutlich geringere Zahlen gibt hingegen Liermann für Erlangen an. Hier fielen 224 Studierende im Vergleich zu 1310 Immatrikulierten bei Kriegsausbruch. Liermann: Die Friedrich-Alexander-Universität. 1977. S. 34 und 39. Nach Winter fielen ein Fünftel der Angehörigen der Universität Oxford. In den jüngeren Altersgruppen erreichten allerdings auch hier die Verlustraten 30 Prozent. Winter: Oxford. 1994. S. 19-23. 


\section{Die Studierenden und der Krieg}

Die nackten Zahlen der Statistiken vermögen nur wenig über das auszusagen, was die Studierenden dieser Zeit tatsächlich erlebten. Zumindest aber zeigen sie, dass mit fast 60\% weit mehr als die Hälfte der Göttinger Studenten bereits im ersten Kriegssemester in das Militär eintraten. Jarausch sieht ähnliche Zahlen für ganz Deutschland, wofür er eine eindeutige Erklärung nennt: Die deutschen Studenten sahen den „Weltkrieg als nationale Bewährung;"67 die Ereignisse im Juli 1914 mit der Dramatik der letzten Friedenstage lösten bei ihnen einen „,vaterländischen Reflex“"68 aus. Dieser vaterländische Reflex war, so Jarausch, in den Studenten seit langem angelegt und gerade durch die Konzentration von nationalen Feierlichkeiten mit entsprechenden Festreden im letzten Jahr vor Ausbruch des Krieges aktiviert worden, wie etwa anlässlich des einhundertjährigen Jubiläums der Völkerschlacht oder des fünfundzwanzigjährigen Regierungsjubiläums Kaiser Wilhelms II. Der Kriegsausbruch hatte, so Jarausch, geradezu etwas Befreiendes, besonders für die Verbindungsstudenten. Sie schienen die Bewährungsprobe herbeigesehnt zu haben, um endlich beweisen zu können, dass sie den so oft bemühten Begriffen wie Ehre und Treue auch Taten folgen lassen würden und tatsächlich den Studenten der Jahre 1870/71 in diesen Eigenschaften in nichts nachstanden. ${ }^{69}$ Gerade in diesem Zusammenhang sahen studentische Verbindungen und Professoren nun eine Bewährungsprobe für ihre Erziehungsarbeit gekommen, wie in zahlreichen Zeitschriftenartikeln und Reden deutlich wurde. ${ }^{70}$

Auch in Göttingen wurden solche Erwartungen offensichtlich nicht enttäuscht, und der Prorektor der Georgia Augusta, Eduard Kaufmann, wandte sich, wie viele seiner Kollegen an diesem Tag, in einer Rede am 1. August an seine Studierenden:

Jeder Deutsche weiß, wo sein Platz ist, wenn das Vaterland zu den Waffen ruft. In deutscher Treue zu unserm Verbündeten, zur Wahrung der Ehre unseres deutschen Namens ist kein Opfer zu groß. Und Deutschlands studierende Jugend war stets bereit, mit Herz und Hand einzutreten, wenn es des Vaterlands Ehre galt. ${ }^{71}$

„Einige Hundert Studenten“ dankten Kaufmann für seine Rede, indem sie „am Abend des 2. August unter Absingung patriotischer Lieder ohne weitere Vorberei-

67 Jarausch: Deutsche Studenten. 1984. S. 106.

68 Jarausch: Deutsche Studenten. 1984. S. 107.

69 Siehe hierzu: Wettmann: Heimatfront. 2000. S. 47ff.

70 Jarausch: Deutsche Studenten. 1984. S. 106ff. Zusammenfassung von Jarauschs Darstellung siehe oben. Weitere Beispiele: o.N.: Die Deutsche Burschenschaft im Felde. In: Burschenschaftliche Blätter, Nr. 10 vom 15.08.1914. S. 229-230; o.N.: Der Krieg. In: Deutsche Korpszeitung (Academische Monatshefte), Nr. 376 vom 15.08.1914. S. 225.

71 Zitiert nach: o.N.: Academische Mobilmachung. Göttingen. In: Burschenschaftliche Blätter, Nr. 10 vom 15.08.1914. S. 240-241. 
tungen zu dem Prorektor zogen" und dort durch einen Redner versicherten, dass er „in seiner warmen Ansprache [...] den Studenten aus der Seele gesprochen“ habe. ${ }^{72}$ So stellten es zumindest die Burschenschaftlichen Blätter, das Zentralorgan der deutschen Burschenschaften, dar.

Hier sind jedoch Zweifel angebracht. Wie bereits eingangs erwähnt, wurden in jüngster Zeit durch die Forschung große Teile der bisher üblichen Darstellung der Ereignisse des August 1914 in Frage gestellt und die Bilder uneingeschränkter Kriegseuphorie als Mythos entlarvt. ${ }^{73}$ Auch die aus Göttingen geschilderten Ereignisse sind typisch für die Bilder, die lange Zeit die Geschichtsschreibung dominierten: ${ }^{74}$ spontane Demonstrationszüge, das Singen patriotischer Lieder und das öffentliche Halten von kriegsbefürwortenden Reden. Auch die von Jarausch in seinen Arbeiten angeführten Beispiele fallen in diese Kategorie. Es bleibt also zu überprüfen, inwieweit sie auch für die Göttinger Verhältnisse zutreffend waren und wie sich die Georgia Augusta als Korporation dazu verhielt. Die Frage, die sich stellt, lautet: Müssen auch Jarauschs Darstellungen im Hinblick auf die von ihm festgestellte weitgehende Kriegsbejahung der Studierenden relativiert werden, so wie dies für nahezu alle anderen Teile der Öffentlichkeit geschehen ist, oder stellen gerade die Studierenden in dieser Hinsicht eine Ausnahme dar? Sind sie vielleicht eine der wenigen Gruppen, in denen die uneingeschränkte Kriegseuphorie Realität war?

Spione in der Gewerbeschule

Die allgemeine nationalistische Erregung wirkte sich erwartungsgemäß auf die in Göttingen und Umgebung lebenden Ausländer und damit auch auf die ausländischen Studierenden am stärksten aus. Es gelang immerhin einem großen Teil von ihnen noch vor dem endgültigen Ausbruch des Krieges, während der Julikrise, Göttingen zu verlassen. Dies spiegelt auch die Statistik der Gesamtzahl der ausländischen Studierenden wider.

Mit Beginn des Krieges brach die Zahl der Studierenden aus dem europäischen Ausland fast völlig ein, da diese fast ausschließlich von Engländern, Franzosen und Russen gestellt wurden. Den allgemeinen Hinweisen für ausländische Studierende, die jedem Vorlesungsverzeichnis voranstanden, wurde eilig der generelle Hinweis hinzugefügt, dass sich Angehörige „feindlicher Nationen“ nicht immatrikulieren dürften. Auch Studierenden, die bereits seit längerem immatrikuliert waren, war es nicht mehr gestattet, ihr Studium abzuschließen.

72 o.N.: Academische Mobilmachung. Göttingen. In: Burschenschaftliche Blätter, Nr. 10 vom 15.08.1914. S. 240-241.

73 Siehe oben. Bruendel, Steffen: Volksgemeinschaft oder Volksstaat: die „Ideen von 1914“ und die Neuordnung Deutschlands im Ersten Weltkrieg. Berlin 2003; Raithel: Das „Wunder“. 1996. Verhey: Der „Geist“. 2000. Sehr gut zusammengefasst bei: Müller: Die Nation. 2002. S. 56ff.

74 Sehr ähnliche Berichte existieren auch für andere deutsche Universitäten und Universitätsstädte. Vergleiche hierzu: Wettmann: Heimatfront. 2000. S. $205 \mathrm{ff}$. 


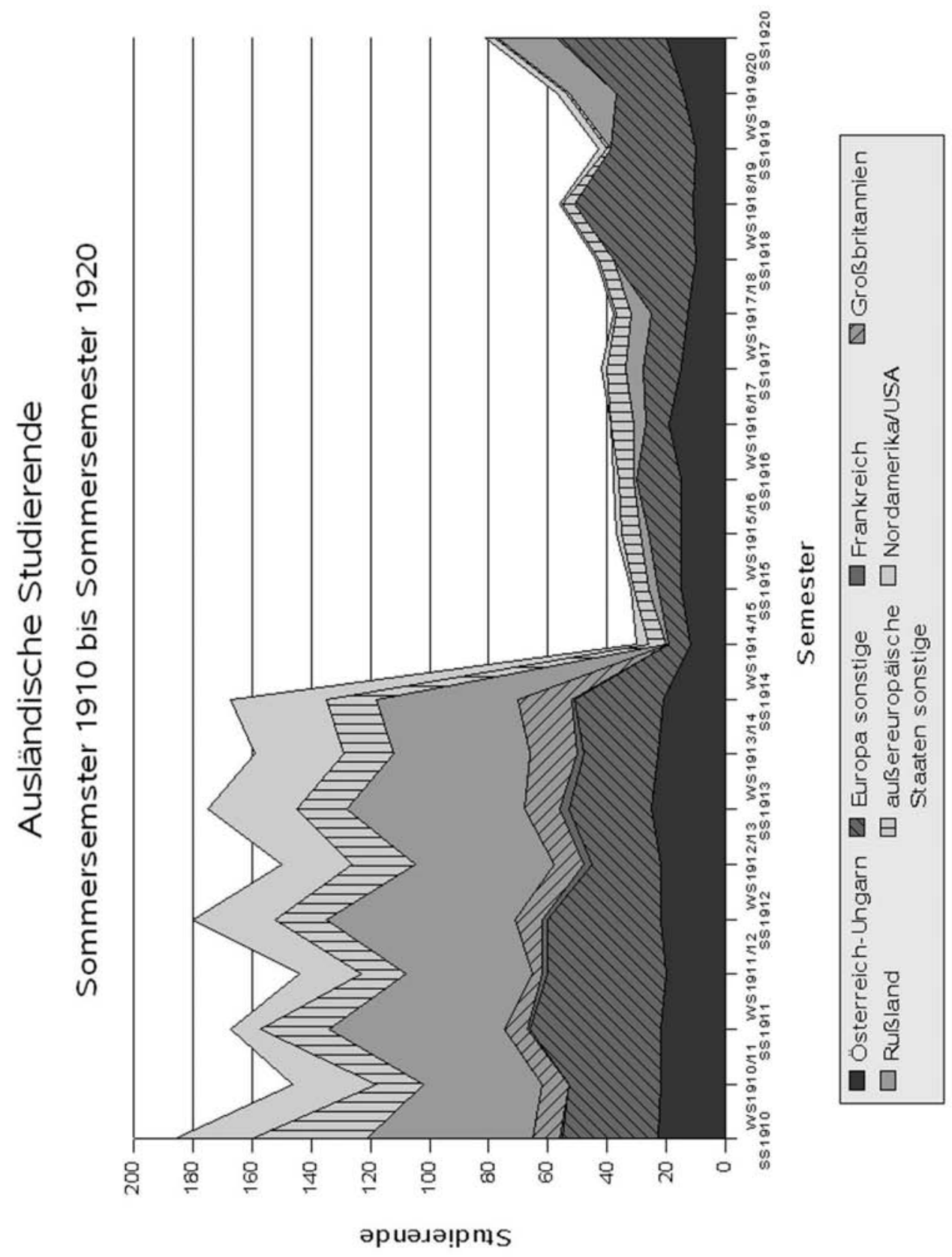

Statistik 4: Daten aus: Universität Göttingen (Hrsg.): Amtliches Verzeichnis des Personals und der Studierenden der königl. Georg-August-Universität zu Göttingen. Göttingen 1910 bis 1920. (Daten jeweils aus der im Folgesemester erscheinenden „Endgültigen Feststellung"). 


\section{Angebörige dieser Staaten sind [...] als Schüler und Schülerinnen zum Unterricht an der Universität bis auf weiteres nicht zuzulassen. Es kann daher auch den immatrikulierten Studierenden aus diesen Ländern der Besuch der Vorlesungen nicht ferner gestattet wer- den, und Neuaufnabmen solcher Studierender sollen nicht stattfinden. ${ }^{75}$}

Auffällig ist auch, dass bereits 1914, also noch vor Kriegseintritt der Vereinigten Staaten von Amerika, die amerikanischen Studierenden Göttingen verließen, die den Hauptteil der außereuropäischen Studierenden stellten. Generell kann man sagen, dass Deutschland verließ, wer noch Gelegenheit dazu hatte. Aber nicht allen gelang dies rechtzeitig. Wahrscheinlich aus finanziellen Gründen waren hiervon vor allem die russischen Studierenden betroffen, ${ }^{76}$ was sich für sie besonders ungünstig auswirkte, da gerade die Russen den schlechtesten Ruf aller Kriegsgegner Deutschlands besaßen und unter zahlreichen Vorurteilen zu leiden hatten, einschließlich dem von der „Überschwemmung“677 Europas mit Spionen. Als Folge des allgemein schlechten Russlandbildes galt Russland folgerichtig in den ersten zwei Kriegswochen noch als der Hauptfeind Deutschlands. Frankreich und England folgten hier erst später. ${ }^{78}$

75 UAG.Phil.Fak.II.96 2.9.1914. Dieser Erlaß wurde am 28.9.1914 nochmals durch den Universitätskurator bekräftigt und ausdrücklich um die Doktoranden erweitert. „Wie der Herr Minister der geistlichen und Unterrichts-Angelegenheiten aus Anlass eines Einzelfalls bemerkt hat, ist derselbe davon ausgegangen, dass Angehörige feindlicher Staaten nach dem Ausbruch des Krieges nicht mehr zu Doktoren promoviert worden sind. Jedenfalls wird ergebenst ersucht für die Folge dafür Sorge zu tragen, dass dies nicht geschieht. Liegen in einem einzelnen Falle Gründe vor, die eine Ausnahme gerechtfertigt erscheinen lassen, so ersuche ich gefälligst darüber zu berichten." Beachtenswert ist sicherlich zumindest die theoretische Möglichkeit einer Ausnahme. UAG.Phil.Fak.II.96 28.9.1914.

Die Umsetzung dieses Erlasses schildert Daniela Siebe für die Universität Gießen. In ganz Deutschland soll der Anteil der Ausländer an der Gesamtzahl der Studierenden mit Kriegsausbruch von 7,7\% auf 2,7\% gesunken sein: Siebe: Ausländische Studenten. 2000. S. 36.

76 Maurer, Trude: Weder Kombattanten noch Kommilitonen. „Feindliche Ausländer“ in einer deutschen Universitätsstadt während des Ersten Weltkriegs. In: Jahrbuch für Universitätsgeschichte, Jg. 2005, H. 8, S. 211-235. S. 216. Laut Bericht der Göttinger Polizeidirektion waren am 20.08.1914 150 Ausländer noch in Göttingen gemeldet. Davon waren mit 78 über die Hälfte russischer Staatsangehörigkeit und davon 23 Saisonarbeiter, also keine Studierenden. Diesem Bericht zufolge gelang es lediglich den hier gemeldeten Japanern als einziger Nation, bereits vor Kriegsausbruch Deutschland zu verlassen. St.A.Gö.Pol.Dir.165,1 Bl. 81.

77 Raithel: Das „Wunder“. 1996. S. 99

78 Zur Wahrnehmung der Kriegsgegner: Raithel: Das „Wunder“. 1996. S. 92ff und 327ff. Russland besaß, gerade in den frühen Phasen des Krieges, das bei weitem niedrigste Ansehen aller deutschen Kriegsgegner. In Frankreich meinte man zwar seit langem eine „Revanchelust“ zu sehen und beargwöhnte die Unterstützung der russischen Rüstungen, sah sich aber andererseits von französischer Kultur, Mode oder Lebensart durchaus angezogen. England wurde vor Ausbruch des Krieges fast überhaupt nicht mit negativen Eigenschaften assoziiert. Es galt vielmehr als Verwandter oder Vetter, dessen politisches und wirtschaftliches Geschick allerdings Misstrauen erweckte. Beiden Nationen war aber gemeinsam, dass Vorurteile oder Ähnliches in deutscher Sicht nicht auf den einzelnen Menschen übertragen wurden, sondern in den politischen Bereich rückten oder man einzelne Politiker kritisierte. Bei Russland war dies anders; hier gab es auch innerhalb Deutschlands keine großen Unterschiede in der Sichtweise. Deutsche Konservative 
Wenig überraschend zeigte diese negative Stimmung bei Kriegsausbruch Wirkung. Scheinbar entluden sich nun lange aufgestautes Misstrauen und Argwohn, wie in der Erinnerung des Göttinger Pastors Albrecht Saathoff deutlich wird:

Wir sahen, als am Nachmittag des 1. August nach tagelanger atemloser Spannung die Mobilmachung verkündet war, den Menschenstrom nach den Kasernen zu durch unsere Straßen fluten. Wirklich die beiden Löwen am Geismartor hatten solches nie gesehen! Und am folgenden Tage nach dem Sonntagsgottesdienste die aufgeregte Menge auf dem Johanniskirchplatz vor dem Stadthause, jedes helle Autosignal mit neuem Triumphgeschrei und mit Ausrufen des Abscheus begrüßend, als wäre jeder eingebrachte russische Student, von Soldaten mit aufgepflanztem Seitengewehr bewacht, ein Bombenwerfer oder Brunnenvergifter! Gingen doch in diesen Tagen die wildesten Gerüchte von Mund zu Mund. Etwa: man habe versucht, die Leinebrücke zu sprengen, die russischen Attentäter seien sofort auf dem Schießstande erschossen. [... $]^{79}$

Weiterhin berichtet er von Gerüchten, dass Bomben unter einem Militärzug im Göttinger Bahnhof gefunden worden seien, ${ }^{80}$ oder dass ein russischer Professor im Solling eine Wasserleitung gesprengt habe. ${ }^{81}$ Bei der Betrachtung solcher Berichte ist eine gewisse Vorsicht geboten, da Saathoff seine Erinnerungen als Beitrag zum dem Göttinger Kriegsgedenkbuch 1935 niederschrieb, also zu einer Hochzeit der Mythologisierung des Augusts 1914. Allerdings existieren in Form der Akten der Göttinger Polizeidirektion auch uneingeschränkt glaubwürdige Quellen, die seine Darstellungen bestätigen. Saathoff wusste sicherlich, das es bei Kriegsausbruch in Göttingen keinen russischen Professor gegeben hatte, aber es

und Sozialdemokraten sahen Russland gleichermaßen negativ. Man sah „Deutschenhass“ und war sich sicher, dass ganz Europa von russischen Spionen überflutet wurde. Außerdem wurde in Zusammenhang mit Russland zumindest von der politischen Rechten ein bestimmter Rassenbegriff eingeführt, und es war die Rede vom deutsch-slawischen Gegensatz. Gerade in verbindungsstudentischen Kreisen konnten solche Vorgaben leicht mit dem schon länger als krisenhaft empfundenen Steigen der Studierendenzahlen und damit schlechteren Studienbedingungen kombiniert werden. Siehe unten.

Auch der Göttinger Privatdozent der Physik und spätere Ordinarius Max Born erzählt rückblickend in seiner Autobiographie vom vorherrschenden schlechten Ansehen Russlands: „Ich kann nicht leugnen, daß ich während dieser Zeit eine starke Abneigung gegenüber den Engländern, den Franzosen und vor allem gegenüber den Russen empfand.“ Born, Max: Mein Leben. München 1975 S. 226-227.

Ausführliche Darstellung und zahlreiche Literatur zu der besonderen Situation der russischen Studierenden: Maurer: Weder Kombattanten. 2005. Die besonderen Immatrikulationsbeschränkungen für russische Studierende schildert Daniela Siebe: Siebe: Ausländische Studenten. 2000. S. 25. Siehe hierzu auch: Wettmann: Heimatfront. 2000. S. $127 \mathrm{ff}$.

79 Saathoff (Hrsg.): Göttinger Kriegsgedenkbuch. 1935. S. 53.

80 Saathoff (Hrsg.): Göttinger Kriegsgedenkbuch. 1935. S. 53.

81 Saathoff (Hrsg.): Göttinger Kriegsgedenkbuch. 1935. S. 59. 
war genau diese Art von Gerüchten, die das Klima innerhalb der Bevölkerung so sehr anheizten. ${ }^{82}$

Von offizieller Seite aus wurde versucht, möglichst schnell aller in Deutschland befindlichen Ausländer habhaft zu werden und damit selbstverständlich auch der betroffenen Studierenden. Laut einem Aktenvermerk des Universitätssekretärs Gassmann waren jeweils mit erfolgter Kriegserklärung alle Angehörigen der entsprechenden Nationen inhaftiert worden.

Göttingen 2. August 1914.

1. Heute ist die Kriegserklärung an Russland ergangen.

2. Infolge Sabotageverdachts sind sämtliche Russen $u$. Russinnen in Schutzhaft gebracht (in der Gewerbeschule). [...]

Am 4.8.14 wird von England der Krieg erklärt. Nachts sind alle Englischen Studenten (auch Südafrikaner) verhaftet und in der Mädchenmittelschule untergebracht. Sie sind jedoch alle mit einer Ausnahme vorher abgereist [... ${ }^{83}$

Die Haftbedingungen in den Schulgebäuden waren nicht gut. In der Gewerbeschule waren sie sogar so schlecht, dass einer von vier dort ebenfalls inhaftierten Japanern, ${ }^{84}$ nach Ende des Krieges auf eine Entschädigung vor dem EnglischDeutschen Gemischten Schiedsgerichtshof klagte. Die Gefangenen mussten sich unter anderem auf eigene Kosten verpflegen und auf Stroh schlafen:

We were detained in two rooms (perhaps old classrooms) on the first floor. Neither entrance nor exit doors were locked, but the rooms were strictly guarded by two armed men day and night. In the beginning these two persons were first reservists but were later replaced by two men who looked like armed firemen. We bought all our food; no bedding was supplied; we had to sleep on straw. At first we were not allowed even to go to toilet or lavatory, but later on our request was granted and we were free to go out of the rooms to satisfy our call of nature with no escort. We could talk and read books, but not newspapers. ${ }^{85}$

82 Max Born spricht von „patriotischen Wahnsinn“ in Bezug auf die genannten Gerüchte und die folgenden Verhaftungen von Ausländern. (Born: Mein Leben. 1975. S. 224-225.) Auch die aus anderen deutschen Universitätsstädten vorliegenden Berichte gleichen sich vielfach in hohem Maße. Insbesondere der Topos des Brunnenvergiftens findet sich immer wieder. Als Beispiele: Anderhub: Das Antoniterkreuz. 1979. S. 1; Siebe: Ausländische Studenten. 2000. S. 35.

83 UAG.Sek.38.1. 02.08.1914 Bei der erwähnten Ausnahme handelte es sich offensichtlich um William Threlfall. Siehe unten.

84 Diese vier Japaner kamen ursprünglich nicht aus Göttingen. Sie wurden lediglich am Göttinger Bahnhof aus ihren Zügen geholt und verhaftet. Ihre Namen waren: Onari Kimura, Ryoichi Kondo, Saito und Ume. St.A.Gö.Pol.Dir.165,2 Bl. 62.

85 St.A.Gö.Pol.Dir.165,2 Bl. 62. 
Den vier Japanern gelang es schließlich, Kontakt mit der amerikanischen Botschaft aufzunehmen, die dann für den 10. Oktober 1914 ihre Ausreise in die Schweiz vermitteln konnte. ${ }^{86}$

Dem Göttinger Garnisonskommando, in Person eines Majors Rübke, waren die Haftbedingungen in der Gewerbeschule allerdings noch nicht streng genug, worüber er sich am 5. August bei der Polizeidirektion beschwerte:

Bewachung der festgesetzten Russen [die dort zunächst ausschließlich inhaftiert waren] in der Gewerbeschule erscheint unzulänglich. Verkehr mit Besuch einzeln und unter Aufsicht. Keine Briefe pp. aus den Fenstern werfen oder durch Besuch herausschmuggeln! Nur von Aufsichtshabenden gelesene unverdächtige Briefe in deutscher Sprache werden befördert. Kein verdächtiger Zeichenverkehr nach außen. Kein Schmieren von Bewachungsmannschaften durch Verabreichung von Essen u.s.w. ${ }^{87}$

Die überaus schnell durchgeführten Inhaftierungen können aber nicht darüber hinwegtäuschen, dass man sich zunächst nicht wirklich klar darüber zu sein schien, wie man mit den sich in Deutschland befindenden Ausländern verfahren wollte. Die Militärbehörden, die mit Ausbruch des Krieges faktisch die Kontrolle übernommen hatten, ${ }^{8}$ waren sich lediglich sicher, dass man die Ausländer nicht einfach ausreisen lassen wollte, sei es, weil sie tatsächlich möglichen Geheimnisverrat befürchteten, oder weil zumindest die Männer in ihrer Heimat in das feindliche Heer eintreten würden. Bis jedoch eine erste offizielle Regelung in Kraft trat, nach der alle Ausländer zwischen 17 und 45 Jahren als Kriegsgefangene behandelt werden sollten, dauerte es mehrere Wochen. Bis dahin genügte ein pauschal ausgesprochener Sabotage- und Spionageverdacht, um die Betreffenden festzuhalten, was auch zu Unklarheiten bei den örtlichen Behörden führte. Am 5. August etwa fragte die Göttinger Polizeidirektion beim örtlichen Garnisonskommando an, wie man mit den in der Mädchenschule und der Gewerbeschule Inhaftierten verfahren solle und bat darum, „das weitere zu veranlassen“. 89

Im Laufe des August kristallisierte sich dann in verschiedenen Erlassen eine vorerst endgültige Lösung heraus. Diese wurde vom stellvertretenden Generalkommando in Hannover herausgegeben und sah überraschenderweise eine Freilassung der Inhaftierten vor, stellte sie allerdings unter engmaschige Überwachung durch die Behörden. Nur ,verdächtige und lästige Angehörige feindlicher Staaten“ sollten weiter in Schutzhaft genommen werden. Zunächst wurde eine Briefsperre gegen alle Ausländer verhängt, die beinhaltete, dass „die Briefsendungen für die hier wohnenden russischen, englischen pp. Staatsangehörigen nicht auszuliefern“ seien und stattdessen an die Polizeidirektion geschickt werden sollten, die diese

\footnotetext{
86 St.A.Gö.Pol.Dir.165,2 Bl. 26v.

87 St.A.Gö.Pol.Dir.163,1 Bl. 40.

88 Siehe hierzu: Deist, Wilhelm: Militär und Innenpolitik im Weltkrieg 1914-1918. Düsseldorf 1970. Chickering: Imperial Germany. 1998. S. 32ff.

89 St.A.Gö.Pol.Dir.165,1 Bl. 13.
} 
dann kontrollierte. ${ }^{90}$ Außerdem war den Ausländern untersagt, den Bereich des zuständigen stellvertretenden Generalkommandos zu verlassen. Größten Wert legten die Militärbehörden ferner darauf, jegliche Gruppenbildung oder Kontakte mit dem Ausland zu verhindern: „Auf strengste Überwachung sämtlicher Angehöriger feindlicher Staaten zur Verhinderung eines jeden Versuchs der Sammlung oder Übermittlung von Nachrichten an das Ausland oder an Mittelspersonen weise ich ganz besonders hin." $" 1$

Um dies zu gewährleisten, mussten Ausländer sich jeweils an bestimmten Wochentagen persönlich bei der örtlichen Polizeidirektion melden. Darüber hinaus wurden ihnen eventuell vorhandene deutsche Ausweispapiere wieder abgenommen, um zu verhindern, dass sie sich bei Kontrollen als Deutsche ausgeben konnten. Stattdessen erhielten die Ausländer provisorische Ausweise, in denen sowohl ihre Nationalität vermerkt war, als auch welchen Bereich sie nicht verlassen durften. ${ }^{92}$ In einem Schreiben vom 26. August fasste das stellvertretende Generalkommando diese Maßnahmen noch einmal zusammen, ${ }^{93}$ und die Göttinger Polizeidirektion meldete umgehend, dass „verfügungsgemäß“ mit allen hier gemeldeten Angehörigen feindlicher Nationen verfahren worden sei. ${ }^{94}$

Die weitere Kontrolle der nun wieder auf freiem Fuß befindlichen Ausländer wurde offensichtlich sehr ernst genommen. Voraussetzung für eine Entlassung aus der Schutzhaft war zuerst eine schriftliche Verpflichtung des Inhaftierten, Göttingen nicht zu verlassen und die vorgeschriebenen regelmäßigen Termine auf der Polizeidirektion einzuhalten, wie etwa im Falle des kanadischen Studenten Winthrop Bell:

Der Student Winthrop Bell geb. 12.5.1884 in Halifax, Nova Scotia, Canada ₹:Zt. bier in Schut:̧haft erklärt:

Ich bitte um Entlassung; da ich während des Krieges nicht in meine Heimat zurückkehren kann, bin ich gezwnngen bier zu bleiben. Ich verpflichte mich, jeden dritten Tag beim Herm Polizei-Inspektor Hennies zu melden [Einfügung unleserlich]. Als erster Tag der Meldung ist mir der Montag 10. d.Mts. abends aufgegeben. [eigenhändige Unterschrift ${ }^{95}$

90 Zusammengefasst aus verschiedenen Fundstellen aus der zweiten Hälfte des Augusts 1914. St.A.Gö.Pol.Dir.164,3 Bl. 1ff; St.A.Gö.Pol.Dir.164,4 Bl. 8; St.A.Gö.Pol.Dir.165,1 Bl. 83-87.

91 St.A.Gö.Pol.Dir.165,1 Bl. 84. Als besonders gefährlich stufte man in dieser Hinsicht die größeren Gruppen landwirtschaftlicher Saisonarbeiter ein, für die es besondere Vorschriften gab. Man empfahl, diese von älteren Mitgliedern von Schützenvereinen oder Ähnlichem bewachen zu lassen und betonte, ,dass jede Widersetzlichkeit mit sofortigem Erschießen bestraft werden kann.“ St.A.Gö.Pol.Dir.165,1 Bl. 85.

92 Gelegentlich wurde den Ausländern auch ihr ursprünglicher Ausweis belassen und diesem diese Informationen hinzugefügt.

93 St.A.Gö.Pol.Dir.164,3 Bl. 3.

94 St.A.Gö.Pol.Dir.164,3 Bl. 3v.

95 St.A.Gö.Pol.Dir.165,1 Bl. 8v. 
Darüber hinaus musste ein Bürge genannt werden, der ebenfalls eine schriftliche Versicherung über die Zuverlässigkeit des Inhaftierten abgeben musste. Im Fall der Studierenden übernahmen dies oft ihre Professoren. Am häufigsten trat hier der Chemiker Gustav Tammann hervor, der selbst im Gouvernement Petersburg geboren war. ${ }^{96}$ Aber auch viele seiner Kollegen setzten sich auf diese Weise für ihre Schüler ein, wie etwa die Professoren Bonwetsch, Coehn, Voigt, von Hippel, Borsche oder Wallach. Aber auch Professor Theodor Simon, der sich im Folgenden nicht unbedingt durch eine große Ausländerfreundlichkeit auszeichnen sollte, ${ }^{97}$ bürgte für einen polnischen Juden, seinen Studenten Michael Tennenbaum. Eine solche Bürgschaft war jedoch keine Selbstverständlichkeit, sondern wurde

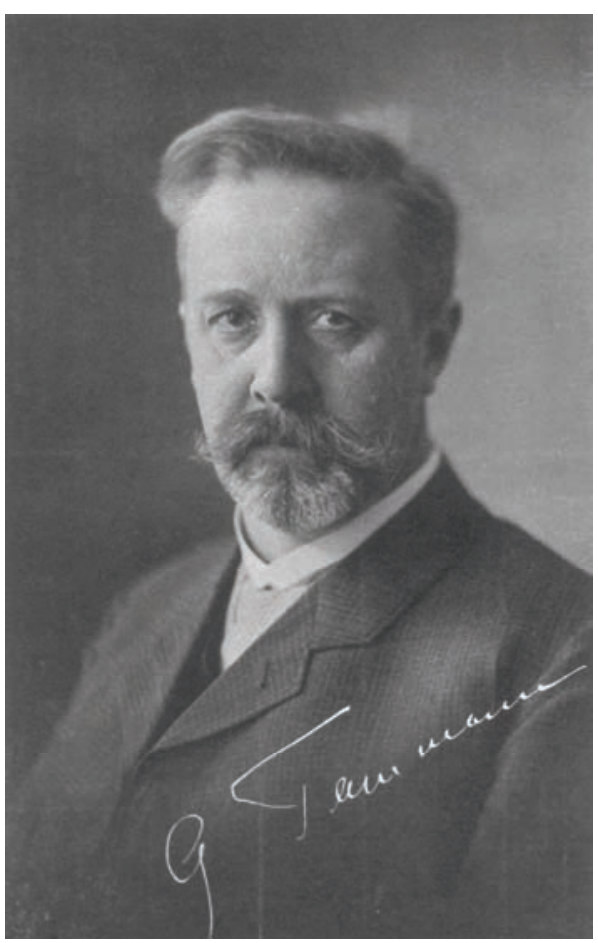

Abbildung 1: Gustav Tammann nur denen zu Teil, die einen ihrer Dozenten tatsächlich persönlich kannten. Der Student Moses Schönfinkel etwa, der erst im Juni nach Göttingen gekommen war und deshalb bei Kriegsbeginn noch keine Kontakte hatte aufbauen können, fand keinen Bürgen. ${ }^{98}$

Für Winthrop Bell bürgte der Prorektor des ersten Kriegssemesters, Professor Carl Runge: „Ich verbürge mich dafür, daß der Canadier Winthrop P. Bell jede Versicherung, die er eingeht, unverbrüchlich halten wird."99 $\mathrm{Ob}$ und welche Konsequenzen es für den Bürgen hatte, wenn dieses scheinbar grenzenlose Vertrauen einmal enttäuscht wurde, kann man leider nicht sagen. Im Fall Runges hatte es zumindest für ihn wohl keine Konsequenzen, als Bell so unvorsichtig war, in der Öffentlichkeit - er stand an seinem Fenster, sein Gesprächspartner und Kommilitone auf der Straße davor - den Kriegseintritt Japans auf Seiten der Alliierten zu kommentieren. „Das Ultimatum Japans sei ein grosses Stück Frechheit, aber für uns (Eng-

\footnotetext{
96 Maurer: Weder Kombattanten. 2005. S. 220.

97 Siehe hierzu die Diskussion um die Berufung eines Nachfolgers für den Göttinger Physiker Eduard Riecke. Siehe oben.

98 Liste der Namen und ihrer Bürgen: St.A.Gö.Pol.Dir.165,1 Bl. 18ff. Detaillierte Schilderung bei: Maurer: Weder Kombattanten. 2005. S. $220 \mathrm{ff.}$

99 St.A.Gö.Pol.Dir.165,1 Bl. 9.
} 
länder) [sic!] sei es besser.“100 Bell jedoch wurde diese Aussage als „ehrverletzend“ gegenüber Deutschland ausgelegt und brachte ihm eine lange Haftstrafe ein, die er zum Teil auch im Karzer der Universität verbüßte. ${ }^{101}$ Die Göttinger Polizei schätzte Bell nach ihren Verhören als „durchaus deutschfeindlich“ und „verdächtig" ein und schlug vor, ihn nach Hannover in den Gewahrsam des stellvertretenden Generalkommandos zu überstellen, was von dort jedoch abgelehnt wurde. ${ }^{102}$

Außerdem war ein namhafter Bürge noch keine Garantie dafür, dass man auch tatsächlich aus der Schutzhaft entlassen wurde, auch wenn dies die Ausnahme blieb. Der Privatdozent in der Abteilung für theoretische Physik des physikalischen Instituts, Baron Dr. Freedericksz, der mit Voigt, Simon und Tammann gleich drei Professoren als Bürgen nennen konnte, blieb trotz Bürgschaft in Haft. Voigt hatte sogar angeboten, dass er in seinem Haus wohnen könne. ${ }^{103}$ Freedericksz, dessen Familie aus Holland stammte, aber seit 150 Jahren in Russland lebte, hatte sich zum einen durch Aussagen wie „wir sind Russen und fühlen uns auch als Russen" verdächtig gemacht, und zum anderen hatte er die Ausreise in seine Heimat beantragt. Diesem Antrag war ein Gutachten eines deutschen Militärarztes angefügt, das besagte, dass er nicht militärtauglich sei. Außerdem machte die Tatsache, dass Freedericksz Assistent gewesen war, ihn für die deutschen Behörden in anderer Hinsicht interessant. Die Göttinger Polizeidirektion bot ihn, zusammen mit zwei anderen Russen, dem Generalstab quasi als Geisel an, da „Russland eine grössere Anzahl von Kultusbeamten pp. festhält, als bei uns festgenommen sind." 104

Wurde man schließlich doch aus der Schutzhaft entlassen, so konnten auch die erteilten Auflagen noch sehr unangenehme Folgen für die Betroffenen haben, gerade wenn, wie im Falle des Manufakturwarenhändlers Natan Blum, vor den Verhaftungen gar nicht allgemein bekannt gewesen war, dass er und seine Familie aus Russland stammten und bereits vor circa 30 Jahren nach Göttingen gekommen waren. Dies galt ebenso für die mit den Blums verschwägerte Familie Silbergleit, die ein Schuhgeschäft betrieb. Der Anwalt der Familie wandte sich deshalb an die Polizeidirektion mit der Bitte, mehr Rücksicht auf die Situation seiner Mandanten zu nehmen. Die Tatsache, dass die gesamte geschäftliche Korrespon-

100 UAG.Sek.598.8.Bell Zitat aus der Universitätsgerichtsakte Bells.

101 Bell wurde vom Rechtspflegeausschuss der Universität am 27. August 1914 in einem universitätsinternen Disziplinarverfahren von der Universität verwiesen. Er legte gegen dieses Urteil Revision ein, um eine Milderung der Strafe zu erreichen. Dieses wurde jedoch am 16. September durch das Kultusministerium abgelehnt. Seine bereits eingereichte Dissertation und seine - in Schutzhaft - erfolgreich ablegte mündliche Prüfung wurden ihm aberkannt. UAG.Sek.598.8.Bell St.A.Gö.Pol.Dir.165,1 Bl. 119-120. Bell half noch während seiner Inhaftierung in der Gewerbeschule den vier bereits erwähnten Japanern, mit der amerikanischen Botschaft Kontakt aufzunehmen, die dann deren Ausreise in die Schweiz vermittelte. St.A.Gö.Pol.Dir.165,2 Bl. 62.

103 St.A.Gö.Pol.Dir.165,1 Bl. 18ff.

104 St.A.Gö.Pol.Dir.165,1 Bl. 130. Diese Passage wurde zwar aus dem Konzept für das endgültige Schreiben wieder gestrichen, aber in ähnlicher Form handschriftlich wieder hinzugefügt. 
denz durch die verhängte Postsperre verspätet eintraf, stellte hier noch das geringste Problem dar. Am schwersten wog vielmehr der Verlust von Ansehen für die Familien, die sich selbst als Göttinger Bürger und keinesfalls als Russen betrachteten. Der Anwalt beschreibt detailliert, in welch unwürdiger Weise die regelmäßigen Meldungen bei der örtlichen Polizei abliefen:

In regelmäßigen Zwischenräumen erhalten sie Aufforderungen, sich an bestimmten Plätzen zur Controlle zu melden. Unter anderem ist dafür einmal der Schulhof der Volkesschule und zwar nachmittags um 4 Uhr, als die Schüler gerade aus der Schule kamen, gewählt. Sie haben mit den ebenfalls geladenen russischen Studenten in Reib und Glied antreten müssen und haben auf dem Platze Verhaltungsmassregeln [sic!] erhalten. Dem $V$ orfall hat eine Anzahl Publikum, insbesondere eine Reibe Schüler beigewohnt und der Erfolg war, dass bei diesen auf dem Platz aufgestellt gewesenen ,Russen' niemand mehr kauft. 105

Den Geschäftsleuten sollte durch diese öffentliche Zurschaustellung geschadet werden. Wahrscheinlich spielten auch Rachegefühle ein Rolle, da den Betroffenen explizit gesagt wurde: „Wie die Deutschen in Russland sollten sie in Deutschland behandelt werden." $" 106$

Inhaftiert wurde, wie bereits erwähnt, erst einmal jeder Ausländer, dessen man habhaft werden konnte, ohne Unterschiede zu machen. Gerade in den ersten Tagen des August 1914 hatte niemand Zeit und Muße, Einzelfälle zu prüfen, wie etwa den des englischen Staatsbürgers und Mathematikstudenten William Threllfall. Er war einer der wenigen Engländer, die sich bei Kriegsausbruch noch in Göttingen aufhielten. Er hatte jedoch gar nicht versucht, das Land zu verlassen, sondern bemühte sich im Gegenteil um eine Einbürgerung, um auf deutscher Seite in den Krieg ziehen zu können. Er fühlte sich als Deutscher, da seine Mutter Deutsche und er offensichtlich in Deutschland erzogen worden war: „In Wahrheit bin ich doch deutsches Erzeugnis, nur mit englischer Etikette. "107 Für ihn trat der Mathematiker Professor David Hilbert als Bürge ein, und auch Threllfall musste sich zunächst verpflichten, Göttingen nicht zu verlassen. ${ }^{108}$ Trotzdem versuchte er zu seinem Onkel nach Berlin zu gelangen, um dort seine Einbürgerung zu erreichen. Diese Reise wurde ihm schließlich auf Vermittlung Hilberts gestattet, und er meldete sich am 26. September aus Berlin bei seinem Lehrer, um ihm für die erwiese Hilfe zu danken. ${ }^{109}$ Auch Threlfalls Mutter hatte sich zuvor bereits bei Hilbert in einem Brief bedankt. ${ }^{110}$ Threlfall unterstreicht in seinen Briefen die besondere Strenge und Unnachsichtigkeit der Göttinger Polizei im Gegensatz zu

\footnotetext{
105 St.A.Gö.Pol.Dir.165,1 Bl. 102-103.

106 St.A.Gö.Pol.Dir.165,1 Bl. 103.

107 SUB.Gött.HSD.Cod.Ms.David Hilbert.406 Bl. 2.

108 St.A.Gö.Pol.Dir.165,1 Bl. 26.

109 SUB.Gött.HSD.Cod.Ms.David Hilbert.406 Bl. 1.

110 SUB.Gött.HSD.Cod.Ms.David Hilbert.406 Beilage.
} 
den entsprechenden Behörden in Berlin und in Dresden, der Heimatstadt seiner Mutter.
Ich hoffte anfangs, sehr bald nach Göttingen zurückkehren zu können. Da aber die dor- tige Polizei im Gegensatz. zur Berliner und zur Militärbebörde darauf bestebt, mich nach meinem Paß und nicht nach meiner Gesinnung und meinem Vorleben zu beurtei- len, so werde ich mit meiner Rückkehr bis zu meiner Einbürgerung warten müssen. ${ }^{111}$

In einem weiteren Brief aus dem Oktober 1914 schreibt Threlfall, dass er nicht mehr wagen würde, zurückzukehren, „wegen der starken Verbitterung gegen die Engländer, in denen sich das Volk jetzt endlich den ärgsten und beinahe einzigen Feind zu erblicken wünscht,“ und da die Affäre um seine Schutzhaft so viel Aufsehen erregt habe, dass nun seine - noch immer - englische Staatsbürgerschaft weithin bekannt wäre. ${ }^{112}$ Hier erging es ihm wie den russisch-stämmigen Geschäftsleuten.

Man muss Threlfalls Vergleiche zwischen den Berliner Behörden und den Göttinger Stellen deutlich relativieren. In der Hektik oder sogar dem Chaos der ersten Kriegstage wird auch in Berlin oder Dresden sich keine Polizeidirektion die Zeit genommen haben, um Einzelfälle zu prüfen. Genau diese ersten Tage hatte Threlfall aber in Göttingen erlebt. Als reine Aussage über die herrschenden $\mathrm{Zu}$ stände in diesen Tagen sind seine Aussagen jedoch ganz sicher von Wert, zumal sie von weiteren Fundstellen ergänzt werden.

Wie aus dem bereits zitierten Schreiben des Major Rübke, in dem er die Bewachung der inhaftierten Russen als unzulänglich bezeichnet, hervorgeht, empfanden die Militärbehörden die in Göttingen anwesenden Russen tatsächlich als ernstzunehmende Bedrohung. Der Bericht des Majors überschnitt sich allerdings mit einem Brief der Polizeidirektion, in dem auch diese eine bessere Bewachung der Schutzhäftlinge forderte. Jedoch sah man hier die Bedrohungslage ganz anders, nämlich auf Seiten der Russen.

\section{Wir halten uns für verpflichtet, die Militärverwaltung darauf aufmerksam zu machen, dass die Erregung gegen die Russen bier derart zugenommen hat, dass eine starke Bewa- chung der untergebrachten Russen erforderlich geworden ist. ${ }^{113}$}

Es galt also, die mutmaßlichen Saboteure und Spione vor der Bevölkerung zu schützen. Als endlich die Möglichkeit einer Entlassung unter Auflagen für die Inhaftierten bestand, führte dies sogar so weit, dass mehrere von ihnen darum baten, in der Schule bleiben zu dürfen. So beispielsweise der Chemiestudent

111 SUB.Gött.HSD.Cod.Ms.David Hilbert.406 Bl. 1.

112 SUB.Gött.HSD.Cod.Ms.David Hilbert.406 Bl. 2. Wiliam Threlfall erreichte wohl schließlich doch seine Einbürgerung und sein großes Ziel, für Deutschland in den Krieg ziehen zu können. Im August 1915 schrieb er Hilbert einen Brief von der Ostfront, in dem er seine Tätigkeiten bei der Entwicklung von Luftbildern beschreibt. Was weiter aus ihm wurde oder ob er gefallen ist, ließ sich leider nicht in Erfahrung bringen. SUB.Gött.HSD.Cod.Ms.David Hilbert.406 Bl. 3.

113 St.A.Gö.Pol.Dir.165,1 Bl. 13. 
Johann Ponomareff, der seit 1913 bei Professor Tammann studierte. Obwohl sein Dozent für ihn mit Sicherheit gebürgt hätte, zog er es vor, trotz der bereits geschilderten Haftbedingungen zusammen mit seiner Frau Marie und seinem erst zehn Monate alten Sohn Georg, der bereits in Göttingen geboren worden war, in der Gewerbeschule zu bleiben. ${ }^{114}$

Diese extrem aufgeheizte Atomsphäre, die es dem Familienvater sicherer erscheinen ließ, mit seiner Familie in Haft zu bleiben, war bei weitem kein Göttinger Problem, sondern sie prägte ganz Deutschland. In der neueren Literatur werden immer wieder die Begriffe Chaos oder Hysterie bemüht, um die ersten Augusttage 1914 zu charakterisieren. Sven-Oliver Müller spricht sogar davon, dass Angst und Aggressivität sich zu einer ,regelrechten Progromstimmung“ verdichteten.115 Diese Stimmung war jedoch keine spontane, sich verselbstständigende und schließlich unkontrollierbar werdende Erscheinung. Es verbarg sich dahinter vielmehr eine durchaus geplante Strategie des deutschen Staates, wie es beispielsweise auch Verhey zeigt. Das Spionagefieber kam der Regierung durchaus gelegen, und die dafür notwendigen Gerüchte wurden zum Teil auch von offizieller Stelle gezielt lanciert. ${ }^{116}$ Diese offensichtliche Bedrohung war eine unerlässliche Stütze für die so wichtige Selbstdarstellung, die besagte, dass Deutschland der Angegriffene war und dass man sich gegen einen heimtückischen Überfall verteidigte. Wer hätte daran gezweifelt angesichts der zahlreichen Spione und Saboteure, die ihr Unwesen trieben. „Die emotionale Gestaltung des Nationalismus erleichterte seine Erfahrbarkeit und Durchsetzungsfähigkeit ganz erheblich, "117 auch wenn dabei oft die Kontrollierbarkeit auf der Strecke blieb.

Dies zeigt sich besonders bei einer Erscheinungsform, die Verhey sehr treffend als „karnevaleske Massen“ bezeichnet. Er setzt sie in Kontrast zu den Massen, die entweder ihr Informationsbedürfnis oder Kriegsfurcht auf die Straße trieb - den „neugierigen“ und den „panischen“ Massen. ${ }^{118}$ Das Karnevaleske im Sinne Verheys steht für die Möglichkeit, die sich in dieser Ausnahmesituation eröffnete, Dinge zu tun, die sonst nicht erlaubt oder zumindest gesellschaftlich nicht geduldet gewesen wären. Nun konnte jeder, der sich dazu berufen fühlte, Spione jagen, ${ }^{119}$ seinen Nachbarn denunzieren ${ }^{120}$ oder, wie Verhey es beschreibt, Schaufensterscheiben einschlagen. Hauptsächlich Jugendliche zogen in diesen Tagen durch die Städte und bedrohten Geschäftsleute, auf deren Türschildern, Werbetafeln oder Schaufenstern französische oder englische Worte standen und erzwangen so beispielsweise die Umbenennung des Berliner Café Belvedere in Kaffeehaus $V$ aterland. Hielten die Inhaber der Geschäfte die ihnen gesetzten Fristen nicht ein,

\footnotetext{
114 St.A.Gö.Pol.Dir.165,1 Bl. $18 \mathrm{ff}$.

115 Müller: Die Nation. 2002. S. 67.

116 Verhey: Der „Geist“. 2000. S. $149 \mathrm{ff}$.

117 Müller: Die Nation. 2002. S. 69.

118 Verhey: Der „Geist“. 2000. S. 129 ff.

119 Müller: Die Nation. 2002. S. 67.

120 Siehe unten. St.A.Gö.Pol.Dir.163,1 Bl. 15.
} 
wurden die Scheiben zerschlagen. ${ }^{121}$ Müller bringt es auf den Punkt, wenn er schreibt: „Der August 1914 eröffnete die Gelegenheit, durch die Übererfüllung nationalistisch interpretierter Pflichten Gewalt gegen beinahe jedermann zu legitimieren." $" 122$

Dabei leitet das Wort Pflicht zu einem weiteren wichtigen Aspekt über: Das allgemeine Spionagefieber war die wichtigste Kompensationsmöglichkeit für alle die, die zwar keinen Zweifel an ihrer persönlichen Pflicht hatten, für ihr Land in den Krieg ziehen zu müssen, es aber aus verschiedenen Gründen nicht konnten sei es, weil sie aus gesundheitlichen Gründen nicht verwendungsfähig waren oder weil die Zahl der Freiwilligen schlicht zu hoch war und in der Kürze der Zeit nicht bewältigt werden konnte. ${ }^{123}$ Gerade die über lange Zeit durch konservative Werte konditionierten Verbindungsstudenten empfanden dies oft als eine Art persönlicher Zurücksetzung, der man irgendwie begegnen musste, um sein Gesicht innerhalb der eigenen Gruppe und nach außen hin zu wahren. ${ }^{124}$

Wie wenig können wir zu Hause Gebliebenen für das Vaterland tun, während die anderen ibr Blut dabingeben! Es ist ein billiger Trost, wir Nichtkämpfer sollten verstärk.t unsere Alltagspflichten erfüllen, um Kulturwerte zu erbalten und zu schaffen. Wir tun es nach Kräften, aber obne Befriedigung zu finden. Wenn doch nur alle diensttauglichen bätten dienen können! Hoffentlich bringt der Krieg auch darin eine Wendung. ${ }^{125}$

Dieser fast flehentliche Ausruf eines Aachener Studenten ist die kurze Zusammenfassung seiner Gefühlslage, die er in einen langen Leserbrief einfließen lässt, in dem er seinen Alltag in der Stadt beschreibt, durch die täglich neue Truppen in Richtung Belgien ziehen. Bereits in den ersten Leitartikeln der großen Verbindungszeitschriften zum Ausbruch des Krieges wird eben dieses Thema angesprochen. Es war für die Verbindungen selbstverständlich, dass ihre Mitglieder geschlossen in den Krieg zogen, und dementsprechend sah man sich nun gezwungen zu betonen, dass es nicht an den Studenten gelegen hatte, dass noch nicht alle von ihnen die Universitätsstädte verlassen hatten. „Nicht allein die Wehrpflichtigen eilen freudig zu den Waffen, nein, Alles was Waffen tragen kann, schart sich um die Fahne des Reiches. [...] Wer nicht angenommen wird stellt seine Kräfte dem Vaterlande sonstwie zur Verfügung,"

121 Verhey: Der „Geist“. 2000. S. 151-153.

122 Müller: Die Nation. 2002. S. 67.

123 Verhey: Der „Geist“. 2000. S. 167ff. Verhey betont, dass die Zahl der Kriegsfreiwilligen stets viel zu hoch angegeben worden ist. Bereits wenige Tage nach der Verkündung der Mobilmachung sei in der Presse von 1.300.000 Freiwilligen die Rede gewesen. Tatsächlich waren es im ganzen August aber nur 185.000.

124 Vergleiche auch für die Universität Marburg: Wettmann: Heimatfront. 2000. S. 213ff. und S. $379 \mathrm{ff}$.

125 Fritze: Unsere Feldpost. In: Burschenschaftliche Blätter, Nr. 11 vom 01.09.1914. S. 282-284.

126 o.N.: Der Krieg. In: Deutsche Korpszeitung (Academische Monatshefte), Nr. 376 vom 15.08.1914. S. 225. 
ihrer ersten Kriegsausgabe und auch die Burschenschaftlichen Blätter betonten, dass dort, wo ihre Mitglieder „abgewiesen worden sind“ sie „andere Wege“ gefunden haben, „dem Vaterlande zu dienen."127 Untätigkeit wäre ganz offensichtlich für einen Verbindungsstudenten dieser Tage nicht zu rechtfertigen gewesen.

Wie konnten solche ,anderen Wege“, seinem Land zu dienen, in einer Stadt wie Göttingen aussehen? Zunächst einmal boten sich hier Aktionen gegen Ausländer, insbesondere Russen, an - also die Verfolgung potentieller Spione und Saboteure.

Am 7. August forderte das Innenministerium alle größeren Gemeinden dazu auf, „aus zuverlässigen Einwohnern, die mit der Handhabung von Schußwaffen vertraut sind, Bürgerwehren zu bilden [...]." ${ }^{\prime 128}$ Dies war nicht mehr als der Versuch, eine Entwicklung, die bereits nahezu vollständig außer Kontrolle geraten war, wieder in einen geordneten Rahmen zu bringen. Bereits seit dem 28. Juli wurden strategisch wichtige Punkte, wie etwa die Eisenbahnbrücken, von bewaffneten Posten bewacht. ${ }^{129}$ Zusätzlich hatte man Polizeiverstärkung für unterschiedliche Aufgaben angefordert, wie etwa zur Aufrechterhaltung der öffentlichen Ordnung an den Sammelstellen für Rekruten und Kriegsfreiwillige. Hierfür hatte sich schnell eine Reihe Freiwilliger bei der Polizeidirektion gemeldet, unter denen Studenten eindeutig die Mehrzahl stellten. Diese Freiwilligen sollten jedoch zunächst nicht alleine auf Streife gehen, sondern es wurde ihnen immer ein „Schutzmann“ als Begleitung zugeteilt. ${ }^{130}$ Allerdings konnte offenbar weder diese Regelung lange durchgehalten werden, noch nahm man sich die Zeit zu überprüfen, wem man Gewehr und Armbinde aushändigte, was folgendes Beispiel verdeutlicht:

Der Student Walter Mindt, geboren in Berlin und Mitglied der Burschenschaft Germania, wollte sich gemeinsam mit seinen Verbindungsbrüdern freiwillig zum Kriegsdienst melden, wurde jedoch noch nicht angenommen. ${ }^{131}$ Daher begab er sich zunächst zur städtischen Meldestelle für freiwillige Kriegshilfe. Dort traf er mit dem, wie sich später herausstellen sollte, psychisch kranken Kaufmann Karl Holborn zusammen, der zuvor 48 Stunden lang Dienst als bewaffneter Posten beim Bahnschutz geleistet hatte. ${ }^{132}$ Sein dortiger Vorgesetzter war ebenfalls kein Polizist, sondern ein Tischlermeister, und diesem war es nicht gelungen, Holborn daran zu hindern, nach Ende seines Dienstes seinen Posten zu verlassen, ohne zuvor Gewehr, Armbinde und Ausweis abzugeben. ${ }^{133}$ Holborn erklärte Mindt, dass er den Auftrag habe, in der nahegelegenen Ortschaft Wellershausen revoltie-

\footnotetext{
127 o.N.: Die Deutsche Burschenschaft im Felde. In: Burschenschaftliche Blätter, Nr. 10 vom 15.08.1914. S. 229-230.

128 St.A.Gö.Pol.Dir.164,7 Bl. 26.

129 St.A.Gö.Pol.Dir.164,1 Bl. 3.

130 St.A.Gö.Pol.Dir.164,1 Bl. 12.

131 St.A.Gö.Pol.Dir.164,1 Bl. 34.

132 St.A.Gö.Pol.Dir.164,1 Bl. 28.

133 St.A.Gö.Pol.Dir.164,1 Bl. 30.
} 
rende polnische Saisonarbeiter zu kontrollieren. Gemeinsam mit einem Schüler, den sie ebenfalls in der Meldestelle trafen, beschlagnahmten sie das Automobil eines Dr. Overding und fuhren damit nach Wellershausen. Obwohl der Gendarmerie-Wachtmeister des kleinen Ortes ihnen mehrfach erklärte, dass „verdächtige Polen nicht ortsanwesend seien“ und dass eine Durchsuchung des Hofes nur unnötige Aufregung mit sich bringen würde, durchsuchten Holborn, Howe und Mindt die Unterkünfte der Landarbeiter und verhafteten deren Vorarbeiter, den sie nach Göttingen zur Kaserne brachten. ${ }^{134}$

Am nächsten Tag, offensichtlich unzufrieden mit der bisherigen Ausbeute, verpflichteten Holborn und Mindt einen Kraftfahrer, der in einem Wagen auf dem Kasernenhof gehalten hatte. Holborn erklärte, dass er nun den Auftrag hätte, alle Franzosen, Engländer und Dänen zu verhaften und alle Polen zu überprüfen. Sie fuhren daraufhin - noch immer bewaffnet - an die Weser und kontrollierten auf dem Weg dorthin erneut polnische Arbeiter. In der Ortschaft Bursfelde bestiegen Mindt und Holborn später einen Passagierdampfer, um nach verdächtigen Fahrgästen zu suchen, während der Fahrer zur nächsten Anlegestelle vorausfuhr. ${ }^{135}$ In einer Kabine des Schiffs trafen sie den Reisenden Wilhelm Franz von Borries Eckendorf an, der sich auf Verlangen Mindts legitimieren musste. Von Borries Eckendorf kam dieser Aufforderung zwar nach, der Student erklärte jedoch ohne zu zögern, dass die Legitimationskarte gefälscht sei. Auch ein hinzugezogener Polizist half dem Reisenden nicht, dessen Gepäck nun durchsucht wurde, woran „sich der Pöbel in der unglaublichsten Weise beteiligt habe“, wie er später zu Protokoll gab. Erst nachdem er sich auch noch teilweise hatte entkleiden müssen, kontrollierte auch der Polizist die Legitimationskarte nochmals und beendete diesen Vorfall. ${ }^{136}$ Holborn und Mindt wurden kurze Zeit später verhaftet, als sie stehend und mit geladenem Gewehr im Anschlag weiter im Automobil an der Weser entlang fuhren. ${ }^{137}$ Holborn wurde umgehend von seinem Vater abgeholt und in eine Heil- und Pflegeanstalt gebracht. ${ }^{138}$ Ein Hinweis auf irgendwelche Konsequenzen für den Studenten Mindt findet sich indessen nicht.

Dieses Beispiel verdeutlicht, wie ein Klima entstand, in dem durch teilweise blinden Aktionismus Gefahr für Leib und Leben entstand. Die lokalen Behörden, wie etwa die Göttinger Polizeidirektion, waren überfordert und konnten keinerlei Kontrolle gewährleisten. Militärbehörden und Regierung förderten zunächst noch solche Entwicklungen, indem das Innenministerium die Aufstellung von Bürgerwehren forderte oder erklärte, dass eine geeignete Qualifikation für die Bewachung von russischen Saisonarbeitern die Mitgliedschaft in einem Schützenverein

\footnotetext{
134 St.A.Gö.Pol.Dir.164,1 Bl. 33.

135 St.A.Gö.Pol.Dir.164,1 Bl. 34.

136 St.A.Gö.Pol.Dir.164,1 Bl. 33.

137 St.A.Gö.Pol.Dir.164,1 Bl. 34.

138 St.A.Gö.Pol.Dir.164,1 Bl. 29.
} 
sei und „dass jede Widersetzlichkeit mit sofortigem Erschießen bestraft werden kann."139

Oft genügte es, nur ein einfaches Gerücht in Umlauf zu bringen, um die Bevölkerung lange beschäftigt zu halten und damit in das große Ganze, den Krieg, zu integrieren. Zweiflern oder Kritikern wurde so keine Chance gegeben. Eine Initialzündung einer Art Kettenreaktion war beispielsweise ein Telegramm des Düsseldorfer Regierungspräsidiums an das Innenministerium vom 3. August 1914, in dem von 80 französischen Offizieren berichtet wurde, die in zwölf Autos Deutschland zu durchqueren suchten, um dem russischen Waffenbruder Gold zu bringen. Die Nachricht wurde dankbar aufgenommen und über Zeitungen und Telegramme im ganzen Land verbreitet, wobei es sich aber am 4. August bereits angeblich um 25 Autos handelte und sich bald auch einige Damen zu den französischen Offizieren gesellten. ${ }^{140}$ In ganz Deutschland wurde nun regelrecht Jagd auf Automobile gemacht ${ }^{141}$ und zwangsläufig erreichten diese, oder besser die Gerüchte, auch Göttingen. ${ }^{142}$ Am 5. August traf ein Telegramm bei der örtlichen Polizeidirektion ein:

meldung der opd duesselorf: angekuendigtes auto 12386 soll nach barmen rittershausen untervegs sein. radfahrer in maurerkleidung suchen franzoesisches von auto herruebrendes gold weiter zu schaffen. auto sucht vielleicht grenze zu erreichen. polizeibehoerden schnellstens benachrichtigen. auch jeden radfahrer anhalten und untersuchen. militärposten benachrichtigen. ${ }^{143}$

Die auch landesweit auftretende Variation dieses Gerüchts, die nun auch von Radfahrern sprach, war wohl eine Reaktion darauf, dass es noch nirgendwo gelungen war, ein entsprechendes Automobil zu stellen. ${ }^{144}$ Allerdings hoffte man in Göttingen, kurz vor einem Erfolg zu stehen. Noch am Abend des Tages, an dem das Telegramm mit den Hinweisen bei der Polizeidirektion eingetroffen war, gelang es einem Posten, ein verdächtiges Automobil ausfindig zu machen, das an einer Strasse parkte. Die Polizeidirektion ordnete sofort an, das Fahrzeug, das mit einem Sarg beladenen war, noch in der gleichen Nacht in einer Autowerkstatt „völlig abmontieren zu lassen.“145 Wie dann festgestellt werden konnte, befand sich in dem Sarg kein Gold, sondern die Leiche des verstorbenen Oberstaatsan-

139 St.A.Gö.Pol.Dir.164,1 Bl. 85.

140 Müller: Die Nation. 2002. S. 67.

141 Müller: Die Nation. 2002. S. 67-68; Verhey: Der „Geist““. 2000. S. 147-148.

142 Auch Saathof berichtet hierüber: Saathoff (Hrsg.): Göttinger Kriegsgedenkbuch. 1935. S. 53.

143 St.A.Gö.Pol.Dir.164,1 Bl. 19.

144 Müller hierzu: „Die schwerindustrielle, Reihnisch-Westfälische Zeitung’ bot ihren gesamten wirtschaftlichen Sachverstand auf und stellte eine Überschlagsrechnung an. Die vermuteten 80 Millionen Goldfranken wögen etwa 26.666 Kilogramm. Um diese Last zu transprotieren, seien ca. 50 Automobile, aber doch mindestens 1066 Radfahrer notwendig. Der geäußerte Zweifel hinderte das Blatt aber nicht, die besagten Telegramme auf der Titelseite zu veröffentlichen." Müller: Die Nation. 2002. S. 68.

145 St.A.Gö.Pol.Dir.164,1 Bl. 16. 
walts Rindfleisch aus Kassel. ${ }^{146}$ Auch im Fahrzeug selber konnte nichts Verdächtiges entdeckt werden, wie auch in allen anderen Fahrzeugen, die in ganz Deutschland aufgebracht wurden. „Von derartigen Meldungen aufgestachelt schossen die Bürgerwehren auf jedes Auto, dass sich blicken ließ." "147 Insgesamt fanden in der ersten Augustwoche auf diese Weise mindestens 28 Menschen den Tod an StraBensperren oder bei Verfolgungsjagden, zahlreiche weitere wurden verletzt. ${ }^{148}$

Wie in ganz Deutschland setzte sich nun auch in Göttingen auf offizieller Ebene die Einsicht durch, dass die Verhältnisse immer unkontrollierbarer wurden und sich zusehends verselbstständigten. Garnisonskommando, Landrat und Polizeidirektion veröffentlichten deshalb am 7. August eine gemeinsame Bekanntmachung in den lokalen Zeitungen.

Angesichts verschiedener tatsächlich vorgekommener Fälle von Spionage hat sich bier wie anderorts der Bevölkerung eine begreifliche Erregung bemächtigt. Die ganze Bevölkerung ist bemüht Spione zu entlarven und zur Untersuchung zu bringen. Der darin zum Ausdruck kommende vaterländische Sinn unserer Bevölkerung und deren Bestreben, mitžubelfen an der Bekämpfung nichtswürdiger, gegen unser V aterland und seine Armee gerichteter Umtriebe verdient volle Anerkennung. Gleichwohl muß nachdrücklichst vor einem Übereifer gewarnt werden. Falsche Meldungen baben bereits zu Feblgriffen bei Verhaftungen und Beschlagnahmen geführt. [... $]^{149}$

Man hatte erkannt, dass es offensichtlich keinerlei weiteren Anstoßes bedurfte, um die Bevölkerung in Kriegsstimmung zu bringen oder zu halten. Im Gegenteil entwickelte sich gerade die Behinderung des Straßenverkehrs langsam zu einem ernsten Problem für die Mobilmachung, und Aktionen wie die Mindts und Holborns störten die öffentliche Ordnung nachhaltig. Letztendlich bedeutete die große Zahl der im Umlauf befindlichen und noch zusätzlich ausgegebenen Waffen ein nicht mehr zu kalkulierendes Risiko. Es dauerte aber noch einige Zeit, bis solche Entwicklungen sich wieder abschwächen sollten, was auch den Behörden klar gewesen sein muss. Die Bekanntmachung schloss daher vorsorglich mit dem Satz: „Schließlich ersuchen wir die Eltern, ihre Kinder von der Straße fernzuhalten.“"150 Unter diesen Umständen ist es ausgesprochen verständlich, dass der Student Johann Ponomareff es vorzog, mit seiner Familie in Schutzhaft zu bleiben.

146 St.A.Gö.Pol.Dir.164,1 Bl. 16.

147 Müller: Die Nation. 2002. S. 68

148 Müller: Die Nation. 2002. S. 70; Verhey: Der „Geist““. 2000. S. 148.

149 St.A.Gö.Pol.Dir.164,1 Bl. 35.

150 St.A.Gö.Pol.Dir.164,1 Bl. 35. 
Ausländer innerhalb der Universität

Es wurde deutlich, dass in der Extremsituation des Kriegsausbruchs in weiten Teilen der Bevölkerung vielfach Misstrauen, Gewaltbereitschaft und tatsächliche Gewalttaten zu Tage traten. Kristallisationspunkt der Gewalt waren zumeist in Deutschland lebende Ausländer. Dies liegt zwar durch die Gegnerschaft im Krieg scheinbar selbstverständlich auf der Hand, bedarf aber doch eines genaueren Blickes, da diese Erklärung deutlich zu kurz greifen würde. ${ }^{151}$ Die Ausländerfeindlichkeit und das Misstrauen müssen schon zuvor vorhanden gewesen sein und kamen nun durch die veränderte Situation an die Oberfläche. Gemäß Verheys These von den karnevalesken Massen war nun plötzlich das erlaubt, was zuvor noch verboten war, und das nutzte man aus. Für die Studierenden, und hier besonders für die Verbindungsstudenten, galt dies in besonders starkem Maße. ${ }^{152}$ Hinzu kam, dass die beschriebene Jagd auf vermeintliche Spione nach verhältnismäßig kurzer Zeit ein Ende gefunden hatte. Wer, aus welchen Gründen auch immer, nun noch immer keine Uniform trug, musste sich bald neue Betätigungsfelder suchen, um in der Öffentlichkeit sein Gesicht zu wahren.

In einem Leserbrief, der in den Burschenschaftlichen Blättern abgedruckt wurde, brüstete sich beispielsweise ein Göttinger Student, der nur mit „H.“ unterzeichnete, dass er es war, der die bereits erwähnten vier Japaner in Göttingen in ihrem Zug verhaftet hatte. Seine Wortwahl gibt einen guten Eindruck von seinen Überzeugungen.

In dem letəten Hefte der ,B [urschenschaftlichen] Bl[ätter]' lese ich, daß es den schlitzäugigen Japsen , bis auf den letzten Mann' gelungen sei, rechtzeitig zu verschwinden. Das trifft nicht ganz. zu. Am 20. August lief hier [in Göttingen] die Meldung ein, daß in einem von Hannover her kommenden Zuge vier Japaner sich befänden. Ich habe, mit Wollust' deren Papiere verlangt. Die Kerle hatten sich noch am 18. v. Mts. von ibrem Gesandten einen Reisepaß ausstellen lassen und diesem am 19. v. Mts. vom Auswärtigem Amte bestätigen lassen. Trotz ihrer Berufung darauf habe ich die vier Japse verhaften und der hiesigen Polizeiverwaltung überweisen lassen; - es waren Berliner Studenten, die nun nach dem eingehenden Genuß deutscher Wissenschaft Gelegenheit und Muße haben, ein deutsches Polizeigewahrsam gründlich kennen zu lernen. ${ }^{153}$

In dem Artikel, auf den sich H. bezieht, wurden Japaner als gerissen oder verschlagen und die ihnen erwiesene Gastfreundschaft auskostend beschrieben. ${ }^{154}$ Dabei genossen sie immer noch ein höheres Ansehen, als ihre russischen Kommi-

151 Zum Bild der Kriegsgegner in der deutschen Öffentlichkeit siehe: Raithel: Das „Wunder“. 1996.

152 Zu Stimmungen und Strömungen innerhalb der Studentenschaft, insbesondere zum Antisemitismus siehe: Jarausch: Students. 1982. Und: Jarausch: Deutsche Studenten. S. 59ff. Gute Analyse bei: Wettmann: Heimatfront. 2000. S. 39ff.

153 o.N. In: Burschenschaftliche Blätter, Nr. 12 vom 15.09.1914. S. 286.

154 o.N. In: Burschenschaftliche Blätter, Nr. 11 vom 01.09.1914. S. 263. 
litonen, deren Volk nach dem Attentat von Sarajewo in Artikeln wie Germanentum und Slawentum verunglimpft wurde. So war zu lesen, dass bei allen Gegensätzen unter den ,,slawischen Völkern“, sie doch zumindest „der Haß gegen das Germanentum“ eine, und es wurde vor den in Deutschland lebenden „Slawen“ eindringlich gewarnt: „Überall maßloser Chauvinismus des Slaventums, glühender Haß gegen das Deutschtum. Wir haben den Feind im eigenen Lande - sind wir uns der Gefahr bewußt, die uns vom Slawentum droht?"155

Ebenso, wie es auf den Straßen mit Ausbruch des Krieges möglich wurde, solches Gedankengut auszuleben, bot der Krieg auch die Möglichkeit, es in die Universität zu tragen. ${ }^{156}$ Wie nicht zuletzt die zahlreichen Bürgschaften von Professoren zu Gunsten ihrer inhaftierten Schüler beweisen, hätten die Studierenden zuvor innerhalb der Universität wahrscheinlich mit solchen Gedanken kein Gehör gefunden. Der Krieg änderte die Situation jedoch vollständig, was die Vertretung der Göttinger Studentenschaft ${ }^{157} 1915$ auszunutzen versuchte:

\section{Ew. Magnificen₹.}

erlaubt sich unterfertigte Vertretung der Göttinger Studentenschaft nachstehendes gehorsamst zur Kenntniss zu bringen.

In der Seminarvorlesung des Herrn Geh.Rats Prof. Hilbert vom 28. Juni waren, der am schwarzen Brett veröffentlichten ministeriellen Bestimmung entgegen drei russische Staatsangehörige zugegen.

Dies Erscheinen von Angehörigen eines mit uns im Kriege stehenden Staates erregte starken Unwillen der anwesenden reichsdeutschen Studenten, zumal im Verlaufe des Krieges von russischer Seite vielfach das Deutschtum geschmäht und beleidigt wird.

Die unterzeichnete Vertretung erhebt hiermit Protest gegen diesen Verstoß gegen die ministerielle Verfügung und bittet Ew. Magnificenz um Aufklärung über diesen Fall.

Ergebenst die Vertretung der Göttinger Studentenschaft B. Kather ₹.Z. Vorsitzender158

155 Lange, Dr. Hans: Germanentum und Slawentum. In: Burschenschaftliche Blätter, Nr. 8 vom 15.07.1914. S. 183-185.

Die besondere Ablehnung, mit der sich russische Studierende in Deutschland konfrontiert sahen schildert Daniela Siebe am Beispiel Gießens. Siebe: Ausländische Studenten. 2000. S. 24ff., S. 39.

156 Andrea Wettmann behandelt die Frage, in welchem Umfang „,der gesamtgesellschaftliche Militarismus" in die Universität hineingewirkt hat. Wettmann: Heimatfront. 2000. S. 44ff.

157 Den Vorsitz der Vertretung der Göttinger Studentenschaft bekleideten zu dieser Zeit B. Kather und sein Stellvertreter C. M. Frommel. UAG.Sek.558(6) Bl. 8.

158 UAG.Sek.558(6) Bl. 1. Daniela Siebe schildert einen ähnlich gelagerten Fall für die Universität Gießen, der allerdings für die Hochschule deutlich glimpflicher verlief. Hier war eine entsprechende Anzeige bei der Polizei erstattet worden. Siebe: Ausländische Studenten. 2000. S. 35-36. 
Diese Eingabe erreichte den Rektor der Georgia Augusta, Professor Carl Runge, am 17. Juli 1915 und wurde von ihm durchaus ernst genommen. In seiner Antwort erklärte er, dass mittlerweile eine ministerielle Verfügung Ausnahmen von der bisher geltenden Regel erlaubte, die Studierende aus mit Deutschland im Krieg stehenden Nationen generell von den Hörsälen ausschloss. Dementsprechend hätten „Personen russischer sowohl von britischer Staatsangehörigkeit [...] in verschiedenem Umfange Erlaubnis bekommen, Einrichtungen unserer Universität zu benutzen." 159 Außerdem versuchte der Rektor, diese Entscheidung, noch über die Betonung ihrer Gesetzmäßigkeit hinaus, den offensichtlich sehr aufgebrachten Studierenden zu erklären, indem er anfügte: „Ich hoffe mich mit der Studentenvertretung in dem Wunsche eins zu wissen, daß es deutschen, in

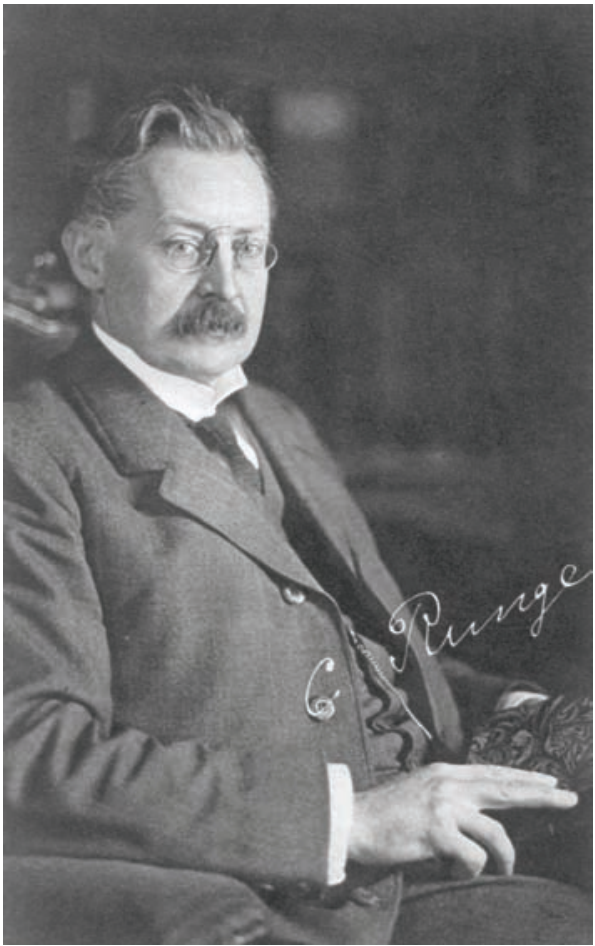

Abbildung 2: Carl Runge Rußland zurückgehaltenen Gelehrten auch gestattet sein möge, dort wissenschaftliche Vorträge zu hören." ${ }^{\text {160 }}$

Die Vertretung der Göttinger Studentenschaft war jedoch in keiner Weise gewillt, sich auf diese Argumentation einzulassen. Sie verfasste eine fünfseitige, überaus scharfe Erwiderung, in der sie zuerst anzweifelte, dass die gemachten Ausnahmen tatsächlich im Einverständnis mit der Regierung stattfanden. Sie glaubte vielmehr, dass

es sich bei diesen Ausnabmefällen - da sie sich nur auf einige und nicht auf alle der ibr bekannten Ausländer erstrecken und da sie nur von einem bestimmten Teil der Göttinger Professorenschaft gebilligt zu werden scheinen - um mebr oder minder persönliche, nur der Universität, vertreten durch Ew. Magnifizens, aber nicht der Regierung bekannte Verwaltungsmaßregeln einzelner Seminar- oder Institutsdirektoren handelt und zwar auf Grund böchstpersönlicher Fürsprache und Vervendung einiger der Göttinger Studenten-

159 UAG.Sek.558(6) Bl. 1v. Ein entsprechender Antrag der Professoren Debye, Hilbert und Runge ging am 11. März 1916 beim Kurator ein. Dieser informierte das Ministerium und erteilte die Genehmigung am 22. März. UAG.Kur.3443 Bl. 159-159v. 


\section{schaft nach jener Richtung hin bereits aus früherer und jetziger Zeit bekannter Lehrer an unserer Georg-August-Universität. ${ }^{161}$}

Dies war selbstverständlich ein überaus schwerer Vorwurf gegen den Rektor, implizierte er doch, dass die Universität aus reiner Willkür und aufgrund persönlicher Bekanntschaften bewusst gegen geltende Gesetze verstoßen habe. Der schneidende Unterton gegen bereits „bekannte Lehrer“ zielte ganz klar in Richtung David Hilbert. Dieser stellte den Vorgang jedoch anders dar. Tatsächlich handelte es sich bei der inkriminierten Veranstaltung um keine „Seminarvorlesung“", wie die Vertretung der Studentenschaft behauptete.

Der Kurator hatte, nachdem er von der Eingabe der Studentenschaft erfahren hatte, am 24. Juli Hilbert mit strengen Worten ermahnt und ihm vorgeworfen, eine ihm erteilte Sondererlaubnis „missbraucht“ zu haben. Diese Sondererlaubnis, die es „russischen Untertanen“ erlaubte, an den Veranstaltungen der rein privaten Mathematischen Gesellschaft teilzunehmen, widerrief der Kurator zugleich. ${ }^{162}$ Hilbert wurde von diesen Vorwürfen von Seiten des Kuratoriums offensichtlich überrascht. Er sagte in seiner noch am gleichen Tag verfassten Antwort zwar widerspruchslos zu, den betroffenen Personen Hausverbot zu erteilen, bestritt aber energisch die geäußerten Anschuldigungen. Die Veranstaltung vom 28. Juni 1915, auf die sich die Vertretung der Studentenschaft bezog, war laut Hilbert keine öffentliche Vorlesung, sondern ein Vortrag im Rahmen der Mathematischen Gesellschaft gewesen, für die die Sondererlaubnis eingeholt worden war. Konkret handelte es sich um einen Vortrag Albert Einsteins auf Einladung des Kuratoriums der Wolfskehlstiftung. ${ }^{163}$ Die beschwerdeführenden Studierenden, die nicht einmal wussten, wer an diesem Tag vorgetragen hatte, konnten demnach auch nicht anwesend gewesen sein, da eine Teilnahme nur auf persönliche Einladung möglich gewesen war. Wegen des großen Interesses an den Vorträgen Einsteins war man allerdings in einen Hörsaal des Auditoriums gewechselt, wo die drei russischen Zuhörer dann erkannt wurden. Es handelte sich bei ihnen um den Privatdozenten Dr. Freedericksz, Dr. Grommer und den Studenten Moses Schönfinkel. Alle drei waren Mitglieder der Mathematischen Gesellschaft. ${ }^{164}$ Die nicht teilnehmenden Studierenden schlossen wahrscheinlich, dass es sich bei der Veranstaltung, deren Zuhörer sie beobachteten, um eine reguläre Vorlesung gehandelt habe. Diese hätte zwar zeitgleich stattfinden müssen, war jedoch wegen der Anwesenheit Einsteins abgesagt worden. ${ }^{165}$ Hilbert machte abschließend deutlich, dass er persönlich enttäuscht war, dass der Kurator, Dr. Ernst Osterrath, der einseitigen Darstellung der Studentenschaft so schnell Glauben geschenkt hatte:

\footnotetext{
161 UAG.Sek.558(6) Bl. 5.

162 UAG.Kur.3443 Bl. 3.

163 UAG.Kur.3443 Bl. 6v.

164 UAG.Kur.3443 Bl. 6.

165 UAG.Kur.3443 Bl. 6.
} 
Die mir seinerzeit von Euer Hochwohlgeboren unter Vorbehalt und bedingt erteilte Erlaubnis habe ich mir als ein mir von Euer Hochwohlgeboren erwiesenes besonderes Vertrauen angesehen: den Vorwurf des Missbrauchs dieser Erlaubnis muss ich daber zugleich als den eines Vertrauensbruches empfinden. Um so sehr, wie dieser schwer wiegt, bätte ich geglaubt, ein Recht zu haben, von Euer Hochwoblgeboren persönlich vorher gebört zu werden. ${ }^{166}$

Der Kurator stellte daraufhin klar, dass er seiner Ansicht nach eine Sondererlaubnis nicht Hilbert gegeben habe, sondern den betroffenen Freedericksz, Grommer und Schönfinkel. Daher habe er keinen Vertrauensbruch Hilberts gesehen, sondern ein Fehlverhalten dessen russischer Schüler. Auflage für diese sei gewesen, sich nur im nichtöffentlichen Rahmen der Mathematischen Gesellschaft zu betätigen.

Durch diese Teilnahme [an einem Vortrag im Auditorium], die ich für missbräuchlich balte, ist es dann dahin gekommen, was durch die gestellte Beschränkung gerade verhindert werden sollte: daß andere Studierende an dem Auftreten der Russen Anstoß genommen und sich beschwert haben. ${ }^{167}$

Der Kurator kritisierte im Weiteren, dass die ,in den Räumen der Universität tagenden Gesellschaften, Vereinigungen etc. “ fremde Gelehrte in die Hörsäle der Universität einluden, ohne mit der Verwaltung Rücksprache zu halten. ${ }^{168}$ Auf die Teilnahme der russischen Staatsangehörigen an solchen Veranstaltungen ging er hingegen nicht weiter ein. Dieses Thema war mit diesem Schreiben Osterraths für Hilbert und das Kuratorium beendet, jedoch nicht für die Vertretung der Studentenschaft.

In der Vorkriegszeit studierten zwischen 140 und 180 ausländische Studierende in Göttingen, wovon in den naturwissenschaftlichen Fächern jährlich circa 12 bis 14 promovierten. ${ }^{169}$ Die Vertretung der Studentenschaft versuchte nicht, zu verbergen, dass ihr das Studium der Ausländer „weil aufgezwungen, niemals angenehm war." ${ }^{170}$ Offensichtlich hatte man gerade in Hilbert einen Vorkämpfer der langsam zunehmenden Internationalisierung der Wissenschaften ausgemacht, die nun auch gerne Ausländerei genannt wurde. ${ }^{171}$ Der Grund für dessen Toleranz

166 UAG.Kur.3443 Bl. 8.

167 UAG.Kur.3443 Bl. 8.

168 UAG.Kur.3443 Bl. 8.

169 Siehe Statistik 4; Zahlen der Promotionen aus: UAG.Phil.Fak.III.34. Promotionsbuch der historisch-philologischen Abteilung bzw. der Philosophischen Fakultät von 1.7.1910 bis 1933.

170 UAG.Sek.558(6) Bl. 8.

171 Göttingen hatte, wie bereits erwähnt, zu dieser Zeit bereits internationale Bekanntheit als Zentrum der Mathematik und der Naturwissenschaften erlangt. Gerade Professoren mit großem Renommee übten auch international eine große Anziehungskraft auf Studierende verschiedenster Länder aus. Dies galt selbstverständlich auch für David Hilbert oder auch Felix Klein. Einen guten Eindruck hiervon vermitteln unter anderem die Briefnachlässe dieser Professoren: SUB.Gött.HSD.Cod.Ms.David Hilbert und SUB.Gött.HSD.Cod.Ms.Felix Klein. 
gegenüber ausländischen Studierenden konnte nach Ansicht der Studentenschaft nur im mangelnden Nationalgefühl ihrer Dozenten liegen:

\section{[... da es sich hier in der Sache weder um eine politische Frage noch um die Frage der Internationalität der Wissenschaft, sondern eben lediglich um nationales Denken, Fühlen und Empfinden, um deutsches Selbstbewußtsein und deutsche Selbstachtung handelt. ${ }^{172}$}

Indem sie Begriffe, wie „nationales Denken“ oder „deutsches Selbstbewusstsein“ in die Diskussion einbrachten, sprachen sie eben diese den angegriffenen Professoren und auch Runge selbst als Rektor der Universität ab, nicht ohne drohend anzufügen, dass man gedenke, diese Fragen nach Ende des Krieges ,im vaterländischen Sinne" 173 zu lösen. Runges Einwand, dass man die ausländischen Studierenden hier so behandeln wolle, wie man hoffe, dass ihre deutschen Kommilitonen in anderen Ländern auch behandelt würden, taten die Studierenden als reine „Träumerei“ ab. ${ }^{174}$

Es bedarf wenig Phantasie, um sich die Erregung Runges vorzustellen, als er dieses Schreiben las. Er verzichtete jedoch auf eine schriftliche Erwiderung und lud kurzerhand die gesamte Vertretung der Göttinger Studentenschaft zu einer Besprechung in das „Prorectur-Zimmer“ des Aulagebäudes für den 30. Juli 1915 vor. ${ }^{175}$ Das Universitätssekretariat fasste später auf ausdrücklichen Wunsch der Studentenschaft dieses Gespräch in einem Protokoll zusammen. Gibt dieses Protokoll die tatsächlichen Gesprächsanteile an dieser Besprechung wieder, wovon man ausgehen kann, so wird deutlich, dass es sich wohl mehr um eine Ansprache mit dem deutlichen Charakter einer Zurechtweisung, als tatsächlich um eine Besprechung gehandelt haben muss. Detailliert werden nochmals alle Argumente des Rektors wiederholt und untermauert, insbesondere wird dabei die Tatsache hervorgehoben, dass es sich bei den gemachten Ausnahmen keineswegs um eigene Verwaltungsmaßregeln der Universität gehandelt habe, sondern um Ausnahmen der Regierung selbst, auf die man von Seiten der Universität keinerlei Einfluss gehabt habe, einer Darstellung an der man anhand des Schriftwechsels zwischen Kuratorium und Hilbert durchaus zweifeln darf. Ferner seien nach Ansicht der Universität diese konkreten Ausnahmen vertretbar und zu begrüßen, man würde auch für die Zukunft sowohl eine generelle Zulassung als auch einen generellen Ausschluss von ausländischen Studierenden feindlicher Nationen ablehnen. Vielmehr sollte immer der konkrete Einzelfall geprüft werden. Interessant ist hierbei, dass Runge auf die Tatsache, dass es sich bei dieser Veranstaltung nicht um eine reguläre Vorlesung gehandelt hat, sondern um einen nichtöffentlichen Vortrag, nicht im Entferntesten eingeht. 
Zu den Positionen der Vertretung der Studentenschaft finden sich indessen lediglich Formulierungen wie „die Studentenvertretung ist mir eine Aufklärung darüber schuldig geblieben“ im Protokoll. ${ }^{176}$ Besonders scharf wurde Runges Ton, als er sich zu den in die Diskussion eingebrachten Begriffen wie dem des „,nationalen Denkens“ oder des „deutschen Selbstbewusstseins“ äußert:
Die Studentenvertretung macht in Anschluß an ihren Protest Betrachtungen aus denen man den Vorwurf gegen einige ibrer akademischen Lehrer entnehmen kann, als ließen sie es an nationalem Denken, Fühlen und Empfinden, an deutschem Selbstbewußtsein und deutscher Selbstachtung fehlen. Der Vorwurf ist völlig unberechtigt. Der einzig un- trügliche Maßstab der Vaterlandsliebe besteht in den Opfern, die man dem Vaterlande bringt; Ich empfeble der Studentenvertretung diesen in nationalen Fragen an sich und an andere anzulegen. ${ }^{177}$

Insbesondere die letzte Passage, in der sich Runge über einen möglichen „Maßstab der Vaterlandsliebe“ äußert, konnten die Mitglieder der Studentenvertretung als eine Spitze gegen die Tatsache werten, dass sie selbst nicht im Kriegsdienst standen. Damit traf er sie an ihrer verwundbarsten Stelle, erreichte aber wahrscheinlich nicht mehr, als dass die Mitglieder der Vertretung nun noch mehr betonten, dass sie sich als Verteidiger ihrer im Kriegsdienst stehenden Kommilitonen verstanden und dieser Protest ihr Beitrag zum Krieg sei. Runge war offensichtlich persönlich durch die Anschuldigungen schwer getroffen: sein jüngerer Sohn Bernhard war bereits am 21. Oktober 1914 gefallen, und dessen älterer Bruder Wilhelm leistete noch immer Kriegsdienst. Wahrscheinlich dachte Runge an seine Söhne, wenn er von Opfern für das Vaterland sprach. ${ }^{178}$

Unter normalen Umständen wäre es sicherlich bei dieser mehr oder weniger deutlichen Zurechtweisung der Studierenden durch ihren Rektor geblieben. Der Krieg, der nun in sein zweites Jahr ging, hatte jedoch die Verhältnisse grundlegend geändert. Selbstverständlich war sich die Vertretung der Göttinger Studentenschaft der Brisanz des angeschnittenen Themas bewusst, und diese Trumpfkarte wollte man nun auch ausspielen. Dass sich die Kräfteverhältnisse innerhalb der Universität änderten, sieht man schon daran, dass das Protokoll der Besprechung im Dienstzimmer des Rektors zuvor schriftlich angemahnt worden war. Mit der großen Zahl der studentischen Kriegsteilnehmer im Rücken konnte die Studentenschaft nun aus einer deutlich stärkeren Position heraus Forderungen vorbringen, als dies zuvor möglich gewesen wäre.

\footnotetext{
176 UAG.Sek.558(6) Bl. 9-10v.

177 UAG.Sek.558(6) Bl. 10v.

178 Wilhelm war gerade im Frühsommer 1915 an einer Lungenentzündung erkrankt, die er sich in den Schützengräben der Westfront zugezogen hatte. Hentschel, Klaus und Tobies, Renate: Brieftagebuch zwischen Max Planck, Carl Runge, Berhard Karsten und Adolf Leopold. Eingeleitet und annotiert von Klaus Hentschel und Renate Tobies. Mit den Promotions- und Habilitationsakten Max Plancks und Carl Runges im Anhang. Berlin 1999. S. 188-189.
} 
Der Grund, warum die Studierenden so dringend auf eine schriftliche Niederlegung der Argumente des Rektors bestanden, wurde bereits einige Tage später deutlich. Am 21. August traf erneut ein Schreiben der Vertretung beim Rektor ein, in welchem in einem geradezu schneidenden Tonfall sehr pointiert nochmals Runges Argumentation wiedergegeben wurde, die besagte, dass nicht die Universität die Ausnahmen zu verantworten habe, sondern die Regierung selbst. Zwischen den Zeilen gab man jedoch deutlich zu verstehen, dass man Runge in dieser Hinsicht nicht traute, um dann eine unverhohlene Drohung auszusprechen.

Auf Grund dieses Sachverhalts stimmt die, Vertretung' mit Ew. Magnifizens darin ü-
berein, daß sie mit ibrem Einspruch die falsche Instanz anging, wenn sie sich - wie
durch Schreiben 17. und 26. VIII geschehen - an Ew. Magnifizenz, wandte, doch ge-
schah dies mit deshalb, weil aus der ersten Beantwortung (vom 21.VIII) und aus jener
Antwort selbst [das Protokoll der Besprechung] auch ein Hinweis auf den Instanzenweg
nicht entnommen werden konnte. 179

Die Studierenden waren sich scheinbar sicher, dass die Universität entweder ganz ohne Kenntnis der Regierung gehandelt oder deren Richtlinien zumindest sehr großzügig ausgelegt hatte. Man drohte, die Göttinger Verhältnisse auf offizieller Ebene prüfen zu lassen, was man ja offensichtlich schon länger gerne getan hätte, wofür nun aber erst der Krieg die praktischen Möglichkeiten bot. Zur Sache selbst äußerte sich die Vertretung nur noch dahingehend, dass man es rundweg ablehnte, Einzelfälle zu prüfen. ${ }^{180}$ Auch nur die theoretische Bereitschaft, einen Angehörigen einer mit Deutschland verfeindeten Nation zu einer deutschen Universität zuzulassen, sei ein Fehler. „Der jetzige Krieg zeigt deutlich genug, was uns Deutschen der Traum des Weltbürgertums, der allumfassenden Kulturgemeinschaft und der allgemeinen Menschheitsverbrüderung eingetragen hat." "181 Stattdessen wollte man „wie Fichte sagt, Charakter haben', und hart [...] werden, d.h. Fremden und fremden Wesen das Eindringen [...] wehren." ${ }^{182}$

Als Mittel hierzu hatte sich die Vertretung der Göttinger Studentenschaft den Landtagsabgeordneten und Theologen Professor Rudolf Otto ausgewählt, der von 1898 bis 1915 noch selbst in Göttingen tätig gewesen war. ${ }^{183}$ Am 7. September 1915 hatte der stellvertretende Vorsitzende der Vertretung, Carl Frommel, eine ausführliche Eingabe an Otto gesandt, in der er den gesamten bisherigen Vorgang

179 UAG.Sek.558(6) Bl. 13.

180 Diese strikte Ablehnung ist durchaus erstaunlich, da eigentlich zu erwarten gewesen wäre, dass man zumindest deutschstämmigen Russen gegenüber kompromissbereiter aufgetreten wäre. Auch ein Engländer ,nach Pass aber nicht nach Gesinnung', wie William Threllfall (Siehe oben.) kann nicht wirklich Anstoß erregt haben. Offensichtlich war es den Studierenden hier jedoch wichtiger, ein schnelles generelles Verbot zu erreichen, als sich in Diskussionen über Ausnahmeregelungen verwickeln zu lassen.

181 UAG.Sek.558(6) Bl. 14.

182 UAG.Sek.558(6) Bl. 15.

183 Ebel, Wilhelm: Catalogus Professorum Gottingensium. Göttingen 1962. 
Schritt für Schritt wiedergab. Diese Darstellung war jedoch einseitig gefärbt. Runges Antworten seien demnach ,,allgemein und ausweichend“ gewesen, die der Vertretung aber ,ausführlich und begründet", auch wurde nicht verschwiegen, dass es erst einer Mahnung der Studentenschaft bedurfte, um ein Protokoll der Besprechung vom 30. Juli zu erhalten. Außerdem sprach Frommel nun auch ganz offen die schon vorher im Raum stehenden Vorwürfe gegenüber der Universität aus: Man vermute, dass es sich um eine bewusste Umgehung ministerieller Vorschriften handele und lediglich die Verantwortung auf die Regierung abgewälzt werden sollte. ${ }^{184}$

Da es sich in dieser Frage nun aber nicht um einen Streit von Studenten mit ihrer Universität handelt, sondern [...] um eine nationale Frage, die allseitige Beachtung, Würdigung und Kritik verlangt, so hat die ,Vertretung' geglaubt, die Angelegenheit in ibre Hände legen zu sollen, damit hier eine Klärung herbeigeführt werde. ${ }^{185}$

Wie eine solche Klärung aussehen sollte, wusste man auch schon sehr genau: Es sollten zwei offizielle Anfragen im Parlament gestellt werden: eine an den Kultusminister und eine an den Kriegsminister. Frommel, der sich in diesen Fragen offenbar für durchaus kompetent erachtete, kam dem Abgeordneten Otto gleich so weit entgegen, dass er die Anfragen für ihn formulierte und als Anlage seiner Eingabe beifügte. Der Kultusminister sollte darüber Auskunft geben, inwieweit Angehörige feindlicher Staaten preußische höhere Unterrichtsanstalten benutzen dürften. Der Kriegsminister sollte darlegen, was für Vorsichtsmaßnahmen getroffen worden seien, damit keine Geheimnisse, etwa in der ,angewandten Kriegswissenschaft, " verraten werden könnten. ${ }^{186}$

Otto war, wahrscheinlich nicht zuletzt wegen des sehr ungeschickten Auftretens Frommels, die ganze Angelegenheit zutiefst suspekt, und so stellte er zunächst einmal Nachforschungen über den Autor der Eingabe an, wobei es ihm gelang, einen Onkel Frommels zu finden, der ihn als ,etwas problematische Natur“ schilderte: „Er ist ein überjähriger Korpsstudent, der sich in allerlei Geschäftigkeiten zu gefallen scheint." Außerdem wunderte sich Otto darüber, dass in dem aktuellen Vorstand der Studentenschaft nur ein einziger „Nichtverbindungsstudent" vertreten sei. ${ }^{187}$ Obwohl er sich offenbar bereits entschieden hatte, nicht auf die Eingabe der Vertretung zu antworten, fragte der Landtagsabgeordnete auch seinen ehemaligen Kollegen Runge um seine Meinung in dieser Angelegenheit und fügte die Eingabe selbst und die Anlagen in Abschrift bei. ${ }^{188}$ Runge zeigte sich zunächst überrascht, da er von der Eingabe noch nicht erfahren hatte, spielte

\footnotetext{
184 UAG.Sek.558(6) Bl. 17-18.

185 UAG.Sek.558(6) Bl. 17v.

186 UAG.Sek.558(6) Bl. 20.

187 UAG.Sek.558(6) Bl. 16. Dies entspricht der Satzung der Vertretung der Göttinger Studentenschaft. UAG.Kur.3407.

188 UAG.Sek.558(6) Bl. 16.
} 
jedoch die ganze Angelegenheit als ,ganz unbedeutend“ und ,aufgebauscht“ herunter und bekräftigte Otto darin, Frommel besser nicht weiter ernst zu nehmen.
Eine formelle Kompetenz, sich an Sie zu wenden, kann den Herren der Studentenvertre- tung zwar nicht abgesprochen werden, denn die Vertretung vertritt die gemeinsamen stu- dentischen und nationalen Interessen der Göttinger Studentenschaft - $\int 1$ der Satzungen - aber sachlich werden sie selbst lebhafte Bedenken haben, im Sinne des Antragstellers zu reagieren. Insbesondere sind die Anfragen, die Ihnen imputiert worden sind, so naiv, dass es sich nicht verlohnt, darüber noch ein $W$ ort zu verlieren. ${ }^{189}$

Allerdings war es wahrscheinlich ein Fehler des Rektorats, die Angelegenheit so herunter zu spielen, da man sich offensichtlich seitens der Universität der Brisanz dieses Themas doch nicht voll bewusst gewesen war.

Die Studierenden nutzten jedoch die Möglichkeiten, die der Krieg bot, und wandten sich an die Presse, als sie auch von Otto keine Antwort in ihrem Sinne erhielten. ${ }^{190}$ Der neue Prorektor Arthur Titius wurde am 13. Oktober 1915 von einem in den Braunschweiger Neuesten Nachrichten erschienen Artikel mit dem Titel „Zustände an einer ,deutschen’ Universität“ überrascht. ${ }^{191}$ Die Zeitungen schenkten der Quelle ihrer Informationen nicht soviel Aufmerksamkeit wie der Landtagsabgeordnete Otto, sondern nahmen sich dankbar eines Themas an, das zu dieser Zeit überaus starke Beachtung versprach. Erkennbar wurde dies zudem durch die Tatsache, dass dieser Artikel in zahlreichen weiteren Zeitungen unverändert nachgedruckt wurde. Dies verhalf der Universität auch überregional zu einer Art traurigen Berühmtheit. Außerdem ging der Diskussion über die ausnahmsweise Zulassung von Angehörigen mit Deutschland im Krieg stehender Staaten nun auch noch die letzte Sachlichkeit verloren.

Daß die Hochburgen deutschen Wesens und deutschen Wissens vor dem Kriege gleichzeitig Brutstätten eines falschen Internationalismus gewesen sind, daß in den Vorlesungsräumen, Seminaren und Laboratorien die Ausländer mit dreistem, rücksichtslosen $W$ esen die reichsdeutschen Studenten verdrängten und daß sich namentlich die Russen dank ihrer Rasseneigenschaft der slavischen Unterordnung bei vielen Professoren einzuschmeicheln gewußt haben, waren Tatsachen, über die die deutsche Studentenschaft oft genug öffentliche Klage geführt, oft genug Protestversammlungen anberaumt hat, die aber sonst durchweg negative Ergebnisse zeitigten. So war es vor dem Kriege. Der Krieg hat das deutsche Volk dann zur Selbstbesinnung gebracht, hat den Blick für das Unwürdige, das in unserer Verehrung und Achtung alles Ausländischen rubte, bedeutsam geschärft

189 UAG.Sek.558(6) Bl. 21.

190 Die Vertretung der Göttinger Studentenschaft bestritt vehement, Informationen wie etwa Abschriften des Briefwechsels, an die Zeitungen gegeben zu haben. Allerdings ist dies absolut unglaubwürdig, da außer ihnen nur Otto oder das Rektorat für diese Indiskretion hätten verantwortlich sein können, was aber mehr als unwahrscheinlich ist. Schriftliche Unschuldserklärungen der Burschenschaften und Verbände: UAG.Sek.558(6) Bl. 55-57. 
$[\cdots]$.

Traurige Einblicke gewährt diese Angelegenheit in die unzeitgemäßen Anschaunngen mancher Professoren, andererseits aber legt das kraftvolle Betreiben der Göttinger Studentenschaft Zeugnis dafür ab, daß der vaterländisch-kriegerische Geist, der Tausende von Studenten ins Feld geführt hat, auch die Dabeimgebliebenen beseelt, daß er die Güter und Rechte der Draußenstehenden mutig und ehrenvoll verteidigt. ${ }^{192}$

Die Universität stand nun unter großem Druck und in der Defensive. Selbstverständlich verfasste der Rektor umgehend eine Gegendarstellung, die er an die entsprechenden Zeitungen verschickte und in denen er die Vorwürfe widerlegte oder, wo sie den Tatsachen entsprachen, erklärte:

Sie haben in Ibrem Blatte eine angeblich auf, zuverlässigen Aktenstücken berubende Darstellung' veröffentlicht, welche geeignet ist, die Universität Göttingen in der öffentlichen Meinung herabzusetzen. Die in der Darstellung gegebenen Tatsachen sind indes tenden ziös entstellt oder direkt unrichtig. [...]193

Aber auch Titius wird klar gewesen sein, dass er bereits zu diesem Zeitpunkt kaum noch eine Chance hatte, gegen die in der Presse dargestellten Verzerrungen mit Zahlen und sachlichen Argumenten anzukämpfen. Selbst wenn Zeitungen sich die Mühe machten, bei der Universität, über die sie berichteten, selbst nachzufragen, wie die Deutsche Volkszeitung aus Hannover, so geschah dies erst, nachdem der zitierte Artikel der Braunschweiger Neuesten Nachrichten nachgedruckt worden war. Die Deutsche Volkszeitung erkundigte sich freundlich, ob tatsächlich in Göttingen „feindliche Ausländer an Vorlesungen über angewandte Kriegswissenschaft teilnehmen, "194 eine Aussage, die der vorformulierten Anfrage Frommels entnommen worden war, die der Studentenvertreter dem Abgeordneten Otto geschickt hatte und die in dem Zeitungsartikel stets mit abgedruckt worden war.

Titius antwortete auf die Nachfrage der Deutschen Volkszeitung, allerdings mit der Bitte, dass man das Rektorat, und damit die Universität, aus der weiteren Berichterstattung heraushalten möge.

,Vorlesungen über angewandte Kriegswissenschaft' werden hier überhaupt nicht gehalten, und damit verliert die tendenziöse Zuspitzung der Braunschweiger Neuesten Nachrichten völlig ihren Boden. [...] Es würde mich freuen, wenn sie die Richtigstellung dieser Notiz. übernähmen. Doch bitte ich Sie, dass Prorectorat als solches auszuschalten [sic!], da ich nicht die Absicht habe, über meine Erklärung hinaus, in der für den sorgfältigen Leser alles notwendige gesagt ist, mich an einer Zeitungspolemik zu beteiligen. ${ }^{195}$

Titius hatte offensichtlich zum Teil resigniert. Er wusste, dass er das verzerrte Bild, das in der Öffentlichkeit entstanden war, nicht mehr korrigieren konnte, nicht zuletzt

192 UAG.Sek.558(6) Bl. 22.

193 UAG.Sek.558(6) Bl. 28.

194 UAG.Sek.558(6) Bl. 23.

195 UAG.Sek.558(6) Bl. 44. 
deshalb, weil die Sympathien der Zeitungen eindeutig auf Seiten der Studentenvertretung lagen. Schließlich hatte diese sehr geschickt und frühzeitig ihren großen Trumpf ausgespielt: Die große Zahl der studentischen Kriegsteilnehmer. Die Universität zog es nun vor, nicht mehr auf jedes neue Detail der Veröffentlichungen zu antworten, um die Diskussion nicht mehr zusätzlich anzuheizen. Der Schaden, der dem Ansehen der Universität trotzdem entstanden war, war sicherlich beträchtlich, wie etwa dieser Brief zeigt, der anonym beim Rektorat einging:

Wenn würdelose Franen, weil sie mit Kriegsgefangenen Briefe wechseln, öffentlich gebrandmarkt werden, so geschieht es mit Recht.

Wenn Universitätsprofessoren in ihrer Eitelkeit soweit gehen, daß sie Kriegsgefangenen die Langeweile zu vertreiben sich zur Ehre anrechnen, dann verdienen sie als, vaterlandslose Gesellen' bezeichnet zu werden. Man fragt sich unwillkürlich, wie ist es möglich, daß gebildete Menschen sich so vergehen können! Dazu sind unsere wissenschaftlichen Institute nicht da, um feindlichen Ausländern zu dienen, wenn Sie es vielleicht noch nicht wissen sollten, Herr Rektor! Zum Mindesten verrät es aber eine niedrige Gesinnung.

\section{Ein feines Kollegium!}

\section{Mebrere Bürger 196}

Inwieweit man anhand dieser Affäre auf das tatsächlich vorhandene $\mathrm{Maß}$ an Ausländerfeindlichkeit unter den Göttinger Studierenden schließen kann, ist selbstverständlich nicht leicht zu beantworten. Auch der Punkt, den bereits der Landtagsabgeordnete Otto bemerkte, nämlich dass die Vertretung der Studentenschaft fast ausschließlich aus Verbindungsstudenten bestand, darf dabei nicht übersehen werden. Tatsache ist aber, dass die Verbissenheit, mit der dieses Thema von der Studentenschaft diskutiert wurde, den Gedanken ausschließt, dieses Phänomen könnte erst durch den Krieg entstanden sein. Es muss, wie ja auch von den Studierenden selbst gesagt wurde, schon deutlich vor dem Krieg ein Thema gewesen sein, allerdings hatte es da noch keine Öffentlichkeit für diese Diskussion gegeben. Nun aber fand sich leicht die geeignete Bühne.

Ein gutes Beispiel dafür ist auch ein Leserbrief, den die München-AugsburgerAbendzeitung am 3. November 1915 veröffentlichte und der noch einmal Titius dazu brachte, eine offizielle Gegendarstellung zu verfassen. Es war der Brief eines Mannes, der behauptete, von 1908 bis 1910 Assistent an der Georgia Augusta gewesen zu sein, jedoch weder sein Institut noch seinen Namen nannte. Er schrieb in seinem Leserbrief, dass die Berichte, die in letzter Zeit über die Göttinger Universität zu lesen gewesen seien, ihn nicht weiter wundern würden. Dieser Assistent beschrieb die „Zustände“ in Göttingen. Dort seien im Anatomischen Institut keine Arbeitsplätze mehr an Deutsche, sondern nur noch an Japaner vergeben worden, die noch dazu nicht selbst arbeiteten, sondern den ersten

196 UAG.Sek.558(6) Schreiben vom 29.10.1915. 
Assistenten des Instituts ausnutzten. Außerdem seien zahlreiche Assistentenstellen an Russen - „Stockrussen - keine ,Deutsch'-Russen“ - vergeben worden, für die es ebenfalls zahlreiche deutsche Bewerber gegeben hätte. Darüber hinaus seien sie besser bezahlt worden, als ihre deutschen Kollegen. ${ }^{197}$

All diese Anschuldigungen konnte Titius leicht widerlegen, ${ }^{198}$ der Vorwurf eines Konflikts zwischen Professoren und Studierenden blieb jedoch im Raum stehen:

Nach meinen Erfahrungen kann ich mich keineswegs wundern, daß sich der lange angesammelte Unmut über die Ausländerwirtschaft in Göttingen endlich einmal Luft gemacht hat, und ich halte die Ausführungen des Artikelschreibers [...] lediglich für einen Ausfluß der seit Jahren unter der Göttinger akademischen Welt bestehenden gereizten Stimmung gegen einzelne Professoren, die ibre Ausländerfreundschaft allzu deutlich bekunden oder doch bekundet haben. ${ }^{199}$

Bei aller mangelnden Glaubwürdigkeit des Autors im Detail kann man doch dieser Wiedergabe der Stimmung in Göttingen vor dem Ersten Weltkrieg wenigstens teilweise Glauben schenken. Die hier gezeigte Affäre, die zuvor geschilderten Ausschreitungen gegen Russen und die gereizte Stimmung gegenüber den Japanern stützen dies.

Die direkte Folge der Zeitungsaffäre war, dass die eigentliche Verhandlung in der Sache zwischen Universität und Vertretung der Studentenschaft zum Erliegen kam. Nach den ersten Veröffentlichungen, in denen deutlich geworden war, dass der Informant der Braunschweiger Neuesten Nachrichten Kenntnis des vollständigen bis dahin abgelaufenen Vorgangs gehabt haben musste, bestellte der Prorektor die Vertreter der Studentenschaft zu einer neuen Besprechung ein, in der er sie der absichtlichen Indiskretion beschuldigte. „Der Prorector machte es endlich den beteiligten Gruppen zur Ehrenpflicht, durch gehörige Untersuchung innerhalb ihrer Gruppe diese von dem Verdachte reinzuwaschen, als ob durch ihre Indiscretion der Artikel der Braunschweiger Neuesten Nachrichten zustande gekommen sei." ${ }^{200}$ Die Studentenschaft bestritt jegliche Beteiligung an dem Zustandekommen des

197 UAG.Sek.558(6) Bl. 45.

198 Titius wandte sich am 18. November 1915 an den Universitätskurator mit der Bitte um eine Prüfung der Anstellungspraxis für Assistenten in dem relevanten Zeitraum. Der Kurator antwortete umgehend und sandte ihm eine tabellarische Aufstellung aller nicht-deutschen Assistenten. „Das Verzeichnis bezieht sich auf alle Assistenten- Volontäre und Hilfsassistenten - und es bedurfte deswegen längere Zeit, um den Auszug fertigzustellen. Selbstverständlich ist, wie ich Ihnen schon mündlich sagte, eine Bevorzugung staatlicherseits niemals erfolgt; die Stellen werden dem Prinzip nach mit Inländern besetzt, -mit Ausländern nur hülfsweise. Inländer stelle ich selbst an, Ausländer darf ich nur mit ministerieller Genehmigung anstellen, - aus dieser Erschwerung geht schon ohne weiteres hervor, dass von einer Bevorzugung von Ausländern keine Rede sein kann- die Stellen mit einer Remuneration über dem Durchschnitt (also über 1500M) sind selten und werden natürlich, wenn wir Inländer für die Besetzung haben können, ebensohoch saliert." UAG.Sek.558(6) Bl. 53v.

199 UAG.Sek.558(6) Bl. 45.

200 UAG.Sek.558(6) Bl. 41. 
Zeitungsartikels, was sie auch durch schriftliche Unschuldsbezeugungen zu untermauern versuchte. ${ }^{201}$ Außerdem, und dies war inhaltlich nicht mit dem Rektorat abgesprochen, veröffentlichte man in den Göttinger Tageszeitungen eine entsprechende Erklärung, in der man zwar bestritt, mit den Zeitungsartikeln in Zusammenhang zu stehen, jedoch nochmals seinen grundsätzlichen Standpunkt untermauerte. Man lehnte die Zulassung von „Angehörigen uns feindlicher Staaten“ ausnahmslos ab, wiederholte den Vorwurf einer Bevorzugung von Ausländern und protestierte ,[...] mit dem Rechte dessen, was jetzt und in Zukunft werden soll - durchaus nicht aus falschem Chauvinismus [...]. " 202

Nun standen sich Universität und die Vertretung der Studentenschaft endgültig unversöhnlich gegenüber, denn zwei wichtige Punkte, die man in der Besprechung mit dem Prorektor zugestanden hatte, fanden sich in dieser Erklärung nicht wieder: Zum einen, dass man die betreffenden Artikel ablehnen würde, da man sich selbst als Mitglieder der Universität dadurch geschädigt sah und zum anderen, dass man den persönlichen Angriffen gegen die Professoren fern stehen würde. Senat und Verwaltungsausschuss der Universität beschlossen daraufhin, die Verhandlungen mit der Vertretung der Studentenschaft für beendet zu erachten. ${ }^{203}$

Titius versuchte, nachdem sich die Wogen wieder geglättet hatten, im Frühjahr 1916 noch einmal zu einer einvernehmlichen Lösung in der Frage des Studiums von Ausländern zu gelangen. Jetzt verweigerte jedoch die Studentenschaft ihre Zusammenarbeit mit der Begründung, dass man überzeugt sei, dass dieses Problem landesweit gelöst werden müsste und deshalb Gespräche an einzelnen Universitäten sinnlos wären. ${ }^{204}$ Wahrscheinlich vergaben die Studierenden durch ihr kompromissloses und manchmal ungeschicktes Auftreten auch Chancen. ${ }^{205}$ Titius wäre sicherlich zu ernsthafteren Gesprächen bereit gewesen. So war er beispielsweise der einzige Teilnehmer an der deutschen Rektorenkonferenz des Jahres 1916 in Halle, der sich in der Frage des Studiums ausländischer Studierender dahingehend äußerte, dass man Benachteiligungen deutscher Studierender unbedingt vermeiden solle, was ja einer der zentralen durch die Vertretung erhobenen Vorwürfe war. ${ }^{206}$

Die extremen Positionen der Vertretung der Studentenschaft waren jedoch realistisch betrachtet nie geeignet, eine wirkliche Lösung dieses Problems herbeizuführen. Man gab offen zu, dass das Studium von Ausländern generell als verhasst und aufgezwungen angesehen wurde. Nun glaubte man durch den Krieg eine Situation gefunden zu haben, in der man Maximalforderungen durchsetzen konnte. Um dies zu erreichen, versuchte man öffentlichen Druck aufzubauen. Der

201 UAG.Sek.558(6) Bl. $55 \mathrm{ff}$.

202 UAG.Sek.558(6) Bl. 42-43.

203 UAG.Sek.558(6) Bl. 40v-41.

204 UAG.Sek.558(6) Bl. 65.

205 Universitätsinterne Kompromisse, wie etwa die Festlegung von Quoten oder garantierte Zeiten für den Zugang zu Laboratorien und Arbeitsplätzen wären durchaus denkbar gewesen. 
Gang zur Presse stellte jedoch einen so schweren Vertrauensbruch dar, dass man sich als Gesprächspartner selbst disqualifizierte, auch wenn dieses Handeln wahrscheinlich dadurch provoziert worden war, dass man sich von Beginn an nicht ernstgenommen fühlte.

Fragt man nach den Gründen dieser massiven Ablehnung ausländischer Studierender, so wird man in der aktuellen Forschung fündig. Gerade in den Kreisen studentischer Korps und Burschenschaften waren die Schlagwörter des politisch rechten Spektrums traditionell stark rezipiert worden, einschließlich eines Rassenbegriffs im Kontext eines angeblichen „slawisch-germanischen“ Gegensatzes. Kombiniert mit dem schon seit längerem als krisenhaft empfundenen Steigen der Studierendenzahlen und sich verschlechternder Studienbedingungen stellten gerade russische Studierende einen willkommenen Kristallisationspunkt solcher Gedanken dar. ${ }^{207}$

207 Siehe zum Bild Russlands in der deutschen Öffentlichkeit und der Einführung eines Rassenbegriffs: Raithel: Das „Wunder“. 1996. S. 92ff und 327ff. Siehe zur ,Überfüllungskrise’: Jarausch: Students. 1982 S. $23 \mathrm{ff}$ und Titze, Hartmut: Enrollment Expansion and Academic Overcrowding in Germany. In: Jarausch (Hrsg.): The Transformation. 1983. S. 57-88. Siehe zu Meinungen und Stimmungen insbesondere der Verbindungsstudenten: Jarausch: Deutsche Studenten. 1984. S. 59ff und Jarausch: Students. 1982 S. $333 \mathrm{ff}$. 
Neue Chancen für Studentinnen

Bei Ausbruch des Ersten Weltkrieges hatte sich das Hochschulstudium für Frauen noch nicht voll etabliert und war erst wenige Jahre alt. Frauen konnten zwar mittlerweile ein reguläres Studium absolvieren, allerdings meist nur mit dem Schullehramt als Ziel. Gerade die weiterführende Ausbildung, wie Habilitation und Assistentenstellen blieben ihnen zunächst genauso verschlossen, wie der Zugang zu verschiedenen staatlichen oder kirchlichen Berufslaufbahnen. ${ }^{208}$ Innerhalb der Universitäten manifestierten sich diese Einschränkungen weniger in Form von expliziten Verboten für Frauen, als vielmehr durch eine geringere Akzeptanz innerhalb des Kollegiums, das ja in seinen Entscheidungen hier weitgehend frei war. Lediglich von einzelnen Veranstaltungen konnten Frauen tatsächlich auf Wunsch der Dozenten ausgeschlossen werden, ${ }^{209}$ allerdings waren die Professoren selbstverständlich weiterhin frei in der Wahl ihrer Assistenten und berücksichtigten hier nur in Ausnahmefällen Frauen. In dem Bereich der naturwissenschaftlichen Fächer war bis vor Ausbruch des Krieges noch keine Assistentin eingestellt worden. ${ }^{210}$

Der Krieg sollte dies allerdings ändern. Als Voraussetzung für die Einstellung eines Bewerbers als Assistent war generell die abgeschlossene Promotion erforderlich und diese Hürde mussten potentielle Assistentinnen zunächst überwinden. Während vor Ausbruch des Krieges lediglich in den Jahren 1913 und 1914 zwei Frauen die Promotion beendeten, gelang es etwa seit dem Wintersemester 1917/18, entsprechend ihres gewachsenen Anteils an den aktiven Studierenden, ${ }^{211}$ nun mehr Studentinnen, dies zu erreichen. Der Aktenlage nach zu urteilen geschah dies weitgehend reibungslos. Offensichtlich thematisierte kein Prüfer oder Gutachter in einem der Promotionsverfahren von Studentinnen die näheren Begleitumstände - zumindest nicht offiziell. Die Promotionsverfahren von Frauen weisen zumindest keinerlei sichtbare Unterschiede zu denen ihrer Kommilitonen auf. ${ }^{212}$

208 Zu diesen Einschränkungen siehe: Maurer, Trude: Der Krieg als Chance? Frauen im Streben nach Gleichberechtigung an deutschen Universitäten 1914-1918. In: Schwinges, Rainer C. (Hrsg.): Jahrbuch für Universitätsgeschichte. Bd. 6 (2003); Universität im Mittelalter. Stuttgart 2003. S. 107-138. S. $109 \mathrm{ff}$.

209 Maurer: Der Krieg. 2003. S. 109.

210 Hierbei von einer bewussten oder unbewussten Diskriminierung von Studentinnen auszugehen würde allerdings sicherlich zu weit gehen. Assistenten mussten grundsätzlich bei ihrer Einstellung promoviert sein. Statistik 5 zeigt, dass es demnach zunächst schlicht noch an Kandidatinnen mangelte.

211 Siehe Statistik 3.

212 Verschiedene Vorgänge in: UAG.Phil.Fak.II.Prom.Spec. 


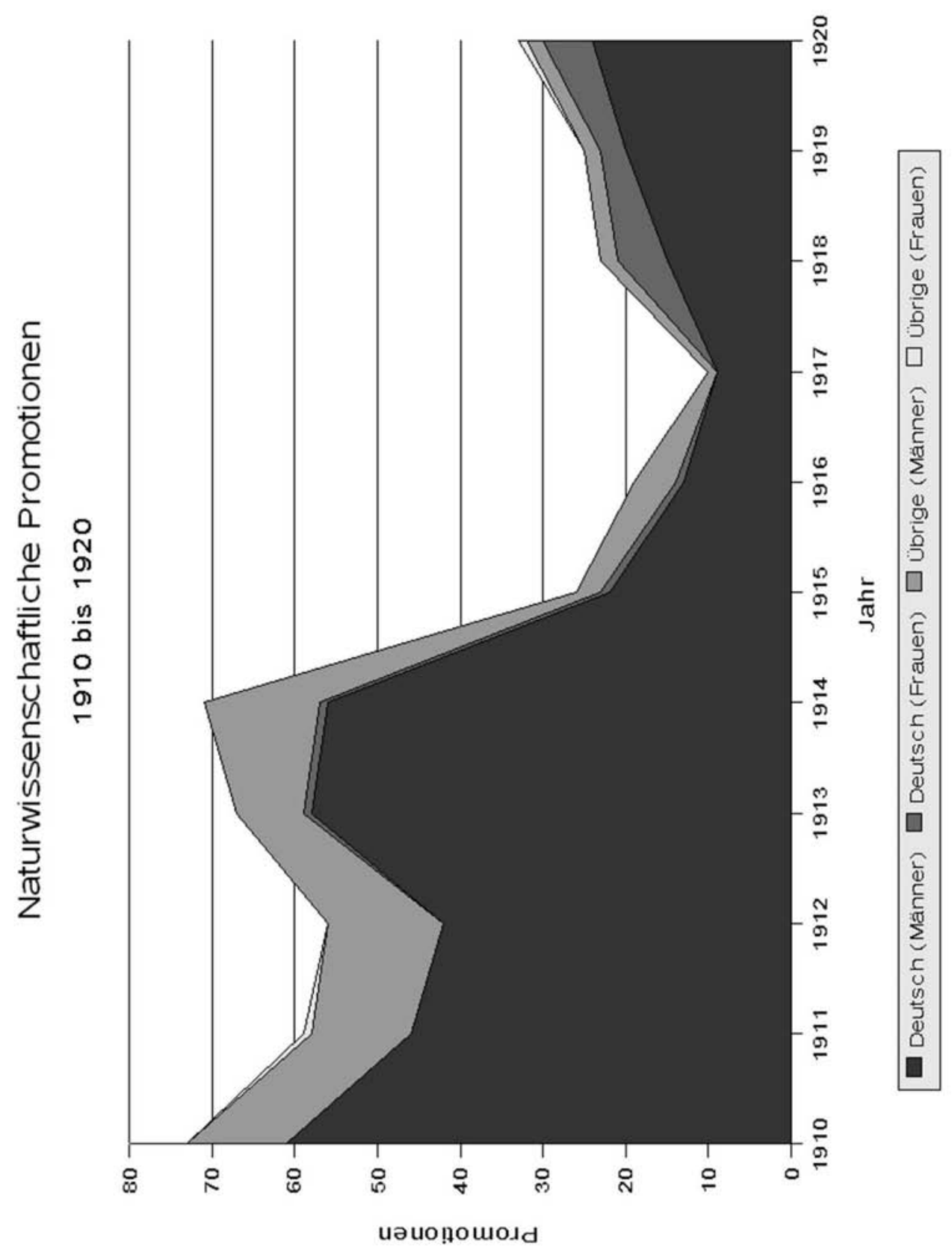

Statistik 5: Daten aus: UAG.Phil.Fak.III.34. Promotionsbuch der historisch-philologischen Abteilung bzw. der Philosophischen Fakultät von 1.7.1910 bis 1933. 
Mit der abgeschlossenen Promotion hatten die Studentinnen die Voraussetzung für die Annahme einer Assistentenstelle erfüllt. In die Auswahl von Assistenten oder Assistentinnen kann man heute leider kaum noch Einblicke gewinnen. Die Professoren wählten mögliche Kandidaten eigenständig aus dem Kreis ihrer Studierenden aus oder holten Empfehlungen von Kollegen ein, so dass es kein Bewerbungsverfahren gab und freie Stellen auch nicht öffentlich ausgeschrieben werden mussten. Dies war zu Friedenszeiten sicherlich auch nicht notwendig, der Krieg hatte jedoch auch hier die Verhältnisse grundlegend geändert.

Mit Ausbruch des Krieges war der größte Teil213 der Stelleninhaber zum Kriegsdienst eingezogen worden oder hatte sich freiwillig gemeldet. Später waren es gerade Assistenten als höher qualifizierte Kräfte, die im Kriegshilfsdienst gesucht wurden. Durch das Einbrechen der Studierendenzahlen und die zurückgehenden Promotionszahlen verringerte sich außerdem der Kreis der möglichen Nachfolger dramatisch, unbenommen der Frage der jeweiligen persönlichen Eignung für Lehr- und Forschungstätigkeiten. ${ }^{214}$ Ein weiterer im Bereich der Assistentenstellen nicht zu unterschätzender quantitativer Faktor war der Verlust der ausländischen Studierenden. ${ }^{215}$ Auch hier brachen die Studierendenzahlen und Promotionen ein; eine Beschäftigung war darüber hinaus ausdrücklich untersagt: „Assistenten, welche einem Staate angehören, der Krieg gegen uns führt, sind zu entlassen." ${ }^{216}$ Diese Anordnungen verwundern nicht weiter, sind aber lediglich der

213 Auch hier würde sich eine Statistik anbieten oder zumindest die Arbeit mit konkreten Zahlen. Dies ist im Rahmen dieser Arbeit aber leider nicht möglich, da Angaben zu den Assistentenstellen leider ganz allgemein nur sehr schwer quantifizierbar sind, da diese recht unregelmäßig verlängert beziehungsweise eingerichtet wurden. Die Dauer einer Assistentenstelle war sehr unterschiedlich und reichte von einigen Monaten bis zu vielen Jahren. Auch ihre Finanzierung war nicht einheitlich. Einige Stellen waren feste Stellen, die einem bestimmten Institut zustanden und immer wieder neu besetzt wurden, andere waren außerplanmäßig und wurden nur für ein Projekt oder eine bestimmte Person beim Wissenschaftsministerium beantragt, und wenige wurden sogar von Professoren aus privaten Mitteln finanziert. Somit besaßen diese Stellen eine teilweise völlig verschiedene Wertigkeit. Der Chemiker Prof.(!) Dr. Walter Borsche fungierte seit 1915 sogar als Abteilungsvorsteher im chemischen Laboratorium. Seine Stelle war aber offiziell eine Assistentenstelle. UAG.Kur.5538 Bl. 92.

214 Andrea Wettmann stellt die These auf, dass eine mangelnde Attraktivität durch die schlechte Bezahlung der Assistentenstellen ein Grund für die Schwierigkeiten der Professoren war, geeignete Kandidaten für freiwerdende Stellen zu finden. Diese Aussage lässt sich für die naturwissenschaftlichen Institute der Universität Göttingen nicht bestätigen. Wettmann: Heimatfront. 2000. S. 284.

215 Die Aufstellung, die der Universitätskurator auf Anfrage des Rektors anlässlich der in einem Leserbrief einer Münchner Tageszeitung geäußerten Vorwürfe erstellt, umfasst allein 24 ausländische Assistenten und Hilfsassistenten nur im anatomischen Institut. Siehe oben. UAG.Sek.558(6) Bl. 53v. und Bl. 54.

216 Dieser Erlaß wurde am 28.9.1914 nochmals durch den Universitätskurator bekräftigt und ausdrücklich um die Doktoranden erweitert. „Wie der Herr Minister der geistlichen und Unterrichts-Angelegenheiten aus Anlass eines Einzelfalls bemerkt hat, ist derselbe davon ausgegangen, dass Angehörige feindlicher Staaten nach dem Ausbruch des Krieges nicht mehr zu Doktoren promoviert worden sind. Jedenfalls wird ergebenst ersucht für die Folge dafür Sorge zu tra- 
offizielle Teil einer selbstgewählten Isolation, die auf anderen Ebenen auch Studierende neutraler Länder betraf. Sogar ein schweizer Assistent wurde entlassen, obwohl qualifizierte Wissenschaftler, die für diese Stellen geeignet waren, immer rarer wurden. ${ }^{217}$ So berichtet Professor Woldemar Voigt vom physikalischen Institut am 10. November 1914 an den Universitätskurator über die Stellensituation an seinem Institut:

Der zweite [Assistent], Dr. [Heinrich] Hertenstein hat auf meine Anregung seine Stelle aufgegeben. Obwobl er keiner feindlichen Nation angebört, schien es mir nicht angemessen, daß während des Krieges ein Schweizer die Stelle innehätte. Von den beiden Hilfsassistenten, die ich bezahlte, ist Dr. Fredericksz als Russe am Anfang des Krieges entlassen $[\ldots] \cdot{ }^{218}$

In die so entstandene und sich immer weiter vergrößernde Lücke gelang es Frauen, mit zunehmender Dauer des Krieges vorzustoßen. Professor Voigt verzichtete aber zunächst noch angesichts mangelnder Alternativen und aus Ersparnisgründen auf eine Neubesetzung seiner Assistentenstellen, nachdem auch der erste Assistent Neubart zum Kriegsdienst eingezogen worden war. Erst Professor Peter Debye beantragte ab März 1915, die freien Assistentenstellen wieder zu besetzen, wofür er den besonders qualifizierten Münchner Studenten Josef Engel vorschlug. ${ }^{219}$ Zwei Jahre später im März 1917, als die Schwierigkeiten, geeignete Bewerber zu finden, weiter gewachsen waren, beantragte Debye schließlich die Einstellung eines Norwegers, des jungen Wissenschaftlers Johann Holtzmark, was durch das Kultusministerium genehmigt wurde. ${ }^{20}$ Noch ein halbes Jahr später stellte er dann einen ungewöhnlich ausführlichen Antrag:

Euer Hochwohlgeboren gestatte ich mir den Antrag zu unterbreiten:

Fräulein Luise Lange als Hilfsassistentin am physikalischen Institut gegen eine monatliche Remuneration von sechiig Mark anstellen zu wollen.

Fräulein Lange hat seit etwa einem Jahre ibr Staatsexamen bestanden, arbeitet seit zwei Jahren im physikalischen Institut an der Fertigstellung einer Dissertation und wird damit zu Ende kommen und promovieren können im Laufe des Wintersemesters. Schon im verflossenem Sommersemester hat Fräulein Lange mich als freiwillige Helferin im Praktikum unterstützt. Ich hatte dabei Gelegenheit ibre Lebrbefähigung kennenzuler-

gen, dass dies nicht geschieht. Liegen in einem einzelnen Falle Gründe vor, die eine Ausnahme gerechtfertigt erscheinen lassen, so ersuche ich gefälligst darüber zu berichten." Beachtenswert ist zumindest die theoretische Möglichkeit einer Ausnahme. UAG.Phil.Fak.II.96 28.9.1914.

217 Andrea Wettmann schildert den Fall des Privatdozenten Nicolai Hartmann, dessen Stipendium in seiner Fakultät heftig umstritten war, obwohl er sogar als Soldat am Krieg teilnahm. Seine Frau war jedoch gebürtige Russin. Dies genügte bereits, um Hartmann in Verruf zu bringen. Wettmann: Heimatfront. 2000. S. 363-364.

218 UAG.Kur.7471 Bl. 127.

219 UAG.Kur.7471 Bl. 129.

220 UAG.Kur.7471 Bl. 136; Genehmigung: 07.04.1917 B1. 137. 
nen. Dieselbe ist bei ibr gut entwickelt, wozu auch die Übung beitragen wird, welche sie sich durch gelegentliche Übernahme von Unterrichtsvertretungen an der Schule erworben hat. Meiner Überzeugung nach ist Fräulein Lange für die ihr zugedachte Betätigung sehr geeignet.

Daß ich bei dem vorhandenen Mangel an Arbeitskräften einerseits und der stetigen Erschwerung des Geschäftsganges andererseits eine Hilfe sehr benötige, möchte ich noch zur näheren Begründung meines obigen Antrags binzufügen. ${ }^{221}$

Debye war sich der besonderen Bedeutung seines Antrages bewusst. Daher formulierte er seinen Antrag sehr vorsichtig und gab sich große Mühe zu begründen, warum er gerade Frau Lange vorschlug. Die von ihm vorgesehene Dotierung der Stelle betrug mit 720 M jährlich etwa die Hälfte des Gehalts für eine volle Stelle, war aber für eine Hilfsassistentenstelle durchaus üblich. Obwohl auch eine volle Assistentenstelle zu besetzen gewesen wäre, hatte Debye Lange für die Hilfsassistentenstelle vorgesehen. Dies machte jedoch für die Universitätsverwaltung keinen Unterschied, denn man lehnte es ab, die Kandidatin überhaupt in eine reguläre Stelle zu übernehmen. Zwar hatte man angesichts der schwierigen Situation keine grundsätzlichen Bedenken gegen eine Einstellung Langes, allerdings ausdrücklich nur als so genannte Kriegsaushilfe:

Mit der Annabme des Frl. Luise Lange vom 1. Oktober 1917 ab bis auf weiteres und längstens bis nach Beendigung des Krieges als Kriegsaushilfe zur vertretungsweisen Wahrnehmung der Geschäfte eines zu Kriegsdienst einberufenen etatsmäßigen Assistenten des physikalischen Instituts, Abteilung für mathematische Physik nach dem Jahressatze von $720 \mathrm{M}\left[\right.$...] erkläre ich mich einverstanden. ${ }^{222}$

Der zentrale Punkt dieser Regelung liegt darin, dass Debyes Schülerin nur als Vertretung für einen Kriegsdienstleistenden beschäftigt werden durfte, nicht aber als dessen Ersatz. Folgerichtig konnte eine solche Beschäftigung nur befristet bis zum Kriegsende vergeben werden. ${ }^{223}$ Dabei galt diese Regelung keinesfalls nur dann, wenn Frauen als so genannte Kriegsaushilfen beschäftigt wurden. Sie fand ebenso Anwendung, wenn ein aus dem Krieg zurückkehrender Soldat eingestellt werden sollte. ${ }^{224}$

221 UAG.Kur.7471 Bl. 141.

222 UAG.Kur.7471 Bl. 142.

223 Im Weiteren geben die Unterlagen keine Hinweise auf eine Verlängerung der Beschäftigung. Da Assistentenstellen jeweils auf ein Jahr vergeben und dann gegebenenfalls wieder verlängert wurden, kann man davon ausgehen, dass Lange ihre Stelle bei Kriegsende wieder verlor oder von sich aus ging.

224 Professor Adolf Windaus stellte am 26. Februar 1917 den Antrag, den Chemiestudenten Otto Dallmer einstellen zu dürfen. Der Kurator stimmte zu, allerdings ebenfalls nur als Kriegsaushilfe zu den gleichen finanziellen Bedingungen, wie etwa bei Luise Lange. UAG.Kur.5538 Bl. 70 und $70 \mathrm{v}$. 
Anders stellte sich die Situation dann da, wenn der bisherige Stelleninhaber im Kriegsdienst gefallen war. Konnte ein Institutsdirektor dann nachweisen, dass er keine geeigneten männlichen Bewerber für eine Stelle finden konnte, war es auch für Studentinnen möglich, in reguläre Assistentenstellen übernommen zu werden. Gleiches galt für Angehörige aus dem neutralen Ausland. Im chemischen Laboratorium wurden beispielsweise schon sehr früh im Krieg Dr. Mathilde Gerhardt und Dr. Johanna Wolff reguläre Assistentenstellen übertragen. Der Direktor des Laboratoriums, Professor Otto Wallach, hatte auch sie zunächst als Kriegsaushilfen einstellen wollen, dem Kurator gelang es dann aber doch, unter Hinweis auf die besonders schwierige Situation in diesem Institut, beim Kultusministerium die reguläre Einstellung beider Frauen für zunächst ein Semester zu erreichen:

\section{$V$ on den 6 Institutsassistenten sind 5 beim Militär. Ebenso die beiden Hilfsassistenten} $[\cdots]$.

Zum 1.X. waren erledigt die Stellungen von Herrn Dr. Klein und Dr. Fry. Dr. Klein ist im August bei Binant [?] gefallen, dessen Remuneration für September also verfügbar. An Stelle von Dr. Klein war E. A. Erben in Aussicht genommen. Dieser ist am 28.IX. bei Reims gefallen.

Von Dr. Fry fehlen Nachrichten. Sein Nachfolger sollte Dr. Gröppel werden, der zwar seit einigen Wochen bier eingetroffen ist, aber so schwer verwundet, daß mit seinem Eintritt in die freie Stelle [...] nicht zu rechnen ist. 225

Da es sich hierbei um das Wintersemester 1914 handelte, kann man Frau Gerhardt und Frau Wolff als die ersten naturwissenschaftlichen Assistentinnen an der Georgia Augusta bezeichnen, wenn auch nur wegen der besonderen Situation im chemischen Laboratorium und stets unter dem Vorbehalt: „[...] da männliche Assistenten zur Zeit nicht zu haben sind.“226

Auch wenn damit ein Tabu gebrochen war, was folgenden Assistentinnen die Einstellung möglicherweise erleichtert haben mag, lässt sich doch an der Art, in der diese Beschäftigung wieder endete, deren provisorischer Charakter ablesen. Mittlerweile hatte Professor Adolf Windaus die Leitung des chemischen Laboratoriums übernommen. Die Verträge beider Frauen waren nach Ende des Wintersemesters nochmals bis zum 15. August 1915 verlängert worden. ${ }^{227}$ Im Oktober wurde jedoch der ehemalige Assistent Dr. Sielisch als kriegsuntauglich eingestuft und ersetzte Gebhardt und Wolff umgehend wieder.

Ew. Hochwohlgebohren ersuche ich ganz ergebenst den bisherigen Assistenten Dr. Sielisch, der als Kriegsfreiwilliger im Felde war und am 16. d. M. als dienstuntanglich ent-

225 UAG.Kur.5538 Antrag Wallach: Bl. 10 22. Oktober 1914; Schreiben des Kurators an das Kultusministerium: Bl. 12.11.1914; Genehmigung durch das Kultusministerium: Bl. 9 29.11.1914.

226 UAG.Kur.5538 Bl. 17v.

227 UAG.Kur.5538 Bl. 17. 
lassen worden ist, von diesem Tage ab bis zum 30. September 1916 unter den früheren Bedingungen wieder anzustellen und ihm auch die bisher bezogene Zulage von jährlich $200 M$ wieder erwirken zu wollen.228

Wie wenig akzeptiert allerdings Assistentinnen zumindest im chemischen Laboratorium waren, wird daran deutlich, dass in den folgenden Jahren mehr Ausländer aus neutralen Nationen eingestellt wurden als Frauen. Dies zog sogar einen höheren Verwaltungsaufwand nach sich, da hier zusätzlich eine Einreise- und Arbeitsgenehmigung eingeholt werden musste. ${ }^{229}$ So wurde im Sommer 1916 der schwedische Chemiker Erik Rahlen eingestellt ${ }^{230}$ und zum Wintersemester 1917 durch den Chilenen Antonio Tomich ersetzt. ${ }^{231}$

Windaus betonte in seinen Anträgen immer wieder, dass ein Bewerber für die Assistentenstelle ihm geeignet erscheinen müsse, ,sich als Assistent am praktischen Unterricht der Anfänger im hiesigen Institut zu beteiligen, “ wofür sich jedoch, „wie unter den jetzigen Verhältnissen vorauszusehen war, nur ein Bewerber nicht deutscher Staatsangehörigkeit" ${ }^{\text {232 }}$ fand. In diesem Punkt zweifelte er scheinbar an dem Grad der Akzeptanz, der einer Frau von seinen Studierenden entgegengebracht worden wäre. In Bereichen, die die Lehre nicht mit einschlossen, hatte er zumindest keinerlei Bedenken gegen die Beschäftigung einer Frau; im Gegenteil: Windaus konnte seit April 1916 die Lehramtskandidaten in seinem Institut nicht mehr wie bisher durch einen Assistenten betreuen lassen. Daraufhin stellte er, ausdrücklich nur für den praktischen Teil der Aufgaben dieses Assistenten, eine weibliche Hilfskraft ein.

Ich beantrage daher, dass das Fräulein Else Klußmann aus Göttingen, als Hilfskraft für Verwaltungsarbeiten, zur Beaufsichtigung der Materialien, Reagentien und Apparate [eingestellt wird].

Fräulein Klußmann hat eine kurze Ausbildung in der Chemie genossen [aber keine Hochschulausbildung7, so daß sie die chemischen Materialien und die gebräuchlichsten Apparate, sowie ibre Behandlung, Aufbewahrung und Kontrolle kennt und einfache chemische Arbeiten [...] ausqufübren in der Lage ist. ${ }^{233}$

Klußmann wurde nach Windaus Darstellung im chemischen Laboratorium schnell unersetzlich, so dass er, um sie halten zu können, jährlich Gehaltserhöhungen für sie beantragte. ${ }^{234}$ Gegen Ende 1917 erhielt Klußmann mit 1500 Mark das gleiche Gehalt wie ein regulärer Assistent.

228 UAG.Kur.5537 Bl. 34.

229 Es wird hier vorausgesetzt, dass es Bewerberinnen gegeben hat.

230 UAG.Kur.5537 Antrag: Bl. 52ff; Genehmigung durch das Kultusministerium: Bl. 63.

231 UAG.Kur.5537 Bl. 83.

232 UAG.Kur.5537 Bl. 52.

233 UAG.Kur.5537 Bl. 45-46.

234 UAG.Kur.5537 Bl. 69 und 79. 
Die große Ausnahme als reguläre Assistentin war Dr. Marie Borchers. Borchers arbeitete vom 10. September 1917 bis zum Ende des Jahres 1921 in der geophysikalischen Abteilung des physikalischen Instituts von Professor Emil Wiechert. Sie war eine der Studentinnen, die während des Krieges ihre Promotion abschließen konnten, und ihr gelang es, die sich ihr bietenden Möglichkeiten zu nutzen. Wiechert hatte 1917 seinen langjährigen Assistenten Repsold an die Aerodynamische Versuchsanstalt von Professor Ludwig Prandtl abgeben müssen. ${ }^{235}$

Der Direk.tor des hiesigen geophysikalischen Instituts, Geh. Rat Prof. Dr. Wiechert, bittet in dem gehorsamst angeschlossenen Berichte vom 7. d. Mts. der Doktorandin Frl. Marie Borchers aus V arel die freie Assistentenstelle vom 10. September bis 31. Dezember d. Js. zu übertragen. Die g. Borchers hat am 4. Juli d. Js. die Doktorprüfung mit ,gut' bestanden.

Bedenken gegen die Genehmigung des Antrags liegen nicht vor. Ew. pp. bitte ich deshalb gehorsamst genehmigen zu wollen, daß das Frl. Borchers als Assistentin bei dem hiesigen geophysikalischen Institut vom 10. September bis 31. Dezember 1917 gegen Gewährung einer Remuneration von jährlich $1500 \mathrm{M}$ angenommen werde. ${ }^{236}$

Mit diesen vergleichsweise kurzen und sachlichen Zeilen beantragte der Kurator Borchers Anstellung beim Kultusministerium, die auch genehmigt wurde. Leider liegen über diesen Vorgang und die folgenden jährlichen Verlängerungen des Vertrages keine ausführlicheren Belege vor. Aber gerade dies macht die Tätigkeit dieser Assistentin so bemerkenswert, denn sie unterscheidet sich von vergleichbaren ihrer männlichen Kollegen in keiner Weise und ist damit der Beweis, dass es durchaus für einen Institutsdirektor möglich war, eine Assistentin zu beschäftigen, wenn er dies wollte und er eine freie Stelle zu besetzen hatte.

Borchers wurde als einzige Assistentin nicht mit dem Kriegsende von ihren zurückkehrenden Kommilitonen verdrängt. Auch als 1919 Wiechert unbedingt seinen Schüler Wilhelm Haubold als Assistenten durchsetzen wollte, dachte er nicht daran, Borchers durch ihn zu ersetzen sondern beantragte, für ihn die zweite Assistentenstelle, die sein Institut vor dem Krieg besaß, wieder zu reaktivieren. ${ }^{237}$

In den Assistentenakten dieser Zeit finden sich nun wieder mehr Rückkehrer; alle mit ähnlichen Biographien, wie etwa im Falle des jungen Physikers Falkenhagen, der 1919 an das physikalische Institut zu Professor Debye zurückkehrte und dort die Assistentenstelle einnahm, die noch während des Krieges mit einem Schweizer besetzt gewesen war.

235 Siehe unten: Repsold drohte die Einberufung zum Militärdienst, und so nutzte er stattdessen die Möglichkeit, sich von Prandtl als unabkömmlich deklarieren zu lassen und so dem Kriegseinsatz zu entgehen.

236 UAG.Kur.7459 Bl. 359.

237 UAG.Kur.7460 Bl. 15. 
Ew. Hochwoblgeboren teile ich mit, dass der Assistent am Physikalischen Institut, Herr Dr. Scherrer, den Wunsch geäußert hat, zum 1. Februar dieses Jahres als solcher von seinen Pflichten entbunden zu werden. Ich bitte dieser Entlassung zustimmen zu wollen und schlage zugleich als neuen Assistent vor Herrn stud.phil. Falkenhagen. Letzterer ist während des Krieges als Hilfsassistent an meinem Institut tätig gewesen und hat sich damals sebr gut bewährt. Durch seine Einziehung zum Kriegsdienst wurde er gezwnngen, die Stellung niederzulegen. Jetzt steht er wieder zur Verfïgung und dürfte, wenn seine Anstellung erfolgt, meinen Erfahrungen nach für die Stellung sich als sehr geeigneter Bewerber ausweisen. ${ }^{238}$

Es stellt sich nun die Frage, inwieweit durch den Krieg innerhalb der Universität tatsächlich neue Chancen für Frauen entstanden und ob sie diese nutzen konnten. Tatsache ist, dass Frauen zunächst nur als Kriegsaushilfen eingestellt wurden und es in keinem Fall gelang, eine solche Beschäftigung als Einstieg für eine längerfristige Tätigkeit zu nutzen. Sie waren lediglich Vertretung ihrer zum Kriegsdienst eingezogenen männlichen Kollegen. Dies hatte zwei Ursachen:

Zum einen zeigt das Beispiel von Marie Borchers, dass es durchaus möglich war, als Frau eine Assistentenstelle zu erlangen. Auch die Universitätsverwaltung oder das Kultusministerium legten in einem solchen Fall nicht pauschal Steine in den Weg. Sie achteten jedoch peinlichst genau darauf, die Rechte der sich im Kriegsdienst befindenden Stelleninhaber zu wahren. Meldete beispielsweise ein Institutsdirektor versehentlich die Stelle eines Betroffenen nicht zur jährlichen Verlängerung an, so wurde er durch den Kurator daran erinnert. 239 War eine Person zum Zeitpunkt ihres Eintrittes in die Armee Assistent, so blieb sie dies auch über die Dauer der regulären Befristung solcher Stellen für ein Jahr hinaus. In diesen Fällen konnte dann nur eine Vertretung mit verkürzten Kündigungsfristen maximal bis zum Kriegsende eingestellt werden. Die personellen Ressourcen, die für solche Vertretungen zur Verfügung standen, waren stark begrenzt. Mögliche Kandidaten und Kandidatinnen stellten vor allem Doktorandinnen und männliche Ausländer aus neutralen Staaten. Die endgültige Entscheidung für oder gegen einen Kandidaten wurde durch viele Faktoren beeinflusst, in die man nur in den wenigsten Fällen Einblick erhalten kann. Unzweifelhaft wird hier die fachliche Qualifikation der Bewerber eine entscheidende Rolle gespielt haben, aber auch persönliche Einschätzungen der Institutsdirektoren. Professor Adolf Windaus

238 UAG.Kur.7471 Bl. 152.

239 Der Direktor des chemischen Laboratoriums Windaus hatte dies im Falle von Dr. Heinrich Wienhaus einmal vergessen: „Hierdurch teile ich Euer Hochwohlgeboren ganz ergebenst mit, dass Herr Dr. Heinrich Wienhaus als Assistent am hiesigen Institut nur bis zum 1. Oktober 1915 angestellt war. Da er zum Kriegsdienst eingezogen ist, hatte ich seinerzeit bei der Übernahme der Leitung des Instituts seine Anstellung nicht verlängert. Durch das Schreiben von Euer Hochwohlgeboren veranlasst, bitte ich Euer Hochwohlgeboren ergebenst eine weiter Anstellung des Dr. Heinrich Wienhaus als Assistent am hiesigen Institut vom 1. Oktober ab genehmigen zu wollen." UAG.Kur.5538 B1. 65. 
griff in Bereichen, in denen die Lehre Teil einer Assistentenstelle gewesen ist, offensichtlich bevorzugt auf männliche Ausländer zurück, weil er deren Akzeptanz bei seinen Studierenden höher einschätzte, als die einer Frau. Sein Kollege Emil Wiechert hatte hier mit seiner langjährigen Assistentin Borchers andere Erfahrungen gesammelt.

Die durch den Krieg bedingten Veränderungen für Frauen gingen jedoch nur so weit, wie die Interessen der zum Kriegsdienst Einberufenen gewahrt blieben. Spricht man über neue Chancen für Frauen während des Krieges, so kann man dies nicht tun, ohne den Namen Emmy Noether erwähnt zu haben, obwohl sich in ihrem Fall der Erste Weltkrieg eher hinderlich auf ihre Karriere auswirkte. ${ }^{240}$

Auch Noether hatte seit 1915 offiziell eine Assistentenstelle im Mathematischen Institut der Göttinger Universität inne, dies allerdings nur als Kompromiss, weil ihr die Zulassung zur Habilitation verweigert worden war. Die aufstrebende Mathematikerin war 1915 auf Anregung von Felix Klein und David Hilbert nach Göttingen gekommen. Klein und Hilbert waren es auch, die Emmy Noether dazu bewegten, einen Antrag auf Habilitation zu stellen und dafür sorgten, dass dieser von der mathematisch-naturwissenschaftlichen Abteilung der Fakultät unterstützt wurde. ${ }^{241}$

Allen Beteiligten war die grundsätzliche Bedeutung der Entscheidung der $\mathrm{Ha}$ bilitationskommission bewusst und auch die Wirkung, die sie über die Grenzen der eigenen Universität hinaus haben würde, da die Habilitation von Frauen in Preußen immer noch offiziell untersagt war. Dementsprechend aufschlussreich sind die Argumente, die in den Gutachten der Kommissionsmitglieder angebracht wurden. Sie geben einen genauen Einblick in das Denken, das den jungen Assistentinnen den Einstieg in die neuen Bereiche erschwerte.

240 Schilderung des Vorgangs nach: Tollmien, Cordula: ,Sind wir doch der Meinung, daß ein weiblicher Kopf nur ganz ausnahmsweise in der Mathematik schöpferisch sein kann...' Emmy Noether 1882-1935. In: Göttinger Jahrbuch, Jg. 1990, H. 38, S. 153-219. Und: Tollmien, Cordula: ,Die wissenschaftliche Höhe der deutschen Universitäten würde durch die fortschreitende Verweiblichung zweifellos sinken'. Die Mathematikerin Emmy Noether (1882-1935). In: Dinghaus, Angela (Hrsg.): Frauenwelten. Biographisch-historische Skizzen aus Niedersachsen. Hildesheim 1993. S. 268-283. Siehe hierzu auch: Maurer: Der Krieg. 2003. S. 120-122.

Maurer: Der Krieg. 2003. S. 120. 
Während Deutschlands Söhne fern von ibrer heimatlichen Berufstätigkeit das blutige Kriegshandwerk üben müssen, haben wir notgedrungen an vielen Stellen Frauen an Stelle der männlichen Arbeitskräfte eintreten lassen. So sebr diese Art der Hülfe zu begrüßen ist, ebenso verwerflich wäre es, wenn man einen ganzen großen Beruf, der bisher Männern vorbehalten war [Universitätsdozentur], gerade jetzt obne jede Not den Frauen ausliefern wollte. ${ }^{242}$

So formulierte es der damalige Direktor der Sternwarte Johannes Hartmann in seinem Gutachten. Außerdem befürchtete Hartmann, dass es, wenn man „den Damen einen neuen Lebensberuf eröffnen würde," Deutschland in Zukunft an „kräftigen Söhnen“ fehlen werde. ${ }^{243}$

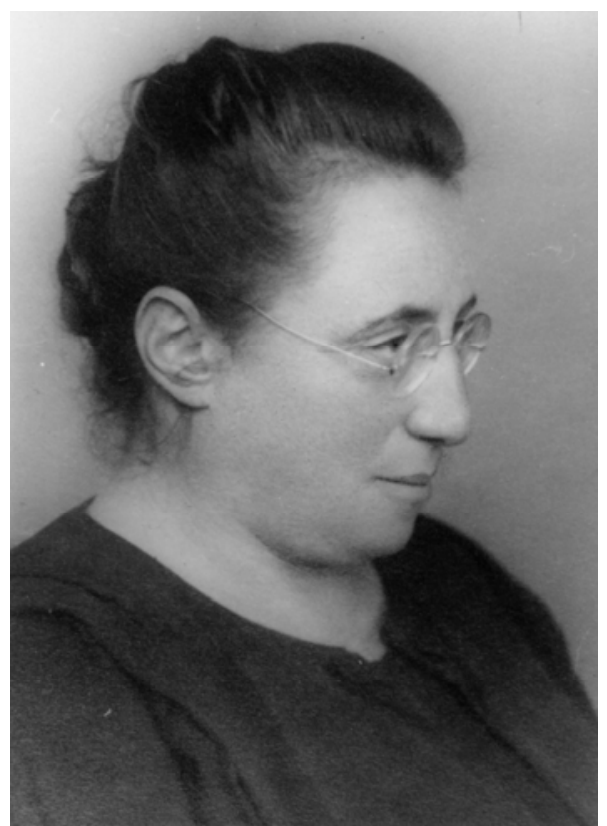

Abbildung 3: Emmy Noether

In der kontroversen Diskussion der entscheidenden Fakultätssitzung am 18. November 1915 konnte keine einstimmige Entscheidung gefunden werden. Zu weit lagen die Ansichten der Mathematiker, die Noethers Fähigkeiten beurteilen konnten und den Vertretern der geisteswissenschaftlichen Fächer, die in ihr vor allem den möglichen Präzedenzfall sahen, auseinander. ${ }^{244}$ Trotzdem wurde ein Antrag auf die Erteilung einer Sondergenehmigung zur Habilitation Noethers an das Kultusministerium eingereicht. ${ }^{245}$ Dieses entschied jedoch erst nach nochmaliger Nachfrage im Jahr 1917, grundsätzlich keine Habilitation einer Frau zu genehmigen. ${ }^{246}$

Obwohl Hilbert und Klein offensichtlich nicht bereit waren, das lange Zögern und schließlich die ablehnende Antwort des Kultusministeriums zu akzeptieren, wählten sie nicht den Weg der Konfrontation, der leicht zu einem größeren Skandal hätte werden können.

242 UAG.Math.Nat.Prüf.Pers.Nöther Bl. 12 des Vorgangs.

243 UAG.Math.Nat.Prüf.Pers.Nöther Bl. 12 des Vorgangs.

244 Vollständige Dokumentation und Analyse des Vorgangs bei Tollmien: Tollmien: ,Sind wir doch der Meinung'. 1990. S. 153-219.

245 Tollmien: ,Die wissenschaftliche Höhe’. 1993. S. 272-273.

246 Tollmien: ,Die wissenschaftliche Höhe’. 1993. S. 275; Nach Ende des Krieges gelang es schließlich, die Erteilung der Venia Legendi zu erreichen, worauf hier aber nicht näher eingegangen werden soll. Siehe hierzu: S. $181 \mathrm{ff}$. 
Hilbert beschäftigte Emmy Noether stattdessen als Assistentin und gab ihr die Möglichkeit, Vorlesungen und Übungen unter seinem Namen anzukündigen, „wobei im Vorlesungsverzeichnis neben seinem Namen der Zusatz ,mit Unterstützung von Fräulein Dr. Noether' erschien. “247 Nachdem er die Unmöglichkeit des Versuchs, diese Habilitation noch während des Krieges zu erreichen, erkannt hatte, versuchte er offensichtlich auf diese Weise Schaden von sich selbst, Emmy Noether und der Universität abzuwenden.

Das Frauenstudium war bei Ausbruch des Krieges eine noch sehr junge Einrichtung, an die sich sicherlich noch nicht alle Professoren gewöhnt hatten und in manchen Fällen auch nicht mehr gewöhnen wollten. Das Hochschullehramt für eine Frau war, von wenigen Ausnahmen abgesehen, für etablierte Professoren vollständig undenkbar. Unter diesen Voraussetzungen konnte man nicht erwarten, dass sich innerhalb kurzer Zeit grundlegende Änderungen vollziehen würden. Der Krieg bot jedoch den Studentinnen in vielen Bereichen tatsächlich neue Chancen, die auch durchaus genutzt wurden, auch wenn dies teilweise nur dadurch geschah, dass vereinzelt und notgedrungen alte Tabus gebrochen wurden. ${ }^{248}$ Weitergehende und nachhaltige Erfolge konnten nicht zuletzt deshalb nicht errungen werden, weil die Kritiker des Frauenstudiums während des Krieges stets mit der möglichen Beschneidung der angestammten Rechte der männlichen Kriegsteilnehmer argumentieren konnten. 249

247 Tollmien: ,Die wissenschaftliche Höhe‘. 1993. S. 274.

248 Für Großbritannien siehe auch: Howarth: Women. 1994. S. 345-375.

249 Andrea Wettmann hebt zudem besonders hervor, dass während des Krieges bewusst keine adäquaten Beschäftigungsmöglichkeiten für Frauen mit akademischer Bildung geschaffen worden waren: „Den während des Krieges studierenden Frauen wurde damit unmißverständlich signalisiert, daß sie vorübergehend zwar den Platz ihrer Kriegsdienst leistenden Kommilitonen einnehmen konnten, aus ihrer in dieser Zeit erbrachten Leistung aber keine weiteren Ansprüche für die Zeit nach Kriegsende ableiten durften." Wettmann: Heimatfront. 2000. S. 385-386. 


\section{Hilfen für Studierende mit und ohne Uniform}

Die Universität konnte sich für ihre Studierenden während des Krieges auf zwei verschiedenen Ebenen einsetzen: Zum einen für die noch in Göttingen anwesenden Studierenden und zum anderen für die, die sich im Kriegsdienst befanden. Letztere blieben während ihrer Abwesenheit weiterhin immatrikuliert und wurden trotz ihrer Beurlaubung immer als Studierende und damit Teil der Korporation Universität angesehen. Dies galt auch für in Gefangenschaft befindliche Kommilitonen. Auch der besondere Schutz der Rechte von Inhabern von Assistentenstellen ist in diesem Kontext zu sehen.

Aber auch die Daheimgebliebenen, wie sie sich oft selber nannten, waren wichtig für die Universität. Ohne sie hätte es während des Krieges keinen Lehrbetrieb geben können. Zu ihnen kamen mit längerer Dauer des Krieges immer mehr Rückkehrer aus dem Kriegsdienst, meist körperlich und psychisch schwer gezeichnet. Gerade sie benötigten Hilfe von den anderen Teilen der Korporation Universität.

\section{Lehrbetrieb und Veranstaltungsangebot}

Die Aufrechterhaltung eines geordneten Lehrbetriebs unter den schwierigen Bedingungen des Krieges war zunächst die wichtigste Verpflichtung für die Universität zu Gunsten der noch in Göttingen anwesenden Studierenden. Ein Schreiben des Kultusministeriums, das nach Kriegsausbruch an alle Hochschulen gerichtet wurde zeigt, dass es auch für die Zeitzeugen durchaus nicht selbstverständlich war, dass die Universitäten zum Wintersemester 1914/15 wieder ganz normal öffneten.

Um mehrfach aufgetretenen Zweifeln zu begegnen, weise ich daraufhin, daß im bevorstebenden Wintersemester die Hochschulen ibre Lehrtätigkeit selbstverständlich aufzunehmen haben. Wie im Jahre 1870/71 trotz des Krieges Vorlesungen und Übungen gehalten sind, so muß auch der Lebrbetrieb im nächsten Winter fortgesetzt werden, wenn auch vielleicht hier und da in beschränkterem Umfange. ${ }^{250}$

Angesichts des dramatischen Rückgangs der Zahlen der aktiven Studierenden war ein relativ normaler Fortgang des universitären Alltags durchaus nicht selbstverständlich. Wenn man sich mit den Veränderungen des Lehrbetriebs und vor allem mit dem Angebot an Veranstaltungen befasst, so offenbart sich eine ähnliche Situation, wie sie sich stellenweise bereits bei dem relativen Anteil der Frauen an

250 UAG.Phil.Fak.II.96 10.09.1914. Tatsächlich wurde im September 1916 die Schließung der Universitäten durch die Oberste Heeresleitung in einer Denkschrift vorgeschlagen. Letztlich sah man hiervon jedoch mit Blick auf das Bild Deutschlands bei den Kriegsgegnern ab. Wettmann: Heimatfront. 2000. S. 99-100. 
den Studierenden zeigte: Die Zeitzeugen scheinen noch wesentlich stärkere Veränderungen wahrgenommen zu haben, als sich dies aus der Aktenlage erschließen lässt. Die folgende Schilderung Karl Brandis verdeutlicht dies:

Zu dem längst erschienenen Vorlesungsverzeichnis [Wintersemester 1914/15] kam ein Nachtrag mit den Ausfällen. Bei der Rechts- und Staatswissenschaftlichen Fakultät fielen 16 Vorlesungen aus, einige blieben zweifelhaft; andere wurden vertretungsweise übernommen. Bei der Medizinischen Fakultät betrug der Ausfall 54 Vorlesungen und Übungen. In der Philosophischen Fakultät wurden die einzelnen Dozenten bezeichnet, deren gesamte Lehrtätigkeit ausfallen mußte. Bleiben wir bei den Vorlesungen, und überblicken wir gleich die folgenden Semester, so gibt die Durchsicht der Verzeichnisse vom Sommer 1915 bis zum Winter 1918/19 noch zu allerlei Beobachtungen Anlaß. Für den Sommer 1915 bemerkten die Mediziner ausdrücklich, daß ibre Ankündigungen nur für den Fall gälten, daß bis dabin demobilisiert werde. Bei den anderen Fakultäten ist das offenbar stillschweigende Voraussetzung gewesen, da regelmäßig von den im Felde stehenden Dozenten Vorlesungen und Übungen angekündigt wurden. Von dem was wirklich gehalten worden ist, geben also die Verzeichnisse kein Bild. ${ }^{251}$

Tatsächlich können die Vorlesungsverzeichnisse, die Brandi zu Rate gezogen hat, keinen endgültigen Aufschluss darüber geben, welche der angekündigten Veranstaltungen stattgefunden haben und welche nicht. Die Akten jedoch bestätigen seine negative Sicht der Situation nur teilweise.

251 Brandi, Karl: Die Universität. 1935. S. 145-153. S. 146-147. 

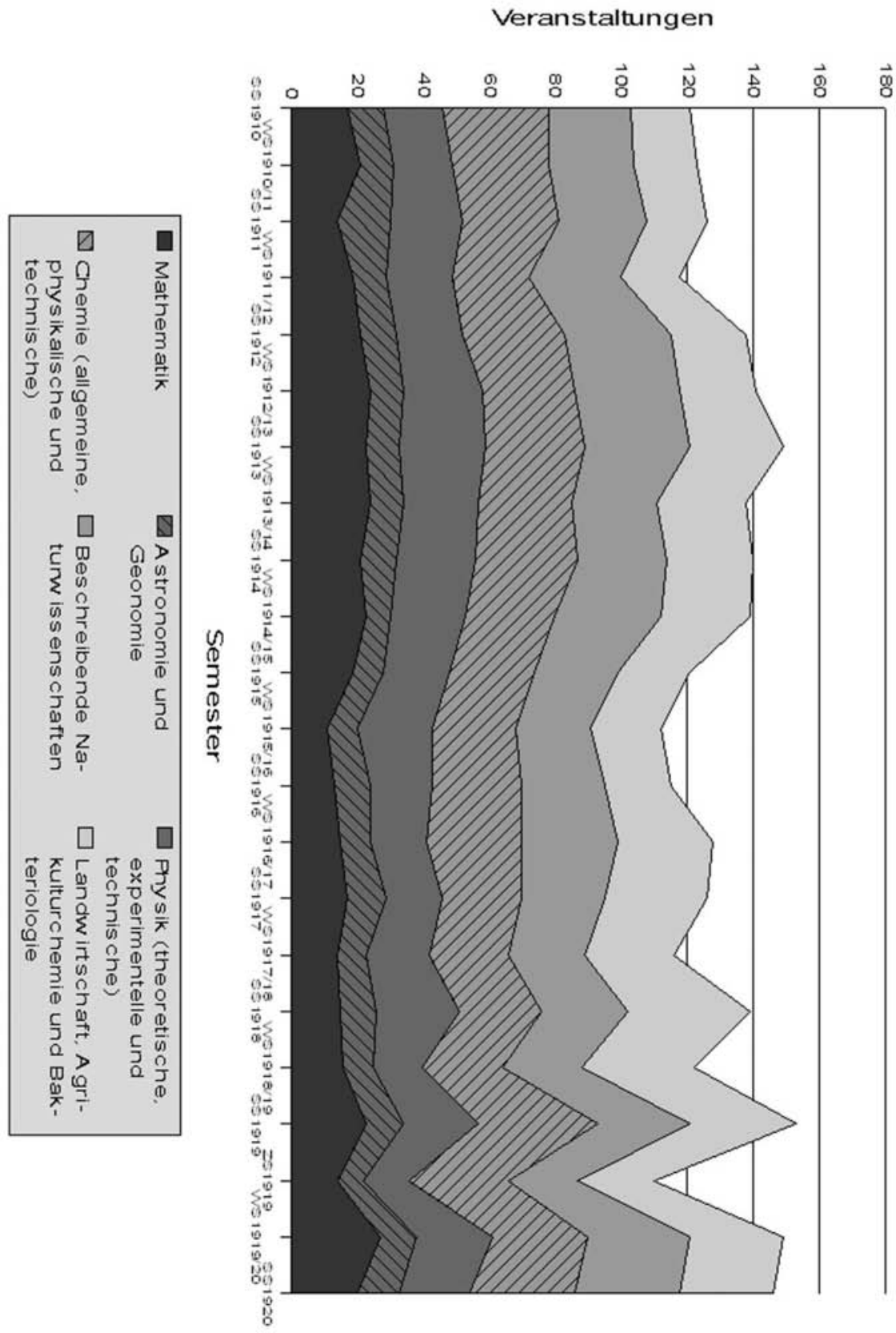

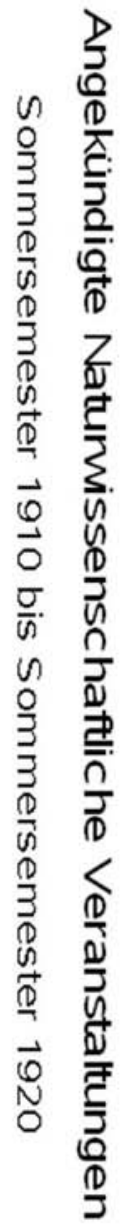

Statistik 6: Daten aus: Universität Göttingen (Hrsg.): Verzeichnis der Vorlesungen auf der Georg-August-Universität zu Göttingen. Göttingen 1910 bis 1920. 
Unbestritten fanden während des Krieges weniger Veranstaltungen statt als zu Friedenszeiten, dies dürfte jedoch nicht zuletzt an der Tatsache liegen, dass eine Vorlesung nicht nur einen Dozenten braucht, sondern auch Studenten. Ihr Fortbleiben ließ einige Veranstaltungen ausfallen, und die tatsächlich stattfindenden wurden nur von einem kleinen Teil der sonst üblichen Studierenden gehört. Für die in Göttingen verbliebenen Studierenden war jedoch das Angebot maßgeblich und das blieb, soweit man dies den Akten nach für die naturwissenschaftlichen Fächer beurteilen kann, weitgehend bestehen. ${ }^{252}$ Statistik 6 gibt nur die Anzahl der angebotenen Veranstaltungen an, also nicht die Anzahl derer, die tatsächlich stattfanden, und auch nicht die Gründe aus denen Veranstaltungen nicht gehalten wurden. Die recht starken Schwankungen rühren hauptsächlich von der schwankenden Zahl an speziellen Kursen und Exkursionen her, die nur unregelmäßig angeboten wurden.

In den Akten, aus denen diese Zahlen stammen, sind alle angebotenen Veranstaltungen mit der Teilnehmerzahl aufgeführt. ${ }^{253}$ Es fällt hier auf, dass die Hörerzahl im Ganzen sehr niedrig im Vergleich zu Friedenszeiten war, und dass manche Übungen nur mit ein oder zwei Studierenden abgehalten wurden. Dabei waren Veranstaltungen der älteren, namhaften Professoren grundsätzlich besser besucht, als die jüngerer und unbekannter Kollegen. Ausfälle sind nur ohne Angabe von Gründen verzeichnet. Das Gesamtbild der Zahlen legt aber den Schluss nahe, dass mehr Veranstaltungen ausgefallen sind, weil sie zu gering besucht waren, als ausfielen, weil ein Dozent zum Kriegsdienst einberufen wurde.

Unter dem Strich ist es müßig, im einzelnen zu diskutieren, warum eine Veranstaltung nicht stattgefunden hat, wenn man die Anzahl der angebotenen Veranstaltungen zu den Studierendenzahlen in Relation setzt. Schätzungsweise fanden in den naturwissenschaftlichen Fächern $75 \%$ aller Veranstaltungen statt, aber nur zwischen 35\% und 25\% der Studierenden waren in Göttingen anwesend. Daher hat wohl auf jeden Fall ein Überangebot bestanden, unabhängig von der Zahl der Dozenten, die sich im Kriegsdienst befanden. ${ }^{254}$

Am Inhalt der Vorlesungen und Übungen lässt sich ebenso wenig wie an deren Zahl eine deutliche Veränderung gegenüber Friedenszeiten feststellen. Die Vermutung liegt nahe, dass jetzt vermehrt kriegsrelevante Themen in den Vorlesungsverzeichnissen zu finden sein könnten.

Jede Universität ist in Kriegs- und Friedenszeiten auch eine große Forschungsgemeinschaft, nicht nur in den Instituten. Alle Fächer dienen als solche irgendwie auch dem Volke und dem Staate. Manche in Kriegszeiten noch unmittelbarer, noch unentbehrli-

252 Andrea Wettmann stellt dar, dass auch für die Universität Marburg nicht von der vielzitierten „Verödung“ der Hörsäle während des Krieges gesprochen werden kann. Wettmann: Heimatfront. 2000. S. 226.

253 Vor allem: UAG.Kur.4090.

254 Siehe Statistik 9. Dieser Befund deckt sich auch mit der Situation an anderen Universitäten. Zum Beispiel: Anderhub: Das Antoniterkreuz. 1979. S. 65. 
cher als im Frieden. Rohstoffbeschaffung und Ersatzwirtschaft, Kriegschemie und Kriegsphysik, künstlicher Stickstoff, Gase, Abhör-Apparate, tausend Nöte in Landwirtschaft und Industrie, in der Ballistike und im Flugwesen riefen nach den Vertretern der Naturwissenschaften. ${ }^{255}$

Diese Annahme bestätigt sich den Titeln der angekündigten Veranstaltungen nach nicht. Zwar verdoppelte sich nahezu die Anzahl der landwirtschaftlichen Veranstaltungen, in Chemie und Physik blieb sie aber weitgehend konstant. ${ }^{256}$ Man muss akzeptieren, dass es nicht mehr rekonstruierbar ist, wie oft die Dozenten sich in Vorlesungen auf die aktuellen Bedürfnisse von Militär und Wirtschaft bezogen. Generell kann man aber für diesen Themenbereich von einer strikten Trennung von Forschung und Lehre ausgehen. Nicht nur, weil der Hauptteil der kriegsrelevanten Forschung deutschlandweit in besonderen Instituten koordiniert und zentralisiert, also von den Universitäten getrennt wurde, sondern auch, weil kriegsrelevante Themen in den Veranstaltungen ausdrücklich untersagt waren:

Unsere Feinde sind unausgesetzt bemüht, ihrer Kriegführung die Errungenschaften deutscher Wissenschaft und Technik nutzbar zu machen - Um dies nach Möglichkeit zu verbindern, ist die Veröffentlichung aller Nachrichten und Nenerungen, durch die das Ausland auf technische Neuerungen und Erfindungen - und zwar nicht nur auf militärischen Gebiete - aufmerksam gemacht wird, verboten. Namentlich fallen unter dies Verbot auch alle Mitteilungen über Erfindungen und neue Gewinnungs- und Herstellungsverfabren auf dem Gebiete der Nahrungsmittel-Versorgung. Bei den grossen Versorgungsschwierigkeiten unserer Feinde muss unbedingt vermieden werden, dass Einzelbeiten über derartige Verfahren in die Oeffentlichkeit kommen und unsere Gegner zu Versuchen auf demselben Gebiete anregen. 257

Mit dieser Zensuranordnung, die der Dekan der philosophischen Fakultät Mitte 1917 für die Dozenten nochmals wiederholte, waren definitiv alle kriegsrelevanten naturwissenschaftlichen Themen vom Lehrbetrieb ausgeschlossen. Wo dennoch solche Inhalte angekündigt wurden, übten die Militärbehörden Zensur aus, wie dies etwa im Sommersemester 1917 geschah. ${ }^{258}$ Welchen Raum diese Themen auf dem Gebiete der Forschung einnahmen, wird an späterer Stelle betrachtet werden.

255 Brandi: Die Universität. S. 145.

256 Auf die Entwicklungen in den landwirtschaftlichen Instituten soll an späterer Stelle noch eingegangen werden. Die Zahl der Veranstaltungen stieg aber wohl nur im Rahmen eines allgemeinen Ausbaus dieser Institute, der kurz vor der Jahrhundertwende begonnen worden war und erst nach 1920 einen vorläufigen Abschluss fand.

257 UAG.Phil.Fak.II.96. [Ohne Datum]; der Beschluss, die Zensuranordnung zu erneuern, wurde am 14.6.1917 gefasst.

258 Wahrscheinlich gab es einen konkreten Anlass für die Erneuerung der Zensuranordnung: Am 31. Mai 1917 hatte das stellvertretende General-Kommando, X. Armeekorps, an den Prorektor der Göttinger Universität geschrieben, worüber dieser den Fakultäten umgehend berichtete, dass im Vorlesungsverzeichnis für das Sommersemester 1917 kriegsrelevante Themen aufgefallen seien. „Bei dem großen Interesse, das die Feinde unserer Kriegstechnik und Kriegswirtschaft 


\section{Ergänzungskurse und Zwischensemester}

Bald wurde klar, dass der Krieg neue Schwierigkeiten und Herausforderungen für die Universität entstehen ließ, die mit den Mitteln des herkömmlichen Unterrichts nicht zu bewältigen waren. Dieses Wissen kann spätestens ab Mitte des Jahres 1916 bei allen Vertretern der deutschen Hochschulen und Bildungspolitikern als weitgehender Konsens betrachtet werden. ${ }^{259}$ In der Göttinger Universität standen Überlegungen über besondere Veranstaltungsangebote und Hilfsmaßnahmen dank ihres wohl bildungspolitisch engagiertesten Mitgliedes Felix Klein schon fast ein Jahr früher auf der Tagesordnung, und Göttingen wurde zu einer Art Pionier in einem ganz neuen Problemfeld.

Wie bereits während der Betrachtung der Studierendenzahlen erwähnt wurde, sollte sich für die Universität nicht so sehr der starke Einbruch der Zahlen zu Beginn des Krieges als belastend erweisen, sondern das noch deutlich stärkere Ansteigen gegen Ende des Krieges. Hierbei war es allerdings nicht nur die Quantität der an die Universitäten drängenden Studierenden, sondern auch deren fehlende fachliche Qualifikation, die für die Universitäten eine Herausforderung darstellte. Dies begann sich schon früh im Jahr 1915 abzuzeichnen, als bereits die ersten verwundeten und erkrankten Soldaten, die überhaupt nicht mehr oder nur langsam wieder einsatzfähig wurden, an ihre Universitäten zurückkehrten.

Aus Sicht der Universität gliederten sich die Kriegsteilnehmer unter ihren Studierenden in zwei Gruppen. Dies waren zum einen Studenten, die vor Kriegsausbruch bereits ihr Studium aufgenommen hatten oder schon weiter darin fortge-

entgegenbringen, ersucht das Generalkommando Euer Magnifizenz ergebenst, die in Betracht kommenden Herren Dozenten dahin verständigen zu wollen, dass sie sich bei ihren Vorlesungen in den Grenzen nachstehender Zensur=Anordnungen halten: [Der folgende Text ist identisch mit der zuvor zitierten Zensuranordnung.]" UAG.Sek.38.1 31.5.1917.

Auch für andere deutsche Universitäten wird von dieser Art der Zensur berichtet. Für Erlangen: Liermann: Die Friedrich-Alexander-Universität. 1977. S. 43; für Marburg: Wettmann: Heimatfront. 2000. S. 304-305.

259 Die deutsche Rektorenkonferenz vom 5. Januar 1916 behandelte auch die Frage der Ergänzungskurse für Kriegsteilnehmer und fasste, trotz Meinungsverschiedenheiten im Detail, folgenden Entschluss: „Die Rektorenkonferenz hält es für wünschenswert, daß an allen Universitäten Ergänzungskurse für Notabiturienten eingerichtet werden, $\mathrm{da}$ in irgendeiner Form ein akademischer Zwang zum Besuch der Ergänzungskurse ausgeübt wird, daß von den Fakultäten in ihren Studienplänen auf die Kurse möglichst Rücksicht genommen werde, daß die Kurse nicht zu einer dauernden Einrichtung werden. UAG.Sek.558(6) Bl. 78v-79v. Siehe auch den Rücklauf einer entsprechenden Umfrage der Göttinger Universität, auf die im folgenden noch näher eingegangen werden soll.“ UAG.Sek.412.g3 15.09.1915 (Datum der Anfrage).

Siehe hierzu auch: Wettmann: Heimatfront. 2000. S. 134ff. und 234ff. An der Universität Marburg entwickelte sich die Betreuung erblindeter Kriegsteilnehmer als Schwerpunkt der Aktivitäten. Die hieraus hervorgegangene Blindenstudienanstalt Marburg besteht noch heute. Wettmann: Heimatfront. 2000. S. 231-232. 
schritten waren. Sie hatten bei ihrer Rückkehr nicht nur für längere Zeit nicht mehr wissenschaftlich gearbeitet, sondern standen auch durch den Einruck des Erlebten den Inhalten ihres Studiums fern und mussten erst wieder an wissenschaftliche Themen und Denkweisen herangeführt werden. Zahlreiche physische und psychische Verwundungen durch den Krieg taten ihr Übriges. Zum anderen handelte es sich bei der zweiten Gruppe Kriegsteilnehmer um Studienanfänger, die erst nach ihrem Kriegsdienst ihr Studium aufnahmen. Die Schüler höherer Schulen, die als letzter Jahrgang ein reguläres, zum Studium berechtigendes Zeugnis erworben hatten, hatten sich bei Kriegsausbruch bereits immatrikuliert. Die folgenden Jahrgänge hatten von den zahlreichen und uneinheitlichen Sonderregelungen Gebrauch gemacht, die es Schülern höherer Schulen ermöglichten, ihr Abitur vorzeitig, teilweise sogar ganz ohne Prüfung, abzulegen. Man sprach in ihrem Falle von so genannten Notabiturienten. ${ }^{260}$ Ebenfalls als Erstsemester schrieben sich nach Ende des Krieges eine Anzahl ehemaliger Offiziere und Berufssoldaten ein, deren berufliche Zukunft durch das Kriegsende und die Bedingungen des Versailler Vertrages massiv bedroht waren. ${ }^{261}$

Noch im Juni 1915 war Felix Klein in der Akademischen Vereinigung262 mit den sich abzeichnenden Schwierigkeiten in Berührung gekommen. In diesem Gremium brachte H. E. Timerding 263 eine Denkschrift ein, in der er für die Einrichtung eines „Vorsemester[s] zur Vorbereitung auf das Hochschulstudium für die mit Notexamen eintretenden Studierenden“ plädierte. ${ }^{264}$ Timmerding erläuterte die Defizite, die in der Vorbildung der zukünftigen Studierenden durch die verschiedenen Formen von vereinfachten Examina für Kriegsfreiwillige entstanden seien und kam zu dem Schluss, dass es keine Alternative zu einem vorbereitenden Unterricht geben könne. Er war sich aber auch der politischen Probleme bewusst, die solche Forderungen mit sich brachten.

Grundsätzlich gab es zwei Möglichkeiten, wo und von wem ein solcher Unterricht geleistet werden konnte. Zunächst kamen hier die höheren Schulen in Betracht, was aber sogleich verworfen und als undurchführbar eingeschätzt wurde. Diese Ablehnung wurde allerdings nicht fachlich begründet, sondern basierte vielmehr auf Denkmustern, die denen ganz ähnlich waren, die bereits im Zusammenhang mit dem Studium von ausländischen Studierenden und der Vergabe von

260 Zur besonderen Problematik der Notabiturienten und ihrer Immatrikulation siehe: Wettmann: Heimatfront. 2000. S. 330ff.

261 Das Kultusministerium erwähnt diese Gruppe im Frühjahr 1919: ,[...] sondern auch solche Herren, welche, durch die Not der Zeit gezwungen, es nachträglich mit dem Studium [...] versuchen wollen, z.B. Offiziere, welche ihre Stellung verloren haben." UAG.Kur.2262 Bl. 26.

262 Auf Felix Kleins umfangreiche wissenschaftsorganisatorische Tätigkeiten wurde in der Einleitung eingegangen. Siehe zur Akademischen Vereinigung die dort angegebene Literatur. Zu der genannten Sitzung wurde für den 19. Juni 1915 eingeladen. „Berichterstatter: Felix Klein.“ SUB.Gött.HSD.Cod.Ms.Felix Klein.I.A.3 Bl. 4.

263 Professor H. E. Timmerding war Rektor der Technischen Hochschule Braunschweig.

264 SUB.Gött.HSD.Cod.Ms.Felix Klein.I.A.3 Bl. 5-8. 
Assistentenstellen an Frauen gezeigt wurden: Man fühlte sich den jungen Kriegsfreiwilligen verpflichtet und für sie verantwortlich und befürchtete, dass sie es als Zumutung und Undankbarkeit empfinden würden, wenn man sie nach geleistetem Kriegsdienst wieder an die Schulen zurückgezwungen hätte, zumal ihre Mehrzahl über eine gültige Hochschulzugangsberechtigung in Form des Notabiturs verfügte.

Dafür aber wäre natürlich an sich ein erneuter Schulbesuch der einfachste Weg. Dieser Weg ist jedoch garnicht zu beschreiten, weil der junge Mann schon das Abgangszengnis der Schule und die Berechtigung zum Hochschulstudium besitzt und von ihm nicht erwartet werden kann, daß er der Gediegenheit seiner Ausbildung zuliebe freiwillig auf diese Berechtigung verzichtet und aufs neue die Schulbank drück.t. Vielmehr muß ihm, um ibn überhaupt für die als notwendig erkannte Ergänzung seiner Vorbildung zu gewinnen, seine Lerntätigkeit als akademisches Studium angerechnet werden.

Es erhebt sich damit die große Schwierigkeit, einerseits dasselbe geben zu müssen, was die Schule während der letzten Zeit des Schulbesuchs gibt, und doch diesen Unterricht in Form eines akademischen Studiums kleiden zu müssen. ${ }^{265}$

Also blieben nur die Universitäten als denkbare Institutionen, um das fehlende Wissen zu vermitteln. Timmerding gab jedoch zu bedenken, dass vom pädagogischen Standpunkt aus ein klassischer Schulunterricht hier sinnvoller sei als Universitätsvorlesungen. Deshalb schlug er vor, Lehrer höherer Schulen hinzuzuziehen. Dabei handelte es sich jedoch bereits um Detailfragen. Als viel entscheidender sollte sich eine Frage erweisen, die Timmerding nur sehr kurz in seinem letzten Absatz anschnitt. Für ihn war es offensichtlich selbstverständlich, dass solche Kurse für die betreffenden Studenten verpflichtend sein müssten. ${ }^{266}$ Jeglicher Eindruck eines Zwanges für Kriegsteilnehmer musste zu dieser Zeit jedoch auf Widerstand stoßen, wie ein Brief Professor W. Borchers an Klein betreffend dieser Fragen beweist. Der Vorstand des Instituts für Metallhüttenkunde und Elektrometallurgie der Technischen Hochschule Aachen drohte darin offen mit seinem Austritt aus der Akademischen Vereinigung aus Verärgerung über diese Diskussion. Seine Argumente sind beispielhaft für zu dieser Zeit weit verbreitete Überzeugungen.

Ist es denn auszudenken, dass wenn diese prächtigen jungen Männer nach Friedensschluss Einlass in unsere Hochschulen begehren, man Ihnen dort sagen könnte: ,Ihr könnt als Vollstudierende nicht aufgenommen werden, denn Ihr habt ja ein wertvolles Schuljahr versäumt, habt also nicht die geistige Reife erlangt, welche die Zulassung zu akademischen und Staatsprüfungen bedingt. Unsere Hochschulen sind nur den fleissigen klugen Jungen offen, die inzwischen auf der ungefährdeten Schulbank ibre Reifezengnisse ersessen haben, während Ihr weiter nichts tatet, als Euer Leben für Euer Volk und für Euer Vaterland zu riskieren.'

265 SUB.Gött.HSD.Cod.Ms.Felix Klein.I.A.3 Bl. 5-6.

266 SUB.Gött.HSD.Cod.Ms.Felix Klein.I.A.3 Bl. 8. 


\section{[...] Die jungen Leute, welche fast noch im Knabenalter von der Schulbank unmittelbar} in die schwersten Stürme des Lebens eingetreten sind, sind doch gewiss in einer ernsteren Schule als in denjenigen, welche die Berechtigung zur Ausstellung des papierenen Zengnis der Reife besitzen, zu Männern gereift und gehärtet worden. ${ }^{267}$

Trotz dieser grundsätzlichen Kritik blieb Timmerdings Eingabe eine Art Prototyp für die folgenden Überlegungen. Bei der konkreten Durchführung musste peinlichst genau darauf geachtet werden, sowohl im öffentlichen Bereich als auch bei den Betroffenen selber eine Verletzung ihrer Gefühle zu vermeiden. Das war Felix Klein spätestens seit dem Brief Borchers bewusst, der wie er selbst Mitglied des preußischen Herrenhauses war.

Klein nahm dieses Thema sehr ernst und brachte es schnellst möglich in den Universitätsgremien ein. Bereits am 3. Juli versandte der Prorektor ein Schreiben an das Corpus Professorum, in dem er bekannt gab, dass Klein dem Senat Mitteilung gemacht hatte:

[...] über die Verbältnisse und die Lage der Studierenden und der Schüler welche am Kriege teilnehmen. Es scheint nötig Massregeln zu beraten um für die mangelhafte Vorbereitung dieser Studenten Abbülfe zu treffen. Geheimrat Klein schlägt vor, der Prorektor möge noch vor den Ferien die Dekane der Fakultäten Herrn Gymnasial Direktor Miller und wer sich sonst für die Frage interessiert, zu einer Besprechung zusammenrufen. ${ }^{268}$

Klein hatte sich um die Mitarbeit des Gymnasialdirektors Miller bemüht, da er mögliche Lösungen nur in Zusam-

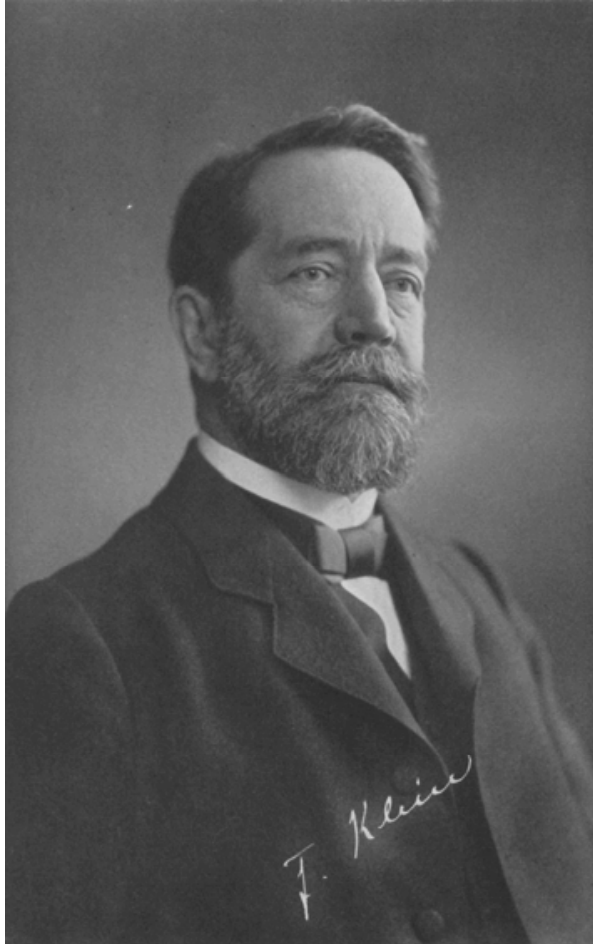

Abbildung 4: Felix Klein menarbeit mit den Schulen finden wollte. Es galt einerseits, über den Wissensstand der Notabiturienten und andererseits über den konkreten Lernstoff, der in dem fehlenden Schuljahr zu absolvieren gewesen wäre, präzise Auskunft zu erhalten. Außerdem hatte ja bereits Timmerding angemahnt, dass Hochschullehrer und Hochschulunterricht vielfach nicht geeignet seien, diese besonderen Anforde- 
rungen zu erfüllen. Bereits eine Woche später, am 10. Juli, fand diese Besprechung statt. Weitere Teilnehmer waren neben Miller, Klein und Prorektor Carl Runge Professoren aller Fakultäten: Titius, Mirbt, Jensen, v. Hippel, Rabl, Morsbach, Pohlenz, Voigt, Sethe, Debye und Landau.

Felix Klein war es offensichtlich gelungen, seine Kollegen innerhalb kürzester Zeit von der Notwendigkeit und Dringlichkeit dieser Frage zu überzeugen. Es wurde die Einrichtung einer Kommission beschlossen, und bereits im ersten diesbezüglichen Rundschreiben an die Dekane war von „einzurichtenden Ergänzungskurse[n] für Studierende, die aus dem Felde zurückkehren“269 die Rede. In den Ergänzungskursen sah man folglich die Lösung für die kommenden Herausforderungen. An ihrer konkreten Gestaltung wurde dann mit Hochdruck gearbeitet. Immer wieder tagte die Kommission, um sich nicht nur über die praktische Durchführung der Ergänzungskurse zu beraten, sondern auch über die wichtigen Fragen, in welcher Art sie in die Studiengänge eingebunden werden und ob sie für die Kriegsteilnehmer verpflichtend sein sollten. Ganz deutlich wollte man noch vor Beginn des Wintersemesters einen Konsens erreichen, und so lag bereits am 18. August 1915 ein erstes Ergebnis der Beratungen vor. Prorektor Runge, der als solcher gleichzeitig Vorsitzender der ständigen Kommission gewesen ist, verschickte eine ausführliche Denkschrift, einschließlich eines Gutachtens des Gymnasialdirektors Miller, an alle Dozenten der Universität.

Den Herren Kollegen übersende ich ergebenst eine Denkschrift, der in der Sitzung des Corpus Professorum am 3. Juli eingesetaten Kommission nebst einer Schrift des Herrn Gymnasialdirektors Miller, der an den ersten Beratungen teilgenommen hat. Der Senat wird in seiner Sitzung bei Gelegenheit der Übergabe des Rektorats gebeten werden, sich die Vorschläge der Kommission zu eigen zu machen. ${ }^{270}$

Um Zeit zu sparen wollte man sicher gehen, dass allen Mitgliedern der Gremien der Universität das Ergebnis der Beratungen der Kommission bereits bekannt war, um möglichst schnell weitergehende Beschlüsse fassen zu können. Als geeigneten Rahmen hierfür hatte man eine der traditionell wichtigsten Sitzungen des Senats gewählt, da man sich hier einer großen Teilnahme sicher sein konnte, ohne innerhalb der Semesterferien Terminabsprachen treffen zu müssen. Am 1. September jeden Jahres wurde das Amt des Prorektors, beziehungsweise des Rektors, an den jeweiligen Nachfolger übergeben - in diesem Jahr von Carl Runge an Artur Titius.

Die [...] Kommission zur Erwägung der für die Kriegsteilnehmer entstandenen Studienlage [...] hat sich der Einsicht nicht verschliessen können, dass einem normalen Studiengange der Kriegsteilnehmer sich sehr ernste Hindernisse in den Weg stellen werden, die nur durch das gemeinsame Wirken der Universitätslehrer einigermassen überwunden

269 UAG.Sek.412.g3 20.07.1915.

270 UAG.Sek.412.g3 18.08.1915. 
werden können und Schritte der Universität als solcher notwendig machen. Der Senat ist die gewiesene Instanz. zur Regelung der Angelegenheit, die ibm in der nächsten Sitzung (am 1. September) zur Beschlussfassung unterbreitet werden soll. ${ }^{271}$

In der Denkschrift, ${ }^{272}$ die die Kommission ausgearbeitet hatte, wurden zunächst im Abschnitt „Der Notstand und die erwachsenden Aufgaben“ die zu erwartenden Schwierigkeiten aufgezählt, jedoch ausdrücklich nur ,nach der intellektuellen Seite hin." Außerdem rechnete man mit finanziellen und physischen Einschränkungen der Kriegsteilnehmer, wie zum Beispiel „,nervösen Überreizungszustän$\operatorname{de}[\mathrm{n}] .{ }^{\text {‘2273 }}$

Die Einrichtung von Ergänzungskursen für Kriegsteilnehmer aller Art wurde ohne jeden Einwand als absolute Notwendigkeit dargestellt. Dass man im Falle der Notabiturienten Sonderklassen an den Schule eigentlich für die sinnvollere Alternative hielt, verschwieg man zwar nicht, stellte aber fest, dass dies gänzlich unmöglich wäre und ,aus mancherlei Gründen nicht einmal zu wünschen." 274 Deshalb akzeptierte man, dass die Universität zwar nicht der geeignetste Ort zur Einrichtung und Durchführung der Kurse war, aber doch der einzig in Betracht kommende.

[...] indes wirkt hier das Bedürnis des Elternhauses auf Entlastung, des Staates auf Nachwuchs für die liberalen Berufsarten, nicht zum wenigsten auch die unter außerordentlichen Umständen schneller erworbene männliche Charakterreife der kriegführenden Jugend gebieterisch zusammen, der Universität Aufgaben zuzuweisen, denen sie sich nicht entziehen kann und denen sie deshalb mit besonderen Mitteln wird begegnen müssen. ${ }^{275}$

Dass man sich den Studierenden, die ihr bereits begonnenes Studium durch den Krieg unterbrochen hatten, in besondere Weise widmen musste, wurde schlicht als Selbstverständlichkeit betrachtet:

Ihnen nach Möglichkeit wieder hineinzuhelfen, wird jeder als selbstverständliche Pflicht empfinden, und es wird Aufgabe der einzelnen Fachvertreter bez[iehungsweise] der Fakultäten sein, die für die verschiedenen Studiengebiete geeignetsten Maßnahmen zu treffen. " 276

Als geeignete Mittel hierzu wurden drei verschiedene Veranstaltungen vorgeschlagen. Zum einen wurden Vorlesungen zur „Vertiefung der allgemeinen Bildung““277

271 UAG.Sek.412.g3 18.08.1915.

272 In den Akten UAG.Sek.412.g3 und UAG.Sek.412.h enthalten. Außerdem im Nachlass Felix Kleins: SUB.Gött.HSD.Cod.Ms.Felix Klein.I.A.3 Bl. 13-18.

273 SUB.Gött.HSD.Cod.Ms.Felix Klein.I.A.3 Bl. 13.

274 SUB.Gött.HSD.Cod.Ms.Felix Klein.I.A.3 Bl. 13v.

275 SUB.Gött.HSD.Cod.Ms.Felix Klein.I.A.3 Bl. 13v.

276 SUB.Gött.HSD.Cod.Ms.Felix Klein.I.A.3 Bl. 14.

277 SUB.Gött.HSD.Cod.Ms.Felix Klein.I.A.3 Bl. 14v-15. 
geplant. Sie sollten den Studierenden aller Fakultäten offen stehen und bewusst auf enge Bezüge zu den einzelnen Fächern verzichten. Man ging davon aus, dass solche Vorlesungen einem „erweiterten Horizont“278 der zurückkehrenden Studierenden Rechnung tragen würden und man sie so an das Universitätsleben heranführen könne. Zum anderen sollten Kurse zur „Ergänzung der Fachkenntnisse“ “279 abgehalten werden. Dadurch hoffte man, vor allem die durch das Notabitur entstandenen Defizite der Neueinsteiger zu beheben, insbesondere im Bereich Sprachen. Als drittes Standbein der Ergänzungskurse schlug man ausführliche Studienberatungen vor. Dieses Angebot sollte sich vor allem an die bereits vor Kriegsbeginn Immatrikulierten wenden, denen zusätzlich die Möglichkeit gegeben werden sollte, besondere Repetitorien und Kolloquien zu besuchen. Die Mitglieder der Kommission nahmen diese beratende Tätigkeit sehr ernst, und man betonte, dass sie weit über die üblichen Sprechstunden der Dozenten hinausgehen müssten, da man vermutete, dass viele Studenten von den Erlebnissen des Krieges so geprägt waren, dass auch grundsätzliche Änderungen von Berufswünschen und damit auch von Studienfächern vorkommen würden. ${ }^{280}$

Obwohl die Denkschrift beispielsweise im Falle der allgemein bildenden Vorlesungen so konkret wurde, dass bereits Namen von Dozenten und Vorlesungsthemen genannt wurden, blieb sie in einem anderen Punkt auffallend unpräzise. Die Frage nach der Verbindlichkeit von Ergänzungskursen war, wie bereits erwähnt, nicht unproblematisch. Offenbar um die Zustimmung des Senats zu den in der Denkschrift geäußerten Vorschlägen nicht zu gefährden, legte sich die Kommission in dieser Frage bewusst nicht fest, aber nicht ohne anklingen zu lassen, dass man sich hier verbindliche Regelungen wünschte.

Zu erwägen bleibt, ob nicht, soweit es Sitte ist, die Erlaubnis zum Seminarbesuch an gewisse Bedingungen zu knüpfen, zweckmäßig der Besuch geeigneter Veranstaltungen den Notabiturienten als Bedingung für die Aufnahme ins Seminar auferlegt wird. ${ }^{281}$

Was bereits durch die Eile der Arbeit der Kommission deutlich wurde, unterstrich man nochmals ausdrücklich: Man wollte unbedingt, gleichgültig wie lange der Krieg tatsächlich noch dauern würde, bereits im kommenden Wintersemester 1915/16 mit der Arbeit in den Ergänzungskursen beginnen. Zum einen sollte dies geschehen, um den bereits vorzeitig zurückgekehrten verwundeten oder erkrankten Kriegsteilnehmern helfen zu können und zum anderen, da man hoffte, anhand dieser ersten Rückkehrer Erfahrungen sammeln zu können, um dem wirklich großen Ansturm nach einem Friedensschluss effektiv begegnen zu können. ${ }^{282}$

\footnotetext{
278 SUB.Gött.HSD.Cod.Ms.Felix Klein.I.A.3 Bl. 14v.

279 SUB.Gött.HSD.Cod.Ms.Felix Klein.I.A.3 Bl. 15.

280 SUB.Gött.HSD.Cod.Ms.Felix Klein.I.A.3 Bl. 15.

281 SUB.Gött.HSD.Cod.Ms.Felix Klein.I.A.3 Bl. 14.

282 SUB.Gött.HSD.Cod.Ms.Felix Klein.I.A.3 Bl. 14-14v.
} 
Die Denkschrift wurde zu einem vollen Erfolg. Der Senat der Universität stimmte ihm wie vorgesehen in der Sitzung vom 1. September des Jahres zu. ${ }^{283}$

Der Senat macht die Denkschrift der Kommission, welche den Mitgliedern zugegangen war, sich zu eigen und ernennt eine Senatskommission, welche die Angelegenheit weiter behandeln und insbesondere im Namen von Prorector und Senat mit Anträgen an den Minister herantreten soll. Diese Senatskommission soll aus den bisherigen Kommissionsmitgliedern Professor Titius, Mirbt, Jensen, Rabel, Morsbach, Poblenz, Klein und Runge bestehen. ${ }^{284}$

Damit stand der Einrichtung von Ergänzungskursen an der Georgia Augusta als erster deutscher Universität nichts mehr im Weg. ${ }^{285}$ Am 5. September tagte die nun offiziell eingerichtete Senatskommission zum ersten Mal, verabschiedete den endgültigen Text der Denkschrift und veranlasste deren Druck. Außerdem beschloss man, erste finanzielle Mittel beim Kultusministerium zu beantragen. 286 Zahlreiche Kollegen sagten ihre Unterstützung zu. Das Vorlesungsverzeichnis für das Wintersemester lag zwar bereits vor, aber schon die während des Krieges obligatorischen Ergänzungen zum Vorlesungsverzeichnis, in denen sonst die kriegsbedingten Ausfälle von Veranstaltungen und Vertretungen bekannt gegeben wurden, enthielten den Anhang „Ergänzungskurse für Kriegsteilnehmer.“287

Vorbemerkung: Kriegsteilnehmer, mit verkë̈rter Schulbildung seien besonders auf die nachstehenden Vorlesungen für Hörer aller Fakultäten sowie auf die Vorlesungen allgemein bildenden Charakters hingewiesen, welche das ,Verzeichnis' enthält. Außerdem kommen natürlich für sie, soweit sie über die notwendigen Vorkenntnisse verfügen, die normalen Fachvorlesungen für die ersten Semester in Betracht.288

Die theologische Fakultät bot in diesem Verzeichnis drei Veranstaltungen an, die juristische zwei und darüber hinaus besondere Studienberatungen:

Bei den theoretischen Vorlesungen und den Übungen der rechts- und staatswissenschaftlichen Fakultät werden besondere Bedürfnisse der Kriegsteilnehmer tunlichst Berücksichtigung finden. Diese Herren werden ersucht, sich bei den betreffenden Dozenten zu melden. Auch sind der Herr Dekan und die Dozenten der Fakultät bereit, den

283 UAG.Phil.Fak.III.Protokollbuch Senat - Konzil 1912 - 1933. S. 73.

284 UAG.Sek.412.g3. 01.09.1915.

285 Universitätsinterne Diskussion und Organisation zur Einrichtung der Ergänzungskurse zusammengefasst auch in: Universität Göttingen (Hrsg.): Chronik der Georg-August-Universität zu Göttingen für das Rechnungsjahr 1915. Göttingen 1916. S. 78-80.

286 UAG.Sek.412.g3. 05.09.1915.

287 Universität Göttingen (Hrsg.): Verzeichnis der Vorlesungen auf der Georg-August-Universität zu Göttingen. Ergänzungen zum Vorlesungsverzeichnis. Göttingen 1915. Außerdem enthalten in: UAG.Sek.412.g3.

288 UAG.Sek.412.g3. 


\section{Herrn Kriegsteilnehmern Auskunft über möglichst zweckmäßige Gestaltung ibres Studi-} ums zu geben. 289

In der medizinischen Fakultät wurden zwar keine speziellen Lehrveranstaltungen angeboten, jedoch ein Kolloquium zur Beratung der Kriegsteilnehmer. Außerdem wurde darauf hingewiesen, dass der Dekan sich den vorzeitigen Schulabgängern und Rückkehrern persönlich widmen werde, um ihnen die jeweils geeigneten Kurse zu empfehlen. Das bei weitem umfangreichste Angebot stellte die philosophische Fakultät mit zwölf Veranstaltungen, sieben davon in den naturwissenschaftlichen Fächern. Scheinbar wurde hier der Wunsch nach einer ausreichenden Vorbildung der Studienanfänger am stärksten empfunden. Unter anderem gelang es, mit Herrn Professor Götting einen Gymnasiallehrer zu gewinnen, der in einem Kurs „Das Mathematikpensum der Prima“ 290 anbot. Diese Kurse fanden innerhalb der Universität statt und waren Teil eines fortgesetzten oder neu begonnen Hochschulstudiums. Damit stellten sie einen Kompromiss zwischen dem allgemeinen Wunsch dar, dass Kriegsteilnehmer nicht wieder an ihre Schulen zurückkehren sollten und dem Denken der Professoren, dass vielfach Schulunterricht mit den regulären Inhalten des letzten Schuljahres die sinnvollere Lösung für die Notabiturienten gewesen wäre.

Selbstverständlich lag es auch im Interesse der Universität, das Wissensniveau der Notabiturienten auf ein studientaugliches Maß zu heben. Man begnügte sich aber nicht damit, nur die eigenen Studierenden zu betreuen, sondern suchte auch die Zusammenarbeit mit den anderen deutschen Universitäten und den Schulen. Bereits in der Sitzung des Senats, in der die Denkschrift angenommen wurde, wurde beschlossen, mit diesen in Kontakt zu treten. Der Rektor bat dann in einem Rundschreiben vom 15. September an alle deutschen Universitäten, Hochschulen und Fachhochschulen, dem jeweils ein Exemplar der Denkschrift beigefügt war, um die Meinungen seiner Kollegen zu der Göttinger Initiative.

Ich darf Ihres freundlichen Interesses für diese Bemühungen gewiß sicher sein und würde Ihnen sehr zu Dank verpflichtet werden, wenn Sie Ihre Gesichtspunkte zur Abänderung oder Ergänzung unserer Vorschläge mir mitteilen wollten. ${ }^{291}$

Ferner schickte man die Ankündigung der ersten Ergänzungskurse, wie sie auch im Nachtrag zum Vorlesungsverzeichnis abgedruckt war, an das Berliner Tageblatt. Die Rückläufe dieses Rundschreibens waren - auch in Anbetracht der Semesterferien - sehr lebhaft. Die ersten Antworten trafen bereits zwei Tage später, am 17. September, im Sekretariat der Universität ein: Das Berliner Tage-

289 UAG.Sek.412.g3.

290 UAG.Sek.412.g3 29.09.1915 Bitte an das Kultusministerium, Professor Götting für die Mathekurse mit Primapensum von seiner Schule abzuordnen.

291 UAG.Sek.412.g3. 15.09.1915. Am 04.10.1915 versandte man außerdem die Denkschrift an über 100 Gymnasien. 
blatt bat um ein Exemplar der Denkschrift und teilte mit, dass es gerne die Bekanntmachung des Göttinger Angebots übernehmen wollte. ${ }^{292}$

Die Antworten der Universitäten und Hochschulen umfassten ein breites Spektrum von größtem Zuspruch bis hin zu betonter Zurückhaltung. ${ }^{293}$ Alle verdeutlichten jedoch, dass Göttingen zwar zu dieser Zeit nicht die einzige Universität war, in der man sich Gedanken um die Zukunft der Kriegsteilnehmer machte, aber doch die Einzige, die bis dahin über das Stadium erster Gespräche und Absichtsbekundungen hinausgekommen war. Durch das offensive Verbreiten der Göttinger Denkschrift schließlich hatte man eine deutschlandweite Diskussion initiiert. Die Mehrzahl der angeschriebenen Hochschulen, wie beispielsweise die Universität Danzig oder die Technische Hochschule Berlin, bedankten sich für eine willkommene Anregung und bestellten weitere Exemplare der Denkschrift beim Göttinger Rektor, um sie an ihre Dozenten verteilen zu können. Die Handelshochschule Berlin schrieb etwa:

\section{[...] den in der Denkschrift ausgesprochenen Gedanken stimme ich obne Einschränkung zu. Die Georg-August-Universität hat sich ein hohes Verdienst erworben, indem sie auf diesem Gebiet vorausgegangen ist. Bei uns ist leider noch nichts geschehen, aber ich werde alsbald versuchen, dem Göttinger Beispiel zu folgen. Eltzbacher ${ }^{294}$}

Besonders interessiert zeigten sich die Hochschulen, die sich selbst schon in Beratungen über dieses Thema befanden. Die junge Universität Frankfurt bedauerte ausdrücklich, dass man dort noch nicht so weit fortgeschritten sei. Ähnliches verlautete aus Karlsruhe, Eberswalde und Marburg:

Euer Magnificenz spreche ich für die Übersendung der Denkschrift über die Einrichtung von Ergänzungskursen für Kriegsteilnehmer ergebensten Dank aus. Da deren Unterstützung wie an anderen Universitäten so auch hier in Aussicht genommen ist, nahmen wir von dem Vorgehen Ihrer Universität mit grossem Interesse Kenntnis und wären Ihnen zu Dank verpflichtet, wenn Sie uns gütigst noch einige (etwa 3-4) Exemplare der Denkschrift zur Verfügung stellen könnten. Rektor Karstedt295

Sogar das bayrische Staatsministerium wurde auf die Göttinger Initiative aufmerksam. Die Technische Hochschule München bestellte nicht weniger als 60 Exemplare der Denkschrift, da dort von offizieller Seite mehrfach auf sie Bezug genommen worden war. ${ }^{296}$ Andere Universitäten, wie etwa Leipzig, antworteten nur knapp mit der Feststellung, dass man für solche Kurse keinerlei Notwendigkeit sehe.

292 UAG.Sek.412.g3. 17.09.1915.

293 Von Mitte September bis in den November 1915 hinein trafen zahlreiche Briefe in Göttingen ein, die alle in der Akte UAG.Sek.412.g3 enthalten sind. Es wird hier davon abgesehen, alle Schreiben einzeln zu belegen.

294 UAG.Sek.412.g3. 29.09.1915.

295 UAG.Sek.412.g3. 21.09.1915.

296 UAG.Sek.412.g3. 07.10.1915. 
Aber es gab durchaus auch deutliche Kritik. Die meisten der sehr frühen Antworten trafen innerhalb von zwei Wochen in Göttingen ein, viele bereits nach wenigen Tagen. Demnach kann es sich bei ihnen nur um spontane und persönliche Meinungsäußerungen der angeschriebenen Rektoren gehandelt haben. Je länger es dauerte, bis eine Antwort an der Georgia Augusta eintraf, desto größer wurde der Anteil an zurückhaltenden Äußerungen oder offener Kritik. Es ist anzunehmen, dass dies daran lag, dass in diesen Fällen die Göttinger Ideen zur Beratung an Gremien und Ausschüsse übergeben worden waren. Unweigerlich traten hier die gleichen Vorbehalte zu Tage, wie Klein sie bereits in der Akademischen Vereinigung kennen gelernt hatte. Als Beispiel kann hier das Schreiben der Universität Tübingen gelten:

[...] beehre ich mich mitzuteilen, das der kleine Senat unserer Universität binsichtlich der für die künftig studierenden Kriegsteilnehmer zu treffenden besonderen Einrichtungen grundsätəlich auf einem etwas anderem Standpunkt steht, als die Universität Göttingen. Bei der Beratung kam allseits zum Ausdruck, dass die Einbuße an Schulbildung, die die Studierenden durch vorzeitigen Schulabgang erlitten, durch ibre Teilnahme am Krieg zu einem gewissen Teil, namentlich binsichtlich der allgemeinen intellektuellen und sittlichen Reife und Selbstständigkeit, ausgeglichen werde. Die gewaltigen inneren und äußeren Erlebnisse, die schweren Aufgaben u.s.w. entwickle die jungendliche Auffassungs- Denkund Ausdrucksfähigkeit wenn auch nicht auf dem schulmäßigen Wege, so doch im GroBen und Ganzen mit dem selben Enderfolg. ${ }^{297}$

Aus diesen Gründen lehnte man Kurse mit allgemein bildenden Themen grundsätzlich ab und war sich sicher, eventuell bestehende Bedürfnisse auf wissenschaftlichem Gebiet im normalen Universitätsbetrieb befriedigen zu können. Offensichtlich empfand man es geradezu als anmaßend, von Kriegsteilnehmern etwas zu verlangen, das man von anderen Studenten nicht forderte. Andere Kritikpunkte am Göttinger Modell waren, dass die ,akademische Freizügigkeit und die Examensfreiheit" ${ }^{298}$ innerhalb Deutschlands durch das Vorauseilen einzelner Universitäten gefährdet werden würden. Die Universität Leipzig etwa reichte mit dieser Begründung die Göttinger Denkschrift an das für sie zuständige Ministerium weiter und wollte zunächst Beschlüsse auf Bundesebene abwarten. Für die Mitglieder der Göttinger Senatskommission wäre ein solches Warten auf den

UAG.Sek.412.g3. 25.10.1915.

298 „Die Frage nach der Behandlung der ohne Maturitätsprüfung ins Feld gerückten Primaner kann nach Meinung des hiesigen akademischen Senats nicht von einer einzelnen Universität, sondern wegen der späteren akademischen Freizügigkeit und Examensfreiheit nur durch gemeinsamen Beschluß der Kultusministerien aller deutschen Bundesstaaten geregelt werden. Der Senat der Universität Leipzig hat sich daher wegen dieser Angelegenheit an das Königlich Sächsische Kultusministerium gewandt [...]:“ UAG.Sek.412.g3. 30.10.1915. 
Gesetzgeber undenkbar gewesen.299 Hier wollte man schnellstmöglich Erfahrungen sammeln. ${ }^{300}$

Eine Extremposition bezog die Albertus Universität Königsberg. Dass die Universität nicht die geeignete Institution zur Auffrischung oder Vermittlung fehlenden Schulwissens war, stellte auch die Göttinger Denkschrift fest. Dass die Albertus Universität unter ihrem Rektor Mitscherlich daraus jedoch ableitete, dass man für die Probleme der Notabiturienten schlicht nicht zuständig sei, will in keiner Weise in das Bild der damaligen Diskussion passen.

\section{[...] teile ich ergebenst mit, dass die Albertus-Universität in der Frage der Vorbildung der Kriegsabiturienten keine weiteren Maßnahmen von sich aus zu treffen gedenkt.}

Da durch die Einführung von besonderen Kursen an der Universität zur Fortbildung der Kriegsabiturienten das Niveau der Universität gedrückt werden würde, hält es das Generalkonzil unserer Universität für wünschenswert, dass derartige Kurse, wenn sie überhaupt nötig sein sollten, bei den höheren Schulen eingeführt werden. ${ }^{301}$

Von studentischer Seite konnte innerhalb der Universität Göttingen keine Kritik an den geplanten Kursen nachgewiesen werden, obgleich die Hilfsangebote für Kriegsteilnehmer auch in ihren Kreisen thematisiert wurden, wie verschiedene Artikel in den Burschenschaftlichen Blättern beweisen. Es wurde deutlich, dass sich große Teile der Professorenschaft den zahlreichen studentischen Freiwilligen verpflichtet fühlten. Auch von studentischer Seite wurde dies so empfunden. Ein Beitrag in dem Zentralorgan der deutschen Burschenschaften bringt zum Ausdruck, dass man von studentischer Seite aus eine gewisse Verantwortung der Hochschulen und Professoren ihnen gegenüber sah.

Auch für sie [Studierende der philosophischen Fakultäten] wird es nach dem Kriege notwendig sein, das während des Feldzuges Vergessene in kurzen schnellen Wiederholungskursen sich wiederanzueignen. Derartige Wiederholungskurse sind zwar von privater Seite bereits vor dem Kriege eingerichtet worden, es ist aber doch nur recht und billig, daß bier die Universitäten selbst eingreifen. [...]

Die Universität und die Wissenschaft werden dadurch nichts verlieren und sich nichts vergeben. Wobl aber dürfte die Kunde von dieser Bereitwilligkeit dankbar in den Schüt-

299 So schrieb der Kultusminister Trott zu Stolz erst am 18. Oktober 1915 an die Universität Frankfurt: „Von verschiedenen Seiten ist vorgeschlagen worden, bei den Universitäten Einrichtungen zu treffen, welche es den Kriegsteilnehmern mit Notreifeprüfung erleichtern, etwaige Mängel ihrer Schulvorbildung zu ergänzen. [...]." Die Universität Frankfurt reichte dieses Schreiben in Abschrift an verschiedene Universitäten weiter. Der Kurator der Universität Göttingen versah dieses Schreiben mit der Bemerkung: „Meines Erachtens ist durch die [bereits erfolgte] Einrichtung der Nachhülfekurse für die hiesige Universität die Bedürfnisfrage bejaht und erledigt." UAG.Phil.Fak.II.33.b 28.10.1915.

$300 \mathrm{Zu}$ dieser Diskussion siehe auch: Wettmann: Heimatfront. 2000. S. $134 \mathrm{ff}$.

301 UAG.Sek.412.g3. 08.11.1915. 
zengräben vernommen werden, und manches ältere Semester würde, einer wichtigen Sorge ledig, froher und freier in die Zukunft schauen können. ${ }^{302}$

Es war also nicht erkennbar, dass von Seiten der Studierenden solche Kurse als undankbare oder anmaßende Zumutung empfunden wurden, wie es streckenweise in der Diskussion anklang. Man wollte Ergänzungskurse und man forderte sie sogar. Auch war nichts davon zu vernehmen, dass die Kriegserlebnisse womöglich fachliche Defizite hätten aufwiegen können. Im Gegenteil befürchtete der Autor die negativen Folgen des Krieges: „Viele von denen, die vor dem Kriege in hohem Idealismus an deutscher Wissenschaft mitzuarbeiten sich bemühten, werden diesen Eifer zwar nicht aufgeben, aber doch vorläufig in die zweite Linie zurückstellen."303 Dieser Artikel erschien am 1. Juni 1915, also noch bevor an der Georgia Augusta an den Ergänzungskursen gearbeitet wurde.

Als in Göttingen kurze Zeit später die ersten Veranstaltungen stattfanden, ließ auch eine entsprechende Würdigung in den Burschenschaftlichen Blättern nicht lange auf sich warten. ${ }^{304}$ Der Autor, ein aus Hamburg stammender Student der Universität München, unterstrich zunächst nochmals, dass der Staat die Pflicht habe, sich um die Kriegsteilnehmer nach dem Ende ihres Dienstes zu kümmern. Er unterschied auch die verschiedenen Gruppen von Rückkehrern, unter anderem nach höheren Semestern und Notabiturienten, und bewegte sich damit sehr eng an der Göttinger Denkschrift. Erstaunlich ist dabei, dass scheinbar von studentischer Seite viele Schwierigkeiten deutlich realistischer und nüchterner betrachtet wurden, als dies in der öffentlichen Diskussion der Fall war. Beispielsweise bestand für den Autor dieses Artikels überhaupt kein Zweifel daran, dass Schüler höherer Schulen, welche noch vor Eintritt in das letzte Schuljahr der Prima die Schulen verlassen hatten, dorthin zurückkehren müssten, um ihre Ausbildung zu beenden. Im Falle der höheren Semester lobte er ausdrücklich die Göttinger Bemühungen und forderte deren weiteren Ausbau. In der Frage der Notabiturienten äußerte er sich noch wesentlich deutlicher, als dies die Senatskommission wahrscheinlich gewagt hätte.

Die Tatsache ist also, dass unsere Hochschulen in den nächsten Jabren von Studenten bezogen werden, die nicht viel mehr als die Primareife besitzen [...]. Damit ist natürlich die Gefahr verbunden, dass das Niveau unserer Hochschulen, das wohl das böchste in der ganzen Welt ist, zu sinken beginnt. Das muss unter allen Umständen verbindert werden, und Abhilfe ist schon jeţt nötig. Der akademische Senat der Universität Göt-

\footnotetext{
302 Dunkers, Hans: Die Einrichtung von Wiederholungskursen für die studentischen Feldzugsteilnehmer nach dem Kriege. In: Burschenschaftliche Blätter, Nr. 5 vom 01.06.1915. S. 96.

303 Dunkers: Die Einrichtung. In: Burschenschaftliche Blätter, Nr. 5 vom 01.06.1915. S. 96.

304 Riebesell, F.: Die Hochschulbildung der Kriegsteilnehmer. In: Burschenschaftliche Blätter, Nr. 5 vom 01.12.1915. S. 93-95.
} 
tingen hat diese Notwendigkeit erkannt und eine Denkschrift ausgearbeitet, in der er die Einrichtung von Ergänzungskursen für Kriegsteilnehmer empfiehlt. 305

Die Göttinger Senatskommission nahm sowohl das ihr gegenüber geäußerte Lob, als auch die Kritik in ihrer Sitzung vom 20. November zur Kenntnis, ließ sich jedoch in keiner Weise davon beeinflussen, nicht zuletzt, da in der selben Sitzung bereits die ersten Erfahrungen aus den Ergänzungskursen besprochen wurden. 306 Um noch genauere Informationen zu erhalten, bat man nun alle beteiligten Dozenten bis zum Dezember um einen kurzen Bericht. Die Ergebnisse dieser internen Umfrage wirkten zunächst ernüchternd. Aufgrund der noch sehr geringen Zahl zurückgekehrter Kriegsteilnehmer waren die wenigsten Veranstaltungen zu Stande gekommen. Außerdem wurde man davon überrascht, dass sich nicht nur ehemalige Soldaten für die Angebote interessierten. Scheinbar sahen zahlreiche andere Studierende, häufig Frauen, in den Kursen willkommene Möglichkeiten zur Wiederholung. Im altgriechischen Sprachkurs des Privatdozenten Dr. Hermann Georg Lommel befand sich beispielsweise nur ein einziger Kriegsteilnehmer: „An den griechischen Anfängerkursen nimmt nur 1 Kriegsteilnehmer in Oberstufe Teil. Ausserdem in Ober- und Unterstufe im ganzen ungefähr 30 Studierende, meist Damen. "307 In den naturwissenschaftlichen Kursen war das Bild ähnlich. Der Physiker Dr. Heinrich Rausch von Traubenberg konnte aber immerhin neben drei Studentinnen vier „Krieger“ begrüßen. Den größten Zuspruch, mit sieben Kriegsteilnehmern im ersten Semester, erfuhr der rein schulische Kurs des Gymnasiallehrers Götting, der „Das Mathematikpensum der Prima" zum Inhalt hatte. Es bestätigte sich also die in der Denkschrift geäußerte Vermutung, dass der vertraute Schulunterricht meist die bessere Lösung blieb im Vergleich zur Vorlesung, welche meist mangels Zuhörern nach wenigen Sitzungen wieder eingestellt worden waren.

Dass diese Form des Unterrichts der vorgesehenen Zielgruppe besonders entgegenkam, bestätigten auch die Burschenschaftlichen Blätter. Während man sich bei den Planungen noch alle Mühe gab, den Eindruck zu vermeiden, man würde die Kriegsteilnehmer wieder auf die Schulbank zwingen, forderte der studentische Autor genau dies:

$W$ as nun die Ergänzungskurse der Göttinger Universität angeht, in denen u.a. das Mathematikpensum der Prima behandelt wird, so sind sie insofern unzulänglich, als dass sie zu wenig mit dem bisherigen Vorlesungsprinzip brechen. Die Kriegsabiturienten gehören weder der Schule noch der Hochschule an, man kann auch sagen beiden, und so werden sich auch diese beiden Einrichtungen an der Ausbildung beteiligen müssen. Die Schule wird in erster Linie verpflichtet sein, das von ihr nicht geleistete Pensum nachzuholen.

305 Riebesell: Die Hochschulbildung. In: Burschenschaftliche Blätter, Nr. 5 vom 01.12.1915. S. 94.

306 Protokoll der Sitzung: UAG.Sek.412.g3 20.11.1915.

307 UAG.Sek.412.g3. Bis Anfang Dezember gingen alle Berichte der Dozenten im Rektorat ein. Es wird hier davon abgesehen, alle Schreiben einzeln zu belegen. 
[...] Es ist klar, dass diese Kurse von der Schule abgetrennt und von Hochschulprofessoren und Oberlehrern gemeinsam geführt werden müssen; denn es ist nötig, dass die Lehrer nicht nur tüchtige Fachgelehrte, sondern auch brauchbare Pädagogen sind. ${ }^{308}$

Selbstverständlich waren die Burschenschaftlichen Blätter nicht eine Zeitschrift eines Verbandes von Kriegsteilnehmern, sondern die einer bestimmten Gruppe von Studierenden. Somit vertraten sie eine ganz eigene Perspektive, die von den betroffenen Notabiturienten nicht zwingend geteilt werden musste. Aus Sicht des Autors war jedoch die Gefahr größer, dass sich die Schulen aus ihrer Verantwortung zurückzogen, als dass die Gefühle der Notabiturienten verletzt werden könnten. Außerdem scheint er kein großes Vertrauen in die pädagogischen Fähigkeiten der Hochschullehrer gehabt zu haben.

In der Frage, ob und in welcher Form die Ergänzungskurse für die Studierenden verpflichtend sein sollten, äußerte sich der Autor erwartungsgemäß, nämlich indem er dies vollständig ablehnte. Er riet dazu, auf Einsicht und Vernunft der Betroffenen selbst zu vertrauen, während in der Denkschrift dieses ja weitgehend ausgeklammert worden war.

Da die Göttinger Senatskommission in dieser frühen Phase der Ergänzungskurse ausdrücklich mit dem Vorsatz in das Semester gegangen war, Erfahrungen sammeln zu wollen, konnte die Senatskommission zum Ende des Jahres 1915 trotzdem ein positives Fazit ziehen und erstattete dem preußischen Kultusministerium Bericht:

[...] Aus dem vorstehenden ergibt sich, dass naturgemäss während der Fortdauer des Krieges die Zahl der Kriegsteilnehmer nur klein ist, immerhin darf hervorgehoben werden, dass schon jetzt das kommende Bedürfnis sich deutlich ankündigt und dass im Augenblick etwa 50 Kriegsteilnehmern ein wertvoller Dienst erwiesen wird. Es kommt hinzu, dass bei der Abhaltung der gegenwärtigen Vorlesungen für die Gestaltung der zukünftigen wertvolle Erfahrungen gemacht werden, insbesondere scheinen sich die Vorlesungen umsomehr zu bewähren, je concreter sie gehalten und je mehr sie nach der Art fester Übungen gestaltet werden. Alles in allem glaubt die Universität Göttingen keinen Anlass zu haben, in der Abhaltung besonderer Vorlesungen für Kriegsteilnehmer schon im laufenden Semester eine verfrübte Massregel erblicken zu sollen. ${ }^{309}$

Das Kultusministerium sah dies offensichtlich ähnlich und teilte nicht Bedenken, wie sie beispielsweise aus Leipzig geäußert worden waren. ${ }^{310}$ Bis zum Ende des Krieges gab es keine landes- oder bundeseinheitliche Regelung für den Umgang mit Kriegsteilnehmern. Es existierten an den meisten Hochschulen eigene Lösun-

308 Riebesell: Die Hochschulbildung. In: Burschenschaftliche Blätter, Nr. 5 vom 01.12.1915. S. 95.

309 UAG.Sek.412.g3. 29.12.1915.

310 Es existiert seitens des Kultusministeriums weder ein zustimmendes noch ein ablehnendes Schreiben. Allerdings hat man bis weit in das Jahr 1919 hinein anstandslos die Aufwandsentschädigungen für die Dozenten übernommen, was als Zustimmung gewertet werden kann. Als letzter erhält Professor Götting eine Zahlung am 30.12.1919. UAG.Sek.412.h. 
gen, wovon sicherlich die Mehrzahl durch das Göttinger Vorbild beeinflusst war. ${ }^{311}$ Hier stiegen die Teilnehmerzahlen kontinuierlich, und bis Ende 1919 erfreuten sich vor allem Göttings Mathematikkurse großer Beliebtheit. Für die Ergänzungskurse schätzt der Kurator der Universität Göttingen beispielsweise im Wintersemester 1918 die Teilnehmerzahl in der Philosophischen Fakultät auf 150 und in der gesamten Universität auf 510 Teilnehmer. ${ }^{312}$ Auch das Kriegsministerium unterstützte die Bemühungen der Universitäten. Man verfügte noch vor Beginn des Wintersemesters, dass Verwundete und kranke Studierende, wenn möglich, in Lazarette in Universitätsstädten verlegt werden sollten, insbesondere solche, bei denen die „Wiederherstellung zur Felddienstfähigkeit nicht zu erwarten“"313 war.

Aus Sicht der Georgia Augusta waren die Ergänzungskurse als solche, aber auch deren schnelle und zielstrebige Umsetzung von den ersten Ideen an ein Erfolg. Bemerkenswert ist an diesem Vorgang vor allem, dass sich im Kreise der Hochschullehrer die Überzeugung durchsetzte, dass man zugunsten der zahlreichen zurückkehrenden Kriegsfreiwilligen in einen sich abzeichnenden Missstand kurz entschlossen, aber nicht unüberlegt eingreifen müsse. Die Initiative hierzu ging von der Universität aus, und sie zeigte, dass sie in schwierigen Situationen auf die Herausforderungen reagieren konnte, die der Krieg mit sich brachte. Das

311 Erst am 12.11.1918 gab das Kultusministerium eine Art Leitfaden zur Einrichtung von Ergänzungskursen heraus. Der darin aufgeführte exemplarische Lehrplan für „Mathematik und Naturwissenschaften“ ist in zwei Gruppen eingeteilt: „I. Ergänzungskurse für Notabiturienten. Zweck der Kurse ist, die Notabiturienten in der Elementarmathematik soweit zu förden, daß sie den Anfangsvorlesungen an der Universität in den naturwissenschaftlichen Fächern folgen können. Auch die Studierenden der Chemie und der Biologie werden an diesen Kursen mit Nutzen teilnehmen. Mit den Vorlesungen werden Übungen zur sicheren Aneignung des erworbenen Wissens fortlaufend verbunden werden." Der Lehrplan enthält vier Veranstaltungen (Elementare Analysis und numerisches Rechnen, Ebene und sphärische Trigonometrie, Stereometrie und eine Einführung in den Koordinatenbegriff und in die Geometrie der Kegelschnitte) von insgesamt 14 Stunden. Dann folgt die zweite Gruppe: „II. Wiederholungskurse. Für solche Kriegsteilnehmer, die bereits einige Semester studiert haben, sind Wiederholungskurse unter Leitung von Unterrichtsassistenten für folgende Fächer einzurichten: [...]" Es folgen jeweils Übungen in den Kerngebieten der Mathematik, Physik, Chemie, Biologie und Mineralogie und Geologie von jeweils 4 Stunden. Die Dauer der Kurse wurde jeweils auf acht Wochen festgelegt.

UAG.Phil.Fak.II.33b 12.11.1918.

312 UAG.Phil.Fak.II.33.b 12.11.1918.

313 „Der Herr Kriegsminister ist der Auffassung beigetreten, dass die weitere Ausbildung Verwundeter und kranker zur Ausheilung in Deutschland befindlicher Heeresangehörigen, deren Studium durch den Kriegsdienst unterbrochen wurde, außerordentlich gefördert werden kann, wenn sie die Wiederherstellung ihrer Gesundheit erforderliche Zeit in Städten mit Universitäten und Technischen Hochschulen zubringen können. Es sind demgemäß Anordnungen getroffen [...]. Hierbei kommen in erster Linie solche Verwundete und Kranke in Betracht, deren Wiederherstellung zur Felddienstfähigkeit nicht zu erwarten ist, sodann solche, deren Genesung nach der Art ihres Leidens ohnehin besonders lange Zeit beansprucht. [...]“ UAG.Sek.412.g3. 28.08.1915. Bei der Durchführung dieser Verordnung gab es aber wohl recht oft Probleme, da das Wachpersonal in den Lazaretten willkürlich den Ausgang verweigerte. UAG.Sek.412.g3. 20.11.1915. 
Kultusministerium honorierte dies, indem es der Universität vollständig freie Hand ließ. Hätte man sich, wie Leipzig vorschlug, auf die politischen Instanzen verlassen, wäre kaum mit einer schnellen und effektiven Lösung zu rechnen gewesen. ${ }^{314}$

Aber auch offizielle Stellen waren durchaus handlungsfähig, wie sie in der Frage der Trimester oder Zwischensemester bewiesen. Hinter solchen zusätzlichen Semestern stand die Idee, den aus dem Krieg zurückkehrenden Studierenden zu ermöglichen, in möglichst kurzer Zeit möglichst viele Veranstaltungen besuchen zu können und auf diese Weise die Verzögerung, die durch ihren Kriegsdienst entstanden war, wieder aufzuholen. Solche Ansätze gewannen durch die Ergänzungskurse noch zusätzlich an Bedeutung, da das Alter der Universitätsabsolventen immer weiter zu steigen drohte. Nicht nur, dass manche Studierende bis zu zehn Semester durch den Krieg verloren hatten, nun wurde nach ihrer Rückkehr ihr Studium durch zusätzliche Veranstaltungen nochmals verlängert. Diese Problematik wurde bereits auf der deutschen Hochschulrektorenkonferenz vom Januar 1916 diskutiert. Dort war von verschiedenen Rektoren die vorübergehende Einführung von Trimestern empfohlen worden, da so „,von Studierenden vielmehr geleistet werden könne.“315 Aus München wurde berichtet, dass auch das bayrischen Kultusministerium an solchen Plänen interessiert sei. An den meisten Universitäten überwogen jedoch die Vorbehalte gegen solche Änderungen, und man war der Meinung, dass die Semesterferien eine wichtige Einrichtung sowohl für die Dozenten als auch für die Studierenden seien, die man nicht antasten sollte. Der Vertreter der Straßburger Universität warnte in diesem Zusammenhang: „Der Ernst der wissenschaftlichen Ausbildung dürfe nie leiden.“316 Dieser Überzeugung waren auch die meisten seiner Kollegen, auch wenn dies bedeutete,

314 Die Universität Göttingen war dadurch, dass sie sich in der Frage der einzurichtenden Ergänzungskurse so exponiert hatte, auch in die politischen Auseinandersetzungen zu diesem Thema hineingezogen worden. Durch die öffentlichen Ankündigungen der ersten Ergänzungskurse war auch der so genannte Ausscbuß der Väter der Kriegsprimaner mit seinem Vorsitzenden Liedtke auf die Göttinger Denkschrift aufmerksam geworden. Dieser glaubte in der Universität Göttingen einen Verbündeten gefunden zu haben, da er die Ergänzungskurse so interpretierte, dass niemand, der die Schule aufgrund des Krieges abgebrochen hatte, nochmals an die Schule zurückzukehren brauche, da das fehlende Wissen auch durch die Universitäten vermittelt werden konnte. UAG.Sek.412.g3 19.09.1915. Dies hätte den Zielen der ,Kriegsprimaner' entsprochen, die unter allen Umständen verhindern wollten, dass ihre Söhne nochmals in die Schulen zurückgehen oder nochmals geprüft werden sollten. Am 24.12.1915 richten sie eine Eingabe an den Reichskanzler. In dem Anschreiben dazu heißt es unter anderem: „,Wir hoffen noch immer, die Reichsleitung wird sich dem von der Georgia Augusta gefundenen Auswege anschließen und die vom Kultusminister dekretierten Sonderkurse verwerfen." UAG.Sek.412.g3 24.12.1915. Es gelang dieser Interessengruppe jedoch weder Titius dazu zu bewegen, ihr Anliegen im Rahmen der Rektorenkonferenz zur Sprache zu bringen (UAG.Sek.412.g3 29.12.1915), noch Klein dazu zu bewegen, einen Antrag Liedtkes am 31.03.1916 im Herrenhaus zu befürworten (UAG.Sek.558(6) Bl. 67).

315 Protokoll der Konferenz in: UAG.Sek.558(6) Bl. 76ff.

316 UAG.Sek.558(6) Bl. 78. 
dass sich für einige Kriegsteilnehmer die Zeit bis zum Examen deutlich verlängerte. So beschloss man folgende Erklärung: „Die Rektorenkonferenz hält jede Trimestrierung des Studienjahres für die Kriegsteilnehmer für ungeeignet im Interesse der wissenschaftlichen Arbeit der Lehrer wie der gründlichen Ausbildung der Studenten. "317 Trotzdem war man weit von einer Einigkeit in dieser Frage entfernt. Diese Erklärung passierte die Abstimmung nur mit knapper Mehrheit und erst nachdem das Wort „verwerflich“ durch das schwächere „ungeeignet" ersetzt worden war.

Innerhalb der Universitäten war damit diese Diskussion zunächst einmal beendet. Das Kriegsende mit dem geradezu explosionsartigen Ansteigen der Studierendenzahlen zwang jedoch sowohl das Kultusministerium als auch die Universitäten, zu reagieren. Göttingen hatte hier den Vorteil, dass man schon auf fünf Semester Erfahrung in der Betreuung von zurückkehrenden Kriegsteilnehmern zurückgreifen konnte. Die offiziellen Stellen waren hingegen in der Situation, dass sie durch die lange Dauer des Krieges und die gewaltigen Verluste schnell Nachwuchs für Behörden, Verwaltungen und dergleichen benötigten. Dies führte nun zunächst dazu, dass man sich seitens des Kultusministeriums gegen Ende des Jahres 1918 endlich in die Frage der Ergänzungskurse einschaltete. Man bat die Universitäten um Vorschläge zur Lösung der Krise und gab bereits eine Zielrichtung für die Überlegungen hierzu vor. ${ }^{318}$

\section{Die Kurse sollen die studierenden Kriegsteilnehmer derart in ihr Studium einführen bezw. wiedereinführen, dass ihnen im Anschluss an die Kurse tunlichst obne allen Zeit- verlust der möglichst baldige Eintritt in den gewöhnlichen Studiengang und zwar den Abiturienten von Anfang an, den übrigen Studierenden an dem Punkt ermöglicht wird, an dem sie ibre Studien unterbrochen hatten. Dieser Zweck wird am ehesten zu erreichen sein, wenn die Kriegsteilnehmer zunächst durch einen Ferienkurs von achtwöchiger Dauer in das Studium eingeführt oder wiedereingeführt werden und wenn sich daran besondere Kriegsteilnehmerkurse während des ersten Semesters, gegebenenfalls auch in den darauf- folgenden Ferien und Semestern anschließen. [... $]^{319}$}

Der Universität Göttingen fiel die Beantwortung dieses Schreibens leicht. Aufbauend auf den Erfahrungen der ersten Ergänzungskurse, die, wie beispielsweise der des Gymnasiallehrers Götting, auch noch längere Zeit weitergeführt wurden, hatte man in den mathematisch-naturwissenschaftlichen Fächern umgehend nach Kriegsende neue Kurse eingerichtet:

\footnotetext{
317 UAG.Sek.558(6) Bl. 78.

318 UAG.Kur.2262 Bl. 1. Schreiben des Kultusministerium vom 12.11.1918.

319 UAG.Kur.2262 Bl. 1.
} 
Eine größere Anzahl jüngerer Doktoren und fortgeschrittener Studenten haben sich uns zur Verfügung gestellt, um unter unserer Oberleitung kleine - nur auf 6-10 Teilnehmer berechnete - 4 mal wöchentlich stattfindende Kolloquia abzubalten, die unter enger persönlicher Bezugnahme mit dem einzelnen Teilnehmer den verschiedenen in Betracht kommenden Bedürnissen gerecht werden sollen. Wir haben dabei zwei Gruppen von Hilfsbedürftigen unterschieden:

1. diejenigen, die ibre Hochschulstudien überhaupt erst beginnen. [...]

2. diejenigen, die in Folge des Krieges ibre mathematischen Studien haben unterbrechen müssen. $[\ldots]^{320}$

Man gab aber zu bedenken, dass man die genauen Inhalte erst dann festlegen könne, wenn man die konkreten Bedürfnisse besser kenne. Außerdem wies man gleichzeitig auf die schwierige finanzielle Situation der Institute hin, indem man bereits ankündigte, dass Heizung und Beleuchtung der Räume ein Problem darstellen könnten. ${ }^{321} \mathrm{Zu}$ der Frage, ob auch Veranstaltungen in den folgenden Semesterferien zwischen dem Wintersemester und dem Sommersemester geplant worden seien, äußerte man sich vor diesem Hintergrund dann auch deutlich zurückhaltender:

Aus diesem Grund hatten wir bisher für die dieses Mal fast dreimonatlichen Osterferien noch keine bestimmten Kurse in Aussicht genommen, sondern nur die Notwendigkeit irgendwelcher zweckmäßiger Einrichtungen ins Auge gefasst; wir wollten ehe wir einen Plan festlegten, wenigstens einen Teil der Januarerfahrungen abwarten. [... $]^{322}$

Das Kultusministerium wollte jedoch nicht mehr diese Erfahrungen abwarten und verkündete bereits am 21. Dezember 1918 seine Entscheidung, nachdem die gesetzte Frist für die Vorschläge der Universitäten erst am 15. Dezember abgelaufen war:

Im Verfolg des Erlasses vom 12. November 1918 [...] wird zur Förderung des Studiums der Kriegsteilnehmer folgendes bestimmt:

Zwischen dem Schluß des laufenden Wintersemesters und dem Beginn des nächsten Sommersemesters ist für die Studierenden der Theologischen, der Juristischen [...] und der Philosophischen (Naturwissenschaftlichen) Fakultäten ein Zwischensemester einzuschieben. ${ }^{323}$

Die Entscheidung für ein Zwischensemester war gefallen - ohne weitere Diskussion oder Einbeziehung der Universitäten in die Planungen. Als Dauer wurde die Zeit vom 3. Februar bis zum 16. April bestimmt. Die Präzision und der Detail-

\footnotetext{
320 UAG.Kur.2262 Bl. 5-6.

321 Siehe folgendes Kapitel.

322 UAG.Kur.2262 Bl. 5-6.

323 UAG.Kur.2262 Bl. 12.
} 
reichtum dieses Erlasses verbieten die Annahme, die Entschließung zu dieser Maßnahme könnte im Ministerium erst in den sechs Tagen nach Ablauf der Frist gefallen sein, die den Universitäten zur Einreichung ihrer Vorschläge gesetzt worden war. Die Kürze dieser Zeitspanne macht deutlich, dass im Kultusministerium offensichtlich wenig Bereitschaft bestand, mit den Hochschulen in eine wirkliche Diskussion einzutreten. Auch die Erklärung der Rektorenkonferenz hatte bereits angedeutet, dass hier wenig Hoffnung auf einen Konsens im Sinne des Ministeriums bestanden hätte.

Als Inhalte der Semester wurde eine Kombination aus den normalen Veranstaltungen und speziellen Ergänzungskurse empfohlen:

Das Zwischensemester soll tunlichst in allen genannten Fakultäten die einen geordneten Studienbetrieb erforderlichen Vorlesungen und Übungen bieten. Daneben sind Ergänzungs- und Wiederholungskurse abzuhalten, die dem Zwecke dienen sollen, den Kriegsteilnehmern die Einarbeitung in ihr Studium durch die Wiederauffrischung ihrer Kenntnisse zu erleichtern. ${ }^{324}$

Diese Vorgaben wurden von der Universität Göttingen auch umgesetzt. Wie ein Blick auf die Zahl der Veranstaltungen in diesem Semester zeigt gelang es, ein weitgehend reguläres Semester zu organisieren. ${ }^{325}$

Trotz aller Probleme der Universitäten betreffend der hohen Studierendenzahlen legte man von ministerieller Seite großen Wert darauf, dass es sich bei dem Zwischensemester nicht um eine bloße Maßnahme zum Abbau der zu hohen Studierendenzahlen handelte, sondern um eine gezielte Fördermaßnahme zu Gunsten der Kriegsteilnehmer, die das ausschließliche Teilnahmerecht hatten.

Im Zwischensemester sind nur Kriegsteilnehmer neu zu immatrikulieren, auch sind nur Kriegsteilnehmer zu den Vorlesungen, Übungen und Kursen zuzulassen. Dem Kriegsdienst ist die Tätigkeit im vaterländischen Hilfsdienst gleichzustellen.

Seitens der Universitäten ist das Zwischensemester als ein Studiensemester anzusehen. ${ }^{326}$

Die Umsetzung dieses Erlasses und die Durchführung des Zwischensemesters bereitete, zumindest nach dem Bild der Akten, erstaunlich wenig Schwierigkeiten. Zwar liegen zahlreiche Anträge bezüglich der Finanzierung der Kurse und der Festsetzung genauer Termine in den Unterlagen vor, jedoch fehlt grundsätzliche Kritik. Will man die Teilnehmerzahl an dieser Maßnahme als Maßstab für ihren Erfolg ansehen, so muss man dem Kultusministerium eine hohe Effektivität seiner Maßnahme bescheinigen. Insgesamt nahmen am Zwischensemester 2500 Studierende teil, wie die Universität auf Anfrage des Ministeriums mitteilte. ${ }^{327}$

\footnotetext{
324 UAG.Kur.2262 Bl. 12.

325 Siehe Statistik 6.

326 UAG.Kur.2262 Bl. 12.

327 UAG.Kur.2262 Bl. 54v. Antwort auf Anfrage vom 12.04.1919.
} 
Noch während das erste Zwischensemester andauerte, wurde bereits ein zweites beschlossen. ${ }^{328}$ Zum einen war man schnell von der Wirksamkeit der Zwischensemester überzeugt und zum anderen zeichnete sich ab, dass noch nicht alle studentischen Kriegsteilnehmer erreicht werden konnten. Viele von ihnen waren verwundet oder erkrankt und waren im Februar des Jahres 1919 noch nicht in der Lage, ihr Studium wieder aufzunehmen. Außerdem konnten zahlreiche Kriegsgefangene erst im Laufe des regulären Sommersemesters wieder in ihre Heimat zurückkehren. Hinzu kam noch, dass viele der wenigen gesunden ehemaligen Soldaten nach kurzer Zeit in einem der zahlreichen Freiwilligenverbände erneut zu den Waffen griffen. Auf diese drei Gruppen, und namentlich den Grenzschutz-Ost, wurde dann auch folgerichtig die Teilnahme an dem zweiten Zwischensemester beschränkt. Auf freie Plätze rückten nach Prüfung der Einzelfälle Kriegsteilnehmer nach, die bereits an dem ersten Zwischensemester in voller Länge teilgenommen hatten. ${ }^{329}$ Das zweite und letzte Zwischensemester begann am 22. September 1919 und endete am 20. Dezember. ${ }^{330}$

Auch wenn im diesem Semester die Teilnehmerzahl erneut ähnlich hoch lag wie im ersten, sollte man nicht unbedingt auf ein hohes Maß an Akzeptanz unter den Studierenden schließen. Das Kultusministerium hatte die Universitäten zwar um ihre Meinungen gebeten, diese dann jedoch kaum berücksichtigt. Die Studierenden hatte man allein schon aus praktischen Erwägungen in der Kürze der Zeit überhaupt nicht fragen können, selbst wenn man es gewollt hätte. Bereits seit 1917 hatte es mehrfach ganz deutlich ablehnende Meinungen seitens der Studierenden gegeben, und erneut waren es die Burschenschaftlichen Blätter, die dieser Diskussion Raum boten. Ausgangspunkt verschiedener Beiträge waren Überlegungen, wie man den Kriegsteilnehmern den Wiedereinstieg in ihr Studium erleichtern und vor allem die Studienzeiten auf ein erträgliches Maß senken konnte. Ein immer wiederkehrender Vorschlag war hier unter anderem die Anrechnung von Militärdienstzeiten als Studiensemester, um so den Mindestsemesterzahlen schneller gerecht werden zu können, die bei einer Meldung zur Prüfung verlangt wurden. In gewissem Maße erkannte man von studentischer Seite dieses Entgegenkommen zwar an, sah aber die Probleme, die eine solche Regelung mit sich bringen würde, sehr realistisch. „Letzen Endes ist aber mit der Anrechnung der Kriegssemester gar nichts erreicht. Denn automatisch lediglich durch die Semesterzahl kommt das nötige Wissen nicht. Das muss eben doch erarbeitet werden. “331 Daraus den Schluss zu ziehen, dass es dann den Studierenden ermöglicht werden solle, möglichst viel Studium in möglichst kurzer Zeit zu bewältigen, was ja der Idee der Trimester zu Grunde liegt, lehnte der Autor ab. Er betonte viel-

\footnotetext{
328 UAG.Kur.2262 Bl. 50. Erlass vom 23.03.1919.

329 UAG.Kur.2262 Bl. 53. Schreiben des Kultusministeriums vom 05.04.1919.

330 UAG.Kur.2262 Bl. 65. Schreiben des Kultusministeriums vom 15.07.1919.

331 Stelzner, Edgar: Das Studium der Kriegsteilnehmer. In: Burschenschaftliche Blätter, Nr. 4 vom 15.05.1917. S. 54-57.
} 
mehr, dass gerade die Kriegsteilnehmer die Erholungsphasen der Semesterferien dringend benötigten und bezweifelte, dass sie den Anforderungen eines deutlich gestrafften Studiums gerecht werden könnten.

Es ist ein falsches Urteil, dass diese nach dem Kriege nur noch den einen Wunsch hätten, jetzt so bald als möglich das Examen abzulegen. Vor allem sind durch den langen Feldzug die Nerven in großem Maße übermäßig beansprucht und verbraucht, so dass eine zu starke Belastung auch im Frieden noch sehr leicht zum Zusammenbruch oder zu langem Siechtum führen kann. [...]

Es ist eben einmal so, dass durch den Krieg die Akademiker unter den Waffen bedeutend älter werden, bis sie ans Examen denken können. Das muss in Kauf genommen werden. Aber es muss nach Möglichkeit gelindert werden. Keineswegs wird es dadurch besser, dass man die neuen Friedenssemester verkürzt oder mit Wissenschaft übermäßig vollpfropft. 332

Die geäußerten Alternativvorschläge wirken hingegen sehr überlegt und sachlich. Zum einen wurde gefordert, Studenten im Falle der Demobilmachung bevorzugt aus dem Heer zu entlassen, damit sie möglichst früh wieder an die Universitäten zurückkehren konnten. Außerdem sollte Kriegsteilnehmern grundsätzlich die Festlegung ihrer Prüfungstermine selbst überlassen bleiben und gegebenenfalls gescheiterte Prüfungen nicht als solche angerechnet werden, um ihnen so den Druck zu nehmen. ${ }^{333}$ Diese Anregungen wurden jedoch von offizieller Seite nicht zur Kenntnis genommen.

Zusammenfassend kann festgehalten werden, dass sowohl Ergänzungskurse als auch Zwischensemester als gezielte Unterstützungsmaßnahmen zu Gunsten der studentischen Kriegsteilnehmer gedacht gewesen sind. Beide wurden schnell und zielstrebig in dem Wissen umgesetzt, dass eine längere Diskussion ihre zeitnahe und wirksame Umsetzung weitgehend unmöglich gemacht hätte. Dies trifft sowohl für die Senatskommission innerhalb der Universität, als auch für das Kultusministerium zu. Beide Maßnahmen entstanden maßgeblich aus einem Bewusstsein der Verantwortung und Verpflichtung gegenüber den Kriegsteilnehmern. Trotzdem bedeuteten die mangelhafte Vorbildung der Notabiturienten, die großen Wissensdefizite derer, die ihr Studium unterbrochen hatten und der extreme Anstieg der Studierendenzahlen nach Ende des Krieges für die Hochschulen selbst eine so große Gefahr, dass man ohnehin hätte reagieren müssen. Letztlich gilt sowohl für die Universität als auch für das Kultusministerium, dass es als bedauerlich anzusehen ist, dass niemand, der mit diesen Planungen befasst gewesen ist, mit den Betroffenen selbst rechtzeitig das Gespräch gesucht hat. Die

332 Stelzner: Das Studium. In: Burschenschaftliche Blätter, Nr. 4 vom 15.05.1917. S. 54-57.

333 Stelzner: Das Studium. In: Burschenschaftliche Blätter, Nr. 4 vom 15.05.1917. S. 54-57. 
gezeigten Beispiele legen die Vermutung nahe, dass eine solche Zusammenarbeit sich durchaus als fruchtbar hätte erweisen können. ${ }^{334}$

Feldpost und Liebesgaben

In der Frage der Ergänzungskurse reagierte die Universität auf ein ihr gestelltes Problem. Die Universität wurde jedoch auch ohne zwingenden Grund aktiv, also ausschließlich aus Verbundenheit zu ihren Studierenden. Beispielsweise verschickte die Universität seit 1915 jedes Jahr zu Weihnachten eine Weibnachtsgabe an ihre Studenten im Feld. Dabei handelte es sich um kleinere Bücher, die die Universität erstellte und drucken ließ. ${ }^{335}$

Beim Betrachten dieser Weihnachtsgaben fällt auf, dass mit zunehmender Dauer des Krieges das Thema Krieg inhaltlich immer weiter in den Hintergrund rückte. Das erste Buch von 1915 steht klar im Dienste einer Legitimation des Krieges mit moralischen und kulturellen Argumenten, um den Studenten Unterstützung im Falle möglicher Zweifel an der Rechtmäßigkeit der eigenen Sache zu geben. Besonders wird dies im ersten Beitrag des Rektors Arthur Titius deutlich, der über „Staat und Staatsidee der Hohenzollern in ihrer Entwicklung““336 schreibt. Dabei handelt es sich um den Druck seiner Rede zum 500jährigen Jubiläum der Herrschertätigkeit der Hohenzollern, in der er Krieg als legitimes Mittel darstellt, um Macht zu schaffen oder zu erhalten, mit einer deutlichen Betonung auf dem Gehorsam und dem Opferwillen des Volkes, der dazu notwendig sei. Robert von Hippel betont im Folgenden die Solidarität der Universität mit ihren Studenten im Kriegsdienst:

Liebe Kommilitonen! Weibnachtsgrüße der alma mater ziehen zu euch ins Feld hinaus. Ein Zeichen treuen Gedenkens Eurer Lehrer sollen sie euch bringen, dem Gefübl inniger

334 In Göttingen war jedoch gerade zur der Zeit, in der die Senatskommission arbeitete, das Verhältnis zwischen Rektorat und Studentenschaft vollständig zerrüttet, aufgrund des Streits um die Teilnahme ausländischer Studierender an Vorlesungen und Übungen und der daraus entstehenden Zeitungsaffäre. (Siehe oben.)

335 Bei den so genannten Liebesgaben handelt es sich nicht um eine für Göttingen spezifische Erscheinung. Von zahlreichen anderen deutschen Universitäten wird hierüber berichtet. Eine zentrale Steuerung existierte jedoch offensichtlich nicht. Beispiele anderer Universitäten sind: Erlangen Liermann: Die Friedrich-Alexander-Universität. 1977. S. 33 und 37; Heidelberg Jansen, Christian: Professoren und Politik. Politisches Denken und Handeln der Heidelberger Hochschullehrer 1914-1935. Göttingen 1992. S. 111; Marburg Wettmann: Heimatfront. 2000. S. 151.

336 Titius, Artur: Staat und Staatsidee der Hohenzollern in ihrer Entwicklung. In: Universität Göttingen (Hrsg.): Weihnachten 1915. Die Georgia Augusta ihren Angehörigen im Felde. Göttingen 1915. S. 3-20. 


\section{Zusammengehörigkeit Ausdruck geben, das uns in der Heimat unlöslich mit Euch ver- bindet. ${ }^{337}$}

Die folgenden Artikel verschiedener Professoren waren zwar immer thematisch am Fachbereich des jeweiligen Autors orientiert, inhaltlich aber stark auf den Krieg bezogen. So beschreibt etwa der Chemiker Otto Wallach die Überlegenheit der deutschen chemischen Industrie und Forschung unter anderem am Beispiel der „Stinkbomben“;338 diese Ausführungen dürften wahrscheinlich Studenten, die die Grausamkeit des Gaskriegs erlebten, bitter aufgestoßen sein. Eine Ausnahme von der allgemeinen thematischen Konzentration auf den Krieg stellt der Aufsatz des Mathematikers Runge dar, der mit „Dimensionsbetrachtungen“ ein rein mathematisches Thema wählte. ${ }^{339}$

Im folgenden Jahr änderte die Weihnachtsgabe ihr Aussehen völlig. Unter dem Titel Alt-Göttinger Stammbuch wurden nun Drucke alter Darstellungen Göttingens und Umgebung veröffentlicht. ${ }^{340}$ Danach widmete ein Dozent jeweils auf einer Seite den Studenten ein klassisches Zitat oder einen eigenen kurzen Vers, dessen Inhalt nicht zwingend nur vom Krieg bestimmt sein musste. So stehen sich etwa auf einer Seite der Vers des Astronomen Leopold Ambronn „In den Sternen steht des Menschen Schicksal nicht geschrieben; doch der freie Blick hinauf zu ihnen zeigt ihm den Weg zu Glück und Frieden“ einem Zitat Friedrich Nietzsches gegenüber: „Einem guten Kriegsmanne klingt ,du sollst’ angenehmer als ,ich will.'، '341

In der letzten Weihnachtsgabe von 1917 finden sich eine Reihe längerer Zitate berühmter Göttinger Professoren in ,[...] einem bunten, raschgepflückten Strauß aus dem reichen Garten der Vergangenheit unserer Universität [...].“342 In diesem „Strauß“ finden sich kaum noch Bezüge zum Krieg. Dies war jedoch kein Zeichen einer etwaigen Kriegsmüdigkeit der Verantwortlichen der Universität, sondern vielmehr die Erkenntnis, dass nach mittlerweile über drei Jahren Krieg der Bedarf der Studenten an intelligenter Unterhaltung größer gewesen sein dürfte, als der an vaterländischem Pathos.

Diese Weihnachtsgaben wurden an die Studenten an der Front verschickt. Voraussetzung dafür aber war, dass man die Feldpostadresse der Studenten

337 Hippel, Robert von: Weihnachten 1915 im Weltkriege. Rückblicke und Ausblicke. In: Universität Göttingen (Hrsg.): Weihnachten 1915. Die Georgia Augusta ihren Angehörigen im Felde. Göttingen 1915. S. 22-28.

338 Wallach, Otto: Krieg und Chemie. In: Universität Göttingen (Hrsg.): Weihnachten 1915. Die Georgia Augusta ihren Angehörigen im Felde. Göttingen 1915. S. 59-65.

339 Runge, Carl: Dimensionsbetrachtungen. In: Universität Göttingen (Hrsg.): Weihnachten 1915. Die Georgia Augusta ihren Angehörigen im Felde. Göttingen 1915. S. 54-59.

340 Universität Göttingen (Hrsg.): Alt-Göttinger Stammbuch. Die Georgia Augusta ihren Angehörigen im Felde. Weihnachten 1916. Göttingen 1916.

341 Universität Göttingen: Alt-Göttinger Stammbuch. 1916. S. 20.

342 Universität Göttingen (Hrsg.): Stimmen aus zwei Jahrhunderten der Georgia Augusta. Weihnachtsgabe 1917 für ihre Angehörigen im Felde. Göttingen 1917. 
kannte. Diese wurde der Universität nicht etwa automatisch mitgeteilt und veränderte sich auch teilweise von Jahr zu Jahr. Viele Adressen fand man in Zusammenarbeit mit den studentischen Verbindungen ${ }^{343}$ heraus, die die Adressen ihrer Mitglieder sammelten und der Universität zur Verfügung stellten. Selbstverständlich waren die so erhaltenen Adressenlisten nicht vollständig. Daher startete die Universität eine wohl beispiellose Anzeigen- und Postkartenkampagne, um möglichst alle Studenten erreichen zu können. In vielen deutschen Zeitungen wurde in Anzeigen dazu aufgerufen, Feldpostadressen von Studierenden an die Universität zu melden, wenn diese Angehörigen oder Freunden bekannt waren. ${ }^{344}$ Zudem war die Universität auch daran interessiert zu erfahren, ob die Weihnachtsgaben ihren Empfänger erreicht hatten. Jedem Exemplar war eine Feldpostkarte beigelegt, die der Student ausfüllen und an den Universitätsrektor zurücksenden sollte. ${ }^{345}$

Gerade das Maß an organisatorischem Aufwand, welches für diese Weihnachtsgaben betrieben wurde, kann unzweifelhaft als Indiz dafür gewertet werden, dass sich die Universität über die Initiativen, die in Göttingen zur Aufrechterhaltung des Lehrbetriebs nötig waren, und über ihre offiziellen Pflichten hinaus um ihre Studenten sorgte und sich mit ihnen in gewisser Weise verbunden fühlte. Die Gründe hierfür liegen auf der Hand. Die Universität, das heißt das Corpus Professorum, sahen die großen Zahlen studentischer Kriegsfreiwilliger auch als Folge ihrer eigenen Erziehungsarbeit. Dies erfüllte mit Stolz, aber es verpflichtete auch; nicht zuletzt war es auch für das eigene Ansehen und Selbstverständnis notwendig.

Aber auch in kleinem und kleinstem Rahmen und auf privater Ebene gab es immer wieder Zeichen von Solidarität und Anteilnahme von Professoren am

343 Die studentischen Verbindungen führten eigene Karteien mit den Feldpostadressen ihrer Mitglieder. Unmittelbar nach Ausbruch des Krieges veröffentlichten diverse Verbindungszeitschriften Aufrufe, in denen sie um die Mitteilung der Feldpostadressen ihrer Mitglieder baten. Auch die großen Zentralorgane Burschenschaftliche Blätter und Deutsche Korpszeitung druckten solche Aufrufe. Der Rektor der Universität trat daher in Kontakt zu den Verbindungen, um diese Adressenlisten zur Versendung der Weihnachtsgaben benutzen zu können. UAG.Sek.683.

344 Im Universitätsarchiv Göttingen sind im Bestand Rektorat die Rückläufe dieser Initiativen in durchaus beeindruckenden Umfang erhalten.

345 Auch hier war der Rücklauf beachtlich. Die Postkarten sind ebenfalls im Bestand Rektorat des Universitätsarchivs Göttingen erhalten. Die Karten enthielten vorgedruckt den Rektor als Adressaten, ein Feld in das die genaue Feldpostadresse eingetragen werden sollte, Felder für Personalia („,Familienname, Rufname, Geburtsort, Geburtstag, Zivilstellung, Militärstellung, Orden und Ehrenzeichen, Wann in Göttingen immatrikuliert, Wann ins Feld gerückt, Anschrift der Angehörigen“), „Die Weihnachtsgabe traf am ... bei mir ein“ und bemerkenswerter Weise das größte freie Feld unter der Überschrift „Von mir ist folgendes zu berichten“ Die meisten Studenten füllten dieses Feld aus. Weitere Erkenntnisse sind daraus aber nur bedingt zu gewinnen, zum einen wegen der großen Menge an Karten, zum anderen wegen des wenig aussagekräftigen Inhalts. Selbst bei einer eingehenden Beschäftigung mit diesen Quellen wäre es äußerst fraglich, ob ein Student dem Rektor mehr als Stationierungsorte, Beförderungen und Verwundungen mitgeteilt hätte. Zumindest in den für diese Arbeit untersuchten Stichproben fand sich kein gegenteiliger Fall. 
Schicksal der im Kriegsdienst befindlichen Studenten. So wurden des Öfteren etwa Schokolade oder Zigarren - so genannte Liebesgaben - an Studenten geschickt, und zum Teil blieb auch auf dem Weg der Feldpost ein relativ enger Kontakt bestehen. ${ }^{346}$ All diesen Einzelfällen, bei denen es sich meistens um Assistenten oder um gerade kurz vor einer Prüfung befindliche Studenten handelte, ist gemein, dass die Wissenschaft und der Kontakt zur Universität offensichtlich zur Verdrängung des Kriegsalltags diente.

Obwohl hier nicht auf alle Briefwechsel, die in den Nachlässen der Göttinger Naturwissenschaftler erhalten sind, eingegangen werden kann, sollen doch einige Beispiele genannt werden. Einen recht engen Kontakt pflegte Professor Ernst Ehlers zu seinen Studenten im Kriegsdienst. Ein typisches Beispiel für eine Feldpostkarte, die ein Student an seinen Professor richtete, stellt etwa diese von Karl R. Berger dar, die hier nur exemplarisch für zahlreiche andere angeführt werden soll.

Sehr geebrter Herr Geheimrat.

Aus unseren erfolgreichen Kämpfen, weitöstlich von Brest-Litowsk sende ich Ibnen fröbliche deutsche Grïßse. Wir haben uns nunmehr durch die Rotistnos[?] sümpfe glücklich durchgeschlagen und haben gestern bereits die Babnlinie Kobrin-Pinsk, östlich von Kobrin, überschritten und unaufhaltsam dringen wir täglich weiter gen Osten vor. Bemerkenswürdig war die so eigenartige [Flora] der Rotistno, nur schade, daß man ,wichtigere Dinge' zu verrichten hatte, als sich mit Botanik zu beschäftigen. Gott gebe, daß das bald wieder anders werden möge! Bitte auch ein freundlichen Gruß an Herrn Dr. Voss.

Ibr Scbüler Karl R. Berger 347

Berger hatte diese Karte am 1. September 1915 geschrieben. Typisch ist die geradezu beiläufige Überleitung zum wissenschaftlichen Interesse, das mit dem jeweiligen Dozenten verband. Der Krieg selber wird hingegen nur ganz leicht angedeutet - hier als „wichtigere Dinge“, die man zu verrichten habe. Eher ungewöhnlich sind die präzisen Ortsangaben, die normalerweise der Zensur zum Opfer fielen.

Der Zoologiestudent Richard Bielert schrieb sich regelmäßiger mit Ehlers. Unter anderem legte Bielert seinen Briefen auch Fotografien bei. Seinen ersten Brief schrieb Bielert an Ehlers bereits kurz nach seinem Eintritt ins Militär, als er noch in einer Magdeburger Kaserne auf den Abmarsch nach Belgien wartete. Es war ihm offensichtlich ein Bedürfnis, sich zu verabschieden und die Dinge zu ordnen, die ihm wichtig waren.

346 Bei der Durchsicht zeitgenössischer Tages- oder Studentenzeitungen fallen zahlreiche Anzeigen auf, in denen Hersteller von Zigaretten oder ähnlichem mit bereits „feldpostmässig“ verpackten Waren warben. Offensichtlich etablierte sich während des Ersten Weltkrieges eine regelrechte ,Liebesgaben-Industrie'.

347 Cod.Ms.E.Ehlers.114 01.09.1915. Berger promovierte 1922 an der Universität Göttingen. 
Es war mir leider nicht vergönnt, jetzt noch meine Examina zu absolvieren, doch hoffe ich, dies nach dem Feldzuge nachbolen zu können. Sollte ich nicht zurückkehren, und so ist es mir auch recht, gefallen zu sein auf dem Feld der Ehre im Dienste des Vaterlandes. In diesem Falle würden dann die Resultate meiner Arbeit Herrn Geheimrat durch meinen Vater zugehen. Vielleicht kann dann ein Anderer das von mir bereits gefundene weiterbauen. Jedoch hoffe ich selbst die Aufgabe später bis zu Ende zu lösen. ${ }^{348}$

Erstaunlich ist die Kombination von Kriegsmetaphorik und die Sorge um seine wissenschaftlichen Ergebnisse. Bielert berichtete dann Ehlers circa zwei- bis dreimal im Jahr von seinen Erlebnissen, allerdings meist nur in der üblichen verharmlosenden Sprache der Zeit

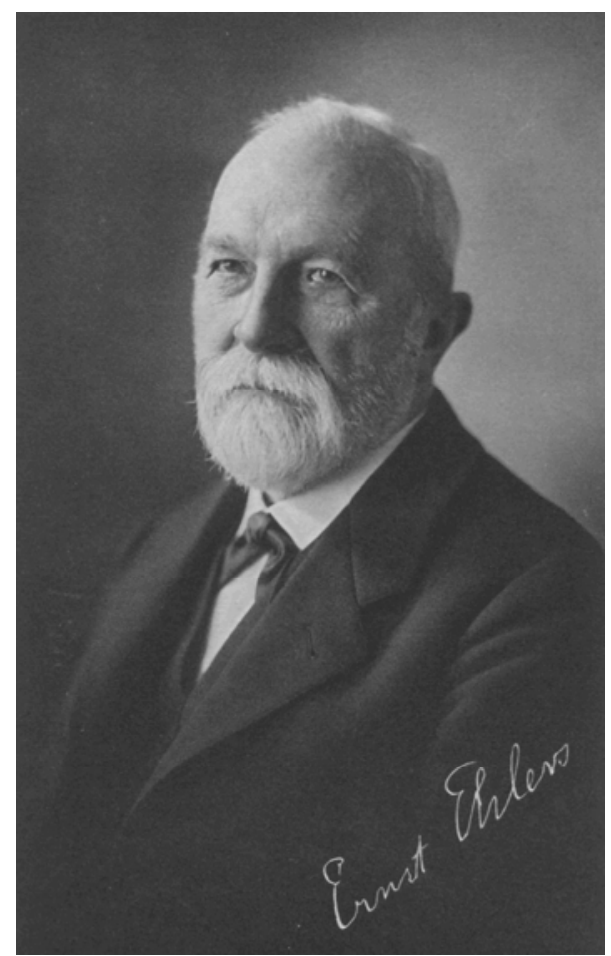

Abbildung 5: Ernst Eblers und ohne wirkliche Aussage.

Am liebesten würde ich mit in Serbien sein, jedenfalls dort, wo Bewegungskrieg ist. Stellungskrieg wird mit der Zeit sehr langweilig, ist dabei jedoch bedeutend nervenzerrüttender und verlustreicher als ersterer. Die Leistungen unserer Truppen bei der letaten großen Offensive der Engländer u. Franzosen sind einfach staunenswert. Was es beißt, in solch fürchterlichem Artilleriefener auszuharren, davon haben wir im Dezember öfter einen Begriff bekommen. An manchen Tagen schickte der Feind bis zu 3000 Granaten berunter. Da meinte man schon die Hölle sei los, und das war doch noch gar nichts gegen die ungeheure Munitionsverschwendung bei dem großen Kampf im September und Oktober. ${ }^{349}$

Mehrfach bedankte sich Bielert im Folgenden für Zigarren, um die er regelmäßig bat, oder einen Druck einer Rede des Reichskanzlers, auch einer gängigen Liebesgabe. Im Gegen-

zug schickte Bielert Ehlers einmal drei Siebenschläfer, die er an der Westfront gefunden und für seinen Professor getötet hatte. ${ }^{350}$ Die folgenden Schreiben

348 SUB.Gött.HSD.Cod.Ms.E. Ehlers.137 Bl. 1 06.10.1914.

349 SUB.Gött.HSD.Cod.Ms.E. Ehlers.137 Bl. 19 07.11.1915.

350 „,...] ich hoffe, daß die Exemplare noch in brauchbarem Zustande in G[öttingen] eingetroffen sind. Ich habe sie nicht anders töten können, als durch werfen gegen eine Wand, wobei ich die Erfahrung gemacht habe, daß diese Tiere ein äußerst zähes Leben haben.“ 
Bielerts wurden ausnahmslos in Lazaretten verfasst. Er war schwer erkrankt und verlor immer mehr die Hoffnung auf seine Gesundung, aber auch den Glauben an ein erfolgreiches Ende des Krieges. Im September 1918 schließlich bat er Ehlers, „da noch kein Ende abzusehen ist, "351 um Hilfe bei dem Versuch, Sonderurlaub zu erhalten. Sein Professor stellte ihm eine Bescheinigung aus, so dass er sein Gesuch mit seiner Dissertation begründen konnte. Nach seiner Rückkehr nach Göttingen promovierte Bielert umgehend und war von 1920 bis 1925 Assistent im Botanischen Garten.

Andere Studenten schrieben meist nur einzelne Briefe, wenn sie einen konkreten Anlass dazu hatten. Dabei handelte es sich meist um Vorgänge, die zu Friedenszeiten in einer normalen Sprechstunde abgehandelt worden wären. Am 22. Juli 1917 schrieb beispielsweise der Student Dormeier an Ehlers, dass er durch Zufall erfahren hätte, dass ein bestimmtes Dissertationsthema von Ehlers vergeben worden sei. Er erinnert seinen Professor daran, dass er dieses Thema bearbeiten wollte und bittet, es ihm zu reservieren. Bereits acht Tage später bedankt er sich in einem weiteren Brief für die entsprechende Zusage. ${ }^{352}$

In anderen erscheint es, als sehnten sich die Kriegsteilnehmer nach wissenschaftlicher Betätigung als bewusster Ablenkung vom Kriegsalltag, wie es etwa in einem Brief Dr. Maximilian Kraffts an David Hilbert deutlich wird.

Ich wäre daher Ihnen, sehr verehrter Herr Geheimrat, sehr dankbar, wenn Sie mir ermöglichen wollten, das zu verfolgen, was seitdem in der von Ihnen damals und wohl auch noch weiter unterstützten und geförderten allgemeinen Relativitätstheorie geschaffen worden ist. Ich bitte es nicht als Mangel an Interesse auslegen zu wollen, wenn ich zwei Jahre völlig geschwiegen habe, der Grund meines Schweigens ist das, was ich erlebt habe. [...]

Besonders interessieren würde mich natürlich das, was Sie Ihren damaligen Resultaten noch hinzugefügt haben und wieweit das damals erstrebte Ziel, das Problem des, Elektrons' erreicht worden ist.

Ich bitte Sie, verehrter Herr Geheimrat, zu verzeihen, wenn ich durch meine Bitte Ihre gewiß knappe Zeit noch in Anspruch nehme, ich wage es in der Erinnerung an das, was ich bei Ihnen und von Ihnen gelernt habe. ${ }^{353}$

Deutlich weniger Karten und Briefe beschäftigen sich hingegen mit dem Krieg selbst, wobei auf immer wiederkehrende Stereotypen zurückgegriffen wurde. So wird zum Beispiel der Stellungskrieg allgemein als langweilig bezeichnet, und es

SUB.Gött.HSD.Cod.Ms.E. Ehlers.137 Bl. 25 10.03.1917. Bielert hatte offensichtlich die Geschwindigkeit der Feldpost überschätzt, so dass die Tiere nicht mehr für die Sammlung des zoologischen Instituts zu gebrauchen waren. Ehlers sandte ihm daraufhin eine Anleitung, nach der er die Tiere konservieren sollte, falls er nochmals welche finden sollte.

SUB.Gött.HSD.Cod.Ms.E. Ehlers.137 Bl. 26 18.04.1917.

351 SUB.Gött.HSD.Cod.Ms.E. Ehlers.137 Bl. 35 13.9.1918.

352 SUB.Gött.HSD.Cod.Ms.E. Ehlers.373 Bl. 2, 3.

353 SUB.Gött.HSD.Cod.Ms.D.Hilbert.195 Bl. 1 31.08.1918. 
wird sich über mangelnde Treffsicherheit der gegnerischen Artillerie lustig gemacht. Oft wird im Zusammenhang mit eigenen Erfolgsmeldungen der Hoffnung auf ein baldiges Ende des Krieges Ausdruck verliehen, dies aber grundsätzlich unter der Voraussetzung eines deutschen Sieges. ${ }^{354}$ Präzisere, vielleicht auch ehrlichere Ausführungen darf man hier jedoch nicht erwarten. Etwaige kritische Bemerkungen hätten die Studenten gewiss nicht gewagt, ihrem Professor zu schreiben, es sei denn, sie wären sich einer ähnlichen Einstellung bei ihm sicher gewesen. Von einem solch engen Vertrauensverhältnis kann man aber in keinem Fall ausgehen. So wurde oft nur das geschrieben, was in der Heimat erwartet wurde. Offenere Worte, wie zwischen dem Studenten Bielert und Professor Ehlers waren absolute Ausnahmen. Dies trifft auch für ein Gedicht zu, das einer der wenigen Studierenden, die entsprechend ihrer fachlichen Qualifikation eingesetzt wurden, seinem Lehrer Felix Klein schickte:

Von Mathematikern umgeben fühl ich mich hier ganz wie zu Haus

Die einen bauen unsere Gräben die anderen rechnen Höhen aus.

Hier baut man gar ein Badezimmer dort bessert man zerfahrene Straßen wo respectable Frauenzimmer unsere Berta fest sonst saßen.

Man rechnet Flach- und Steilflugbahnen man rechnet wie man Flieger schießt man rechnet wieviel Kilo Samen und wann der nächste Hafer sprießt.

Nur in den allerschönsten Dingen das Rechnen keinem will gelingen.

Vielleicht könnt Ihr mir rechnen aus wann wieder heimkehrt man nach Haus. 355

Deutlich offener äußerten sich Studierende wahrscheinlich untereinander oder gegenüber ihren Familien. Auf diese Korrespondenzen hat man jedoch kaum Zugriff. Eine Ausnahme stellen jedoch, zumindest für die Verbindungsstudenten, die Zeitschriften der Korps und Burschenschaften dar. ${ }^{356}$ Sie etablierten sich

354 Ähnliches berichtet Liermann für Erlangen: Liermann: Die Friedrich-Alexander-Universität. 1977. S. 38.

355 Feldpostkarte undatiert aus der Nähe von Metz SUB.Gött.HSD.Cod.Ms.F.Klein.8.206.

356 Neben den bekannten Problemen bei der Arbeit mit Feldpost im Allgemeinen und nicht zuletzt wegen der Zensur durch die Militärbehörden, treten bei der Arbeit mit den hier benutzten Zeitschriften weitere Schwierigkeiten zu Tage. Ganz grundsätzlich darf man nicht den Fehler machen, aufgrund dieser zwei Zeitschriften Aussagen zu den Studierenden als Ganzes treffen zu wollen. Dafür ist die repräsentierte Gruppe zu klein. Des Weiteren darf nicht außer Acht gelassen werden, dass die letztendlich veröffentlichten Briefe in den Schriftleitungen und Redaktionen eine Auswahl durchlaufen haben. So gesehen kann nicht einmal die Authentizität der Briefe bewiesen werden. Dies schmälert aber nur bedingt ihren Quellenwert. Die Burschenschaftlichen Blätter und die Deutsche Korpszeitung waren wichtige Medien, die in studentischen Kreisen wahrgenommen wurden. Man kann also aus ihnen Rückschlüsse auf Meinungen und Stimmungen unter den Verbindungsstudenten ziehen, gleichgültig, ob die veröffentlichten Briefe tatsächlich die eingesandte Feldpost repräsentieren. 
während des Krieges als wichtiges Medium für die Studierenden im Kriegsdienst, um mit Gleichgesinnten und der Heimat in Kontakt zu bleiben. Selbstverständlich kamen im August 1914 die normalen Tätigkeiten der Verbindungen ${ }^{357}$ nahezu vollständig zum Erliegen, wie etwa ein Bericht aus der Göttinger Burschenschaft Brunsviga zeigt:
Die Burschenschaft Brunsviga hatte auf die 31. Juli bis 2. August zum Stiftungsfeste geladen; aber am 31. Juli, an dem der Begrüßßungsabend stattfinden sollte waren nur we- nige erschienen. [...] Am 1. August fand noch ein schwach besuchter Alter Herren- Konvent statt. Am Nachmittag, als die Mobilmachung bekannt wurde, eilte der größte Teil der Bundesbrüder in die Heimat, um dem Rufe des Kaisers zu folgen. [...]
Das Brunsvigenhaus ist gleich zu Beginn des Krieges wie alle anderen hiesigen Verbin- dungshäuser dem Roten Kreuz, zur Verfügung gestellt [...]. Von einer Suspension der Burschenschaft ist bisher abgesehen. ${ }^{358}$

Das Verbindungsleben wurde daraufhin vielfach von den Alten Herren aufrecht erhalten. ${ }^{359}$ Eine ihrer Haupttätigkeiten bestand im Sammeln der Feldpostadressen ihrer Mitglieder und in der Veröffentlichung in aufbereiteter Form über die Verbindungszeitschriften, um so weiterhin Kontakte zu ermöglichen. Außerdem dienten die an die gesammelten Feldpostadressen versandten Zeitschriften als Nachrichtenbörsen. Sowohl die Deutsche Korpszeitung als auch die Burschenschaftlichen Blätter veröffentlichten in jeder Ausgabe aktuelle Listen der Kriegsteilnehmer, Auszeichnungen und Gefallenen, oft auch mit kurzen Nachrufen.

Außerdem wurden über dieses Medium die sich schnell vermehrenden Treffpunkte für Verbindungsstudenten an den Fronten bekannt gemacht und Termine für Treffen verbreitet, die dann alphabetisch geordnet unter der Überschrift „Burschenschaftler-Zusammenkünfte im Felde“ aufgeführt wurden: „Marché-lepot: Jeden Mittwoch nachmittag 4-6 Uhr im Kasino des Infanterie-Regiments. Auskunft Oberstabsarzt Dr. Bertholdt (Germania-Erlangen). "360 Diese Treffen standen den Mitgliedern aller Verbindungen offen, und häufig wurde später ein kurzer Gruß mit einer Teilnehmerliste veröffentlicht.

Einer der Hauptinhalte der beiden Zentralorgane der studentischen Verbindungen waren die Veröffentlichung von Feldpostbriefen, die entweder direkt an die Redaktionen gerichtet waren oder von den einzelnen Verbindungen eingereicht wurden. In Art und Umfang des abgedruckten Materials unterschieden sich

\footnotetext{
357 Übersicht über alle in Göttingen gemeldeten studentischen Verbindungen und akademischen Vereine in: UAG.Sek.691.

358 o.N.: Brunsviga-Göttingen. In: Burschenschaftliche Blätter, Nr. 1 vom 01.10.1914. S. 14.

359 Ausführliche Darstellung für Marburg: Wettmann: Heimatfront. 2000. S. 406ff.

360 o.N.: Burschenschaftler-Zusammenkünfte im Felde. In: Burschenschaftliche Blätter, Nr. 11 vom 01.03.1916. S. 233.
} 
die Korps von den Burschenschaften ganz wesentlich. Im Falle der Korps beschränkten sich die Mitteilungen meist auf kurze Grüße in sehr knappen Worten:

Lens, 28. August 1915. Der ,Deutschen Korpszeitung' wie allen deutschen Corpsstudenten senden von der Schützengrabengrenze in tiefem Bedauern, daß es hier kein Bier gibt, herqliche Grüße: [Namen] $]^{361}$

In den Burschenschaftlichen Blättern hingegen wurden deutlich längere und sehr detaillierte Berichte abgedruckt. Teilweise über mehrere Druckseiten erstreckten sich hier lange Erfahrungsberichte der Burschenschaftler, die aus allen Truppenteilen stammten. Sowohl Ärzte berichteten aus ihren Lazaretten, als auch Flieger oder Artilleristen von ihren Einsätzen.

Die Art und die Offenheit, in der dort vom Erlebten berichtet wird, überrascht häufig; sie wandelte sich im Laufe des Kriegsverlaufs und spiegelt diesen wider. ${ }^{362}$ Die ersten Kriegsmonate waren dabei zwar nicht unbedingt von Euphorie, aber doch von Siegeszuversicht geprägt. Während an der Ostfront ein Überlegenheitsgefühl dominierte, sind die Briefe aus dem Westen von einer erschreckenden Brutalität geprägt, besonders vom belgischen Kriegsschauplatz. Immer wieder wird von Erschießungen von Zivilisten und Durchsuchungen ganzer Dörfer erzählt, die dann meist in Brand gesteckt wurden. ${ }^{363}$

In Arlon marschiert ein langer Zug Zivilisten, darunter eine jüngere Frauensperson, über die Gleise des Güterbahnhofes nach einer hohen Böschung. Es sind 102 Bewohner der umliegenden Dörfer, welche mit der Waffe in der Hand gefangen wurden oder welche sich scheußliche Verbrechen gegen verwundete deutsche Soldaten zu Schulden kommen ließen. Das Weib z.B. hat einem deutschen Offizier die Augen ausgestochen! Tod durch erschießen. Jeder Schuß saß. Mit der letzten Gruppe wurde die weibliche Hyäne erschossen, welche die vorhergehenden Vollstreckungen hatte mitanschauen müssen. Eine Stunde lagen die toten Körper übereinandergehäuft da, bis Einwohner von Arlon die Leichname auf zweirädrigen Karren fortschafften. ${ }^{364}$

Die deutschen Truppen waren von dem Widerstand der belgischen und französischen Truppen überrascht und überfordert. Das Schlagwort der Franktireurs ${ }^{365}$ -

361 o.N.: Aus dem Kriege. In: Deutsche Korpszeitung (Academische Monatshefte), Nr. 400 vom 15.09.1915. S. 296.

362 Siehe hierzu auch: Wettmann: Heimatfront. 2000. S. $391 \mathrm{ff}$.

363 Unter anderem: o.N.: Vor und in Namur. In: Burschenschaftliche Blätter, Nr. 1 vom 01.10.1914. S. 15-16. Oder: o.N.: Vom belgischen Kriegsschauplatze. In: Burschenschaftliche Blätter, Nr. 1 vom 01.10.1914. S. 18.

364 Bierbaum, Otto Erich: Kriegsrecht im Feindesland. In: Burschenschaftliche Blätter, Nr. 3 vom 01.11.1914. S. 66.

365 Unter anderem: o.N.: Vom belgischen Kriegsschauplatze. In: Burschenschaftliche Blätter, Nr. 1 vom 01.10.1914. S. 18. Siehe hierzu: Kramer, Alan: Franktireur. In: Hirschfeld, Krumeich, Renz, (Hrsg.): Enzyklopädie. 2003. S. 500-501. 
der Freischärler - wurde als Begründung für angeblich legitime Repressalien angesehen, und beteiligte Studierende berichteten freimütig über abscheuliche Kriegsverbrechen. Artilleristen berichten von der nächtlichen Beschießung eines lothringischen Dorfes, als Vergeltung für angebliche Unterstützung französischer Truppen, ${ }^{366}$ oder von der gezielten Zerstörung der Kathedrale der Stadt Ypern. ${ }^{367}$

Spätestens seit dem zweiten Kriegswinter wird in den Berichten die zunehmende Niedergeschlagenheit deutlich und es häufen sich Berichte über Schmutz, Ungeziefer und Krankheiten. ${ }^{368}$ „Aber das schlimmste ist das [Artilleriebeschuss] noch lange nicht; uns machen Dreck, Nässe und Ungeziefer mehr zu schaffen als der Gegner. “369 Auch von Hunger war nun die Rede. ${ }^{370}$ Das zuvor geäußerte Überlegenheitsgefühl verschwand allmählich, und es wurde von Verbrüderungen an der Ostfront berichtet, kurz vor und nach dem Ende der Kampfhandlungen gegen Russland. ${ }^{371}$ In einer der letzten Kriegsausgaben der Burschenschaftlichen Blätter findet sich dann der sehr ausführliche Bericht eines Dr. Goldmann, der die ganze Niedergeschlagenheit der letzten Monate des Krieges widerspiegelt. Über eine Nacht nach einem schweren Artilleriebeschuss schrieb er:

Die Stunden verrinnen, langsam, ach wie langsam. Will dieser Tag denn niemals enden? Bleierne Gleichgültigkeit beschleicht einen. Um die Gedanken legt sich ein lähmender, eiserner Reif. Die Kälte zieht durch die steifen Knochen. Man hat abgeschlossen. Furcht? Nein. Der Tod muß doch einmal kommen. Kommt er jetzt, sind wir bereit. Und es wird Abend. Ich lebe noch, atme. Friedliche Rube ziebt über das weite blutgetränkte Feld. Ein stilles Amen den Kameraden, die starr zwischen uns liegen schon seit vielen Stunden, das gebrochene Auge nach oben gerichtet, wo die Seele bereits weilt. Wir anderen erheben uns, drücken gegenseitig stumm die Hände. 372

Aber auch wenn ein deutlicher Stimmungswandel in den veröffentlichten Briefen zu erkennen ist, werden zu keinem Zeitpunkt Kritik an der deutschen Kriegführung oder allgemein an dem Sinn und Zweck des Krieges geäußert.

366 o.N.: Von den Kämpfen in Lothringen. In: Burschenschaftliche Blätter, Nr. 6 vom 15.12.1914. S. 135-138.

367 o.N.: Die Zerschießung der Kathedrale von Ypern. In: Burschenschaftliche Blätter, Nr. 10 vom 15.02.1915. S. 235-236.

368 Schröder, M.: Im Kampf mit Gestank und Schmutz. In: Burschenschaftliche Blätter, Nr. 6 vom 15.06.1915. S. 128-129. Oder: o.N.: Aus den Feldpostbriefen von Leipziger Normannen. In: Burschenschaftliche Blätter, Nr. 3 vom 01.11.1916. S. 39.

369 Doring, Toni: Landwehr. In: Burschenschaftliche Blätter, Nr. 7 vom 01.01.1917. S. 102-103.

370 Schneider, Paul: Von den Karpathenkämpfen. In: Burschenschaftliche Blätter, Nr. 6 vom 15.06.1915. S. 125-126.

371 Gerrath: Die ersten Tage des Waffenstillstands. In: Burschenschaftliche Blätter, Nr. 7 vom 18.01.1918. S. 102-103.

372 Goldmann: Vor dem Sturm. In: Burschenschaftliche Blätter, Nr. 2 vom 01.05.1918. S. 22-24. 
Angesichts solcher Erlebnisse konnten alle Bemühungen der Universität, ihren im Kriegsdienst befindlichen Studierenden zu helfen, nur symbolischer Natur bleiben. Fast hilflos wirkt in diesem Kontext ein weiterer Versuch, der die Verbundenheit der Universität mit ihren Studenten oder ein Verantwortungsgefühl ihnen gegenüber zeigen sollte und der bereits zu Beginn des Krieges stattfand. Wahrscheinlich wurde dieser Vorgang ganz bewusst von der Universität als ein symbolischer Akt geplant und durchgeführt, um diese Verbundenheit zum Ausdruck zu bringen. Als einer der ersten von 768 Göttinger Studenten fiel bereits am 10.11.1914 vor Langemarck der Zoologiestudent Gerhard Engel. Er hatte sich unmittelbar vor den letzten Prüfungen seines Doktorexamens freiwillig gemeldet und konnte dieses nicht mehr beenden. Die Fakultät entschied sich, Engel sozusagen posthum zu promovieren, ohne mündliche Prüfungen. Anstatt einer Doktorurkunde stellte man ein Gedenkblatt mit dem folgenden Text aus:

Die Philosophische Fakultät der Georg August-Universität hat beschlossen, die von dem Kandidaten der Naturwissenschaften Herrn Gerhard Engel [...] verfaßte und als sehr gut bezeichnete Arbeit, Zur Kenntnis des Verbaltens der Stärke in den wintergrünen Blättern im Verlaufe des Jahres' unter die Zabl ibrer Dissertationen aufzunebmen. Der Verfasser stand unmittelbar vor der Einlieferung seiner Arbeit als Dissertation; der ausbrechende Krieg rief auch ibn unter die Fahne. Als Kriegsfreiwilliger im Reserve-Infanterie-Regiment 234 zog er, nach vollendeter Ausbildung, Mitte Oktober mit vielen Göttinger Kommilitonen ins Feld nach Flandern, wo er bei dem Sturmangriff vor Langhemark schon am Morgen des 10. November 1914 den Heldentod starb. Mit tiefstem Dank, der den für das Vaterland rubmreich gefallenen Streitern gebührt, und mit bewegter Trauer weibt die Philosophische Fakultät der Georg August-Universität dem für seine Wissenschaft begeisterten, durch hervorragende Beobachtungsgabe ausgezeichneten Jüngling an Stelle der Promotionsurkunde dieses Erinnerungsblatt. Gerhard Engel zur Ehre und zum Angedenken. ${ }^{373}$

Von diesem Vorgang, den hauptsächlich der Prüfer des Gefallenen, der Botaniker Prof. Dr. Gottfried Berthold, initiierte, ${ }^{374}$ wurde auch über Göttingen hinaus Kenntnis genommen. ${ }^{375}$ Obwohl es ein einmaliger Vorgang war, verfehlte er seine

373 UAG.Phil.Fak.Prom.E.II.7.

374 Berthold meldete Anfang 1915 die Prüfung seines Schülers bei der Fakultät an und schrieb ein Gutachten über die Dissertation mit dem Ergebnis magna cum laude. Zusammen mit Professor Ludwig Prandtl initiierte er den entsprechenden Fakultätsbeschluss und veranlasste den Druck der Arbeit. Der Text des Erinnerungsblatts ist ein Vorschlag von Berthold. UAG.Phil.Fak.Prom.E.II.7.

375 Unter anderem wandte sich am 31.12.1915 die Stadtbibliothek Hamburg an den Rektor der Universität Göttingen mit der Bitte um einen Druck des Erinnerungsblattes für Engel, um es in einem Gedenkband zum Ersten Weltkrieg aufnehmen zu können. Am 12.9.1916 findet sich eine ähnliche Anfrage der Deutschen Bücherei des Börsenvereins der Deutschen Buchhändler zu Leipzig. UAG.Phil.Fak.II.96. 
Wirkung nicht, die Verbundenheit der Universität mit ihren Studenten im Kriegsdienst zu symbolisieren.

Auch die in Kriegsgefangenschaft geratenen Studenten wurden von den Universitäten nicht vergessen. Hier stießen die Hochschulen jedoch aufgrund ihres mangelnden politischen Gewichts an ihre Grenzen. Der Rektor der Georgia Augusta schloss sich 1916 einer Initiative der Universität Würzburg an, nach der alle kriegsgefangenen Studenten aller Nationen in der Schweiz interniert werden sollten und ihnen so eine Fortsetzung ihres Studiums an schweizer Universitäten ermöglicht werden sollte. ${ }^{376}$ Der schweizer Professor Eugen Huber hatte sich an die Universität Würzburg gewandt, die sich wiederum in Göttingen beim damaligen Rektor, dem Theologen Prof. Dr. Arthur Titius, Unterstützung erhoffte.

Dem Rektor der biesigen Universität [Würzburg] ist von sebr maßgebender Schweizer Seite - Professor Dr. Eugen HUBER - mitgeteilt worden, daß man in der Schweiz sehr bereit wäre, eine Vereinbarung zwischen den kriegführenden Mächten zu vermitteln, wonach die sämtlichen gefangenen Studenten an Schweizer Universitätsorten in Gefangenenlagern interniert würden und dann am Universitätsunterricht teilnehmen könnten. Eine solche Vereinbarung würde einen unermeßlichen Segen für unsere Studenten bedeuten, die in der Gefangenschaft jetzt für ibr ganzes Leben verkümmern, besonders diejenigen, die für ihr Studium auf Institute angewiesen sind. Deshalb regt der Senat der Universität Würzburg an, die Universitäten möchten in einer gemeinsamen Schrift bei der Reichsregierung den Abschluß eines solchen Ausweges erwirken. 377

Diese Initiative, die ohne Frage in ihrer Bedeutung und Tragweite schwer zu realisieren ist, fand beim Göttinger Rektor Titius keine Zustimmung. Er äußerte in seiner Antwort vom 26. August 1916 seine Bedenken. Er bezweifelte zunächst, ob es der Öffentlichkeit und den anderen Kriegsgefangenen verständlich gemacht werden könne, warum man gerade Studenten in diesem Maße bevorzugte. Außerdem war er der Meinung, dass man, wenn überhaupt, die Regelung dann auch auf die kriegsgefangenen Schüler ausdehnen müsste.

\footnotetext{
376 Hierbei handelte es sich nur um eines von verschiedenen internationalen Projekten, die darauf abzielten, besonders schwer verwundeten oder erkrankten Gefangenen durch eine Internierung in der Schweiz zu helfen. Siehe hierzu: Wettmann: Heimatfront. 2000. S. 180-190. 
Des Weiteren befürchtete er negative Auswirkungen auf Göttinger Projekte im hiesigen Gefangenenlager, ${ }^{378}$ die er von seinem Kollegen Professor Carl Stange übernommen hatte, mit dem er zuvor Rücksprache gehalten hatte. Stange, der in einem wissenschaftlichen Beirat in Zusammenarbeit mit der Lagerleitung wissenschaftliche Kurse organisierte, ${ }^{379}$ berichtete von einem ähnlichen Vorschlag der „amerikanischen Christlichen Vereine Junger Männer,“ die eine sehr ähnliche Initiative auf bilateraler Ebene zwischen England und Deutschland vermitteln wollten.

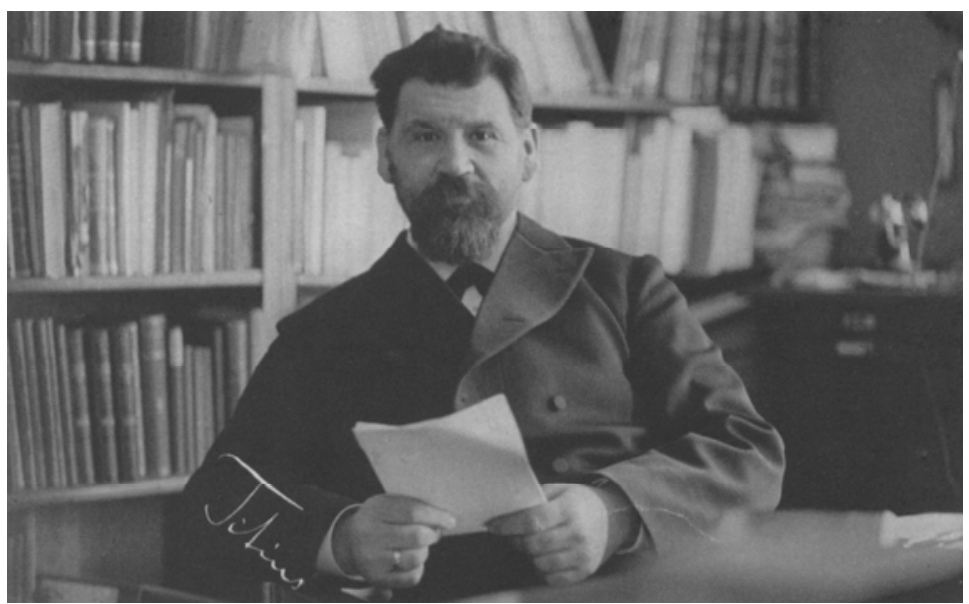

Abbildung 6: Arthur Titius

378 Im Göttinger Gefangenenlager gab es Dozenten der Universität, die dort für gefangene Studenten anderer Nationen Kurse abhielten. „In dem Gefangenenlager Göttingen bestehen schon seit längerer Zeit Einrichtungen, welche es den Gefangenen ermöglichen, ihre Studien fortzusetzen. Für die französisch sprechenden und für die vlämisch sprechenden Studenten sind besondere Kurse eingerichtet, die sich auf die verschiedensten Fächer beziehen. Diese Kurse stehen z.T. unter der Leitung von älteren Kriegsgefangenen, z.T. werden sie von den Angehörigen der hiesigen Universität abgehalten." Diesen Bericht schrieb Prof. Dr. Carl Stange, Theologe an der Göttinger Universität, am 29.7.1916 im Zusammenhang mit dem Studium kriegsgefangener Studenten in der Schweiz. UAG.Sek.412.i Bl. 2. Ausführlicher in: Stange, Carl: Das GefangenenLager in Göttingen. Göttingen 1916.

379 Siehe hierzu: Mirwald, Christa: Ausländer in Göttingen - von 1914 bis heute. Kriegsgefangene des Lagers Ebertal. In: Schmeling, Hans-Georg (Hrsg.): 100 Jahre Göttingen und sein Museum : Texte u. Materialien zur Ausstellung im Städt. Museum u. im Alten Rathaus 1. Oktober 1989 7. Januar 1990. Göttingen 1989. S. 88-117. 
Vor mehreren Monaten ist von England aus durch Vermittlung der amerikanischen ,Christl. Vereine Junger Männer' an uns die Frage gestellt worden, ob es nicht möglich sei, die gefangenen englischen Studenten in einem dortigen Lager zur Fortsetzung ibrer Studien zu sammeln. Es bestehe die Aussicht, dass alsdann die englische Regierung die gleiche Einrichtung auch für die dortigen gefangenen Studenten treffen und ibnen den Besuch der Vorlesungen an einer englischen Universität ermöglichen werde. Das Kriegsministerium in Berlin hat auf diese Anfrage seine Bereitwilligkeit erklärt, auf diese Vorschläge einzugehen. Da bereits bei uns Anfänge mit Studenten-Kursen gemacht sind, erwartet das Kriegsministerium, dass für weitere Schritte die englische Regierung den Anfang macht. ${ }^{380}$

Ein Abkommen mit England wurde offensichtlich nicht grundsätzlich ausgeschlossen. Die Würzburger Initiative schloss jedoch alle kriegführenden Nationen ein. Titius zweifelte allerdings stark an, ob auch Russland sich einer solchen Regelung anschließen würde, was er als unabdingbare Voraussetzung erachtete. Realistisch betrachtet waren solche Überlegungen jedoch weitgehend hypothetisch. Auch die Veranstaltungen, die im Göttinger Lager bereits stattfanden, waren nicht etwa aus Überlegungen der Menschlichkeit oder Ähnlichem entstanden. Vielmehr handelte es sich hierbei um hartes politisches Kalkül: Die deutsche Regierung wollte durch gezielte Erleichterungen vom innerbelgischen Nationalitätenkonflikt profitieren, indem sie versuchte, einen Keil zwischen Flamen und Wallonen zu treiben. Das Kriegsministerium hatte gemeinsam mit dem Brüsseler Generalgouverneur entschieden, alle gebildeten Flamen nach Göttingen zu bringen, um so das Ziel einer Teilung Belgiens zu fördern. ${ }^{381}$ Auch wenn dies nicht die Motivation des Theologen Stange war, so war er doch ausführendes Organ. Immerhin profitierten auch Gefangene anderer Nationalitäten von seiner Arbeit, wie etwa dem Aufbau einer Lagerbibliothek und der Herausgabe einer Lagerzeitschrift in den verschiedenen Sprachen. ${ }^{382}$

Trotzdem waren solche Angebote, wie sie für die in Göttingen gefangen gehaltenen Soldaten bestanden, nicht unumstritten: Auch in der Zeitungsaffäre um die Zulassung ausländischer Studierender wurde das Göttinger Kriegsgefangenenlager thematisiert:

Ein Theologieprofessor [Stange] hat sogar, wie das Gerücht geht, die Absicht geäußert, im kommenden Semester seine Vorlesungen einstellen zu wollen, damit er seine ganze

380 UAG.Sek.412.i Bl. 2.

381 Mirwald: Ausländer. 1989. S. 90. Pöppinghege, Rainer: Das Kriegsgefangenenlager Ebertal als Zentrum flämischer Propaganda im Ersten Weltkrieg. In: Göttinger Jahrbuch, Jg. 2003, H. 51, S. 49-60. Dolderer, Winfried: Deutscher Imperialismus und belgischer Nationalitätenkonflikt. Die Rezeption der Flamenfrage in der deutschen Öffentlichkeit und deutsch-flämische Kontakte 1890-1920. Melsungen 1989. (= Kasseler Forschungen zur Zeitgeschichte; 7).

382 Es existieren umfangreiche Studenpläne und Veranstaltungslisten, die dokumentieren, dass sich im Göttinger Kriegsgefangenenlager eine Art Lagerschule entwickelt hat. Besonders:

St.A.Gö.KGL43 Nr.40 und St.A.Gö.KGL44 Nr.41. 
Kraft den Kriegsgefangenen in Göttingen, denen er bekanntlich Zeitungen in englischer und französischer Sprache verfaßt, widmen kann. ${ }^{383}$

Ebenso erregten organisierte Spaziergänge, Führungen und Besichtigungen in der Universität und den Instituten des Öfteren Ärger in der Bevölkerung. ${ }^{384}$ Auch Titius zeigte mit seinem letzten Gegenargument schließlich unverblümt, wie sehr ihm dieser ganze Gedanke zuwider war:

Es dürte für unsere gefangenen deutschen Studierenden viel zweckmäßiger sein, wenn sie die Gelegenheit ibres Aufenthalts im feindlichen Lande dazu benutzen, dieses Land kennen zu lernen, als wenn sie in der Schweiz. Aufenthalt nebmen. Auch ist es für uns von Wert, den hier inhaftierten feindlichen Studierenden deutsche Cultur näher zu bringen. ${ }^{385}$

Ungeachtet des Göttinger Einspruchs reichte die Universität Würzburg ihren Vorschlag mit der Zustimmung fast aller deutschen Hochschulen noch im August 1916 bei Reichskanzler Bethmann-Hollweg ein. Dieser signalisierte zwar grundsätzliche Zustimmung und Unterstützung, unterstrich jedoch, dass er dem Projekt auf diplomatischer Ebene zwischen Kriegsparteien wenig Chancen einräume. ${ }^{386}$ Auch wenn nach dieser Antwort des Reichskanzlers politisch keine große Hoffnung auf einen erfolgreichen Abschluss dieses Projekts mehr bestanden haben dürfte, trat immerhin auf Göttinger Seite mit dem Amtsantritt des neuen Rektors Robert von Hippel eine Wendung ein. Dieser wollte die Bedenken seines Amtsvorgängers nicht teilen und versicherte bereits im September der Universität Würzburg seine „,warme Zustimmung““.387 Diese änderte jedoch nichts daran, dass die Idee, kriegsgefangenen Studenten aller Nationen ein Studium in der Schweiz zu ermöglichen, am 22. Oktober 1916 durch das Kriegsministerium abgelehnt wurde. Auch eine nochmalige Vorlage brachte am 8. Dezember dann nur die nun endgültige Absage. Trotz einer Reihe anerkennender Bemerkungen sah sich das Kriegsministerium, welches für die Kriegsgefangen zuständig war, nicht in der Lage, dieses Projekt zu unterstützen. Man befürchtete eine dramatische Verschlechterung der Moral der Kriegsgefangenen, falls „eine bestimmte Volksklasse“ in dieser Weise bevorzugt werden würde. ${ }^{388}$ Die wenigen Studenten, die bereits im

383 Zahlreiche Zeitungsausschnitte in: UAG.Sek.558(6) Bl. 22ff. Der Kurator bestätigte in seiner Gegendarstellung diese Aussagen und erklärte, dass Professor Stange vom Wintersemester 1915/16 an für seine Tätigkeit im Auftrag der Lagerverwaltung von seinen Pflichten seitens der Universität entbunden worden ist. Mirwald: Ausländer. 1989. S. 91.

385 UAG.Sek.412.i Bl. 4.

386 UAG.Sek.412.i Bl. 6.

387 UAG.Sek.412.i Bl. 7.

388 UAG.Sek.412.i Bl. 11, 18. 
Rahmen anderer Initiativen in der Schweiz interniert worden waren, durften trotzdem an den dortigen Universitäten studieren. ${ }^{389}$

Unbenommen dieses Scheiterns kann man zusammenfassend festhalten, dass die verschiedenen Bestandteile der Korporation Universität miteinander in Kontakt blieben, auch wenn sich große Teile weit entfernt im Kriegsdienst befanden. Die Studierenden, die in das Militär eintraten, gleichgültig ob freiwillig oder nicht, blieben durch ihre fortdauernde Immatrikulation ein Teil der Universität. Dabei handelte es sich jedoch nicht um einen bloßen Verwaltungsvorgang. Vielmehr mühte man sich, diesen auch mit Taten zu füllen. Die Versendung der jährlichen Weihnachtsgaben durch die Universität war hier beispielsweise ein wichtiger Punkt, der als Geste von den Studierende im Kriegsdienst sicher honoriert wurde. Auch auf privater Ebene standen einzelne Professoren mit ihren Schülern in Verbindung, wenn auch nur mit den wenigen, zu denen sie ein engeres Verhältnis pflegten. Die nicht zum Kriegsdienst eingezogenen Studierenden standen ebenfalls in Kontakt zu ihren Kommilitonen. Hierfür stellten die studentischen Verbindungen in Form von Adressenlisten, aber auch durch ihre Zeitschriften die Infrastruktur zur Verfügung. Zum Kriegsdienst eingezogene Studierende waren also in den Augen der Universität keine Soldaten mit akademischer Vorbildung, sondern Studierende in Uniform.

Mit Blick auf die eingangs gestellte Frage wird deutlich, dass auch für die Studierenden der Göttinger Universität das Bild einer ungeteilten Kriegseuphorie korrigiert werden muss, so wie dies in anderen Bereichen bereits geschehen ist. Es ist unstrittig, dass es gerade Studenten - vornehmlich Verbindungsstudenten waren, die die Teilnehmer an den Begeisterungs-Kundgebungen stellten, die dann für ganz Deutschland verallgemeinert wurden; dies wird auch in der neueren Forschungsliteratur deutlich. ${ }^{390}$ Auch in Göttingen gab es bei Kriegsausbruch Kundgebungen, an denen sich große Teile der Studierenden beteiligten. Wie viele von ihnen tatsächlich jubelten, bleibt unsicher. Im Anschluss an die erste Begeisterung verloren gerade Studenten, die sofort in den Militärdienst eintreten wollten, dies aber aus verschiedenen Gründen nicht konnten, in überhasteten Aktionen oft jedes Maß. Daraus jedoch zu schließen, dass die Studierenden die Gruppe waren, auf die das alte Bild des August-Erlebnisses zutrifft, würde zu kurz greifen und den für ganz Deutschland bereits gemachten Fehler nur in kleinerem Maßstab wiederholen. Man würde die Gruppe, in der tatsächlich die ungeteilte Kriegseuphorie herrschte, stellvertretend für die schweigende Mehrheit betrachten.

Die, die handelnd in Erscheinung traten, stellten doch eine Minderheit unter den Studierenden dar. Auch die Agitation gegen die Immatrikulation feindlicher Ausländer hatte innerhalb der Universität letztendlich keine Chance - nicht zuletzt, da sie nur von dem relativ kleinen Kreis der Vertretung der Studentenschaft

389 Wettmann spricht von insgesamt 1050 deutschen Studenten. Wettmann: Heimatfront. 2000. S.

184. Ein Beispiel eines Medizinstudenten: UAG.Sek.412.i Bl.9.

390 Als Beispiel: Verhey: Der „Geist“. 2000. S. 122. 
betrieben wurde. Es ist durchaus denkbar, dass die Universität anders reagiert hätte, wenn sie sich großen Demonstrationen oder einem gut organisierten Vorlesungsboykott gegenüber gesehen hätte; dafür fehlte dem Protest aber offensichtlich die Basis. Zur Kompensation dieser Tatsache hatte die Vertretung der Studentenschaft letztlich erfolglos den Weg an die Öffentlichkeit gesucht, weil sie keinen anderen Weg sahen, gegen den entschiedenen Widerstand innerhalb der Universität, ihre Ziele durchzusetzen. Der so entstandene Konflikt ist anhand der Quellen vollständig rekonstruierbar; die ganz offensichtlich nicht vorhandene Unterstützung bei der Mehrzahl der Studierenden muss letztlich aus dem Fehlen weiterer Nachrichten geschlossen werden, ist jedoch auch eine nicht zu leugnende Tatsache. 



\section{Zwischen Sparzwang und neuen Chancen - die finanzielle Situation}

In diesem Kapitel soll anhand der finanziellen Verhältnisse der einzelnen Institute das Maß der Beeinträchtigungen vor allem der Forschungsarbeit durch den Ersten Weltkrieg betrachtet werden. Es wird außerdem untersucht, ob bestimmte Institute oder andere Einrichtungen sogar Vorteile durch den Krieg erfahren haben, weil sie etwa auf Grund kriegs- und rüstungsrelevanter Forschungsthemen auf besondere Unterstützung hoffen konnten. Als Mittel für diese Betrachtungen sollen die Verwendung des Fonds für unvorhergesehene Mehrausgaben des Kurators und die außerordentlichen Bewilligungen des Kultusministeriums dienen, die als Indikatoren für tatsächliche Veränderungen und den Fortschritt einzelner Institute innerhalb der Universität gelten können, da die regulären Jahresetats hierfür nicht ausreichten. Damit wird hier eine bewusst enge Perspektive gewählt, die so in der bisherigen Forschung noch nicht verwendet worden ist. Der groß angelegte Ausbau Göttingens zu einem Zentrum der Mathematik und der Naturwissenschaften wurde mit Mitteln wie gezielten Neuberufungen und Institutsneugründungen verfolgt. ${ }^{391}$ Den Alltag der Wissenschaftler bestimmte jedoch der deutlich kleinere finanzielle Rahmen der Jahresetats und der beantragten Sondermittel, die hier zur Analyse herangezogen werden.

391 Siehe oben. 
Außerhalb der Universität soll darüber hinaus versucht werden, anhand der Aerodynamischen Versuchsanstalt Ludwig Prandtls zu prüfen, welche Möglichkeiten sich durch die durch den Krieg veränderte Situation boten.

\section{Universitätsinstitute und Seminare}

Grundlage der folgenden Untersuchungen stellen hauptsächlich die Akten des Kurators der Georgia Augusta mit dem Titel Etat und Mittelbewilligungen dar, die für jede Abteilung, jedes Institut oder Seminar ${ }^{392}$ an der Georg-August-Universität Göttingen existieren. In diesen Akten werden sämtliche Etatangelegenheiten der jeweiligen Institution mit dem Kurator verhandelt, der über alle finanziellen Angelegenheiten der Universität die Aufsicht hatte. Enthalten in diesen Akten sind fast ausschließlich Anträge der Institute, das heißt ihrer Direktoren, auf finanzielle Unterstützung über ihren normalen Jahresetat hinaus.

Den größten Teil der enthaltenen Vorgänge stellen kleinere Rechnungen dar, die aus verschiedenen Gründen, etwa weil noch eine Gewährleistung abgewartet werden musste, nicht mehr in dem Rechnungsjahr bezahlt werden konnten, in dem sie gestellt wurden, weshalb eine Übernahme in den nächsten Etat beantragt werden musste. ${ }^{393}$ Wo dies nicht möglich war, weil der Etat bereits erschöpft war, kam es zu Etatüberschreitungen. Etatüberschreitungen aus den verschiedensten anderen Gründen finden sich ebenfalls recht regelmäßig in den Akten; diese bewegten sich aber im Normalfall im Rahmen weniger hundert Mark. ${ }^{394}$

Deutlich seltener sind Anträge auf Bewilligung von Sondermitteln zur Anschaffung teurer Geräte oder Ähnlichem enthalten. Diese Vorgänge stellen eine hochinteressante Quelle dar, da die Anträge mit einer ausführlichen Begründung gestellt werden mussten, die genaue Einblicke in die Verhältnisse der Institute zulässt. Es gab zwei mögliche Wege für das Stellen eines Antrags: Zum einen

392 In dieser Arbeit soll einheitlich von Instituten die Rede sein, auch wenn die damalige Bezeichnung eine andere gewesen ist. „Seminar“, „Institut“ oder „Laboratorium“ und gegebenenfalls auch „Abteilung“ als Untereinheit waren die gebräuchlichsten Bezeichnungen. Diese veränderten sich jedoch ständig, so dass auch in dem recht kurzen, hier untersuchten Zeitraum von 1910 bis 1920 einige Verwirrung entstehen könnte. Selbst die Direktoren und Abteilungsvorsteher scheinen teilweise die offiziellen, gerade aktuellen Namen ihrer Institute nicht gekannt zu haben, so dass oft in einem Vorgang Diskrepanzen in der Bezeichnung als Seminar, Institut oder Abteilung auftreten. Grundsätzlich wurde, wenn der genaue Titel eines Instituts genannt wird, die Bezeichnung zu Grunde gelegt, die in dem Personal- und Studierendenverzeichnis des entsprechenden Jahres Verwendung findet.

393 Das Ansparen oder Zusammenlegen von Mitteln aus Etats verschiedener Jahre war grundsätzlich nicht gestattet. Rechnungen mussten aus den Mitteln des Jahres bezahlt werden, in dem sie gestellt wurden.

394 Wie im Weiteren noch gezeigt werden wird, jedoch mit deutlichen Unterschieden zwischen den Instituten. 
konnte man sich an das Kultusministerium ${ }^{395}$ wenden, wobei man aber trotzdem den Dienstweg einhalten und den Antrag dem Universitätskurator zur Befürwortung und Weiterleitung übergeben musste. Zum anderen konnte man eine solche Sonderzuwendung direkt beim Kurator beantragen, der für unvorhergesehene Mehrausgaben einen speziellen Fonds verwaltete. Aus diesem Fonds wurden meist relativ problemlos, nur auf formlosen Antrag, die bereits erwähnten kleineren Etatüberschreitungen abgewickelt.

Seltener, dann jedoch mit sehr ausführlichen Begründungen, wurde eine Erhöhung des regulären Etats eines Instituts über den Kurator beim Kultusministerium beantragt. Grundsätzlich bleibt noch zu erwähnen, dass im Rahmen der hier behandelten Etatangelegenheiten auch alle Stellen unterhalb denen der Professoren ausgehandelt wurden, also auch die in dieser Arbeit ausführlich behandelten Assistentenstellen und außerdem die Kosten für Reinigungskräfte, Hilfsarbeiter und Handwerker.

Leider können diese Etat und Mittelbewilligungs-Akten nicht oder nur indirekt den Normalzustand in den Instituten widerspiegeln. Ein Vorgang, wie er oben beschrieben wurde, entstand immer nur dann, wenn der reguläre Etat nicht mehr ausreichte, also wenn von dem Normalzustand abgewichen werden musste. Die alltäglichen Zahlungen oder Anschaffungen konnten die Institute im Rahmen ihres Jahresetats direkt bei der Universitätskasse anweisen lassen. Über diese Vorgänge sind jedoch leider keine Archivalien erhalten. ${ }^{396}$ Aus diesem Grund ist es unmöglich, die finanziellen Aufwendungen der einzelnen Einrichtungen in Form einer Statistik oder tabellarisch zusammenzufassen. Gelegentlich finden sich jedoch im Rahmen von Anträgen auf eine Erhöhung des regulären Etats genaue Aufstellungen über die Verwendung der bisher zur Verfügung stehenden Mittel.

395 Der korrekte Titel lautet: Bis 1911 „Ministerium der geistlichen, Unterrichts- und Medzinalangelegenheiten“. Seit 1911: Ministerium der geistlichen und Unterrichtsangelegenheiten“. Seit 1919 „Ministerium für Kunst, Wissenschaft und Volksbildung“. Siehe hierzu: Hubatsch, Walther (Hrsg.): Grundriß zur deutschen Verwaltungsgeschichte. 1815-1945. Reihe A: Preußen. Marburg/Lahn 1978. S. 114ff. Und: Jeserich, Kurt G. A.; Pohl, Hans; Unruh, Georg-Christoph von (Hrsg.): Deutsche Verwaltungsgeschichte. Bd. 3: Das Deutsche Reich bis zum Ende der Monarchie. Stuttgart 1984.

396 Es existieren quartalsweise erstellte Abrechnungen im Bestand Kuratorium des Universitätsarchivs Göttingen, in denen der Haushaltstitel abgerechnet wird, der dem Kurator zum Ausgleich unvorhergesehener Mehrausgaben zur Verfügung stand. Um die Verwendung und die Höhe dieser Zuwendungen genau betrachten zu können, bieten jedoch die in diesem Kapitel behandelten Akten die bessere Quelle. Differenzen zwischen den in den Etatakten bewilligten Summen und denen in den Abrechnungen der Universitätskasse konnten nicht festgestellt werden. UAG.Kur.9824. 


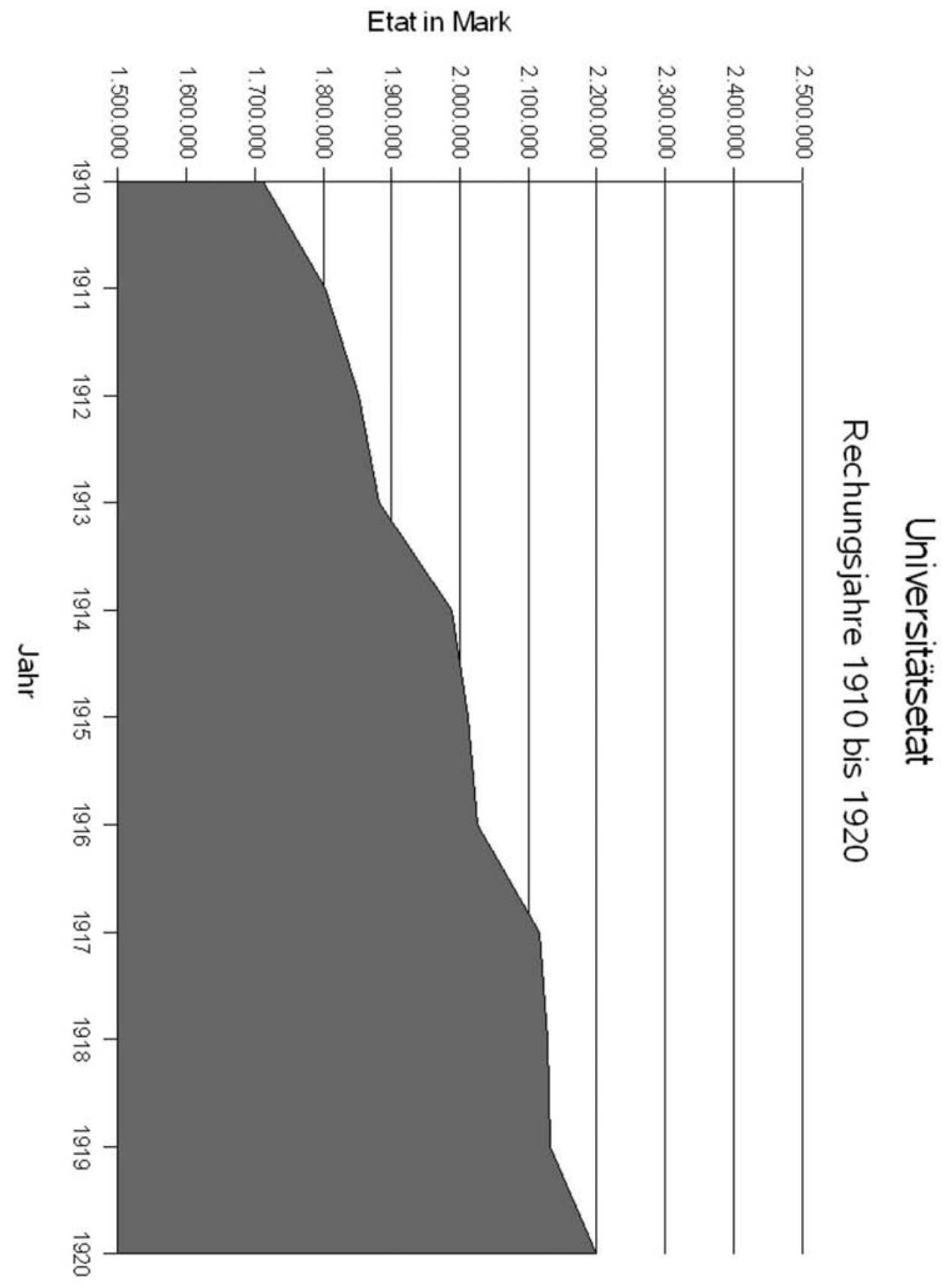

Statistik 7 Daten aus: Staatshaushaltsplan [Preußen]: für das Rechnungsjabr 1910 bis 1920. Berlin 1909 bis 1919. 
Aus dem Gesamtbild der Akten geht hervor, dass der Normalfall, also das Wirtschaften mit den regulären Etats, keine größeren Investitionen zuließ. Solche mussten immer gesondert beantragt werden. Ein bestimmter Anteil des Etats entfiel zwar immer auf Neuanschaffungen und Instandhaltung des Inventars, den größten Anteil nahmen aber stets Betriebskosten wie Gas, Wasser, Strom und Gebäudereinigung ein. Auch für Zeitschriften und Bücher für die Institutsbibliotheken mussten recht große Summen aufgewendet werden. Welche Mittel hier konkret zur Verfügung standen, lässt sich grob aus dem preußischen Staatshaushaltsplan entnehmen, allerdings mit deutlichen Einschränkungen für die Kriegszeit.

Die Betrachtung der Entwicklung des Gesamtetats der Universität Göttingen innerhalb des preußischen Staatshaushaltsplans und die darin enthaltenen Posten zeigen eine überraschende Konstanz und sogar einen leichten Anstieg auch während des Krieges. In dieser Arbeit soll sich jedoch nicht mit den Planungen auf ministerieller Ebene beschäftigt werden, sondern lediglich mit deren konkreten Auswirkungen auf die Universität. 397 Wie im Folgenden gezeigt werden wird, konnte es sich bei den preußischen Staatshaushaltsplänen während des Ersten Weltkrieges tatsächlich nur um Pläne im eigentlichen Sinne des Wortes handeln. Auch wenn man wirtschaftliche Faktoren wie Inflation und steigende Löhne nicht berücksichtigt, zeigen die Etatakten der Institute erwartungsgemäß, dass von einer Konstanz oder gar einem Anstieg der verfügbaren Mittel nicht die Rede sein kann. In Einzelfällen finden sich sogar Bemerkungen der Direktoren darüber, dass bewilligte Mittel nicht ausgezahlt oder nur halbe Etats überwiesen worden sind. ${ }^{398}$

Die regulären Etats waren, wie aus den Akten hervorgeht, immer recht knapp bemessen. Daher sind hier, wie bereits erwähnt, lediglich die Sondermittel, also der Titel „Deckung von Einnahmeausfällen und unvorhergesehene Mehrausgaben" von Interesse. Sie stellen eine Art für den Kurator frei verfügbarer Reserve des Etats dar, mit der besondere Projekte oder Verbesserungen, also alles, was über den normalen Betrieb und die Erhaltung hinausging, realisiert werden konnte.

Aus den angesprochenen quartalsweisen Abrechnungen dieses Titels ${ }^{399}$ geht hervor, dass auch diese Zahlen, die ja eine recht deutliche Steigerung zeigen, während des Krieges die Realität immer weniger widerspiegelten. Während des Krieges traten immer größere Fehlbeträge in den Abrechnungen auf, die offensichtlich daher rührten, dass diese Mittel mit den Einnahmen von Gebühren, die etwa für Praktika erhoben wurden, verrechnet werden mussten. Zunächst konnten

397 Andera Wettmann schildert die Diskussion anlässlich der Verabschiedung des Kultusetats für das Jahr 1915. Demnach herrschte ein hohes Maß an Einigkeit darüber, dass der Etat des preuBischen Kultusministeriums auch ein Signal an die Kriegsgegner im Rahmen des internationalen Propagandakriegs sein sollte. Siehe hierzu: Wettmann: Heimatfront. 2000. S. 94.

398 Ausgesprochen schwierig stellte sich die Situation in den Universitäten Großbritanniens dar, die finanziell deutlich stärker von Studiengebühren abhängig waren. Winter berichtet, dass allein in Oxford 191817 Lehrstühle aus finanziellen Gründen nicht besetzt waren. Winter: Oxford. 1994. S. 11.

399 UAG.Kur.9824. 
so Defizite noch ausgeglichen werden. Mit dem Ausbleiben der Praktikanten, parallel zum allgemeinen Rückgang der Studierendenzahlen, geriet dieser Posten im Universitätshaushalt jedoch immer mehr aus dem Gleichgewicht. Obwohl sein Volumen im Jahr 1917 sogar von 71933 Mark auf 86744 Mark nochmals aufgestockt wurde, konnten kaum noch Mittel bewilligt werden. ${ }^{400}$

Es lässt sich verallgemeinernd sagen, dass die Zahlen des gesamten Staatshaushaltsplans kaum Aussagekraft über die tatsächlichen Verhältnisse an den Instituten der Georgia Augusta haben. ${ }^{401}$ Aus diesem Grund wird hier versucht werden, anhand der Etat und Mittelbewilligungs-Akten der Jahre 1910 bis 1920 und der darin enthaltenen Anträge sowie deren Begründungen durch die Direktoren, die Auswirkungen des Ersten Weltkrieges auf die Forschung - oder allgemeiner, die Arbeit - der Institute nachzuvollziehen. Bereits sehr früh, am 19. August 1914, machte der Universitätskurator in einem Rundschreiben auf den Sparzwang aufmerksam:

\section{Die kriegerischen Ereignisse machen auch in der Universitätsverwaltung größtmögliche Sparsamkeit zur Pflicht. Sofern daher nicht bestimmte, auf früheren Zusicherungen be- rubende oder durch besondere dringende Verbältnisse begründete Zablungsverpflichtungen vorliegen, soll auf Anordnung des Herrn Ministers der geistlichen und Unterrichts- Angelegenheiten von der Bewilligung von Zuschüssen an Universitätsinstitute aus dem Titel ,Insgemein' des Universitäts-Etats bis auf weiteres ganz, abgesehen werden. ${ }^{402}$}

Wie diese Forderungen umgesetzt wurden, soll im Folgenden an einigen Beispielen untersucht werden.

Kriegsalltag

Aus den physikalischen Instituten verlauteten gerade zu Beginn des Kriegsjahrzehnts immer wieder massive Klagen über zu kleine Etats, wobei besonders eine Rückständigkeit im internationalen Vergleich beklagt wurde, obwohl dieser Bereich in den letzten Vorkriegsjahren massive Förderungen erfuhr. 1911 etwa stellten Prof. Dr. Eduard Riecke und Prof. Dr. Woldemar Voigt, Direktoren der beiden Abteilungen des Instituts für Experimentalphysik beziehungsweise mathematische Physik, einen sehr umfangreichen, detailliert begründeten Antrag.

Der Etat unserer Institute, über dessen ungenügende Höhe wir wiederholt vorstellig geworden sind, wird im wesentlichen für die Kosten des laufenden Betriebes, eingeschlossen Reparaturen und Umarbeitungen vorhandener Apparate aufgebraucht. Grössere Neu-

\footnotetext{
400 Staatshaushaltsplan [Preußen]: für das Rechnungsjahr 1910-1920. Berlin 1909-1919.

401 Siehe hierzu auch: Wettmann: Heimatfront. 2000. S. 149-151.

402 UAG.Sek.38.1 19.8.1914. Andrea Wettmann zitiert den entsprechenden Erlass des Kultusministeriums an die preußischen Universitäten. Wettmann: Heimatfront. 2000. S. 221.
} 
anschaffungen gestattet derselbe in keiner Weise. Wir sind daher genötigt, um den Anforderungen zu entsprechen, um eine außerordentliche Beibülfe zu bitten. ${ }^{403}$

Insgesamt wurden mehr als 19000 Mark beantragt, hauptsächlich begründet mit dem schnellen Fortschritt des Faches und den dadurch steigenden Studentenzahlen. Ohne erst die Antwort des Kultusministeriums abzuwarten, forderte Riecke noch im gleichen Jahr eine Art Vorschuss auf die beantragten Mittel vom Kurator, der auch bewilligt wurde. ${ }^{404}$ Als kurze Zeit später das Kultusministerium immerhin 15000 Mark bewilligte, ${ }^{405}$ wurde der Kostenvoranschlag dementsprechend abgeändert ${ }^{406}$ und 1912 die Summe angewiesen, wobei dem Institut zusätzlich noch 2100 Mark jährliche Etaterhöhung für einen dritten Assistenten bewilligt wurden. ${ }^{407}$ Obwohl im folgenden Jahr nochmals 3000 Mark Sondermittel genehmigt wurden, überschritt das Institut auch in diesem Jahr seinen Etat um circa 2000 Mark, die der Universitätskurator 1914 übernehmen musste. ${ }^{408}$

Mit Kriegsbeginn erscheinen aber hier, wo offensichtlich trotz fast regelmäßig gezahlter, erheblicher Sondermittel der jeweilige Jahresetat in der Regel nicht ausreichte, keine Anträge oder Bewilligungen mehr. Im Gegenteil, Prof. Dr. Peter Debye und Prof. Dr. Robert Pohl, die neuen Direktoren, verzichteten wegen des Krieges auf Anregung des Kultusministeriums auf eine bereits bewilligte Mechanikerstelle und beantragten sie erst 1918 wieder neu:

Nach Aussage von Herrn Professor Debye wurde auf Anregung von Herrn Geheimrat Elster [Kultusministerium] von einer tatsächlichen Anstellung vor 4 Jahren mit Rücksicht auf die Kriegsverhältnisse abgesehen. Zur Begründung der Notwendigkeit der experimentellen Abteilung einen eigenen Mechaniker zuzuteilen, darf ich anführen, dass mein Lehrauftrag, den Unterricht den Sonderbedürfnissen der Biologen, Chemiker und Mediziner anzupassen, den Bau und die Umänderung zablreicher Demonstrationsapparate notwendig macht, und ferner mein eigenes und meiner Schüler Arbeitsgebiet nich [t] unerbebliche experimentelle Mittel erfordert. ${ }^{409}$

Ein ähnliches Bild zeigte sich in der Abteilung für mathematische Physik des physikalischen Instituts. ${ }^{410}$ In den Jahren 1910, 1911 und 1912 stellte Prof. Dr.

403 UAG.Kur.7469 Bl. 45-49. In dem Antrag, dem ein genauer Kostenvoranschlag über diverse elektrische Geräte beigefügt ist, erklären Riecke und Voigt genau, wofür welches Gerät benötigt wurde. Der Tenor des Ganzen ist, dass in einem Fach wie der Physik, in dem es auf hochtechnischem Gebiet innerhalb weniger Jahre große Fortschritte geben kann, das gesamte Inventar sehr schnell veraltet.

404 UAG.Kur.7469 Bl. 55.

405 UAG.Kur.7469 Bl. 59.

406 UAG.Kur.7469 Bl. 62.

407 UAG.Kur.7469 Bl. 66, 69.

408 UAG.Kur.7469 Bl. 86-90.

409 UAG.Kur.7469 Bl. 115.

410 Zusätzlich zu den hier aufgeführten Anträgen profitierte Voigt auch von der großen Bewilligung des Jahres 1912 (Siehe oben.), die er gemeinsam mit Riecke beantragt hatte. 
Woldemar Voigt diverse Anträge, die sich in der Schärfe der Formulierungen immer weiter steigerten. ${ }^{411} 1910$ erreichte er so immerhin die Zuteilung von 500 Mark Sondermitteln vom Kurator, wovon er jedoch 200 Mark nochmals anmahnen musste. 1911 erhielt er einen zweiten Assistenten und insgesamt 5200 Mark vom Kultusministerium und dem Kurator. Nach Zahlung von weiteren 2000 Mark erreichte Voigt endlich die Zusage, dass seine Forderungen erfüllt würden, was 1913 mit der Bewilligung von insgesamt 6300 Mark Sondermitteln für Neuanschaffungen, einer Etaterhöhung um 575 Mark auf 2500 Mark und weiteren 1500 Mark für eine zusätzliche Assistentenstelle auch geschah. ${ }^{412}$ Voigts Hauptinteresse galt dabei der Forschung auf dem Gebiet der Optik. In seinen Anträgen des Jahres 1912 führte er unter anderem aus, dass er Teile der jetzt vorhandenen Geräte persönlich angeschafft habe und andere von „freundlichen Gönnern“ “413 bezahlt worden seien. Fast schon flehentlich klingt der Schluss seines vorerst letzten Antrags:

Um nicht in dem einen Gebiet, in dem ein Provinzialinstitut Recht und Pflicht hat, erstklassig eingerichtet zu sein, aus der vorderen Reihe verdrängt zu werden, sehe ich mich genötigt, um eine außerordentliche Unterstütrung aus staatlichen Mitteln ₹u bitten. ${ }^{414}$

Es muss als unwahrscheinlich bezeichnet werden, dass Woldemar Voigt mit dem bis dahin Erreichten wirklich zufrieden gewesen ist, nachdem er ja schon 1910 die Meinung geäußert hatte, dass mindestens 5000 Mark Jahresetat notwendig wären, also das Doppelte des 1913 bewilligten Etats. Trotzdem bricht auch hier mit Beginn des Krieges die Anzahl der Anträge bis fast auf Null ein, nachdem 1914 noch einmal 600 Mark Sondermittel vom Kurator gezahlt worden waren. ${ }^{415}$ Und auch um diesen Status quo musste Voigt bangen, nachdem seinem Institut für das Jahr 1917 lediglich ein halber Etat überwiesen worden war. ${ }^{416}$

Auch im Institut für physikalische Chemie gab es zunächst starke Aktivitäten, besonders in der dort gerade im Aufbau befindlichen photochemischen Abteilung unter Prof. Dr. Alfred Coehn, die erstaunlicherweise noch während des Krieges am 13.4.1918 offiziell selbstständig gemacht werden konnte, wenn auch mit einem recht bescheidenen Etat von 1500 Mark. ${ }^{417}$ Die Abteilung bestand bereits seit 1910, hatte jedoch keinen eigenen Etat, sondern wurde aus Mitteln des Instituts für physikalische Chemie unterhalten. Bis zur offiziellen Etatzusage durch das Kultusministerium 1918 trat Coehn jährlich an den Kurator heran, und es wurden stets zwischen 200 und 500 Mark Sondermittel bewilligt - auch während des

\footnotetext{
411 UAG.Kur.1449: 11.1.1910, 31.1.1911, 21.3.1912.

412 UAG.Kur.1449: 22.11.1912, 16.5.1913, 25.11.1913.

413 UAG.Kur.1449: 26.11.1912.

414 UAG.Kur.1449: 26.11.1912.

415 UAG.Kur.1449: 18.4.1914.

416 UAG.Kur.1449: 16.3.1917.

417 UAG.Kur.1514: 13.4.1918.
} 
Krieges. Dabei muss man allerdings berücksichtigen, dass dies die einzigen Mittel waren, die Coehn zur Verfügung standen. ${ }^{418}$

Das Institut für physikalische Chemie, in dem die photochemische Abteilung zunächst organisatorisch angesiedelt war, war bei der Beantragung von Mitteln erfolgreicher, zumindest vor dem Ersten Weltkrieg. 1910 waren einmalig 9200 Mark Sondermittel vom Kultusministerium eingegangen.419 1912 schrieb der Direktor des Instituts, Prof. Dr. Gustav Tammann, einen sehr ausführlichen Bericht, in dem er die Rückständigkeit seiner Abteilung, besonders im Vergleich mit den USA, betonte.

Auf dem Gebiet hoher Temperaturen sind unsere sebr bescheidenen Einrichtungen durch das Carnegie-Institut für Geophysike in Washington, das mit einem Jahresetat von $50000 \mathrm{M}$ arbeitet, in den tiefsten Schatten gestellt. Mit diesem Institut auf dem Gebiete der Chemie und Physike der Silicate zu konkurrieren ist uns die Lust ziemlich vergangen, obwohl dieses Gebiet [...] von größter Bedeutung ist. [Es folgen weitere Vergleiche mit amerikanischen Instituten.]

Wir dürfen uns hier nicht nur auf die Theorie des Verhaltens der Stoffe bei hohen Drucken beschränken und uns damit trösten, dass bierin unser Institut noch einen Vorsprung hat, sondern müssen suchen zum wenigsten das, was der Amerikaner erreicht hat, ebenfalls zu erreichen und zu erweitern.

Nicht aus Lust am Recordbrechen, sondern um unsere Theorien zu prüfen und dann dieselben auf gesicherter Unterlage weiter auszubauen. ${ }^{420}$

Außerdem gab er in diesem Antrag, in dem er insgesamt 6635 Mark für neu anzuschaffende Geräte beantragte, eine genaue Aufstellung über die Verwendung seines bisherigen Jahresetats. ${ }^{421}$ In dieser Aufstellung wird deutlich, dass der gesamte Etat für laufende Kosten aufgebraucht wurde. Von 6400 Mark jährlich waren nur 600 Mark für Geräte vorgesehen, die laut Tammann fast ausschließlich zur Anfertigung von Provisorien aufgewendet werden mussten, da das Geld nicht für moderne Geräte ausreichte. Von seinen Forderungen wurden 5000 Mark bewilligt, was einer vollständigen Bewilligung gleichkam, da die fehlende Summe den Preis der Schränke für die neuen Geräte ausmachte, die von der Universität

418 UAG.Kur.7578 Bl. 269, 271 (Bericht Coehns über die photochemische Abteilung von 1910), 280 (Unterstützung Coehns durch Prof. Dr. Gustav Tammann, dem Direktor des physikalischchemischen Instituts), 281, 287, 292, 297, 299.

Alfred Coehn selbst war Titularprofessor, wurde jedoch bis 1919 als Assistent bezahlt, was einem jährlichen Einkommen von 1500 Mark entsprach. Erst als er 1919 dem Kurator schrieb, „dass ich nicht in der Lage bin, meine Tätigkeit unter den bisherigen Bedingungen weiter auszuüben“, wurde er zum außerordentlichen Professor ernannt, 1921 zum Beamten und erst 1928 zum ordentlichen Professor. UAG.Kur.1514: 24.2.1919.

419 UAG.Kur.7578 Bl. 265-266.

420 UAG.Kur.7578 Bl. 277.

421 UAG.Kur.7578 Bl. 276-277. 
selber angeschafft werden sollten. ${ }^{422}$ Bereits 1914, ein Jahr nach der Überweisung dieser Summe, klagte Tammann erneut über seinen Etat und prognostizierte dem Kurator ein Defizit von 1000 Mark. ${ }^{423}$ Der Kurator bewilligte vorab 500 Mark. ${ }^{424}$ Trotzdem betrug das Defizit des Jahres 1914 immer noch 793 Mark. 425 Obwohl man demnach die Finanzsituation des Instituts für physikalische Chemie alles andere als geklärt nennen konnte, folgten auch hier für den Rest des Jahrzehnts keine weiteren Anträge.

Dies stellte den Normalfall während des Krieges dar, weshalb hier auch davon abgesehen werden soll, auf alle naturwissenschaftlichen Einrichtungen im Einzelnen einzugehen. Grundsätzlich war es in der Mehrzahl der Institute so, dass seit Kriegsbeginn keine nennenswerten Anträge mehr gestellt wurden - gleichgültig, ob vor Ausbruch des Krieges Etatüberschreitungen und Anträge auf Sondermittel im jeweiligen Institut alltäglich waren oder nicht. Daher findet sich auch während der Dauer des Krieges keine Flut abgelehnter Anträge in den Akten, sondern es wird ein hohes Maß an finanzieller Disziplin deutlich. Kritik oder Unmutsäußerungen von Direktoren ist nicht überliefert.

In der Universitätschronik des Jahres $1920^{426}$ wird lediglich für das agrikulturchemische Institut, das vor allem mit Düngeversuchen beschäftigt war, eine direkte Aussage über die Auswirkungen des Ersten Weltkrieges getroffen: „Der Betrieb des Instituts litt stark unter den Folgen des Krieges. “427 Betrachtet man unter den oben genannten Gesichtspunkten die Etatakten der Abteilungen landwirtschaftliches Institut, landwirtschaftliches Versuchsfeld und agrikulturchemisches Institut, so fällt auf, dass ganz offensichtlich ein groß angelegter Ausbau des landwirtschaftlichen Fachbereichs an der Universität Göttingen durch den Krieg jäh unterbrochen wurde. ${ }^{428} \mathrm{Zu}$ Beginn des Jahrzehnts wurde mit der Übergabe des

422 UAG.Kur.7578 Bl. 279.

423 UAG.Kur.7578 Bl. 284-286.

424 UAG.Kur.7578 Bl. 289.

425 UAG.Kur.7578 Bl. 290.

426 Die Chronik der Universität Göttingen erschien jährlich, wurde jedoch während des Krieges vorübergehend ausgesetzt. Die letzte reguläre Ausgabe erschien 1916: Universität Göttingen (Hrsg.): Chronik der Georg-August-Universität zu Göttingen. Für das Rechnungsjahr 1915. Göttingen 1916. 1921 erschien wieder eine Chronik als Sonderabdruck aus den Mitteilungen des Universitätsbundes Göttingen, Jhrg. 4, Heft 2, der bis 1925 die Chroniken erstellte. In der ersten Nachkriegschronik von 1921 wurden die Rechnungsjahre von 1916 bis 1920 abgedeckt: Universität Göttingen (Hrsg.): Chronik der Georg-August-Universität für die Rechnungsjahre 19161920. Göttingen [1921]. (=Sonderabdruck aus den Mitteilungen des Universitätsbundes Göttingen, Jhrg. 4, Heft 2).

427 Universität Göttingen: Chronik 1916-1920. [1921]. S. 27.

428 Die landwirtschaftlichen Fächer erfuhren seit den 1890er Jahren einen beachtlichen Ausbau. Den Auftakt machte zu dieser Zeit die landwirtschaftliche Abteilung des chemischen Laboratoriums, die nun dem landwirtschaftlichen Institut unterstellt wurde. Nach ersten Neugründungen um die Jahrhundertwende und kurz danach stagnierte die Zahl der landwirtschaftlichen Institute bis Anfang der 1920er Jahre. Dann begann jedoch ein Ausbau, wie er in keinem anderen naturwissenschaftlichen Fachbereich stattfand. Bis Anfang der 1930er Jahre gab es bereits neun 
Direktoriums des landwirtschaftlichen Instituts von Prof. Dr. Wilhelm Fleischmann an Prof. Dr. Konrad von Seelhorst eine Neuorganisation der Institutsfinanzen durchgeführt, wobei wenig verwundert, dass dies mit der Beantragung von Etaterhöhungen und Sondermitteln einherging. Für die organisatorischen Veränderungen, die von Seelhorst plante, wurden bis einschließlich 1914 diverse Sondermittel beantragt.

Durch den Ausbau einer ehemaligen Assistentenwohnung sollten Arbeitsräume für den 1912 nach Göttingen berufenen Professor Gustav Frölich geschaffen

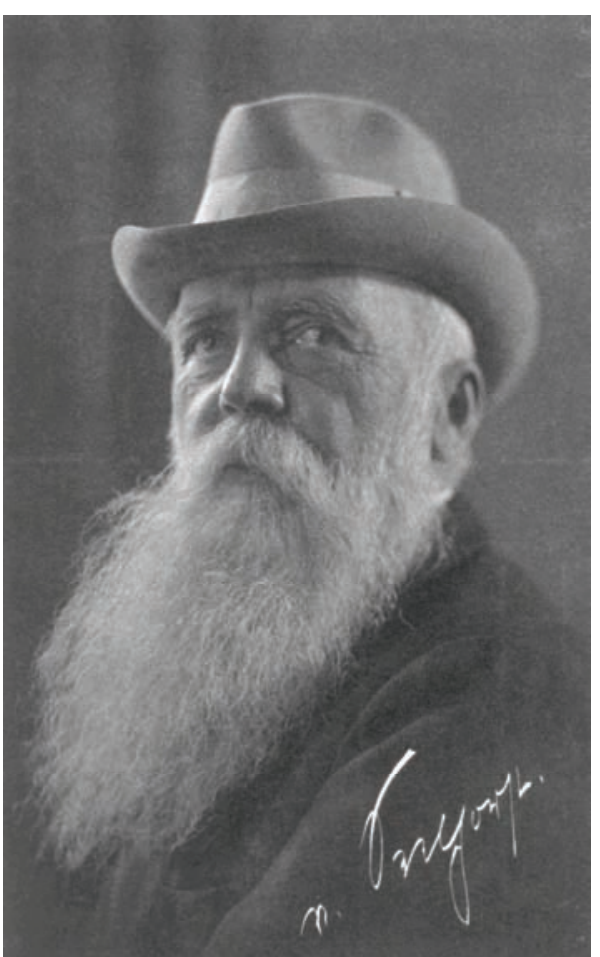

Abbildung 7: Konrad von Seelhorst werden, der das Fach der landwirtschaftlichen Betriebslehre vertrat.

Die Institutsräume sind sämtlich besetzt. Erst in Zukunft können die jetzt von Herrn Geheimrat [Prof. Dr. Wilhelm] Fleischmann innegehabten Herrn Prof. Frölich ganz oder zum Teil zugewiesen werden. So lange Herr Geheimrat Fleischmann aber nicht vom Lebramt zurücktritt [Fleischmann blieb bis zu seinem Tod 1920], muss deshalb irgend ein Ausweg geschaffen werden. Der einrige Ausweg, den ich sebe, ist die interimistische Ueberlassung der Assistenten-Räume in der Gärtnerwohnung. ${ }^{429}$

Seelhorst führte im Weiteren aus, dass „dadurch allerdings eine Schädigung des Versuchsfeldes entstehen" ${ }^{\text {430 }}$ würde, wohl um seinem Antrag bessere Chancen zu ermöglichen, indem er zeigte, dass auch er kompromissbereit war. Die notwendigen Instandsetzungen in Höhe von 431 Mark wurden 1913 zwar vom Universitätskurator bewilligt, ${ }^{431}$ es konnten aber vom Kultusministerium zunächst keine dauerhaften

selbstständige landwirtschaftliche Institute. (Diese Beurteilung entstand nach rein quantitativen Gesichtspunkten der Anzahl von landwirtschaftlichen Instituten. Eine genauere Untersuchung über den Ausbau dieses Fachbereichs mit Aspekten wie Studentenzahlen, Etatentwicklungen oder Neuberufungen existiert leider noch nicht. Aber allein das Maß an Neuorganisation, das hier durchgeführt wurde, ist beispiellos an der Universität Göttingen vor dem Zweiten Weltkrieg.)

429 UAG.Kur.7756 Bl. 290.

430 UAG.Kur.7756 Bl. 290.

431 UAG.Kur.7756 Bl. 303. 
Mittel in Aussicht gestellt werden, da es sich bei diesem Ausbau nur um ein Provisorium handelte: „Da diese Maßnahme zunächst nur eine provisorische ist, so bleibt der Universitätsetat davon einstweilen unberührt. "432 Zum anderen versuchte von Seelhorst bereits seit 1911 die Vegetationshalle des landwirtschaftlichen Versuchsfelds zu teilen, damit er sie gemeinsam mit dem Agrikulturchemiker Prof. Dr. Paul Ehrenberg nutzen konnte, der 1911 als außerordentlicher Professor nach Göttingen gekommen war. Zusammen mit diesem verfasste er ein ausführliches „Promemoria“, in dem beide betonen, dass eigentlich eine zweite Halle benötigt würde.

Die moderne Agrikulturchemie braucht für ihre Untersuchungen auf dem Gebiete der Bodenkunde und der Pflanzenernährungslehre unbedingt als Forschungsmittel eine Vegetationshalle. Dementsprechend besitzen sämtliche agrikulturchemischen Institute der Universitäten und landw. Hochschulen Vegetationshallen. Nur Göttingen macht aus Gründen, welche auf persönlichem Gebiete lagen [eine Anspielung auf Differenzen mit Prof. Dr. Wilhelm Fleischmann], in dieser Beziehung eine Ausnahme.433

Seelhorst und Ehrenberg räumten ein, dass der Bau einer zweiten Vegetationshalle als aussichtslos eingestuft werden müsse. Daher boten sie an, die vorhandene Halle zu teilen.

Die vorgeschlagenen Veränderungen würden dem agrikulturchemischen Institut die unentbehrlichen Lehr- und Forschungsmittel - wenn auch nur im bescheidensten Umfange - und dem landw. Versuchsfeld die Möglichkeit verschaffen, wenigsten $[s]$ in primitiven Räumen die für die Fortführung der Pflanzenzucht notwendigen Arbeiten und die für den Unterricht notwendigen Demonstrationen vornehmen zu können. 434

Dieses recht dunkle Bild wurde wohl von Seelhorst und Ehrenberg vor allem mit der Motivation gezeichnet, die Bewilligung von Baukosten für die Teilung der Halle in Höhe von 5000 Mark und eine Erhöhung des regulären Etats wegen steigender Betriebskosten von 2250 auf 3000 Mark durchzusetzen. Mit geringfügigen Modifikationen in der Beantragung, so etwa einer Teilung der Gesamtsumme in Bau- und Einrichtungskosten, wurde die Doppelnutzung der Vegetationshalle vom Kultusministerium genehmigt und finanziert, nicht jedoch die Etaterhöhung. ${ }^{435}$

Im Gegensatz dazu musste von Seelhorst bei seinen Projekten bezüglich des Arbeitsplatzes von Prof. Dr. Frölich in seinem Institut 1913 eine empfindliche Niederlage hinnehmen. Das Ministerium bewilligte keinen der drei 1913 beantragten Posten und berief sich in seiner Ablehnung auf mutmaßliche Einsparmöglichkeiten für von Seelhorst. ${ }^{436}$ Diese Niederlage bewegte ihn jedoch keineswegs zur Aufgabe seiner Pläne, so dass er 1913 und 1914 bereits wieder neue, teilweise

432 UAG.Kur.7756 Bl. 294.

433 UAG.Kur.7749 Bl. 334.

434 UAG.Kur.7749 Bl. 335.

435 UAG.Kur.7749 Bl. 345.

436 UAG.Kur.7756 Bl. 322. 
scharf formulierte Anträge stellte. Unter anderem schrieb er am 29. August 1913 an den Kultusminister:

Kurz, ich füble mich in jeder Bequehung zurückgesetzt. Ich würde, wenn diese Zurücksetzung eine rein persönliche wäre, nicht vorstellig werden. Aber das mir anvertraute Institut leidet. Es muß ja trotz, meiner und meiner Herrn Collegen Streben es zu beben, die wie Ew. Excellenz wissen, auch nicht ganz erfolglos geblieben sind, allmählich durch die weit besser ausgestatteten Institute zu denen außer den genannten [Breslau und Königsberg] noch Poppelsdorf und Berlin, und vom außerpreussischen Leipzig und Hohenheim gehören allmählich gan₹ zurückgedrängt und unterdrückt werden. Und darauf Ew. Excellenz aufmerksam zu machen halte ich für eine ernste Berufspflicht. 437

So erreichte er sogar, über die Bewilligung der 1912 beantragten 1600 Mark hinaus, eine Zuteilung von 1850 Mark, ${ }^{438}$ zuzüglich einmaligen 500 Mark $^{439}$ für den Unterhalt der Institutsbibliothek sowie eine dauerhafte Übernahme der Betriebskosten der neuen Räume durch den Kurator in einer Höhe von 100 Mark pro Jahr. ${ }^{440}$

Auch im agrikulturchemischen Institut ${ }^{441}$ Prof. Ehrenbergs traten, zusätzlich zu der von von Seelhorst betriebenen Teilung der Vegetationshalle, seit seiner Berufung 1911 deutliche Verbesserungen ein. Zunächst gelang es Ehrenberg, wahrscheinlich noch im Rahmen seiner Berufungsverhandlungen, seinen regulären Jahresetat von 3071 Mark durchzusetzen. Des Weiteren erreichte er vom Kultusministerium die Bewilligung von insgesamt 5000 Mark, die in drei Raten bis einschließlich 1913 überwiesen wurden. ${ }^{442}$ Trotz dieser Förderungen erwiesen sich die Mittel aber nicht als ausreichend, und es kam regelmäßig zu Etatüberschreitungen, ${ }^{443}$ woraufhin Ehrenberg 1914 eine Erhöhung seines Jahresetats auf insgesamt 3600 Mark beantragte. ${ }^{444}$

Diese Überschreitungen der verfügbaren Mittel sind trotz der möglichsten Sparsamkeit nicht zu vermeiden gewesen, da die für die Zwecke des Instituts zur Deckung der laufenden Ausgaben verfügbaren Mittel ganz ausnahmsweise beschränkte sind. [...] Es scheint in keiner Weise möglich, den wissenschaftlichen und sonstigen Aufgaben des Instituts auf die Dauer ferner gerecht zu werden, wenn die verfügbaren Mittel ebenso, wie bislang, beschränkt bleiben. ${ }^{445}$

437 UAG.Kur.7756 Bl. 329.

438 UAG.Kur.7757 Bl. 3.

439 UAG.Kur.7756 Bl. 330.

440 UAG.Kur.7757 Bl. 2.

441 Der Name wurde 1911 von „,agrikulturchemisches Laboratorium“ in ,,agrikulturchemisches Institut“" geändert. UAG.Kur.1679; 12.10 .1911 (Antrag), 20.11 .1911 (Genehmigung).

442 UAG.Kur.1679: 16.3.1912.

443 UAG.Kur.1679: 26.5.1913, 10.4.1914.

444 UAG.Kur.1679: 1.5.1914.

445 UAG.Kur.1679: 22.5.1913. Weitere Anträge, teils mit genauen Aufstellungen über den bisherigen Etat und seine Verwendung: 24.11.1913 und 7.4.1914. 
Da aber bereits der Krieg begonnen hatte, wurde dieser Antrag vom Kultusministerium in knapper Form abgelehnt: „Dem Antrag auf Einstellung der Mittel zu sächlichen Zwecken für das dortige Agriculturchemische Institut in den Entwurf zum Staatshaushaltsetat kann unter den jetzigen Zeitverhältnissen nicht entsprochen werden." 446 Auch in den anderen Instituten unter der Leitung Konrad von Seelhorsts verebbte nun mit Kriegsbeginn bis zum Ende des Jahrzehnts die Zahl der Anträge, womit der Ausbau der landwirtschaftlichen Fächer fast völlig zum Erliegen kam. In den Akten nach 1914 finden sich lediglich kleinere Rechnungen oder minimale Etatüberschreitungen. ${ }^{447}$

Als einzige Einrichtung erfuhr das agrikulturchemische Institut, scheinbar parallel zur immer schlechter werdenden allgemeinen Versorgungssituation in Deutschland, eine beachtliche finanzielle Unterstützung noch während des Krieges. 1916 und 1917 erhält Professor Ehrenberg insgesamt 10000 Mark Sondermittel vom Reichsgesundheitsamt und nicht etwa vom Kultusministerium, bedauerlicherweise ohne dass Anträge dafür erhalten sind. ${ }^{448}$ Grund für diese beachtliche Sonderzuwendung, die in Relation zum Jahresetat von 3071 Mark immerhin mehr als das Dreifache in kaum mehr als 12 Monaten ausmachte, waren Düngeversuche mit Kalidüngern, die das Institut im Auftrag durchführte. Diese Forschungsarbeit war angesichts der Lage, in der Deutschland sich damals befand, in ihrer Bedeutung nicht hoch genug einzustufen.

446 UAG.Kur.1679: 6.9.1915. Bemerkenswert ist, dass dies die direkte Antwort auf den von Prof. Ehrenberg am 1.5.1914 eingereichten Bericht ist. Die Bearbeitung dauerte also 16 Monate!

447 Zwar gelang noch 1916 mit dem außerordentlichen Professor Heinz Henseler eine Neuberufung für das Fach der Tierzuchtlehre, dem auch im Zuge seiner Berufungsverhandlungen noch 3000 Mark Sondermittel des Kultusministeriums zugesagt wurden.UAG.Kur.7757 Bl. 9. Danach wurden jedoch alle weiteren Anträge für Henseler auf die Zeit nach dem Krieg verschoben. So auch ein Antrag auf Erhöhung seines regulären Etats von 1500 auf 2500 Mark, obwohl er darin ausdrücklich die Relevanz seiner Arbeit für die Kriegszeit unterstreicht. Der Hauptgrund dafür, dass diese Anträge 1917 vom Kultusministerium abgelehnt wurden, ist wahrscheinlich darin zu suchen, dass Henseler selbst Kriegsdienst zu leisten hatte. UAG.Kur.7757 Bl. 22. Aber auch nach Kriegsende gelang es ihm nicht, seine Forderungen durchzusetzen, bevor er 1920 Göttingen verließ.

448 Schreiben Prof. Ehrenbergs an den Kurator vom 24.5.1916: An [...] den Kurator [...] richte ich [...] die ergebene Bitte, die Universitätskasse, falls dies angänglich ist, bevollmächtigen zu wollen, für mein Institut im Verlauf des Jahres vom 1. April 1916-dahin 1917 [sic!] im ganzen Beträge bis z e h n t a u s e n d Mark von der gleichen Stelle [Reichsgesundheitsamt] und zu dem gleichen Zweck [Versuche mit Kalidünger] entgegennehmen zu dürfen. Es würden demnach, mit Einschluß der bereits vereinnahmten zweitausend Mark, und der augenblicklich zu erwartenden dreitausend Mark [...] im ganzen zehntausend Mark, also noch weitere fünftausend Mark im Laufe des Jahres April 1916-1917 zu erwarten sein [...].“ UAG.Kur.1679: 24.5.1916. 
Brüche der Spardisziplin

Im Wesentlichen konnte nur in zwei Fällen ein Bruch der bisher deutlich gewordenen finanziellen Disziplin der naturwissenschaftlichen Institute festgestellt werden, jedoch unter ganz unterschiedlichen Voraussetzungen. Der Betrieb des Botanischen Gartens litt außergewöhnlich unter den Folgen des Krieges, obwohl die Ursachen hierfür anders gelagert waren, als bei den übrigen Instituten. Durch die Etatakte ziehen sich über das gesamte Jahrzehnt hinweg Berichte über teilweise dramatische Personalsorgen. ${ }^{449}$ Der Botanische Garten, der 1905 noch durch ein Versuchsfeld auf dem Brocken im Harz erweitert worden war, welches 1910/11 noch weiter ausgebaut wurde, ${ }^{450}$ war wie kein anderes Institut der Universität auf eine große Zahl von Arbeitskräften, nämlich Gartenarbeitern, angewiesen. Diese waren ausnahmslos nicht fest angestellt, sondern Tagelöhner. Daher war Direktor Prof. Dr. Albert Peter darauf angewiesen, zeitgemäße Löhne zahlen zu können, um sein Personal halten zu können. Aus diesem Grund gelang es ihm 1910, eine Etaterhöhung von 650 Mark beim Kultusministerium durchzusetzen, 451 1911 von 1160 Mark $^{452}$ und 1912 von 650 Mark. ${ }^{453}$ Im Rahmen des Antrags von 1912 schilderte er die Verhältnisse:

Euer Hochwohlgeboren [Universitätskurator] habe ich vor einigen Tagen mündlich berichtet, dass das gesamte Gartenpersonal des hiesigen Botanischen Gartens wegen Erhöbung der Löhne vorstellig geworden ist. Die Gebilfen erklären bei den ibnen bier gewährten Löhnen von 60-80 M monatlich ihr Auskommen nicht zu finden; sie haben den Dienst nun schon zum zweitenmal fast sämtlich zu gleicher Zeit verlassen, weil sie anderwärts bedeutend höhere Löhne bekommen. Die Arbeiter haben den Antrag gestellt, dass der Tagelohn auf durchschnittlich 3,00 bis 3,20 M gebracht werde, dadurch könne es ibnen erst ermöglicht werden, die notwendigsten Lebenserfordernisse für sich und ibre Familien zu bestreiten. 454

Danach kam es 1913 zu einer vorerst abschließenden Regelung mit dem Ministerium, durch die das Institut dann nochmals über zusätzliche 2970 Mark verfügte. 455 Damit war aber erst das 1913 aktuelle Lohnniveau gesichert. 1914 folgten

449 Das qualifizierte Personal befand sich schon früh nahezu vollzählig im Kriegsdienst. In den Akten des Kuratoriums finden sich immer wieder Anträge des botanischen Gartens auf die Zurückstellung von Gartenarbeitern vom Militärdienst, die jedoch selten Berücksichtigung fanden. Beispiel: UAG.Kur.3443 Bl. 1 oder Bl. 112.

450 UAG.Kur.1579: 16.6.1910, 18.7.1910, 23.12.1910.

451 UAG.Kur.1579: 18.11.1910.

452 UAG.Kur.1579: 21.4.1911.

453 UAG.Kur.1579: 13.6.1912.

454 UAG.Kur.1579: 4.4.1912.

455 UAG.Kur.1579: 18.4.1913. Dies bedeutete noch eine Aufstockung einer ersten Zusage aus dem November 1912 um 750 Mark. UAG.Kur.1579: 16.11.1912. 
zunächst nur noch kleinere Anpassungen. ${ }^{456} \mathrm{Da}$ in den folgenden Jahren bei akutem Arbeitskräftemangel und starker Preissteigerung während des Krieges keine zusätzlichen Mittel mehr aufgebracht werden konnten, drohten Ende 1918 endgültig alle Arbeiter fernzubleiben.

Eine Folge der zu geringen Besoldung ist nun, dass wir hier anstatt einem Obergehilfen und 5 Gehilfen nur noch 2 Gehilfen von herabgeminderter Leistungsfähigkeit haben. Auf alle Zuschriften Stellungssuchender erhalten wir nach Bekanntgabe unserer Anstellungsbedingungen nur abschlägige, in den meisten Fällen überhaupt keine Antwort. Wir bitten daher durch schleunige Gewährung unseres Antrages diesen unhaltbaren Zuständen ein Ende zu bereiten. ${ }^{457}$

Inhalt dieses Antrages war es, die Löhne im botanischen Garten auf ein Niveau anzuheben, das den von der Stadt Göttingen gezahlten Bezügen entsprach. Dies war besonders nötig, da man nur Gärtner mit einer gewissen Qualifikation gebrauchen konnte:

\section{Dabei ist in Betracht zu ziehen, dass die Kulturen des Botanischen Gartens erheblich böhere Anforderungen an das fachliche Wissen und Können der Gärtner stellen, als dies bei den einfachen Arbeiten der Stadtgärtnerei und den Handelsgärtnereien der Fall ist. 458}

Da aber während des Krieges keine Anpassungen der Löhne mehr vorgenommen worden waren, war die geforderte Erhöhung von 5984 Mark auf 11700 Mark im Jahr beachtlich und verdeutlicht gut, wie weit man unter dem aktuellen Lohnniveau lag. In den nächsten Jahren eskalierte die Situation immer mehr, bis schließlich sogar die Arbeiter sich selbst an den Kurator wandten:

Wir bitten das Kuratorium uns bis Donnerstag den 7.8.19. 3 Ubr nachmittags eine ergiebige Nachricht zu geben, da wir sonst andernfalls gezwungen werden Maßnahmen zur Erreichung unserer rechtlichen Forderungen zu treffen. [gezeichnet] Die Gehilfen und Arbeiter des ,Botanischen Gartens'459

Im botanischen Garten lag der Grund dafür, dass trotz des Krieges immer wieder Mittel beantragt wurden, darin, dass diese Einrichtung eine besonders große Zahl an Lohnarbeitern benötigte. Anders stellte sich die Situation für den Chemiker

\footnotetext{
456 UAG.Kur.1579: 10.4.1914.

457 UAG.Kur.1579: 13.12.1918.

458 UAG.Kur.1579: 13.12.1918.

459 UAG.Kur.1579: 5.8.1919. In dieser Angelegenheit scheint eine einvernehmliche Lösung gefunden worden zu sein, da es offensichtlich nicht zu weiteren Protesten der Arbeiter gekommen ist. In der nächsten Zeit wurden kaum noch reguläre Etaterhöhungen beantragt oder bewilligt, sondern man ging immer mehr dazu über, pauschal im voraus das Überschreiten des Etats zu genehmigen.
} 
Carl Mannich dar. Bei den chemischen Instituten ${ }^{460}$ fanden beispielsweise im Gegensatz zu den landwirtschaftlichen Instituten kaum organisatorische oder expansive Aktivitäten statt. Im gesamten Zeitraum von 1910 bis 1920 finden sich für das chemische Laboratorium und das Institut für anorganische Chemie fast keine oder nur sehr geringe Anforderungen oder Anträge. ${ }^{461}$ Charakteristisch für diese Institute ist ein Schreiben des Direktors des Instituts für anorganische Chemie, Professor Richard Zsigmondy an den Universitätskurator aus dem Jahr 1914. In diesem entschuldigt er sich ausdrücklich für eine Etatüberschreitung, die der Kurator zuvor beglichen hatte, und das, obwohl der Betrag von 858 Mark im Vergleich zu anderen Instituten nicht außergewöhnlich hoch war. Dieser Vorgang stellt in allen Akten, die für diese Arbeit eingesehen wurden, einen absoluten Einzelfall dar. Zsigmondy schließt dieses Schreiben mit den Worten: „Ich gebe Euer Hochwohlgeboren gleichzeitig die Versicherung, dass ich alles tun werde, um Etatüberschreitung im Etatsjahre 1914 zu vermeiden." ${ }^{462}$

Eine Abteilung des chemischen Laboratoriums sticht aber trotzdem aus diesem Bild hervor: Die Abteilung für pharmazeutische Chemie von Professor Carl Mannich, der 1911 als außerordentlicher Professor nach Göttingen berufen worden war. Es wirkt wie ein unglücklicher Zufall, dass die Entstehung des späteren pharmazeutisch-chemischen Instituts in die Zeit des Ersten Weltkrieges fiel. Gegen Anfang 1911 stellte Prof. Dr. Mannich die ersten Anträge. Mit detaillierten Begründungen forderte er insgesamt 10000 Mark Sondermittel und einen Jahresetat von 1000 Mark.

Die Studienverbältnisse in Göttingen sind dringend verbesserungsbedürftig, das ergibt sich schon aus der auffallend geringen Zabl von 11 bzw. 12 Studierenden in den letzten Semestern, aus der hervorgeht, daß Göttingen zur Zeit keinerlei Anziehungskraft auf

460 Gemeint sind die Abteilungen des chemischen Laboratoriums und das Institut für anorganische Chemie.

461 Zusätzlich zu den eigenen Anträgen des Instituts für anorganische Chemie finden sich in der Akte einige Anträge des Dekans der medizinischen Fakultät für den Göttinger Mediziner Dr. J. Voigt, der im Institut für anorganische Chemie über „koloides Jodsilber“ forschte, das zur Thyphusbehandlung eingesetzt werden konnte. UAG.Kur.1516: 16.3.1914. Voigt bekam für drei Jahre jeweils 500 Mark Zuschuss durch das Kultusministerium bewilligt. Während des Krieges musste Dr. Voigt dann Kriegsdienst als Chefarzt im Lazarett Schütt in Czersk leisten, konnte aber trotzdem seine Forschungen fortsetzen und bekam weitere Mittel bewilligt. UAG.Kur.1516: 5.6.1917, 30.6.1917, 28.8.1917, 20.6.1919.

462 Ein weiterer Vorgang aus der Akte des chemischen Laboratoriums scheint bemerkenswert: Dem Direktor Prof. Dr. Otto Wallach gelang es, 1915 insgesamt 4300 Mark einzusparen. Dieser Vorgang ist deshalb so bemerkenswert, da es sich nach Aktenlage um den einzigen Fall einer Einsparung in einem naturwissenschaftlichen Institut zwischen 1910 und 1920 an der GeorgAugust-Universität handelt und der Kurator damit einverstanden war, den Betrag auf den nächstjährigen Etat zu übertragen. In mehreren anderen Fällen erteilt der Kurator diesbezüglichen Vorhaben immer eine kategorische Absage. Dies war wahrscheinlich der Grund dafür, warum niemand sonst sich um Einsparungen bemüht hat. Außerdem liegt die Vermutung nahe, dass Wallach dieses Vorgehen im Voraus mit dem Kurator abgesprochen haben muss, worüber aber leider keine weiteren Schreiben erhalten sind. UAG.Kur.5544 Bl. 304. 


\begin{abstract}
Pharmazeuten ausübt. Dabei spielen sicher eine nicht unwesentliche Rolle die traurigen $V$ erbältnisse des hiesigen Laboratoriums hinsichtlich des baulichen Zustandes und der apparativen Ausstattung. Der den Pharmazeuten zugewiesene älteste Flügel des Allgemeinen Chemischen Laboratoriums, erbaut 1842, ist in jeder Weise zurückgeblieben, sodaß dort Verhältnisse obwalten, wie sie eines Universitätslaboratoriums unwürdig sind. ${ }^{463}$
\end{abstract}

Bewilligt wurden ihm aber nur 1000 Mark vom Kultusministerium und 800 Mark vom Kurator sowie ein Jahresetat von 750 Mark, worauf ein neuer Antrag Mannichs an das Ministerium mit der Bitte um einen eigenen Assistenten folgte. ${ }^{464}$ Nach der offensichtlichen Erfolglosigkeit ${ }^{465}$ seiner Bemühungen stellte er 1913 erneut einen Antrag, in dem er seine Forderungen wiederholte. Er untermauerte diese Forderungen mit einer drastischen Beurteilung der Verhältnisse: „Damit stand [zu Beginn seiner Beschäftigung] Göttingen hinsichtlich der von mir vertretenen Disziplin an letzter Stelle nicht nur der preußischen, sondern aller deutschen Universitäten. “466 Daraufhin gewährte ihm das Kultusministerium zwar keinen vollen Assistenten, so aber doch einen Hilfsassistenten, der aus den Mitteln für unvorhergesehene Mehrausgaben des Kurators bezahlt werden sollte. ${ }^{467}$ Für das nächste Jahr wurde eine Erhöhung des Etats des chemischen Instituts um 1500 Mark in Aussicht gestellt, die wahrscheinlich größtenteils für die Arbeit Prof. Mannichs gedacht waren, da das Kultusministerium sich direkt auf seinen letzten Antrag bezieht. ${ }^{468}$ Weniger als einen Monat später stellte er bereits wieder einen Antrag auf eine eigene Assistentenstelle. ${ }^{469}$

Dies alles war soweit nicht ungewöhnlich. Mit Ausbruch des Krieges jedoch brach dieser Vorgang nicht ab und begann sich damit von anderen vergleichbaren zu unterscheiden: 1915 begann Mannich damit, seine Abteilung vom chemischen Laboratorium abzuspalten und zu einem eigenen Institut auszubauen, was naturgemäß mit einer deutlichen Steigerung des Finanzbedarfs verbunden war.

Er beantragte jetzt im Einzelnen eine Assistentenstelle, die im Jahr zuvor bereits abgelehnt worden war, 3100 Mark Jahresetat und einen Wärter oder die Verpflichtung eines Wärters des chemischen Instituts. ${ }^{470}$ Mit diesem Antrag als

463 UAG.Kur.1499: 9.11.1911.

464 UAG.Kur.5544 B1. 259-261.

465 Der zweite Antrag Mannichs wurde zurückgewiesen. Der Grund dafür war offensichtlich, dass er zwar auftrat, als sei er Abteilungsvorsteher einer separaten Abteilung, dies aber zu diesem Zeitpunkt noch nicht war. Das Kultusministerium urteilte nur über die Lage des gesamten chemischen Laboratoriums, dessen Personalausstattung es als ausreichend ansah. UAG.Kur.5544 Bl. 270.

466 UAG.Kur.5544 Bl. 277.

467 UAG.Kur.5544 Bl. 281.

468 UAG.Kur.5544 Bl. 291. Mannich bezifferte trotzdem ein Jahr später seinen eigenen Etat immer noch auf 750 Mark, was dem offiziellen Haushalt auch entsprach. UAG.Kur.1499: 25.6.1915.

469 UAG.Kur.5544 Bl. 292.

470 Dabei handelte es sich um einen ausgesprochen ausführlichen und sehr detaillierten Antrag von insgesamt sechs maschinenschriftlichen Seiten und einer Skizze der Räume. UAG.Kur.1499: 25.6.1915. 
Verhandlungsgrundlage reisten am 17. September 1915 Professor Mannich und Prof. Dr. Adolf Windaus, mittlerweile Direktor des chemischen Laboratoriums, nach Berlin und führten dort persönlich weitere Verhandlungen mit Geheimrat Elster, einem Vertreter des Kultusministeriums. Die Ergebnisse dieser Gespräche waren für die Göttinger Professoren äußerst positiv: Die wesentlichen Punkte aus Mannichs Antrag wurden eindeutig zugesagt. ${ }^{471}$ Von den beantragten 3100 Mark Jahresetat wurden 3000 Mark bewilligt, wovon 1500 Mark von dem Etat des chemischen Instituts abgezogen werden sollten. Auch die Wärterstelle wurde zugesagt und die Selbstständigkeit der Abteilung genehmigt, was wohl für Mannich am wichtigsten war, da er von nun an auch offiziell in der Lage war, weitere Anträge für sich zu stellen, ohne den Direktor des chemischen Instituts hinzuziehen zu müssen. Geheimrat Elster scheint jedoch mit diesen Zusagen seine Kompetenzen überschritten zu haben. Wenige Tage nach dieser Besprechung traf beim Universitätskurator ein Schreiben des Kultusministeriums ein. Darin rückte man deutlich von den gemachten Zusagen ab. Zwar hatte man keine grundsätzlichen Bedenken gegen eine organisatorische Teilung der chemischen Institute, aber man war offenbar nicht bereit, Mittel zu bewilligen:

Ich nehme einstweilen an, daß durch die etwaige Abzweigung eines Sonderetats für das gedachte Laboratorium die Bereitstellung besonderer Mittel nicht erforderlich wird, daß vielmehr die dem Professor Dr. M a n n i c b etwa zur Verfügung zu stellenden Sonderfonds aus der Dotation des Chemischen Instituts in voller Höhe abgezweigt werden können. [...] Über die Notwendigkeit dieser Personalvermehrungen [Assistent und Wärter] und über die Deckung, für die der Titel Insgemein des Universitäts-Etats in Frage käme, sehe ich noch einer eingehenden Begründung entgegen. ${ }^{472}$

Obwohl Mannich in den beiden folgenden Jahren 1916 und 1917 nicht wieder durch neue Anträge hervortrat, scheint tatsächlich kaum eine Zusage des Jahres 1915 eingelöst worden zu sein. Zum einen erscheinen die neuen Mittel nicht im Staatshaushaltsplan der Jahre ab 1916 und zum anderen versuchte 1916 Windaus die Trennung von der pharmazeutischen Chemie, die ja bereits zugesagt worden war, intern und ohne Beteiligung des Kultusministeriums zu vollziehen, „da im Ministerium anscheinend wenig Neigung [bestand], die getroffenen Bestimmun-

471 Ein Protokoll ist in der Akte als Anlage an ein Schreiben vom 26.11.1915 angefügt. UAG.Kur.1499: 26.11.1915.

472 UAG.Kur.1499: 23.11.1915. Es ist die Möglichkeit in Betracht zu ziehen, dass bei Abgang des Schreibens aus dem Kultusministerium die Besprechung mit Elster noch nicht bekannt gewesen ist. Dafür spricht, dass sich in diesem Schreiben ausschließlich auf den Antrag Mannichs vom 25.6.1915 bezogen wird, dagegen spricht, dass keine weiteren Schreiben des Kultusministeriums in dieser Angelegenheit eingingen. Im Antrag vom Juni begründet Mannich tatsächlich die Notwendigkeit der Assistentenstelle nicht. Er schreibt lediglich: „Es wird um die Bewilligung eines Assistenten gebeten. Die Notwendigkeit braucht wohl kaum begründet zu werden.“ UAG.Kur.1499: 25.6.1915. 
gen von dort aus in Kraft zu setzen“. 473 Der Kurator lehnte die Umsetzung der Trennung jedoch ab. ${ }^{474}$ Die Vermutung, dass fast keine der 1915 gemachten Zusagen eingelöst wurde, bestätigt sich endgültig 1918 durch einen neuen Antrag Professor Mannichs. Er untermauerte seine Forderungen dadurch, dass er eine Abschrift des Besprechungsprotokolls von 1915 beilegte. Als 1919 immer noch keine Antwort auf diesen letzten Antrag eingegangen war, wurde Mannich sehr deutlich:

Im Anschluß bieran [Wiederholung seiner Forderungen] erlaube ich mir, erneut darauf binquweisen, daß ich mich seit 71/2 Jahren hier in einer unmöglichen Position befinde, und ich habe daher manche Kränkung erfahren müssen. Denn es ist von jeher ganz. unklar gewesen, was zur Erfüllung meines Lehrauftrages mir zur Verfügung steht. Die Vereinbarung vom 17.9.15 [Siehe oben.] ist getroffen worden, um diesem Zustande ein Ende zu machen. Da ich es aber bisher nicht habe erreichen können, daß diese Vereinbarung in Kraft gesetzt wird, so ist die Lage nach wie vor unklar. Dieser Zustand ist auf Dauer für mich unerträglich $[\ldots]^{475}$

1920 verließ er dann die Georgia Augusta, offenbar frustriert über sein Scheitern.

Obwohl nicht zu beweisen ist, dass Mannichs Scheitern direkt durch den Ersten Weltkrieg bedingt wurde, weil man nicht beurteilen kann, ob sein teilweise wenig diplomatisches Vorgehen zu Friedenszeiten mehr Erfolgsaussichten gehabt hätte, kann man doch sagen, dass seine diversen Anträge nach dem Gesamtbild der Akten dieses Zeitraums während des Krieges keinerlei Aussichten auf Erfolg hatten. ${ }^{476}$

473 UAG.Kur.5544 Bl. 323-234.

474 Die Antwort des Kurators befindet sich in Konzeptform auf der Rückseite von Windaus Antrag. UAG.Kur.5544 Bl. 324 v.

475 UAG.Kur.1499: 16.4.1919.

476 Am Rande sei erwähnt, dass Mannich noch auf andere Weise versuchte, wenigstens einen eigenen Assistenten bewilligt zu bekommen. Er bemühte sich, sich mit der Stadt Göttingen dahingehend zu einigen, dass seine Abteilung zu einer „Anstalt zur Untersuchung von Nahrungsund Genussmitteln“ erklärt werden sollte. Die Stadt war verpflichtet, Nahrungsmittel, die hier angeboten wurden, in regelmäßigen Abständen untersuchen zu lassen. Dies war jedoch seit 1906 nur noch in Braunschweig möglich. Die Stadt hätte die dadurch entstehenden Kosten einsparen können, indem sie Mannich einen Assistenten mit 1500 Mark im Jahr bezahlt hätte. Mannich hätte außerdem davon profitiert, da er so spezielle Nahrungsmittelchemiker hätte ausbilden können. Der ganze Vorgang ist in der Akte UAG.Kur.1505 enthalten. Es gelang nicht, hauptsächlich wegen Formalitäten, vor dem Krieg zu einer Einigung zu kommen. Während des Krieges ruhte dann der Vorgang vollständig und wurde 1920 mit dem Weggang Mannichs endgültig abgeschlossen. 


\section{Großprojekte}

Neben den bisher geschilderten alltäglichen Vorgängen gab es selbstverständlich auch größere Vorhaben, die einer längerfristigen Planung bedurften. Hier sind in Göttingen besonders der Erwerb eines landwirtschaftlichen Versuchsguts und der Neubau des mathematischen Instituts zu nennen. Diese Projekte umfassten beide Volumen von mehreren Hunderttausend Mark, weshalb zu ihrer Durchführung langjährige Vorbereitungen notwendig waren.

Das mathematische Institut ${ }^{477}$ selbst und auch das Lesezimmer des mathematisch-physikalischen Seminars ${ }^{478}$ stellten im gesamten Jahrzehnt keine wirklich nennenswerten Anträge auf Sondermittel. Jedoch arbeitete man hier fast zwei Jahre an der Verwirklichung eines Großprojekts, nämlich dem geplanten Neubau des mathematischen Instituts in der Bunsenstraße. Maßgeblich beteiligt an diesen Plänen war Prof. Dr. Felix Klein, der dominierende Wissenschaftsorganisator an der Georg-August-Universität, und mit ihm die Göttinger Vereinigung. ${ }^{479}$ Seit Längerem reifte in diesen Kreisen der Plan, die Bunsenstraße zu einem Zentrum der mathematisch-physikalischen Institute zu machen, mit einer besonderen räumlichen Nähe zu ihren Abteilungen für angewandte Wissenschaften. Das Herzstück dieses Zentrums sollte der Neubau des mathematischen Instituts bilden.

Ein Einschnitt in diese Bestrebungen, die gegen 1910 ihren Anfang genommen hatten, durch den Beginn des Krieges ist nicht in der gleichen Schärfe festzustellen, wie bei anderen Instituten. Trotzdem ruhte auch dieser Vorgang zumindest zwischen 1915 und 1918 weitgehend. Finanzielle Verluste musste das Projekt aber nicht hinnehmen. Der staatliche Anteil war noch kurz vor Kriegsbeginn von Felix Klein auf 408000 Mark veranschlagt worden ${ }^{480}$ und wurde in den weiteren Verhandlungen mit 300000 Mark beziffert. Diese Summe war jedoch keineswegs

\footnotetext{
UAG.XVI.V.C.c.1 Bd. 1.

UAG.XVI.V.C.b.3.

479 Bei der Göttinger Vereinigung zur Förderung der angewandten Physik, wie der Name zum Zeitpunkt ihrer Gründung 1898 offiziell lautete, handelte es sich um ein sehr effektives Werkzeug, das Felix Klein gemeinsam mit dem Industriellen Henry Theodor Böttinger, Vorstandsmitglied der Firma Bayer, ins Leben gerufen hatte, um seine Ziele des weiteren Ausbaus der Naturwissenschaften in Göttingen und der besonderen Förderung ihrer Anwendungen zu erreichen. Die Mitglieder dieser Vereinigung stellten, neben Göttinger Professoren naturwissenschaftlicher Fächer, Vertreter bedeutender Unternehmen wie der Firmen Krupp oder Siemens und Halske. Auf diese Weise gelang es, große Mengen finanzieller Mittel für die naturwissenschaftlichen Institute der Göttinger Universität zu beschaffen. Anregungen zu diesem neuartigen Weg der Wissenschaftsförderung hatte Felix Klein auf mehreren Reisen in die Vereinigten Staaten von Amerika in den 1890er Jahren gesammelt. Die Geschichte der Göttinger Vereinigung gibt unter anderem Karl Heinz Manegold sehr ausführlich wieder: Manegold: Universität. 1970. S. 157-188 und S. 221-248. 
fest zugesagt worden. Vielmehr mussten Regierung und private Investoren ${ }^{481}$ der Göttinger Vereinigung noch vertragliche Bindungen eingehen. So wollte etwa die Regierung eine verbindliche Aussage darüber, wer für mögliche Mehrkosten aufkommen würde. ${ }^{482}$ Die Gesamtsumme der staatlichen Mittel blieb während der Verhandlungen im Wesentlichen konstant und wurde am 17.1.1920 offiziell bewilligt. 483

Der wichtigste Grund dafür, dass das Projekt über die Kriegszeit gerettet werden konnte, lag mit Sicherheit in den ambitionierten Aktivitäten der beiden Vorsitzenden der Göttinger Vereinigung, Felix Klein und Henry Theodor Böttinger. Wie sich zum Beispiel aus dem Briefnachlass Kleins entnehmen lässt, liefen diese Aktivitäten fast immer auf informeller Ebene ab, so dass schließlich in den Verwaltungsakten nur scheinbar problemlos bewilligte Anträge erscheinen. Aber auch Klein und von Böttinger gelang es nicht, unter den schwierigen Verhältnissen der Kriegszeit der Umsetzung ihrer ehrgeizigen Pläne spürbar näher zu kommen. Ihr Vorhaben nahm zwar keinen dauerhaften Schaden, ruhte aber im Wesentlichen für die Dauer des Krieges. 484

Ähnlich verhielt es sich im Falle des landwirtschaftlichen Versuchsgutes. Bereits seit Beginn des Jahrhunderts bemühte sich das landwirtschaftliche Institut, und insbesondere Konrad von Seelhorst, um den Erwerb beziehungsweise die Anpachtung eines Versuchsgutes, also eines regulären landwirtschaftlichen Betriebes, in dem beispielsweise neue Züchtungen von Tieren oder Pflanzen unter alltäglichen Bedingungen untersucht werden konnten. ${ }^{485}$ Das Kultusministerium vertrat in dieser Angelegenheit den Standpunkt, dass es am zweckmäßigsten sei, die bereits bestehende landwirtschaftliche Versuchsstation in Friedland, die der Landwirtschaftskammer Hannover gehörte und von Professor Lehmann geleitet wurde, zu erweitern, ${ }^{486}$ was von Seelhorst jedoch vollständig ablehnte. Er favorisierte den Erwerb des ehemaligen Klosterguts Reinshof, das zum einen näher an Göttingen lag und zum anderen, zumindest nach von Seelhorsts Einschätzung, günstig von der Klosterkammer zu pachten war. ${ }^{487}$ Das Kultusministerium konnte er jedoch nie von diesen Vorteilen überzeugen, da das Gut Reinshof auch schwerwiegende Nachteile aufwies, wovon die Größe der wohl Wichtigste war.

481 UAG.Kur.2408: 29.6.1914. Allein Herr Krupp von Bohlen und Halbach wollte 140.000 Mark für den Erwerb des Bauplatzes geben, den Henry Theodor Böttinger zuvor mit privaten Mitteln gesichert hatte.

482 UAG.Kur.2408: 17.8.1918.

483 UAG.Kur.2408: 17.1.1920.

484 Der gesamte Vorgang ist anhand der Akte UAG.Kur.2408 gut nachzuvollziehen. Außerdem befindet sich in der Akte UAG.Sek.543.3 eine hervorragende, insgesamt 20 Seiten umfassende Zusammenfassung des Vorgangs von Universitätskurator Valentiner für das Kultusministerium vom 29.6.1925.

485 Zahlreiche Denkschriften, Anträge und Gutachten befinden sich in der Akte Kur.1656.

486 Zum Beispiel: Kur.1656 04.07.1914.

487 Zum Beispiel: Kur.1656 01.12.1913. 
Das Gut war über 400 Hektar $^{488}$ groß und zusätzlich bestand für eine Fläche von 123 Hektar, also mehr als der doppelten Größe der Friedländer Versuchsstation mit ihren 48,5 Hektar, eine Anbaupflicht für Zuckerrüben. ${ }^{489}$ Andere Angebote, wie etwa die Domäne Eddigehausen oder das Klostergut Diemarden, hatte von Seelhorst jedoch immer abgelehnt. ${ }^{490}$ Er forderte den Reinshof.

Den Ausschlag für einen neuerlichen Anlauf von Seelhorsts im September 1917 gab der Tod des bisherigen Pächters von Reinshof. Die Klosterkammer hatte zu diesem Zeitpunkt bereits einen neuen Pächter ausgewählt. Wollte von Seelhorst vermeiden, dass das Gut erneut vergeben wurde und dann endgültig nicht mehr verfügbar war, musste er schnell handeln, bevor die neuen Verträge geschlossen waren. ${ }^{491}$ Noch einmal legte er alle Argumente für sein Vorhaben in einer Eingabe an das Kultusministerium dar und erinnerte an ihm bereits gemachte Zusagen, wobei er aber auch betonte, sich der schwierigen Situation bewusst zu sein.

Die Lage der preussischen Finanzen und aus den biesigen Verbältnissen sich ergebende Rücksichten verboten mir lange Jahre die weitere energische Verfolgung meiner Wünsche auf ein Versuchsgut. ${ }^{492}$

Im Weiteren schildert er, dass er einen gut dotierten Ruf aus Berlin nur in der Aussicht abgelehnt habe, doch noch in Göttingen ein Versuchsgut zu erhalten. Die Mittel, die er wie gesagt umgehend benötigte, waren allerdings beachtlich und überschritten das Maß des zu dieser Zeit Möglichen bei Weitem.

Zur Übernahme von Reinshof würde ein Kapital von etwa $500.000 \mathrm{M}$ gebören, und zwar zirka 300.000 M zur Erwerbung des Inventars, für welches der Pächter [also dessen Erben] Kriegspreise fordert, $100.000 \mathrm{M}$ zur Instandsetzung der Gebäude für Versuchszwecke und 100.000 M als Betriebskapital. ${ }^{493}$

Von Seelhorst konnte sogar seit Oktober eine „hohe Beteiligung“"494 der Landwirtschaftskammer der Provinz Hannover in Aussicht stellen. Trotzdem wurde der Antrag schließlich am 3. Dezember 1917 vom Kultusministerium abgelehnt; offiziell aus rechtlichen Gründen, da keine Möglichkeit bestünde, in die Verpachtung an den bereits bestimmten Nachfolger einzugreifen. ${ }^{495}$ Am 31. Januar 1919 findet sich hierzu jedoch in einem anderen Schreiben des Kultusministeriums eine

488 In den Akten finden sich unterschiedliche Maßeinheiten, die hier auf die Einheit Hektar umgerechnet wurden.

489 Kur.1656 01.12.1913, 27.09.1917 und 03.12.1917. Zu dem Gut gehörten 76 so genannte Rübenaktien der Zuckerfabrik Nörten, mit denen diese Anbaupflicht verbunden war.

490 Kur.1656 27.09.1917.

491 Kur.1656 27.09.1917.

492 Kur.1656 27.09.1917.

493 Kur.1656 27.09.1917.

494 Kur.1656 05.10.1917 und 13.10.1917.

495 Kur.1656 03.12.1917. 
klare Aussage: „Den Wünschen [nach einem Versuchsgut] konnte bisher mangels bereiter Mittel leider nicht entsprochen werden." 496 An anderen Stellen waren jedoch sehr wohl große Mittel verfügbar. Seit dem Jahr 1918 bestand das Angebot des Hannoverschen Viehbandelsverbandes, insgesamt 1,5 Millionen Mark zu von Seelhorsts Projekten beizusteuern. Am 5. August 1918 bat dieser das Kultusministerium, dieses Angebot anzunehmen. Er plante, 500000 M für den Bau eines Tierzuchtinstituts und $1000000 \mathrm{M}$ für den Ankauf eines Versuchsgutes zu verwenden. ${ }^{497} \mathrm{Im}$ Ausgleich für diese Mittel hatte von Seelhorst seinem Schreiben eine sechs Punkte umfassende Liste mit „Gegenleistungen“ beigefügt. Im Wesentlichen wurden hier zukünftige Forschungsschwerpunkte garantiert, die im Interesse des Viehhandelsverbandes lagen. Die Verhandlungen über die Details einer solchen Regelung zogen sich jedoch bis zum Kriegsende hin, so dass erst im Jahr 1919 konkrete Ergebnisse erzielt werden konnten. ${ }^{498}$ Zu Kriegszeiten war offensichtlich keinerlei finanzieller Spielraum im Kultusministerium vorhanden. Aber auch dieses Großprojekt ruhte nur für die Dauer des Krieges und wurde durch ihn nicht endgültig beendet.

\section{Zusammenfassung}

Abschließend kann festgestellt werden, dass die Etatakten des Universitätskuratoriums zweifelsohne einen aussagekräftigen Indikator für die Situation der naturwissenschaftlichen Institute an der Georgia Augusta darstellen. Außerdem kann festgestellt werden, dass ihre Aussage eindeutig ist: In den hier untersuchten Instituten kam jeglicher Ausbau, jede Modernisierung oder sonstiger Fortschritt während des Krieges vollständig zum Erliegen. ${ }^{499}$ Etats, die bereits vor dem Krieg häufig als zu knapp bemessen empfunden wurden, bedeuteten durch die ausbleibende Anpassung an die enormen Preissteigerungen de facto herbe Einschränkungen im Institutsbetrieb. Die Symptome dieser Entwicklung treten von Institut zu Institut verschieden stark hervor. Bei den landwirtschaftlichen Instituten etwa werden sie besonders deutlich, da hier der Kriegsausbruch in eine Phase umfangreicher und ehrgeiziger Ausbauvorhaben fiel und diese vorerst beendet wurden. Am Beispiel des botanischen Gartens wiederum zeigen sich wie in keinem anderen Bereich der Universität die bedrohlichen Auswirkungen des sich schnell verändernden Lohn- und Preisniveaus in Deutschland. Für die physikalischen Fächer mit ihrem großen Bedarf an aktuellen und teuren Geräten oder Apparaturen kann man größtenteils nur erahnen, welchen Verlust der jahrelange Stillstand bedeutete.

496 Kur.1656 31.01.1919.

497 Kur.1656 05.08.1918.

498 Zum Beispiel: Protokoll vom 13.05.1919 Kur.1656.

499 Andrea Wettmann gelangt für die Universität Marburg zum gleichen Ergebnis. Wettmann: Heimatfront. 2000. S. 325. 
Aber die Einbußen durch den Krieg waren bei Weitem nicht nur auf rein wirtschaftlichem Gebiet zu suchen. Natürlich wirkten sie sich in besonderem Maße auch auf dem Gebiet des Personals aus. Es gab nicht nur die im ersten Teil dieser Arbeit festgestellten Schwierigkeiten, junge Wissenschaftler zur Besetzung der für die Forschung so wichtigen Assistentenstellen zu finden, da diese kriegs- oder kriegshilfsdienstpflichtig waren. Vielmehr mussten diese Assistentenstellen auch zunächst einmal finanziert werden. Assistentenstellen waren immer ein wichtiger Faktor, so etwa bei Neuberufungen oder Bleibeverhandlungen. Aber auch hier kam für die Kriegsdauer jegliche Entwicklung zum Erliegen.

Erstaunen muss angesichts der festgestellten Beeinträchtigungen vor allem ein weiterer Punkt: Es gab auffallend wenig Klagen seitens der Ordinarien. Mit Kriegsbeginn häuften sich nicht etwa abgelehnte Anträge in den Akten und schon gar nicht etwaige Beschwerden - es wurden keine Anträge mehr gestellt. Leider lässt sich nicht endgültig feststellen, ob es sich bei dieser Zurückhaltung um eine Art freiwilliges Opfer für das Vaterland handelte, oder ob nicht vielmehr Realismus und Resignation dafür verantwortlich waren, weil etwa im Vorfeld informell die Sinnlosigkeit des Unterfangens bereits geklärt worden war. Das Scheitern der wenigen Fälle, in denen trotzdem Mittel beantragt wurden, legt zunächst die letzte Möglichkeit nahe. Tatsächlich ist aber das hohe Maß an finanzieller Disziplin, die mit wenigen Ausnahmen von allen Göttinger Naturwissenschaftlern eingehalten wurde, wahrscheinlich doch Ausdruck eines als selbstverständlich erachteten und daher nicht weiter thematisierten nationalen Pflichtgefübls gewesen. Wie kaum in einem anderen Bereich der Universität wird bei den Etats und Mittelbewilligungen deutlich, welche Bedeutung dem reibungslosen Funktionieren der Institution Universität von ihren Mitgliedern beigemessen wurde. Dieses Ziel wurde mit großer Disziplin verfolgt. Gerade das unspektakuläre und signifikant sachliche Bild des hier verwendeten Aktenmaterials, welches wahrscheinlich auch für dessen bisherige Nichtbeachtung in der Forschung verantwortlich ist, zeigt dies deutlich.

Aber unbenommen dieser Frage und auch der Frage, wie stark nun das eine oder das andere Institut unter den Kriegsauswirkungen gelitten hat, kann eines definitiv festgestellt werden: Kein naturwissenschaftliches Institut der Göttinger Universität konnte in irgendeiner Form vom Krieg profitieren. Auch nicht in dem einzig nachweisbaren Fall, in dem ein Institut Zahlungen größeren Umfanges erhalten hatte. Das agrikulturchemische Laboratorium selbst war es, das feststellte, dass es durch den Krieg gelitten habe. ${ }^{500}$ Bei den eingegangenen Zahlungen des Reichsernährungsamtes handelte es sich um reine Aufwandsentschädigungen für Auftragsarbeiten, von denen man nicht über das Kriegsende hinaus profitieren konnte. Es wurden keine Anschaffungen getätigt, die auch noch nach Kriegsende zur Verfügung gestanden hätten. Es wurden keine baulichen Maßnahmen durchgeführt und keine dauerhaften zusätzlichen Stellen geschaffen.

500 Universität Göttingen: Chronik 1916-1920. S. 27. 
Trotzdem weist dieser Vorgang in eine wichtige Richtung, die es sich weiter zu verfolgen lohnt. Es war ganz offensichtlich nicht so, dass keine finanziellen Mittel für naturwissenschaftliche Forschungen mehr vorhanden waren. Lediglich das Kultusministerium als klassischer Geldgeber der Universität fiel sozusagen während des Krieges aus. Die geschilderten Großprojekte des mathematischen Instituts und des landwirtschaftlichen Versuchsfeldes mussten deshalb unterbrochen werden, obwohl der Viehhandelsverband oder die Göttinger Vereinigung auch weiterhin ihre finanziellen Zusagen aufrecht erhielten. In anderen Bereichen, wie etwa der Nahrungsmittelversorgung oder vor allem auch auf militärischem Gebiet, fanden wahrscheinlich jetzt um so größere Aktivitäten statt. Eindrucksvollstes Beispiel hierfür waren sicherlich die Forschungen Fritz Habers in Berlin auf dem Gebiet der chemischen Waffen. ${ }^{501}$ Wie bereits beschrieben, wurde von offizieller Seite versucht, kriegsrelevante Themen von der regulären Universität fern zu halten. Die wichtigsten Gründe hierfür waren die Gewährleistung der Geheimhaltung und mangelnde Kontroll- und Einflussmöglichkeiten. Kriegs- und rüstungsrelevante Forschung wurde aus den Universitäten abgezogen und in eigens dafür geschaffenen außeruniversitären Forschungseinrichtungen zusammen gefasst. ${ }^{502}$

501 Siehe hierzu: Szöllösi-Janze, Margit: Fritz Haber 1868-1934. Eine Biographie. München 1998. Martinez, Dieter: Der Gaskrieg 1914/18: Entwicklung, Herstellung und Einsatz chemischer Kampfstoffe. Das Zusammenwirken von militärischer Führung, Wissenschaft und Industrie. Bonn 1996.

502 Zum gleichen Befund gelangt Andrea Wettmann: Wettmann: Heimatfront. 2000. S. 96-97. Sie formuliert treffend, dass die „,...] Ressourcen der Universität - in diesem Fall die Studenten und das wissenschaftliche Personal - in erster Linie abgezogen, Know-how und Arbeitskraft also im Interesse der Kriegführung abgeschöpft, aber nicht an der Hochschule selbst für den kriegsrelevanten Einsatz gefördert worden sind.“ Wettmann: Heimatfront. 2000. S. 141. 


\section{Die Modellversuchsanstalt Ludwig Prandtls}

Auch in Göttingen gab es in Form von Professor Ludwig Prandtls Forschungen auf dem Gebiet der Strömungsforschung solche kriegs- und rüstungsrelevanten Forschungen. Sie werden hier dazu dienen, die Diskrepanz zwischen Sparzwang und Mittelverknappung innerhalb und der staatlichen Förderung von Forschungen außerhalb der Universität zu zeigen.

\section{Die Entwicklung bis zum Ersten Weltkrieg}

Wie im Folgenden gezeigt werden wird, stellt es wohl keine unzulässige Verkürzung dar, wenn man bei der Göttinger Modellversuchsanstalt von der Modellversuchsanstalt Ludwig Prandtls spricht, denn sie war unzweifelhaft sein Werk. ${ }^{503}$

Prandtl, am 4. Februar 1875 in Freising geboren, kam, nach einem Maschinenbaustudium an der Technischen Hochschule München und anschließender Promotion, 1900 das erste Mal mit dem noch völlig unerforschten Thema der Strömungsforschung in Kontakt, als er sich für seinen Arbeitgeber, die Maschinenbaugesellschaft Nürnberg, mit dem Absaugen von Spänen befasste. In Fachkreisen erregten seine Arbeiten einiges Interesse, und so wurde er bereits 26jährig zum Wintersemester 1901 ordentlicher Professor für Mechanik an der Technischen Hochschule Hannover. ${ }^{504}$ Wieder einmal war es Felix Klein, der so engagierte Wissenschaftsorganisator, der auf Prandtl aufmerksam wurde und ihn, wie zahlreiche andere Talente auch, nach Göttingen holte. ${ }^{505}$ Hier übernahm er die

503 Die Aerodynamische Versuchsanstalt und das Kaiser-Wilhelm-Institut für Strömungsforschung waren bereits Gegenstand verschiedener Untersuchungen. Für diese Arbeit war die detaillierte und reich bebilderte Darstellung Julius C. Rottas besonders wichtig, die allerdings weitgehend unkritisch bleibt (Rotta, Julius C.: Die Aerodynamische Versuchsanstalt in Göttingen. Ein Werk Ludwig Prandtls. Ihre Geschichte von den Anfängen bis 1925. Göttingen 1990). Differenzierter urteilt Helmuth Trischler (Trischler, Helmuth: Luft- und Raumfahrtforschung in Deutschland 1900-1970. Politische Geschichte einer Wissenschaft. Frankfurt a.M. 1992. (= Studien zur Geschichte der deutschen Großforschungseinrichtungen; 4) S. 56-69 und 89-108).

Siehe außerdem: Betz, Albert: Geschichte der Aerodynamischen Versuchsanstalt Göttingen e.V. in der Max-Planck-Gesellschaft zur Förderung der Wissenschaften in Göttingen. In: Jahrbuch der Max-Planck Gesellschaft zur Förderung der Wissenschaften e.V., Jg. 1961, S. 3-15. Tollmien, Cordula: Luftfahrtforschung. Die Aerodynamische Versuchsanstalt in Göttingen. In: Tschimer, Martina; Göbel, Heinz-Werner (Hrsg.): Wissenschaft im Krieg - Krieg in der Wissenschaft. Ein Symposium an der Philipps-Universität Marburg 50 Jahre nach Beginn des II. Weltkriegs. Marburg 1990. (=Schriftenreihe des Arbeitskreises Marburger Wissenschaftler für Friedens und Abrüstungsforschung (AMW) und der Interdiziplinären Arbeitsgruppe Friedens- und Abrüstungsforschung an der Philipps-Universität Marburg; 15) S. 51-81. Wüst, Walter: Sie zähmten den Sturm. Zur Geschichte der AVA, einem Forschungszentrum der Deutschen Forschungsanstalt für Luft- und Raumfart (DLR) in Göttingen. Göttingen 1991. Biographische Daten aus Lebenslauf Prandtls. Bl. 12-13, UAG.Kur.0609

505 Der gesamte Berufungsvorgang wird von Julius Rotta sehr detailiert dargestellt, einschließlich der Reproduktion zahlreicher Schreiben. Haupthinderungsgrund bei dieser Berufung war wohl, 
Leitung des Instituts für technische Physik, aus dem später das Institut für angewandte Mechanik entstand. Auch wenn es schien, als bedeute der Wechsel von einem Ordinariat in Hannover auf ein Extraordinariat in Göttingen zumindest für den Moment keinen Aufstieg, so war es doch mit Sicherheit diese Entscheidung, die Prandtls Karriere ihren entscheidenden Impuls gab. Damit ist weniger die Übernahme eines eigenen Instituts gemeint, als viel mehr das personelle Umfeld in Göttingen. Prandtl konnte nun von dem beeindruckenden wissenschaftsorganisatorischen Netzwerk profitieren, das um Felix Klein und Friedrich Theodor Althoff seit den 1880er Jahren gewachsen war. Über Klein, der von Prandtls Fähigkeiten überzeugt war, kam dieser mit Henry Theodor von Böttinger und der Göttinger Vereinigung in Kontakt. Diese neue Verbindung sollte bereits 1907 Früchte tragen.

Ein Jahr zuvor war in Berlin unter maßgeblichem Einfluss Althoffs die Motorluftschiff-Studiengesellschaft gegründet worden, die sich mit der Förderung der immer populärer werdenden Luftfahrt und besonders mit der Erforschung ihrer wissenschaftlichen Grundlagen befasste. Gründungsmitglieder und Kapitalgeber waren vor allem Industrielle, die Interesse am Luftschiffbau hatten, aber auch Althoff und von Böttinger. Innerhalb der Motorluftschiff-Studiengesellschaft wurde ein technischer Ausschuss gebildet, der wiederum über Untergruppen verfügte. Offensichtlich durch geschickte Personalpolitik gelang es der Göttinger Vereinigung und Felix Klein, sich maßgeblichen Einfluss in der so genannten Dynamischen Gruppe zu sichern. „Von den 18 Mitgliedern dieser Gruppe gehörten außer Klein noch die Professoren Lexis, von Linde, Prandtl, Schilling und Wiechert der G[öttinger] V[ereinigung] an. Letztere waren auf Veranlassung Kleins in die Gruppe aufgenommen worden." 506 Damit war ein gutes Stück des Weges für Prandtls ersten Strömungs- bzw. Windkanal, der die Grundlage seiner zukünftigen Arbeiten bilden sollte, bereits bereitet.

Noch im Jahr 1906, also bereits im Gründungsjahr der MotorluftschiffStudiengesellschaft, reichte Felix Klein einen Antrag Prandtls und Emil Wiecherts ein. Neben seiner Erfahrung auf dem Gebiet von Messinstrumenten hat sich Wiecherts Rolle wahrscheinlich darauf beschränkt, möglichen Einwänden dagegen vorzubeugen, dass man ein solches Projekt einem noch nicht 30jährigen Wissenschaftler wie Prandtl anvertraute.

Anbei bringe ich Ibnen eine Denkschrift in Sachen der Motorluftschiff-Frage zur Kenntnis, welche die Herren Prandtl und Wiechert auf meinen Wunsch angefertigt haben, wobei ich gleichzeitig binzufüge, was die Herren aus Bescheidenheit zu fragen unterlassen

dass Ludwig Prandtl in Hannover bereits über eine ordentliche Professur verfügte, Göttingen ihm aber vorerst nur eine außerordentliche bieten konnte, was nicht zuletzt auch finanzielle Einbußen bedeutete. Schließlich überwog die Tatsache, dass er in Göttingen die Leitung eines eigenen Instituts übernehmen konnte. Rotta: Die Aerodynamische Versuchsanstalt. 1990. S. 917.

506 Rotta: Die Aerodynamische Versuchsanstalt. 1990. S. 25 
haben: daß Prof. Prandtl nicht nur bereit sein würde, die Einrichtung der geplanten Versuchsstation zu leiten, sondern auch später selbst die Direktion zu übernehmen, Prof. Wiechert aber in der Lage sein würde, ibm dabei beratend zu Seite zu stehen. ${ }^{507}$

Die in dieser Denkschrift enthaltenen Pläne waren bereits bemerkenswert detailliert, einschließlich erster Skizzen und einem Kostenvoranschlag sowohl für den Bau der Anlage als auch für die jährlichen Betriebskosten. Für die Errichtung veranschlagte Prandtl einmalig 32600 Mark, davon 8000 Mark für die benötigten Maschinen und 6600 Mark für Modelle und Messinstrumente. Der Jahresetat wurde mit insgesamt 5800 Mark veranschlagt, worin bereits das Gehalt eines wissenschaftlichen Mitarbeiters und eines Mechanikers enthalten waren. ${ }^{508}$ Als mögliche Aufgaben wurden zunächst nur Messungen an Luftschiffen und Ballonen genannt. Die später so wichtigen Tragflügel wurden noch nicht erwähnt. ${ }^{509}$

Die Motorluftschiff-Studiengesellschaft versandte daraufhin Stimmzettel folgenden Inhalts an ihre Mitglieder:

Stimmzettel

Zu dem Antrag auf Bewilligung einer einmaligen Summe von 20.000 M für den Bau, und eines jährlichen Zuschusses von 7000 M vorläufig auf 3 Jahre für die Unterhaltung einer Modellversuchsanstalt nach den Vorschlägen des Professors Prandtl zu Göttingen, beziehungsweise einer von der Höhe des vom Kultusministerium zu erwartenden $\mathrm{Zu}$ schusses abbängigen, entsprechend geringeren Summe stimme ich mit

Name:

(Das Nichtgewünschte bitte durchzustreichen). 510

Bei der Betrachtung des Wortlauts des Stimmzettels fällt auf, dass die Mitglieder der Motorluftschiff-Studiengesellschaft fest mit einer Beteiligung des Kultusministeriums rechneten. Genau dieser Sachverhalt war aber zugleich der Grund für die einzige Gegenstimme im Rahmen der Befragung. Überraschenderweise stammte diese Gegenstimme ausgerechnet von Friedrich Althoff, einem der wichtigsten Fürsprecher Prandtls. Allerdings hegte er nicht etwa generelle Bedenken gegen das

507 DLR.GOAR.2661 Antrag an die dynamische Gruppe des Technischen Ausschusses der Motorluftschiff-Studiengesellschaff vom 27.12.1906. Anschreiben Kleins, Bl. 1.

508 DLR.GOAR.2661 Antrag an die dynamische Gruppe des Technischen Ausschusses der Motorluftschiff-Studiengesellschaff vom 27.12.1906. Anlage II, Bl. 5.

509 DLR.GOAR.2661 Antrag an die dynamische Gruppe des Technischen Ausschusses der Motorluftschiff-Studiengesellschaff vom 27.12.1906. Anlage I, Bl. 1-2.

510 DLR.GOAR.2661 Anlage zum Schreiben der Motorluftschiff-Studiengesellschaft vom 11.11.1907. 
Projekt. Er befürchtete vielmehr, dass die erhoffte deutliche Beteiligung des Kultusministeriums nicht mehr durchsetzbar sein würde, wenn man bereits im Vorfeld alle notwendigen Mittel bereitstellte. Man erkannte Althoffs Sorge zwar an, wollte aber offensichtlich nicht mehr länger warten und verband die Erteilung der Bewilligung deshalb mit einer Bitte:

\section{Dagegen hat sich nur Exc. Althoff erklärt, weil er meint, dass wir nun wenig oder nichts vom Kultusministerium ${ }^{511}$ bekommen. Ich möchte Sie daher bitten, falls Sie in irgend eine Berührung mit dem Kultusministerium in dieser Angelegenheit kommen, recht zu betonen, dass die Gesellschaft mit Sicherheit auf die Übernahme der Hälfte der Kosten durch das K.M. rechnet, und nur in dieser sicheren Voraussicht das nötige Geld jetrt bewilligt hat. ${ }^{512}$}

Inwieweit Prandtl der Bitte der Motorluftschiff-Studiengesellschaft nachgekommen ist, bleibt Spekulation. Tatsächlich jedoch behielt Althoff Recht, denn das Kultusministerium zahlte keinen Bauzuschuss. ${ }^{513}$ Bereits bevor alle Stimmen eingegangen waren, wurde am 11. November 1907 Ludwig Prandtl die vorläufige Bewilligung der Mittel erteilt. „Die Bewilligung ist hiermit ausgesprochen. [...] Ich denke mir, das Sie je nach Bedarf Geld bei mir bestellen, was ich Ihnen in Cheks zusenden würde. “514

Prandtl begann sogleich mit den ersten Vorarbeiten, und 1908 wurde die Modellversuchsanstalt gebaut. Hierbei handelte es sich um einen äußerst bemerkenswerten Vorgang, der auch die spätere Bedeutung von Prandtls Einrichtung erklärt. Man konnte 1907/08 erst auf wenige Erkenntnisse zum Bau solcher Anlagen zurückgreifen. Vielmehr war die Modellversuchsanstalt selbst eine Art Versuch. Die Idee, Luft an einem fixierten Modell vorbeiströmen zu lassen, existierte zwar bereits, nicht jedoch in der Form, in der Prandtl seine Anlage plante. 515

511 An dieser Stelle des Schreibens der Motorluftschiff-Studiengesellschaft ist noch ein im Hinblick auf die spätere Entwicklung hochinteressantes Detail zu erwähnen: Das Wort „Kultusministerium“ lautete ursprünglich „Kriegsministerium“ und ist erst nachträglich mit Tinte geändert worden. Selbstverständlich kann es sich hierbei auch nur um einen Zufall handeln, allerdings scheint der Gedanke, die Militärbehörden für Prandtls Arbeiten zu interessieren, auch bereits 1907 nicht ganz undenkbar gewesen zu sein.

512 DLR.GOAR.2661 Schreiben der Motorluftschiff-Studiengesellschaft vom 11.11.1907.

513 Rotta: Die Aerodynamische Versuchsanstalt. 1990. S. 43

514 DLR.GOAR.2661 Schreiben der Motorluftschiff-Studiengesellschaft vom 11.11.1907.

515 Noch heute ist der Begriff „Göttinger Bauart“ für Windkanäle dieser Art verbreitet. Trischler: Luft- und Raumfahrtforschung. 1992. S. 61. 
Prandtl gelang es von Beginn an, wichtige Untersuchungsergebnisse zu sammeln. Er erhielt 1909 den ersten Lehrauftrag für „wissenschaftliche Aeronautik“.516 Göttingen stand somit durch Prandtls Können und Kleins, Althoffs und von Böttingers Umtriebigkeit an der Spitze einer ganz neuen Entwicklung.

Die nächste wichtige Veränderung trat dann 1912/13 ein. Die MotorluftschiffStudiengesellschaft hatte satzungsgemäß ihr Kapital aufgebraucht und sollte nun aufgelöst werden. Gerne hätte man die Modellversuchsanstalt, die ja durch die personelle und thematische Nähe beziehungsweise Kongruenz mit Prandtls Institut für angewandte Mechanik eng verbunden war, der Göttinger Vereinigung geschenkt. Dies war jedoch aufgrund des Rechtsstatus der Vereinigung als Verein nicht möglich und wurde von dieser auch nicht gewollt, da man seine Aufgabe nur in der Förderung sah und keine eigenen Einrichtungen unterhalten wollte. Also einigte man sich mit dem Kultusministerium und der Universität im Dezember 1912.

Euer Hochwohlgeboren beehre ich mich bierdurch ergebenst zu berichten, daß die Motorluftschiff-Studiengesellschaft m.b.H. [...] der Göttinger Vereinigung für angewandte Physik und Mechanik. das Anerbieten gemacht hat, ihr die in ibrem Besitz befindliche ,Göttinger Modellversuchsanstalt für Luftfahrt' zu übergeben, unter der Bedingung, daß auf jede weitere Zablung seitens der Motorluftschiff-Studiengesellschaft, die vor einiger Zeit in Liquidation getreten ist, verzichtet wird. Die Göttinger Vereinigung hat den Antrag der MotorluftschiffStudiengesellschaft angenommen und es ist dadurch, weil nach bisheriger Gepflo-

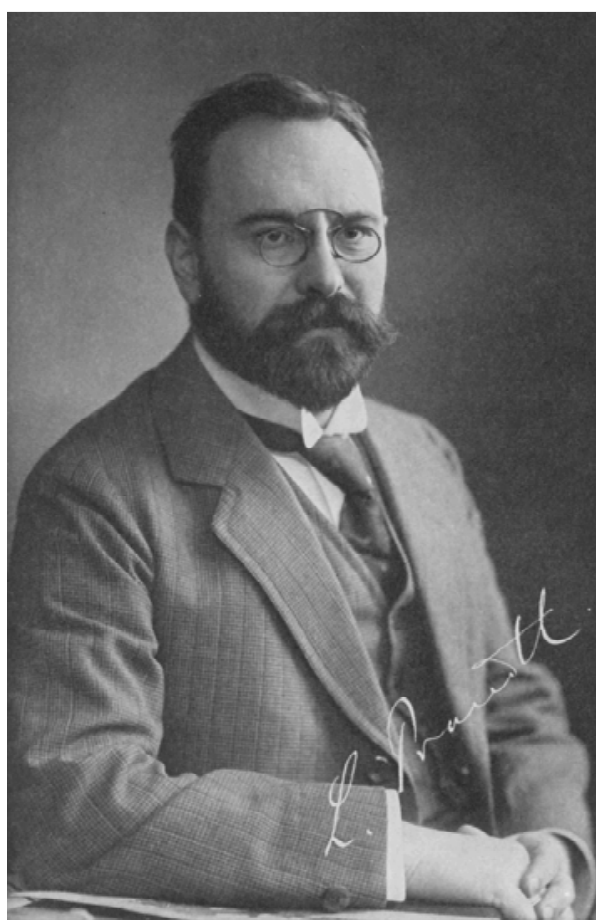

Abbildung 8: Ludwig Prandtl genheit alle von der Göttinger Vereinigung erworbenen Unterrichts- und Forschungseinrichtungen unmittelbar in den Besitz der Unterrichtsverwaltung übergehen, die Modellversuchsanstalt Eigentum des Staates geworden ist. [sic!] [...] 
Ich bitte Euer Hochwoblgeboren beim Herrn Minister die Freigabe dieser Summe [7.200 Mark. Als Anlage ist eine genaue Aufstellung der Kosten beigefiugt.] für die Bezablung der laufenden Ausgaben der Modellversuchsanstalt erwirken zu wollen. 517

Mit der Zustimmung des Ministeriums, die im Februar 1913 erfolgte, verfügte die Georgia Augusta dann über eine Modellversuchsanstalt der Universität Göttingen. 518

Aber bereits zu diesem Zeitpunkt genügte die erste Modellversuchsanstalt Ludwig Prandtls Ansprüchen nicht mehr. Sie hatte ihren Zweck dahingehend erfüllt, dass er nun genug Erfahrungen gesammelt hatte, um einen Windkanal planen zu können, der seinen Forschungen den benötigten Raum gewähren würde. Als möglichen Geldgeber fassten Klein und Prandtl schon sehr früh die 1911 gegründete Kaiser-Wilhelm-Gesellschaft ins Auge.519 Schon vom 16. Februar 1911 datiert das Anschreiben Prandtls, mit dem er der Kaiser-WilhelmGesellschaft seine erste Denkschrift übersandte. ${ }^{520}$ Diese „Denkschrift für die Errichtung eines Forschungsinstituts für Aerodynamik und Hydrodynamik in Göttingen "521 umfasst insgesamt sieben maschinenschriftliche Seiten, in denen Prandtl die möglichen Aufgaben eines solchen Instituts sowie die dafür seines Erachtens nach notwendigen Mittel umreißt. Es wird darin deutlich, dass sein Interesse sich nun völlig von den „Luftschiffen“ abgewandt hatte, die ja zu dieser Zeit auch in der praktischen Luftfahrt immer mehr an Bedeutung gegenüber den Motorflugzeugen einbüßten. Entsprechend dieser Entwicklung wollte sich auch Prandtl auf die so genannte „dynamische Luftfahrt" konzentrieren und sich mehr mit generellen Theorien der Strömungsforschung beschäftigen. Als mögliche Aufgabengebiete schlug er daher in seiner Denkschrift folgende fünf Punkte vor:

1. Luftwiderstandsuntersucbungen aller Art.

2. Studien über das Strömen von W asser und Luft in Kanälen.

3. Untersuchung der Wirkung von Schraubenpropellern und von Schaufelrädern der Gebläse.

\section{Ausarbeitung von geeigneten Meßinstrumenten für strömende Luft und Durchfübrung von Präzisionseichungen dieser Instrumente.}

\section{Studium der Bewegung des natürlichen Windes und seines Einflusses auf den Luftwi- derstand. ${ }^{522}$}

Bei näherer Betrachtung von Prandtls Schreiben fällt auf, wie wichtig es ihm und wohl vor allem Felix Klein und von Böttinger war, sicherzustellen, dass das neue

517 Schreiben Prandtls an den Kurator der Universität. UAG.Kur.7464 08.12.1912.

518 UAG.Kur.7464 10.02.1913.

519 Rotta: Die Aerodynamische Versuchsanstalt. 1990. S. 96 ff.

520 Hierzu besonders relevant: DLR.GOAR.2632-2633.

521 DLR.GOAR.2632 17.02.1911

522 DLR.GOAR.2632 17.02.1911 Bl. 2 der Denkschrift. 
Institut in Göttingen errichtet wurde. Die Sorgfalt, die er auf die Formulierung seiner Argumente für den Standort Göttingen verwandte, lässt darauf schließen, dass es durchaus nicht selbstverständlich gewesen sein muss, dass das neue Forschungsinstitut dort errichtet wurde. „Es liegt so auf dem in Rede stehenden Gebiete hier bereits eine Summe von Erfahrungen und Tradition vor, wie es wohl zur Zeit sonst nirgends in Deutschland der Fall ist. " ${ }^{\text {"523 }}$ Außerdem argumentierte er, dass gerade der enge Kontakt zu den mathematischen Instituten besonders wichtig sei:

Hinzu tritt noch der Umstand, daß bei den Fragestellungen der Aerodynamik und Hydrodynamik der mathematischen Behandlung ein wichtiger und wesentlicher Anteil zukommt, und zwar ist es vielfach höhere und höchste Mathematik. Es wird also von größtem Nutzen sein, wenn die Beamten des Forschungsinstituts mit der Mathematik rege Fühlung halten bezw. soweit nötig, durch Hören von mathematischen Vorlesungen ibre mathematischen Kenntnisse auf den erforderlichen bohen Stand bringen können. Für solche Aufgaben ist aber Göttingen als die Mathematiker-Universität par excellence hervorragend geeignet. 524

Diese Argumente veranlassen Prandtl zu folgendem Schluss: „Fasst man alles zusammen, so kann man wohl sagen, dass ein solches Forschungsinstitut, wenn überhaupt irgendwo, dann sicher in Göttingen gelingen muss. ${ }^{525}$

Der Umfang der in der Denkschrift beantragten Mittel war ausgesprochen bemerkenswert. Die von Prandtl kalkulierten Baukosten betrugen mehr als das Elffache der Mittel, die er 1906 für die erste Modellversuchsanstalt beantragt hatte: 360000 Mark. Verglichen mit den Maßstäben der Universität wäre dies das Fünffache der gesamten Baumittel, die im preußischen Staatshaushaltsplan für die Universität Göttingen im Jahr 1911 veranschlagt waren oder fast die Hälfte der Mittel, die allen preußischen Universitäten gemeinsam zur Verfügung standen. 526 Der Kostenvoranschlag für den benötigten Jahresetat liest sich dann ähnlich beeindruckend. Allein der Punkt „Kosten für elektrische Kraft“ etwa entspricht annähernd drei Vierteln des Gesamtetats der physikalischen Institute der Georgia Augusta.

Die Denkschrift reichte von Böttinger im Namen der Göttinger Vereinigung bei der Kaiser-Wilhelm-Gesellschaft ein, jedoch nur mit beschränktem Erfolg. Offensichtlich überstiegen die Dimensionen des Beantragten dann doch das, was die Kaiser-Wilhelm-Gesellschaft so kurz nach ihrer Gründung zu leisten im Stande war, nicht zuletzt, da zeitgleich auch verschiedene andere Großprojekte in

523 DLR.GOAR.2632 17.02.1911 Bl. 4der Denkschrift.

524 DLR.GOAR.2632 17.02.1911 Bl. 4 der Denkschrift.

525 DLR.GOAR.2632 17.02.1911 Bl. 4-5 der Denkschrift.

526 Staatshaushaltsplan [Preußen]: für das Rechnungsjahr 1911. Berlin 1911. 
Angriff genommen werden sollten. ${ }^{527}$ In der damaligen Situation war es schon als Erfolg zu werten, dass zumindest ein völliges Einschlafen des Projekts verhindert werden konnte.

Über ein Jahr nachdem Prandtl die erste Denkschrift eingereicht hatte, kam wieder Bewegung in die scheinbar festgefahrene Situation, als Theodor von Böttinger Prandtl in das Berliner Hotel Adlon zu einer vertraulichen Besprechung bat:

\section{Nun findet am Montag Nachmittag eine Sitžng des Vervaltungsausscbusses der Kai- ser-Wilhelm-Gesellschaft, bei welcher ich bin, statt und muss ich unbedingt [sic!] vorher die ganze Angelegenheit mit Ibnen durchsprechen, um noch weiteres Material in den Händen zu haben. [...] Ich schicke Ihnen den mir zwar streng vertraulich zugegangenen Schriftsatz, damit Sie ibn vorher lesen können, aber mit der Bitte, ibn ebenfalls absolut vertraulich zu behandeln. Bringen Sie mir denselben aber ja mit nach Berlin, denn ich muss ibn unbedingt Sonntag dort baben, weil ich noch eine Vorbesprechung mit den Herren im Ministerium vor der Montags-Sitzung herbeiführen möchte. 528}

Man erhält einen guten Einblick in die Art der diplomatischen Arbeit von Böttingers, mit der er immer wieder das Göttinger Projekt in Berlin vorantrieb. Schließlich, wieder ein halbes Jahr später im November 1912, legte Prandtl auf Aufforderung der Kaiser-Wilhelm-Gesellschaft einen zweiten und diesmal detaillierteren Bericht über seine Pläne vor. Ludwig Prandtl hatte sein Projekt erneut überarbeitet, war aber in der Substanz nicht deutlich von der ersten Denkschrift abgewichen. Es gelang ihm, die Baukosten zu reduzieren - von 360000 auf 325000 Mark - und die laufenden Kosten ebenfalls von 57000 auf 52000 Mark jährlich zu senken. Wichtigster Unterschied zu seinen Ausführungen des Vorjahres war aber, dass er vorsorglich gleich mögliche Einsparmöglichkeiten anbot. So war er, um das Projekt nicht zu gefährden, dazu bereit, auf die Bereiche „HochdruckHydraulik“ und „Gasdynamik“" zu verzichten, was die Bausumme nochmals auf 273000 und den benötigten Jahresetat auf 36000 Mark reduziert hätte. Außerdem lagen dem neuen Vorschlag bereits detaillierte Zeichnungen bei. ${ }^{529}$

So verändert waren Prandtls Ideen schon deutlich mehrheitsfähiger geworden, aber es bedurfte eines weiteren halben Jahres zäher Verhandlungen ${ }^{530}$ von Böttingers bis eine Entscheidung zu Stande kam. Die Kaiser-Wilhelm-Gesellschaft

527 Julius Rotta beschreibt die Verhandlungen und Vorgänge des folgenden Jahres sehr ausführlich. Zusätzlich zu den hohen Kosten kam erschwerend hinzu, dass die Verantwortlichen der KaiserWilhelm-Gesellschaft eine Kollision zwischen den Göttinger Plänen und der gerade in Berlin mit großem Aufwand ins Leben gerufenen „Deutschen Versuchsanstalt e.V.“ befürchteten. Von Böttinger, der mittlerweile auch in den Senat der Kaiser-Wilhelm-Gesellschaft als zweiter Schatzmeister berufen worden war, arbeitete jedoch hart daran, Prandtls Pläne immer wieder von Neuem auf den Tagesordnungen zu platzieren. Siehe hierzu Rotta: Die Aerodynamische Versuchsanstalt. 1990. S. $100 \mathrm{ff}$. 
konnte sich nicht entschließen, die erforderlichen Mittel alleine aufzubringen, was angesichts der personellen, fachlichen und nicht zuletzt räumlichen Nähe zur Universität auch nachvollziehbar ist. Schließlich einigte man sich darauf, dass die Baukosten, die man mit 300000 Mark veranschlagte, zu gleichen Teilen vom Kultusministerium und der Kaiser-Wilhelm-Gesellschaft getragen werden sollten und dass sich die Göttinger Vereinigung an den laufenden Kosten mit 6000 Mark pro Jahr beteiligen sollte. Das Grundstück, das von Böttinger bereits privat gekauft hatte, um es für die Zeit der Verhandlungen zu sichern, sollte dieser unentgeltlich zur Verfügung stellen.

Endlich, über zwei Jahre nach dem Verfassen der ersten Denkschrift, erhielt Prandtl am 18. Juni 1913 ein Telegramm von Böttingers mit den Worten: „hurra senat einstimmig gestern angenommen hocherfreut und grüsse böttinger". ${ }^{531}$ Allerdings erfolgte diese Annahme vorbehaltlich der Bereitstellung des staatlichen Anteils, weshalb auch die Presse noch nicht informiert werden sollte. 532

Auch wenn die finanziellen Maßstäbe andere sind, so ist doch der Vorgang als solcher durchaus mit anderen ambitionierten Göttinger Projekten dieser Zeit zu vergleichen, wie etwa mit dem Ausbau der landwirtschaftlichen Institute oder noch am ehesten mit dem erwähnten Neubau des mathematischen Instituts, an dem auch die Göttinger Vereinigung beteiligt war. Auch ein anderes Charakteristikum haben die Pläne zum Bau der neuen Modellversuchsanstalt mit anderen Vorhaben gemeinsam: Die Gewährung der staatlichen Mittel zögerte sich noch etwas hinaus und kollidierte dann im August 1914 mit dem Ausbruch des Ersten Weltkrieges. Wie auch im Falle des Neubaus des mathematischen Instituts bedeutete dies vorerst das Aus für dieses Projekt. ${ }^{533}$

\section{Neue Möglichkeiten durch den Krieg}

An diesem Punkt begann sich die geplante Gründung der Modellversuchsanstalt signifikant von den vorher beschriebenen Vorgängen an anderen Instituten zu unterscheiden. Ob die Idee von Ludwig Prandtl selbst, von Felix Klein oder von Theodor von Böttinger stammte und ob sie nicht vielleicht schon viel früher ins Spiel gebracht worden war, lässt sich leider nicht mehr nachvollziehen: Im Gegensatz zu den Arbeiten im mathematischen Institut waren Prandtls Forschungen direkt rüstungsrelevant, wie noch im Jahr 1914 erste militärische Aufträge gezeigt hatten. ${ }^{534}$ Schnell erkannte man die neue Situation, die auch in den anderen Instituten der Universität eintrat: Vom Kultusministerium konnte kein Geld mehr erwartet werden. Dafür boten sich nun aber neue Wege, vorausgesetzt man konnte im Gegenzug etwas anbieten. Im Frühjahr 1915 vereinbarten Felix Klein und

531 DLR.GOAR.2632 Telegramm von Böttingers 18.06.1913.

532 DLR.GOAR.2632 Brief von Böttingers 18.06.1913.

533 Siehe hierzu Rotta: Die Aerodynamische Versuchsanstalt. 1990. S. 114.

534 Rotta: Die Aerodynamische Versuchsanstalt. 1990. S. 117-120. 
Theodor von Böttinger, mit den Militärbehörden in solcher Weise in Kontakt zu treten, dass von Böttinger davon sprach, die Angelegenheit „von der Seite zu betreiben, “ ${ }^{535}$ womit zunächst eine informelle Ebene der Verhandlungen gemeint war. Ziel war es, die bisherige Planung beizubehalten und nur den staatlichen Zuschuss von anderer Stelle zu erhalten. Offensichtlich verliefen diese ersten Kontaktaufnahmen recht vielversprechend, so dass die Pläne schnell konkreter wurden:

Bezüglich der Durchfübrung des Kaiser-Wilhelm-Instituts für Göttingen scbließe ich mich Ibren Vorschlägen an, daß wir jetżt den günstigen Moment ergreifen und versuchen sollen, im Kriegsministerium und Reichsmarineamt vorwärts zu kommen, unter Beiseitelassung des Finanzministeriums. Ich glaube, daß wir sogar in Kreisen der K.W.G. noch bessere Stimmung finden und die Herren ibren früberen Beschluß umso leichter aufrecht erbalten werden. 536

Ganz im Gegensatz zu den zähen und langwierigen Verhandlungen mit der Kaiser-Wilhelm-Gesellschaft und, nach deren Zustimmung, mit dem Kultusministerium, lief die weitere Entwicklung erstaunlich reibungslos ab. Vom 26. April 1915 datiert eine neue Denkschrift Prandtls mit dem Titel: „Ausbau der Göttinger Modellversuchsanstalt zu einem vollwertigen aerodynamischen Forschungsinstitut für Heer und Marine. ${ }^{\text {“537 }}$ Er beschreibt in dieser zunächst den augenblicklichen Zustand der alten Modellversuchsanstalt. „Die Anstalt hat mit sehr beschränkten Mitteln (rd. 20.000 M Bausumme) in der billigsten Bauweise errichtet werden müssen und trägt in vielen Punkten den Stempel des Provisoriums an sich. "“538 Für den Fall, dass diese Schilderungen die Notwendigkeit eines Neubaus noch nicht überzeugend genug vertraten, setzte Prandtl im Folgenden auf einen Vergleich mit mittlerweile überlegenen französischen Einrichtungen.

Ein besonderer Mangel der Anstalt ist ibre geringe Luftgeschwindigkeit von 91/2 $\mathrm{m} / \mathrm{sec}$; neuere Versuche in der Eiffelschen Versuchsanstalt in Paris haben gezeigt, wie wichtig es ist, die bei den Flugzengen wirklich erreichten Gescbwindigkeiten von $30 \mathrm{~m} /$ sek. und mehr auch beim Modellversuch einhalten ₹u können. 539

Im Weiteren versichert Prandtl dann, diesen von ihm beschriebenen Rückstand wettmachen zu können.

Es erscheint somit als ein sebr erstrebenswertes Ziel, eine neue grosse Modellversuchsanstalt zu schaffen, die alle inzwischen als notwendig erkannten Verbesserungen in sich vereinigt. Der Unterzeichnete, der sich bereits seit längerem sehr eingehend mit solchen Neubauplänen befasst hat, glaubt zusagen zu können, dass er eine Anlage zu schaffen

535 Böttinger an Klein vom 07.02.1915 SUB.Gött.HSD.Cod.Ms.F.Klein.III.I 58-61.

536 Böttinger an Klein vom 29.03.1915 SUB.Gött.HSD.Cod.Ms.F.Klein.III.I 58-61.

537 DLR.GOAR.2633 26.04.1915. Bl. 1 der Denkschrift.

538 DLR.GOAR.2633 26.04.1915. Bl. 1 der Denkschrift.

539 DLR.GOAR.2633 26.04.1915. Bl. 1-2 der Denkschrift. 
imstande ist, die sowohl an Zuverlässigkeit der Einrichtungen, an Stärke des Luftstroms, sowie an Genanigkeit der Messungen die bisherigen Anlagen um ein Gutes übertreffen wird. ${ }^{540}$

Prandtl skizziert dann kurz die 1913 gefundene Regelung der Lastenverteilung, die dann am Ausbleiben des staatlichen Anteils durch den Rückzug des Kultusministeriums gescheitert war. Selbstverständlich betont er nochmals, dass man schon jetzt für die militärische Luftfahrt arbeite und dass es im Interesse der Militärbehörden notwendig sei, dass dies in Zukunft noch besser geschehen könne. ${ }^{541}$

Wenn man sich nun nochmals das 1911/12 beantragte Volumen vor Augen hält, wird deutlich, wie sicher Ludwig Prandtl sich bereits in Bezug auf das militärische Interesse an seiner Arbeit gewesen sein muss. Er versicherte, dass die Kaiser-Wilhelm-Gesellschaft auch weiter an den von ihr zugesagten Beiträgen festhalten würde, verschweigt aber nicht nur die Einsparmöglichkeiten, die er schon einmal einreichen musste, sondern geht in seinen Forderungen noch über die Beträge der ersten Denkschrift hinaus.

Bei der Abschätzung der hierbei auf die Heeres- und Marineverwaltung entfallenden Beträge wäre allerdings zu beachten, dass die Modellversuchsanstalt, um allen Ansprüchen zu genügen, wohl noch etwas grösser gebaut werden müsste, als in dem im Jahre 1912 aufgestellten Kostenanschlag vorgesehen war [... . ${ }^{542}$

Er begründet dies mit der Notwendigkeit eines Überschallkanals zur Erforschung von Geschosswiderständen. Außer diesem Gebiet der Ballistik gibt er den Flugzeugbau, das heißt die Erforschung von Tragflächenformen, den Luftschiffbau, die Untersuchung von Luftschraubenmodellen, den Luftschiffhallenbau und die Navigation in der Luft sowie den Bombenabwurf als mögliche Forschungsgebiete an. ${ }^{543}$

Trotz all dieser Versprechungen versuchte Prandtl deutlich zu machen, dass er eine Forschungseinrichtung für Heer und Marine bauen wollte, aber keine reine Heereseinrichtung.

Neben diesem kriegstechnischen Programm besteht ein gleich reichhaltiges rein wissenschaftliches Programm, das der Entwicklung der tieferen Einsicht in die aerodynamischen Vorgänge gewidmet sein wird, dessen Ergebnisse daher mittelbar auch der Kriegstechnik. wieder zugute kommen werden. ${ }^{544}$

Offensichtlich schon mit der Befürchtung einer zu starken Vereinnahmung durch das Militär nennt Prandtl den nächsten Abschnitt seiner Denkschrift „Gesichtspunkte für die Verteilung der Lasten und der Rechte“. ${ }^{545}$ Darin macht er deutlich, 
dass er an eine gleichmäßige Verteilung dieser Lasten und Rechte zwischen reiner Wissenschaft und Rüstungsforschung dachte.

Die Einrichtungen des Instituts sollen jährlich, bis insgesamt zu einem halben Jahre für Versuche im Interesse der Heeresverwaltung und der Marineverwaltung zur Verfügung stehen; die übrige Zeit sollen sie der wissenschaftlichen Forschung dienstbar sein. [...]

Die Kaiser-Wilhelm-Gesellschaft pflegt den von ihr gegründeten Forschungsinstituten ein Kuratorium und einen wissenschaftlichen Beirat an die Seite zu stellen; in beiden Körperschaften würden die Militär- und Marinebehörden eine entsprechende Vertretung erhalten. ${ }^{546}$

Wohl wegen seiner schlechten Erfahrungen mit der Deutschen Versuchsanstalt in Berlin versäumte es Prandtl diesmal nicht, eine ausdrückliche Abgrenzung gegenüber bereits bestehenden Forschungseinrichtungen zum Abschluss seines Textes zu machen.

Nun erfuhr dieser Vorgang eine ebenso unerwartete wie hilfreiche Unterstützung. Für die Übergabe an die entsprechenden Berliner Stellen war der Werftbesitzer Oertz vorgesehen, der zu diesem Zweck drei Exemplare der Denkschrift erhielt. Zufällig war genau an diesem Tag Prinz Heinrich von Preußen, der jüngere Bruder des Kaisers, bei Oertz. Prinz Heinrich war schon seit Jahren ein engagierter Förderer der Fliegerei in Deutschland, der immer wieder im Rahmen der Nationalflugspende oder als Schirmherr oder Veranstalter von Wettflügen in Erscheinung trat. Außerdem war er selbst Inhaber eines der ersten deutschen Flugscheine. Oertz zeigte die Denkschrift Prandtls dem Prinzen, der daraufhin kurzerhand die weitere Verteilung übernahm.

$V$ on der Bedeutung des Inhalts der Schriften, sowie von der Notwendigkeit der Vergrösserung und Unterstützung der Göttinger Anstalt überzengt, habe ich mich sofort bereit erklärt das Weitere, soweit es in meinen Kräften steht, zu veranlassen und habe ich dementsprechend umgehend je zwei Exemplare an den Kriegsminister, sowie an Admiral von Dick vom R.M.A. [Reichsmarineamt] mit einem kurzen Geleitschreiben übersandt, in welchem ich versucht habe in Kürze darzulegen, welche Wechselwirkung zwischen dem Göttinger Institut und den Erbauern von Flugzengen bestünde, unter dem besonderen Hinweis darauf, dass wir aus dem Stadium der Empirik nunmehr tatsächlich herausgetreten seien und dass die Wissenschaft den Bau von Flugfahrzengen in erster Linie unterstütze und durch wissenschaftliche Untersuchungen, sowie Feststellung von Tatsachen wesentlich fördere. ${ }^{547}$

Am 5. Mai dankte Prandtl Prinz Heinrich und nannte diesen Zufall „ein gutes Omen,"548 womit er auch offensichtlich Recht hatte.

\footnotetext{
546 DLR.GOAR.2633 26.04.1915. Bl. 9 der Denkschrift.

547 DLR.GOAR.2633 30.04.1915.

548 DLR.GOAR.2633 05.05.1915.
} 
Bereits am 8. Mai 1915 wurde Prandtl per Telegramm ${ }^{549}$ aufgefordert, sich im Kriegsministerium einzufinden. Scheinbar zweifelte er zu diesem Zeitpunkt nicht mehr an der Umsetzung seiner Pläne. Ein erhaltener Notizzettel, den er sich offensichtlich vor seinem Termin im Ministerium gemacht hatte, zeigt vielmehr, dass in ihm wieder die Sorge wuchs, Göttingen, und damit seine wichtigsten Förderer und die so wichtige naturwissenschaftliche Infrastruktur, in Richtung Berlin verlassen zu müssen.

treibende [?] Argumente

- Universität Göttingen mit schön entwickeltem mathem. Physikal. Betrieb und ibrer dezennienlangen Verbindung von Universität und Technik ist der richtige Boden für dieses Forschungswerk.

- Berliner Univ. hat sich bisher nicht im mindesten für solche Dinge interessiert, die Techn. Hochschule ist kein sehr geeigneter Platz für exakte Forschung (unangenebme persönliche Verbältnisse).

- Nur in Göttingen der beständige Fluß von jungen Kräften gut zu erreichen.

- Es entspricht der deutschen Kultur, daß überall Schaffens-Zentren geschaffen werden (Schlechte Folgen der Zentralisation in Frankreich).

Gründe die im Kultusministerium bereits sebr gewürdigt werden.

- Verödung der Provinz aus politischen Gründen nicht opportun. ${ }^{550}$

Im Rahmen dieser Besprechung wurden Prandtl wohl schon die wichtigsten Zusagen gegeben, wie man aus dem selbstbewussten Stil eines zusammenfassenden Berichts vom 26. Mai entnehmen kann. Zumindest schien ihm jetzt die finanzielle Seite keine allzu großen Sorgen mehr zu bereiten.

Dadurch [Vergrößerung der geplanten Gebäude] ist das Projekt etwas umfangreicher geworden. Es schien aber richtiger zu sein, sich nicht auf später wabrscheinlich hinzukommende Einrichtungen stützen zu wollen, sondern vielmehr jetzt eine in sich geschlossene Anlage mit allem erforderlichen Zubehör zu schaffen. ${ }^{551}$

Des Weiteren sollten die Größe und die Luftgeschwindigkeit des neuen Windkanals nochmals ausgebaut werden. Die Notwendigkeit hierzu untermauert Prandtl gegen Ende seines Berichts mit einer tabellarischen Gegenüberstellung des geplanten Windkanals mit französischen und englischen Einrichtungen in Paris und London. ${ }^{552}$ Dies verwundert wenig, da seine Pläne in fast allen Punkten ihre direkten Konkurrenten übertreffen sollten. Der Kostenvoranschlag für die erwei-

\footnotetext{
549 DLR.GOAR.2633 08.05.1915.

550 DLR.GOAR.2633 [08. oder 09.05.1915]

551 DLR.GOAR.2633 26.05.1915 Bl. 2 des Berichts.

552 DLR.GOAR.2633 26.05.1915 Bl. 5 und 6 der Anlage 1 des Berichts.
} 
terten Pläne umfasste 83600 Mark für die technische Einrichtung ohne die Baukosten. Diese sollten von der technischen Abteilung des Kriegsministeriums selbst anhand von Prandtls Zeichnungen ermittelt werden. Die laufenden Kosten veranschlagte er mit 27200 Mark pro Jahr, allerdings nur unter der Voraussetzung, dass er selbst und einer seiner Ingenieure auch weiterhin vom Kultusministerium bezahlt werden würden. 553

Offenbar um noch weitere Unterstützung zu erhalten, schrieb von Böttinger noch am gleichen Tag, an dem der neue Bericht abgeschickt wurde, an Prinz Heinrich, um ihn darauf aufmerksam zu machen, dass die Entscheidung unmittelbar bevorstand. ${ }^{554}$ Prinz Heinrich versicherte ihnen nochmals seine Unterstützung, die allerdings wahrscheinlich schon nicht mehr notwendig war. ${ }^{555}$ Am 10. Juni 1915 nahm Ludwig Prandtl erneut an einer Besprechung in Berlin teil, diesmal im Reichsamt des Innern. Außerdem war zu diesem Termin, an dem ebenfalls ein Antrag der Deutschen Versuchsanstalt für Luftfahrt behandelt wurde, neben zahlreichen hochrangigen Militärs ${ }^{556}$ auch der erste Präsident der Kaiser-WilhelmGesellschaft, Prof. Dr. Adolf von Harnack, anwesend. Es war diese Sitzung, in der Prandtl die endgültige Zusage erteilt wurde. Kriegsministerium und Reichsmarineamt sicherten zunächst pauschal 200000 Mark für den Aufbau der neuen Einrichtung zu. Allerdings wird im Gegenzug auch klar, was man dafür von Prandtl erwartete:

Hinsicbtlich der Göttinger Versuchsanstalt herrscht darin Übereinstimmung, daß die
Anstalt wegen der seitens der Militärressorts ₹ur Errichtung der Anlage zur Verfügung
gestellten Beträge verpflichtet sei, unter voller Wabrung ibres wissenschaftlichen Charak-
ters die ibr von den Militärressorts zugewiesenen Aufträge in erster Linie ₹u erledigen
und bei Bemessung der Kosten den Militärressorts eine Vorzugstellung einzuräumen. ${ }^{557}$

Die anwesenden Vertreter des Kultusministeriums wurden ihrerseits damit beauftragt, die genaue Organisationsform sowie den Rechtsstatus und ähnliche weitergehende Angelegenheiten zu klären. Das Ergebnis dieser Überlegungen war dann die so genannte Verständigung oder wie sie vollständig hieß „Verständigung über die Errichtung einer Modellversuchsanstalt und deren Eingliederung in das zu errichtende Kaiser-Wilhelm-Institut für Aerodynamik und Hydrodynamik.“" ${ }^{\circ} 58$ Diese Verständigung blieb die Grundlage der gesamten Organisation und des

\footnotetext{
553 DLR.GOAR.2633 26.05.1915 Anlage 2 des Berichts.

554 DLR.GOAR.2633 26.05.1915.

555 DLR.GOAR.2633 31.05.1915.

556 Für das Kriegsministerium Oberst Oschmann, Hauptmann Bartsch, Hauptmann Wilck, Regierungsbaumeister Bruker, Graf von Oppersdorf, Hauptmann Coerper, für die Inspektion der Fliegertruppen Hauptmann Keller und Oberleutnant Hermann. Für das Reichs-Marineamt Korvettenkapitän von Müller-Berneck sowie Marinebaumeister Dröseler. DLR.GOAR.2633 14.06.1915.

557 DLR.GOAR.2633 14.06.1915.

558 DLR.GOAR.2633 06.1915.
} 
Betriebes der Modellversuchsanstalt während der Dauer des Krieges. Ihre wichtigste Bedeutung bestand in der präzisen Definition des Verhältnisses zwischen allen Beteiligten, nämlich dem Kriegsministerium, dem Reichsmarineamt, dem Kultusministerium, der Kaiser-Wilhelm-Gesellschaft, der Göttinger Vereinigung und der Universität Göttingen - sowie natürlich Prandtl selbst.

Die Grundlage des gesamten Plans bildete der „verminderte Vorschlag“ Prandtls aus dem Jahr 1912, also der Vorschlag ohne die Bereiche Hochdruckhydraulik und Gasdynamik, der damals mit 273000 Mark veranschlagt worden war. Die Summe für den eigentlichen Bau der Modellversuchsanstalt, also ohne die Kosten für Grundstück und Inventar, sollte nun von den Militärbehörden alleine aufgebracht werden. Prandtl hatte hierzu zugesagt, dass 200000 Mark zunächst ausreichend wären, da wahrscheinlich bereits verschiedene Vorarbeiten aus Mitteln der Göttinger Vereinigung geleistet worden waren. Diese Summe wurde dann auch so in der Verständigung fixiert. Die angesprochenen Mittel der Göttinger Vereinigung, nämlich 6000 Mark p.a., sollten auch in Zukunft weiter gezahlt werden. Außerdem verpflichtete sich die Göttinger Vereinigung, das in Aussicht genommene Grundstück in der Bunsenstraße kostenlos zur Verfügung zu stellen. Dieses Grundstück gehörte ja von Böttinger persönlich, da die Göttinger Vereinigung, wie bereits erwähnt, selbst keinen Grundbesitz haben konnte. So wurde vereinbart, dass das Grundstück in den Besitz der Kaiser-Wilhelm-Gesellschaft übergehen sollte.

Die Kaiser-Wilhelm-Gesellschaft war ohnehin diejenige der Beteiligten an dieser Absprache, die voraussichtlich bei Kriegsende am meisten profitieren würde, denn in ihren Besitz sollte die gesamte Einrichtung übergehen. Sie wurde verpflichtet, nach Ende der Kämpfe 150000 Mark - also exakt den bereits 1913 zugesagten Anteil - zu zahlen und mit diesen Mitteln die Differenz zwischen dem verminderten Projekt von 1912 und dem umfassenden Vorschlag Prandtls auszugleichen. Die dann voraussichtlich fertiggestellte Modellversuchsanstalt sollte, zusammen mit den noch durch die Mittel der Kaiser-Wilhelm-Gesellschaft zu errichtenden Teilen, ein neues Kaiser-Wilhelm-Institut für Aerodynamik und Hydrodynamik bilden. Die laufenden Kosten von 36000 Mark p.a. sollten durch das Kultusministerium und die Kaiser-Wilhelm-Gesellschaft zu je 15000 Mark aufgebracht werden; die übrigen 6000 Mark pro Jahr waren der bereits erwähnte Anteil der Göttinger Vereinigung.

Zusätzlich zu den anteiligen Kosten von 15000 Mark sollte das Kultusministerium die Vergütung des Direktors der Einrichtung, also Prandtls, übernehmen, für den nun ein eigenes Ordinariat eingerichtet wurde. Dies sollte bereits während des Krieges erfolgen, allerdings wurde der Beitrag zum regulären Etat noch ausgesetzt. Für die Dauer des Krieges verpflichteten sich die Militärbehörden, sämtliche 
laufenden Kosten zu tragen, die über die 6000 Mark der Göttinger Vereinigung hinausgingen. .59

Selbstverständlich erwarteten Kriegsministerium und Reichsmarineamt für diese beachtlichen Zusagen Gegenleistungen und ließen keinerlei Zweifel daran, dass sie, entsprechend ihres finanziellen Anteils, den vollen Nutzen aus der neu gegründeten Einrichtung ziehen wollten. So war nun auch keine Rede mehr von der von Prandtl favorisierten gerechten Zweiteilung von Rechten und Pflichten, wie er es in seiner Denkschrift von 1915 genannt hatte. „Während des Krieges dient die Modellversuchsanstalt unter Leitung Professors Prandtl den aus der Kriegslage sich ergebenden praktischen und wissenschaftlichen Bedürfnissen. “560 Außerdem sicherte man sich noch für die Nachkriegszeit gewisse Sonderkonditionen für militärische Aufträge. Dies war mit Sicherheit nicht das, was Prandtl sich erhofft hatte, aber jedwede Form von Opposition wäre zu diesem Zeitpunkt, selbst wenn Prandtl dies gewollt hätte, sicherlich nicht mehr möglich gewesen.

Ludwig Prandtl wurde offiziell als „Bauherr“ bestimmt, größere Zahlungen musste er jedoch gemeinsam mit von Böttinger anweisen. Die Bauaufsicht sollte Professor Burgsch aus Hannover übernehmen. Die Konto- und Rechnungsführung übernahm zukünftig die Universitätskasse. Außerdem wurde dafür Sorge getragen, dass man die Einhaltung der Verständigung gewährleisten konnte.

\section{Die Einhaltung des Kostenanschlags und die Verwendung des Baues nach den Zwecken des Instituts soll durch die Kaiser-Wilhelm-Gesellschaft, die Göttinger Vereinigung und die beteiligten Ressorts überwacht werden. Zu diesem Zwecke wird schon jetzt ein vorläu- figes Kuratorium eingesetzt, dem außer Professor Prandtl Vertreter der beiden Kriegsver- waltungen, des Unterrichtsministeriums, der Kaiser-Wilhelm-Gesellschaft, der Göttinger Vereinigung, sowie vorbehaltlich entsprechender Regelung für die Deutsche Versuchsan- stalt für Lufffahrt in Adlershof ein Vertreter der letżteren angehören. 561}

Die Militärbehörden machten außerdem unmissverständlich klar, dass diese Zusagen nur unter der Bedingung gegeben wurden, dass umgehend, also auch ohne weitere langwierige Verhandlung von Details, mit der sofortigen Umsetzung der Pläne begonnen würde, damit sich die Investitionen möglichst bald im Krieg auszahlen konnten. ${ }^{562}$ Damit übte man natürlich einen gewissen Druck auf alle Beteiligten aus, entweder die nun gefundene Verständigung zu akzeptieren oder das gesamte Projekt zu gefährden.

Tatsächlich ging nun alles sehr schnell. Am 10. Juni hatte, wie bereits erwähnt, die entscheidende Besprechung im Reichsamt des Innern stattgefunden. Bereits

\footnotetext{
DLR.GOAR.2633 06.1915. Alle finanziellen Details aus Punkt 2 und 3 der Verständigung.

DLR.GOAR.2633 06.1915. Punkt 4 der Verständigung.

DLR.GOAR.2633 06.1915. Punkt 6 der Verständigung.

„Der Bau, auf dessen alsbaldige Ausführung die beiden Kriegsverwaltungen den größten Wert legen, soll sofort in Angriff genommen werden, daß die Inbetriebnahme noch während des Krieges erfolgen kann.“ DLR.GOAR.2633 06.1915. Punkt 3 der Verständigung.
} 
am 17. Juni verschickte die Kaiser-Wilhelm-Gesellschaft den Entwurf der Verständigung. Im weiteren Verlauf des Junis fanden dann noch letzte Abstimmungen zwischen Prandtl und der Kaiser-Wilhelm-Gesellschaft statt. So wünschte sich Prandtl etwa noch eine Veränderung im Namen des zukünftigen Kaiser-WilhelmInstituts: Es sollte nur noch das Wort Aerodynamik im Namen tragen, da ja die Hydrodynamik für die Göttinger Arbeiten viel weniger bedeutsam sei. Bis dahin wünschte er sich für die Modellversuchsanstalt den Namen: Modellversuchsanstalt für Luftfahrt, ${ }^{563}$ wovon er aber wieder Abstand nehmen musste, wegen der zu großen Ähnlichkeit zur Deutschen Versuchsanstalt für Luftfahrt in Adlershof. Schließlich entschied man sich kurzerhand für Modellversuchsanstalt Göttingen. ${ }^{564}$

Die meiste Zeit nahm jedoch die Vorbereitung des Neubaus in Anspruch. Zuerst trat Regierungsbaumeister Bruker vom Kriegsministerium auf den Plan, der offenbar bereits vor der ersten Besprechung die Zeichnungen des ursprünglichen Antrags von 1912 begutachtet hatte. Er befürchtete, dass der Bau mindestens 300000 Mark verschlingen werde, also 100000 Mark mehr, als Prandtl veranschlagt hatte, was aber wohl daran lag, dass er teilweise grundlegend andere Vorstellungen bezüglich der Ausführung des Baus hatte: „Die Anlage wird, soweit ich bis jetzt übersehen kann, sich auch architektonisch reizvoll lösen lassen. "565 Prandtl selbst bestand jedoch auf einem betont zweckorientierten und schlichten Stil, wohl um seine Pläne nicht durch zu hohe Preise zu gefährden.

Was Ihre Pläne betrifft, so muss ich leider feststellen dass sie nicht ganz dem entsprechen, was ich mir vorgestellt hatte. Mein Gedanke war, einen Nutzbau aller schlichtester Art zu schaffen, in allen Formen wesentlich einfacher, als Ihr Projekt. Der Versuchsraum z.B. sollte eine einfache, offene Dachkonstruktion erhalten und nicht eine besondere unter dem Dach angeordnete Decke. [...] Unter Berücksichtigung dieser und anderer Vereinfachungen, (das Türmchen würde auch besser wegfallen, da für die in Frage kommenden Zwecke eine ganz einfache schmale Treppe an der Wand vollkommen ausreicht) glaube ich, dass sich die Bausumme ganz erheblich erniedrigen lässt. ${ }^{566}$

Prandtl hatte offensichtlich ganz präzise Vorstellungen und war wenig gewillt, externe Gutachter an seinen Planungen zu beteiligen, nicht zuletzt, da er erkannt hatte, dass dies auch immer zeitliche Verzögerungen bedeuten musste. So versuchte er auch nach der Besprechung im Reichsamt des Innern die Rolle des für die Bauaufsicht vorgesehenen Professor Burgsch möglichst einzuschränken.

Was nun die anderen Angelegenheiten betrifft, so möchte ich bezüglich der Art, wie Herr Professor Burgsch an den Arbeiten beteiligt wird, vorschlagen, dass Herr Professor Burgsch die Pläne und den Kostenanschlag, die wir hier ausarbeiten, prüfen wird und dass er darüber eine kurze gutachtliche Aeusserung abgeben wird, die den in Betracht

$\begin{array}{ll}563 & \text { DLR.GOAR.2633 18.06.1915. } \\ 564 & \text { DLR.GOAR.2633 25.06.1915. } \\ 565 & \text { DLR.GOAR.2633 29.05.1915. } \\ 566 & \text { DLR.GOAR.2633 05.06.1915. }\end{array}$ 
kommenden Behörden und Korporationen vorgelegt wird und auf Grund deren die Bebörden und Korporationen Ihre Zustimmung zu dem Bau geben können. Ich denke, dass bei diesem Verfahren am wenigsten Zeit verloren gehen wird, möchte aber um Ihr Einverständnis zu diesem Verfahren bitten. Herrn Professor Burgsch habe ich bereits in vorläufiger Weise in diesem Sinne geschrieben. ${ }^{567}$

Schließlich gelang es Prandtl, sich mit seinen Vorstellungen durchzusetzen, und das Kriegsministerium verzichtete auf eine weitere Einflussnahme. Dies teilte er umgehend dem Kultusministerium mit, ungeduldig, mit den Arbeiten beginnen zu können.

Gestern erbielt ich vom allgemeinen Kriegsdepartement ein von Herrn Oberst Oschmann gezeichnetes Schreiben, worin mir mitgeteilt wird, dass die gesamte Leitung und Ausführung des Neubaues der Versuchsanstalt der Unterrichtsverwaltung überlassen wird. Eine weitere Einflussnahme auf die Gestaltung der Baupläne und die Bauausführung sei seitens des Kriegsministeriums nicht beabsichtigt. Es werde mir daher anheimgestellt, bezüglich aller weiteren Einzelheiten, wie Zahlungsart, Bauangelegenheiten und erste Betriebsmittel, mich unmittelbar mit der Unterrichtsverwaltung ins Einvernehmen zu setzen.568

Auch das Kultusministerium ließ ihm weitgehend freie Hand, so dass erstaunlich schnell mit dem Neubau begonnen werden konnte. Diesen prägten aber unglaubliche Versäumnisse der beteiligten Architekten und Bauunternehmen über die gesamte Bauzeit, was nicht zuletzt durch die Knappheit guter Baumaterialien im Krieg verursacht wurde. Dies führte sogar dazu, dass bereits errichtete Mauern wieder eingerissen werden mussten. ${ }^{569}$ Man kann sich leicht vorstellen, wie ärgerlich diese Angelegenheit für Prandtl sein musste, nicht nur wegen der zeitlichen Verzögerungen, sondern auch, weil ihm gerade auf sein Drängen quasi die gesamte Bauaufsicht überlassen worden war. Schließlich musste er doch noch einen externen Gutachter, Prof. Dr. Ing. Quietmeyer aus Hannover, in Anspruch nehmen, als es galt, die Verantwortlichen für den Pfusch zu ermitteln. Dieser schrieb in seinem Gutachten dann unter anderem:

Hier ist allein in der Ausführung auf das gröblichste gegen die Regeln des Handwerks verstossen, es kommt noch hinzu, dass ein Mörtel verwandt ist, der diesen Namen garnicht verdient. [...] Es gelang mir an recht vielen Stellen, einen recht schwachen, zusammen klappbaren Taschenmassstab 20 bis 30, ja in einem Falle $34 \mathrm{~cm}$ tief in die offenen Fugen hineinzuschieben, obne auf Mörtel zu stossen. [...] Nach Aufsetzen des Daches und Schliessen der Fensteröffnungen werden sich aber die Kantenpressungen im Mauer-

567 DLR.GOAR.2633 25.06.1915.

568 DLR.GOAR.2633 29.06.1915.

569 Der Neubau der Modellversuchsanstalt verlief jedoch alles andere als planmäßig, worauf hier aber nur am Rande eingegangen werden soll, da dies bereits etwa bei Rotta sehr ausführlich beschrieben wurde. Rotta: Die Aerodynamische Versuchsanstalt. 1990. S. 139ff Ferner dokumentieren die Akten DLR.GOAR.2634 und DLR.GOAR.2635 die Zeit des Baus sehr gut. 
werk - roh überschlagen - mindestens verdreifachen, sodass man dann mit einem raschen Zerfall ja vielleicht mit einem plötzlichen Einsturz des Gebäudes rechnen müsste. ${ }^{570}$

Viel schneller und geradliniger verlief dagegen die weitere Entwicklung auf der administrativen Ebene. Nach der Klärung letzter Detailfragen wurde noch im August 1915 zur ersten Sitzung des in der Verständigung bestimmten Kuratoriums im Berliner Kultusministerium eingeladen. Die Tagesordnungspunkte sollten zum einen ein Bericht über die Vorarbeiten und eine Vorstellung der Baupläne sein. Zum anderen sollte eine „Regelung des Institutsbetriebes während der Bauzeit" gesucht werden.571 Wichtigstes Ergebnis dieser Sitzung war die erste vorläufige Satzung der Modellversuchsanstalt. 572

Diese Satzung bestätigte weitgehend die bereits in der Verständigung getroffenen Vereinbarungen. So erscheint auch bereits im ersten der 12 Paragraphen die Feststellung, dass die Modellversuchsanstalt für die Kriegsdauer ausschließlich den Militärbehörden zur Verfügung zu stehen habe. Das neue Kuratorium setzte in seiner ersten Sitzung zwei Ausschüsse ein, die zukünftig die konkrete Verwaltungsarbeit übernehmen sollten. Unabhängig von der Tatsache, dass Ludwig Prandtl die alltäglichen Geschäfte weitgehend eigenverantwortlich führen sollte, ließen die Zusammensetzungen der ihn überwachenden Ausschüsse keinen Zweifel daran, dass die Militärbehörden ihre Forderungen nach dem alleinigen Nutzungsrecht der neuen Einrichtung während des Krieges durchzusetzen gedachten. Diese Ausschüsse, die je fünf Mitglieder hatten, waren zum einen der so genannte Verwaltungsausschuss und zum anderen der Betriebsausschuss. ${ }^{573}$

Der Verwaltungsausschuss befasste sich im Wesentlichen mit Haushaltsfragen, wie etwa der Kontrolle der Jahresabschlüsse. Den Vorsitz hier führte ein Mitglied, das von der Kaiser-Wilhelm-Gesellschaft gestellt wurde. Außerdem entsandten das Kultusministerium, das Kriegsministerium und die Göttinger Vereinigung je ein Mitglied. Das fünfte Mitglied schließlich war Prandtl selbst. Realistisch betrachtet war dieses Gremium für ihn jedoch nicht von großer Bedeutung, zumal es nur recht selten im entfernten Berlin zusammentrat. ${ }^{574}$

Viel unmittelbarer war Prandtl vom Betriebsausschuss abhängig, in dem er auch Mitglied, ja sogar Vorsitzender war. Dieser tagte deutlich häufiger in Göttingen und hatte seinen Sitz direkt in der Modellversuchsanstalt. Dieses zweite Gremium entschied de facto, welche Arbeiten durchgeführt und welche abgelehnt werden sollten. Prandtl war zwar der Vorsitzende des Betriebsausschusses, die übrigen vier Mitglieder waren jedoch Angehörige der Militärbehörden. Im Einzelnen waren das je zwei Mitarbeiter des Reichsmarineamtes und des Kriegsministeriums. Damit hatten diese eine strategisch wichtige Position besetzt, aus der

$\begin{array}{ll}570 & \text { DLR.GOAR.2634 29.12.1915. } \\ 571 & \text { DLR.GOAR.2632 26.08.1915. } \\ 572 & \text { DLR.GOAR.2637 Bl. 23ff. } \\ 573 & \text { DLR.GOAR.2637 Bl. 23ff. @3. } \\ 574 & \text { DLR.GOAR.2637 Bl. 23ff. \$6. }\end{array}$ 
heraus sie dauerhaft gewährleisten konnten, dass ihre Investitionen gut angelegt waren. Es lassen sich zwar keine konkreten Beispiele eines Aufbegehrens Prandtls gegen den Betriebsausschuss nachweisen, aber trotzdem ist offensichtlich, wer letztendlich die Entscheidungskompetenz besaß.575

Zusammengenommen war die Situation der Modellversuchsanstalt in jeder Hinsicht völlig anders als in irgendeinem naturwissenschaftlichen Institut der Göttinger Universität. Zum einen war der gesamte Maßstab des Projekts um ein Vielfaches größer und zum anderen war man nur in der kurzen Periode der Liquidation der Motorluftschiff-Studiengesellschaft wirklich unabhängig vom Geld und dem Einfluss Dritter. Aber trotz aller offensichtlichen Verschiedenartigkeit drängt sich doch ein genauerer Vergleich zu den Instituten der Universität auf. ${ }^{576}$

\section{Personalausstattung}

Zunächst, solange die Modellversuchsanstalt noch die Modellversuchsanstalt der Universität Göttingen und Teil des Instituts für angewandte Mathematik war, befand sie sich selbstverständlich in der gleichen Situation wie alle anderen Institute. Dies änderte sich allerdings, als man sich schließlich 1915 an die Militärbehörden wandte.

$$
\begin{aligned}
& \text { Außer den beiden Assistenten der Modellversuchsanstalt, Betz, und Wieselsberger, waren } \\
& \text { auch die Assistenten des Instituts für angewandte Mechanik und die Doktoranden bis } \\
& \text { auf eine Ausnabme sämtlich im Kriege, und der Betrieb an Vorlesungen und Übungen } \\
& \text { war auf ein Minimum zusammengeschrumpft. Leider kamen auch schon bald zwei Ver- } \\
& \text { lustmeldungen, G. Fubrmann, am } 7 \text {. Oktober } 1912 \text { zur DVL [Deutsche Versuchsan- } \\
& \text { stalt für Lufffahrt] übergetreten, und W. Deimler waren gefallen. }{ }^{577}
\end{aligned}
$$

Somit stand, zumindest was das wissenschaftliche Personal anbelangte, Prandtl fast alleine, aber bereits erste Aufträge der Firma Dornier und des Reichsmarineamts nutzte er, um zwei seiner Mitarbeiter zu reklamieren, das heißt, sie nachträglich für unabkömmlich erklären zu lassen. ${ }^{578}$ Außerdem gelang es ihm, mit Max Munk einen dritten wichtigen Mitarbeiter für seine Einrichtung zu gewinnen. 579

Wenn man sich an diesem Punkt nochmals an den enormen Einbruch der Studierendenzahlen und an die völlig veränderte Situation bei den Assistentenstel-

575 DLR.GOAR.2637 Bl. $23 \mathrm{ff.} \$ 7$.

576 Selbstverständlich kann hier keine chronologisch aufgebaute Geschichte der Modellversuchsanstalt in der Zeit des Ersten Weltkrieges geschrieben werden. Es soll vielmehr versucht werden, anhand ausgewählter Quellen aussagekräftige Vergleiche mit der Universität anzustellen. Rotta: Die Aerodynamische Versuchsanstalt. 1990. S. 118.

578 Der hier gebrauchte Begriff ,reklamieren' wurde aus den Quellen übernommen. Er stand umgangssprachlich für das Beantragen, einen Mitarbeiter trotz etwaiger Dienstpflichten weiter beschäftigen zu dürfen und ihn für unabkömmlich erklären zu lassen. Ein solcher Antrag konnte bei den zuständigen örtlichen Militärbehörden (hier das Bezirkskommando und die Landwehrinspektion Hannover) gestellt werden. Sie hierzu auch: Wettmann: Heimatfront. 2000. S. 119.

579 Rotta: Die Aerodynamische Versuchsanstalt. 1990. S. 120. 
len erinnert, die im ersten Kapitel beschrieben worden sind, gewinnt die damit beginnende Entwicklung eine ganz besondere Bedeutung. Gerade im Bereich der Assistenten war ja der Mangel an jungen Doktoranden besonders stark spürbar, so dass zum ersten Mal auch Doktorandinnen in diese Stellen vorrücken konnten.

Ludwig Prandtl allerdings kannte diese Probleme nicht mehr, nachdem er die Allianz mit den Militärs eingegangen war. Zivildienst- und Wehrpflicht waren nun Faktoren, von denen er sogar profitieren konnte, wie folgender Aushang zeigt:

Betrifft Kriegs-Hilfsdienst

Auf Wunsch und mit Unterstützung der Inspektion der Fliegertruppen soll mit Beginn des neuen Jahres die Tätigkeit der

Modell-Versuchsanstalt für Luftfahrtindustrie

(angegliedert dem Institut für angewandte Mechanike der Göttinger Universität) wesentlich ausgedehnt werden. Es sollen den deutschen Flugzengfabriken in weit grösserem Masse als bisher durch Versuche an Modellen wissenschaftliche Grundlagen für ibre Konstruktionen geboten werden, um sie auch weiter in Stand zu setzen, den Wettbewerb mit den durch ibre Zabl und ibre Hilfsquellen überlegenen feindlichen Fabriken mit Erfolg zu bestehen.

Die Modellversuchsanstalt kann diese Aufgabe nur erfüllen, wenn Sie freiwillige Helfer in genügender Zabl findet, die sie bei ihren Arbeiten unterstützen wollen.

Sie fordert deshalb Studierende der mathematisch-physikalischen Fächer (Damen und Herren), die in der Lage sind, sich ganzoder halbtägig für diese Arbeiten zur Verfügung zu stellen, bierzu auf.

Es handelt sich im Wesentlichen um die Ausführung von physikalischen Messungen, um deren numerische Auswertung, ferner um zeichnerische Arbeiten verschiedener Art. Bei längerer Mitarbeit wird für die geleisteten Arbeiten eine angemessene Vergütung gewährt werden. Für die der Zivildienstpflicht unterstehenden Herren wird ausdrücklich hervorgehoben, dass die Mitwirkung bei den vorgenannten Arbeiten als Zivildienst im Sinne des neuen Gesetzes anzusehen ist.

Solche Damen und Herren (nur Reichsdeutsche), welche geneigt sind, sich ganz- oder balbtägig diesen Arbeiten zu widmen, werden gebeten, sich in den Tagen vom 8. bis 10. Januar in eine Liste einzutragen, die im Büro der Modell-Versuchsanstalt Prinzenstr. 21, ausliegt. Eine Besprechung mit einführendem Vortrag findet am Mittwoch den 10. Januar nachmittags 3 Ubr im Hörsaal Prinzenstr. 21 statt. Hierzu sind auch solche willkommen, die sich zur Mitarbeit noch nicht entschlossen haben.

Gez. Prandtl.580

580 DLR.GOAR.2647 Aushang vom 06.01.1901. 
Es ist wenig verwunderlich, dass es ausreichend Bewerber und auch Bewerberinnen für die zu besetzenden Stellen gab. ${ }^{581}$ Besonders für die männlichen Interessenten musste Prandtls Angebot sehr verlockend sein. Sie konnten jetzt in Göttingen etwaige Dienstpflichten ableisten. Aber nicht nur das; alle Hilfskräfte erhielten bei ihrem Ausscheiden ein Zeugnis und konnten den geleisteten Dienst als eine Art Praktikum ansehen, und dies in einer der modernsten Forschungseinrichtungen weltweit.

\section{ZEUGNIS!}

Herr stud.math. Wilhelm Melchert aus Hildesheim war vom 8. Oktober 1917 bis 15. Dezember 1918 an der Modellversuchsanstalt für Aerodynamik mit der rechnerischen Auswertung von aerodynamischen Untersuchungen beschäftigt. Die ihm übertragenen Arbeiten hat er mit grossem Fleiss und Geschick durchgeführt, so dass wir mit seinen Leistungen ausserordentlich zufrieden waren. Er war uns besonders wegen seiner Zuverlässigkeit ein sehr wertvoller Mitarbeiter. Sein Weggang erfolgt, um sein durch den Krieg unterbrochenes Studium an der hiesigen Universität fortzusetzen.

Der Direktor L.P. ${ }^{582}$

Aber auch höher qualifizierte Stellen konnte die Modellversuchsanstalt durchaus auf dem Wege des Reklamierens mit jungem Personal besetzen.

\section{Die bisher bei der Göttinger Versuchsanstalt beschäftigten Hilfskräfte sind auf Grund der vom K.M. [Kriegsministerium] ausgestellten Bescheinigungen bisher obne weiteres durch die Bezirkskommandos zurückgestellt worden. Falls bierin in Zukunft Schwie- rigkeiten entstehen sollten, wird sich Professor Prandtl an das K.M. oder an die Idflieg. [Inspektion der Fliegertruppen] wenden. ${ }^{583}$}

581 DLR.GOAR.2647 Antwortschreiben an Bewerber auf Kriegshelferstellen bei der Modellversuchsanstalt vom 18.08.1917 an „Herrn Fred. Hubert, Herrn Wilh. Melchert, Herrn Karl Stelter, Herrn Friedr. Eitz, Frl. Ida Maske, Frl. Hildegard von Scheve, Kriegsprimaner Schaab Die Modellversuchsanstalt bedarf zur Ausführung von zur Landesverteidigung notwendigen wissenschaftlichen Arbeiten einiger weiterer Mitarbeiter. Deren Arbeit würde in der Ausführung und Auswertung aerodynamischer Versuche, sowie in der Ausarbeitung der fertigen Ergebnisse bestehen. Besondere Vorkenntnisse sind für die in Betracht kommenden Arbeiten nicht notwendig, dagegen wäre ein wenn auch begrenztes Vertrautsein mit der Ausführung von physikalischen Messungen erwünscht. Wir ersehen, dass Sie sich in der Hilfsdienstliste der Universität eingetragen haben. Wir bitten Sie um nähere Angaben darüber, ob Ihnen die Mitarbeit in der Modellversuchsanstalt möglich ist und ob Sie hierzu geneigt wären. Wir bemerken noch, dass auch eine halbtägige Mitarbeit in Betracht käme, jedoch müsste Ihnen entweder jeder Vormittag oder jeder Nachmittag unbeschränkt zur Verfügung stehen. Für ganztägige Mitarbeit würden wir monatlich $120 \mathrm{M}$ vergüten. Im Auftrage Munk."

582 Ein Beispiel zahlreicher stereotyper Zeugnisse, die nach Kriegsende geschrieben wurden. In weitgehend identischer Form beispielsweise noch für neun andere Studenten. DLR.GOAR.1356 15.12.1918.

583 DLR.GOAR.2637 21.12.1916. Niederschrift einer Besprechung im Kriegsministerium. 
Tatsächlich machte man von diesen Möglichkeiten auch regen Gebrauch. Meistens folgte das Reklamieren einem gewissen Schema: Zuerst schrieb Prandtl an namhafte Kollegen mit einer kurzen Stellenbeschreibung und der Bitte um die Empfehlung geeigneten Personals. Diese Umfragen brachten in der Regel gute Rückläufe. Es ist anzunehmen, dass in dieser Zeit jeder Kollege Schüler hatte, die er gerne bei Prandtl im sicheren Göttingen gewusst hätte. Aus diesen Rückläufen wurden dann mehrere Kandidaten ausgewählt, ihre Eignung gegebenenfalls nochmals überprüft und schließlich persönlich angeschrieben.

Ein Beispiel verdeutlicht diesen Vorgang: Am 25. Juli 1917 schrieb Prandtl an insgesamt elf Kollegen in ganz Deutschland mit der Bitte, ihm einen geeigneten Laboratoriums-Ingenieur zu empfehlen, der besonders auf dem Gebiet der Messtechnik Erfahrungen haben sollte. Aerodynamische Kenntnisse verlangte er ausdrücklich nicht. ${ }^{584}$ Allerdings wies er explizit auf die ihm zur Verfügung stehenden Mittel hin.

Falls Sie in der Lage sein sollten, mir einen bierfür geeigneten tüchtigen Herren zu nennen, so wäre ich Ihnen hierfür zu grossem Danke verbunden. Wenn der Betreffende zur Zeit im Heeresdienste ist, so ist das kein Hindernis, da es sich hier um Arbeiten im Auftrage der Militärbehörde handelt. In diesem Falle würde ich bitten, Angaben über sein Militärverbältnis und den Truppenteil, soweit Ihnen bekannt, beizufügen. ${ }^{585}$

Auf das erste Rundschreiben antworteten nahezu alle der angeschriebenen Wissenschaftler, von denen die meisten auch Vorschläge machten. Professor Otto Berndt von der Technischen Hochschule Darmstadt nannte gleich drei mögliche Kandidaten. Einer von diesen war der Unteroffizier Hugo Berkes, der zu dieser Zeit als Funker eingesetzt wurde.586 Interessanterweise wurde Prandtl deshalb auf ihn aufmerksam, weil er im Gegensatz zu den beiden anderen Vorschlägen Professor Berndts nicht promoviert war. Prandtl fragte dann diesbezüglich auch noch einmal nach:

Ich habe allerdings bisher mit Physikern und Mathematikern nicht die gleich guten Erfahrungen gemacht, wie mit Diplom-Ingenieuren, wenigstens soweit die bei uns in Betracht kommenden Arbeiten infrage kommen.

584 DLR.GOAR.1359 25.07.1917. Die Adressaten waren im Einzelnen: Prof. Dr. Ing. Schröter (München), Prof. Dr. Ing. M. Grübler (Dresden), Prof. Dr. Knoblauch (München), Prof. Dr. Berndt (Darmstadt), Prof. Dr. Brauer (Karlsruhe), Prof. Dr. H. Lorenz (Danzig), Prof. Josse (Technische Hochschule Charlottenburg T.H.), Prof. Dr. Ing. Eug. Meyer (Technische Hochschule Charlottenburg), Prof. Dr. Ing. C. v. Bach (Stuttgart), Dr. Treffz (Aerodynamisches Labor Technische Hochschule Aachen), Prof. Schlink (Technische Hochschule Braunschweig). 
Ich wäre Ibnen sehr dankbar, wenn Sie mir kurz noch angeben könnten, welchen Bildungsgang der von Ihnen erwähnte Herr Hugo Berkes aufauweisen hat, und was Sie von seinen persönlichen Eigenschaften halten. ${ }^{587}$

Berndt bestätigt daraufhin beste persönliche Eigenschaften Berkes und, was Prandtl wohl mehr interessierte, berichtet, dass Berkes direkt nach seinem Diplom in die Industrie gegangen, also ein ausgewiesener Praktiker sei. Nach dieser befriedigenden Antwort schrieb Prandtl dann den Kandidaten persönlich an:

Herr Geheimrat O. Berndt in Darmstadt nannte mir gelegentlich einer Anfrage wegen eines für die Modellversuchsanstalt zu gewinnenden weiteren Versuchsleiters Ihren Namen. Es handelt sich bei uns in der Hauptsache um Luftwiderstandsversuche, doch sind für den neu zu gewinnenden Mitarbeiter aerodynamische Kenntnisse weniger notwendig als allgemeine Erfahrung in Laboratoriumsdingen und in der Durchführung von Versuchen, Kenntnis der Gesetze der Mechanik u.s.w. Da unsere Arbeiten im militärischen Auftrage erfolgen, ist es nicht ausgeschlossen, zu erreichen, dass Heeresangebörige für diese Arbeiten zurückgestellt oder durch die Flugzengmeisterei in Berlin nach bier abkommandiert werden.

Für den Fall, dass Sie geneigt sind, eine solche Tätigkeit zu übernebmen, so bitte ich sie, mich dies wissen zu lassen, und mir auch anzugeben, mit welchen für die hiesige Tätigkeit in Betracht kommenden Sondergebieten Sie sich vor dem Kriege - und vielleicht auch im Kriege - beschäftigt haben. ${ }^{588}$

Mit Berkes kam zwar keine Beschäftigung zustande - warum lässt sich in diesem Fall leider nicht ermitteln - aber Prandtl führte immer parallele Verhandlungen mit mehreren Bewerbern. Wurde man sich schließlich einig, war die Tatsache, dass der Kandidat sich im Militärdienst befand, kein Hindernis. Im Gegenteil entlastete es sogar Prandtls Personalkosten. In Berlin Adlershof, dem Sitz der schon oft erwähnten Deutschen Versuchsanstalt, befand sich auch die sogenannte Inspektion der Fliegertruppen mit der Flugzeugmeisterei. ${ }^{589}$ Prandtl konnte seinen zukünftigen Mitarbeiter dorthin versetzen lassen. Dieser blieb dann Militärangehöriger und wurde nach Göttingen abkommandiert. Man konnte also in der Göttinger Modellversuchsanstalt seinen Kriegsdienst leisten. Prandtls Mitarbeiter, wenn sie nicht als unabkömmlich reklamiert waren, blieben Soldaten und erhielten anstelle eines Assistentengehalts oder Ähnlichem ihren regulären Sold. In diesem Schreiben wird das offensichtlich Alltägliche und die Leichtigkeit dieses Vorgangs besonders deutlich:

Wenn Sie meinen, das etwas Derartiges [Prandtl gab zuvor eine Stellenbeschreibung] Ihnen zusagen würde, so glaube ich, dass Ihre Versetzung nach hier sich würde erreichen

587 DLR.GOAR.1359 01.08.1917.

588 DLR.GOAR.1359 04.08.1917.

589 Siehe hierzu: Trischler: Luft- und Raumfahrtforschung. 1992. S. 94ff. Rotta: Die Aerodynamische Versuchsanstalt. 1990. S. 117. 
lassen. Mit Rücksicht auf die Mittel der mir unterstellten Anstalt wäre es wobl am besten, wenn wir Sie unter Beibehaltung Ibres militärischen Dienstverbältnisses hierber bekämen, was auf dem Wege über die Inspektion der Fliegertruppen ausfübrbar erscheint. Im anderen Falle, wenn Sie aus dem Heeresdienst entlassen würden, würde sich ein kleines Assistentengehalt wohl auch verantworten lassen. 590

Darüber hinaus scheint es in diesem Falle sogar so gewesen zu sein, dass Prandtl zu jener Zeit gar keine offene Stelle besetzen musste, sondern von seinem Kollegen Woldemar Voigt um einen Gefallen gebeten worden war, der sich um seinen Schüler Walter Ackermann sorgte. ${ }^{591}$ In einem Personalverzeichnis, wahrscheinlich aus der zweiten Hälfte dieses Jahres, taucht Ackermann dann auch tatsächlich unter „Punkt C - Offiziere“ auf. 592 Prandtl hatte also nicht zu viel versprochen.

Außerdem enthält dieses Verzeichnis drei Abteilungsleiter, zwei Ingenieure, zwei Offiziere, elf Kriegshilfsdienstleistende, 13 Personen Büropersonal und 18 Werkstattpersonal. Mit Prandtl verfügte die Modellversuchsanstalt damit über die beachtliche Zahl von über 50 Mitarbeitern. Die Zurückstellungen seiner Mitarbeiter musste Prandtl in regelmäßigen Abständen beim zuständigen Bezirkskommando beantragen. In dem dafür vorgesehenen Formular ${ }^{593}$ vom 15. März 1918 beantragt er die Zurückstellung von immerhin 27 Personen, die er bis auf drei als „unabkömmlich“ oder „schwer abkömmlich“ einstuft. Nur drei bezeichnet er als „ersetzbar“ und keinen als „entbehrlich“. In dieser Zahl von 27 Personen sind noch nicht die neun Soldaten enthalten, die zu ihm abkommandiert waren.

Ungleich schwerer war es für die Universitätsinstitute, qualifiziertes Personal zu bekommen. Hier finden sich im Vergleich deutlich weniger Einzelfälle, in denen versucht wurde, bereits zum Kriegsdienst eingezogenes Personal nachträglich für die Universität zu reklamieren. ${ }^{594}$ Exemplarisch ist hier etwa der Fall Sagawe zu nennen. Der Privatdozent Dr. Berthold Sagawe war ein Agrarwissenschaftler, der als Dozent durch die Universität als unabkömmlich deklariert werden sollte. Sagawe war bei Kriegsbeginn Assistent an der Universität Rostock und erhielt für das Wintersemester 1916 einen Lehrauftrag für landwirtschaftliche Betriebslehre in Göttingen. ${ }^{595}$ Er war jedoch seit Kriegsbeginn Soldat ${ }^{596}$ und hätte nun vom Militär freigestellt werden müssen. ${ }^{597}$ In das hiesige Vorlesungsverzeichnis war er bereits aufgenommen worden. Die Entscheidung durch das Kriegsministerium hierüber fiel jedoch negativ aus:

590 DLR.GOAR.2647 25.03.1918.

591 Voigt hatte einen Brief Ackermanns, in dem dieser von seiner Verwundung berichtet, Prandtl gegeben. Dieser jedoch wusste jedoch zunächst keine geeignete Beschäftigung für den Schüler seines Kollegen. DLR.GOAR.2647 25.03.1918.

595 UAG.Kur.6333 Bl. 8.

596 UAG.Kur.6333 Bl. 2.

597 Der entsprechende Antrag ist leider nicht enthalten. 
Euer Exzellenz, beehre ich mich ergebenst zu erwidern, daß ich zu meinem Bedauern nicht in der Lage bin, die Entlassung oder Versetzung des inzwischen zum Leutnant der Landwehr beförderten Assistenten [...] Dr. Sagawe zu verfügen, da er kriegsverwendungsfähig ist und Mangel an kriegsverwendungsfähigen Offizieren bestebt.598

Personal, welches noch keinen Kriegsdienst geleistet hatte, konnte hingegen meist längere Zeit als unabkömmlich bei den Militärbehörden angemeldet werden. Dies galt für Ordinarien und Assistenten, aber auch für Verwaltungsbeamte, Wärter oder Heizer, hing jedoch jeweils eng mit dem bei der Musterung festgestellten Tauglichkeitsgrad zusammen. Besagte der beispielsweise, dass eine Person ohne-

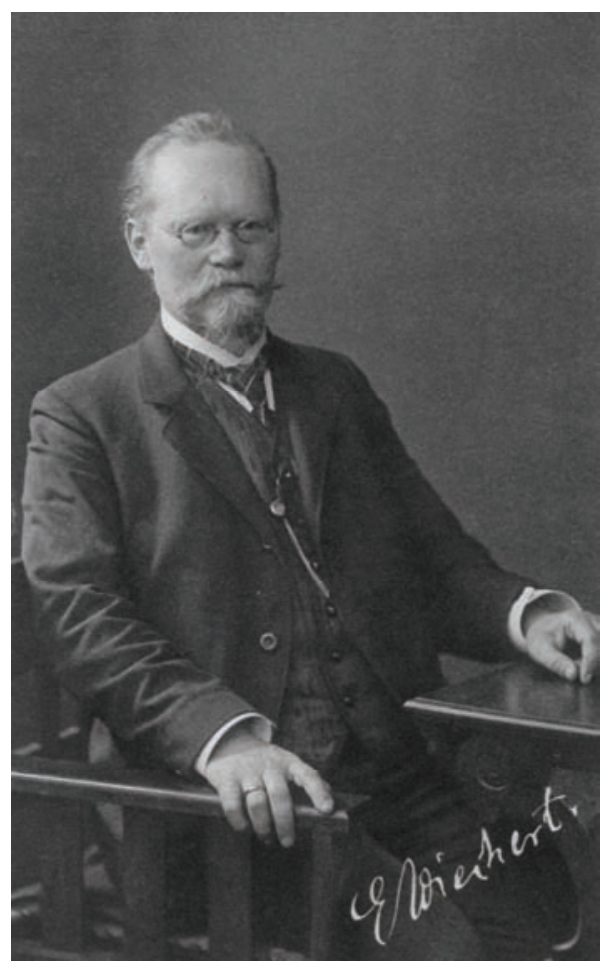

Abbildung 9: Emil Wiechert hin nur zu leichten Schreibarbeiten eingesetzt werden konnte, fiel es der Universität verhältnismäßig leicht, die betreffende Person in ihren Diensten zu halten. Im Falle jüngerer, kampffähiger Männer war dies deutlich schwerer. 599

Es ist ein Fall belegt, in dem Ludwig Prandtl es so schaffte, einem Göttinger Kollegen, dem Geophysiker Emil Wiechert, unter tätiger Mithilfe des Militärs, einen Assistenten förmlich abzuwerben. Wiecherts Assistent Dr. Adolf Repsold hatte im Mai 1917 seinen „Gestellungsbefehl“ erhalten, wollte aber den Kriegsdienst umgehen. Deshalb wandte er sich an Prandtl, der dann sogleich die Gelegenheit nutzte, um Repsold zu verpflichten. „Mir blieb unter den obwaltenden Umständen keine andere Wahl, als meine Einwilligung zu geben. So hat Herr Repsold gestern am 7. d. Mts. schon die neue Stellung an der Versuchsanstalt angetreten." ${ }^{600}$

598 UAG.Kur.6333 Bl. 9.

599 Zahlreiche Vorgänge und tabellarische Übersichten in: UAG.Kur.3441-3448. Solche Anträge mussten immer wieder neu gestellt werden. Teilweise kurz auf einander folgende Musterungsuntersuchungen und kurze Befristungen der Freistellungen machten dies notwendig.

600 UAG.Kur.7459. Bl. 358. Zuvor hatte Wiechert noch vergeblich versucht, selbst kriegswichtige Aufgaben für Repsold zu erhalten und sich an die „Geschäftsstelle der Kaiser Wilhelm-Stiftung für Kriegstechnische Wissenschaft [...] gewandt." UAG.Kur.3443 Bl. 215v und 221. 
Aber auch auf nichtwissenschaftlichem Gebiet, etwa bei den Handwerkern, wurden Arbeitskräfte immer knapper. Wozu dies in Kombination mit der Inflation und mangelnden finanziellen Mitteln führen konnte, hat das Beispiel des botanischen Gartens gezeigt. Auch hier verdeutlicht das Beispiel der Modellversuchsanstalt, was effektiv möglich gewesen ist, sofern man auf die Unterstützung des Militärs vertrauen konnte. Trotz aller finanziellen Mittel, die Ludwig Prandtl für den Neubau gewährt wurden, benötigte er noch Arbeiter, die diesen schließlich errichten konnten. Geld allein konnte hier nicht zum Ziel führen, da ja die privaten Bauunternehmen die gleichen Personalsorgen bewältigen mussten, wie alle anderen Betriebe und Einrichtungen auch. Männer, die im Baugewerbe wirklich leistungsfähig waren, gehörten natürlich zu den ersten Soldaten. Gerade größere Erdarbeiten, wie sie für die Modellversuchsanstalt jetzt anstanden, verlangten eine große Zahl von Arbeitern, sollte sich die Errichtung des Neubaus nicht über Gebühr hinauszögern.

Prandtl hatte hier verschiedene Möglichkeiten. Er konnte Bauarbeiter entweder selbst für die durchführenden Baufirmen reklamieren oder deren eigene Anträge auf Freistellung befürworten. ${ }^{601}$ Noch weiter ging er allerdings gegen Ende des Jahres 1915. Prandtl wandte sich am 27. November an das Kriegsministerium, offensichtlich mit der Bitte, die Bauarbeiten mit Soldaten, genauer mit Pionieren, zu unterstützen. ${ }^{602}$ Tatsächlich gewährte ihm dies das Ministerium, und am 11. Dezember erhielt Prandtl ein Schreiben des zuständigen Generalkommandos in Kassel, in dem ihm die Bedingungen für den Arbeitsdienst der Pioniere mitgeteilt wurden.

Das von Euer Hochwohlgeboren an das Kriegsministerium gerichtete Schreiben vom 27. November 1915 ist hierher zur Erledigung abgegeben worden. Es wird ergebenst ersucht, sich wegen Handwerkern mit dem Garnisonskommando Göttingen und dem PionierErsatz-Bataillon 11 in Hann.Münden unmittelbar in Verbindung zu setzen. Bemerket wird, dass eine Kommandierung von Mannschaften unzulässig ist, es kann sich nur um eine Beurlaubung obne Gebübrnisse handeln, vorausgeset₹t, dass die Mannschaften zu der Tätigkeit an dem beabsichtigten Bau freiwillig bereit sind. ${ }^{603}$

Sobald im Frühjahr 1916 die Arbeiten wieder aufgenommen werden konnten, nachdem sie vom Winter unterbrochen worden waren, forderte Prandtl dann die zusätzlichen Arbeitskräfte an. Auch von der Göttinger Garnison, dem Infanterieregiment 82, kamen einige Arbeitskräfte. Die meisten Arbeiter stellte jedoch das Pionier-Ersatz-Bataillon 11 aus Hannoversch Münden.

Durch eine Verfügung des stellv. Generalkommandos des XI.A.K. In Cassel (vom 11.Dez.1915) war mir gestattet worden, mich behufs Beurlaubung von Bauarbeitern für

601 DLR.GOAR.2641.

602 DLR.GOAR.2641 Die konkrete Anfrage ist nicht enthalten, aber die Antwort, in der sich darauf bezogen wird. 11.12.1915.

603 DLR.GOAR.2641 11.12.1915. 
den Neubau der Modellversuchsanstalt für Luftfahrt in Göttingen, der aus Heeresmitteln errichtet wird, an das Pionier-Ersatz-Bataillon 11 zu wenden.

Da die Bauarbeiten inzwischen eingestellt worden waren und erst jetzt nach Eintritt des guten Bauwetters wieder in grösserem Umfange aufgenommen wurden, erlaube ich mir nunmehr an das Bataillon das Gesuch zu richten, zunächst 3 ungelernte Bauarbeiter und 4 Maurer, obne Gebührnisse nach hier zu beurlauben. Was die Maurer betrifft, so bitte ich nur solche auszuwählen, die mit der Verarbeitung von Bruchsteinmanerwerk gut vetraut sind. Die Beurlaubungen bitte ich, wenn zulässig, auf die Zeit von 8 Wochen zu erteilen.

Die Arbeitsleute hätten sich auf der Baustelle, Göttingen, Böttingerstrasse bei dem Polier Rixner der Firma Gerdum und Breuer, die Maurer dagegen bei der Firma Gebr. Krafft, bier zu melden. ${ }^{604}$

Soweit dies feststellbar war, kann man davon ausgehen, dass Prandtl einmal mehr seine personellen Bedürfnisse voll durchsetzen konnte. Auch regelmäßige Verlängerungen der Freistellungen über die genannten acht Wochen hinaus ließen sich immer wieder erreichen. ${ }^{605}$

Trotz all dieser Bemühungen dauerten die Arbeiten das gesamte Jahr 1916 hindurch an, die Installation der Maschinenanlage und anderer wichtiger Einrichtungen darüber hinaus bis ins Frühjahr 1917. Bis dahin war allerdings die alte Modellversuchsanstalt in der Hildebrandtstraße schon ununterbrochen in Betrieb. Im März 1917 konnte Ludwig Prandtl dann endlich Bericht an das Große Hauptquartier, genauer an den kommandierenden General der Luftstreitkräfte, erstatten:

Ich beehre mich nunmehr Euer Exzellenz biermit den ersten Bericht ergebenst zu überreichen, wobei der Umstand die spezielle Veranlassung gibt, dass gestern, nachdem in den let_ten Wochen die elektrische Maschinenanlage fertig geworden war, der erste Versuch für die Praxis gemacht worden ist. ${ }^{606}$

Damit war es endgültig gelungen, ein Projekt von einer enormen Größe, das zwar seit langem geplant gewesen war, aber immer wieder vertagt wurde, doch noch zu verwirklichen. Dies alles geschah unter ausgesprochen schlechten äußeren Bedingungen. Aber es war gerade diese durch den Krieg so massiv veränderte Situation, die die Institute der Universität so stark beeinträchtigte, die dem Neubau der Modellversuchsanstalt den entscheidenden Impuls verlieh.

Die Ausführung des Baus und der inneren Einrichtung der Anstalt hat, wie so viele andere im Kriege fertig zu stellende Unternehmungen, grosse unvorhergesehene Schwierigkei-

604 DLR.GOAR.2641 Prandtl an das Pionier-Ersatz-Bataillon 11. Ohne Datum; wahrscheinlich Ende März 1916.

605 DLR.GOAR.2641.

606 DLR.GOAR.2639 20.03.1917. Abschrift des Berichts an das Große Hauptquartier für den Präsidenten der Kaiser-Wilhelm-Gesellschaft. 
ten und im Zusammenhang damit auch grosse Veränderungen in der Fertigstellung erlitten. Dass diese Schwierigkeiten überhaupt haben überwunden werden können, ist allein der tatkräftigen Unterstützung zu danken, die ich von Seiten der Militär- und Marinebehörden erfabren habe. ${ }^{607}$

Die Arbeiten

Um Art und Bedeutung der in der Modellversuchsanstalt durchgeführten Versuche verstehen zu können, empfiehlt es sich zunächst, einen kurzen Blick auf die Entwicklung der Flugtechnik dieser Zeit im Allgemeinen und der militärischen Fliegerei im Besonderen zu werfen. Prandtls Berufung nach Göttingen, der Bau der ersten Versuchseinrichtungen und schließlich die Fertigstellung der neuen Modellversuchsanstalt fielen in eine Zeit dramatischer Veränderungen. Erst am 17. Dezember 1903, also keine elf Jahre vor Ausbruch des Ersten Weltkrieges, waren die Gebrüder Wright zum ersten Mal geflogen, und erst 1906 unternahm Alberto Santos-Dumont den ersten Flug über europäischem Boden, der 21,5 Sekunden dauerte und eine Strecke von 220 Metern überwand. Die folgenden Jahre waren geprägt durch weitgehend sportlich motivierte Bemühungen. Es wurden zahlreiche Wett- oder Orientierungsflüge veranstaltet und unzählige Rekordversuche unternommen. Wie bereits erwähnt, war in Deutschland Prinz Heinrich von Preußen bei solchen Veranstaltungen stark engagiert.

Selbstverständlich entwickelten auch bald Militärs Interesse an der jungen Erfindung Flugzeug, dies allerdings zunächst nur zu Aufklärungs- und Beobachtungszwecken. Lange Zeit war den empfindlichen, mit Stoff bespannten Holzkonstruktionen wohl auch nicht mehr zuzutrauen. Der Erste Weltkrieg wirkte hier jedoch in beeindruckender Weise als Katalysator. Private Flugzeuge wurden zusammen mit ihren Piloten eingezogen, und so verfügte Deutschland über etwas mehr als 300 Flugzeuge bei Ausbruch des Krieges, England und Frankreich sogar über 1200. Allerdings existierte noch keine Luftwaffe oder Ähnliches als selbstständige Waffengattung. So waren in Deutschland die Flieger Teil der so genannten Verkehrstruppen. ${ }^{608}$

Schnell begannen die Piloten aus ihren zunächst noch unbewaffneten Flugzeugen heraus mit Pistolen aufeinander zu schießen, womit der direkte Weg zum fest eingebauten Maschinengewehr bereits eingeschlagen war. Noch während des Ersten Weltkrieges, gerade 15 Jahre nach den ersten Flügen der Gebrüder Wright, gab es Bombenflugzeuge mit Leergewichten von fast 10 Tonnen, drei bis vier Motoren und über 40 Metern Spannweite - außerdem fielen die ersten Bomben auf Wohngebiete.

607 DLR.GOAR.2639 20.03.1917. Abschrift des Berichts an das Große Hauptquartier für den Präsidenten der Kaiser-Wilhelm-Gesellschaft.

608 Siehe hierzu: Trischler: Luft- und Raumfahrtforschung. 1992. S. 90-94. 
Angesichts dieser rasanten Entwicklung kann man erahnen, mit welcher Vielzahl verschiedenster Arbeiten Ludwig Prandtl und seine Mitarbeiter konfrontiert wurden. ${ }^{609}$ Auftraggeber waren sowohl private Firmen als auch Militärbehörden. Den weitaus größten Teil der Untersuchungen für die Flugzeugfirmen machten Messungen an Einzelteilen und verschiedenen Baugruppen aus. An Tragflächen unterschiedlichen Profils wurden vergleichende Messungen bezüglich des zu erwartenden Auftriebs oder der möglichen Höchstgeschwindigkeit vorgenommen, oder bei Doppeldeckern die günstigste Anordnung der Tragflächen zueinander ermittelt. Großen Einfluss auf die Gesamtleistung eines Flugzeugs hatte außerdem sein Luftwiderstand, der zu großen Teilen durch notwendige Anbauteile bestimmt und begrenzt wurde. So war es etwa möglich, nur durch Form und Anbaupunkt des Motorkühlers große Verbesserungen zu erreichen. Auch an Fahrwerken und Ähnlichem ermittelte man den Luftwiderstand, und auch scheinbar kleine Dinge, wie die zahlreichen Streben und Drähte, die die einzelnen Flugzeugteile bei den immer noch sehr leichten Konstruktionen gegeneinander verspannen und abstützen mussten, offenbarten in Prandtls Versuchen großes Verbesserungspotenzial.

Aber nicht nur Flugzeuge oder deren Teile waren Untersuchungsgegenstand der Modellversuchsanstalt. Man untersuchte außerdem Geschossformen, Leitbleche von Bomben, Stoffe von Ballon- und Luftschiffhüllen, Schiffsschrauben oder Luftschiffhallen, die aufgrund ihrer enormen Größe größten Windkräften ausgesetzt waren. Auch an der Entwicklung von Instrumenten für die Luftfahrt war man beteiligt. So gab es immer noch keine Kompasse, die in Flugzeugen genau anzeigten und keinerlei Höhen- und Geschwindigkeitsmessgeräte.

Besonders bei den letztgenannten Punkten, aber auch bei allen anderen, wurde eine zielgerichtete, weitergehende Entwicklung nur dadurch ermöglicht, dass man die Fragestellungen mit den Methoden der exakten Wissenschaften anging. Bis dahin brauchte ein Flugzeugbauer vor allem Fingerspitzengefühl und Erfahrung, um schließlich bereits fertige Flugzeuge im praktischen Versuch zu erproben. Nun war es möglich, neue Ideen bereits vor dem Bau eines Flugzeugs im Versuch zu prüfen, weiterzuentwickeln oder gegebenenfalls gleich zu verwerfen. Auch einige Skurrilitäten fanden ihren Weg nach Göttingen, wie etwa die Idee eines Flugzeugs mit Schlagflächen, also Tragflächen, die in gewissen Flugsituationen zur Steigerung des Auftriebs schlagen sollten wie die Flügel eines Vogels. ${ }^{610}$

In der Modellversuchsanstalt wurde nur in seltenen Fällen am Original gearbeitet. Meistens benutzte man verkleinerte Modelle. In der Herstellung dieser hochpräzisen Miniaturen hatte man in Göttingen mittlerweile einige Erfahrung

609 Grundlage dieser und der folgenden Darstellungen bildet die umfangreiche und mehrere Meter starke erhaltene Kundenkorrespondenz der Versuchsanstalt, deren genaue Titel und Signaturen im Quellenverzeichnis dieser Arbeit zu finden sind. Die Akten sind innerhalb gewisser Zeiträume alphabetisch nach den Auftraggebern sortiert und werden hier nicht vollständig wiedergegeben. Es soll sich vielmehr auf einige aussagekräftige Beispiele beschränkt werden.

610 Vorschläge des Staatssekretärs im Reichsmarineamt A. Beldimann aus dem Jahr 1915.

DLR.GOAR.2654.1-2. 
gesammelt, allerdings nahm die Herstellung der Modelle einen großen Anteil der Arbeitszeit in Anspruch, die für einen Versuch benötigt wurde. ${ }^{611}$ Originalteile wären in den meisten Fällen zu groß für die Anlagen gewesen oder aus anderen Gründen nicht für die sehr speziellen Messinstrumente der Versuchseinrichtungen geeignet. Von den Firmen selbst hergestellte Modelle waren fast immer nicht ausreichend genau gefertigt. Oft waren die eingeschickten Zeichnungen und Maßangaben recht ungenau. So berichten die Ingenieure Hopf und Fuchs von der Flugzeugmeisterei von einer Dienstreise nach Göttingen über Prandtls Klagen Folgendes:

Die von den Firmen selbst gelieferten Modelle hätten bisher in allen Fällen versagt, die Firmen seien nicht einmal im Stande gewesen, Modelle, an deren Durchmessung sie selbst das grösste Interesse gehabt hätten, herzustellen. Es ist also am besten, wenn das Modell in G. [Göttingen] selbst hergestellt wird [...].Zu diesem Zweck benötigt G. rechtreitig vollständige Zeichnungen: Umriss und Profile der Flügel an verschiedenen Stellen, Rumpfansichten und -querschnitte, Leitwerk, Zusammenstellungszeichnung. 612

Zur Untersuchung angenommen wurde jedoch fast jede Vorlage, auch ganze Tragflächen, ungefüllte Geschosse oder einzelne Drähte oder Stoffstücke. An der Erprobung der Teile in der Praxis hatte man jedoch in den seltensten Fällen Anteil. Eine Ausnahme stellte hier die Teilnahme von Prandtls wichtigstem Mitarbeiter, Albert Betz, an Versuchsfahrten auf U-Booten dar. Betz hatte an den UBooten UC56, U25, U113 und U114 eine Vielzahl verschiedener Schiffsschrauben untersucht, die nach den Ergebnissen vorheriger Modellversuche hergestellt worden waren. Ziel dieser Versuche war es, die Geräuschentwicklung der Schrauben möglichst zu minimieren, um die Ortung der U-Boote durch den Gegner zu erschweren, ohne jedoch den Wirkungsgrad der Schrauben herabzusetzen. Zu diesem Zweck testete Betz zunächst möglichst leise Schrauben und versuchte dann, die entstandenen Leistungseinbußen auszugleichen. Offenbar im ganzen Jahr 1917 und Anfang 1918 wurden zahlreiche Versuchsfahrten unternommen, ${ }^{613}$ deren Ergebnisse in Tabellen festgehalten wurden. ${ }^{614}$ Vom 10. Oktober 1918 schließlich datiert dann Betz Abschlussbericht, in dem er die durchgeführten Versuche nochmals schildert und Vorschläge für die ,weitere Bearbeitung der Aufgabe“ macht. ${ }^{615} \mathrm{Zu}$ dieser weiteren Bearbeitung der Aufgabe kam es durch das

611 Die Technik zur Herstellung der Modelle beschreibt Wüst: Wüst: Sie zähmten den Sturm. 1991.

612 DLR.GOAR.1353 o.D. Aus dem „Bericht über die Dienstreise der Ing. Hopf und Fuchs nach Göttingen“.

613 Dies zeigen verschiedene Telegramme und Briefe aus dieser Zeit. So etwa ein Schreiben Prandtls an Prof. Dr. Ing. Gümbel bei der Inspektion des Unterseebootswesens in Kiel vom 23.02.1918 „In der Zeit zwischen Weihnachten und Mitte Februar haben wir von hier aus nacheinander fünf Entwürfe für U-Bootschrauben an die U.I. geschickt (3 vollständige Entwürfe und 2 Abänderungen des Teils an der Nabe) [...]. Bitte um Bestätigung.“" DLR.GOAR.1239

614 Die Tabellen sind in der Akte DLR.GOAR.1239 erhalten.

615 DLR.GOAR.1239 10.10.1918. 
Kriegsende allerdings nicht mehr, worauf Betz seine wissenschaftlichen Erkenntnisse in einem Aufsatz über die „Geräuschminderung bei Schiffsschrauben“ im Dezember 1918 zusammenfasste. ${ }^{616}$

Wesentlich typischer für die alltäglichen Arbeiten war da etwa der Auftrag der Firma Albatros, die am 19. Mai an die Modellversuchsanstalt schrieb:
Im Auftrage der Inspektion der Fliegertruppen sandten wir an Sie 1 unteres Tragdeck D III [i.e. die untere der beiden Traglächen eines Doppeldeckers], sowie eine Anzahl Rippen zur Untersuchung der Druckpunktswanderung. Über den Ausgang der Versu- che erbitten wir umgehenden Bescheid.617

Allein die Kürze und Sachlichkeit dieses Schreibens zeigt, wie selbstverständlich Versuche dieser Art waren, denn Briefe wie dieser trafen täglich ein. Und auch die Schwierigkeiten waren täglich die gleichen.

\section{Die Modellversuchsanstalt bestätigt hiermit den Empfang des in Ihrem Schreiben vom 19. d.M. angekündigten unteren Tragdecks DIII. Wie der Inspektion der Fliegertrup- pen bereits vor einiger Zeit mitgeteilt, werden wir die Versuche daran nicht ausführen können, sondern sie an einem Modell vornehmen. Wir bitten deshalb, uns eine Rippen- zeichnung des Flügels zu übersenden, oder, falls wir diese schon besitzen, uns die Be- zeichnung des Profils anzugeben. ${ }^{618}$}

Wie bereits erwähnt, waren die Angaben, nach denen Modelle für den Versuch angefertigt wurden, oft mangelhaft. Um wenigstens verhindern zu können, dass identische Versuche mehrfach ausgeführt oder Modelle doppelt hergestellt wurden, hatte man im Bereich der Tragflächen die verschiedenen Profile nach einem Schema nummeriert und konnte so bei Bedarf wieder darauf zugreifen. Schließlich, am 27. Juni 1918, schickte Dipl.-Ing. Max Munk die eingesandte Tragfläche zurück nach Berlin an die Gesellschaft für Flugunternehmungen m.b.H Albatros, wie sie mit vollem Namen hieß. Anbei befanden sich wie immer die Messergebnisse und ein Vorschlag für die nach wissenschaftlichen Kriterien günstigste Form. ${ }^{619}$

Erstaunlich ist, dass die Militärbehörden im Wesentlichen den Privatunternehmen in der Behandlung gleichgestellt waren. Ein regelmäßiger Kunde der Modellversuchsanstalt war beispielsweise die Artillerieprüfungskommission, die unter anderem für die Erprobung und Einführung neuer Geschütze und deren Geschosse beim deutschen Heer zuständig war. Auch sie suchte im Mai 1917 Hilfe in Göttingen.

Für eine neu zur Einführung kommende Flügelmine [i.e. sehr schweres Geschoss, ähnlich einer Granate] ist es diesseits von groszem Wert, die wichtigsten ballistischen Eigenschaften experimentell festzustellen. Hierzu würde sich vermutlich das dortige Institut
616 DLR.GOAR.1239 03.12.1918.
617 DLR.GOAR.106 19.05.1917.
618 DLR.GOAR.106 30.05.1917.
619 DLR.GOAR.106 27.06.1917. 
eignen. Die Mine, nach der beigefügten Skizze, wird aus einem glatten Minenwerfer mit rd. $115 \mathrm{~mm}$ Anfangsgeschwindigkeit abgeschossen und zwar mit Erhöhungswinkel von 50-750. Die Flügel (2 kreurweise gestellte Bleche) sollen die Mine so steuern, dasz sich ihr Flug der Flugbahn möglichst vollkommen anschmiegt.

[...] Zur Besprechung von Einzelheiten würde ein diesseitiger Vertreter [der Artillerieprüfungskommission] nach dort [zur Modellversuchsanstalt] gesandt werden. ${ }^{620}$

Für die Untersuchungen an dem später 100 Kilogramm schweren Geschoss sollten verschiedene Modelle bei unterschiedlichen Neigungswinkeln und Geschwindigkeiten untersucht werden. In der Antwort Prandtls auf diese Anfrage spiegelt sich dann die ganze Routine wieder, die man mittlerweile bei solchen Versuchen hatte.

Untersuchungen wie die gewünschte sind von uns mehrfach schon gemacht, hauptsächlich an Fliegerbomben. Wir bitten ein geometrisch getreues Modell ungefähr im balben Masstab des Originals einzusenden, das möglichst nicht über $5 \mathrm{~kg}$ wiegen soll. Der Körper wird zweckmässig aus Holz hergestellt und poliert, der Flügelkërper aus Blech. Wo der Schwerpunkt des Modells liegt, ist dabei gleichgültig.

Wir werden Ibnen Grösse und Lage der Resultierenden [sic!] bei einer Reibe von Winkeln zwischen Körperachse und Flugrichtung angeben; aus diesen Angaben werden sie das, was sie zu wünschen wissen, entnehmen können. ${ }^{621}$

Mit seiner Erfahrung konnte Prandtl dann auch das Angebot, einen Vertreter der Artillerieprüfungskommission geschickt zu bekommen, dankend ablehnen. ${ }^{622}$ Die insgesamt sechs verschiedenen Modelle waren einen Monat später fertiggestellt und als Eilgut nach Göttingen gesandt worden. ${ }^{623}$ Einen Monat später konnte Max Munk die Ergebnisse der Versuche zurück nach Berlin schicken. ${ }^{624}$ Die genannte Gleichstellung von privaten und militärischen Auftraggebern setzte sich aber auch über den Abschlussbericht der Versuche hinaus fort. Auch Militärbehörden mussten für die geleisteten Arbeiten bezahlen. „Bei der Durchsicht unserer Bücher stellen wir fest, dass der Betrag vom M 80,-- laut beifolgender Rechnung noch unbeglichen ist. Wir bitten höflichst um Überweisung desselben auf unser Konto ,Aeronautik' beim Bankverein Göttingen. “625 Die Zahlungsmoral ließ jedoch zu wünschen übrig. Die geforderte Überweisung erfolgte erst am 30. Oktober. ${ }^{626}$

\footnotetext{
620 DLR.GOAR.106 16.05.1917.

621 DLR.GOAR.106 19.05.1917.

622 DLR.GOAR.106 19.05.1917.

623 DLR.GOAR.106 21.06.1917.

624 DLR.GOAR.106 27.07.1917.

625 DLR.GOAR.106 24.08.1917.

626 DLR.GOAR.106 30.10.1917.
} 
Die hier dargestellten Einzelfälle stellen selbstverständlich nur einen kleinen Ausschnitt aus einer großen Menge fast identischer Vorgänge dar. Die Auslastung der Modellversuchsanstalt war ganz offensichtlich vollständig, was sich besonders auswirkte, solange die Neubauten noch nicht fertiggestellt waren und alle Versuche noch in der alten Modellversuchsanstalt durchgeführt werden mussten. Aus diesem Grund musste Ludwig Prandtl beispielsweise im Februar 1917 an Professor von Parseval in Berlin, der seit längerer Zeit als Luftschiffkonstrukteur bekannt war und nun an Hubschraubenversuchen arbeitete, einen Brief mit hinhaltendem Charakter schreiben.

Ich hoffe, dass Sie mit der Anfertigung [der zu untersuchenden Modelle] einige Zeit zu tun haben werden; bis dabin dürfte die neue Anstalt soweit sein, dass man die normalen Versuche in ibr machen kann. Einstweilen arbeitet die alte Anstalt wie nie vorher; 3 Modelle pro Tag, teilhveise unter Benützung der Abendstunden. Da ibre Versuche nicht an einem Tage gemacht werden dürften, könnte ich Ihnen zur Zeit nicht einmal den alten Luftstrom anbieten. Aber das wird ja, wie schon enwähnt, in einigen Monaten besser. ${ }^{627}$

In den Berichten und Protokollen der Sitzungen des Betriebsausschusses finden sich genauere Zahlen zu den durchgeführten Versuchen. So wurden in der Zeit vom 1. August 1917 bis zum 1. Februar 1918 im Ganzen 440 Messungen durchgeführt, was in etwa Prandtls Angabe gegenüber von Parseval von circa drei Versuchen pro Tag entsprechen dürfte. Zusammen konnten dafür 24699 Mark Gebühren eingenommen werden, davon allein 20289 Mark von Privatunternehmen. ${ }^{628}$ So früh nach der Inbetriebnahme der neuen Einrichtungen wurden noch die meisten Versuche in der alten Modellversuchsanstalt durchgeführt (297 Messungen), darunter auch 79 , in eigenem Auftrag der Anstalt.“629 Dabei handelte es sich allerdings keineswegs um eigene Forschungen, sondern vielmehr um die Klärung von weiterreichenden Fragen, die sich aus der normalen Arbeit ergaben und die schlicht keinem einzelnen Auftraggeber zuzuordnen waren, wie zum Beispiel die Frage nach der Vergleichbarkeit der Ergebnisse des alten und des neuen Kanals oder die Eichung der Messinstrumente. Aber schon recht bald verschoben sich die Anteile der Versuchszahlen hin zur neuen Modellversuchsanstalt. Für die Zeit vom 1. März bis zum 1. Juni 1918 wurden in der alten Anstalt 106 Messungen durchgeführt, denen bereits 160 in der neuen Anstalt gegenüberstanden. ${ }^{630}$ Allerdings waren von diesen 160 Messungen 97 in eigenem Auftrag, was mit Eichung und Tests der neuen Anlagen zu erklären ist.

627 DLR.GOAR.1360 12.02.1917.

628 DLR.GOAR.2637 Bl. 2 des Protokolls der 2. Sitzung des Betriebsausschusses vom 05.02.1918.

629 DLR.GOAR.2637 Bl. 2 des Protokolls der 2. Sitzung des Betriebsausschusses vom 05.02.1918.

630 DLR.GOAR.2637 Anlage 1 des Protokolls der 2. Sitzung des Betriebsausschusses vom 10.06.1918. 
Neben den hohen Versuchszahlen, die immer wieder von Forderungen nach mehr Personal begleitet wurden, ${ }^{631}$ um die Arbeit bewältigen zu können, ist vor allem die große Anzahl verschiedener Auftraggeber auffallend. Für die insgesamt 263 Messungen in Firmenauftrag zwischen August 1917 und Februar 1918 treten für die alte Anstalt 17 verschiedene und für die Neue nochmals elf Unternehmen als Auftraggeber auf.632

Dies zeigt nicht nur, wie vielfältig die noch junge Flugzeugindustrie war. Die Betrachtung der großen Anzahl von Versuchen und der vielen verschiedenen Auftraggeber wirft die Frage nach der Organisation der Versuchsarbeiten auf. Welche Aufträge wurden angenommen, welche wurden abgelehnt, und gab es Sonderkonditionen für gewisse Gruppen oder Ähnliches? Bei der Durchsicht der Kundenkorrespondenz der Modellversuchsanstalt findet sich die Antwort auf solche Fragen sehr schnell: Die Militärbehörden hatten durch den Betriebsausschuss einen zwar komplizierten, aber sehr effektiven Mechanismus installiert, der ihnen die Kontrolle über die auszuführenden Arbeiten sicherte. Da es zunächst noch keine selbstständige Luftwaffe gab, unterstanden die Flieger der so genannten Inspektion der Fliegertruppen (IdFlieg) innerhalb der Verkehrstruppen, mit Sitz in Berlin und Nachbarschaft zur Deutschen Versuchsanstalt. Wie in allen rüstungsrelevanten Fragen herrschte selbstverständlich auch bei der Entwicklung neuer Flugzeugtypen strengste Geheimhaltung, was natürlich bedeutete, dass ein Zugang zu den neuen Forschungseinrichtungen nur über die Militärbehörden möglich war - also nur mit deren Wissen und unter deren Aufsicht.

Zur Durchsetzung dieses durch die fast alleinige finanzielle Trägerschaft erworbenen Anspruchs wurde bei der Inspektion der Fliegertruppen die Wissenschaftliche Auskunftei für Flugwesen (W.A.F.) gegründet. Diese verschickte an Firmen, die an neuen Flugzeugen arbeiten wollten und sich dort registrieren lassen mussten, die so genannten Technischen Berichte, allerdings nur unter der Voraussetzung, dass man den strengen Geheimhaltungsvorschriften zustimmte:

Die Uebersendung der Technischen Berichte der Flugzeugmeisterei erfolgt eingeschrieben.

Jeder Bezieher erhält stets die gleichen Abdruck-Nummern. Auf der jedem Heft beigefügten Empfangsbescheinigung ist vorgedruck.t, daß die Einsendung der Empfangsbescheinigungen ,Eingeschrieben' zu erfolgen hat. Es ist deshalb unzulässig, wenn die Zusendung der Empfangsbescheinigungen durch gewöhnlichen Postverkehr erfolgt.

Ich bitte um pünkttiche Einsendung der Empfangsbescheinigungen, da nur bei ordnungsgemäßem Eingang derselben, die Einrichtung der ,Technischen Berichte’ beibehalten werden kann.

631 Beispielsweise in dem „Bericht über die Dienstreise der Ing. Hopf und Fuchs nach Göttingen“ unter Punkt 10. DLR.GOAR.1353 o.D.

632 DLR.GOAR.2637 Bl. 3 des Protokolls der 2. Sitzung des Betriebsausschusses vom 05.02.1918. 
Ich ersuche die Flugzengfirmen, die Empfangsbescheinigungen unmittelbar, d.h. nicht über ibre Bau-Aufsicht an die auf den Empfangsbescheinigungen vorgesebene Anschrift zu senden.

Ich erwarte, daß die Bezieher der ,Technischen Berichte' die einzelnen Hefte gleicher Abdruck-Nummern ge s a $m$ m e l t verwahren.

Diejenigen Herren, welche die ,Technischen Berichte' infolge ihrer dienstlichen Stellung erhalten, bitte ich, bei der Aufgabe ihrer Stellung die Hefte gegen Empfangsbescheinigung an den Nachfolger zu übergeben und das Geschehene an die Flugzengmeisterei, Wissenschaftliche Auskunftei für Flugwesen, Charlottenburg 5, eingeschrieben, mitzuteilen.

Anschriftenänderungen sind unverzüglich ebenfalls der Flugzeugmeisterei, Wissenschaftliche Auskunftei für Flugwesen, Charlottenburg, aufzugeben. 633

War man schließlich Mitglied dieses „Unternehmens“, wie Ludwig Prandtl es oft nannte, konnte man Anfragen an die Modellversuchsanstalt richten, wenn nicht, wurde man teilweise recht schroff abgewiesen und auf den offiziellen Weg verwiesen. So fragte etwa die Firma Mannesmann Waffen- und Munitionswerke an, ob es möglich sei, Informationsmaterial über Rumpfformen und Flügelprofile zu erhalten.

Auf Ihre geschätrte Anfrage erwidere ich, dass die Modellversuchsanstalt sowohl ihren Vereinbarungen mit den Militärbebörden, wie auch der Massgabe ibrer Arbeitskräfte nicht in der Lage ist, Ihnen Versuchsmaterial zur Verfügung zu stellen. Der einzig gangbare Weg ist der, dass Sie sich mit der Flugzengmeisterei W.A.F. (= Wissenschaftliche Auskunftei für Flugwesen), Charlottenburg 5., in Verbindung setzen, welche unser Material in den ,Technischen Berichten der Flugzengmeisterei' hat abdrucken lassen. Diese ,TB' werden den Flugzeugfirmen gegen gewisse Verpflichtungen zur Geheimhaltung ausgehändigt. 634

Ein weiterer wichtiger Aspekt neben der Abschottung des W.A.F.-Unternehmens nach außen war die Transparenz im Inneren. Versuche sowie die damit im Zusammenhang stehenden Entwicklungen mussten der Auskunftei mitgeteilt werden. Darüber hinaus wurden sie auch in den oben genannten Technischen Berichten veröffentlicht und damit allen anderen teilnehmenden Flugzeugfabriken zur Verfügung gestellt. Für Prandtl waren diese Technischen Berichte von großer Bedeutung, da sie das einzige Publikationsorgan für ihn darstellten. Jede andere Form der Verwertung der Ergebnisse seiner Arbeit verbot ja die Geheimhaltung. Damit wurden zunächst zwar nur die W.A.F.-Mitglieder erreicht, aber zumindest wurde vorerst verhindert, dass die Masse der erzielten Versuchsergebnisse für spätere wissenschaftliche Arbeiten verloren gingen. Diese Angst war bei Prandtl

633 DLR.GOAR.1353 19.04.1917. Rundschreiben der Wissenschaftlichen Auskunftei für Flugwesen an alle Bezieher der Technischen Bericbte.

634 DLR.GOAR.1360 23.02.1918. 
durchaus vorhanden, und er begann schon recht früh diesbezüglich Vorsorge zu treffen. Bereits im Frühjahr 1917 fühlte er bei Oberleutnant Hoff von der Wissenschaftlichen Auskunftei für Flugwesen vor.

Weiter brachte Professor Pröll [Hannover] zur Sprache, welchen Standpunkt wobl die W.A.F. einnehmen würde, dass Aufsätze, die jetzt für die T.B. geliefert werden, im Frieden noch in einer anderen Zeitschrift abgedrucket werden würden, um sie weiteren Kreisen zugänglich zu machen. Auch mir scheint die Klärung dieser Angelegenheit von recht grosser Wichtigkeit. Man würde, um eine Beeinträchtigung derjenigen wissenschaftlichen Interessen, wie sie in Friedenszeiten in Geltung sind, zu vermeiden, entweder die Auflage der für den Frieden zurückzulegenden Exemplare der T.B. ziemlich reichlich wählen müssen, um alle Bibliotheken und privaten Interessenten damit versorgen zu können, oder man würde für solche Aufsätze, die nicht etwa auch im Frieden der vollen Oeffentlichkeit vorenthalten werden sollen, das Recht zu einer zweiten Veröffentlichung zugestehen müssen. Ich selbst bin in meiner Eigenschaft als wissenschaftlicher Leiter der Zeitschrift für Flugtechnike und Motor-Luftschiffahrt in der Angelegenheit nicht unparteiisch, und stimme natürlich mehr für den letzteren Modus, der übrigens den ersteren keineswegs auszuschließen braucht. 635

Hoff konnte Prandtl in dieser Hinsicht jedoch beruhigen, indem er ihm versicherte, dass die Flugzeugmeisterei hier für die Nachkriegszeit keinerlei gegensätzliche Interessen anmelden würde und dass bereits regelmäßig mindestes 750 überzählige Exemplare der Technischen Berichte gedruckt würden, die später zur Verfügung ständen.

Der Entstehung der ,T.B.' entsprechend, kann meiner Ansicht nach bei der Flugzengmeisterei nach Friedensschluss nur die Absicht bestehen, vor Herausgabe aller, Technischen Berichte' in den Verkehr zunächst die Zustimmung zur Veröffentlichung für den einen oder anderen dringlich erachteten Aufsatz der ,T.B.' zu erteilen. Die ,Technischen Berichte der Flugzeugmeisterei' sind kein Erwerbsunternebmen, sondern aus dem Gefühl beraus entstanden, einen Ersatz für die durch die Zensur stark eingeengten Fachzeitschriften zu finden. Ich glaube nicht, dass die Flugzengmeisterei andere Rechte als die der Zustimmung zur Veröffentlichung geltend machen wird. Eine Entscheidung in dieser Frage jetzt herbeizufübren, halte ich für unrichtig, sie bleibt am besten einer späteren Zeit vorbehalten. 636

Bei aller Bedeutung, die die Technischen Berichte für Prandtl hatten, bestand allerdings zwischen der Militärbehörde und den Flugzeugfirmen auf diesem Gebiet ein erheblicher Interessenkonflikt. Die Inspektion der Fliegertruppen hatte größtes Interesse daran, dass möglichst schnell genaue Erkenntnisse an alle Konstrukteure gelangten. Man wollte neue Ideen und neue Erfindungen allen Firmen zugänglich machen, da man kurzfristig wirksame Waffen brauchte. Dies konnte

635 DLR.GOAR.1353 01.03.1917.

636 DLR.GOAR.1353 05.03.1917. 
aber nur erreicht werden, sofern alle, die Flugzeuge entwarfen, auch immer auf dem aktuellsten Kenntnisstand waren. Für die Firmen waren die Prioritäten natürlich anders verteilt. Wichtig war ihnen nicht unbedingt, dass dem Militär das nach dem jeweiligen Stand der Erkenntnisse bestmögliche Flugzeug zur Verfügung stand, sondern dass das Militär das Produkt der eigenen Firma beschaffte. Wollte man sich also einen Vorteil gegenüber seinen Konkurrenten sichern, konnte es wenig sinnvoll sein, neue Ideen vorab in Göttingen untersuchen zu lassen. ${ }^{637}$

Die wohl unglücklichste Rolle in diesem Konflikt fiel allerdings Prandtl zu, so dass er sich schließlich an Oberleutnant Hoff, seinen wichtigsten Ansprechpartner in Berlin, wandte.

Wir werden hier über das, was die Firmen aufgrund unserer Resultate erreichen, fast gänzlich in Unkenntnis gelassen. Es wäre für unsere Arbeiten sehr förderlich, wenn wir, sei es von den Firmen, sei es von der Fl\%. [Flugzeugmeisterei], von den jeweiligen aerodynamischen Fortschritten in solcher Weise unterrichtet werden, dass wir daraus etwas entnehmen können, sei es, dass diese Fortschritte auf Grund unserer Arbeiten oder trotz unserer Arbeiten erreicht wurden. ${ }^{638}$

Er saß gleichsam zwischen den Stühlen. Ohne jeden Zweifel stand er natürlich zunächst seinen Geldgebern gegenüber in der Pflicht. Den Löwenanteil seiner Aufträge erhielt er jedoch von Privatfirmen. Bezogen diese ihn aus Angst vor Industriespionage nun nicht mehr in ihre wichtigsten Projekte mit ein und ließen Erfindungen entweder gar nicht mehr oder nur in völlig aus dem Zusammenhang gerissenen, quasi atomisierten Details untersuchen, konnte die Modellversuchsanstalt nicht mehr effektiv arbeiten. Daher wandte sich Prandtl an den Betriebsausschuss. Er machte einen Vorschlag zur Änderung der W.A.F.-Bestimmungen, ließ ihn zunächst Hoff zukommen und brachte die Problematik dann auf die Tagesordnung des Betriebsausschusses. In dem Begleitschreiben zu seinen Änderungsvorschlägen an die Mitglieder ergriff er deutlich Partei für seine Kunden.

Die W.A.F. stellt den ihr angebörigen Flugzeugfabriken Bedingungen, die in mancher Hinsicht als ungewöhnlich bezeichnet werden müssen. Einige Firmen sind daher der W.A.F. nicht beigetreten, die übrigen Firmen empfinden z.T. die Bedingungen als sehr lästig und möchten sich ibnen, soweit wie möglich entziehen. Hierunter leidet das $\mathrm{Zu}$ sammenarbeiten zwischen M.V.A. und den W.A.F.-Firmen. Es kommt hinzu, dass die Vorteile, die die W.A.F.-Firmen geniessen, im Grunde nur in einer Benachteiligung der übrigen Firmen bestehen, da diesen Firmen streng genommen jede Lieferung von Messungen und Auskünften seitens des M.V.A. versagt werden müsste. Diese Versagung erscheint andernteils ungerechtfertigt und hart, da manche Firmen schon vorher mit der

637 DLR.GOAR.2637 Bl. 60. Prandtl schildert die Problematik ausführlich in einem Schreiben an die Mitglieder des Betriebsausschusses.

638 DLR.GOAR.1353 09.07.1917. 
M.V.A. zusammen gearbeitet haben und die Aenderung der Bedingungen ja nicht von der Firma ausgeht. ${ }^{639}$

Nun stieß Prandtl jedoch sehr schnell an die Grenzen seiner Möglichkeiten. Die Stimmenverhältnisse im Betriebsausschuss waren klar verteilt, und die Militärbehörden hatten keinerlei Interesse daran, irgendwelchen Veränderungen der Bestimmungen zu Gunsten der Firmen zuzustimmen. Der Kern von Prandtls Vorschlägen bestand darin, die auftraggebende Firma und das betreffende Projekt nicht mehr zu nennen, sondern sowohl in den Technischen Berichten als auch der Flugzeugmeisterei gegenüber nur noch „das rein wissenschaftliche Ergebnis“ zu veröffentlichen und gegebenenfalls, im Falle einer „wirklichen Erfindung“, auf Antrag der Firma die Veröffentlichung sogar ganz zu unterlassen. ${ }^{640}$ Hoff machte ihm im wahrsten Sinne des Wortes postwendend klar, dass er die Bedenken einzelner Firmen für irrelevant hielt und es als ausgeschlossen erachtete, dass die Militärbehörden Aufsichtsbefugnisse abtreten würden, die ja dann de facto Prandtl übernommen hätte, da er der Einzige gewesen wäre, der die Auftraggeber und die vollständigen Projekte gekannt hätte und auch hätte entscheiden müssen, welche Erfindungen veröffentlicht worden wären und welche nicht.

Keinesfalls wird die Flugzengmeisterei mit dem Vorschlag einverstanden sein, dass sie bezw. die W.A.F. lediglich das wissenschaftliche Ergebnis, das sich aus der Messung ergibt, obne Nennung der Firma mitgeteilt erhält. Ich glaube, dass Sie bezüglich der Geschäftsgeheimnisse in der Flugzeugindustrie sich eine grössere Vorstellung machen, als es notwendig ist. Die Flugzengindustrie ist derart auf den Erfahrungsaustausch mit den Offizieren und Ingenieuren der Fliegertruppe angewiesen, dass es eigentlich ein Geschäftsgeheimnis im Sinne anderer Industrie zur Zeit nicht gibt. ${ }^{641}$

Möglicherweise entsprang Prandtls abweichende Sicht der Dinge der Tatsache, dass er sich sozusagen näher am Geschehen befand und den engeren Kontakt zu den Firmen hatte. Hoff machte jedoch deutlich, dass es Punkte gab, in denen keine Diskussionsbereitschaft bestand.

Es wird gut sein, wenn diese Punkte bei der Betriebsausschusssitzung eingehend beraten werden. Ich hielt es jedoch für richtig, Sie schon vorher davon zu unterrichten, dass die Flugzengmeisterei Ihren Vorschlägen gegenüber, welche allerdings bis jetzt noch nicht durch gegenseitige Aussprache begründet worden sind, ablehnend sein wird.642

Anderen Vorschlägen Prandtls gegenüber war er deutlich aufgeschlossener. Die Punkte vier, fünf und sechs der insgesamt sieben, die Prandtl aufgeführt hatte, behandelten im Wesentlichen einen stärkeren Einfluss Prandtls auf die durchzuführenden Arbeiten. Er wollte unter anderem eine Auskunftsstelle für aerodyna-

639 DLR.GOAR.2637 Bl. 60.

640 DLR.GOAR.2637 B1. 60.

641 DLR.GOAR.2637 Bl. 61, 2.

642 DLR.GOAR.2637 Bl. 61, 3. 
mische Fragen in Göttingen einführen und vor allem selbstständig entscheiden, ob ein Versuch überhaupt durchgeführt werden sollte oder ob eine Frage aufgrund bereits gesammelter Ergebnisse durch die Auskunftsstelle beantwortet werden konnte. ${ }^{643}$ Bis dahin musste die Modellversuchsanstalt Messungen durchführen, wenn sie den Auftrag dazu erhielt, auch wenn sie zuvor ganz ähnliche Versuche bereits gemacht hatte.

In der Sitzung des Betriebsausschusses am 23. Juli 1917 wurden Prandtls Vorschläge unter Tagesordnungspunkt sieben beraten. Wie Hoff prophezeit hatte, wurde der Einrichtung einer Auskunftsstelle zugestimmt. ${ }^{644}$ Die ,gewissen Schwierigkeiten, die sich im Verkehr zwischen der Modellversuchsanstalt und den Flugzeugfirmen" ergaben und über die Prandtl berichtete, tat man jedoch dadurch ab, dass man kurzerhand „feststellte“, dass ,in Kürze“ alle Firmen den Bedingungen zugestimmt haben würden. ${ }^{645}$ Immerhin rang man sich zu dem Zugeständnis durch, dass die Firmen ihre Identität zwar nicht vor der Flugzeugmeisterei verbergen konnten, aber zumindest nicht zwingend in den Technischen Berichten erwähnt werden mussten - dies galt jedoch nicht für die in Auftrag gegebenen Versuche. ${ }^{646}$ Nach dem so beschlossenen Modus wurde dann bis zum Kriegsende weitergearbeitet. Es fällt schwer, in diesem Zusammenhang vom Erreichen eines Kompromisses zu sprechen, obwohl man den tatsächlichen Ablauf der Sitzung des Betriebsausschusses den Protokollen natürlich nicht entnehmen kann. Die Stimmenverhältnisse und damit ganz konkret die Machtverhältnisse im Betriebsausschuss waren einfach zu deutlich zu Gunsten der Militärbehörden verteilt.

Kriegsende und Bewertung des Gesamtbilds

Das Bild der alltäglichen Arbeiten in der Modellversuchsanstalt änderte sich erwartungsgemäß nicht. Für die gesamte Kriegszeit kann man feststellen, dass man sich hauptsächlich mit Detailfragen befasste. Sehr selten wurden Prandtl oder seine Mitarbeiter um die Begutachtung eines vollständigen Projekts gebeten oder in die Entwicklung einer neuen Idee durch eine Flugzeugfirma einbezogen. Als Summe der Vielzahl an Versuchen kann zumindest eines als sicher angenommen werden: Die Modellversuchsanstalt entwickelte zu keiner Zeit eigeninitiativ Waffen. Die Modellversuchsanstalt in Göttingen stellte lediglich passiv wissenschaftliches Know-how bereit, zu dem die Militärbehörden den Zugang durch die Industrie überwachten und regulierten. Es war nicht so, dass man an weitergehenden und eigenständigen Arbeiten auf Göttinger Seite kein Interesse gehabt hätte, wie nicht zuletzt Prandtls weitgehend gescheiterter Versuch zeigte, enger in die Arbei-

\footnotetext{
643 DLR.GOAR.2637 Bl. 60.

644 DLR.GOAR.2637 Bl. 68a, 7.

645 DLR.GOAR.2637 Bl. 68a, 6.

646 DLR.GOAR.2637 Bl. 68a, 7.
} 
ten der Industrie eingebunden zu werden. Realistisch betrachtet hätte man aber auch gar nicht die Zeit gefunden, eigenen Ideen nachzugehen. Die Anlage und das Personal waren von ihrer Gründung bis zum Kriegsende vollständig ausgelastet.

Außerdem ist fraglich, ob man in militärischen Kreisen tatsächlich Interesse an solchen Arbeiten gehabt hätte, wie der einzige nachweisbare Versuch Ludwig Prandtls zeigt, einen eigenen Vorschlag einzubringen. Die Tatsache, dass Prandtl diesen ausgerechnet in seinem Urlaub im Winter 1916 formulierte, zeigt zum einen, wie vollständig seine Auslastung in Göttingen gewesen ist und zum anderen, wie stark seine Identifikation mit den Themen seiner Arbeit gewesen sein muss. Im Januar 1916 wandte sich Prandtl aus Garmisch an Professor Dr. C. Cranz.

Erschrecken Sie nicht, wenn ich heute als, Erfinder' zu Ihnen komme. Es betrifft eine Sache, an der ich schon lange herumdenke, die aber noch nicht richtig reif geworden ist. ${ }^{647}$

Bei dieser „,noch nicht ganz reifen Sache“ handelte es sich um den Entwurf einer Artilleriegranate unter Berücksichtigung der aktuellen Erkenntnisse aus der Strömungsforschung zur Steigerung der Reichweite und der Zielgenauigkeit. Der auffallend spitze Geschosskörper sollte sich im Gegensatz zu einer herkömmlichen Granate auch nach hinten verjüngen, was allerdings seine Führung durch das Geschützrohr unmöglich gemacht hätte. Prandtl wollte dieses Problem durch einen separaten Führungskörper lösen, in dem das eigentliche Geschoss befestigt war und der sich nach dem Verlassen der Mündung durch eine kleine Sprengladung von ihm trennen sollte. Professor Cranz legte diese Idee der Artillerieprüfungskommission vor, deren Präsidium sich schon bald darauf bei Prandtl meldete. Zunächst dankte man ihm in einem betont knapp gehaltenen Schreiben „für das Interesse, das Sie [Prandtl] an der Verbesserung der Kampfmittel bekunden“648 um dann unmissverständlich klar zu stellen, dass man seinen Vorschlag weder für neu noch für nützlich erachte und deshalb keinerlei Interesse habe.

Neu ist aber weder die Vervendung eines auch binten zugespitzten und somit torpedoartigen Geschosskörpers, noch die Verwendung eines Führungskörpers [...]. Neuartig ist nur die Verbindung von Geschoss und Führungsstück, durch eine Schraube, die z.B. durch eine besondere Pulverladung losgerissen werden soll. Mit diesem Vorschlage könnte sich das Präsidium [der Artillerieprüfungskommission] nicht anfreunden. ${ }^{649}$

Mit dieser schroffen Ablehnung hatte Prandtl ganz offensichtlich nicht gerechnet, glaubte jedoch weiterhin an seine Erfindung. Umgehend reichte er eine Abschrift seines Vorschlages bei der Firma Krupp, namentlich bei Professor von Eberhardt, ein.

\footnotetext{
647 DLR.GOAR.2654.1 12.01.1916. Die in dieser Akte enthaltene Konzeptschrift seines Briefes an Professor Cranz ist ausgesprochen schlecht lesbar. Die Details lassen sich jedoch aus einer beigefügten Zeichnung und den Antwortschreiben entnehmen.

648 DLR.GOAR.2654.1 13.02.1916.

649 DLR.GOAR.2654.1 13.02.1916.
} 
Da ich trotz dieses ablebnenden Urteils der Artillerieprüfungskommission die Möglichkeit [für] nicht ganz ausgeschlossen halte, daß irgendeiner der ausgesprochenen Gedanken eine praktisch anwendbare Anregung enthalten könnte, habe ich mir erlaubt, eine Abschrift meines Berichts Ihnen für die Firma Krupp qu überreichen. 650

Prandtl bat von Eberhardt um eine Äußerung darüber, ob er seine Idee für durchführbar hielt und bot seine Unterstützung für den Fall an, dass man sich näher damit beschäftigen wollte. Außerdem stellte er, um möglichen Spekulationen entgegen zu treten, seine Motivation klar.

[...] so möchte ich gleich bier erklären, daß ich mir für meine, Erfindung' durchaus keinen materiellen Lohn erwarte, sondern mit dem Bewußtsein völlig zufrieden wäre, eine Anregung zur Verbesserung unserer Waffen gegeben zu haben. ${ }^{651}$

Dieses Bewusstsein sollte ihm jedoch versagt bleiben. Ebenso wie die Militärbehörden war auch die Rüstungsindustrie nicht an den Ideen Prandtls interessiert. Professor von Eberhardt gestand zwar zu, dass es von Interesse sein könnte, die Vorschläge im Versuch zu überprüfen, schloss jedoch mit den viel sagenden Worten, dass ein Termin für derartige Versuche unter den jetzigen Verhältnissen „auch nicht entfernt“" angegeben werden könne. ${ }^{652}$ Angesichts dieses Echos ist es wenig verwunderlich, dass offensichtlich der erste Versuch Prandtls, selbstständig neue Waffen zu entwickeln, auch zugleich der letzte blieb.

An der Uneigennützigkeit seiner Vorschläge kommen jedoch keine Zweifel auf. Durch die Frage nach der Motivation Prandtls gelangt man allerdings auch zwangsläufig in größerem Rahmen zu der Überlegung, inwieweit Prandtl, beziehungsweise seine Modellversuchsanstalt, vom Krieg profitieren konnte oder ob der Krieg hier sogar bewusst instrumentalisiert wurde. Die Forschungen Trischlers und Rottas dokumentieren die Entwicklungen dieser Zeit minutiös. Beide entwerfen das Bild einer im Wesentlichen kontinuierlichen und gezielten Entwicklung der Göttinger Forschungseinrichtungen durch Felix Klein und Prandtl selbst. Die Verwirklichung ihrer ehrgeizigen Pläne wird dabei stets als geschicktes politisches Handeln dargestellt, mit dem man sich in den verschiedenen Gremien Geld und Kompetenzen erkämpfte. Das Kriegsministerium trat dabei als eine von vielen Behörden auf.

Diese Darstellung entspricht zweifellos auch den Tatsachen, muss jedoch um weitere Aspekte erweitert werden: Man darf nicht aus den Augen verlieren, dass die ,günstigen Umstände“653 oder die ,,veränderten politischen Rahmenbedingungen" "654 von denen Trischler spricht, lediglich Umschreibungen für den Ersten Weltkrieg sind. Damit soll unter keinen Umständen eine moralische Bewertung

650 DLR.GOAR.2654.1 15.02.1916.

651 DLR.GOAR.2654.1 15.02.1916.

652 DLR.GOAR.2654.1 08.03.1916.

653 Trischler: Luft- und Raumfahrtforschung. 1992. S. 98.

654 Trischler: Luft- und Raumfahrtforschung. 1992. S. 99. 
des Vorgehens Kleins und Prandtls erfolgen, sondern hervorgehoben werden, dass ein Forscher, der sich in seinem Urlaub mit Artilleriegranaten beschäftigt, nicht einfach eine günstige Gelegenheit nutzte, um seinen Lebenstraum zu verwirklichen, sondern durch seine Forschungen aktiven Kriegsdienst leistete. Dass ein Wissenschaftler in dieser Zeit mit Engagement, Überzeugung und Herzblut seine Arbeit versah, war wohl nur normal. Allerdings zeigt sein Verhalten, dass Prandtl den Krieg nicht nur als einen zeitlich begrenzten Abschnitt ansah, der es ihm ermöglichte, seine Ziele zu verwirklichen; er verstand sich auch als eine Art Kriegsfreiwilliger.

Es ist überdeutlich geworden, dass von der von Prandtl zunächst angestrebten Zweiteilung der Nutzung der Anstalt keine Rede sein konnte. Die Modellversuchsanstalt war für die Dauer des Krieges eine rein militärische Einrichtung ohne die geringste Einschränkung. Daraus aber zu schließen, dass Prandtls Forschungen durch den Ersten Weltkrieg behindert wurden, wäre unzulässig. Vielmehr war es so, dass der Erste Weltkrieg Prandtls spätere Arbeiten erst ermöglichte. Wie oben geschildert wurde, erhielten auch andere Institute Zahlungen externer Einrichtungen oder Behörden, wenn auch in wesentlich geringerem Volumen. Dabei handelte es sich jedoch unzweifelhaft um reine Aufwandsentschädigungen für durchgeführte Auftragsarbeiten. Auch Prandtl führte während des Krieges solche Auftragsarbeiten durch. Der wesentliche Unterschied liegt indes darin, dass hier mit der neuen Modellversuchsanstalt und dem Umzug und der Modernisierung der alten Einrichtungen etwas geschaffen wurde, was auch noch über das Kriegsende hinaus zur Verfügung stand. Es war Ludwig Prandtl gelungen, durch den Ersten Weltkrieg ein schon lange zuvor ins Auge gefasstes Ziel zu erreichen.

Neben der Tatsache, dass in Göttingen eine der modernsten, wenn nicht sogar die modernste Forschungseinrichtung weltweit auf dem Gebiet der Strömungsforschung entstanden war, hatte man anderen Instituten gegenüber auch noch den Vorteil, dass die mit enormem Personalaufwand während des Krieges durchgeführten Arbeiten auch Ergebnisse geliefert hatten, die nicht nur für die Rüstungsindustrie von Bedeutung waren, sondern die Grundlage für eine weitere Beschäftigung mit diesem Thema bieten konnten. Allein die Untersuchung der unzähligen verschiedenen Tragflächenprofile, die im Auftrag der Industrie durchgeführt worden war, wäre bei normaler Personalstärke undenkbar gewesen oder hätte zumindest viele Jahre in Anspruch genommen. Prandtls entscheidender Vorteil war der, dass sich seine Interessenschwerpunkte weitgehend mit denen seiner Auftraggeber und vor allem seiner Geldgeber deckten.

Wie hoch er auch den nicht-militärischen, wissenschaftlichen Wert seiner Forschungen einschätzte, erkennt man nicht zuletzt daran, dass es im Rahmen seiner Verhandlungen mit dem Betriebsausschuss nicht zuletzt darum ging, Exemplare der Technischen Berichte in ausreichender Zahl zu Tauschzwecken zur Verfü- 
gung zu haben - auch für den Austausch mit dem Ausland. ${ }^{655}$ Der Erste Weltkrieg war gerade eine Woche beendet, als Prandtl an die Inspektion der Fliegertruppen eine detaillierte Liste mit Vorschlägen für mögliche Empfänger der von jeder Ausgabe zurückgelegten 750 Exemplare schickte. Diese Liste enthielt neben wahrscheinlich allen einschlägigen deutschen Einrichtungen, wie dem Institut seines Schwiegervaters Professor Föppl in München, auch bereits mindestens sechs Exemplare, die er für den Austausch mit ausländischen Wissenschaftlern benötigte. ${ }^{656}$

Angesichts des baldigen Endes des Krieges im Laufe des Jahres 1918 lässt sich jedoch eine gewisse Veränderung im Verhalten Prandtls ausfindig machen. Zu Beginn des Krieges hatte er die sich ihm bietenden Möglichkeiten konsequent genutzt und mit Hilfe der Militärbehörden seine schon länger bestehenden Pläne verwirklicht, war dann jedoch wohl durch die Art und Weise, in der sich die Zusammenarbeit mit der Industrie gestaltete und den Umfang der Arbeiten irritiert, fügte sich jedoch in seine Rolle, nachdem er sich einmal mit sehr begrenztem Erfolg an den Betriebsausschuss gewandt hatte. Der Erste Weltkrieg hatte zwar länger gedauert, als nahezu alle Beteiligten dies erwartet hatten, aber als sich dann doch das unausweichliche Ende immer deutlicher abzeichnete, begann Prandtl, sich ganz gezielt zu bemühen, einen möglichst hohen Nutzen für seine Modellversuchsanstalt aus dem Krieg zu ziehen - auch in dem völligen Bewusstsein, dass seine Arbeit für die Militärbehörden keinerlei Nutzen mehr haben konnte.

Zunächst galt es für Prandtl, unbedingt noch während des Krieges, also bei gesicherter Finanzierung, die alte Modellversuchsanstalt in der Hildebrandtstrasse aufzulösen und die Versuchseinrichtungen in Form eines Erweiterungsbaus der neuen Anstalt anzuschließen. Am 8. August 1918 schrieb Prandtl daher an die Abteilung für Bautenprüfung des Kriegsamts Hannover.

Sie werden in diesen Tagen von der Göttinger Baupolizei ein Gesuch um Genehmigung eines Erweiterungsbaus der Modellversuchsanstalt erhalten, [...].

Da es schon etwas spät im Bayjahr ist, und wir unter allen Umständen noch vor dem Winter unter Dach kommen wollen, bitte ich Sie, das Genehmigungsverfahren nach Möglichkeit beschleunigen zu wollen. Jeder Tag mehr ist uns wertvoll. ${ }^{57}$

Und noch einmal spielt er seine wichtigste Trumpfkarte aus:

Die Modellversuchsanstalt ist für die Zwecke der Kriegführung und aus Kriegsmitteln 1915/16 erbaut. Der geplante Erweiterungsbau entspricht einer dringenden Notwendigkeit und ist von den Bebörden, die unsere Geschäftsfübrung zu überwachen haben, auch als dringlich anerk.annt. ${ }^{658}$

\footnotetext{
655 DLR.GOAR.1353 01.03. und 05.03.1917.

656 DLR.GOAR.1353 19.11.1918.

657 DLR.GOAR.2637 08.08.1918.

658 DLR.GOAR.2637 08.08.1918.
} 
Tatsächlich hatte er mit der Beschleunigung des Verfahrens Erfolg. Bereits am 27. August 1918 sagt das Kriegsdepartement zu: „Mit dem Bau kann begonnen werden. “659 Mit diesen knappen Worten wurden insgesamt 90000 Mark in Aussicht gestellt, vorbehaltlich einer Prüfung der Kosten, und bereits am 7. Oktober konnte Prandtl dem Kurator der Universität den Eingang des Geldes ankündigen und schreiben, dass eine weitere Pachtung des Grundstücks in der Hildebrandtstrasse nicht mehr notwendig sei. ${ }^{660}$ Dieser Umzug der alten Modellversuchsanstalt, wie Prandtl ihn nannte, war selbstverständlich schon zuvor Teil des Gesamtplans gewesen und es war durchaus verständlich, dass Prandtl alles daran setzte, sämtliche Arbeiten bis zum jederzeit möglichen Kriegsende mit all den zu erwartenden Unsicherheitsfaktoren abgeschlossen zu haben. Trotzdem muss betont werden, wie außergewöhnlich die Bereitstellung eines solch hohen Betrages zu diesem Zeitpunkt war. Erinnert man sich etwa an den botanischen Garten, in dem Preissteigerung und Arbeitskräftemangel fast zum Zusammenbruch führten, so erhalten diese 90000 Mark Umzugskosten und die schnelle Durchführung der Arbeiten ein ganz andere Bedeutung.

Darüber hinaus überschnitt sich dieser Erweiterungsbau zeitlich mit einem anderen, ebenfalls bereits älteren Projekt, das nun doch noch in Angriff genommen werden sollte. In den frühen Planungsstadien fanden sich in Prandtls Entwürfen der Modellversuchsanstalt auch Ideen für den Bau eines speziellen Strömungskanals, der Untersuchungen bei Überschallgeschwindigkeit ermöglichen sollte. Allerdings wurden diese Pläne, hauptsächlich aus finanziellen Gründen, zunächst bis zur Übernahme der Modellversuchsanstalt durch die Kaiser-WilhelmGesellschaft zurückgestellt. Es war offensichtlich Felix Klein, der im Sommer 1918 den Impuls dazu gab, zu versuchen, diese Pläne noch während des Krieges mit Mitteln aus Kriegsfonds zu verwirklichen, wohingegen Prandtl selbst bereits Zweifel an der Durchführbarkeit der Angelegenheit hatte. ${ }^{661}$ Wahrscheinlich auch, um den möglichst schnellen Umzug der alten Modellversuchsanstalt nicht zu gefährden, zögerte er etwas, einen solchen Antrag zu stellen. ${ }^{662}$

[...] bei der für den Frieden geplanten Enweiterung der hiesigen Anlagen zu einem ,Kaiser-Wilhelm-Institut für Aerodynamik' soll auch die Überschallgeschwindigkeit zur Berücksichtigung kommen. [...]

Eines der wichtigsten Arbeitsgebiete dieses Versuchskanals würden natürlich die Luftwiderstandsfragen der Artilleriegeschosse sein, und ich glaube, dass eine gan z. nütəliche

659 DLR.GOAR.2637 27.08.1918.

660 DLR.GOAR.2637 07.10.1918.

661 Prandtl äußert dies in einem Brief an Professor Cranz: „Ich will gern zugestehen, dass ich selbst in dieser Richtung nicht so optimistisch war, dass vielmehr meine Anfrage bei Ihnen auf Impuls von Herrn Geheimrat Klein, hier, zurückzuführen ist." DLR.GOAR.2647 19.06.1918. Siehe hierzu auch: Rotta: Die Aerodynamische Versuchsanstalt. 1990. S. 165-167. 
Erweiterung der aus den Schiessversuchen gewonnenen Erkenntnisse durch diese Versuchseinrichtung zu erwarten ist. 663

Tatsächlich gelang es nicht mehr, Mittel vom Kriegsministerium für einen Überschallkanal zu erhalten, was aber hauptsächlich daran lag, dass die Artillerieprüfungskommission, deren Geschossuntersuchungen das wichtigste Arbeitsgebiet des neuen Kanals darstellen sollten, plante, eine eigene Einrichtung vor Ort in Berlin bauen zu lassen, um schneller und unkomplizierter Ergebnisse zu erhalten. ${ }^{664}$ Die weiteren Verhandlungen komplizierte indes zusätzlich die Tatsache, dass gerade Professor Cranz, ein Ballistiker an der militärtechnischen Akademie Charlottenburg, an den sich Prandtl zunächst gewandt hatte, um bei den Militärbehörden vorfühlen zu lassen, damit beauftragt wurde, diese Einrichtung zu entwerfen und zu bauen.665 Prandtl geriet schließlich in die ungünstige Lage, seinem schärfsten Konkurrenten um die voraussichtlich letzten militärischen Fördermittel des Krieges bei dessen Entwürfen helfen zu müssen.

Viel wichtiger als die letztlich durch das Kriegsende unterbrochenen Verhandlungen waren jedoch die in diesen angeführten Argumente, da sie recht unverblümt zeigen, dass im Angesicht seines nahenden Endes offen der Versuch unternommen wurde, aus dem Krieg Kapital zu schlagen. Prandtl und vor allem auch Felix Klein, dem er ja ausdrücklich die Initiative in dieser Angelegenheit zuschreibt, waren sich von Anfang an über die besondere Situation im Klaren. Bereits in seiner ersten vorsichtigen Anfrage an Professor Cranz sprach Prandtl dieses Thema an:

Hat es wobl Aussicht, aus den Kriegsmitteln einen Geldbetrag für die Schaffung dieser Einrichtungen zu beantragen, wenn die Einrichtungen im Frieden erst gebaut werden können? Im Kriege würde es sowobl wegen meiner eigenen Arbeitsbelastung im Betrieb der Modellversuchsanstalt, wie auch wegen der ungeheuren Schwierigkeiten der Beschaffung der Apparate (Einzelanfertigungen!!) kaum möglich sein, das Projekt durchzuführen. ${ }^{666}$

Professor Cranz führte in seiner Antwort verschiedene Punkte auf, die seines Erachtens nach von den Militärbehörden wahrscheinlich kritisiert werden würden, darunter auch, dass der neue Kanal nicht mehr für den „Zweck des Weltkrieges“ in Betracht käme.667 Prandtl konnte diesem Einwand allerdings nicht uneingeschränkt folgen und hielt sein Anliegen offensichtlich für gängige Praxis.

Dass die Versuchseinrichtung für den jetrigen Krieg nicht mehr in Betracht kommt, ist natürlich ein sehr gewichtiges Bedenken gegen die Bewilligung von Mitteln aus dem

663 DLR.GOAR.2647 13.06.1918.

664 „Zwei Abteilungen einer hiesigen Militärbehörde (APK) [Artillerieprüfungskommission] haben den Wunsch ausgesprochen, das hier in Berlin eine lediglich für militärische Zwecke der Artillerie dienende aerodynamische Einrichtung geschaffen werde [...].“ DLR.GOAR.2647 11.09.1918. Siehe hierzu auch: Rotta: Die Aerodynamische Versuchsanstalt. 1990. S. 165-167.

666 DLR.GOAR.2647 13.06.1918.

667 DLR.GOAR.2647 15.06.1918. 
Kriegsfonds. Jedoch wird von den Militärbehörden selbst vielfach jetzt so verfahren, dass sie sich irgendwelche Einrichtungen, die für die kommende Friedenszeit bestimmt sind, jetzt sichern. Da lag es - das Einverständnis über die technischen Fragen vorausgesetzt - nabe, dass auch in der Richtung von Unterstützung von Laboratorien die Möglichkeit für vorausschauende Vorbereitungen für die Friedenszeit jetzt vorliegen würde. ${ }^{668}$

In dieser Sicht der Dinge wurde Prandtl, wie bereits erwähnt, kurze Zeit später bestätigt, als die Artillerieprüfungskommission selbst mit ähnlichen Plänen auftrat, die ebenfalls unmöglich vor Kriegsende hätten verwirklicht werden können oder gar noch praktischen Nutzen hätten erbringen können. Dieser Versuch einer vorausschauenden Vorbereitung der Friedenszeit scheiterte zwar, der Umzug der alten Modellversuchsanstalt konnte jedoch noch abgeschlossen und damit das Projekt in geplantem Umfang umgesetzt werden. Es wurde deutlich, dass besonders mit fortschreitender Dauer des Krieges und vielleicht in besonderem Maße nach den nur bedingt erfolgreichen Versuchen Prandtls, tiefer in die militärische Forschung eingebunden zu werden, gezielt versucht wurde, die sich durch den Krieg bietenden Möglichkeiten auszunutzen, und dies auch ohne Berücksichtigung des effektiv zu erwartenden militärischen Nutzens.

Wie bereits abzusehen war, veränderte das Kriegsende die Situation der Modellversuchsanstalt völlig und es herrschte zunächst allgemeine Unsicherheit nicht nur darüber, wie sie in Zukunft weiterarbeiten sollte, sondern durchaus auch darüber, ob sie überhaupt weiterarbeiten konnte. Bereits unmittelbar nach dem Waffenstillstand schrieb man an die Mitglieder der nun nicht mehr bestehenden Organisation des ,Technische Berichte und Wissenschaftliche Auskunftei für Flugwesen-Unternehmens“.

Um für die zukünftigen Entwicklungsmöglichkeiten der Modellversuchs-Anstalt ein Bild zu bekommen, wären wir Ibnen für eine Mitteilung darüber dankbar, ob und in welchem Umfange Sie die Flugzengfabrikation im Frieden fortzuführen gedenken. Gleichzeitig teilen wir Ibnen mit, dass die Versuchsanstalt zur Zeit nicht sebr stark beschäftigt ist und daher irgendwelche gewünschten Versuche für Ihre Friedensprojekte verbältnismässig kurafristig ausgeführt werden können. 669

Auf dieses Schreiben trafen in Göttingen immerhin 21 Antworten ein, allerdings alle mit dem gleichen ernüchternden Inhalt.

Auf Ihr Schreiben vom 12.d.Mts. erwidern wir höflichst, dass die inzwischen eingetretene politische Sachlage z.Zt. keine Perspektive ergibt, ob und in welchem Umfange die Flugzeug-Fabrikation in der nächsten Zeit nach dem Frieden fortgeführt werden kann. Auch wir sind uns darüber noch im Ungewissen und können Ihnen infolgedessen, so leid es uns tut, irgendwelche Aufträge zur Ausführung von Versuchen jetzt und in allernächster

668 DLR.GOAR.2647 19.06.1918.

669 DLR.GOAR.1298 12.11.1918. 
Zeit wohl kaum zuweisen. Wir stellen deshalb ergebenst anheim, zur gegebenen Zeit dieserhalb bei uns wieder Rückfrage halten zu wollen. ${ }^{670}$

Dieser Brief der Siemens-Schuckert-Werke ist nur ein Beispiel für die vielen gleichlautenden Antworten. Die Eigenfinanzierung der Modellversuchsanstalt aus privaten Aufträgen war definitiv nicht möglich, aber auch staatliche Geldgeber waren angesichts der unsicheren politischen Lage nicht verfügbar, wie Prandtl erfahren musste, als er sich zum letzten Mal an die Mitglieder des Betriebsausschusses wandte.

Die inzwischen eingetretene Veränderung der Gesamtlage, macht es jedoch wünschenswert, dass wenigstens die Berliner Mitglieder des Ausschusses in diesen Tagen zu einer Aussprache zusammenkommen, um zu der Frage der Weiterführung der Arbeiten der Modellversuchsanstalt prinzipiell Stellung zu nebmen:

1. Legen die Heeres- und Marinebehörden Wert darauf, dass die Modellversuchsanstalt in der nächsten Zeit mit der gleichen Intensität weiter arbeitet, wie bisher? [...]

2. Inwieweit legen die Behörden Wert darauf, dass nach Eintritt des Friedens die Modellversuchsanstalt von Seiten der Heeres- und Marineverwaltung weiter für ibre Arbeiten unterstütz̧t wird? [...]

Ich glaube, dass für diese Beratungen meine Anwesenheit nicht notwendig sein wird, von einem gewissen Standpunkt aus ist es sogar richtiger, dass ich fernbleibe, damit die Herren sich umfangreicher aussprechen können. ${ }^{671}$

Der Betriebsausschuss kam im Dezember 1918 tatsächlich noch einmal zusammen, setzte mit einem geradezu flammenden Appell für ein Fortbestehen der Modellversuchsanstalt einen Schlusspunkt unter dieses Kapitel ihres Bestehens und entließ sie in einen ungewisse Zukunft.

Wie auch die kiunftige Gestaltung des deutschen Staates sein mag, mit einem Untergang der hoch entwickelten deutschen Fliegerei kann und darf nicht gerechnet werden. Sie wird dabei das Bedürnnis hegen, wie während des Krieges so auch im Frieden, sich auf die Modell-Versuchsanstalt für Aerodynamik in Göttingen zu stützen und von ibr erwarten, die richtigen $W$ ege gewiesen zu werden.

[...] Die Mitglieder des Betriebsausschusses erachten es daher für ibre Pflicht, darauf binzuweisen, dass diejenigen Staatsbehörden, welche anstelle des Preussischen Kriegsministeriums und des Reichs-Marine-Amtes die Pflege der Luftfahrt übernebmen werden, die tatkräftige Unterstützung der Modell-Versuchsanstalt für Aerodynamik in Göttin-

670 DLR.GOAR.1298 19.11.1918.

671 DLR.GOAR.1353 29.10.1918. 
gen in den Bereich ibrer Obliegenheiten aufnehmen müssen, wenn dem deutschen Volkee die hohe Stellung, die es in der Flugtechnik erworben hat, erhalten bleiben soll. ${ }^{672}$

Wenige Tage bevor dieser Beschluss gefasst wurde, erhielt Prandtl bereits eine Anfrage der Kaiser-Wilhelm-Gesellschaft der Wissenschaften, wie sich Krieg und „politische Umwälzung“ auf den Betrieb der Anstalt auswirkten. ${ }^{673}$ Entsprechend der „Verständigung über die Errichtung einer Modellversuchsanstalt und deren Eingliederung in das zu errichtende Kaiser-Wilhelm-Institut für Aerodynamik und Hydrodynamik“"674 war diese nun Prandtls neuer Ansprechpartner. ${ }^{675}$ Auch wenn zunächst die unsichere Situation bedrohlich wirkte, konnte er sich über die Auswirkungen des Ersten Weltkrieges auf seine Arbeit und seine Modellversuchsanstalt durchaus positiv äußern.

Von mir kann ich im allgemeinen Gutes berichten, wenn auch der Niederbruch des $V a$ terlandes schwer auf allen lastet. Der Krieg hat meine wissenschaftliche Arbeit in einem unerwartetem Maße gefördert. Ich habe eine große aerodynamische Anstalt erbaut mit einem starken Luftstrom und guten Messeinrichtungen; bei der langen Dauer des Krieges ist an dieser Anstalt, die im letzten Jahr rd 50 Angestellte hatte, sehr viel nützliche Arbeit geleistet worden. Daneben sind wir auch theoretisch gut vorwärts gekommen und haben jetzt eine recht vollständige bydrodynamische Theorie der Tragflïgel, die auch auf Luftschrauben usw. übertragbar ist. ${ }^{676}$

672 DLR.GOAR.2637 Beschluss des Betriebsausschusses, gefasst auf seiner letzten Sitzung vom 17.12.1918.

673 DLR.GOAR.2639.

674 Siehe oben. DLR.GOAR.2633 06.1915.

675 Bezüglich der weiteren Entwicklung siehe vor allem: Rotta: Die Aerodynamische Versuchsanstalt. 1990. S. 199ff. Trischler: Luft- und Raumfahrtforschung. 1992. S. 109ff. Wüst: Sie zähmten den Sturm. 1991. Vorgänge unter anderem in: DLR.GOAR.2637 und DLR.GOAR.2639.

676 Diese durchweg positive Bewertung der Ergebnisse seiner Arbeit schreibt Prandtl nach Kriegsende an seinen ukrainischen Kollegen Timoschenko. DLR.GOAR.3664 24.02.1919. 



\section{Schweigen und Forschen - die Rolle der Dozenten}

Betrachtet man das Bild der naturwissenschaftlichen Professoren zur Zeit des Ersten Weltkrieges in der Sekundärliteratur, gewinnt man schnell den Eindruck, dass es offensichtlich wenig erfolgversprechend sein müsse, an der Göttinger oder irgend einer anderen deutschen Universität nach Besonderheiten in deren Verhalten oder gar auffälligen Aktivitäten zu suchen.

Eine zentrale Rolle unter den einschlägigen Untersuchungen spielt sicherlich zu Recht immer noch das bereits 1969 erschienene Werk Klaus Schwabes Wissenschaft und Kriegsmoral. ${ }^{677}$ In diesem Buch wird detailliert die Haltung der deutschen Hochschullehrer, besonders zu den bald aufkommenden Diskussionen über mögliche Kriegsziele und später über mögliche Friedensschlüsse analysiert, unter anderem mit dem Ergebnis, dass, laut Schwabe, ein „Gegensatz“ zwischen den beiden Hauptgruppen der Professoren, den „Annexionisten“ und den „Gemäßigten“", entstand. ${ }^{678}$ Der Diskurs als solcher habe aber die Dozenten in ihrer Mehrheit „sehr viel näher an das politische Geschehen herangeführt.“"679 Anhand zahlreicher Beispiele werden die Konflikte dieser Gruppen untereinander nachgezeichnet und die Verteilung der Hochschullehrer auf sie untersucht. Allerdings kann man sich beim Lesen dieses Werks dem Eindruck nicht verschließen, dass

677 Schwabe (Hrsg.): Wissenschaft. 1969.

678 Schwabe (Hrsg.): Wissenschaft. 1969. S. 179.

679 Schwabe (Hrsg.): Wissenschaft. 1969. S. 184. 
Naturwissenschaftler und Mathematiker, bezogen auf politische Aktivitäten und öffentliche Sichtbarkeit, deutlich hinter ihren Kollegen anderer Fächer zurück gestanden haben müssen, denn sie finden kaum Beachtung. Für Schwabe scheint dies selbsterklärend zu sein: „Wir haben zu unterscheiden zwischen Wissenschaften, die von sich aus der Politik ferner stehen, und solchen, die ihr innerlich verwandt sind.“ ${ }^{680}$ Dieser Prämisse folgend, war es für ihn ,gewiß kein Zufall, daß von den Naturwissenschaftlern sich nur die wenigsten auf die politische Bühne wagten"681 und diese bereitwillig Rechtswissenschaftlern, Historikern, Philosophen und Theologen überließen.

Fast zwanzig Jahre nach dem Erscheinen von Wissenschaft und Kriegsmoral nahm Lothar Burchardt sich in deutlich differenzierterer Form dieser Fragestellung an, und zwar in Naturwissenschaftliche Universitätslehrer im Kaiserreich, ${ }^{682}$ seinem Beitrag zu dem ebenfalls von Klaus Schwabe herausgegebenen Werk Deutsche Hochschullehrer als Elite: 1815-1945.683 Burchardt stellt dar, dass es den naturwissenschaftlichen Hochschullehrern im Allgemeinen genügte, innerhalb ihres Fachbereichs Karriere zu machen.

In ihrer ganz großen Mehrzahl saben sie ihr Karriereziel mit dem Ordinariat erreicht, waren mit den Gegebenheiten einverstanden und wollten nichts anderes, als die ibnen als Institutsleitern offenstehenden Arbeitsmöglichkeiten optimal nutzen. ${ }^{684}$

Damit spricht Burchardt den Naturwissenschaftlern nicht nur aktive politische Ambitionen ab, sondern bestreitet die Existenz jeglicher Form von politischer Meinungsäußerung durch diese. Vielmehr hätten sie ihre Energien in wissenschaftsorganisatorische Tätigkeiten investiert, wie etwa Felix Klein in Göttingen. ${ }^{685}$ Eine Ursache, die Burchardt für diese Zurückhaltung nennt, ist die hohe zeitliche Belastung der Naturwissenschaftler, die jedoch die zwei Hauptgründe nur unterstützt habe: Der eine hiervon sei ein hohes Maß an Zufriedenheit mit den bestehenden Verhältnissen gewesen, der andere ein „Mangel an politischem Sendungsbewußtsein“.686

Gerade weil er keinen Anlaß sah, an den bestehenden Verbältnissen zu rütteln, und weil er sich obendrein in politics nicht für sachkundig erachten mochte, bielt sich der $\mathrm{Na}$ turwissenschaftler politisch weit mehr zurück als ein Angehöriger jener Disziplinen, die der Tagespolitik näher standen: Wo Staatsrechtler, Nationalökonomen, Historiker, Philosophen oder Theologen fachlich unmittelbar angesprochen waren, sab der Naturwissenschaftler keine direkten Bezüge zu seiner Tätigkeit. Daß er in vielen Fällen zeitlich

680 Schwabe (Hrsg.): Wissenschaft. 1969. S. 187.

681 Schwabe (Hrsg.): Wissenschaft. 1969. S. 187.

682 Burchardt: Naturwissenschaftliche Universitätslehrer. 1988. S. 151-214.

683 Schwabe (Hrsg.): Deutsche Hochschullehrer. 1988.

684 Burchardt: Naturwissenschaftliche Universitätslehrer. 1988. S. 204.

685 Burchardt: Naturwissenschaftliche Universitätslehrer. 1988. S. 205.

686 Burchardt: Naturwissenschaftliche Universitätslehrer. 1988. S. 213. 
stärker belastet war als seine geisteswissenschaftlichen Kollegen (oder sich jedenfalls stärker belastet fühlte) kam erschwerend hinzu. ${ }^{687}$

Insbesondere aus Göttinger Perspektive ${ }^{688}$ leuchtet die Annahme der Zufriedenheit der Wissenschaftler mit ihrer Situation zunächst unmittelbar ein:

[...] der Universitätsprofessor der Wilhelminischen Zeit [stand] fest auf dem Boden der bestehenden Verhältnisse. Er hatte mehr als je zuvor die Freiheit zu forschen, zu lehren und zu veröffentlichen, was er wollte. 689

Die Arbeitsmöglichkeiten der Naturwissenschaftler verbesserten sich seit einiger Zeit kontinuierlich, und eine scheinbar unbegrenzte Technik- und Fortschrittsgläubigkeit trat in nahezu allen Lebensbereichen zu Tage. An keiner anderen preußischen Universität wurde diese Entwicklung deutlicher als in Göttingen, dem neuen Zentrum der Mathematik und der Naturwissenschaften.

Burchardt führt weiter aus, dass dieser allgemeine Bedeutungszuwachs nun auch den Naturwissenschaftlern half, einen Status als echte Wissenschaftler zu erwerben, der bis dahin bei Weitem noch nicht selbstverständlich war, nicht zuletzt, da die Öffentlichkeit die neugewonnenen Erkenntnisse nur selten verstand. ${ }^{690}$

Was insbesondere den Mathematiker betrifft, so hat er von jeher vor der großen Menge einen schweren Stand gehabt, die seine Leistungen, soweit sie sie sich zu eigen gemacht hat, ihm nicht gutschreibt und, soweit sie sie nicht versteht, für wertlos erachtet. 691

Dieses Problem, das der Göttinger Mathematiker Professor Carl Runge 1915 mit einem Augenzwinkern eingangs einer Festrede beschreibt, hatte ganz offensichtlich doch einen ernsten Hintergrund, der sicherlich auch in den Komplex des zweiten Hauptgrundes mathematisch-naturwissenschaftlicher Zurückhaltung hineinspielt, nämlich dem besagten Mangel an politischem Sendungsbewusstsein, den Burchardt attestiert. Zusammenfassend schreibt er:

Der Naturwissenschaftler der Kaiserzeit sah keinen Anlaß und hatte keine Zeit, sich für politische Reformen stark zu machen; wo es galt Bekenntnisse zum Status quo abəulegen, wußte er diese Aufgabe bei seinen Kollegen aus den übrigen Fakultäten in guten Händen. Noch mehr als diese verstand er sich als unpolitischer Diener seiner Wissen-

687 Burchardt: Naturwissenschaftliche Universitätslehrer. 1988. S. 211.

688 Am Rande sei bemerkt, dass man Burchardt wohl den Vorwurf machen muss, zwar die naturwissenschaftlichen Universitätslehrer im Kaiserreich zu untersuchen, dabei aber Göttingen, als im Aufbau befindliches preußisches Zentrum der Mathematik und der Naturwissenschaften, nahezu vollständig zu übergehen.

689 Burchardt: Naturwissenschaftliche Universitätslehrer. 1988. S. 211.

690 „So wird man insgesamt wohl festzuhalten haben, daß der naturwissenschaftliche Ordinarius im Untersuchungszeitraum zwar sicherlich die Distanz verkürzte, die ihn von den Angehörigen der älteren Fakultäten trennte, daß er aber noch nicht völlig gleichziehen konnte.“ Burchardt: Naturwissenschaftliche Universitätslehrer. 1988. S. 207.

691 Runge, Carl: Mathematik und Bildung. Festrede im Namen der Georg-August-Universität zur Jahrfeier der Universität am 9. Juni 1915. Göttingen 1915. 
schaft und des Staates. Sein Selbstverständnis war nicht das eines politische oder gesellschaftliche Führungsaufgaben wahrnehmenden oder auch nur beanspruchenden Angebörigen einer sozio-politischen Elite; vielmebr sah er sich als ein fern vom öffentlichen Getriebe in wissenschaftlich-zweckfreier Askese tätiger Experte böchster Qualität [...].692

Trotz dieses recht eindeutigen Urteils Burchardts kann man unmöglich darauf verzichten, sich in dieser Arbeit trotzdem mit den Göttinger Professoren und Privatdozenten im Detail zu beschäftigen und zumindest das Bild, welches die Sekundärliteratur zeichnet, am lokalen Beispiel zu überprüfen.

Dabei leuchtet es zunächst unmittelbar ein, dass die Naturwissenschaftler niemals isoliert in ihrer Zeit stehen konnten, selbst wenn sie es gewollt hätten. Auch sie waren Bürger einer Stadt, Angehörige einer Universität und nicht zuletzt Mitglieder ihrer Familien. Auch sie erlebten die besondere Dynamik der ersten Kriegstage im August 1914, litten unter der sich bald verschlechternden Versorgungslage und sahen, wie Verwandte und Bekannte sich freiwillig meldeten und erfuhren von ihrer Verwundung oder ihrem Tod. Die ersten beiden Teile dieser Arbeit haben außerdem gezeigt, wie dramatisch sich ihr berufliches Umfeld, die Universität, in dieser Zeit wandelte.

Es fällt schwer, Burchardts Annahme von einem außerordentlich hohen Maß an „Zufriedenheit mit den herrschenden Verhältnissen“ ${ }^{693}$ zumindest für die Zeit des Ersten Weltkrieges, zu folgen. Der Krieg schränkte, wie zuvor gezeigt wurde, die Forschungsfreiheit ein und wurde auf personeller und finanzieller Ebene deutlich spürbar - auch für einen „,fern vom öffentlichen Getriebe in wissenschaftlich-zweckfreier Askese tätige[n] Experte[n] höchster Qualität" , ${ }^{694}$ den es in dieser überspitzt dargestellten und isolierten Form nie gegeben hat. Unter diesen Umständen konnte es keine neutrale Position geben. Gleichgültig, wie man die Frage Engagement oder Rückzug? auch beantwortet, muss man von einer bewussten Entscheidung ausgehen und somit auch einen möglicherweise weitgehend negativen Befund bei der Suche nach außeruniversitären Aktivitäten oder Äußerungen als solchen bewerten.

Man war sich der besonderen Situation bewusst und hatte klare Vorstellungen bezüglich der Implikationen für die Naturwissenschaftler, wie Professor Carl Runge in seiner Einleitung zu der bereits kurz zitierten Rede deutlich macht. Dies tat er als amtierender Rektor der Universität anlässlich der Jahresfeier der Georgia Augusta am 9. Juni 1915.

Hochgeehrte Versammlung! Der Ernst der Zeit ist den wissenschaftlichen Studien nicht günstig, weil alle unsre Gedanken auf den einen Punkt, das Wobl und Wehe unsres $V$ aterlands gerichtet sind. Andern Überlegungen sind wir nur insofern geneigt, Bedeutung zuzuerkennen, als sie für die Allgemeinheit eine Rolle spielen. Der Gelebrte, der

692 Burchardt: Naturwissenschaftliche Universitätslehrer. 1988. S. 213.

693 Burchardt: Naturwissenschaftliche Universitätslehrer. 1988. S. 213.

694 Burchardt: Naturwissenschaftliche Universitätslehrer. 1988. S. 213. 
gewohnt war, seine Wissenschaft als Selbstziveck zu betreiben, fragt sich jetzt nach ibrer Berechtigung, sucht sich ibre Beziehung zu dem geistigen Leben unsres Volkes und ibre Stellung darin klar zu machen und dadurch vor der Öffentlichkeit und vor sich selbst ₹u rechtfertigen, dass er ibr seine Arbeit widmet. 695

In diesem Zitat wird sehr deutlich, dass Runge ganz offensichtlich das Bedürfnis hatte, sich dafür zu rechtfertigen, dass er und seine Kollegen sich auch während des Krieges weiterhin mit Mathematik beschäftigten. Auch für Carl Runge persönlich ist dieses Bedürfnis verständlich: Wenige Monate zuvor hatte er den jüngeren seiner beiden Söhne in den grausamen Kämpfen im Herbst 1914 verloren. Sein älterer Sohn befand sich noch in den Schützengräben des Stellungskrieges an der Westfront. ${ }^{696}$ Runge stellt somit ein Beispiel für die zahlreichen Schnittstellen der Naturwissenschaftler zum Geschehen außerhalb der Universität dar und widerspricht zugleich dem von Burchardt gezeichneten Bild einer aus Zufriedenheit selbst gewählten Isolation der Professoren.

\section{Professoren im Kriegseinsatz}

Bevor man sich im Einzelnen mit dem Verhalten der Göttinger Dozenten während des Ersten Weltkrieges befassen kann, drängt sich zunächst die Frage auf, wie viele der Dozenten überhaupt noch in Göttingen anwesend waren. Kriegsdienst- oder kriegshilfsdienstpflichtig wie ihre Studierenden waren sie natürlich ebenfalls, allerdings lag ihr Durchschnittsalter deutlich höher, was selbstverständlich Auswirkungen auf die Möglichkeiten ihrer Verwendung für das Militär hatte. Es scheint daher angebracht, zunächst kurz den zahlenmäßigen Umfang der kriegsdienstleistenden Dozenten zu betrachten. Die folgende Statistik verdeutlicht dies:

695 Runge: Mathematik. 1915.

696 Hentschel, Tobies: Brieftagebuch. 1999. S. 188-189. 


\section{D ozenten}

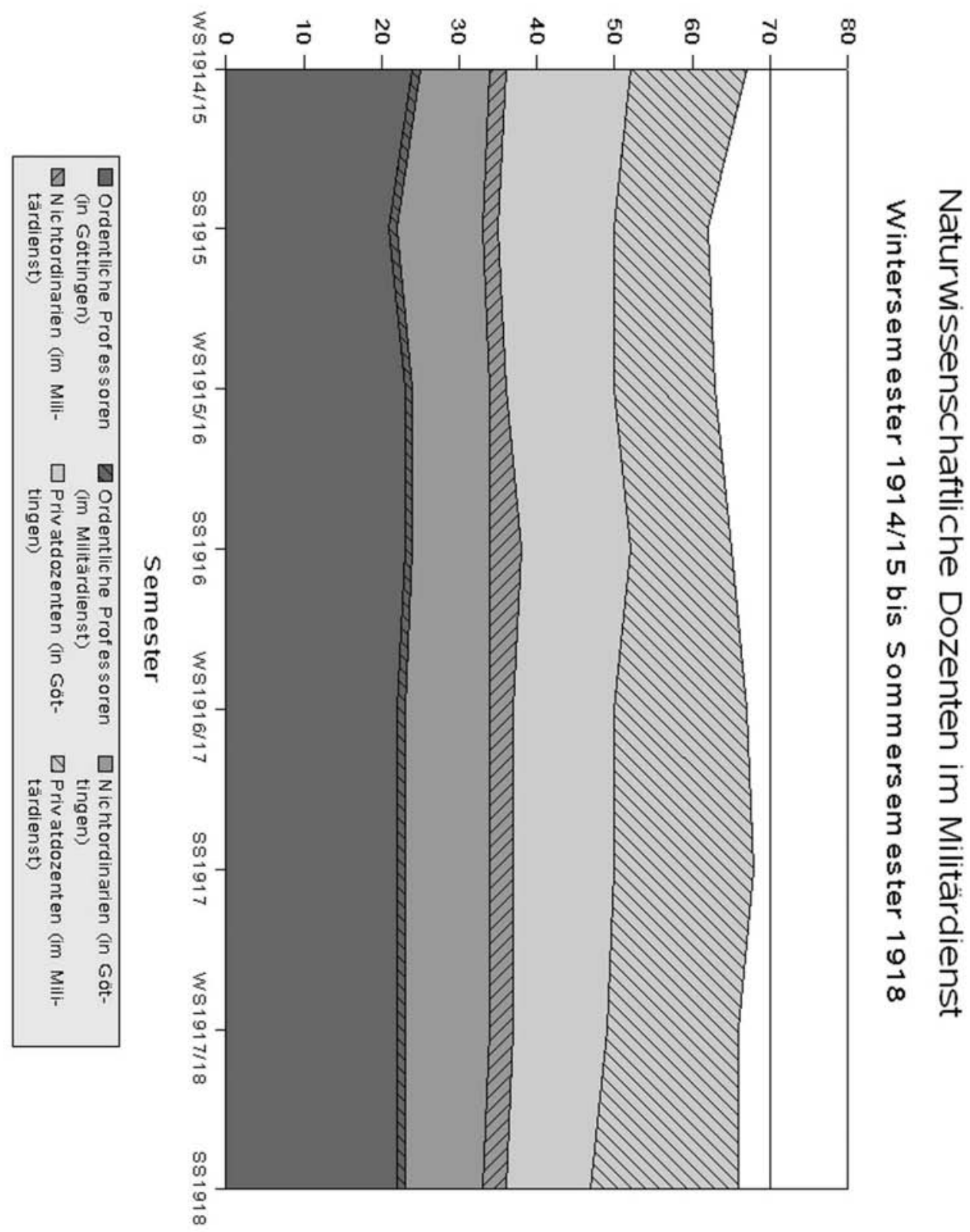

Statistik 8: Daten aus: Universität Göttingen (Hrsg.): Amtliches Verzeichnis des Personals und der Studierenden der königl. Georg-August-Universität zu Göttingen. Göttingen 1914 bis 1918. 
Beim Betrachten dieser Statistik fällt zunächst die relative Konstanz der Zahlen auf. Ganz anders als es bei den Studierendenzahlen der Fall war, traten bei den Dozenten keine besonderen Schwankungen auf. Besonders der zu erwartende Anstieg der Zahl der im Kriegsdienst befindlichen Personen blieb hier weitgehend aus.

Entsprechend ihres Alters waren die jüngeren Privatdozenten am stärksten betroffen. Seit dem Wintersemester 1916/17 fehlten von ihnen dauerhaft deutlich über die Hälfte an der Göttinger Universität. Im Falle der Studierenden führte der Kriegsausbruch zu einem allgemeinen Ansteigen der Studierendenzahlen: Da sich auch mit längerer Dauer des Krieges weiterhin Studierende immatrikulierten, die dann wieder eingezogen wurden, wurde so nicht nur die Zahl der Kriegsdienstleistenden in die Höhe getrieben, sondern auch die Gesamtzahl der Studierenden. Dies war auf dem Gebiet der Dozenten vollständig anders: Die Inhaber einer Stelle behielten diese selbstverständlich, wenn sie in das Militär eintraten und galten genau wie auch die Studierenden nur als beurlaubt. ${ }^{697}$ Also konnte die Universität weder ihre Stellen neu besetzen, noch neue Dozenten für sie einstellen. Daher blieb ihre Gesamtzahl im Gegensatz zu der der Studierenden weitgehend konstant. Auch kurzfristige Vertretungen kamen meist nicht in Frage. Das Kultusministerium lehnte solche Anfragen unter Hinweis auf die geringe Zahl aktiver Studierender ab.

Gerade mit Bezug auf die Privatdozenten soll hier noch auf eine andere Problematik des Krieges hingewiesen werden. ${ }^{698}$ Sie waren die Gruppe unter den Dozenten, die wahrscheinlich am unmittelbarsten unter dem Ersten Weltkrieg litt, da mit den Studierendenzahlen auch ihre Verdienstmöglichkeiten einbrachen. Privatdozenten waren keine Beamte und hatten kein festes Grundgehalt. Ihre einzige Einnahmequelle waren die Kolleggelder, die ihre Hörer entrichten mussten, wobei wirklich lukrative Veranstaltungen mit erfahrungsgemäß großen Hörerzahlen oder gar Prüfungen und die dort zu entrichtenden Gebühren meist ihren etablierten Kollegen vorbehalten blieben. ${ }^{699}$ Bei dauerhaft hohen Studierendenzahlen konnten die ordentlichen und außerordentlichen Professoren jedoch nicht alle wichtigen Lehrveranstaltungen selbst halten. Während des Krieges war dies jedoch anders. Auch die Professoren spürten den Rückgang der Kolleggelder und der Prüfungsgebühren, behielten aber immer noch ihr Grundgehalt. So konnten sie es sich erlauben, Vorlesungen auch vor nur wenigen Hörern zu halten. Für einen Privatdozenten war dies wirtschaftlich ein enormes Problem.

697 Vergleiche die Handhabung bei den Assistenten.

698 Zu Fragen des Status und des Einkommens von Assistenten und Privatdozenten: Burchardt: Naturwissenschaftliche Universitätslehrer. 1988. S. 162-163. Busch, Alexander: Die Geschichte des Privat-Dozenten. Eine soziologische Studie zur großbetrieblichen Entwicklung der deutschen Universitäten. Stuttgart 1959. (= Göttinger Abhandlungen zur Soziologie unter Einschluß ihrer Grenzgebiete; 5).

699 Burchardt: Naturwissenschaftliche Universitätslehrer. 1988. S. 162-163. Und: Wettmann: Heimatfront. 2000. S. 120-121. 


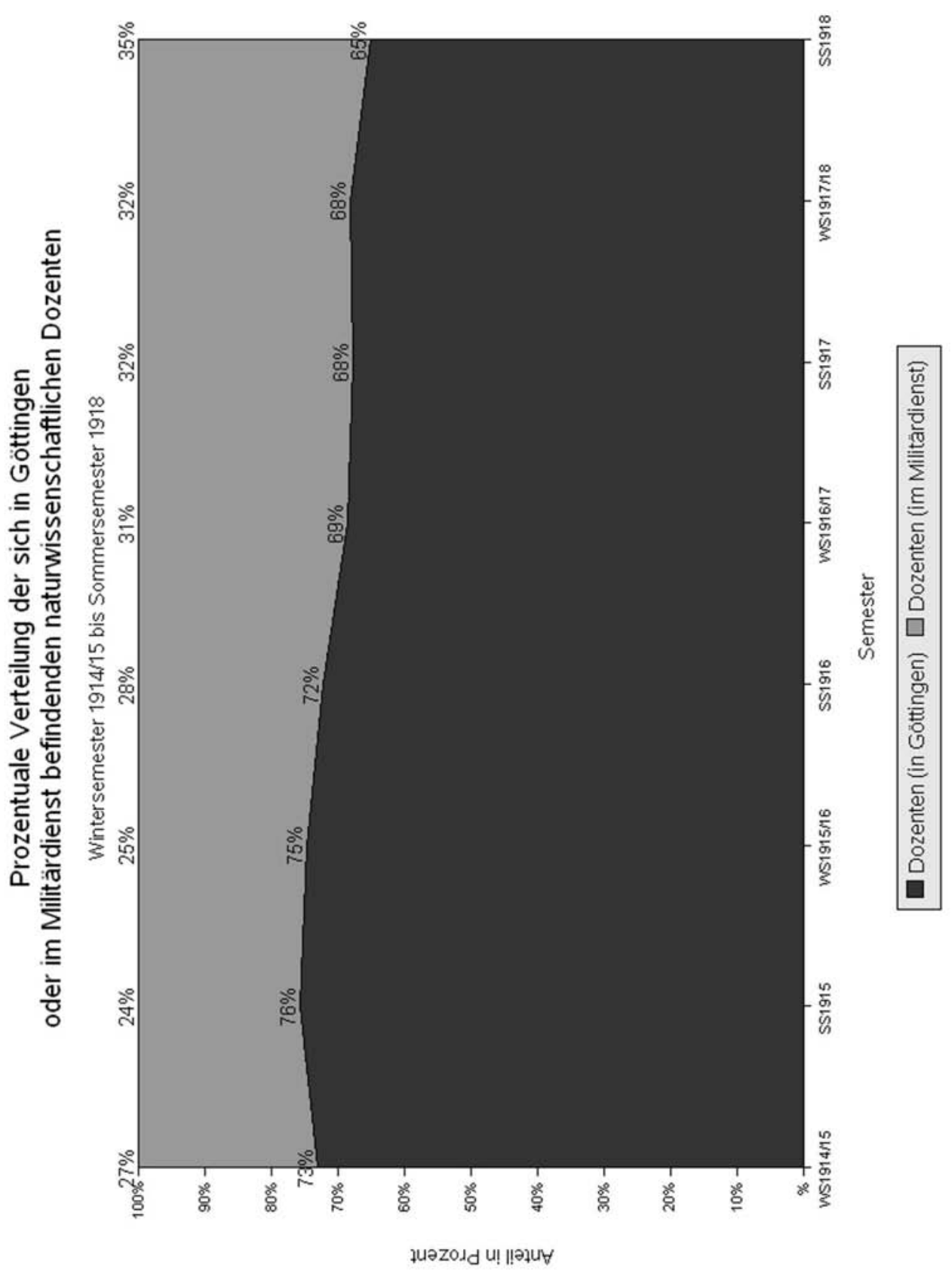

Statistik 9: Daten aus: Universität Göttingen (Hrsg.): Amtliches Verzeichnis des Personals und der Studierenden der königl. Georg-August-Universität zu Göttingen. Göttingen 1914 bis 1918 . 
Die Statistik verdeutlicht, welche Auswirkungen sich durch den Kriegsdienst der Dozenten für die konkrete Arbeit an der Universität ergaben: Hauptsächlich wegen ihres hohen Durchschnittsalters war der zahlenmäßige Einbruch auf Seiten der Dozenten zwar nicht so groß, wie bei den Studierenden, aber dennoch beachtlich. Zwischen einem Viertel und einem Drittel aller naturwissenschaftlichen Dozenten befand sich im Kriegsdienst. Gemessen an der Tatsache, dass sich aber nur noch zwischen einem Viertel und einem Drittel der Studierenden in Göttin-

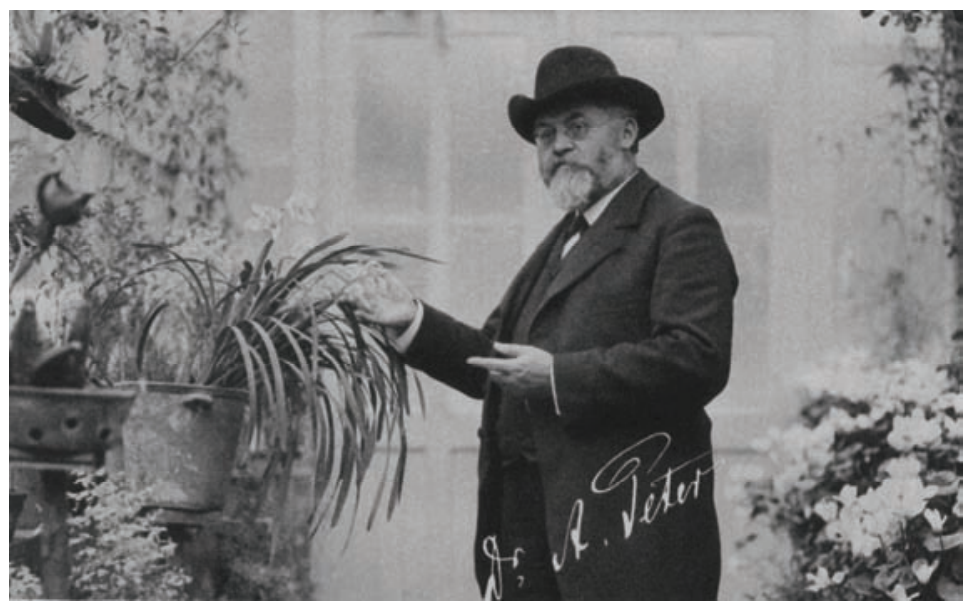

Abbildung 10: Albert Peter

gen befand, dürfte dies, bezogen auf die Unterrichtsversorgung, aber nie ein Problem für die Universität dargestellt haben. ${ }^{700}$

Lediglich ein Ordinarius, Prof. Dr. Hans Stille, ${ }^{701}$ der Direktor des geologischpaläontologischen Instituts, stand während des Krieges im Militär. Dies allerdings vom ersten bis zum letzten Kriegssemester. Bezogen auf die lange Dauer des Kriegsdienstes handelte es sich hier jedoch um keinen Einzelfall. Betrachtet man die Namen der sich im Kriegsdienst befindenden Dozenten, so fällt auf, dass ein Dozent, war er erst einmal in das Militär eingetreten, meist bis zum Ende des Krieges dort blieb.

700 Sehr ähnliche Zahlen existieren auch für andere deutsche Universitäten, allerdings, wie Andrea Wettmann darstellt, reichsweit betrachtet, mit großen Schwankungen. Wettmann: Heimatfront. 2000. S. 116ff. In Heidelberg waren ebenfalls die jüngeren Dozenten am stärksten betroffen, einige Ältere hatten sich jedoch freiwillig gemeldet. Reichert: Wissenschaft. 2001. S. 497-498. In Gießen war die Quote der im Kriegsdienst stehenden Dozenten mit 29\% mit den Göttinger Zahlen beinahe identisch, allerdings gelang es der Leitung der Universität Gießen diese Quote bis auf 15\% zu senken. Moraw: Kleine Geschichte. 1982. S. 194.

701 Stille war Oberleutnant und offensichtlich in der Landvermessung eingesetzt („,bayr. Vermessungs-Abteilung 9“), erhielt jedoch am 3. Oktober 1917 die Erlaubnis „,monatlich für einige Tage nach Göttingen zur Regelung von beruflichen Angelegenheiten zu fahren." UAG.Kur.3443 Bl. 107. Er selbst gibt in einem Lebenslauf in seiner Personalakte lediglich „1914-18 im Felde als Landwehr-Offizier“" an. UAG.Kur.Pers.Stille, Hans Bd. 2 Bl. 5. 
Mit Professor Albert Peter fehlte noch ein weiterer Ordinarius für die gesamte Dauer des Ersten Weltkrieges. Der über sechzigjährige Botaniker befand sich bereits seit dem Wintersemester 1913/14 auf einer Forschungsreise durch Afrika und hielt sich gerade in Deutsch-Ostafrika auf, als der Krieg ausbrach. ${ }^{702}$ Es gelang ihm nicht mehr rechtzeitig, zurückzukehren, und so musste er bis auf Weiteres beurlaubt werden.703 Im September 1915 versuchte der Rektor der Universität, Artur Titius, Peters Rückkehr auf diplomatischem Weg zu ermöglichen, indem er anregte, von England einen „Geleitbrief“" zur Ausreise in ein neutrales Land zu erwirken, was jedoch von ministerieller Seite nicht unterstützt wurde. ${ }^{704}$ Schließlich geriet Peter in englische Gefangenschaft und konnte erst 1919 nach Deutschland zurückkehren. ${ }^{705}$

Bei der Durchsicht der zur Verfügung stehenden Personal- und Institutsakten sieht man sich zunächst mit dem Problem der militärischen Geheimhaltung konfrontiert. Außerdem war die Universität verwaltungstechnisch hier nicht zuständig. ${ }^{706}$ Daher ist es in den seltensten Fällen möglich, in den Verwaltungsakten Hinweise darauf zu finden, was Dozenten konkret taten, während sie Soldat oder zu anderen Aufgaben eingezogen waren. ${ }^{707}$ Private Briefe oder sogar Biografien existieren ebenfalls nur sehr selten, so dass man hier kein vollständiges Bild entwerfen kann.

Über den Vorgang der Einberufung zum Kriegshilfsdienst hingegen lassen sich durchaus einige Aussagen treffen. Das Kriegs- und das Kultusministerium forderten die Universität mehrmals auf, geeignete Personen für Aufgaben in der kriegswichtigen Industrie zu nennen: ${ }^{708}$

Ew. Exzellenz ersuche ich [...] Ermittlungen darüber anzustellen, ob sich in dem Lehrkörper der Universitäten und technischen Hochschulen Persönlichkeiten befinden,

702 Antrag und Reiseroute in: UAG.Kur.Pers.Peter, Albert 14.06.1913.

703 UAG.Kur.Pers.Peter, Albert 05.03.1915.

704 UAG.Kur.Pers.Peter, Albert Antrag: 18.09.1915; Ablehnung 01.12.1915.

705 UAG.Kur.Pers.Peter, Albert 02.06.1919. Das erste Schreiben Peters an den Kurator nach seiner Rückkehr, in dem er Urlaub beantragt, um nach der langen Gefangenschaft seine Mutter besuchen zu können.

706 Ein Zugriff auf die Überlieferung der Militärbehörden ist nicht möglich: „Die Akten des Heeresarchives wurden in den Jahren 1937 und 1938 an das Militärarchiv Potsdam abgeliefert. Dort sind sie während des Zweiten Weltkriegs fast vollständig vernichtet worden. Der kleine Restbestand im Geheimen Staatsarchiv lässt kaum Bezüge zur Universität Göttingen erwarten. Eine separate Bestandsgruppe über die Beziehung von Wissenschaft und Militär existiert offenbar nicht.“ Hunger; Wellenreuther (Hrsg.): Spezialinventar. Göttingen 2002. S. 757.

707 Im Rahmen dieser Arbeit wurden alle Personalakten von naturwissenschaftlichen Dozenten der Göttinger Universität, die während des Ersten Weltkrieges dem Militär angehörten, eingesehen. Es finden sich fast keine Hinweise auf die militärischen Laufbahnen oder Aufgaben. In seltenen Fällen, in denen während der Dienstzeit Anträge gestellt wurden, finden sich kurze Bemerkungen oder die Angabe der Feldpostadresse des Dozenten.

708 Vorgänge in Kur.Alt.2.188. Siehe auch die für den Bereich der Studierenden bereits geschilderten Details zur Dienstpflicht gemäß dem Gesetze über den Vaterländischen Hilfsdienst vom Dezember 1915. 
die gemäß ihrer Vorbildung geeignet und geneigt wären, bei den stellvertretenden Generalkommandos, Bezirkskommandos und Gewerbe-Inspektionen als fachkundige Berater und Hilfsarbeiter in industriellen und gewerblichen Angelegenheiten, insonderbeit auf dem Gebiete des Arbeitsnachweises für die Kriegsindustrie, tätig zu sein. ${ }^{709}$

Generell kann man die Reaktion der Dozenten auf diese Aufforderung als breite Unterstützung charakterisieren. Man gab bereitwillig Auskunft, erstellte Listen und füllte Fragebögen aus, wie beispielsweise der Direktor der Sternwarte, Professor Johannes Hartmann, der folgende Angaben machte:

Johannes Hartmann; geb. 11.1.1865; d.u. [dienstunfähig]; Astronom, technisch nicht ausgebildet; Geheimer Regierungsrat, ordentlicher Professor, Direktor der Sternwarte; bereit, doch wo möglich so, dass die Leitung des Instituts weitergeführt werden kann; Unterstützung der Betriebsleitung, Aufsicht, feinste Messungen, Prüfungen mechanischer und optischer Apparate, Neukonstruktion solcher Hülfsmittel zur Lösung vorgelegter Aufgaben; verheiratet; Der Betrieb der Sternwarte kann nicht ganz geschlossen werden, da die städtischen Uhren von ihr aus reguliert werden.

Leopold Ambronn; 27.10.1854; gedient, Feldartill. Gefreiter; Astronom; a.o. Prof., Observator der Sternwarte; bereit, hier am Orte, da er 12 Unterrichtsstunden in der Fachschule für Feinmechanik erteilt; Überwachung feinmechanischer Arbeiten; verheiratet.

Heinrich Rauschelbach; 13.10.1888; d.u.; Astronom, geschicketer Feinmechaniker; Hilfsassistent; bereit, möglichst bier am Orte; ledig. 710

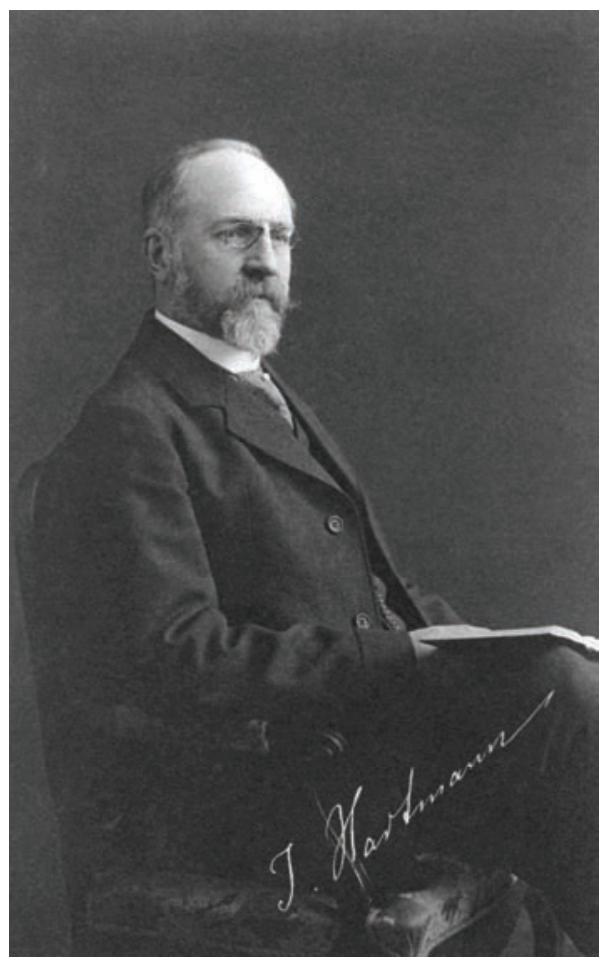

Abbildung 11: Johannes Hartmann

Allerdings, auch wenn man zunächst bereitwillig Auskunft gab, waren wohl die meisten Institutsdirektoren sehr darauf bedacht, die personelle Situation ihres

709 UAG.Phil.Fak.II.96 Schreiben des Kriegsministeriums vom 31.10.1915, in Abschrift durch das Kultusministerium an die Universitätskuratoren weitergeleitet am 3.1.1916 mit der Bitte „schleunigst darüber zu berichten“.

710 SUB.Gött.HSD.Cod.Ms. J. Hartmann.32 Bl. 31. Zahlreiche weitere Vorgänge in: UAG.Kur.3441-3448 und UAG.Kur.3452. 
eigenen Instituts nicht mehr als unbedingt notwendig zu schwächen. Die zuständigen Stellen ließen sich jedoch zu keinem Zeitpunkt auf Diskussionen zu der Frage ein, ob ein Universitätsangehöriger tatsächlich abkömmlich war oder nicht, sondern stellten vielmehr unmissverständlich die Kompetenzen klar. So schreibt am 25. Juni 1915 der Minister der geistlichen und Unterrichts-Angelegenheiten, also das Kultusministerium, an die ihm unterstellten Universitätskuratoren, ausdrücklich mit Bezug auf jegliche Art von Kriegsdienst:

Bei der Beurteilung der Frage, ob während des Krieges ein zum Militärdienst ausgemusterter oder einberufener Universitätslehrer als abkömmlich oder unabkömmlich anzuerkennen ist, sind die Interessen der Heeresverwaltung in den Vordergrund zu stellen. Auf der anderen Seite liegt es aber der Unterrichtsverwaltung ob, dafür Sorge zu tragen, daß der Universitätsunterricht, wenn auch in eingeschränktem Umfange, so doch in dem Maße aufrechterhalten wird, daß die Studierenden Gelegenheit haben, an den für ihre Ausbildung und für die Ablegung der Prüfungen wichtigsten Vorlesungen und Übungen teilzunehmen. Mit Rücksicht hierauf wird bei der Behandlung der Anträge auf Zurückstellung oder Befreiung eines Universitätslehrers vom Heeresdienst nach folgenden Gesichtspunkten verfahren:

Sind für ein Lehrfach mehrere Professoren bestellt, so wird es in der Regel genügen, wenn ein Vertreter den Unterricht übernimmt. Ist dagegen ein Fach nur einmal besetrt, so wird in Frage kommen, ob nicht ein Privatdozent oder ein anderer geeigneter Vertreterunter Umständen durch Abordnung von einer anderen Universität - die Vorlesungen pp. übernehmen kann. Dieser Grundsatz, gilt indes nur für solche Fächer, die für das Studium und die sich daran anschließenden Prüfungen unentbebrlich sind. Kommen derartige Rücksichten nicht in Betracht, so wird es keinen Bedenken begegnen, die betreffenden Vorlesungen an der einen oder anderen Universität wäbrend der Kriegsdauer gan₹. ausfallen zu lassen.

Die Fakultäten sind nicht in der Lage zu übersehen, ob im Falle der Abkömmlichkeit eines Universitätslehrers sich die Bestellung eines Vertreters ermöglichen läßt, und da es weiterhin erwünscht ist, die Anträge auf Befreiung vom Heeresdienst nach einheitlichen, für alle Universitäten maßgeblichen Gesichtspunkten zu behandeln, so muß daran festgehalten werden, daß die Frage der Abkömmlichkeit oder Unabkömmlichkeit des betreffenden akademischen Lehrers in jedem einzelnen Falle meiner Entscheidung vorbehalten bleibt. ${ }^{711}$

Der Gedanke an eine Verwendung der Wissenschaftler entsprechend ihrer Qualifikation liegt zweifelsohne nahe, was auch die Zeitgenossen so sahen, wie es beispielsweise in der Aufstellung Professor Hartmanns über sein Personal deutlich wird. Er empfahl sich und seine Mitarbeiter ja für „feinste Messungen“ oder feinmechanische Arbeiten im Rahmen des Kriegshilfsdienstes. Trotzdem gab es

711 UAG.Phil.Fak.II.96 25.6.1915. Siehe hierzu auch: Wettmann: Heimatfront. 2000. S. 118-119. 
auch zahlreiche Fälle, in denen eingezogene Wissenschaftler zunächst im normalen Fronteinsatz verwendet wurden, was selbstverständlich auch Widerspruch provozierte.

So wandte sich im Januar 1916 der Dekan der philosophischen Fakultät Professor Kurt Sethe mit folgender Bitte an das Kriegsministerium:

Euer Exzellenz erlaubt sich die philosophische Fakultät ehrerbietigst Folgendes zu gütiger Berücksichtigung zu unterbreiten. Nachdem die Heeresverwaltung in umfangreichem Masse auch zur Einziehung der ältesten Jahrgänge des ungedienten Landsturms übergegangen ist, wurden fortgesetzt ältere Gelehrte zum Heeresdienst einberufen. So fern es uns liegt, für die akademischen Lehrer oder andere Gelehrte irgendwelche Bevorzugungen befürworten zu wollen, und so sehr wir im Gegenteil der Ansicht sind, dass gerade der Gelehrtenstand in dieser schweren Zeit in der Erfüllung der Pflichten gegen das Vaterland mit gutem Beispiel vorangehen soll, so können wir uns doch nicht der Erkenntnis verschließen, dass in manchen Fällen der Sache besser gedient sein dürfte, wenn Gelehrte, die schon in vorgerücktem Alter stehen, anstatt als Rekruten mit der Waffe ausgebildet zu werden, von der Heeresverwaltung in einer ihrem Können mehr entsprechenden nutzbringenderen Weise im Dienst des Heeres verwendet werden. In Anbetracht dieser Überlegungen möchten wir Euer Exzellenz bitten, Ihren Einfluss in dieser Richtung bei der Militärbebörde geltend machen zu wollen. ${ }^{712}$

Es besteht kein Grund daran zu zweifeln, dass hier nicht versucht wurde, sich seiner - durchaus akzeptierten - Pflichten zu entziehen, sondern dass man als Naturwissenschaftler seinen Beitrag leisten wollte. Ein Einsatz mit der Waffe schien also quasi einer Nichtanerkennung des Wertes der wissenschaftlichen Arbeit gleichzukommen, was im Kontext der zuvor erwähnten, erst langsam wachsenden Akzeptanz der Naturwissenschaftler als echte Professoren gesehen werden muss. ${ }^{713}$ Im vorherigen Kapitel dieser Arbeit wurde gezeigt, dass innerhalb der Universitäten keinerlei rüstungsrelevante Forschung betrieben wurde, ja nicht betrieben werden durfte. Solche Themen wurden in eigens dafür geschaffenen Einrichtungen bearbeitet, wie etwa von Fritz Haber in Berlin oder Ludwig Prandtl in Göttingen. Offensichtlich stieß diese straffe und abgeschlossene Organisation bei den Naturwissenschaftlern selbst nur bedingt auf Verständnis. Vielfach wäre

712 Schreiben an den Kurator mit der Bitte um Weiterleitung an das Kriegsministerium. UAG.Phil.Fak.II.96 18.1.1916.

713 In Großbritannien stellte sich die Situation vollständig anders dar. In Oxford wurden zahlreiche Universitätsinstitute durch Regierungsbehörden und Militär mit kriegstechnischen Aufgaben betraut. Insbesondere arbeiteten die chemischen Institute auf dem Gebiet der Entwicklung des Gaskriegs. Winter: Oxford. 1994. S. 14-15.

Für Deutschland stellt Andrea Wettmann fest, dass die nach Ende des Krieges übermäßig betonten Verdienste der deutschen Wissenschaft im Ersten Weltkrieg erfolgten, um öffentliche Erwartungen zu erfüllen und ,nicht zuletzt um ihr [der Hochschullehrer] eigenes Prestige zu stärken und den Führungsanspruch der wissenschaftlichen Elite zu unterstreichen. "Wettmann: Heimatfront. 2000. S. 279. 
die Bereitschaft vorhanden gewesen, seine eigene Arbeitskraft zur Verfügung zu stellen; der Tod eines Naturwissenschaftlers an der Front dagegen wurde gleichsam als eine Vergeudung von Ressourcen gesehen.

Gerade die jüngeren Privatdozenten hatten sich zu Beginn des Krieges meist freiwillig zum Kriegsdienst gemeldet. Über ihr Schicksal liegen jedoch bis auf wenige Ausnahmen keinerlei Quellen vor. Der Privatdozent am botanischen Institut Dr. Siegfried Veit Simon etwa meldete sich ebenfalls gleich zu Beginn des Krieges als Freiwilliger. Dies schrieb Professor Gottfried Berthold am 27. Oktober 1916 an den Universitätskurator, als er für Simon in dessen Abwesenheit um die Verleihung des Professorentitels bat, wozu das Kultusministerium am 21. Dezember seine Zustimmung gab. ${ }^{714}$ In diesem Antrag skizzierte Berthold kurz Simons ganz alltägliche militärische Laufbahn:

Von Beginn des Krieges an hat er [Simon] sich als freiwilliger Krankenpfleger in den Dienst des Heeres gestellt und war zuletzt längere Zeit im Osten als Truppfübrer tätig. Mit diesem Sommer ist er als Landsturmmann beim Landw. Inf. Regt. 74 in Peine eingezogen, そ: Zt. ist er entweder schon an die Front abgerückt, oder steht unmittelbar vor dem Ausmarsch dorthin. 715

Auch der Privatdozent Dr. August Wolkenhauer erhielt, während er im Kriegsdienst stand, den Professorentitel zugesprochen. ${ }^{716} \mathrm{Ihn}$ erreichte diese Anerkennung jedoch nicht mehr. Der Geograph, der seit Beginn des Krieges Infanterist gewesen war, fiel bereits am 25. Februar 1915. Seine Todesanzeige erschien am gleichen Tag in der Göttinger Zeitung ${ }^{717}$, an dem beim Kurator das Schreiben vom Kultusministerium einging, in dem ihm der Titel verliehen wurde. Außer Wolkenhauer fielen noch weitere Göttinger naturwissenschaftliche Universitätslehrer: Der Lehrbeauftragte für Forstwissenschaft Karl Fricke (27. Oktober 1914), der beurlaubte Privatdozent der Physik Dr. Gustav Rümelin (16. Dezember 1914) und schließlich der Mathematiker Dr. Wilhelm Behrens. ${ }^{718}$ Er hatte sich erst kurz vor Kriegsbeginn, im März 1914, habilitiert und leistete fast drei Jahre Militärdienst, bevor er am 23. Juni 1917 fiel. $^{719}$

Im Gegensatz zu Behrens bestehen über die militärische Laufbahn des damaligen Privatdozenten und späteren Ordinarius, des Physikers Dr. Richard Courant,

714 Antrag Bertholds: UAG.Kur.6290 Bl. 10. Bewilligung: UAG.Kur.6290 Bl. 11.

715 UAG.Kur.6290 Bl. 10.

716 UAG.Kur.6263 Bl. 35.

717 Zeitungsausschnitt enthalten in: UAG.Kur.6290 Bl. 36.

718 UAG.Phil.II.1.c jeweils unter Punkt II.a der Fakultätsberichte.

719 Erteilung der venia legendi für Mathematik am 13.3.1914: UAG.Kur.6323 Bl. 5. Das Todesdatum ist lediglich auf dem Aktendeckel vermerkt. Die Akte selbst enthält keinerlei Hinweise auf die Zeit des Ersten Weltkrieges. Behrens war der Familie Felix Kleins freundschaftlich verbunden. Dies geht aus einem Feldpostbrief aus dem August 1914 an Klein hervor, in dem Behrens berichtet, Adjutant des Kommandeurs des Kriegsgefangenenlagers Munsterlager zu sein. SUB.HSD.Cod.Ms.F.Klein.8.75-76. 
äußerst ausführliche Quellen. ${ }^{720}$ Courant war von Kriegsbeginn an Frontsoldat und wurde am 27. September 1915 schwer verwundet. Nach dieser Verwundung wurde er im Jahr 1916 nach Berlin versetzt, um dort an der so genannten Erdtelegraphie zu arbeiten.

Ich hatte schon während meiner Infanteristenzeit ein für die in vorderster Linie kämpfende Truppe bestimmtes Hilfsmittel erdacht, die sogenannte Erdtelegraphie, welche den Nachrichten-Signaldienst in der vordersten Kampfzone sicherstellen sollte. Meine Kommandierung diente sowohl der technischen Entwicklung der Erdtelegraphie als auch ihrer Erprobung an exponierten Stellen der Front, sowie später der Organisation ibres Einsatzes. Von Anfang 1916 bis zum Schluss des Krieges bin ich obne Urlaub für diese Aufgaben tätig gewesen, teils im Laboratorium u.s.w., teils bei höheren Stäben, teils im Schützengraben. Ich erlitt dabei vor Verdun eine Gasvergiftung. Meine Verdienste wurden durch einen ausdrücklichen Befehl der Obersten Heeresleitung anerkannt. ${ }^{721}$

In Courants Fall finden sich erneut deutliche Indizien dafür, dass es nicht etwa gängige Praxis war, Wissenschaftler entsprechend ihrer Qualifikation einzusetzen, sondern dass es vielmehr deren eigener Initiative bedurfte, um ihr Wissen in kriegsrelevanten Bereichen einbringen zu können. Courant hatte im Hause seines zukünftigen Schwiegervaters Carl Runge die Grundideen der neuen Technologie kennen gelernt, die Runge gemeinsam mit seinem Kollegen Professor Peter Debye entwickelt hatte, wie er in einem Brieftagebuch, das er gemeinsam mit drei Kollegen führte, schrieb:

[...] an deren Einführung [der Erdtelegraphie] ich auch ein wenig beteiligt bin, in so fern ich im Sommer 1915 bier in Göttingen mit Debye wohl mit die ersten Versuche darüber gemacht habe, deren Resultat ein ganz brauchbarer Apparat war. Mein zukünftiger Schwiegersohn Dr. Courant Mathematiker und Privatdozent unsrer Universität kam damals auf Urlaub von der Front und drang darauf, man müsse eine Methode haben, um aus dem Schützengraben zum Kommandeur und umgekehrt signalisieren zu können, auch wenn alle Telefondrähte zerschossen wären. Das gab den Anlaß zur Erdtelegraphie. ${ }^{722}$

Courant war sofort durch seine Erfahrungen an der Front von der neuen Technologie und deren Notwendigkeit überzeugt, musste aber offensichtlich noch bei den verantwortlichen Stellen um die Möglichkeit zur Umsetzung kämpfen, wie Runge weiter beschreibt: „Es hat aber unverhältnismäßig lange gedauert, bis die Methode eingeführt worden ist. Courant hat sich sehr große Mühe darum gegeben

720 Am 15. Mai 1933 hatte der Direktor des mathematischen Instituts, Prof. Dr. Hermann Weyl, Courant im Rahmen der Durchführung des nationalsozialistischen Berufsbeamtengesetzes aufgefordert, „eine genaue und vollständige Darstellung ihrer militärischen Vergangenheit“ zu geben. UAG.Kur.4092-4093 Bl. 49. Courant kam dieser Aufforderung in einem insgesamt siebzehnseitigen Schreiben nach, das auch zahlreiche beglaubigte Abschriften mit Dienstzeugnissen aus der Zeit des Ersten Weltkrieges enthält. UAG.Kur.4092-4093 Bl. 50-67.

721 UAG.Kur.4092-4093 Bl. 50-51.

722 Hentschel, Tobies: Brieftagebuch. 1999. S. 191. 
und endlich ist es denn auch dahin gekommen. ${ }^{6723}$ Für Runge war dieser Vorgang noch aus einer weiteren Perspektive wichtig: Es gelang Courant, quasi im Gegenzug für die erhaltenen Anregungen, seinen künftigen Schwager, Runges Sohn Wilhelm, aus dem Schützengraben in seine Abteilung zu holen. Wilhelm Runge war angehender Ingenieur und erhielt so die Möglichkeit, Erfahrungen zu sammeln und sich zu qualifizieren. ${ }^{724}$

Zwar bieten die zur Verfügung stehenden Zeugnisse nicht die Möglichkeit eines vollständigen Vergleichs, jedoch stellte Courant mit dieser Tätigkeit ganz offensichtlich eine der wenigen Ausnahmen dar: Er wurde entsprechend seines Fachs und seiner Qualifikation für kriegstechnische Forschungen eingesetzt. Dies gelang jedoch erst, nachdem er dem Krieg im Schützengraben durch seine Verwundung entkommen war und vor allem auf sein eigenes Engagement hin. Das Unverständnis der Betroffenen spiegelt sich deutlich in einem Brief des Physikers Alfred Landé an seinen Göttinger Kollegen David Hilbert wieder, in dem er von seinen Versuchen berichtet, zur Artillerieprïfungskommission (A.P.K.) und dem dort tätigen Göttinger Privatdozenten und späteren Ordinarius Max Born versetzt zu werden:

\section{Meine militärische Zukunft geht trotz Prof. Borns Fürsprache nur langsam einer Klä- rung entgegen; die Bürokraten machen sich selbst fortwährend die größten Schwierigkei- ten, einen Physiker auf einen physikalischen Posten zu lassen. Born ist gerade [...] bei der Artillerieprïfungskommission [...] befördert worden, nachdem er sich 11/2 Jahre fürs $V$ aterland fast kaputt gearbeitet hat. ${ }^{725}$}

Der Privatdozent der Physik und spätere Göttinger Ordinarius Max Born hatte den Ausbruch und die ersten Wochen des Krieges noch in Göttingen erlebt. ${ }^{726} \mathrm{Im}$ Frühjahr 1915 nahm Born einen Ruf an die Universität Berlin an und verließ Göttingen. ${ }^{727}$ In Berlin bestanden nach den Schilderungen Borns deutlich günstigere Möglichkeiten für Naturwissenschaftler, entsprechend ihrer wissenschaftlichen Qualifikation militärisch eingesetzt zu werden. Born, der auf Grund eines Asthmaleidens nicht kriegsverwendungsfähig war, meldete sich bereits im Juni 1915 freiwillig zu einer Einheit, in der unter Leitung des Physikers Max Wien junge Wissenschaftler an der Weiterentwicklung der Funktechnik arbeiteten. ${ }^{728}$ Bereits kurze Zeit später wurde Born jedoch innerhalb Berlins zur Artillerieprüfungskommission versetzt. Dort arbeitete er an einem Schallmessverfahren, mit dem es möglich werden sollte, gegnerische Geschütze anhand des beim Abfeuern

723 Hentschel, Tobies: Brieftagebuch. 1999. S. 192.

724 Hentschel, Tobies: Brieftagebuch. 1999. S. 192.

725 SUB.HSD.Cod.Ms.D.Hilbert.207 31.10.1916.

726 Born schildert in seiner Autobiographie diese Zeit in lebendiger Form und berichtet von einem freiwilligen Einsatz als Erntehelfer, der schnell um sich greifenden Furcht vor Spionen und dem ersten Gefallenen, den er persönlich kannte. Born: Mein Leben. 1975. S. $223 \mathrm{ff}$.

727 Born: Mein Leben. 1975. S. 231.

728 Born: Mein Leben. 1975. S. 235. 
entstehenden Knalls genau zu orten, um diese selbst beschießen zu können. ${ }^{729}$ Born blieb bis zum Kriegsende bei der A.P.K. ${ }^{730}$ Er unternahm in dieser Funktion zahlreiche Reisen und erlebte so unter anderem auch die Schlacht an der Somme. ${ }^{731}$

Born zeichnet in seiner Autobiographie ein Bild der Militärforschung in Berlin, das vor allem durch freundschaftliche Verhältnisse und wissenschaftliche Diskussionen geprägt war. ${ }^{732}$ Für einen jungen Wissenschaftler war es jedoch sicher nicht einfach, Teil dieses Systems zu werden. Born war es nur gelungen, da er vor Ort in Berlin war und bereits über die notwendigen Kontakte verfügte, also einen Namen hatte. Wie stark dieses System auf persönlichen Kontakten basierte zeigt nicht zuletzt die Tatsache, dass Born schnell begann, seine eigenen Schüler zu sich nach Berlin zu holen.

\section{Ich begann, diese Möglichkeit, begabte junge Männer davor zu bewabren, daß sie an der Front verheizt wurden, als große Aufgabe zu betrachten. In mebreren Fällen hatte ich Erfolg, in anderen gab es bittere Enttäuschungen. ${ }^{733}$}

Der erste Schüler, um den Born sich erfolgreich bemühte, war Alfred Landé, mit dem er bereits in den ersten Kriegstagen gemeinsam als Erntehelfer gearbeitet hatte. ${ }^{734}$

Ebenso wie Richard Courant, äußerte sich der Chemiker Professor Adolf Windaus 1933 anlässlich der Einführung des nationalsozialistischen Gesetzes zur Wiederherstellung des Berufsbeamtentums zu seiner Arbeit während des Krieges: „In Göttingen bin ich hauptsächlich mit der Ausarbeitung für Glycerindarstellung (für

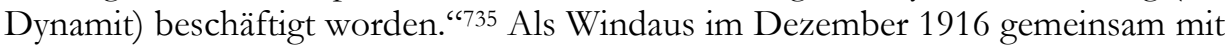
den anderen Institutsdirektoren aufgefordert wurde, geeignete Personen für den Kriegshilfsdienst aus seinem Institut zu nennen, füllte er nicht nur den entsprechenden Fragebogen aus, sondern verfasste auch ein ausführliches Schreiben an das stellvertretende Generalkommando, in dem er versuchte, die Tätigkeiten

729 Born: Mein Leben. 1975. S. 237ff.

730 Born: Mein Leben. 1975. S. 244-245.

731 Born: Mein Leben. 1975. S. 240-241.

732 Landés Äußerung, Born habe sich für das Vaterland fast kaputt gearbeitet, deckt sich nicht mit den Schilderungen Borns. Offensichtlich nimmt er Bezug auf den zeitweise schlechten Gesundheitszustand Borns, der jedoch auf das bereits vor Kriegsausbruch bestehende Asthmaleiden Borns zurückzuführen ist und nicht auf harte Arbeitsbedingungen.

733 Born: Mein Leben. 1975. S. 239-240.

734 Born: Mein Leben. 1975. S. 224-225.

735 Die Formulierung ,hauptsächlich“ muss wahrscheinlich zu einem erheblichen Teil aus der Situation heraus erklärt werden, in der sie gemacht wurde. Windaus war nicht bereit, die von ihm im Rahmen des nationalsozialistischen Gesetzes zur Wiederherstellung des Berufsbeamtentums geforderte Erklärung, dass er „rückhaltlos für den nationalen Staat“ eintrete, wie sie jeder Beamte abgeben musste, kommentarlos zu unterschreiben. „Ich nehme an, dass eine solche Erklärung nicht bedeutet, dass ich mich mit allen Maßnahmen der jetzigen Regierung einverstanden erkläre. Eine solche Erklärung würde ich ablehnen." Also versuchte er seine Arbeiten während des Ersten Weltkrieges so darzustellen, dass sie zeigten, dass er trotzdem jederzeit „rückhaltlos für sein Vaterland“ eingetreten sei. UAG.Kur.0548 31.05.1933. 
seiner Mitarbeiter als kriegswichtig zu definieren. ${ }^{736}$ Sein Ziel war es, seine Assistenten behalten zu können, indem sie in seinem Institut ihre Dienstpflicht erfüllten, so wie dies in Prandtls Modellversuchsanstalt üblich war. Zunächst stellte Windaus in seinem Schreiben ausführlich die schwierige Personalsituation in seinem Institut dar und erklärte, dass er keinen Mitarbeiter abgeben könne, obwohl ,alle zur Zeit noch im Institut tätigen Docenten und Studierenden mit Freuden bereit sind, ihre Kräfte dem vaterländischen Hilfsdienst zur Verfügung zu stellen. "737 Windaus führte hiernach weiter aus, dass es seiner Ansicht nach unverantwortlich wäre, die fortlaufende Ausbildung neuer Chemiker zu gefährden, in dem man seinem Institut Personal abziehe. ${ }^{738} \mathrm{Um}$ dies zu verhindern, sollten die Mitarbeiter des chemischen Laboratoriums daher wissenschaftliche Fragen für die Industrie bearbeiten. Windaus wurde selbst aktiv und setzte sich mit „einigen führenden Firmen der Grossindustrie“" in Verbindung. ${ }^{739}$

Die Direktion der Farbenfabriken, vorm. F[irma] Bayer u. Co., Elberfeld haben mir darauf geantwortet, dass eine der dringlichsten kriegswirtschaftlichen Aufgaben auf chemischem Gebiet die Auffindung eines technisch brauchbaren Verfahrens zur Erzeugung von Glycerin sei, das für die Darstellung hochwertiger Sprengstoffe unbedingt erforderlich und durch kein anderes Material qu ersetzen ist. Die Farbenfabriken würden die Übernahme dieser Aufgabe durch das hiesige Institut um so lieber sehen, als ihnen selbst wegen des Mangels an wissenschaftlichen Hilfskräften die Durcharbeitung eines entsprechenden Verfahrens unmöglich sei. ${ }^{740}$

Windaus konnte so beantragen, die Arbeiten in seinem Institut als Kriegshilfsdienst anerkennen zu lassen. Dies sollte nicht nur für seinen Mitarbeiter Professor Walter Borsche und die Studenten Otto Dalmer und Rudolf Seng gelten, sondern auch für die Leiter der pharmazeutischen und der photochemischen Abteilung, Professor Carl Mannich und Professor Alfred Coehn, die separate Anträge stellten. ${ }^{741}$ Der Kurator unterstützte diese Initiative und reichte die Anträge am 9. Januar 1917 an das zuständige stellvertretende Generalkommando weiter. ${ }^{742}$ Offensichtlich waren Windaus Bemühungen erfolgreich. Auch wenn keine direkte Antwort der Militärbehörden überliefert ist, blieben Mannich, Borsche und Coehn weiter an der Universität und wurden nicht eingezogen. ${ }^{743}$

In welchem Umfang tatsächlich Arbeiten für die Industrie durchgeführt wurden, ist jedoch nicht nachvollziehbar. In den Akten des Instituts sind weder ein konkreter Auftrag noch Arbeitsberichte enthalten. Noch schwerer wiegt, dass

736 UAG.Kur.3452 Bl. 11.

737 UAG.Kur.3452 Bl. 11.

738 UAG.Kur.3452 Bl. 12-13.

739 UAG.Kur.3452 Bl. 36.

740 UAG.Kur.3452 Bl. 36-37.

741 UAG.Kur.3452 Mannich: Bl. 39, Coehn: Bl. 41.

742 UAG.Kur.3452 Bl. 42.

743 Liste aus dem Dezember 1917: UAG.Kur.3443 Borsche und Mannich: Bl. 181, Coehn: Bl. 187. 
keine Materialkosten oder sonstige Gelder erstattet wurden. Dies wäre jedoch bei Forschungen in größerem Umfang unbedingt zu erwarten gewesen, wie das Beispiel des agrikulturchemischen Laboratoriums gezeigt hat. Die von Windaus 1933 gewählte passive Formulierung, er sei „,mit der Ausarbeitung für Glycerindarstellung beschäftigt worden,“ lässt sich also nicht belegen. Es handelte sich vielmehr um einen Versuch, den Personalbestand seines Instituts zu erhalten. ${ }^{744}$ Das Interesse der Militärbehörden an kriegswichtigen Forschungen der Hochschulen beschränkte sich meist darauf, „durch entsprechende Zensurmaßnahmen ihr Bekanntwerden im feindlichen Ausland zu verhindern," wie Andrea Wettmann in gleicher Weise für die Universität Marburg feststellt. ${ }^{745}$

Wirklich belegbare Fälle, in denen einzelne Professoren oder Universitätsinstitute in Göttingen - außerhalb von Militärdienst und Kriegshilfsdienst - mit im weitesten Sinne kriegsrelevanten Aufträgen betraut wurden, finden sich nur sehr bedingt, so etwa als am 25. Januar 1915 das stellvertretende Generalkommando des X. Armeekorps beim Prorektor der Universität anfragte, ob Göttinger Wissenschaftler Vorschläge machen könnten, wie bei der industriellen Produktion von Klebstoffen der Mehlverbrauch verringert werden könnte. ${ }^{746}$ Dafür, dass ein einzelner Professor mit einer speziellen Aufgabe betraut wurde, fanden sich nur sehr wenige Beispiele: Der Agrarwissenschaftler Professor Paul Ehrenberg schrieb am 26. April 1918 an den Universitätskurator, dass er Urlaub für eine Reise im Auftrag der chemischen Abteilung des Kriegsministeriums an Orte benötige, „an denen im Vorjahre mit Kampfgasen gegen die Russen gearbeitet worden ist. ${ }^{\text {" } 747}$

[Dem Kurator] beehre ich mich biermit mitzuteilen, dass ich gestern abend eine Drabtnachricht des Kgl. Preuss. Kriegsministeriums, chemische Abteilung, erhielt, nach der erwünscht ist, dass ich vom Sonntag an mich an einer Reise in das Gebiet von Ober-Ost beteilige, die mit der Verwendung von Kampfgasen für landwirtschaftliche Zwecke zusammenhängt.

Da ich überzengt bin, dass auch seitens des Universitätskuratoriums gewünscht wird, dass ich dieser Aufforderung folge leiste, so habe ich [...] dem Kriegsministerium die gewünschte Antwort zusagend gegeben, mit dem Vorbehalt der Genehmigung meiner Reise durch das Kuratorium. ${ }^{748}$

Auch wenn die Vermutung sich nicht bestätigte, dass während und aufgrund des Ersten Weltkrieges sich eine verstärkte Zusammenarbeit zwischen Militärbehörden und Wissenschaftlern bildete, so blieben solche Kontakte doch dort, wo sie schon vor dem Krieg bestanden hatten, weiterhin bestehen, wenn auch in veränderter Form. Professor Hermann Theodor Simon hatte schon seit längerem eng

\footnotetext{
744 Siehe hierzu auch: Wettmann: Heimatfront. 2000. S. 148-149.

745 Wettmann: Heimatfront. 2000. S. 305.

746 UAG.Sek.38.1 25.1.1915.

747 UAG.Kur.6019 Bl. 98.

748 UAG.Kur.6019 Bl. 98.
} 
mit der Marine - in Form des Torpedo-Versuchs-Kommandos in Kiel - zusammengearbeitet. In der an seine Abteilung für angewandte Elektrizität angeschlossenen radioelektrischen Versuchsanstalt, die offiziell der Militärbehörde gehörte, wurde beispielsweise an Torpedoantrieben und -steuerungen geforscht. Außerdem wurden Marineoffiziere in der so genannten drahtlosen Telegraphie ausgebildet. Mit Ausbruch des Krieges blieben die Zahlungen des Militärs für Material und Kurse plötzlich aus. Der Kontakt brach in der Kriegszeit offensichtlich weitgehend ab, so dass auch Simon im Januar 1916 ausdrücklich anbot, ihm ,kriegstechnische Aufgaben zur Lösung“ einzureichen, ${ }^{749}$ was demnach bis dahin noch nicht geschehen war. Im November 1917 wurde Simon dann ,im Interesse kriegstechnischer Versuche“ nach Kiel gerufen. ${ }^{750}$ Auch im Januar 1918 beantragte er noch einmal Urlaub zu diesem Zweck. Allerdings dauerten seine Aufenthalte bei der Torpedoinspektion jeweils nur wenige Tage, so dass man davon ausgehen kann, dass er dort entweder eine neue Technik begutachtete oder eine eigene Idee vorstellte. Am 22. November 1917, also unmittelbar im Anschluss an seine erste Reise zu Kriegszeiten nach Kiel, wurde Simon durch den Inspekteur des Torpedowesens, Konteradmiral Ritter von Mann, für seine Zusammenarbeit mit der Marine das Eiserne Kreuz verliehen. ${ }^{751}$ Ausreichend Zeit hatte Simon während des Krieges gewiss, denn er konnte wegen der geringen Hörerzahlen sogar Erholungsurlaub beantragen, und dies ohne, wie es üblich gewesen wäre, einen Vertreter für seine Amtsgeschäfte als Abteilungsvorsteher zu benennen.

Eine Vertretung für mich wird in keiner Weise notwendig sein, da zur Zeit überhaupt nur wenig Studierende hier sind, die sich den von mir vertretenen Spezialfächern zu wenden. Sie können getrost ihre Wünsche ein Semester zurückstellen, obne, dass dadurch ibre Studien eine Schädigung erfahren. ${ }^{752}$

Mit Sicherheit erfüllten zum Kriegsdienst eingezogene Dozenten noch weitere Aufgaben, von denen aber, gerade wenn sie kriegsrelevant waren, keine Spuren in den Akten der Universität auftauchen. Weiterhin ist denkbar, dass auch vor Ort in Göttingen verschiedene Hilfstätigkeiten ausgeführt wurden. Als Zeitungsente entpuppte sich jedoch die Meldung, dass sich Professoren der Georgia Augusta als Briefträger betätigten, um Engpässen auf diesem wichtigen Gebiet zu begegnen. Am 22. August 1914 war beim Prorektor der Göttinger Universität ein Schreiben eines verwunderten Hamburgers eingegangen, dem ein Ausschnitt der Hamburger Fremdenblätter mit folgendem Inhalt beigefügt war:

749 UAG.Phil.Fak.II.96 10.01.1916.

750 UAG.4.V.b.259 Bl. 82.

751 UAG.4.V.b.259 Bl. 85. Simon schrieb dazu an den Kurator: „Ich nehme an, dass es auch Ihnen eine Freude sein wird, wenn es der Göttinger Wissenschaft gelungen ist, dem Vaterlande in der Stunde der Gefahr wertvolle Dienste zu leisten."

752 UAG.4.V.b.259 Bl. 94. 
Göttingen, 19. Aug. Eine Anzabl Göttinger Professoren hat Stellen als Landbriefträger übernommen, um andere Kräfte dadurch freizumachen und den Postbetrieb aufrecht zu erhalten. ${ }^{753}$

Der Prorektor antwortete darauf am 24. August, dass er diese Meldung nicht bestätigen könne und dass ihm auf Nachfrage die Postbehörde versichert habe, unter Zuhilfenahme der Jugendwehr mit ihrem Personal auszukommen. ${ }^{754}$ Am gleichen Tag erhielt er noch eine Feldpostkarte von Krankenschwestern eines Lazaretttrupps, die auf der Fahrt an die Westfront in den Leipziger Neuesten Nachrichten einen Artikel gleichen Inhalts gelesen hatten und ihre Freude hierüber zum Ausdruck bringen wollten. Die Karte war adressiert an die „Herren Professoren der Göttinger Universität. Jetzige Landbriefträger“. ${ }^{755}$ Der Prorektor antwortete auch ihnen ausgesprochen höflich, ohne jedoch auf die Frage einzugehen, ob die Meldung richtig war. ${ }^{756}$ 


\section{Rückwirkungen auf das Kollegium}

Zeitungsartikel über Professoren als Landbriefträger sind zwar hauptsächlich als Anekdote zu sehen, haben aber doch im Kern durchaus eine ernsthafte Aussage: Es konnte keine selbst gewählte Isolation, keine zweckfreie Askese, wie Burchardt es nennt, ${ }^{757}$ zur Zeit des Ersten Weltkrieges geben. Man wurde, ob man es wollte oder nicht, ständig mit der Realität des Krieges konfrontiert, sei es auch manchmal durch eine nicht ganz ernsthafte Postkarte von Krankenschwestern auf dem Weg an die Front. Diese Realität ließ sich nicht ausblenden, gab auch innerhalb der Universität alltäglichen Vorgängen ganz neue Bedeutung und ließ Konflikte und Spannungen entstehen, wo dies zuvor nicht der Fall war. ${ }^{758}$

Ein eindrucksvolles Beispiel hierfür ist der Berufungsvorgang eines Nachfolgers für die Professur für Experimentalphysik, die zuvor Professor Eduard Riecke innehatte. Riecke wollte sich zum April 1915 aus seinem Amt zurückziehen. Ende Oktober 1914 begann dieser Vorgang routinemäßig damit, dass das Kultusministerium die Philosophische Fakultät dazu aufforderte, wie immer vor einer Emeritierung oder nach dem Tod eines Lehrstuhlinhabers, Ersatzvorschläge ,unverzüglich in der üblichen dreizahl einzureichen“. ${ }^{759}$ Die Fakultät bildete daraufhin einen Berufungsausschuss, der diese Vorschläge erarbeiten und in Form einer Liste über den Kurator an das Kultusministerium einreichen sollte. Auf Platz eins dieser Liste befand sich als klarer Favorit des Ausschusses Professor Willi Wien, der zu dieser Zeit in Würzburg lehrte. Unter anderem heißt es über ihn in dem Gutachten: „Seine wissenschaftlichen Verdienste auf theoretischem wie experimentellem Gebiete sind allgemein so anerkannt, dass es kaum nötig scheint, im einzelnen darauf einzugehen." ${ }^{\text {"760 }}$ Alternativ zu Wien setzte der Ausschuss den Namen Professor Friedrich Paschens aus Tübingen, der zuvor bereits in Hannover tätig gewesen war, auf die Liste. Auch die Bewertung seiner Fähigkeiten fällt in der fertigen Vorschlagsliste ausgesprochen positiv aus. ${ }^{761}$

Auf Platz drei, allerdings mit „gewissen Bedenken“ und ausdrücklich nur, um der Vorschrift zu genügen, wurden schließlich noch zwei weitere Kandidaten genannt.

Wir schätz̧en die Fähigkeiten der beiden im Vorstehenden charakterisierten Männer [Wien und Paschen] so hoch und würden die Berufung eines jeden von ibnen mit so leb-

\footnotetext{
757 Burchardt: Naturwissenschaftliche Universitätslehrer. 1988. S. 213.

758 Andrea Wettmann berichtet für die Universität Marburg über sich verstärkende antisemitische Konflikte im dortigen Kollegium. Vergleichbares konnte für Göttingen nicht nachgewiesen werden. Wettmann: Heimatfront. 2000. S. 360-362.

759 UAG.Phil.Fak.II.36.c 27.10.1914.

760 UAG.Phil.Fak.II.36.c 24.12.1914.

761 UAG.Phil.Fak.II.36.c 24.12.1914.
} 
hafter Genugtuung begrüssen, dass wir uns am liebsten auf die Nennung nur ibrer $\mathrm{Na}$ men beschränkten.

Um indessen der Vorschrift zu genügen, vervollständigen wir unsere Liste durch die Bezeichnung von zwei Gelehrten an dritter Stelle, die uns nach ibren Leistungen als Forscher und Lehrer gleichfalls den im Eingang präzisierten Anforderungen zu entsprechen scheinen, gegen die wir aber doch gewisse Bedenken in anderer Hinsicht nicht unterdrücken können. ${ }^{762}$

Die beiden Kandidaten, die sich den dritten Platz der Vorschlagsliste teilten, waren Professor J. Stark aus Aachen und zuletzt Professor P. Zeemann aus Ams-

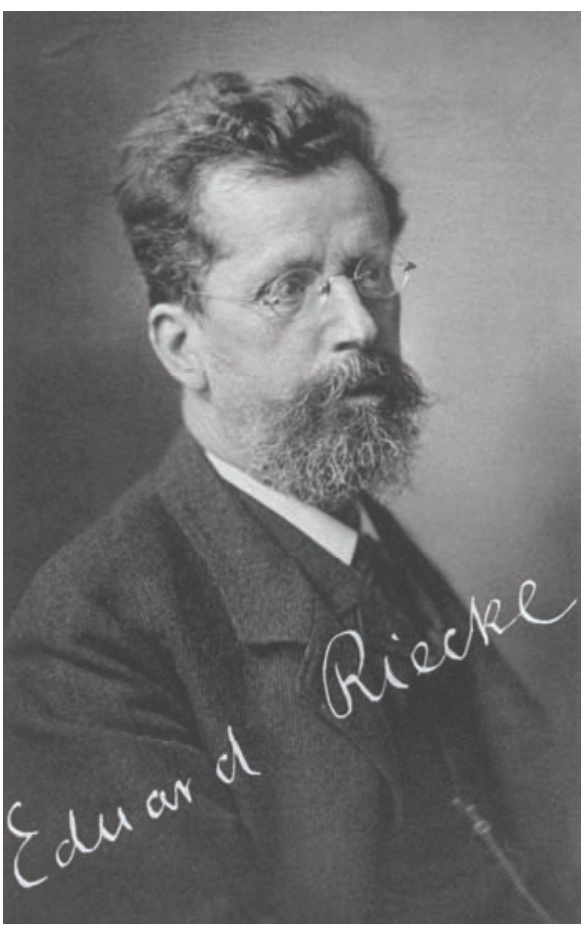

Abbildung 12: Eduard Riecke terdam. Die Bedenken gründeten sich im Falle Starks, der 40 Jahre alt und damit zehn Jahre jünger war, als die anderen drei Kandidaten, auf die Tatsache, dass er zwar große Erfolge auf experimentellem Gebiet erzielt hatte, der Weg dorthin jedoch nicht immer den Vorstellungen der Kommissionsmitglieder entsprach: „Wie bei manchen anderen aussergewöhnlich nach der experimentellen Seite begabten Forschern tritt bei Stark das Bedürfnis und die Fähigkeit zu exakter theoretischer Behandlung der Probleme zurück. “"763 Unterschwellig klingt dieser Vorwurf auch gegenüber Zeemann an, der ebenfalls seine Stärken mehr im Experiment zeige, als in der Theorie. Auf experimentellem Weg habe ,ihn die Verbindung von glücklicher Intuition mit technischer Geschicklichkeit zu seinen Erfolgen geführt" “.764

Wichtigstes Argument, das gegen eine Berufung Zeemanns sprach, war jedoch laut der Berufungskommission die Tatsache, dass Zeeman kein Deutscher war, obgleich er als Niederländer kein feindlicher Ausländer war. Es wurde befürchtet, dass er daher die Verhältnisse an deutschen Hochschulen nicht kannte, was in einem anderen Fach nicht problematisch gewesen wäre, für eine so zentrale Professur aber sehr wohl.

762 UAG.Phil.Fak.II.36.c 24.12.1914.

763 UAG.Phil.Fak.II.36.c 24.12.1914.

764 UAG.Phil.Fak.II.36.c 24.12.1914. 
Immerhin entnebmen wir aus dem Umstande, dass Zeemann mit deutschen Verhältnissen und Unterrichtseinrichtungen nicht innig vertraut ist, ein gewisses Bedenken gegen ibn. Der Experimentalphysiker an einer deutschen Universität hat die Aufgabe einer Einwirkung auf eine breite und inhomogene Masse, und hierin liegt eine Schwierigkeit, die bei Professuren für speziellere Gebiete nicht obwaltet und eine besonders große Erfahrung erwünscht macht. ${ }^{765}$

Ausdrücklich stellte der Ausschuss klar, dass nicht etwa die Tatsache, dass Zeeman kein deutscher Staatsangehöriger war, an sich gegen eine mögliche Berufung sprach.

Dass er Ausländer ist, hat uns nicht abgehalten, ibn seiner wissenschaftlichen Potenz. gemäss zu nennen, und dies um so weniger, als er dem nächst verwandten niederländischen Volke angehört, das in dem gegenwärtigen Kriege unter grössten Opfern eine korrekte Neutralität innehält. ${ }^{766}$

Hätte man hier grundsätzliche Bedenken gehabt, so hätte man ihn wahrscheinlich überhaupt nicht auf die Liste gesetzt. Die hier angeführten Zitate stammen aus der endgültigen Vorschlagsliste, so wie diese an das Kultusministerium abgeschickt worden ist. Leider ist nicht mehr nachzuvollziehen, ob die Frage der Nationalität Zeemanns von Beginn an Teil der Erörterungen war. Sie wirkt wie eine Stellungnahme zu einer vorangegangenen Diskussion innerhalb der Fakultät, die in Form und Umfang bei weitem das bis dahin normale Maß übertraf: Insgesamt wurden sechs Kommissionssitzungen, drei Sitzungen der mathematischnaturwissenschaftlichen Abteilung der philosophischen Fakultät und sogar eine Sitzung der gesamten philosophischen Fakultät abgehalten, und dies, ohne dass ein Konsens gefunden wurde. ${ }^{767}$

Es war Hermann Theodor Simon, der empört über den Gedanken war, während des Krieges einen Ausländer auf die Vorschlagsliste zu setzen. Offenbar bereits nach längeren erfolglosen Diskussionen und vor allem verlorenen Abstimmungen richtete er ein letztes Schreiben an die anderen Mitglieder des Berufungsausschusses, in dem er seine Gründe dafür darlegte, warum es ihm unmöglich sei, sich dem Willen der Mehrheit des Ausschusses anzuschließen, obwohl dies das sonst übliche Vorgehen gewesen wäre:

In letzter Stunde beantrage ich noch einmal dringend, Herrn Professor ZEEMAN nicht auf die Vorschlagsliste zu setzen, sondern den gegen ibn vorgebrachten Gründen Gebör zu geben.

Die mathematisch-naturwissenschaftliche Abteilung steht - mit Recht oder mit Unrecht - schon jetzt innerhalb der übrigen Universität und in weiten Kreisen der Bürgerschaft

\footnotetext{
765 UAG.Phil.Fak.II.36.c 24.12.1914.

766 UAG.Phil.Fak.II.36.c 24.12.1914.

767 UAG.Phil.Fak.II.36.c 23.12.1914.
} 
im Geruche einer weltbürgerlichen Ideologie und nationalen Laxheit, gegen die sich in der jetzigen Zeit das natürliche Empfinden leidenschaftlich auflehnen muss. Man kommt immer wieder in die Lage, die Abteilung gegen solche Vorwürfe, auch rubig denkenden Leuten gegenüber, verteidigen zu müssen. ${ }^{768}$

Zum einen bezieht sich Simon damit ganz allgemein darauf, dass die Georgia Augusta in hohem Maße an der bei weitem noch nicht allgemein akzeptierten Internationalisierung der Wissenschaften, insbesondere der Naturwissenschaften, teilnahm; zum anderen war gerade erst der Lehrstuhl für theoretische Physik ebenfalls an einen Niederländer, Professor Peter Debye, vergeben worden. Wahrscheinlich aber dachte er auch an den kanadischen Studenten Winthrop Bell. Dieser hatte das Kollegium beinahe schon einmal gespalten, als vier Professoren der philosophischen Fakultät ihm sein mündliches Doktorexamen im Gefängnis, während seiner Schutzhaft, abgenommen hatten. ${ }^{769}$

Der Sachverhalt ist dieser, dass ein aus Canada stammender Student, der hier mehrere Jahre studiert hat, seine umfangreiche Dissertation in diesem Sommer eingereicht und daraufhin den Termin für sein mündliches Examen gegen Ende des Semesters bekommen hatte. Durch die Erkrankung des inqwischen verstorbenen Professor Lexis, der einer seiner Lehrer gewesen war, wurde eine Vertretung notwendig und dadurch geschah es, dass der Termin für das mündliche Examen hinausgeschoben wurde. Da kam am 4ten August die englische Kriegserklärung und es wurden alle hier in Göttingen befindlichen Personen britischer Staatsangehörigkeit in Schutzhaft genommen. Nach wenigen Tagen am 9. August wurden sie wieder entlassen. In der Zwischenzeit ist in der Tat am 7. August die mündliche Prüfung abgehalten worden. [...]

Die Examinatoren sahen in dem Kandidaten mehr den ausgezeichneten Göttinger Studenten als den britischen Staatsangehörigen und wollten an ibm die Handlungsweise seines Staates nicht rächen. ${ }^{770}$

Diese Schilderung dieser wohl einzigartigen Prüfung entstammt einem Brief, den der Dekan der philosophischen Fakultät an einen empörten Dresdener Oberlandesgerichtsrat schreiben musste, nachdem dieser einen sehr negativ verfassten Zeitungsartikel in einer örtlichen Zeitung gelesen hatte. ${ }^{771}$ Diesen Vorgang hatte Simon vor Augen, als er von ,nationaler Laxheit“" sprach und stand dabei mit seiner Auffassung auch innerhalb der Universität durchaus nicht allein: Der damalige Prorektor Eduard Kaufmann legte mit deutlichen Worten vorsorglich Einspruch gegen eine mögliche Verleihung der Doktorwürde an Bell ein.

Ohne diese Angelegenheit, soweit sie ausschließlich die Sache der philosophischen Fakultät ist, dadurch anrübren zu wollen, bemerke ich in meiner Eigenschaft als Prorector

768 UAG.Phil.Fak.II.36.c 18.12.1914.

769 Siehe hierzu auch: Tollmien: Der Krieg. 1993. S. 143.

770 UAG.Sek.598.8.Bell 14.09.1914.

771 UAG.Sek.598.8.Bell 10.09.1914. Der Zeitungsartikel liegt bei. 
ganz ergebenst, dass, falls keine Annullierung des Doktorexamens des Bell erfolgen sollte, wenn die philosophische Fakultät vielmehr ohne Rücksicht auf die besonderen Zeitumstände, unter welchen wir uns befinden und ungeachtet der Stellung als Feind Deutschlands, die stud. Bell als Brite eo ipso einnimmt, beschließen sollte, der Doktorpromotion ibren gewohnten Lauf zu lassen, dies als Angelegenheit anzusehen wäre, welche meines Erachtens das Ansehen der gesamten Göttinger Universität angeht, indem sie deren patriotisches Empfinden, deren deutschnationalen Stolz empfindlichst treffen würde. Indem ich wobl erklären zu können glaube, dass ich mich in dieser Auffassung in Übereinstimmung mit dem Gros der Herren Kollegen unserer Universität befinde, darf ich versichern, dass eine eventuelle Promotion des Bell durch die Göttinger philosophische Fakultät mit zwingender Notwendigkeit zu lebhaften öffentlichen Protesten Anlass geben würde, und zweifellos unliebsame scharfe Gegensätze in unseren Kollegenkreis tragen müsste. 772

Die philosophische Fakultät beugte sich schließlich dieser Drohung, ${ }^{773}$ was allerdings schon nicht mehr relevant war, da Bell zu diesem Zeitpunkt bereits durch den Rechtspflegeausschuss der Universität verwiesen worden war. Dieser Vorgang trug das Potential für einen deutlich größeren Konflikt innerhalb des Kollegiums in sich, wurde aber dadurch vorzeitig beendet, dass das Disziplinarverfahren es auch Bells Fürsprechern ${ }^{774}$ unmöglich machte, seine Promotion weiter zu betreiben.

Simon führt in seinem Einspruch gegen eine Aufnahme Zeemanns in die Vorschlagsliste weiter aus, dass es zwar durchaus Fälle geben könne, in denen sich ein Wissenschaftler bewusst gegen die öffentliche Meinung stellen müsse, dieser konkrete Fall aber zu dieser besonderen Zeit dazu nicht im Geringsten geeignet sei - zumal der Berufungsausschuss selbst kein wirkliches Interesse an einer tatsächlichen Berufung Zeemanns habe, wie dessen Listenplatz zeige. Darüber hinaus sei in den ersten Sitzungen der Kommission der Name Zeemann noch gar nicht genannt worden. Hier liegt Simons Hauptkritikpunkt: Er wollte nicht einsehen, warum man auch nur das Risiko eines Konflikts eingehen sollte, wenn man eine Berufung Zeemanns offensichtlich gar nicht in Betracht zog.

Eine Fakultät, die sich obne Notwendigkeit in Widerspruch mit dem allgemeinen Volksempfinden setrt, schadet ibrem Anseben und darf sich nicht wundern, wenn ibre Stimme künftig weniger Gewicht hat. Es sollte aber gerade jetzt unsere Aufgabe sein, uns recht viel Anteil an Geltung und Wirkung für die kommenden Zeiten zu erhalten, in denen so vieles neugebaut werden muss.

Mein Widerspruch ist - wie man sieht - aus dem Impuls eines heissen Verantwortungsgefühls für das Ansehen und die Geltung von Fakultät und Universität hervorgegangen,

772 UAG.Sek.598.8.Bell 28.08.1914.

773 UAG.Sek.598.8.Bell 03.09.1914.

774 Da es kein offizielles Prüfungsverfahren und damit auch keinen schriftlichen Vorgang gab, ist nicht festzustellen, wer genau Bells Promotion befürwortete. Zumindest kann man davon ausgehen, dass Professor Carl Runge dazu gehörte, da er auch als Bürge für Bell auftrat (Siehe oben.). 
und ich hatte geglaubt, dass es nur eines Hinweises bedïrfte, um obne weiteres diese Verkettung der Frage mit der allgemeinen Universitätspolitik zur Erkenntnis zu bringen. ${ }^{775}$

Nach dieser Bekräftigung der Motive für seinen Widerspruch geht Simon auf den wohl schwersten Makel seines Standpunkts ein:

Es war nicht meine Schuld, dass die Kollision zustande gekommen ist, welche hinterher für meinen Widerspruch den Schein persönlicher Motive zulässt. Auch wenn ich eine solch übelwollende Deutung hätte voraussehen können, war es Pflicht, meine Stimme zu erbeben. Es wäre tief zu beklagen, wenn ibr durch jene Suggestion ibr Gewicht genommen werden könnte. ${ }^{776}$

Tief gekränkt versuchte sich Simon des Vorwurfs zu erwehren, der ihm zumindest unterschwellig gemacht worden sein muss, er wolle aus persönlicher Eifersucht der Fakultät Steine in den Weg legen und die Arbeit des Berufungsausschusses vorsätzlich blockieren. Hintergrund dieser Angelegenheit war ein Brief Simons, den dieser gleich zu Beginn des Berufungsvorgangs an die Fakultät gerichtet hatte. Am 3. November hatte er den Dekan ausdrücklich darum gebeten, nicht in die zu bildende Kommission eingeladen zu werden. Simon war zu diesem Zeitpunkt noch außerordentlicher Professor und unzufrieden mit seiner Position: ${ }^{777}$

Wenn ich die in Betracht kommenden Physiker ihrer wissenschaftlichen Leistungen nach ordne, - dann bei jedem hinzufüge, was er an spezifischer Lebrbefähigung u[nd] Organisationsbegabung in der für uns notwendigen Richtung mitbringt, - schließlich abziehe, was ihm im Hinblick auf unser bisher so wirkungsvolles Kollegiales Zusammenarbeiten fehlt, - so kommt eine Reihe heraus, in der auch meine eigene Kandidatur in den Bereich des möglichen rück.t. ${ }^{778}$

Mit dieser Sicht der Dinge stand Simon jedoch allein in der Fakultät. Er wurde Mitglied der Kommission und war damit endgültig aus dem Kreis der möglichen Kandidaten ausgeschieden, in dem nur er sich selbst gesehen hatte. ${ }^{779}$ Es fällt nicht schwer, sich auszumalen, welchen Eindruck Simons Eingabe bei seinen

775 UAG.Phil.Fak.II.36.c 18.12.1914.

776 UAG.Phil.Fak.II.36.c 18.12.1914.

777 Simon hatte sich ein Jahr zuvor, im Dezember 1913, in einem mehrseitigen Schreiben an den Kurator gewandt und ihn gebeten, seine Stellung aufzuwerten: „Nun werde ich demnächst 44 Jahre alt [...]. Dazu kommt, dass ich mir nach der ganzen Lage der Dinge nunmehr sagen muss, dass eine Berufung an eine andere Universität oder Hochschule nicht mehr in Frage kommen kann. [...] Nun ist fraglos meine hiesige Stellung und Aufgabe sachlich eine, die durchaus alles gewährt, was ein Gelehrter sich für seine Lebensarbeit wünschen kann. Ich muss aber [...] darauf bedacht sein, dass mir für meine Tätigkeit dasjenige Entgelt wird, worauf sie ihrem Umfange und Werte nach Anspruch hat." UAG.4.V.b.259 Bl. 60-61.

778 UAG.Phil.Fak.II.36.c 03.11.1914.

779 Simon schätzte die Wahrscheinlichkeit, an einer anderen Universität oder Hochschule ein Ordinariat zu bekommen, als ausgesprochen gering ein (Siehe oben.). Offensichtlich sah er die Möglichkeit, in Göttingen ein solches zu erhalten, als letzte Chance. UAG.4.V.b.259 Bl. 60-61. 
Kollegen machen musste. Die positivste Möglichkeit war hier die Deutung seines Briefes als etwas ungeschickten Versuch, sich ins Gespräch zu bringen.

Simon reichte dann ein so genanntes Separatvotum, in dem er sich gegen einen Vorschlag Zeemanns aussprach, an den Dekan ein, der dieses gemeinsam mit dem Votum der Fakultätsmehrheit an das Kultusministerium weiterleiten musste. In den langen und zahlreichen Diskussionen gelang es Simon aber trotz seiner geschwächten Position, durchaus namhafte Kollegen auf seine Seite zu ziehen und von seinen Argumenten zu überzeugen. Dem drei maschinenschriftliche Seiten umfassenden und damit sehr umfangreichen Separatvotum schlossen sich Georg Elias Müller, Inhaber des Lehrstuhls für Psychologie, der Direktor der Universitätssternwarte, Johannes Hartmann, sowie die Professoren Gustav Frölich, Lorenz Morsbach und Konrad von Seelhorst an. In seiner Stellungnahme betont Simon besonders zwei Punkte: Zum einen unterstreicht er die besondere Bedeutung der Professur für Experimentalphysik und zum anderen weist er auf das besondere Gewicht hin, das dieses Berufungsverfahren durch den Krieg erhielt.

Der Lehrstuhl für Experimentalphysik an den Universitäten besitzt eine besonders breite Wirkung auf alle gebildeten Stände unseres Vaterlandes [...] Trotz aller Sachlichkeit der physikalischen Wissenschaft fehlt es in ihr doch durchaus nicht an wertvoller nationaler Eigenart, sei es der historischen oder didaktischen Begriffsbildung, sei es der Methodik, sei es der theoretischen Gruppierung der Tatsachen. [...]

Bei dieser Sachlage scheint es mir schon in normalen Zeiten nur unter ganz aussergewöhnlichen Umständen zu verantworten, für diesen Lebrstubl einen Ausländer zu empfehlen. [...]

Vollends aber in dieser Zeit unseres nationalen Ringens, welches viele von ibnen ins Feld und leider auch schon manchen in den Tod geführt hat, müsste es sie geradezu verbittern und mehr noch wie sie vielleicht die der wissenschaftlichen Sphäre fernerstehenden Kreise unseres Volkes. Denn jeden Tag erleben wir es ja doch mit innerer Empörung, dass uns das Ausland all unser langjähriges Streben nach Zusammenarbeit und Verständnis mit einer abgrundtiefen Verständnislosigkeit für deutsches Wesen, ja mit wilder Gehässigkeit vergilt. Für die dadurch geweckete Stimmung der Gegenwart scheint mir schon der Gedanke, eine für unsere Volksbildung so wichtige Professur mit einem Ausländer zu besetzen, unerträglich. [...]

Nur die Überzengung, dass es sich um eine für das volkstümliche Ansehen und die nationale Geltung der Fakultät grundlegende Frage handelt, konnte mich bestimmen, meine abweichende Meinung einer Mitteilung an, Ew. Exzellenz, wert zu halten. ${ }^{780}$

Die Mehrheit der Fakultät ließ es sich jedoch nicht nehmen, neben der eigentlichen Vorschlagsliste eine Erklärung ihrer Position als Antwort auf das Separatvotum mit nach Berlin zu schicken. In dieser Erklärung rechtfertigte sie jedoch

780 UAG.Phil.Fak.II.36.c 22.12.1914. 
weniger den Vorschlag Zeemanns, sondern verneint vielmehr ihre Zuständigkeit für die von Simon aufgeworfenen Fragen.

Das anbei überreichte Minoritätsvotum gibt den allgemeinen politischen Überlegungen, welche bei den beute vorliegenden Verhältnissen im Vordergrunde stehen und deren Wichtigkeit niemand leugnet, einen u[nseres] E[rachtens] einseitigen Ausdruck. Es könnte sein, dass die Regierung, welche die in dieser Hinsicht in Betracht kommende Sachlage besser übersieht als wir, möglicherweise geradezu zu dem umgekehrten Ergebnis käme. Jedenfalls schien es der Majorität der Fakultät zweckmässiger, die Entscheidung über die Wertung der nationalpolitischen Faktoren der Regierung zu überlassen und sich selbst auf Geltendmachung derjenigen Momente zu beschränken, binsichtlich deren die Regierung in erster Linie von uns Auskunft erwarten wird, nämlich auf Würdigung der wissenschaftlichen und unterrichtlichen Qualitäten der in Betracht kommenden Persönlichkeiten. ${ }^{781}$

Mit dieser Erklärung scheinen auf den ersten Blick die Mitglieder der Fakultät genau dem Bild zu entsprechen, welches Burchardt von ihnen entwirft: „,...] weil er sich obendrein in politics nicht für sachkundig erachten mochte, hielt sich der Naturwissenschaftler politisch weit mehr zurück als ein Angehöriger jener Disziplinen, die der Tagespolitik näher standen." ${ }^{\text {"782 }}$ Bei genauerer Betrachtung ist allerdings zu bedenken, dass dieser Vorgang innerhalb der philosophischen Fakultät ablief, in der es ja durchaus Mitglieder gab, die der Tagespolitik näher standen. Außerdem wäre der einzige Weg wirklicher politischer Zurückhaltung gewesen, Simons Einwänden stattzugeben und von einer Nennung Zeemanns schlicht abzusehen.

Aber gerade die Tatsache, dass man diese Option bewusst nicht wahrgenommen hatte, macht es ausgesprochen schwierig, das Verhalten der Fakultätsmehrheit zu deuten. Folgt man der Aussage der Mitglieder der Fakultätsmehrheit, man habe nur über wissenschaftliche Faktoren ein Urteil abgeben wollen, so ist es bei allen möglichen Erklärungen stets der Listenplatz Zeemanns, der sich nicht in das Bild einfügen will. Zeemann wurde quasi als Vierter von Dreien genannt. Schätzte man tatsächlich Zeemanns Fähigkeiten so hoch ein, dass man sich eine Berufung ernsthaft wünschte, hätte man ihn auf einen höheren Listenplatz setzen müssen. Andererseits hätte man, wenn man Zeemanns Eignung - aus welchen Gründen auch immer - geringer einschätzte, leicht Simons Argumenten nachgeben können. Man hatte schließlich bereits drei Kandidaten gefunden und damit bestand keine Notwendigkeit, sich diesem Konflikt auszusetzen. Der Umkehrschluss muss also lauten, dass man diesen Konflikt bewusst gesucht hat. Hier ging es offensichtlich um eine Frage, die man grundsätzlich geklärt wissen wollte, oder um ein Zeichen, das man bewusst so setzen wollte.

781 UAG.Phil.Fak.II.36.c 23.12.1914.

782 Burchardt: Naturwissenschaftliche Universitätslehrer. 1988. S. 211. 
In der Eingabe Simons an die Mitglieder der Kommission, in der er das Separatvotum ankündigt, schreibt er: „Ich gebe zu, dass es Fälle geben kann, wo eine Fakultät sogar die Pflicht haben muss, gegen eine ganze Volksströmung anzukämpfen. Die vorliegende Frage ist dazu nicht angetan [...].“783 Diese Formulierung, insbesondere die Worte „ich gebe zu“, zeigt deutlich, dass Simon hier konkret auf einen Gegenstand der Diskussion innerhalb des Berufungsausschusses eingeht. Ganz offensichtlich wollten seine Kollegen aber genau das erreichen, was Simon zu vermeiden suchte: Sie wollten gegen eine ihnen unangenehme Strömung ankämpfen und ein Zeichen setzen, und dies war auch Thema der Sitzungen gewesen. Wie im ersten Kapitel dieser Arbeit beschrieben wurde, war Göttingen, wie wohl das ganze Land, von den fast hysterischen ausländerfeindlichen Auswüchsen einer enormen Spionage- und Sabotageangst nicht verschont geblieben. Dies machte auch vor der Universität nicht halt. Studierende zahlreicher Nationalitäten waren inhaftiert worden, und im September 1914, also nur wenige Wochen zuvor, waren auf Anweisung des Kultusministeriums die nichtdeutschen Assistenten entlassen worden, und auch promovieren durften nur noch Angehörige ,nichtfeindlicher Nationen".784 Andrea Wettmann stellt im Kontext des Endes der Internationalität der Wissenschaften fest, dass kaum Wissenschaftler „den Mut zu öffentlicher Selbstkritik“ fanden.785 Sie hätten vielmehr den "Zusammenbruch der internationalen Wissenschaftsgemeinschaft [...] als eine notwendige und nur wenig beklagenswerte Konsequenz des Krieges akzeptiert." "786 Für diesen

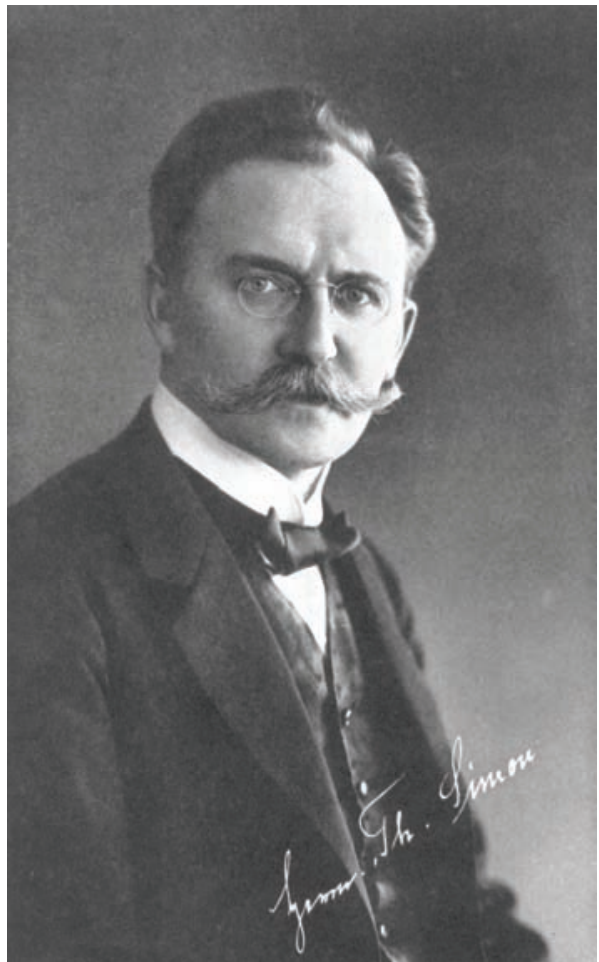

Abbildung 13: Hermann Theodor Simon Berufungsvorgang ist richtig, dass keine öffentliche Kritik geäußert wurde. Ein Ausrufungszeichen in Richtung des eigenen Kollegiums und des Ministeriums

\footnotetext{
783 UAG.Phil.Fak.II.36.c 18.12.1914.

784 Siehe oben. UAG.Phil.Fak.II.96 28.9.1914.

785 Wettmann: Heimatfront. 2000. S. 92.

786 Wettmann: Heimatfront. 2000. S. 92.
} 
stellte die Nennung Zeemanns aber trotzdem dar, da sie keinen anderen erkennbaren Nutzen gehabt hätte.

Wichtig ist außerdem die Art, in der dieses Zeichen gesetzt wurde. Man vermied einen öffentlichen Eklat, man richtete keine Protestschreiben an das Kultusministerium und wandte sich erst recht nicht an die Presse. In dem sehr bewusst gewählten Rahmen eines Berufungsvorgangs konnte man Stellung beziehen und sich zugleich sicher sein, dass man nur den eigentlichen Adressaten erreichte, ohne Gefahr zu laufen, einen Skandal zu provozieren, indem man die Regierungsmeinung öffentlich angriff. So forderte man das Kultusministerium auf eine recht subtile Art auf, die bis dato gängige Praxis zu überdenken, die Forschung, Lehre und Studium von feindlichen Ausländern grundsätzlich ausschloss, in deren Sog aber auch ein Schweizer seiner Assistentenstelle verwiesen worden war. ${ }^{787}$ Leider lassen sich keine Anzeichen für irgendeine Reaktion des Ministeriums finden. Auch die Tatsache, dass die Fakultät entgegen der sonstigen Praxis keinen einstimmigen Beschluss fassen konnte, wurde nicht kommentiert.

$\mathrm{Ob}$ das Kultusministerium einer der Adressaten dieses Signals war, kann man letztlich nur vermuten. Einen anderen Adressaten kann man jedoch mit ziemlicher Sicherheit bestimmen: Hermann Theodor Simon. Ohne den weiteren Darstellungen dieses Kapitels vorgreifen zu wollen, muss man feststellen, dass Simon mit Sicherheit nicht immer ein einfacher Kollege war. ${ }^{788}$ Er war zutiefst von sich und seiner Arbeit überzeugt, haderte jedoch mit seinem Status als außerordentlicher Professor. ${ }^{789}$ Als ein Beispiel für seine sehr spezielle Art des Selbstvertrauens sei hier seine Rektoratsrede mit dem Titel „Leben und Wissenschaft, Wissenschaft und Leben“" vom 26. Juni 1918 erwähnt. ${ }^{790}$ In der Einleitung dieser Rede nimmt Simon zuerst Stellung zu der Bedeutung seines Faches, der angewandten Elektrizitätslehre:

Doch ist wohl eine starke innere Rechtfertigung vorhanden, gerade dieses Gebiet zum Ausgang [für sein Thema siehe oben.] zu wählen. Die Energiewissenschaft ist - dies

Siehe oben. Entlassung des Assistenten Dr. Heinrich Hertenstein: UAG.Kur.7471 Bl. 127.

Womit ausdrücklich nicht gesagt werden soll, dass Simon generell abgelehnt wurde und als Mensch oder im Kollegium keine Anerkennung fand. Nicht zuletzt die zahlreichen namhaften Unterzeichner seines Separatvotums zeigen dies. Im Gegenteil war er auch außerhalb der Universität ein angesehener Mann. So war er bereits im Jahr 1908 zum Bürgervorsteher (Stadtverordneter) gewählt worden. UAG.Kur.5999 Bl. 33. Seine Stellung innerhalb der Universität dokumentiert außerdem seine Wahl zum Rektor im Jahr 1917/18 und seine maßgebliche Beteiligung an der Gründung des Göttinger Universitätsbundes während seiner Amtszeit.

789 Simon war seit 1907 so genannter ,persönlicher Ordinarius.“ UAG.Kur.5999 Bl. 1. Dies bedeutete, dass er zwar den Titel „ordentlicher Professor“ führen durfte und Direktor seines Instituts war, aber nur als außerordentlicher Professor besoldet wurde. Dies beklagte er auch offiziell gegenüber dem Kurator. UAG.Kur.5999 Bl. 60-61. Erschwerend hinzu kam, dass Simon sich durch die Annahme des Rufs nach Göttingen finanziell verschlechtert hatte, nachdem er zuvor beim Physikalischen Verein in Frankfurt a.M. beschäftigt gewesen war.

790 Simon, Hermann Theodor: Leben und Wissenschaft, Wissenschaft und Leben. Rektoratsrede zur Jahresfeier der Georgia Augusta am 26. Juni 1918. Leipzig 1918. 
zeigen auch ibre großen Erfolge in diesem Kriege - in ibren Wirkungen auf und für das Leben unstreitig die zuverlässigste und fruchtbarste von allen Wissenschaften. Man darf darum schließen, daß sie das Allgemeine und Typische in den Beqiehungen zwischen Wissenschaft und Leben besser erkennen lassen wird, als es zurzeit jede andere Wissenschaft tun könnte. Und zwar, wie ich behaupten möchte, aus dem Grunde, weil sie überhaupt das Prinzip aller Wissenschaft am klarsten begriffen und am vollendetsten zur Ausführung gebracht hat. ${ }^{791}$

Diese Worte sollen dokumentieren, dass es für seine Kollegen nicht leicht gewesen sein kann, im Dialog mit Simon zu einem Konsens zu gelangen. Dies versuchte man nun auch nicht mehr. Vielmehr wollte man Simons Drohung mit einem Separatvotum, die dieser in seinem letzten Brief an den Dekan der philosophischen Fakultät unverhohlen geäußert hatte, ${ }^{792}$ dadurch entkräften, dass man es schlicht darauf ankommen ließ - gewiss auch, um sich nicht in zukünftigen Streitfällen erpressbar zu machen.

Der Abschluss dieser Affäre verlief ausgesprochen unspektakulär und zeigt nicht zuletzt, wie wenig der Fakultät tatsächlich an einer Berufung Zeemanns gelegen war. Bereits in den letzten Sätzen der Vorschlagsliste klang an, dass man lediglich an der Berufung eines der beiden ersten Kandidaten interessiert war.

Die Fakultät ist sich bewusst, dass die Frage der im Vorstehenden behandelten Berufung durch den gegenwärtigen Krieg in besonderem Masse erschwert wird. Sie würde es aber lebhaft beklagen, wenn insbesondere die Berufung eines der zuerst genannten beiden Physiker nur an zeitlichen und vorübergehenden finanziellen Schwierigkeiten scheitern würde; sie würde in diesem Falle die Vertagung der Berufung und die vorläufige Beibebaltung des gegenwärtigen Zustandes vorziehen. ${ }^{793}$

Endgültig abgeschlossen wurde die Nachfolge Eduard Rieckes erst nach Ende des Krieges: In dem ein Jahr später vollständig neu begonnenen Berufungsvorgang spielten die Namen Zeemann und auch Simon keine Rolle mehr. ${ }^{794}$ Zum 1. April 1916 gelang es, Robert Pohl für Göttingen zu gewinnen, der sein Amt allerdings erst nach Ende des Krieges antreten konnte. Riecke selbst war am 11. Juni 1915 verstorben. Professor Debye, der seit 1914 Professor für theoretische Physik war, übernahm vertretungsweise seine Professur. Debyes eigenes Extraordinariat wurde daraufhin im Sommersemester an Pohl übertragen, der allerdings bis zum Kriegsende durch den jungen Privatdozenten Heinrich Rausch von Traubenberg vertreten wurde. ${ }^{795}$

\footnotetext{
791 Simon: Leben.1918. S. 3.

792 UAG.Phil.Fak.II.36.c 22.12.1914.

793 UAG.Phil.Fak.II.36.c 24.12.1914.

794 UAG.Phil.Fak.II.1.c Fakultätsbericht über das Dekanat Landau 1. Juli bis 31. Dezember 1915.

795 UAG.Phil.Fak.II.1.c Fakultätsbericht über das Dekanat Sethe 1. Januar bis 30. Juni 1916.
} 


\section{Göttinger Naturwissenschaftler im internationalen Propaganda-Krieg}

Die Art, in der man schließlich Simons unverhohlene Drohung in Form eines Separatvotums pariert hatte, eignet sich als Beispiel für den Umgang des Kollegiums mit den verschiedenen Herausforderungen, die die Ausnahmesituation Krieg mit sich brachte. Es existierten über lange Zeiträume eingeübte Verhaltensregeln, die man auch weiterhin penibel befolgte - vielfach offensichtlich viel bewusster als vor dem Krieg. Differierende Meinungen in Berufungsausschüssen waren zu keiner Zeit ungewöhnlich. Als auch die zahlreichen Fakultätssitzungen keine Lösung brachten, gestand man der Minderheit ihr Recht auf ein Minderheitsvotum zu und nahm so Simons Drohgebärden den Wind aus den Segeln. Man zog sich also bewusst auf den Geschäftsgang zurück, folgte streng den Vorschriften und bot somit keine Angriffsfläche für weitergehende Diskussionen. Man wies sogar ausdrücklich jede weitere Zuständigkeit von sich und überließ alles Weitere dem Kultusministerium. Auch wenn man tatsächlich ein bewusstes Zeichen setzen wollte, so vermied man doch einen offenen Konflikt mit dem Ministerium, der leicht zu einem öffentlichen Konflikt hätte werden können.

Ganz ähnlich wie sich die naturwissenschaftlichen Dozenten in dieser Situation als Gruppe im Rahmen ihrer Aufgaben in der akademischen Selbstverwaltung verhalten hatten, verhielt sich die Mehrzahl im privaten Bereich, etwa bezogen auf ihre Beteiligung am so genannten Krieg der Geister. ${ }^{796}$ Gemeint ist damit die lange Folge von offenen Briefen, Erklärungen und anderen Veröffentlichungen Intellektueller der Krieg führenden Nationen, in denen diese mit teilweise unerwartet drastischen Formulierungen zu Fragen wie der Verletzung des Völkerrechts, Kriegsverbrechen und Ähnlichem für ihr Land Stellung bezogen. Verbreitet wurden die Beiträge meistens über Zeitungen oder per Post an von den Professoren zur Verfügung gestellte Privatadressen Intellektueller im neutralen Ausland. ${ }^{797}$

796 Der Begriff, Krieg der Geister' wurde von Cordula Tollmien übernommen, die ihrerseits in der Anmerkung 1 ihres Aufsatzes Der „Krieg der Geister“ in der Provinz erläutert, den Begriff aus zeitgenössischen Quellen übernommen zu haben. Tollmien: Der „Krieg“. 1993. S. 137.

797 Grundlegend zu diesem Thema: Schwabe (Hrsg.): Wissenschaft. 1969. Den besten Überblick zu diesem Komplex bietet Bernhard vom Brocke: Brocke: „Wissenschaft und Militarismus“. 1985. Für Göttingen und damit auch dieses Kapitel maßgeblich ist die umfassende Darstellung und Analyse Cordula Tollmiens: Tollmien: Der „Krieg“. 1993.

Siehe auch: Für Marburg: Wettmann: Heimatfront. 2000. S. 90ff. Für die Universität: Heidelberg: Reichert, Folker: Wissenschaft und „Heimatfront“. Heidelberger Hochschullehrer im Ersten Weltkrieg. In: Kohnle, Armin; Engehausen, Frank (Hrsg.): Zwischen Wissenschaft und Politik. Studien zur deutschen Universitätsgeschichte. Festschrift für Eike Wolgast zum 65. Geburtstag. Stuttgart 2001. S. 494-520. S. 501-503; Jansen: Professoren. 1992. S. 109ff. Für Gießen: Moraw: Kleine Geschichte. 1982. S. 196ff. Für Großbritannien: Winter: Oxford. 1994. S. 16ff.; Hammerstein: Epilogue. 2004. S. 641-645. 
Einen der Höhepunkte dieser Auseinandersetzung auf deutscher Seite bildete das so genannte Manifest der 93, der Aufruf ,An die Kulturwelt!' vom 4. Oktober 1914. ${ }^{798}$ Dieser Aufruf erlangte so viel traurige Berühmtheit wegen seiner ,provozierend formulierten und aufreizend begründeten“"799 sechs Thesen, die jeweils mit den Worten „Es ist nicht wahr, daß [...]“800 eingeleitet und im Ausland durchgängig mit Empörung aufgenommen wurden. ${ }^{801}$ In ihnen wurde eine mögliche Kriegsschuld Deutschlands abgestritten, die Verletzung der belgischen Neutralität gerechtfertigt und deutsche Kriegsverbrechen gegen belgische Bürger und die Stadt Löwen geleugnet. Ein besonders deutliches Beispiel für den Stil, in dem der Aufruf gehalten war, stellt die fünfte These dar:

Es ist nicht wahr, daß unsere Kriegführung die Gesetze des Völkerrechts mißachtet. Sie kennt keine zuchtlose Grausamkeit. Im Osten aber tränkt das Blut der von russischen Horden hingeschlachteten Frauen und Kinder die Erde, und im Westen zerreißen Dumdumgeschosse unseren Kriegern die Brust. Sich als Verteidiger europäischer Zivilisation zu gebärden, haben die am wenigsten das Recht, die sich mit Russen und Serben verbünden und der Welt das schmachvolle Schauspiel bieten, Mongolen und Neger auf die weiße Rasse zu betzen. ${ }^{802}$

Im letzten Abschnitt schließlich wird betont, dass es keinen Unterschied zwischen deutschem Heer, deutschem Volk und deutscher Kultur gäbe, womit man sich auf eine seit Kriegsbeginn geführte Diskussion mit englischen Intellektuellen bezog, die die These von „zwei Deutschland“ vertraten, „[...] dem geistigen Deutschland Goethes (bis 1870) und dem militaristischen Deutschland Bismarcks [... $]^{\text {“. } .803 ~ Z u ~}$ dieser Diskussion erschien am 16. Oktober 1914 eine Erklärung der Hochschullehrer des Deutschen Reiches, die in ihrem Ton deutlich moderater und differenzierter war, als der keine zwei Wochen zuvor erschienene Aufruf, An die Kulturwelt!' und die

Auch auf privater Ebene nahmen europäische Wissenschaftler an dieser Auseinandersetzung teil. Max Born berichtet in seiner Autobiographie davon, dass auch er einen Brief an einen niederländischen Wissenschaftler geschrieben habe, in dem er sich zu angeblichen russischen Kriegsverbrechen äußerte und den sein Korrespondenzpartner mit einem Hinweis auf deutsche Verbrechen beantwortete: „Ich schrieb einen dummen Brief an meinen Freund Ehrenfest in Leiden und erhielt eine angemessen scharfe Antwort.“ Born: Mein Leben. 1975. S. 227.

798 Speziell zu diesem Aufruf empfiehlt sich das mit einem umfangreichen Quellenteil ausgestattete Buch von Jürgen und Wolfgang Ungern-Sternberg: Ungern-Sternberg, Ungern-Sternberg: Der Aufruf. 1996.

799 Brocke: „Wissenschaft“. 1985. S. 654.

800 Zitiert nach: Ungern-Sternberg, Ungern-Sternberg: Der Aufruf. 1996. S. 144-147 (Abbildungen 3-6). [Abbildung eines Originals aus dem Schiller-Nationalmuseum und Deutschen Literaturarchiv Marbach a.N.].

801 Cordula Tollmien berichtet sogar, dass 1919 der französische Ministerpräsident Clemenceau in einer Rede vor dem Pariser Senat den Aufruf, An die Kulturweltt' als „ein schlimmeres Verbrechen als alle anderen Taten von denen wir wissen“ bezeichnete. Tollmien: Der „Krieg“. 1993. S. 171.

802 Ungern-Sternberg, Ungern-Sternberg: Der Aufruf. 1996. S. 145 (Abbildung 4).

803 Brocke: „Wissenschaft“. 1985. S. 652. In Anmerkung 4 zeichnet vom Brocke diese Diskussion nach. 
wahrscheinlich deshalb auch weniger Beachtung fand. ${ }^{804}$ Dies ist umso erstaunlicher als der Organisator der Erklärung, der Althistoriker Ulrich von WilamowitzMoellendorf, mit über 4000 Unterzeichnern von allen 53 deutschen Hochschulen eine um ein Vielfaches breitere Basis mobilisieren konnte, als sie die 93 Unterzeichner des Aufrufs darstellten, obwohl sich deren Namen, „[...] wie ein Who's Who der Kunst und Wissenschaft" ${ }^{\text {"805 }}$ lasen.

Felix Klein hatte den Aufruf, An die Kulturwelt!' als einziger Göttinger Professor unterzeichnet. Die Erklärung der Hochschullehrer des Deutschen Reiches unterschrieben sogar 178 Göttinger Dozenten, darunter 80\% der Ordinarien. ${ }^{806}$ Auch unter den Unterzeichnern der folgenden Veröffentlichungen, zu denen die zwei hier erwähnten lediglich den Auftakt bildeten, fand sich durchgängig eine Reihe Göttinger Professoren. Trotzdem ist Göttingen im Hinblick auf den Krieg der Geister mit Sicherheit nicht in einem Atemzug mit Universitäten wie Berlin, München oder Tübingen zu nennen. Cordula Tollmien, die in ihrem Aufsatz Der ,Krieg der Geister' in der Provinz - das Beispiel der Universität Göttingen 1914-1919807 die Göttinger Beteiligung am internationalen Propagandakrieg umfassend dokumentiert, relativiert die Bedeutung der Universität Göttingen auf diesem Gebiet bereits in ihrer Einleitung:

Kein einziges der bekannten Manifeste ist in Göttingen formuliert oder von hier aus verbreitet worden. Keiner der prominenten Protagonisten von Sieg- oder Verständigungsfrieden stammte aus Göttingen; hier wurden keine annexionistischen Programme entworfen und keine zur Mäßigung aufrufenden Gegenerklärungen verfaßt. An der Göttinger Universität hat man sich zu entsprechenden Initiativen anderer immer nur verhalten, sie mitgetragen oder - im Einzelfall - auch abgelehnt. ${ }^{808}$

In ihrem Beitrag geht Tollmien sehr detailliert auf die jeweilige Beteiligung der Göttinger Dozenten an den einzelnen Eingaben, Erklärungen oder Aufrufen ein. Hier sollen exemplarisch einige ihrer Ergebnisse betrachtet werden, an denen die Situation innerhalb des Kollegiums sowie die konkreten Auswirkungen auf Einzelne und auf die gesamte Georgia Augusta deutlich werden.

Einen guten Eindruck davon, wie an der Göttinger Universität diskutiert wurde und wie Unterschriften zustande kamen, erhält man bei der Betrachtung der Geschehnisse um drei Erklärungen - die so genannte Seeberg Adresse vom 8. Juli 1915, die darauf antwortende Gegenerklärung Hans Delbrücks vom 27. Juli und die Erklärung gegen die Reichstagsmehrheit vom Oktober 1917. Bei ihnen handelte es sich um Beiträge zur Kriegszieldiskussion in Deutschland. Sie sind ein Indiz dafür,

\footnotetext{
804 Siehe hierzu: Brocke: „Wissenschaft“. 1985. S. 650ff.

805 Brocke: „Wissenschaft“. 1985. S. 657. Cordula Tollmien spricht von „über 3000 Unterschriften“. Tollmien: Der „Krieg“. 1993. S. 143.

806 Tollmien: Der „Krieg“. 1993. S. 145.

807 Tollmien: Der „Krieg“. 1993.

808 Tollmien: Der „Krieg““. 1993. S. 137.
} 
dass die deutsche Gesellschaft zunehmend gespalten war und auch die Aufrufe und Erklärungen der Intellektuellen sich zunehmend nach innen wandten, weg von dem zuvor erklärten Ziel der Aufklärung der internationalen Öffentlichkeit. Der Streit um Sieg- oder Verständigungsfrieden gewann immer mehr an Bedeutung. 809

Zunächst wurde an der Göttinger Universität um Unterschriften für die Schrift des Berliner Theologen Reinhold Seeberg geworben, eines Vertreters annexionistischer Meinungen. ${ }^{810}$ Diese Schrift, die für einen Frieden nur unter der Voraussetzung von maximalen Gebietsgewinnen sowohl im Westen als auch im Osten und in den Kolonien plädierte, konnte insgesamt 1347 Unterschriften auf sich vereinigen, wovon 352 von Hochschullehrern stammten, davon jedoch nur acht aus Göttingen. ${ }^{811}$ Aus dem naturwissenschaftlichen Fachbereich waren der Physiker Leopold Ambronn, der Geograph Hermann Wagner und der Agrarwissenschaftler Konrad von Seelhorst vertreten, die, wie Tollmien beschreibt, auch sonst sehr engagiert waren, etwa im vaterländischen Hilfsdienst oder der Soldatenbetreuung. Von Seelhorst war als ehemaliger Marineoffizier bereits vor dem Ersten Weltkrieg für den Flottenbau eingetreten und Vorsitzender der Göttinger Ortsgruppe des Alldeutschen Verbandes. ${ }^{812}$

Deutschlandweit konnte die deutlich vorsichtiger formulierte und weniger auf Gebietsgewinne zielende Antwort des Berliner Historikers Hans Delbrück eine deutlich geringere Zahl an Unterzeichnern - lediglich 141 - vorweisen. Von diesen stammten jedoch insgesamt 15, also über 20\%, aus Göttingen, darunter so namhafte Naturwissenschaftler wie Constantin Caratheodory, David Hilbert, Carl Runge, Alfred Coehn und Heinrich Rausch von Traubenberg. ${ }^{813}$ Tollmien schreibt den größeren Erfolg der Gegenerklärung in Göttingen einem intensiven Werben des hier lehrenden Historikers Max Lehmann zu, der ein persönlicher Freund Delbrücks war. ${ }^{814}$ Gleichgültig, wie die Unterschriften im Einzelnen zustande gekommen sind, muss als wirklich beachtlich betrachtet werden, dass trotz intensiver Suche keinerlei Anzeichen für einen Streit oder auch nur eine schärfere Diskussion im Göttinger Kollegium gefunden werden konnten.

Im Gegensatz hierzu kam es 1917 im Zuge der Diskussion um die so genannte Erklärung gegen die Reichstagsmehrheit zu heftigen Auseinandersetzungen in der Georgia Augusta. ${ }^{815}$ Bei dieser Erklärung handelte es sich um eine kritische Reaktion auf einen Beschluss des Reichstages, in dem am 19. Juli 1917 gefordert wurde, bei Friedensverhandlungen auf übermäßige Annexions- und Kriegsentschädigungsforderungen zu verzichten. Dem Initiator der Erklärung, dem Tübinger

809 Bernhard vom Brocke bezeichnet den August 1915 und die Erklärungen Seebergs und Delbrücks als „Höhepunkt der ersten Kriegszieldiskussion“. Brocke: „Wissenschaft“. 1985. S. 689.

$810 \mathrm{Zu}$ den persönlichen Hintergründen Seebergs: Tollmien: Der „Krieg“. 1993. S. 146.

811 Zahlen aus: Tollmien: Der „Krieg“. 1993. S. 148-149.

812 Tollmien: Der „Krieg“. 1993. S. 147-149.

813 Tollmien: Der „Krieg“. 1993. S. 151.

814 Tollmien: Der „Krieg“. 1993. S. 152.

815 Der betreffende Schriftverkehr findet sich in: UAG.Sek.39.5. 
Historiker Johannes Haller gelang es, 1100 Unterschriften zu sammeln. Bei den Unterzeichnern handelte es sich ausschließlich um Hochschullehrer, darunter 77 aus Göttingen, also deutlich mehr, als bei den beiden vorher erwähnten Veröffentlichungen. In dieser Erklärung wurde dem Reichstag unter anderem „die Qualifikation für die politische Führung des deutschen Volkes abgesprochen".816 Tendenziell verfolgte sie damit also auch annexionistische Ziele, wie zwei Jahre zuvor die Seeberg-Adresse, war jedoch deutlich vorsichtiger und allgemeiner formuliert. Dies war vielleicht ein Grund dafür, warum sie so deutlich mehr Unterzeichner aus Göttingen gewinnen konnte.

Man kann sich wohl Cordula Tollmiens Argumentation anschließen, dass dies weniger durch den Inhalt der Erklärung bedingt wurde, als durch die besondere Art, in der in Göttingen für die Unterschriften geworben worden war:

Diese ,vaterländische Kundgebung' war nämlich aus Tübingen über den Geologen Joseph Pompecky [ehemals Direktor des geologisch-paläontologischen Instituts an der Universität Göttingen] nach Göttingen gekommen, der von 1907 bis 1913 an der Göttinger Universität gelebrt hatte. Er hatte die Erklärung seinem Kollegen und Freund, dem Physiker Theodor Hermann Simon mit der Bitte übersandt, eine möglichst große Zabl von ,Zustimmungen' zu sammeln. [...] Nun war aber Simon im Oktober 1917 gerade Rektor der Universität geworden und versandte den Erklärungsvordruck als Rektor (!) an alle (auch die im Feld befindlichen) Dozenten der Universität.817

Dadurch war es Simon möglich, eine ungleich höhere Zahl an Dozenten zu erreichen, als dies auf dem privaten Wege möglich gewesen wäre, den die vorherigen Veröffentlichungen gegangen waren. Auch wenn die Autorität, die ein offiziell wirkendes Schreiben besaß, wie das, in dem Simon für die Unterschriften warb, mit Sicherheit in einigen Fällen ihre Wirkung nicht verfehlt hat, gab es trotzdem Ablehnungen und vor allem sehr kritische Schreiben zu dieser besonderen Vorgehensweise. ${ }^{818}$

Nach einigen kurzen schriftlichen Diskussionen erhielt dieser Vorgang jedoch noch das, was Cordula Tollmien ein „fast grotesk wirkendes Nachspiel“819 nennt: Einer der Göttinger Hochschullehrer hatte, offenbar aus Ärger über Simons Vorgehen, das Rundschreiben dem Berliner Tageblatt zukommen lassen, nach dessen Vorlage auch das Göttinger Tageblatt den Brief am 17. September 1917 abdruckte. Empört über diese Indiskretion verlangte Simon daraufhin von jedem, der den ersten Brief erhalten hatte, in einem zweiten Schreiben eine Unschuldserklärung durch ein Ehrenwort und hoffte so, den Täter zu finden. Dies gelang auch - es handelte sich um den Mediziner Werner Rosenthal -, jedoch war nun die

\footnotetext{
816 Tollmien: Der „Krieg““. 1993. S. 160.

817 Tollmien: Der „Krieg“. 1993. S. 160-161.

818 Beispiele: Tollmien: Der „Krieg““. 1993. S. 161-164.

819 Tollmien: Der „Krieg““. 1993. S. 164.
} 
Empörung innerhalb des Kollegiums über das Vorgehen Simons als Rektor nochmals größer als über das eigentliche Schreiben. ${ }^{820}$

Das wirklich Bemerkenswerte an dieser Diskussion ist, wie Tollmien schreibt, ${ }^{821}$ dass zu keinem Zeitpunkt der Inhalt der Erklärung, um die es ging, diskutiert wurde, wie dies auch bei den Veröffentlichungen Seebergs und Delbrücks der Fall gewesen war. Gestritten wurde vielmehr um die Verfahrensweise Simons, denn hier hatte er den Rahmen der gültigen Verhaltensregeln verlassen. Wahrscheinlich hätte niemand aus dem Kollegium eine Agitation Simons auch während seiner Amtszeit als Rektor der Universität kritisiert. Kritisiert wurde lediglich, dass er sein Amt instrumentalisierte und damit den Anschein erweckte, als wäre die Universität, also die gesamte Korporation, politisch aktiv. Dies wollte man offenbar unter allen Umständen vermeiden.

Im Kern der Sache war man also wieder bei dem bereits in der Angelegenheit der Nachfolge Eduard Rieckes diskutierten Komplex angelangt: Man hätte jederzeit Simons Meinungsäußerung in Form der Agitation für oder gegen einen Aufruf akzeptiert, genauso wie man zuvor seinen Standpunkt in Bezug auf den Vorschlag des Niederländers Zeemann akzeptiert hatte. Man hatte jedoch klargestellt, dass man sich als Fakultät zur Frage der Berufung eines Ausländers nicht äußern wollte, sondern die Entscheidung hier der Regierung überließ. Man hatte dadurch, dass man Zeemann überhaupt auf die Vorschlagsliste gesetzt hatte, sicherlich Kritik üben wollen, allerdings bewusst in einem Rahmen, in dem man sich sicher sein konnte, keinen öffentlichen Eklat zu provozieren. Simon wollte diese Kritik nicht mittragen, und man billigte ihm und den anderen Mitgliedern der Minorität dies zu.

Genau entgegengesetzt zu diesem Vorgehen war jedoch Simons Werbung für die Erklärung gegen die Reichstagsmehrbeit angelegt. Zum einen bezog der Rektor der Universität - und damit implizit die gesamte Universität - nun Stellung zu tagespolitischen Fragen, zum anderen gelangte dieses Thema an die Öffentlichkeit. Letzteres ist Simon zwar nur mittelbar anzulasten, seine überaus scharfe Reaktion jedoch zeigt wohl am Besten, dass auch er zumindest einen Teil der Verantwortung hierfür bei sich selbst sah, wovon er nun ablenken wollte.

\footnotetext{
820 Der gesamte Vorgang findet sich bei Cordula Tollmien mit ausführlichen Beispielen der Kritik an Simon. Tollmien: Der „Krieg“. 1993. S. 164-170.

821 Tollmien: Der „Krieg“. 1993. S. 169.
} 


\section{Politische Stellungnahmen und ihre Folgen}

In den Diskussionen um das Werben des Rektors Theodor Simon für die Erkelärung gegen die Reichstagsmehrheit wird sichtbar, dass zwei Fragen offensichtlich von den Zeitgenossen als am Wichtigsten eingestuft wurden: Erstens, ob der Anschein entstand, dass die Universität als Ganzes sich politisch äußerte und zweitens, ob interner Streit nach außen an die Öffentlichkeit drang. Zwei weitere Beispiele können diesen Befund untermauern - die Fälle Heinrich Rausch von Traubenbergs und Leonard Nelsons.

Der Physiker Heinrich Rausch von Traubenberg war Privatdozent und übernahm nach dem Tode Eduard Rieckes dessen Vertretung, bis Robert Pohl nach Kriegsende die freie Professur für Experimentalphysik übernehmen konnte. ${ }^{822}$ Am 26. April 1917 erstattete Frau Baurat Felicitas Nolte aus Göttingen Anzeige gegen von Traubenberg beim damaligen Rektor Professor von Hippel. ${ }^{823}$ Von Hippel konnte nur feststellen, dass für einen Privatdozenten disziplinarisch die jeweilige Fakultät zuständig war und empfahl Nolte, entweder eine schriftliche Eingabe zu machen oder die Anzeige beim Universitätsrichter zu wiederholen. ${ }^{824}$

Das Vergehen, dessen Rausch von Traubenberg bezichtigt wurde, bestand darin, dass er sich in einem Zugabteil mit drei Soldaten auf Fronturlaub über die schlechte Versorgungssituation unterhalten hatte. Nolte war Zeugin dieses Gesprächs und nahm insbesondere daran Anstoß, dass der Physiker den mangelnden Friedenswillen in Deutschland beklagte, wofür er vor allem den so genannten Alldeutschen die Schuld gab. Frau Nolte stellte in ihrer Zeugenaussage den Sachverhalt folgendermaßen dar:

Als letzter stieg der Dr. Fhr. Rausch v. Traubenberg ein, der mir von Ansehen bekannt war. Er wurde von seiner Schwester an den Zug begleitet. Aus ibrer lebhaften Unterhaltung ergab sich, dass er nach Berlin fahren wollte und grosse Sorge wegen der Ernährung dort hatte. Er wollte unter Umständen, wenn es zu schwierig würde, sofort wieder abreisen.

Als sich der Zug in Gang setzte, ging die Unterhaltung über die Ernährungsschwierigkeiten weiter. Rausch von Traubenberg sprach darüber namentlich auch mit den Soldaten, von denen der eine offenbar sehr müde war. Die beiden Infanteristen kamen, wie die Unterhaltung ergab, aus den Kämpfen im Westen, der eine auf Erholungsurlaub, der

822 Siehe oben.

823 UAG.Kur.6317 Bl. 87. Der gesamte Vorgang befindet sich in dieser Akte, die aus zwei verschiedenen Provenienzen zusammengefügt wurde. B1. 87-94, die diesen Vorgang enthalten, befinden sich in der ehemaligen Personalakte Rausch von Traubenbergs bei der Philosophischen Fakultät, die seiner Personalakte im Bestand Kuratorium hinzugefügt wurde. Es war also nicht so, wie die heutige Signatur der Personalakte dies vermuten ließe, dass sich der Universitätskurator mit diesem Vorgang befasst hätte. Auch Cordula Tollmien beschreibt diesen Fall in ihrem Exkurs „Die Freiheit des Wortes.“ Tollmien: Der „Krieg“. 1993. S. $153 \mathrm{ff}$.

824 UAG.Kur.6317 Bl. $87 \mathrm{ff}$. 
andre zur Landbestellung. Rausch von Traubenberg stellte die Verbältnisse in einer so niederdrückenden $W$ eise dar, dass ich es nicht ertragen konnte. Ich mischte mich deshalb ein und suchte nach Möglichkeit auszugleichen und wandte mich deshalb an die beiden Soldaten. Dem einen sagte ich: da er vom Lande wäre, würde er es sehr gut haben, und dem anderen, der aus Hamburg war, sagte ich: er sollte den Riemen etwas enger schnallen, aber gute Stimmung halten [...]

Nunmebr sagte Rausch von Traubenberg zu den Soldaten: Für einen Frieden wäre wobl keine Aussicht. Denn die ganze Strömung ginge doch bier so, dass nur die Alldeutschen Patrioten wären und dass andere vernünftige Leute, die auf entgegengesetotem Stand-

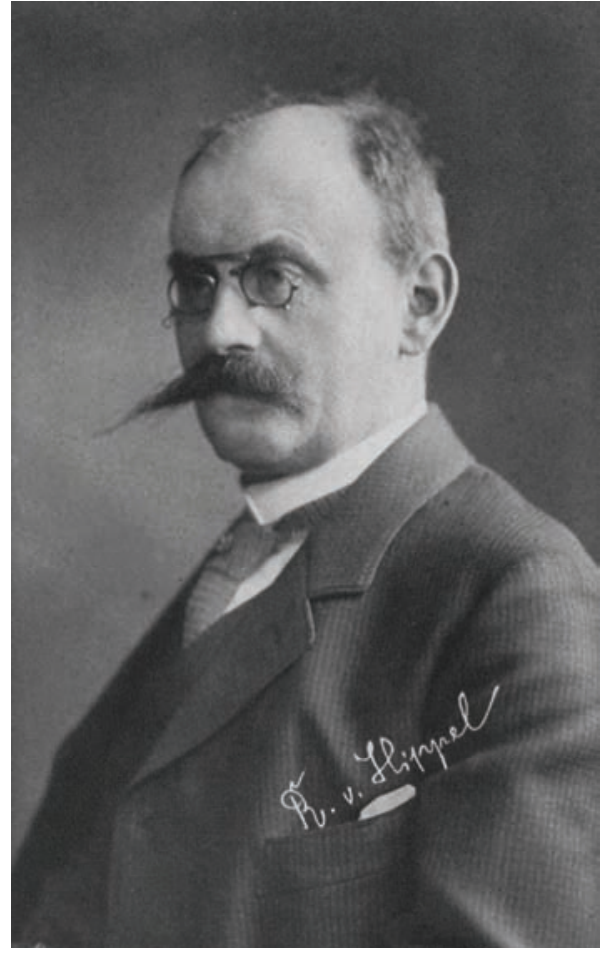

Abbildung 14: Robert von Hippel punkte ständen, Nichtpatrioten wären. Einen Frieden könnten wir haben, wenn wir auf jegliche Annexionen verzichteten.

Ich sagte zu den Soldaten, sie sollten nicht glauben, dass das eine deutsche Ansicht wäre, der Herr wäre ein Deutschrusse. Er widersprach, er sei Deutscher Reichsangehöriger, seit seinem 11 Jahr sei er in Deutschland. Ich erwiderte: das sei kein Beweis, nach meiner Auffassung habe er kein Deutsches Empfinden. ${ }^{825}$

Rektor Robert von Hippel war Jurist und schien dem Standpunkt von Frau Nolte näher zu stehen. Obwohl er sich für nicht zuständig erachtete, hatte er bereits beim Generalkommando angefragt, ob die Militärbehörden Strafbestimmungen ,in solcher Richtung“" erlassen hätten, was allerdings nicht der Fall war. 826 Von Hippel reichte diese Angelegenheit an die philosophische Fakultät weiter, konnte jedoch nur schwer seine Erwartung verbergen, dass wenigstens diese die disziplinarischen Maßnahmen einleitete, zu denen er nicht befugt war.

825 UAG.Kur.6317 Bl. 87-88.

826 Handschriftlicher Zusatz am Ende des Blattes. UAG.Kur.6317 Bl. 87v. 
So betonte er in dem entsprechenden Anschreiben, mit dem er seine Darstellung der Angelegenheit und die Aussagen, die mittlerweile vor dem Universitätsrichter gemacht worden waren, weitergab: „Ich enthalte mich durchaus des Urteils darüber, ob sich für die Fakultät hieraus irgend welche praktische Konsequenzen ergeben." ${ }^{827}$ Bei der Aussage des Angeklagten Rausch von Traubenbergs war von Hippel auch anwesend. Dort wurde diesem mitgeteilt:

[...] dass Frau Baurat Nolte eine Anzeige gegen ibn erstattet habe, dass Se. Magnifizenz. [von Hippel] aber keine Disciplinarbefugnis gegen ihn zustehe, dass diese vielmehr der philosophischen Fakultät und dem Herrn Minister zustehe, dass aber Se. Magnifizenz im Interesse der Universität eine Klarstellung der Sache für notwendig erachte. 828

Rausch von Traubenberg ließ sich jedoch offensichtlich nicht verunsichern und bekannte sich offen als Pazifist.

Ich bin Parifist und wünsche einen gemässigten Verständigungsfrieden, weil ich diesen auch in deutschem Interesse für den besten halte. [...] Ich finde es schade, wenn unsre deutschen Soldaten für überspannte Kriegsziele totgeschossen werden. Als überspannte Kriegsziele betrachte ich zu weit gehende Annexionen, ein Verteidigungskrieg ist jederzeit gerechtfertigt. 829

Er bekannte sich damit ganz selbstverständlich zu seiner Überzeugung und rückte von seinen Aussagen in keiner Weise ab. Der Rektor hatte bereits mehrfach erklärt, dass ihm disziplinarisch die Hände gebunden waren und somit musste er sich darauf beschränken, Frau Nolte am 7. Mai noch einen Brief zu schreiben, in dem er das Geschehene bedauerte und zu beschwichtigen versuchte. Außerdem ließ er es sich nicht nehmen, auch an Rausch von Traubenberg zu schreiben und ihm persönlich seine Missbilligung auszusprechen: „Gerade heute, wo es im nationalen Interesse nur die Parole ,Durchhalten' geben kann, erscheint mir solches Vorgehen als bedenklich und daher auch nicht den Interessen der Universität entsprechend. " 830

Mehr konnte von Hippel nun nicht mehr tun und musste auf die philosophische Fakultät hoffen. Diese Hoffnungen wurden jedoch vollständig enttäuscht. Schon am 22. Mai, bereits wenige Tage nachdem der Fall der Fakultät bekannt gemacht worden war, erhielt Rausch von Traubenberg einen Brief des Dekans Professor Heinrich Maier. In diesem wurde ihm mit knappen Worten zwar ebenfalls eine Missbilligung seines Verhaltens ausgesprochen, jedoch mitgeteilt, „dass die Fakultät nicht beabsichtigt, in eine disziplinarische Behandlung der Angelegenheit einzutreten. "631 In dem Fakultätsbericht dieses Semesters fand dieser

\footnotetext{
827 UAG.Kur.6317 Bl. 89.

828 UAG.Kur.6317 Bl. 92.

829 UAG.Kur.6317 Bl. 92.

830 UAG.Kur.6317 Bl. 94.

831 UAG.Kur.6317 Bl. 97.
} 
Vorgang bezeichnenderweise nicht einmal Erwähnung. Ganz offensichtlich sah man weder in den gemachten Aussagen selbst noch allgemein in der Tatsache, dass sie gemacht worden waren, etwas Strafwürdiges.

Ganz anders verhielt sich dies im Fall des naturwissenschaftlich orientierten Philosophen Leonard Nelson, während des Ersten Weltkrieges ebenfalls Privatdozent in der Philosophischen Fakultät der Georgia Augusta. Am 7. Mai 1915 informierte Professor J. Wackernagel den damaligen Dekan der philosophischen Fakultät, Edmund Landau darüber, dass am Vortag im Verwaltungsausschuss der Fakultät „nebenbei erzählt" worden sei, Nelson habe in den von ihm gehaltenen philosophischen Übungen „die Frage [...] behandeln lassen, ob der Durchmarsch der deutschen Truppen durch Belgien ethisch gerechtfertigt sei“. ${ }^{832}$ Landau gab diese Meldung dann offiziell der Fakultät zur Kenntnisnahme und stellte offensichtlich Nelson noch am gleichen Tag zur Rede, als er von der Angelegenheit erfuhr. ${ }^{833}$

Nelson äußerte sich zu den gegen ihn erhobenen Vorwürfen zunächst in Form einer schriftlichen Stellungnahme. Zwecks Untermauerung seiner Sicht der Dinge fügte er diesem sehr umfangreichen, drei maschinenschriftliche Seiten umfassenden Schreiben die Notizen einer seiner Hörerinnen bei, aus denen hervorgehen sollte, wie sich die Situation tatsächlich entwickelt hatte. Nelson stritt hierbei zu keinem Zeitpunkt ab, das Thema der Verletzung der belgischen Neutralität berührt zu haben, allerdings nur in der Form,

\section{[...] daß in eine Erörterung der Frage, ob die Verletzung der belgischen Neutralität sei- tens der deutschen Heeresleitung berechtigt war, überhaupt nicht eingetreten worden ist, daß vielmehr die Frage nur als ein Beispiel eines für einen Staatsmann möglichen Pflich- tenkonflikets erwähnt worden ist. ${ }^{834}$}

Darüber hinaus sei dieses Beispiel außerdem als Beispiel für einen berechtigten Vertragsbruch angeführt und folglich keinerlei Kritik an der Heeresleitung geübt worden sondern höchstens Zustimmung. In insgesamt drei Punkten widerlegte Nelson die gegen ihn erhobenen Vorwürfe. Allerdings hatte er Landau in einem Punkt missverstanden: Er glaubte, die Angelegenheit sei offiziell vor dem Verwaltungsausschuss besprochen worden, was nicht der Fall war. ${ }^{835}$ Trotzdem kann es als wahrscheinlich angesehen werden, dass diese Angelegenheit bereits hier ihr

832 UAG.Phil.PA.Nelson 07.05.1915. Dieser Vorgang wird ebenfalls kurz in der Biographie Nelsons von Holger Franke beschrieben. Franke, Holger: Leonard Nelson. Ein biographischer Beitrag unter besonderer Berücksichtigung seiner rechts- und staatsphilosophischen Arbeiten. Hamburg 1997. S. 120-122. Auch Cordula Tollmien beschreibt diesen Fall in ihrem Exkurs „Die Freiheit des Wortes.“'Tollmien: Der „Krieg“. 1993. S. 153ff.

833 Diese geradezu hektische Betriebsamkeit zeigt, wie ernst Landau diese Angelegenheit nahm. Nelson bezieht sich in seiner schriftlichen Stellungnahme vom 8. Mai auf dieses Gespräch als „gestrige Unterredung“. UAG.Phil.PA.Nelson 08.05.1915.

834 UAG.Phil.PA.Nelson 08.05.1915. Bl. 1.

835 UAG.Phil.PA.Nelson 08.05.1915. Bl. 1. 
Ende gefunden hätte, wenn Nelson es bei diesen drei Punkten belassen hätte. Wahrscheinlich hätte man ihm, ebenso wie Rausch von Traubenberg einige Zeit später, eine Missbilligung ausgesprochen oder ihn maximal noch zu einer persönlichen Anhörung gebeten.

Betrachtet man aber Nelsons bisherige und spätere Karriere, die von Beginn an von Konflikten mit seinen etablierten Kollegen durchzogen war, und nicht zuletzt seine ganz persönlichen Eigenarten, so wird offensichtlich, dass es ihm geradezu unmöglich gewesen wäre, eine solche Missbilligung stillschweigend zu akzeptieren, wie Rausch von Traubenberg dies später tat.836 Nelson war sehr erfolgreich im Kreise seiner Schüler, wo er geradezu verehrt wurde, im Gegensatz hierzu aber hatte er im Kreise seiner philosophischen Kollegen sicherlich keine Freunde. Ihnen gegenüber war er schon zu oft - teilweise bevor er einen akademischen Rang bekleidete - durch harsche Kritik aufgefallen, die nicht selten ins Polemische abglitt.837 Eines der größten Hindernisse für seine Karriere etwa war eine Rezension, die er über ein Werk Hermann Cohens mit dem Titel System der Philosophie. 1. Teil. Logik der reinen Erkenntnis verfasst hatte. Bei dem kurze Zeit später gescheiterten Versuch der Habilitation gehörten zu seinen wenigen Fürsprechern nicht Philosophen, sondern die Mathematiker David Hilbert und Felix Klein, was auch in zukünftigen Streitfällen oft so blieb. 838

An dieser Stelle soll nicht weiter auf dieses Thema eingegangen werden, aber ein Blick in Nelsons Biographie erleichtert es ungemein, zu verstehen, warum er versuchte, seine detaillierte Stellungnahme dazu zu benutzten, eine neue, noch weiter reichende Diskussion zu beginnen. Er zeigte keinerlei Interesse daran, den drohenden Konflikt mit der Fakultät frühzeitig zu beenden, sondern forderte vielmehr „Genugtuung für die gegen mich gerichtete grundlose Beschuldigung “639 und ging zum Gegenangriff über. Er beschuldigte die Fakultät offen, ihn in seinem Grundrecht der Lehrfreiheit einzuschränken.

Schwerer indessen als diese Seite des erhobenen Vorwurfs berührt mich, die grundsätzliche Voraussetzung, von der er ausgeht und auf die einzugehen ich mich verpflichtet füble. Ich meine die vorausgesetzte Beschränkung der Lehrfreiheit durch außerhalb der Wissenschaft liegende Rücksichten. [...] Es ist in meinen Augen nichts anderes als eine solche Beschränkung der akademischen Freiheit, wenn die wissenschaftliche Lehre von der Übereinstimmung oder Zustimmung irgend welcher noch so hoch gestellter Personen oder

836 Siehe hierzu Nelsons Biographie von Holger Franke, insbesondere die Schilderungen der Umstände seiner Promotion, seiner Habilitation, aber auch betreffend seines Verhältnisses zu seinen Mitarbeitern oder seiner Frau. Franke: Leonard Nelson. 1997.

837 Franke zitiert einen Briefentwurf Nelsons: „Daß die Polemik mir in meiner Laufbahn hinderlich und schädlich werden wird, ist auch mir durchaus wahrscheinlich und ich war mir von vornherein darüber klar." Franke: Leonard Nelson. 1997. S. 76.

838 Franke: Leonard Nelson. 1997. S. 73ff. Besonders zu beachten sind hier die zahlreichen Zitate Nelsons, die Franke wiedergibt. Ihr Ton und ihre Wortwahl können auch nach heutigen Maßstäben als scharf bezeichnet werden.

839 UAG.Phil.PA.Nelson 08.05.1915. Bl. 2. 


\begin{abstract}
Behörden abhängig gemacht wird, ihre Bewegungsfreiheit ihr somit nach außerwissenschaftlichen Gesichtspunkten zugemessen und sie dadurch dem reinen Dienst der Wahrbeit entfremdet wird. Ich würde mich der mit Recht von mir verlangten Achtung und des Vertrauens, das meine Stellung erfordert, für unwürdig erachten wenn ich die Mitteilung meiner wissenschaftlichen Überzeugung von dem zufälligen Zusammenstimmen mit irgend welchen fremden Meinungen oder Wünschen abhängig machen wollte. ${ }^{840}$
\end{abstract}

Der Dekan legte Nelsons Stellungnahme bei der nächsten Sitzung der Fakultät den Mitgliedern vor. Leider besteht keine Möglichkeit, festzustellen, wie diese auf Nelsons Vorhaltungen reagierten, aber zumindest muss sich eine Mehrheit gegen ein disziplinarisches Vorgehen gegen den Privatdozenten ausgesprochen haben. Man einigte sich vielmehr auf ein betont kurzes Schreiben, das dem, welches später Rausch von Traubenberg erhalten sollte, sehr ähnlich war, lediglich mit einem kurzen Zusatz betreffend Nelsons Aussagen zum Problem der Freiheit der Lehre.
Ich [der Dekan] habe Ihnen darauf mitzuteilen, daß die F[akultät] eine Kritik der mi- lit[ärischen] oder polit[ischen] Maßnahmen unserer leitenden Stellen während des Krieges von einem Katheder unserer Univ[ersität] herab für schlechterdings unzulässig bält. Auch die Ausführungen Ihres Schreibens über den wissensch [aftlichen] Ehrbegriff muß die Fak. [ultät] durchaus ablehnen. ${ }^{841}$

Tollmien hat zweifellos Recht mit ihrer Annahme, dass dieses Schreiben seitens der Fakultät als Abschluss der Angelegenheit gedacht gewesen ist. ${ }^{842}$ Die Ruhe währte jedoch nicht lange, da Nelson am 29. Juni 1915 auf den betont kurzen Brief der Fakultät mit einem noch umfangreicheren, nun vierseitigen Brief antwortete, in dem er nur kurz feststellte, dass er gar keine Kritik an der Militärführung hätte üben können, da er ,,von der vollkommenen Gerechtigkeit des Vorgehens der deutschen Heeresleitung überzeugt war“" ${ }^{443}$ um dann ohne Umwege zu dem zu kommen, was in seinen Augen der eigentliche Streitpunkt war: Ihm wurde die geforderte Genugtuung verwehrt und man versuchte sich seiner Frage nach dem wissenschaftlichen Ehrbegriff zu entziehen.

Ich nehme an, daß diese Ablehnung [seiner Ausfübrungen] nur der Ausdruck der eigenen Ansicht der Mitglieder der Fakultät und nicht einen für mich verbindlichen Beschluß darstellen soll. Andernfalls wäre ich auf eine Belehrung über den der Fakultät maßgebend geltenden Ehrbegriff angewiesen um mich nach ibm richten zu können. ${ }^{844}$

Diese ganz offensichtliche Provokation betrieb Nelson dann auch im Rest seines Briefes weiter und steigerte sie noch. Er erklärte, dass er sich im Einklang mit

840 UAG.Phil.PA.Nelson 08.05.1915. Bl. 2-3.

841 Konzept auf der Rückseite Nelsons Schreibens vom 8. Mai. UAG.Phil.PA.Nelson 08.05.1915. Bl. 3v.

842 Tollmien: Der „Krieg““. 1993. S. 155.

843 UAG.Phil.PA.Nelson 29.06.1915. Bl. 1.

844 UAG.Phil.PA.Nelson 29.06.1915. Bl. 2. 
Kant, Schiller, Fichte und von Humboldt befände. Er zitierte Treitschke und Lagarde und verglich sich schließlich mit Galileo Galilei und damit auch die Fakultät mit der Inquisition:

Die Unrichtigkeit meiner in Übereinstimmung mit den genannten Gelehrten stehenden Ausführungen kann offenbar nur durch die Aufweisung wissenschaftlicher Gegengründe und nicht durch Beschlüsse irgend einer Körperschaft festgestellt werden. Denn sittliche Wabrheiten lassen sich durch Fakultätsbeschlïsse ebensowenig umstoßen, wie astronomische W abrheiten durch Konzilien oder päpstliche Dekrete umgestoßen werden können. ${ }^{845}$

Man nahm diesen fast schon als Schmähschrift einzustufenden Brief Nelsons innerhalb der Fakultät zu Kenntnis - mehr aber nicht! Man kann sich beim Lesen seiner umfangreichen Darstellungen des Eindrucks nicht erwehren, dass Nelson sich beim Schreiben in einen Zustand des Zorns und der Wut steigerte, mit einigen kurzen Zeilen wie ein Schuljunge abgefertigt worden zu sein. Er wollte die Fakultät provozieren und die etablierten Kollegen aus der Reserve locken, da er sich im Recht sah und sich sicher war, in einer Diskussion auf gleicher Augenhöhe die Oberhand zu behalten. Außerdem hatte er ganz offensichtlich Vergnügen an der Provokation. Diese Freude an der Auseinandersetzung teilten die Mitglieder der Fakultät jedoch in keiner Weise und versuchten, den hartnäckigen Privatdozenten durch Nichtbeachtung abzustrafen. Vielleicht spielte aber auch der Gedanke eine Rolle, Nelson dadurch zum Schweigen zu bringen, dass man ihm das letzte Wort in dieser Angelegenheit ließ. ${ }^{846}$

Sollte dies die Absicht der Fakultätsmitglieder gewesen sein, hatten sie sich jedoch in Nelson getäuscht, denn dieser war keinesfalls gewillt, die Angelegenheit auf sich beruhen zu lassen. Einen Monat später, am 25. Juli 1915, bestand er erneut auf seiner „Genugtuung“ und forderte in überaus scharfem Tonfall die Bescheinigung seiner Unschuld und die Bestätigung seiner Lehrfreiheit nach seinem „wissenschaftlichen Ehrbegriff“، 847 Dieses Auftreten Nelsons, das eher dem eines Gläubigers gegenüber seinem säumigen Schuldner entsprach, veranlasste dann die Fakultät zu einer Reaktion: In einem nun auch längeren Brief in jetzt ebenfalls scharfem Tonfall stellte man unmissverständlich klar, dass man keinerlei Interesse verspüre, an der von Nelson geforderten Diskussion teilzunehmen, sondern wiederholte noch einmal die Fakten: Es habe ein Gerücht gegeben, dies war dem Dekan gemeldet worden. Der Dekan habe daraufhin eine Aussprache verlangt und in dieser Aussprache sei nach Auffassung der Fakultät bereits die Unwahrheit des Gerüchts festgestellt worden. „Wo da ein Anlass und ein Recht für Sie [Nelson] blieb, von der Fakultät noch irgendwelche Erklärungen zu verlan-

845 UAG.Phil.PA.Nelson 29.06.1915. Bl. 3-4.

846 Der Beschluss zur Nichtbeantwortung wurde offiziell in der Fakultätssitzung vom 22. Juli 1915 gefasst. UAG.Phil.PA.Nelson 06.08.1915. Bl. 3.

847 UAG.Phil.PA.Nelson 25.07.1915. 
gen, ist unerfindlich. “848 Des Weiteren habe sich die Ablehnung seiner Ausführungen zum akademischen Ehrbegriff vor allem auf die Form bezogen, in der die Vorwürfe gegen die Fakultät erhoben worden waren und nicht zuletzt auf die Tatsache, dass er dieser unterstellte, sie wolle seine rechtmäßigen Freiheiten beschneiden.

\section{Die Fakultät hat in ibrer Sitzung vom 29.VII. beschlossen, auf Ihren weiteren Brief vom 29.VI. mit seinen Belehrungen über das, was als wissenschaftlicher Ehrbegriff Ge- meingut der deutschen Gelehrten sei, nicht zu antworten, da sie es für unter ibrer Würde bielt, auf die Auffassung einzugehen, sie könnte von einem Mitglied ibres Lebrkörpers eine Verleugnung seiner wissenschaftlichen Überzengung verlangt haben. Das taktvolle Meiden einer Kritik militärischer und politischer Maßnabmen wäbrend des Krieges ist keine Verleugnung wissenschaftlicher Überzengung. 849}

Aus heutiger Perspektive muss man Nelson wohl dankbar dafür sein, dass er es durch seine Beharrlichkeit und seine streitbare Natur geschafft hat, seine Kollegen soweit zu provozieren, dass sie diese ausführliche Zurückweisung seiner Anschuldigungen verfassten. In keiner anderen Quelle aus der Zeit des Ersten Weltkrieges wird deutlicher, was wirklich der Konsens im Kollegium zu dieser Frage war. Ausdrücklich distanzierte man sich von der Idee, man würde irgendeine Einschränkung der akademischen Freiheiten selbst fordern oder auch nur hinnehmen. Prinzip war vielmehr das taktvolle Meiden. Es war irrelevant, ob man sich nun positiv oder negativ zu Fragen der aktuellen Tagespolitik und dem Krieg äußerte, man sollte innerhalb der Universität und als Mitglied der Universität solche Themen am besten ganz meiden. Dies bedeutete selbstverständlich auch eine gewisse Einschränkung der Lehrfreiheit, dessen war man sich bewusst, und das versuchte man auch nicht zu leugnen: Es gab Grenzen für die Lehrfreiheit: „Die Fakultät hat Sie auf die in der Kriegszeit gebotenen Grenzen der Lehrfreiheit in ihrem Briefe vom 11.VI. bestimmt hingewiesen. In dieser Hinsicht liegt in ihrer Beschlussfassung allerdings eine Vorschrift." ${ }^{\text {"850 }}$

Wie kaum anders zu erwarten war, ließ Nelson auch diesen Brief der Fakultät nicht unbeantwortet. Diesmal verwendete er am 12. Oktober 1915 insgesamt neun maschinenschriftliche Seiten dazu, darzulegen, worin er sein Recht begründet sah, von der Fakultät eine Erklärung seiner Unschuld zu fordern, wobei allein der enorme Umfang bereits eine Provokation darstellte. Auf seine Ausführungen soll hier nicht mehr im Detail eingegangen werden. Bemerkenswert ist aber vor allem, dass er die Darstellung Landaus, ein Gerücht sei der Auslöser der ganzen Angelegenheit gewesen, nicht akzeptierte, sondern auch weiterhin von einer „formelle[n], schriftlich abgefassten Beschuldigung" ausging. ${ }^{851}$ Außerdem sei ihm nicht mitgeteilt worden, dass der Dekan in der betreffenden Aussprache zu der Überzeugung

\footnotetext{
848 UAG.Phil.PA.Nelson 06.08.1915. Bl. 1.

849 UAG.Phil.PA.Nelson 06.08.1915. Bl. 3.

850 UAG.Phil.PA.Nelson 29.06.1915. Bl. 3.

851 UAG.Phil.PA.Nelson 12.10.1915. Bl. 2, Punkt 1.
} 
gelangt war, er, Nelson, sei unschuldig. ${ }^{852}$ Allerdings hätte er dem ohnehin keine Bedeutung zugemessen, da es sich nur um die persönliche Meinung eines Einzelnen gehandelt hätte und nicht um einen offiziellen Fakultätsbeschluss. ${ }^{853}$ Den Rest dieses Schreibens nimmt eine Analyse der Frage ein, ob ein taktvolles Meiden gewisser Themen eine Beschränkung der akademischen Freiheit darstellen kann. Nelson stellt sich auf den Standpunkt, dass ,,soweit es nur vom Takt abhängt, eine solche Kritik zu meiden, "854 er darin auch keine unzumutbare Einschränkung sehen würde, sehr wohl jedoch, sobald eine solche Kritik für „schlechterdings unzulässig“ erklärt würde.

Mit diesem Schreiben behielt Nelson dann doch endgültig das letzte Wort in dieser Angelegenheit. Dies allerdings ganz sicher nicht, weil er seine Kollegen überzeugt hätte, sondern vielmehr, weil diese wahrscheinlich resignierten. Professor Johannes Hartmann sprach dies auch ganz deutlich aus, als der Dekan die Mitglieder des Verwaltungsausschusses fragte, ob sie, bevor Nelsons letztes Schreiben von der gesamten Fakultät behandelt würde, noch eine weitere Sitzung ihres Ausschusses wünschten:

Schon in den früheren Ausschusssitzungen wurde ja die Erwartung ausgesprochen, dass Herr Dr. Nelson auf keinen Fall schweigen, sondern mit einem mindestens doppelt so langen Briefe antworten würde. Der vorliegende Brief entspricht nur unseren damaligen Erwartungen. Neues enthält er nicht. Der der ganzen Fakultät gegenüber angeschlagene unverschämte Ton erfordert meines Erachtens auch eine Stellungnahme der ganzen Fakultät - sollte diese auch nur die Nichtbeantwortung beschliessen. ${ }^{855}$

Die Mehrheit der Verwaltungsausschussmitglieder sprach sich allerdings für die Abhaltung einer weiteren Sitzung aus. Aber hier wie auch in der Fakultät selbst hielt man offensichtlich die Nichtbeantwortung für die beste Reaktion. Die unmittelbare Folge dieses sich über Monate hinziehenden Streits war die, dass Nelsons Verhältnis zur philosophischen Fakultät nun endgültig zerrüttet war. Nelson selbst hatte wiederholt davon gesprochen, dass solche Vorwürfe gegen ihn nicht zum ersten Mal erhoben worden seien. Sie wurden hier aber auch nicht zum letzten Mal erhoben: Noch am gleichen Tag, an dem Professor Oldenberg, ein Mitglied des Ausschusses, Nelsons letztes Schreiben vorgelegt bekam, wurde er erneut über „pazifistische Äußerungen“ in dessen Eröffnungsvorlesung zum Wintersemester informiert und teilte dies dem Dekan postwendend mit. ${ }^{856}$ Es wurden auch Untersuchungen angestellt und eine Zeugin befragt, wobei allerdings keine stichhaltigen Beweise zu Tage gefördert wurden. 857 Offenbar hatte man jedoch aus der

UAG.Phil.PA.Nelson 12.10.1915. Bl. 2, Punkt 2.

UAG.Phil.PA.Nelson 12.10.1915. Bl. 2-3, Punkt 3.

854 UAG.Phil.PA.Nelson 12.10.1915. Bl. 7-8, Punkt 9.

855 UAG.Phil.PA.Nelson 25.10.1915.

856 UAG.Phil.PA.Nelson 25.10.1915.

857 Befragung von Dr. Johanne von Bahr. UAG.Phil.PA.Nelson 06.-18.11.1915 
letzten Angelegenheit Lehren gezogen und ließ sich diesmal nicht wieder wegen eines Gerüchts zu einer Ermahnung oder Ähnlichem hinreißen, sei es, weil man schlicht müde war, oder weil man Nelson nicht noch einmal eine Bühne bieten wollte.

Beide Seiten sahen also zunächst von offenen Auseinandersetzungen ab. Allerdings hatte sich der Graben zwischen dem jungen Privatdozenten und zumindest den geisteswissenschaftlichen Mitgliedern der philosophischen Fakultät weiter vertieft. Nelson schrieb über die Geschehnisse des Jahres 1915 später an seinen Freund, den Mediziner Otto Meyerhof. Seine Worte geben ein Bild davon, wie unversöhnlich er weiterhin war.

Sie meinen, ich bätte die Fakultät erst durch mein Verhalten in dieser Sache gegen mich aufgebracht. Davon ist keine Rede. Denken Sie nur nicht, ich hätte das getan, um diese Horde von Verrückten zu bekehren. Das ist mir gar nicht eingefallen. Solche Albernheiten sollten Sie von mir nicht erwarten. 858

Die „Horde von Verrückten“, wie Nelson sie nannte, hatte natürlich einstweilen mehr Möglichkeiten, ihrem mit Sicherheit genauso großen Zorn Ausdruck zu verleihen. Im Frühjahr 1917 überging die Berufungskommission der philosophischen Fakultät Nelson beim Vorschlag für die Nachfolge von Husserls Extraordinariat für Philosophie. ${ }^{859}$ Die naturwissenschaftliche Fraktion innerhalb der Fakultät bemühte sich zwar noch um ihn, indem David Hilbert, unterstützt von Peter Debye, Max Lehmann, Carl Runge und Gustav Tammann, ein Separatvotum verfasste, ${ }^{860}$ in dem er Nelson auf die erste Stelle setzte, konnte aber letztlich nicht mehr verhindern, dass Nelson weiter auf einen Lehrstuhl warten musste. Zu vernichtend war die Kritik, die Nelsons Kollegen in ihrer Gegenerklärung zum Separatvotum an seinen wissenschaftlichen Qualitäten übten. Außerdem sprachen sie den Naturwissenschaftlern die Qualifikation ab, diese beurteilen zu können. 861 Um ihre Ablehnung vollständig zu machen, kamen sie zum Abschluss ihres Schreibens nochmals auf den Schriftwechsel mit Nelson aus dem Jahr 1915 zurück, was ein Übriges bei der Entscheidung des Ministeriums getan haben dürfte. ${ }^{862}$

858 Zitiert nach: Franke: Leonard Nelson. 1997. S. 127.

859 UAG.Phil.Fak.II.36.c 01.03.1917.

860 UAG.Phil.Fak.II.36.c 03.03.1917.

861 Franke geht in seiner Biographie Nelsons sogar soweit, in den Konflikten um die Berufung Nelsons den Grund für die Trennung von mathematisch-naturwissenschaftlicher und philosophischer Abteilung zu sehen. Dabei dürfte ihn jedoch eine zu starke Konzentration auf seinen Protagonisten irregeführt haben. Die Entstehung selbstständiger mathematischnaturwissenschaftlicher Fakultäten begann in Deutschland bereits im 19. Jahrhundert und war ein allgemeiner Prozess. Göttingen war im Gegenteil sogar ausgesprochen spät in der Vollziehung dieses Schritts. Leonard Nelson kann in dieser Entwicklung durchaus ein Faktor gewesen sein; dass aber die Trennung der beiden Zweige durch ihn in irgendeiner Form beschleunigt wurde, muss stark bezweifelt werden. Franke: Leonard Nelson. 1997. S. 132-133.

862 Dieser Vorgang wird bei Cordula Tollmien und auch Holger Franke detailliert dargestellt: Tollmien: Der „Krieg“. 1993. S. 156. Und: Franke: Leonard Nelson. 1997. S. 124ff. 
Besondere Gelegenheit, Dr. Nelsons rabulistische und überhebliche Art kennen zu lernen, gab der Fakultät ein Briefwechsel, den Nelson aus Anlass einer gegen ibn erhobenen Beschwerde vom Mai bis Oktober 1915 mit ibr hatte. Wir würden gleichwobl die damals gewonnenen Eindrücke unbedingt zurückdrängen, wenn Nelsons wissenschaftliche Persönlichkeit und Leistung auch nur annähernd dem im Minoritätsgutachten entworfenen Bild entspräche. ${ }^{863}$

Nelson hatte seiner Karriere mit dieser mit soviel Herzblut geführten Auseinandersetzung keinen Gefallen getan. ${ }^{864}$ Aus Sicht seiner Kollegen war sein Verhalten zumindest menschlich verständlich. Wirklich schaden wollte zumindest ihre Mehrheit dem rebellischen Privatdozenten, der sie so heftig attackiert hatte, aber nicht, obwohl sie dazu durchaus die Möglichkeiten und die Gelegenheit gehabt hätten: Am 11. Dezember 1915 hatte sich das stellvertretende Generalkommando Hannover bei der philosophischen Fakultät erkundigt, was es mit den „Verhandlungen gegen [...] Dr. Nelson“ auf sich habe. ${ }^{865}$ Der Dekan Landau antwortete darauf umgehend, dass zwar zwei Anzeigen eingegangen seien über ,,angebliche Äußerungen“, es jedoch „keinen Grund zum disziplinarischen Einschreiten“ gegeben habe. ${ }^{866}$ Die Bitte um kurzzeitige Überlassung der Akten wurde scheinbar einfach übergangen. 867 Wie im Folgenden noch deutlich werden wird, hätte es gerade gegenüber dieser Militärbehörde wohl nur einer kleinen Andeutung in einem Nebensatz bedurft, um Nelson das Leben deutlich schwerer zu machen, als es ohnehin schon für ihn war.

Warum aber deckte die philosophische Fakultät Nelson? Die Antwort auf diese Frage muss leider Spekulation bleiben. Sicher war es nicht in erster Linie Kollegialität, die die Professoren dazu bewog. Nur zu deutlich hat man gesehen, dass sie Nelson nur bedingt als Kollegen akzeptierten, wofür er selbst ihnen auch wenig Anlass gegeben hatte. Vielmehr finden sich in diesem Vorgang Charakteristika wieder, die auch in den zuvor geschilderten Fällen, der Nachfolge Rieckes, Simons Werben für die Erklärung gegen die Reichstagsmehrheit und Rausch von Traubenbergs Äußerungen im Zugabteil, sichtbar wurden. Man setzte alles daran, das

863 UAG.Phil.Fak.II.36.c 08.03.1917.

864 Damit stellte Nelson keinen Einzelfall dar, wie Burchardt zeigt. Er führt etwa den Fall des Berliner Physik- und Philosophiedozenten Arons an, den seine Nähe zur Sozialdemokratie seine Karriere kostete. Bezogen auf das Scheitern bereits habilitierter Wissenschaftler sagt Burchardt: „Ähnliches galt nicht selten für Einzelkämpfer ohne Fürsprecher und Schulzugehörigkeit - sofern sie nicht durch außergewöhnliche Leistungen Interesse zu wecken vermochten." Burchardt: Naturwissenschaftliche Universitätslehrer. 1988. S. 174-175. Ganz besonders gilt dies für Nelsons Schüler und politischen Freund Kurt Grelling. Tollmien: Der „Krieg“. 1993. S. $157 \mathrm{ff}$. UAG.Phil.PA.Nelson 11.12.1915. Außerdem wurde nach Dr. Grelling gefragt. Dies steht mit den im Folgenden noch beschriebenen Ermittlungen in Zusammenhang.

866 UAG.Phil.PA.Nelson 11.12.1915.

867 Davon kann man ausgehen, da in solchen Fällen immer Spuren auftreten, wie beispielsweise am 19. März 1917, als der Kurator im Zuge der Nachfolge Husserls Nelsons Personalakte anforderte. UAG.Phil.PA.Nelson 19.03.1917. 
Bild einer funktionierenden Korporation zu wahren, die sich strikte Ruhe auferlegte und in keiner Weise politisch Stellung bezog. Die Diskussion um die 'Erklärung gegen die Reichstagsmehrheit' entbrannte, weil nicht der Privatmann Herrmann Theodor Simon für sie warb, sondern der Rektor der Universität. Rausch von Traubenberg vertrat seine sicherlich nicht allgemein akzeptierte Meinung außerhalb der Universität als privater Reisender in einem Zugabteil. Nelson dagegen schnitt ein hochbrisantes Thema innerhalb der Universität und in Ausübung seines Amtes an. Dies rief die Fakultät auf den Plan, die sich allerdings weigerte, die Frage zu diskutieren, ob Nelson für oder gegen die Heeresleitung argumentierte oder die Verletzung der Neutralität Belgiens tatsächlich nur als Beispiel heranzog. Solche Themen bargen eine Gefahr, der man sich sehr bewusst war, nämlich die einer öffentlichen Diskussion oder eines handfesten Skandals. Also versuchte man, die ganze Angelegenheit mit so wenig Aufsehen wie irgend möglich zu regeln und ihr nicht zu viel Bedeutung zu verleihen. Eine Aussprache beim Dekan und eine kurze schriftliche Ermahnung sollten genügen, wie sie es bei Rausch von Traubenberg später auch taten. Man hatte jedoch nicht mit Nelsons Wehrhaftigkeit gerechnet und merkte schnell, dass hier das Potenzial für einen noch größeren Skandal lag. Man versuchte, das Problem nach Nelsons erster Eingabe auszusitzen - jedoch vergeblich. Nelson musste allerdings schon seine vollen rhetorischen Fähigkeiten aufbringen, um die Fakultät so zu provozieren, dass sie sich noch einmal äußerte. Was aber wäre passiert, wenn der Fall Nelson von einer Zeitung veröffentlicht worden wäre? Dies durfte nicht passieren, und deshalb ging man auch kein Risiko ein, als das stellvertretende Generalkommando sich meldete. Die Gefahr war zu groß, dass diese Angelegenheit doch noch nach außen drang.

Vielleicht war es so, dass gerade Naturwissenschaftler solch rationale Persönlichkeiten waren, dass sie angesichts solcher Überlegungen ihre eigenen Ansichten und Emotionen besonders gut zurückstellen konnten. Besonders im Falle Nelsons ist es fraglich, wie sich die Situation entwickelt hätte, wenn nicht die mathematisch-naturwissenschaftlichen Dozenten innerhalb der Fakultät sich für ihn eingesetzt hätten. Es gab auch durchaus Gegenbeispiele. Denn für Heinrich Rausch von Traubenberg hatte die Anzeige von Frau Nolte noch eine sehr unangenehme Konsequenz: Der Sprachwissenschaftler Professor Edward Schröder zeigte sich ausgesprochen verärgert über den milden Fakultätsbeschluss und wollte nicht akzeptieren, dass für Rausch von Traubenberg diese Angelegenheit mit dem förmlichen Aussprechen einer Missbilligung durch die philosophische Fakultät bereits beendet war. Schröder war zu dieser Zeit aber nicht nur Hauptmann der Landwehr außer Dienst, sondern auch Vorsitzender des Göttinger Einberufungsausschusses. Als solcher unterzeichnete er am 8. Juni 1917 ein Schreiben an das örtliche Bezirkskommando, in dem er die gesamte Anklage von Frau Nolte detailliert wiederholte und erklärte, dass Rausch von Traubenberg alle Vorwürfe „zuge- 
geben“ und sich offen als Pazifist bekannt habe. ${ }^{868}$ Die milde Reaktion der Fakultät auf diesen Vorfall umschrieb er mit den resignierenden Worten: „Mehr ließ sich auch hier nicht machen. "869 Welche mögliche Strafe er sich für den pazifistischen Privatdozenten vorstellte, sprach Schröder zwar nicht offen aus, legte den Militärbehörden aber nahe, Rausch von Traubenberg in den Krieg zu schicken:

Dem Dr. Rausch von Traubenberg ist durch besonderes Vertrauen des Ministers während des Krieges ein Lebrauftrag zur Vertretung des im Felde stehenden Prof. Dr. Pobl erteilt und er ist daraufhin von der philosophischen Fakultät, d.h. auf deren Antrag von dem Herren Kurator wiederholt reclamiert worden. Die letzte bewilligte Reclamation läuft m.W. Am 31. Juli ab.

Dr. R.v.Tr. Ist als ke[riegs]v[erwendungsfähig] für die Feldartillerie notiert. Ich habe mich als Landwehroffizier für verpflichtet gehalten, diese Tatsachen mit der Bitte um Weitergabe zunächst zur Kenntnis des Bezirkeskommandos zu bringen. 870

Um seine Darstellung nochmals zu untermauern, ergänzte Schröder in seinem Schlusssatz den Vorwurf des Pazifismus auch noch durch einen Hinweis auf Rausch von Traubenbergs Abstammung:

Ich füge hinzu, dass man in weiten Kreisen der Universität wie der Bürgerschaft über dies Treiben des pazifistischen Dr. R.v.Tr. empört ist, der, ein geborener Deutschrusse, erst später die preußische Staatsangehörigkeit erworben hat. 871

Der Brief Schröders wurde zwischen den verschiedenen Militärbehörden weitergereicht und gelangte über einen Monat später, am 21. Juli 1917, zum Kurator der Universität mit der Bitte um Stellungnahme. Der so genannten Kriegsamtstelle des stellvertretenden Generalkommandos in Hannover war er bereits mit einer „Nichtbefürwortung der Zurückstellung“" vorgelegt worden. ${ }^{872}$

Der Kurator Dr. Osterrath antwortete auf diese Anfrage, dass die gegen Rausch von Traubenberg erhobenen Vorwürfe der Wahrheit entsprächen, da dieser sie weitgehend eingeräumt habe. Er sprach sich jedoch gegen dessen Einziehung zum Kriegsdienst aus. Vielmehr forderte er das Bezirkskommando dazu auf, dass Rausch von Traubenberg „energisch korrigiert und auf das Strafbare seines Handelns hingewiesen wird.“873 Außerdem betonte er die Bedeutung von

\footnotetext{
868 UAG.Kur.3446 Bl. 38.

869 UAG.Kur.3446 Bl. 38v.

870 UAG.Kur.3446 Bl. 38v. Die Behauptung Schröders, dass Rausch von Traubenberg besondere Fürsprache im Ministerium erfuhr, kann nicht nachgewiesen werden. Seine Zurückstellung unterscheidet sich nicht von zahlreichen anderen. Positiv hat sich für ihn wahrscheinlich vor allem seine Tätigkeit im Rahmen der Ergänzungskurse für Kriegsteilnehmer ausgewirkt.

UAG.Kur.3442 Bl. 193.

871 UAG.Kur.3446 Bl. 38v.

872 UAG.Kur.3446 Bl. 39.

873 UAG.Kur.3446 Bl. 40.
} 
Rausch von Traubenbergs Lehrtätigkeit und bemerkte, dass die Aufnahme in das deutsche Heer keine Strafe darstellen dürfe, sondern schließlich eine Ehre sei. ${ }^{874}$

Am 7. August forderte die Militärbehörde aber bereits den Kurator dazu auf, sich um einen Ersatz für Rausch von Traubenberg beim Kultusministerium zu bemühen. Osterrath lud daraufhin dessen Kollegen Professor Peter Debye zum Gespräch über die Situation ein ${ }^{875}$ und schilderte dann in einem Schreiben den gesamten Vorgang dem Kultusministerium. ${ }^{876}$ Sollte Osterrath zu den in diesem Schreiben geäußerten Ansichten durch sein Gespräch mit Debye gelangt sein, so muss man davon ausgehen, dass es um das Verhältnis zwischen diesem und Rausch von Traubenberg nicht gut bestellt gewesen sein kann:

Auf die Persönlichkeit des bisher mit der Vertretung des Prof. Pohl beauftragten Privatdozenten von Traubenberg wird bier seitens der nichtbeteiligten Herren der Fakultät kein Wert gelegt; die selben würden damit ganz einverstanden sein, wenn Eurer Exzellenz ein anderer Dozent für diese Vertretung zur Verfügung stehen sollte. ${ }^{877}$

Im November 1917 wurde das Kuratorium aufgefordert, eine genaue Beschreibung der Aufgaben Rausch von Traubenbergs zusammenzustellen, ${ }^{878}$ und im Januar 1918 teilte das Kultusministerium mit, dass es gebeten wurde, „von weiteren Schritten wegen Zurückstellung des Rausch von Traubenberg vom Heeresdienst" abzusehen. ${ }^{879}$ Als Osterrath dies der philosophischen Fakultät mitteilte, wies er ausdrücklich darauf hin, dass es sich hierbei um eine Entscheidung des Kultusministeriums handelte. ${ }^{880}$

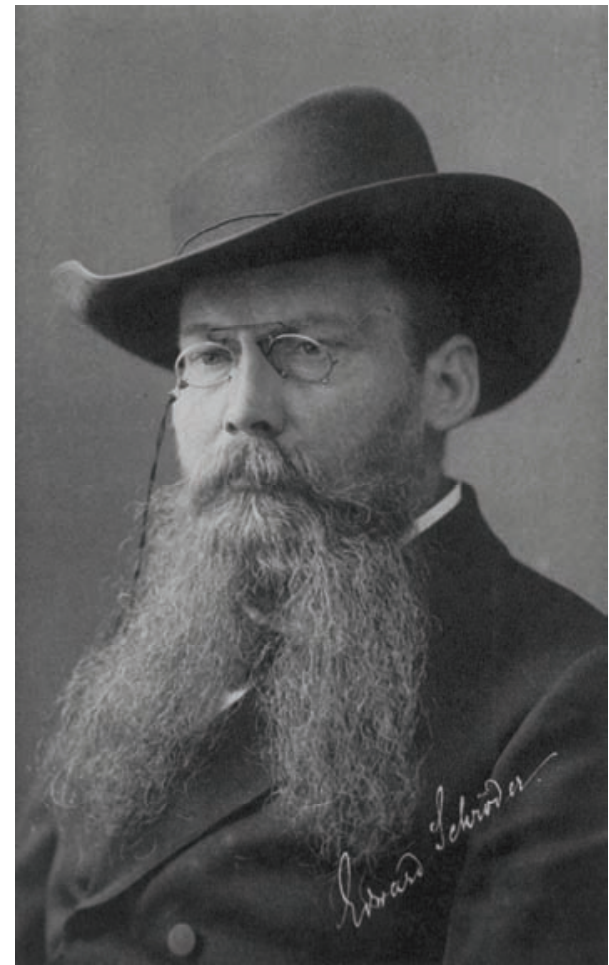

Abbildung 15: Edward Schröder

874 UAG.Kur.3446 Bl. 40.

875 UAG.Kur.3446 Bl. 41v.

876 UAG.Kur.3446 Bl. 42-42v.

877 UAG.Kur.3446 Bl. 42v.

878 UAG.Kur.3446 Bl. 208.

879 UAG.Kur.3446 Bl. 279.

880 UAG.Kur.3446 Bl. 279. 
Eine Woche später ging bei ihm die offizielle Mitteilung der Militärbehörde ein, dass Rausch von Traubenberg zum 1. Februar 1918 eingezogen werden würde. ${ }^{881}$ Schröder hatte schließlich sein Ziel erreicht.

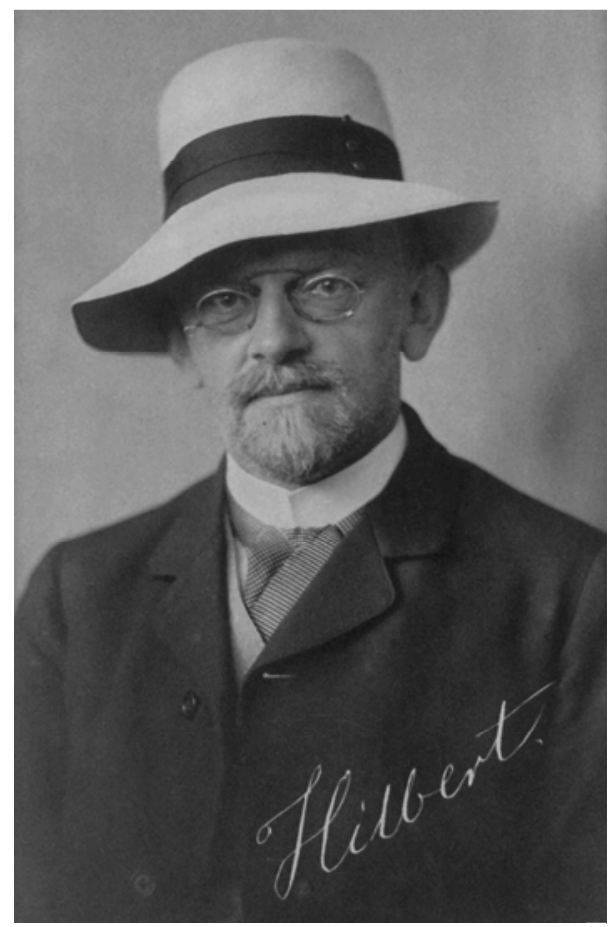

Abbildung 16: David Hilbert

Beachtenswert bei dieser Angelegenheit ist, dass der Kurator sie nicht offiziell mit den Naturwissenschaftlern in der Fakultät besprach, sondern mit Debye lediglich einen einzelnen Professor ins Vertrauen zog. Andernfalls hätte er die Denunziation durch Schröder öffentlich machen müssen, was zweifellos zu großer Unruhe im Kollegium geführt hätte, da dieser einen fakultätsinternen Vorgang nach außen weitergegeben und damit eine schwere Indiskretion begangen hatte. So hatten nur Schröder selbst, der Kurator Osterrath und Professor Debye Kenntnis von diesem Vorgang. Es gelang jedoch nicht vollständig, diesen im Verborgenen zu halten. Nach Ende des Krieges wandte sich David Hilbert an Carl Runge und berichtete ihm, wovon er erfahren hatte:

In der hiesigen philos.-Fak. wurde vor mebr, als Jahresfrist über eine Denunziation verbandelt, die gegen unseren Kollegen

Rausch v. Tr. [aubenberg] gerichtet war: nach Auflelärung des Sachverbaltes gelangte die Fakultät dazu, überbaupt von einer Einleitung des Dišiplinarverfabrens gegen R.v.T. abzusehen. Obwobl nun Herr Schröder, falls er mit der Auffassung und Entscheidung der Fakultät nicht einverstanden war, ein Recurs an den Minister jederzeit freigestanden bätte, so bat derselbe dennoch, seiner eigenen Erklärung zufolge, in dieser ibm amtlich von Fakultäts wegen bekannt gewordenen Angelegenbeit seinerseits R.v.T. der Militärbehörde denunziert. [...]

In beiden Fällen [Schröder soll außerdem auch den Historiker Darmstädter denunziert baben] hat die Handlungsweise des Hern Schröder dazu gefübrt, dass die beiden denunzierten Kollegen, die bis dabin reklamiert waren, eingezogen wurden und damit ist in der Tat die Aufrechterbaltung des wissenschaftlichen Betriebes an unserer Universität, ₹"u der wir Professoren zumal in der Kriegszeit berufen waren, schwer geschädigt worden. 882 
Neben der von Hilbert betonten Schädigung des Lehrbetriebs war die Einberufung für Rausch von Traubenberg persönlich als erklärtem Pazifisten mit Sicherheit eine schwere Strafe, ungeachtet der evidenten Gefahr für Leib und Leben.

Dieser Vorgang beweist, dass es in der Tat eine lebhafte Diskussion innerhalb des Kollegiums über diese Themen gab. Hilbert hatte seinen Brief an Professor Carl Runge geschickt, den ehemaligen Prorektor der Universität, der mittlerweile Sekretär der Gesellschaft der Wissenschaften in Göttingen war. Hilbert war empört über die Aktivitäten Schröders und versuchte nach dem Krieg, gemeinsam mit einem nicht näher zu spezifizierenden Kreis anderer Wissenschaftler, 883 einen Boykott von Sitzungen der Gesellschaft der Wissenschaften zu organisieren, deren Vorsitzender jetzt Edward Schröder war.

Herr Schröder scheint uns biernach nicht der rechte Mann für das Amt des Vorsitzen-
den einer Korporation, die ausschliesslich die Förderung der reinen Wiss. zum Zweck
hat. Wir bringen diese Überzengung jetzt zur Kenntniss, wo den denunzierten Kollegen
kein Schaden mehr daraus entstehen kann und werden zu ibrer Bekräftigung den Sit-
zungen der Ges.d.W. fernbleiben, solange Herr Schröder den Vorsitz fübrt. ${ }^{884}$

Für den Erfolg oder Misserfolg dieses Versuches lassen sich leider keine Belege finden, jedoch erfuhr auch Hilbert nicht ausschließlich Unterstützung. Der Göttinger Chemiker Prof. Dr. Adolf Windaus etwa antwortete ihm, dass er zwar grundsätzlich das Vorgehen Schröders auch verurteile, jedoch dessen Schuld als nicht hinreichend bewiesen ansehe. 885 Außerdem sah er keinen Sinn mehr darin, Schröder so spät noch für das Geschehene verantwortlich zu machen. Er versuchte vielmehr, dessen Verhalten mit den während des Krieges herrschenden Verhältnissen zu entschuldigen:

Ganz abgesehen davon glaube ich allerdings, dass Ihr Schritt, der vor einigen Monaten noch wichtig und nützlich hätte sein können, durch die Zeitereignisse überholt ist. Herr Schröder kann nicht mehr schaden; und die Verwirrungen eines falsch verstandenen Patriotismus, der so viel Kollegen ergriffen hatte, sind erkannt. Ich kann nicht leugnen, dass es mir widerstrebt, jetzt nach der Revolution, den Anhängern des früheren Regiments noch einen Fusstritt zu versetzen. ${ }^{886}$

Daher mahnte er Hilbert, auf den Boykott möglichst zu verzichten, „da die Zwietracht und der Kampf, den Ihr Schritt auslösen wird“ nur gelohnt hätte, „so lange

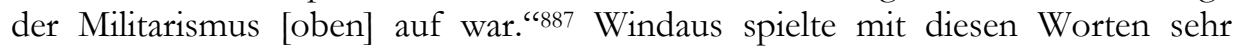
kritisch auf die Beteiligung Göttinger Professoren am Propagandakrieg an und

\footnotetext{
883 Hilbert hatte seinen Brief im Plural formuliert, jedoch befinden sich auf dem erhaltenen Konzept keine Unterschriften oder Namen. SUB.Gött.HSD.Cod.Ms.D.Hilbert.457 Nr.13.

884 SUB.Gött.HSD.Cod.Ms.D.Hilbert.457 Nr.13.

885 Diese Aussage beweist, dass der Kurator Schröders Schreiben nicht bekannt gemacht hat.

886 SUB.Gött.HSD.Cod.Ms.D.Hilbert.438. Brief vom 8.2.1919.

887 SUB.Gött.HSD.Cod.Ms.D.Hilbert.438.
} 
sprach sich dafür aus, besser diese Aktivitäten zum Thema in der Gesellschaft der Wissenschaften zu machen, als die öffentliche Verurteilung eines Einzelnen:

\section{Es bleibt zu erwägen, ob nicht bei der Aussprache über die Reform der Universitäten irgend ein (nicht persönlich gegen ein bestimmtes Mitgleid gerichteter) Antrag einzubrin- gen wäre, in dem besonders zu betonen wäre, dass die Universität die Förderung der rei- nen Wissenschaft zur Aufgabe hat und (wie weiss ich nicht) die törichte Tätigkeit der Professoren im Unterschreiben aller möglichen Aufrufe u.s.w. zu brandmarken wäre. 888}

Gerade diese letzte Formulierung hätte für einen Teilnehmer des Krieges der Geister, wie etwa Herrmann Theodor Simon, wie eine schallende Ohrfeige wirken müssen. Es gab demnach massive Spannungen innerhalb des Kollegiums. Es wurde diskutiert und gestritten, allerdings nie so, dass nach außen sichtbare Spuren hinterlassen wurden. Auch in diesem konkreten Fall kann nicht mehr festgestellt werden, was aus Hilberts Protestaufruf geworden ist. 889

Es wurde deutlich, dass die Vermeidung eines offenen Skandals bei den Entscheidungen der Fakultät während des Ersten Weltkrieges stets Priorität besaß. Es sollte unter allen Umständen vermieden werden, dass nach außen das Bild entstand, die Universität sei ein Ort, an dem Themen wie die Neutralität Belgiens oder mögliche Friedensschlüsse diskutiert wurden. Dies muss spätestens seit den Erfahrungen der Zeitungsaffäre um das Studium feindlicher Ausländer Konsens innerhalb des Kollegiums gewesen sein. Besonders im Falle Leonard Nelsons hat dies ganz offensichtlich dazu geführt, dass man ihm defensiver gegenübertrat, als man dies zu Friedenszeiten getan hätte. Die Denunziation durch Schröder und die Reaktion Hilberts zeigen, dass auch unter den Professoren diesbezüglich tiefe Brüche entstanden waren. Es war jedoch gelungen, zumindest für die Dauer des Krieges die Fassade aufrecht zu erhalten. ${ }^{890}$

888 SUB.Gött.HSD.Cod.Ms.D.Hilbert.438.

889 Weder in den Briefwechseln der beteiligten Dozenten noch in den Unterlagen der Göttinger Akademie der Wissenschaften finden sich über die hier zitierten Schreiben hinausgehende Spuren. Edward Schröder blieb weiterhin Sekretär und nahm im Jahre 1919 an den Sitzungen der Akademie teil. Am 21.02.1919 und am 07.03.1919 hielt er dort jeweils einen Vortrag. Ob David Hilbert zu diesen Sitzungen erschien, ist indes nicht mehr nachzuvollziehen. Der entsprechende Band, in dem sich die Sitzungsprotokolle der Zeit des Ersten Weltkrieges und der Jahre bis 1925 befinden (Chron.4.7), fehlt im Archiv der Göttinger Akademie der Wissenschaften. Listen der gehaltenen Vorträge und der bekleideten Ämter in: Königliche Gesellschaft der Wissenschaften zu Göttingen (Hrsg.): Nachrichten von der Königlichen Gesellschaft der Wissenschaften zu Göttingen. Geschäftliche Mitteilungen aus dem Jahre 1919. Berlin 1919.

890 Damit war die Universität Göttingen kein Einzelfall. Andrea Wettmann schildert für die Universität Marburg die Auseinandersetzungen um und mit Prof. Dr. Walther Schücking. Der Völkerrechtler war bekennender Pazifist und bereits vor Ausbruch des Krieges durch verschiedene Äußerungen aufgefallen, die eine Gruppe Studenten nun nochmals dem Kurator der Universität Marburg vortrug. Schücking verteidigte, wie Nelson in Göttingen, entschlossen seine Lehrfreiheit, nachdem er ebenfalls zum Meiden der entsprechenden Themen aufgefordert worden war. Auch in Marburg versuchte man alles, um einen größeren Skandal zu vermeiden, als ein Artikel zu diesem Vorgang in der Presse erschien. Eine Denunziation aus den Reihen des Kollegiums fand in Marburg allerdings nicht statt. Wettmann: Heimatfront. 2000. S. 366ff. 


\section{Das Klima außerhalb der Universität}

Der Tatsache, dass Heinrich Rausch von Traubenberg ausgerechnet von einen Germanisten und keinem Naturwissenschaftler denunziert worden ist, wird man keine allzu große Bedeutung beimessen dürfen. Sie weist vielmehr den Weg aus der Universität heraus. Wie eingangs gesagt, fand auch das Leben eines naturwissenschaftlichen Dozenten natürlich nicht nur innerhalb der Universität statt. Vielmehr ist es so, dass die Außergewöhnlichkeit des recht rationalen und unaufgeregten Umgangs der Professorenkollegen miteinander erst dadurch wirklich einzuordnen ist, dass man ihn zu den Verhältnissen außerhalb der Universität in Relation setzt.

Wie bereits im ersten Teil dieser Arbeit festgestellt wurde, war das ganze Land gerade in den ersten Kriegstagen und -wochen geradezu von einer Welle der Spionage- und Sabotageangst erfasst worden. Besonders hatten dies die ausländischen Studierenden erfahren müssen. Auf diesen Themenbereich soll hier nicht nochmals eingegangen werden, sondern es soll untersucht werden, in welcher Form und in welchem Umfang Göttinger Naturwissenschaftler außerhalb der Universität in Erscheinung traten und welche Verhältnisse ihnen dort begegneten. Dazu ist grundsätzlich zu sagen, dass das bisher festgestellte Bemühen, möglichst nicht in Erscheinung $\mathrm{zu}$ treten, offensichtlich nahezu vollständig erfolgreich gewesen ist. Nur bei intensiver Suche lassen sich Spuren erkennen. Belege für Aufsehen erregende Aktionen oder auch Skandale fanden sich in keinem Fall.

Erneut sind es die Personen, die sich offensichtlich bereits nur schwer mit der allgemeinen Zurückhaltung innerhalb des Kollegiums abfinden konnten, die auch außerhalb der Universität in Erscheinung traten. Dies geschah allerdings zumindest im Falle Leonard Nelsons und seines Vertrauten und Schülers Kurt Grelling unfreiwillig und auf Veranlassung des Kunsthistorikers Professor Heinrich Alfred Schmid. ${ }^{891}$ Offensichtlich hatte sich Schmid an das stellvertretende Generalkommando gewandt und dort besonders Grelling belastet. Nelson geriet in die nun einsetzenden Ermittlungen wohl hauptsächlich durch seine enge Beziehung zu Grelling und wurde gleichsam als dessen geistiger Vater angesehen und als dafür verantwortlich, dass Grelling in Göttingen wohnte, da dieser ihm gefolgt sei. Denkt man also an Professor Schröder, so scheint Denunziation innerhalb des Kollegiums zumindest kein Einzelfall gewesen zu sein - außerhalb der Universität

891 Am 6. Dezember 1915 erhielt die Göttinger Polizeidirektion telefonisch den Auftrag, Ermittlungen über Dr. Grelling in „politischer Hinsicht“ zu veranlassen. In der handschriftlichen Notiz heißt es weiter: „Die Feststellungen könnten gemacht werden bei Herrn Prof. Schmid, Nikolausbergerweg 51."St.A.Gö.Pol.Dir.159,3 Bl. 1. In der am folgenden Tag durchgeführten Befragung Schmids sagt dieser aus, ,, seine Vermutungen bereits Sr. Exzellenz dem Herrn stellvertretenden Generalkommandanten mitgeteilt zu haben." St.A.Gö.Pol.Dir.159,3 Bl. 3. 
war sie zu dieser Zeit offensichtlich die Regel, wie man den Akten der Göttinger Polizeidirektion entnehmen kann. ${ }^{892}$

Der enge zeitliche Zusammenhang zwischen Schmids Anzeige und dem Ende der Affäre um die Diskussion der Neutralität Belgiens in Nelsons Kolleg legt den Schluss nahe, dass es sich hier ebenfalls um die Reaktion eines unzufriedenen Fakultätsmitgliedes auf die nachsichtige Behandlung Nelsons durch die Fakultätsmehrheit handelte. Schmid war es, der das Generalkommando auf die Verhandlungen innerhalb der Fakultät aufmerksam gemacht hatte:

\section{In der philosophischen Fakultät der Universität hier sind Verhandlungen gegen Dr. Grelling und Dr. Nelson eingeleitet worden, die die philosophische Fakultät durch ibren Abteilungsvorsteher Herrn Professor Sethe, Schildweg 16 wohnhaft, auf Ersuchen zur Verfügung stellen wird. 893}

Das entsprechende Schreiben des Generalkommandanten wurde bereits oben zitiert. Dass es sich direkt auf die Anzeige Schmids bezog, ist eindeutig daran zu sehen, dass es unüblicher Weise an die Privatanschrift Sethes adressiert war, die die Polizeidirektion gewohnheitsmäßig dem Namen Sethe hinzugefügt hatte. Eventuell wollte Schmid seine Denunziation aber auch vor dem damaligen Dekan Landau verbergen, da dieser Naturwissenschaftler war und damit eher auf der Seite Nelsons stand. Diese Befürchtung war jedoch unnötig, da das Generalkommando seinen Informanten nicht genannt hatte. Es wurde nur gesagt, dass „es hier zu Kenntnis gekommen [...]“ sei, dass Verhandlungen eingeleitet worden seien. ${ }^{894}$ Landau wusste also wahrscheinlich nicht, wer diese Indiskretion begangen hatte.

Die Tatsache, dass Schmid gerade Kurt Grelling ins Spiel brachte, ist wahrscheinlich dadurch zu erklären, dass sich seine Anzeige gar nicht primär gegen Grelling selbst richtete, wie er gegenüber der Militärbehörde angegeben hatte, sondern er vielmehr Nelson dadurch schaden wollte, dass er ihn mit der als sehr zwielichtig dargestellten Persönlichkeit Grelling in Verbindung brachte. War dies tatsächlich sein Ziel, so hatte er nahezu vollständigen Erfolg. Nelson selbst war bis zu diesem Zeitpunkt noch nicht öffentlich politisch hervorgetreten, obwohl er sich später als Gründer des Internationalen Jugendbundes (IJB) und dann des Internationalen Sozialistischen Kampfbundes (ISK) weit mehr exponierte als sein Schüler Grelling. ${ }^{895} \mathrm{Da}$ auch die Untersuchungen der Fakultät kein greifbares Ergebnis erbrachten, gab es also realistisch betrachtet wenig, das man Nelson hätte vorwerfen können. Bei Grelling war dies anders, was letztlich auf seinen Lehrer zurückstrahlte. Grelling war nicht nur Mitglied der unter Beobachtung stehenden Deutschen

892 In der Akte der Polizeidirektion Göttingen mit dem Titel „Spionageverdächtige Personen, Pazifisten u.s.w." nehmen Ermittlungen wie die gegen Grelling und Nelson einen großen Raum ein. St.A.Gö.Pol.Dir.159,3.

893 St.A.Gö.Pol.Dir.159,3 Bl. 3.

894 UAG.Phil.PA.Nelson 11.12.1915.

895 Zu Nelsons politischer Karriere siehe: Franke: Leonard Nelson. 1997. S. 143ff. 
Friedensgesellschaft, sondern zudem Vorsitzender ihrer Göttinger Ortsgruppe. AuBerdem war offensichtlich allgemein bekannt, dass die anonym in der Schweiz veröffentlichte Schrift $J^{\prime}$ accuse, ${ }^{896}$ in der Deutschland die Alleinschuld am Krieg gegeben wurde, von dessen Vater Richard Grelling stammte, worauf auch Schmid in seiner Aussage zu sprechen kam. 897

Nachdem das stellvertretende Generalkommando einmal auf Grelling und Nelson aufmerksam gemacht worden war, ließ die Militärbehörde nicht mehr von ihnen ab. In ihrem Auftrag begann die Göttinger Polizeidirektion mit intensiven Nachforschungen, die vor keinem Bereich des Lebens halt machten. Neben Professor Schmid, der hiernach nicht wieder in Erscheinung trat, wurden außerdem Mitbewohner der Pension befragt, in der Grelling mit seiner Familie zunächst wohnte, sowie die Bewohner des Hauses, in dem Grelling später eine Wohnung hatte. Bereits am 17. Dezember konnte die Polizeidirektion einen detaillierten Bericht nach Hannover abgeben. ${ }^{898}$ Neben den finanziellen und familiären Verhältnissen aller Beschuldigten gab man jede Information weiter, die man irgendwie erhalten konnte, wobei es offensichtlich unwichtig war, wie hoch deren nachprüfbarer Wahrheitsgehalt war. Abgesehen von Namen und Geburtsdaten handelte es sich hier ganz eindeutig um Gerüchte. Zur Person Nelsons etwa wurden genau die Behauptungen wiederholt, für die die philosophische Fakultät keine Beweise hatte finden können:

Nelson's scharfe zersetzende Art hat ihn bei den meisten seiner Kollegen unbeliebt gemacht, und es wurde zu Beginn des Winter-Semesters 1914/15 ein Disziplinarverfahren gegen ihn vor der philosophischen Fakultät eingeleitet, weil er in seinen Uebungen die Frage zur Bearbeitung gestellt hatte, ob der Einmarsch der deutschen Truppen in Belgien sich rechtfertigen liesse. ${ }^{899}$

Es gab niemals ein offizielles Disziplinarverfahren gegen Nelson, und die Formulierung, dass er diese Frage ,zur Bearbeitung gestellt habe“, wurde ebenfalls nicht weiter vertreten. Diese Aussagen verfehlten aber sicher ihre Wirkung bei der Militärbehörde nicht. Da half es auch wenig, dass man sie in umständlichen Worten relativierte:

Man nahm wohl an, dass Nelson erwartet hatte, seine Schüler würden die Frage mit Nein beantworten. Er hat aber [gestrichen: ziemlich] glaubhaft gemacht, dass er durchaus im gegenteiligen Sinne die Frage behandelt wissen wolle. Personen, die ibn näher kennen und ibn nicht schätzen, trauen ihm eine vaterlandslose Gesinnung in keiner Weise zu..$^{900}$

\footnotetext{
896 Siehe hierzu auch: Tollmien: Der „Krieg“. 1993. S. 157-158.

897 St.A.Gö.Pol.Dir.159,3 Bl. 3.

898 St.A.Gö.Pol.Dir.159,3 Bl. 4-8.

899 St.A.Gö.Pol.Dir.159,3 Bl. 4.

900 St.A.Gö.Pol.Dir.159,3 Bl. 4.
} 
Es fällt leicht, sich den Verlauf des Gesprächs vorzustellen, in dem Professor Schmid seine Aussage machte. Möglicherweise wurde er wieder enttäuscht, aber auch die Polizeidirektion fand keine wirklichen Anhaltspunkte gegen Nelson oder Grelling.

Aus allem, was wir haben ermitteln können, haben wir besonderen Verdacht gegen Grelling oder die mit ihm verkehrenden Personen nicht schöpfen können. [...] dass die genannten Personen sich erst während des Krieges hier niedergelassen haben, um Spionagedienst zu betreiben, dürtte daber wohl ausgeschlossen sein. ${ }^{901}$

Damit war diese Situation für die Verdächtigen aber noch keineswegs ausgestanden. Für die gesamte folgende Kriegszeit blieben sie unter Beobachtung des Generalkommandos, und es genügten kleinste Anlässe, um die gesamte Maschinerie von Gerüchten, Ermittlungen, Zeugenaussagen und Berichten erneut in Gang zu setzen. Solche Anlässe gab es in der Tat genug, und zwar meistens in der Form von Anzeigen durch Nachbarn. Ungefähr ein halbes Jahr nach dem ersten Abschlussbericht der örtlichen Polizeidirektion erhielt diese einen erneuten Auftrag für Ermittlungen. „Frau Amtsgerichtsrat Laves“ waren viele „,befremdliche Vorkommnisse“ erzählt worden, worüber sie zwar längere Zeit geschwiegen habe, nun aber schrieb: „[Es] lässt mir die ganze Geschichte keine Ruhe mehr, bis ich wenigstens den Versuch gemacht habe, die vielen wunderlichen, befremdlichen Geschehnisse einer massgebenden Stelle zur Klärung zu unterbreiten."902 Die maßgebende Stelle war in ihren Augen die Kommandantur in Berlin, die den Vorgang dann an das stellvertretende Generalkommando in Hannover weiterreichte.

Laves schildert im Folgenden sehr ausführlich und umfänglich die verschiedenen Gerüchte, die ihr über die Grundlagen des Lebensunterhalts von Familie Grelling zu Ohren gekommen waren, denn ihre Informationen hatte sie größtenteils nicht selbst gesammelt, sondern von „Frau Regierungsrat Besser“ erzählt bekommen, die sich allerdings bedroht fühlte und nicht aussagen wollte. Dabei gewinnt man den Eindruck, dass Grelling und sein persönliches Umfeld geradezu von ihren besorgten Nachbarn beschattet wurden. Auch seine Verbindung zu dem „hiesige[n] Professor Nelsen [sic!], einem zumindest mit eigenartigem Ruf beleumundeten Menschen“ wird selbstverständlich erwähnt. Es wird von langen Fahrradfahrten berichtet, dem Verkehr mit Russen, dem Versenden von hohen Geldsummen mit der Post und selbstverständlich dem verdächtigen Aufenthalt in der Nähe von Truppentransporten. ${ }^{903}$ Damit stand für Frau Laves fest:

Ich kenne keine Furcht, wenn es sich um Pflichterfüllung handelt, und da mir das ganze Leben und Treiben der Leute dunkel erscheint, halte ich es im Interesse des Vaterlandes

901 St.A.Gö.Pol.Dir.159,3 Bl. 8.

902 St.A.Gö.Pol.Dir.159,3 Bl. 10.

903 St.A.Gö.Pol.Dir.159,3 Bl. 10-13. 
und der zu vetrauensseeligen Göttinger Gesellschaft, in der sowieso eine mir stark unsympathische pazifistische Strömung immer mehr zunimmt, für richtig, meine Befürchtung auszusprechen und den Antrag zu stellen, 1) die pekuniäre Lage Dr. Grellings aufzuklären und nachzuforschen was dieser stark jüdisch aussehende Mann für eine politische Mission haben kann [von der er gesprochen haben soll]; 2) festzustellen ob Dr. Gierke [ein schwerkeranker Schriftsteller und Freund Grellings] in der Schweiz, ist, ob sein Verkehr dort verdächtig, wo seine Frau weilt; 3) ob Frau Dr. Grelling, geb. HaassBerkow irgendwie in der Schweiz zu Dr. Gierke in Verbindung tritt; 4) und woher Herr Haass-Berkow [Grellings mittelloser Schwager] seines Lebens Unterhalt nimmt $[\ldots] .904$

Diese drastischen Worte und vor allem die Selbstverständlichkeit, mit der Laves, nur auf Gerüchten aufbauend, Ermittlungen gegen Familie Grelling und ihren gesamten Freundes- und Bekanntenkreis einfordert, spiegeln ein, aus heutiger Perspektive, bedrückendes Bild des während des Ersten Weltkriegs herrschenden Klimas wider. Die Militärbehörden aber, nicht zuletzt nach der ersten Denunziation durch Professor Schmid, waren offensichtlich der aufmerksamen Bürgerin regelrecht dankbar und gaben bei der Göttinger Polizeidirektion die von Frau Laves gewünschten Nachforschungen in Auftrag. ${ }^{905}$ Zuerst wurden Frau Besser und Frau Laves selbst zu Zeugenaussagen bestellt. Dabei kamen weitere wunderliche Dinge zu Tage, wie rätselhafte Kreidezeichen auf der Straße und das Gurren von Brieftauben aus Dr. Gierkes Wohnung. ${ }^{906}$ Am 19. Juni 1916 verfasste die örtliche Polizei dann erneut einen umfangreichen Abschlussbericht für das stellvertretende Generalkommando, allerdings mit einer eindeutigen Aussage. Wieder konnte man nichts Verdächtiges feststellen, sondern äußerte dieses Mal sogar ganz offen die Ansicht, dass man Laves und Besser nicht ernst nehmen könne.

Nach dem bislang festgestellten ist es nicht annehmbar, dass man es hier mit einer Spionageangelegenheit zu tun hat. Viel eher ist anzunehmen, dass die genannten Personen andere Gründe, vielleicht in sittlicher Beziehung für ibren Verkehr baben. [...] es ist ja nicht ausgeschlossen, dass die Genannten zu einer Gesellschaft der Theosophen, der sogenannten Geisterseher und Schwärmer angehören, vielleicht hat man es auch mit Homosexuellen zu tun. ${ }^{907}$

Man konnte und wollte ein gewisses Misstrauen gegenüber „Grelling und Genossen "908 nicht verbergen, aber ein konkreter Spionageverdacht konnte laut der Polizeidirektion ausgeschlossen werden, da „,es sich bei der Frau Regierungsrat

\footnotetext{
904 St.A.Gö.Pol.Dir.159,3 Bl. 12.

905 St.A.Gö.Pol.Dir.159,3 Bl. 14.

906 St.A.Gö.Pol.Dir.159,3 Bl. 17-18.

907 St.A.Gö.Pol.Dir.159,3 Bl. 19v.

908 St.A.Gö.Pol.Dir.159,3 Bl. 16.
} 
Besser, der Tochter [von Frau Besser] und deren sonstigen Bekannten um einen ausgesprochenen Ausländerhass und persönliche Feindschaft handelt.“909

Die Rekonstruktion dieser Vorgänge könnte hier noch beliebig fortgesetzt werden. Der Ablauf dieser Angelegenheit ist als ein Beispiel für das angespannte Klima in der Zeit des Ersten Weltkrieges zu sehen, in dem Ausländerhass und Spionageangst teilweise erstaunliche Blüten trieben. Die unzähligen Details, die Frau Besser, ihre Tochter und Frau Laves über die Bespitzelten zu berichten wussten, konnten nach ernsthafter Nachprüfung der verschiedenen Gerüchte von der örtlichen Polizei nicht mehr ernst genommen werden, von den Militärbehörden aber sehr wohl. Diese veranlassten immer wieder neue Nachforschungen. Die Göttinger Polizeidirektion etwa berichtet am 4. August 1916 nach Hannover: „Feststellungen über Dr. Grelling und Genossen, die auf Spionage oder deutschfeindliche Tätigkeit dieser Personen schließen lassen, haben nicht mehr getroffen werden können." ${ }^{1010}$ Fast schon postwendend traf dann am 2. September die nächste Anfrage der Abteilung Abwehr des stellvertretenden Generalkommandos betreffend neuer Nachforschungen ein. ${ }^{911}$

Im Anbetracht des üblichen Vorgehens des Generalkommandos war die Denunziation einer Person bei dieser Behörde, wie es Schröder mit Rausch von Traubenberg und zuvor Schmid im Falle Nelsons getan hatten, also ein schwerwiegender Schritt mit durchaus weitreichenden Folgen. Nelson fiel nur kurz aus den Ermittlungen heraus, da er zum Kriegsdienst nach Kassel eingezogen worden war. Aber noch bevor er wieder in Göttingen ankam, nachdem er aus gesundheitlichen Gründen vorzeitig aus dem Heer entlassen worden war, ${ }^{912}$ meldete sich die Abteilung Abwehr am 7. März 1918 bei der Göttinger Polizeidirektion:

Nach hierher gelangten Mitteilungen soll der Privatdozent Dr. Nelson inzwischen wegen Krankheit aus dem Militärdienst entlassen worden sein oder jedenfalls in wenigen Tagen entlassen werden. Das stellvertretende Generalkommando ersucht um Mitteilung, ob, eventl. wann Dr. Nelson seine Tätigkeit an der Universität wieder aufgenommen hat.

Dr. Nelson soll ein ausgesprochener Pazifist sein und in starkem Maße in antinationalem Sinne auf einen Kreis von Studenten einwirken. Auch soll der Verkehr mit seinen Zubörerinnen moralisch nicht ganz einwandfrei sein. Es wird ersucht, hierüber vertrauliche Mitteilungen anzustellen. ${ }^{913}$

Wie man in Hannover zu diesen Verdächtigungen kam, bleibt dabei völlig offen. Insbesondere von dem angeblich moralisch nicht einwandfreien Verhältnis zu Studentinnen war vorher nie die Rede, und so kann man sich des Eindrucks nicht erwehren, dass die Anschuldigungen gegen Nelson weitgehend frei erfunden

\footnotetext{
909 St.A.Gö.Pol.Dir.159,3 Bl. 20.

910 St.A.Gö.Pol.Dir.159,3 Bl. 27.

911 St.A.Gö.Pol.Dir.159,3 Bl. 28.

912 Siehe zu Nelsons Militärzeit: Franke: Leonard Nelson. 1997. S. 138ff.

913 St.A.Gö.Pol.Dir.159,3 Bl. 319.
} 
waren. Trotzdem wurde nun auch Nelson wieder für den Rest des Krieges engmaschig überwacht. Am 15. August 1918 schließlich wurde, ohne Angabe von Gründen und selbstverständlich ohne dass Nelson selbst davon erfuhr, die so genannte geheime Postsperre gegen ihn verhängt. ${ }^{914}$ Dies war die letzte Stufe der Beschattungstechniken und bedeutete nichts Anderes, als dass der Betroffene keinen Brief, kein Telegramm und kein Paket mehr erhielt, das nicht zuvor geöffnet worden war.

Die Postkontrolle muss heimlich und so schnell wie möglich ausgeübt werden, damit der Kontrollierte keinen Argwohn schöpft. Briefe sind mittels heisser Wasserdämpfe zu öffnen und nach Entnabme einer Abschrift sofort wieder zu verschliessen. Von Telegrammen ist ebenfalls schleunigst Abschrift zu nehmen. Falls allerdings der begründete Verdacht einer Geheim- oder Chiffreschrift aufkommt, so sind die Briefe und Telegramme in Urschrift [also im Original] hierher zu übersenden. ${ }^{915}$

Dabei wurde im Zweifelsfall meist gegen den Verdächtigen entschieden. Bereits ein Jahr zuvor hatte die Postüberwachungsstelle Hamburg sich bei der Göttinger Polizeidirektion nach Nelson erkundigt, weil dieser von einem schwedischen Kollegen 290,70 Mark geschickt bekommen hatte. ${ }^{916}$ Die Göttinger Polizei ermittelte, dass es sich dabei um ein Honorar für einen Aufsatz handelte, der in einer schwedischen Zeitschrift abgedruckt worden war. ${ }^{917}$ Man behielt das Geld kurzerhand ein, da man offensichtlich das schwedische Anschreiben nicht verstand.

\footnotetext{
914 St.A.Gö.Pol.Dir.159,3 Bl. 324.

915 St.A.Gö.Pol.Dir.159,3 Bl. 324.

916 St.A.Gö.Pol.Dir.159,3 Bl. 35.

917 St.A.Gö.Pol.Dir.159,3 Bl. 36.
} 


\section{Spenden sammeln und Streife gehen}

Leonard Nelson und Kurt Grelling traten also nur passiv und unfreiwillig außerhalb der Universität in Erscheinung. Was aber taten die Göttinger Naturwissenschaftler während des Krieges? Man kann sich nur schwer vorstellen, dass sie völlig untätig blieben, denn neben rein politischen Auftritten, deren man sich enthielt, gab es ja noch andere denkbare Betätigungsfelder. Als Erstes wären hier selbstverständlich im weitesten Sinne wohltätige Zwecke zu nennen, die allerdings in dieser Zeit auch immer mehr oder weniger direkt mit dem Krieg in Verbindung standen. Sammlungen wurden fast immer zugunsten von Soldaten, Verwundeten oder Hinterbliebenen durchgeführt.

Zunächst wäre zu vermuten, dass die naturwissenschaftlichen Professoren ihren Namen und ihre Autorität verstärkt in Form von Aufrufen oder Aushängen zur Beteiligung an Hilfsaktionen oder Ähnlichem genutzt hätten. Jedoch ist hier der Befund weitgehend negativ. ${ }^{918}$ Lediglich die Agrarwissenschaftler Konrad von Seelhorst und Gustav Frölich initiierten schon am 1. August 1914 einen Aufruf, der in der Universität ausgehängt wurde und die Studenten, die sich nicht im Kriegsdienst befanden, zur freiwilligen Hilfstätigkeit in der Ernte aufforderte. Darin hieß es unter der Anrede „Kommilitonen!“‘:

Glücklich zu preisen sind diejenigen von Euch, welche mit den Waffen in der Hand ins Feld ziehen können, um für unsere heiligsten Güter zu kämpfen. Sie werden von allen denen, die das Herz auf dem rechten Fleck haben, welche aber zurückbleiben müssen, weil sie militär-untanglich und den Strapazen eines Feldzuges nicht gewachsen sind, beneidet werden.

Aber auch diese können dem Vaterlande große Dienste leisten. Soweit sie sich nicht in der Verwundeten- und Krankenpflege betätigen, werden sie dadurch von großem Nutzen sein können, daß sie sich der Landwirtschaft zur Verfügung stellen, die eines Teils ibrer Hilfs- und Arbeitskräfte durch die Mobilmachung beraubt wird.

Es gilt die diesjährige Ernte schleunigst zu bergen und die neue Ernte durch rechtzeitige Aussaat vorzubereiten, damit die Ernährung des deutschen Volkes während des Krieges gesichert ist. Eine Lebensmittelzufubr vom Ausland ist absolut unmöglich. 919

Im Lesezimmer des landwirtschaftlichen Instituts war von den Professoren zu diesem Zweck eine „Vermittlungsstelle ${ }^{(6920}$ eingerichtet worden. Offensichtlich

\footnotetext{
918 In diesem konkreten Fall ist davon auszugehen, dass es tatsächlich nicht mehr Aufrufe oder Aushänge gegeben hat, da die Akten UAG.Sek.38.1, 2 und 3 hier ein recht vollständiges Bild geben. Sie wurden von dem Universitätssekretär Gassmann eigens zu dem Zweck einer möglichst vollständigen Überlieferung angelegt. (Siehe oben.)

919 UAG.Sek.38.1 1.8.1914.

920 UAG.Sek.38.1 1.8.1914.
} 
waren sie nicht die Einzigen, die an eine solche Initiative dachten, mit Sicherheit gehörten sie jedoch in deren Umsetzung zu den Schnellsten. Erst einen Tag nach dem Göttinger Aushang, am 2. August, verfasste das Kultusministerium ein Schreiben, in dem es dazu aufforderte, „die auf Heranziehung der nicht militärpflichtigen Studierenden zur Bergung der Ernte gerichteten Bestrebungen, [...] mit allen Kräften zu unterstützen“.921 Nochmals drei Tage später, am 5. August, ging beim Prorektor der Göttinger Universität ein Rundschreiben des Professors Philipp aus Greifswald ein, in dem angekündigt wurde, dass ein Vermittlungsamt zu diesem Zweck dort eingerichtet werden sollte.922 Die Planungen dieser Stelle scheinen jedoch wenig durchdacht gewesen zu sein und wären auch mit Sicherheit nicht in der Lage gewesen, schnell Erfolge zu erzielen. Es handelte sich bei dem Schreiben zunächst nur um eine Anfrage, wie viele Vordrucke zur Registrierung der Freiwilligen für Göttingen benötigt wurden. Diese sollten dann vom Prorektor in Göttingen an alle Studenten adressiert werden, da noch nicht abzusehen gewesen wäre, wer tatsächlich im Kriegsdienst stand und wer nicht. In der Göttinger Antwort wurde dann auch dieses Ansinnen als wenig zweckmäßig bezeichnet, jedoch nicht ohne eine generelle Unterstützung zuzusagen. Man verwies Professor Philipp kurzerhand an die von von Seelhorst und Frölich eingerichtete Vermittlungsstelle.

Des Weiteren gehörte das Sammeln von Geldspenden zu den Aktivitäten der Göttinger Professoren. ${ }^{923}$ So ging etwa am 21. Oktober 1914 eine Einladung zur Teilnahme an einer Versammlung des Kriegsausschusses für warme Unterkleidung des Reichstages in Berlin beim Prorektor Carl Runge ein. Ziel dieses Ausschusses war es, den „den Unbilden der kalten Witterung ausgesetzten Truppen in Feindesland“924 ausreichend warme Unterbekleidung zur Verfügung zu stellen. Ob Abgesandte der Göttinger Universität an der in Berlin stattfindenden Versammlung teilgenommen haben, geht aus diesem Vorgang zwar nicht hervor, zumindest aber war die Spendenbereitschaft aus dem Kollegium beachtlich. Runge organisierte eine Sammlung, indem er Vordrucke von Spendenerklärungen an die Professoren verschickte und setzte ein Ziel von 10000 Mark. In einem Konzept für ein Rundschreiben, dem diese Erklärungen beilagen, schrieb er:

921 UAG.Sek.38.1 2.8.1914.

922 UAG.Sek.38.1 5.8.1914.

923 Das Sammeln von kriegswichtigen Rohstoffen wie etwa Metallen, Wolle in jeglicher Verarbeitungsform oder Chemikalien war staatlich organisiert. Für jegliche Institutionen oder Betriebe also auch die Universitätsinstitute - waren Höchstmengen festgeschrieben, die nicht abgegeben werden mussten, und Nichtbeteiligung an diesen Sammelaktionen war unter schwere Strafen gestellt. Daher soll auf diesen Themenbereich hier nicht weiter eingegangen werden. Einen guten Überblick über die verschiedenen Materialien, die abgegeben werden mussten, bietet die Akte UAG.Sek.38.4, in der sämtliche Bekanntmachungen des dafür zuständigen Generalkommandos enthalten sind. Die Vorgänge der Abgaben befinden sich in der Akte UAG.Kur.3441-3448. 
Nach Rücksprache mit einer Anzabl Kollegen glaube ich, dass es möglich sein wird einen Betrag von ca. 10000M aufzubringen, was etwa der Lieferungseinheit [an warmer Unterbekleidung f für ein Infanterie-Regiment entspricht.

Um keinerlei Druck ausquüben, haben wir von einer öffentlich herumgehenden Liste abgesehen und bitten den bewilligten Betrag auf dem angeschlossenen Blatte einzeichnen und dieses bis zum 10. November an den Unterzeichneten einsenden zu wollen. ${ }^{925}$

Dieses Vorgehen hatte Erfolg, und bereits am 5. November vermerkte der Prorektor auf dem ersten Schreiben des Kriegsausschusses: „Von 62 Dozenten sind gezeichnet 6853 M. “926 Endgültig kamen laut einer in diesem Vorgang enthaltenen namentlichen Liste 9953 Mark an Spenden zusammen. Carl Runge hatte also sein Ziel erreicht. ${ }^{927}$

Auch der Agrarwissenschaftler Professor Konrad von Seelhorst sammelte Spenden. Er war Kassenwart ${ }^{928}$ des so genannten Ortsausschusses für die U-BootSpende. Für diese beantragte er etwa am 8. Mai 1917 beim Magistrat der Stadt Göttingen die polizeiliche Erlaubnis, ,in den Häusern, auf den Straßen und an öffentlichen Plätzen durch von uns [dem Ortsausschuss der U-Boot-Spende] legitimierte Personen Geldsammlungen vornehmen lassen zu dürfen. "929 Selbstverständlich wurde ihm umgehend die entsprechende Erlaubnis erteilt.

Dass Dozenten auch nicht organisiert und rein privat für verschiedene Institutionen spendeten, ist anzunehmen, lässt sich jedoch nur in wenigen Fällen nachweisen, und zwar dann, wenn sie solche Spenden direkt von ihren Einkünften abziehen ließen. ${ }^{930}$ Dies war erneut bei Konrad von Seelhorst in beeindruckendem Maße der Fall, der sich schon mehrfach durch sein Engagement hervorgetan hatte. Er schrieb am 24. August 1914 an den Universitätskurator: „Euer Hochwohlgeboren theile ich ergebenst mit, daß ich für die Kriegszeit vom 1. October ab auf 1/3 meines Gehalts zugunsten der Staatskasse verzichte." "931 Zeitgleich verzichtete auch der Astronom Professor Johannes Hartmann auf 10\% seiner Bezüge, was der Kurator am 26. August dem Kultusministerium mitteilte. ${ }^{932}$ Diese Art der Spende schien indes auch für das Ministerium nicht alltäglich gewesen zu sein, so dass man am 24. August mit dem Kurator eine Vorgehensweise zur

925 UAG.Sek.38.1 23.10.1914. (Endgültiges Rundschreiben: UAG.Sek.38.1 29.10.1914. Am gleichen Tag wurde dieses Schreiben durch den Verwaltungsausschuss der Universität genehmigt.)

926 UAG.Sek.38.1 17.10.1914.

927 UAG.Sek.38.1 [ohne Datum; Wahrscheinlich Anfang November 1914]. Die erste Überweisung erfolgte am 13. November. Ein verspätet eingegangener Teil von 265 Mark wurde am 3. Dezember überwiesen.

928 Dies geht aus einem Schreiben bezüglich einer Konzertveranstaltung hervor. St.A.Gö.Pol.Dir.164,20 Bl. 83.

929 St.A.Gö.Pol.Dir.164,20 Bl. 76-77.

930 Ähnliches berichtet Liermann für Erlangen: Liermann: Die Friedrich-Alexander-Universität. 1977. S. 42.

931 UAG.Kur.4095 Bl. 1.

932 UAG.Kur.4095 Bl. 2. 
Einbehaltung der gespendeten Gehaltsteile absprach und diesen bat, den beiden Professoren Dank zu sagen. Außerdem war noch zu klären, wofür das Geld, das ja ohne Zweckbindung, lediglich ,zugunsten der Staatskasse“, zur Verfügung gestellt worden war, verwendet werden sollte.

Ich nehme an, daß die Genannten [von Seelhorst und Hartmann] damit einverstanden sind, daß die zur Verfügung gestellten Gehaltsteile für vaterländische Zwecke, etwa für das Rote Kreuz oder zu Unterstützung unserer ostpreußischen Landsleute oder der Familien von Kriegshinterbliebenen etc. Verwendung finden. ${ }^{933}$

Von Seelhorst antwortete hierauf, daß er „,selbstverständlich die Verfügung über die betr. Gehaltstheile ganz und gar dem Herrn Minister überlasse“.934 Auch Hartmann äußerte sich dahingehend. ${ }^{935}$ Ein weiteres Indiz dafür, dass es keine sehr große Zahl ähnlicher Vorgänge ${ }^{936}$ in Deutschland gegeben haben kann ist, dass das Kultusministerium monatlich Bericht über die Verwendung der Mittel an den Kurator erstattete, den dieser an die Professoren weitergab. Gängige Empfänger waren etwa das Rote Kreuz, das Kapital zur Unterstützung erblindeter Krieger oder die Ostpreußische Jugendhilfe. Als erster Dozent trat Johannes Hartmann bereits im März 1915 von seiner Zusage zurück und begründete dies mit einem „unerwartet eingetretenen Vermögensverlust". .937 Wieder war es von Seelhorst, der als Einziger sogar über das Kriegsende hinaus auf monatlich 600 Mark verzichtete. Im Februar 1919 ging von dem mittlerweile in Ministerium für Wissenschaft, Kunst und Volksbildung umbenannten Kultusministerium die letzte Nachricht über die Verwendung der Spenden ein. ${ }^{938}$

Die Möglichkeiten, sich wirklich handfest $\mathrm{zu}$ engagieren, waren für einen $\mathrm{Na}$ turwissenschaftler meist höheren Alters naturgemäß recht begrenzt. Hierzu bedurfte es schon des Enthusiasmus eines Hermann Theodor Simon, von dem man bereits in dem zuvor geschilderten Berufungsvorgang einen Eindruck bekommen konnte. Wie bereits im ersten Kapitel dieser Arbeit dargestellt wurde, bildeten sich im Zuge der allgemeinen Spionage- und Sabotageangst schnell Bürgerwehren, die als bewaffnete Trupps zunächst recht unorganisiert an Bahnstrecken patrouillierten oder Brücken bewachten. Auch Professor Simon schulterte im August 1914

933 UAG.Kur.4095 Bl. 5.

934 UAG.Kur.4095 B1. 8.

935 UAG.Kur.4095 Bl. 9.

936 Zumindest in Göttingen spendeten recht sporadisch auch der Jurist Prof. Dr. Karl Lehmann und der Historiker Prof. Dr. Paul Darmstädter. Der Theologe Prof. Dr. Nathanael Bonwetsch spendete „so lange der Krieg andauert“ vierteljährlich 150 Mark. Zum Beispiel: UAG.Kur.4095 Bl. 7 (Darmstädter), Bl. 8 (Lehmann) und Bl. 21 (Bonwetsch).

938 UAG.Kur.4095 Bl. 98. 
nach seiner Arbeit in der Universität noch das Gewehr und tat Dienst als Führer des Postens IX, städtisches Elektrizitätswerk. ${ }^{939}$

Auch der Astronom Professor Leopold Ambronn arbeitete für den so genannten Sicherheitsdienst, der sich spontan gebildet hatte. ${ }^{940}$ Seine Beteiligung wurde aktenkundig, als sich im September Polizei und Militärbehörden bemühten, die für sie weitgehend unkontrollierbaren Zustände zu ordnen. Am 11. September legte Generalmajor Freiherr von Toll die Leitung des Sicherheitsdienstes nieder, nachdem das örtliche Ersatz-Bataillon 82 den Schutz der Bahnstrecken selbst übernommen hatte. ${ }^{941}$ Posten standen zu dieser Zeit noch am Pulverturm, den Wasserspeichern und in der Gewerbeschule, in der die Angehörigen feindlicher Nationen inhaftiert waren. Ambronn scheint innerhalb des Sicherheitsdienstes für die Verteilung der Waffen zuständig gewesen zu sein. Zumindest wurde er von von Toll der Polizeidirektion als zuständiger Ansprechpartner empfohlen.

In der Gewerbeschule befänden sich noch sehr viele Waffen, die zweckmäßig im Rathaus aufbewabrt würden. Herr Prof. Ambronn würde helfen können, bei der Rückgabe der $W$ affen an die Besitzer. $\mathrm{Ob}$ alle W affen abgeliefert seien, könne er nicht sagen; es sei sehr wohl möglich, dass in den Händen Einzelner beim Sicherheitsdienst beschäftigten Personen noch $W$ affen wären. ${ }^{942}$

Unter solchen Verhältnissen konnte es die „entschieden unpolitische Haltung“ der Naturwissenschaftler nicht geben, von der Burchardt spricht. Zwar fällt es nicht leicht, die Frage Engagement oder Rück.zug? eindeutig zu beantworten, aber es kann doch gezeigt werden, dass der naturwissenschaftliche Dozent an einer Universität wie Göttingen in so vielen Bereichen direkt mit dem Weltkrieg konfrontiert wurde, dass sogar wenn er es versucht hätte, ein wirklicher Rückzug niemals hätte gelingen können. Innerhalb und außerhalb der Universität geriet man immer wieder in Kontakt mit dem Krieg. Unter solchen Umständen ist es schlicht undenkbar, dass man „fern vom öffentlichen Getriebe in wissenschaftlichzweckfreier Askese“943 tatsächlich hätte leben können. Vielmehr musste man sich positionieren und Stellung beziehen - dies taten auch die Naturwissenschaftler, und sie entschieden sich bewusst für die Zurückhaltung.

939 St.A.Gö.Pol.Dir.164,5 Bl. 9. Auch Heidelberger Ordinarien taten Dienst in Bürgerwehren. Reichert spricht in diesem Kontext von einem hohen $\mathrm{Maß}$ an Idealismus, der allerdings mit einem ebenso so hohen Maß an Diletantismus einhergegangen sei. Reichert: Wissenschaft. 2001. S. 498,500 .

940 Der spontane und wenig organisierte Charakter von Einrichtungen wie dem Sicherheitsdienst oder der Bürgerwehr bedingt, dass sich in den entsprechenden Akten nur recht lückenhafte Nachweise finden lassen.

941 St.A.Gö.Pol.Dir.164,1 Bl. 131.

942 Niederschrift eines Gesprächs durch die Polizeidirektion. St.A.Gö.Pol.Dir.164,1 Bl. 131.

943 Burchardt: Naturwissenschaftliche Universitätslehrer. 1988. S. 213. 
Daraus zu schließen, dass man sich, ,in politics nicht für sachkundig erachte[te]“, 944 greift jedoch zu kurz; man tut den Naturwissenschaftlern sicherlich Unrecht, wenn man ihr Schweigen als Befürchtungen abtut, vielleicht etwas Falsches zu sagen. Dieses Schweigen war ein bewusstes und klares Bekenntnis zu den bestehenden Verhältnissen. Burchardt stellt zu recht fest, dass man „keinen Anlass sah, an den bestehenden Verhältnissen zu rütteln“.945 Durch die selbst auferlegte Zurückhaltung rüttelte man aber nicht nur nicht an ihnen, sondern man stützte sie aktiv, indem man genau das tat, was erwartet wurde, was man als seine Pflicht ansah: Man funktionierte widerspruchslos. Die Tatsache, dass von naturwissenschaftlichen Hochschullehrern kaum greifbare Stellungnahmen aus der Zeit des Ersten Weltkrieges vorliegen, war eine Stellungnahme an sich. Diese wurde bislang jedoch entweder falsch gedeutet oder gar nicht wahrgenommen.

Es gab selbstverständlich verschiedene Meinungen und Strömungen im Kollegium, aber man tat alles, um keine Nachrichten von internem Streit oder sogar offener Regierungskritik nach außen dringen zu lassen. Man arbeitete hart daran, das Bild einer funktionierenden Universität zu wahren und unter allen Umständen zu verhindern, dass in der Öffentlichkeit der Eindruck entstand, die Universität äußere sich politisch und kritisch, in welche Richtung auch immer. So gesehen kann man die Frage Engagement oder Rückzug? mit den Worten Rückzug als Engagement beantworten. Man wählte die bedingungslose Zurückhaltung nicht, weil man sich kein anderes Verhalten zutraute, sondern weil man die kritiklose Arbeit auf dem Gebiet, das man am Besten beherrschte, für seine Pflicht gegenüber Staat und Regierung hielt.

Die ganze zivilisierte Welt erbebt in ibren Fugen, und auch heute weiss noch kein Mensch, wie das fürchterliche Morden endigen wird. Inmitten dieses gewaltigen Dramas fühlt sich der Einzelne so klein und unwesentlich, dass es auch mir etwas Mühe kostet, hier hauptsächlich von mir selber zu berichten; aber andererseits scheint mir auch gerade wieder dies das erste, höchste Gebot des Tages zu sein, dass ein Jeder mag er nun sich wichtig vorkommen oder nicht, statt zu grübeln oder blind um sich zu schlagen, seine Pflichten erkennt und im Grossen und Kleinen danach handelt. ${ }^{946}$

Ja Max, Du hast recht, es bleibt uns nichts übrig, als die grausame Zeit zu ertragen und im Übrigen unsre Pflichten zu erfüllen. ${ }^{947}$

944 Burchardt: Naturwissenschaftliche Universitätslehrer. 1988. S. 213.

945 Burchardt: Naturwissenschaftliche Universitätslehrer. 1988. S. 213.

946 Max Planck in seinem Beitrag zum Brieftagebuch vom 13. März 1917. Hentschel, Tobies:

Brieftagebuch. 1999. S. 189.

947 Carl Runge an Max Planck gerichtet am 21. März 1918. Hentschel, Tobies: Brieftagebuch. 1999. S. 191 . 


\section{Schlussbetrachtung}

Als im August 1914 der Erste Weltkrieg ausbrach, verhielten sich die Mitglieder der Georg-August-Universität so, wie man dies von ihnen erwartet hatte. Es wurden Reden gehalten und die Studenten meldeten sich in ihrer Mehrzahl freiwillig zum Kriegsdienst, auch wenn es die allgemeine und vollständige Kriegseuphorie auch innerhalb der Universität nicht gegeben hat. Die Verwaltung rief zur Sparsamkeit auf und die Dozenten unterstützten all dies wo sie konnten, sammelten Spenden oder organisierten Ernteeinsätze für noch nicht eingezogene Studierende. Damit nahmen alle drei Bestandteile der Korporation Universität am Krieg teil und erfuhren jeder auf seine Weise das August-Erlebnis. Nichts Anderes hätten die Zeitgenossen erwartet, und auch aus heutiger Perspektive besteht kein Anlass, daran zu zweifeln. Ziel dieser Arbeit war es weniger, diese Ereignisse zu dokumentieren, als vielmehr zu untersuchen, welche Auswirkungen der Erste Weltkrieg auf die Institution Universität hatte, also auf das Gebilde, das Studierende, Verwaltung und Dozenten gemeinsam konstituierten.

Die direkteste Auswirkung des Krieges auf die Universität wird anhand der Studierendenzahlen sichtbar. Ihr Einbruch war enorm. Verglichen mit dem letzten Vorkriegssemester fehlten sofort ab Kriegsbeginn 66\%, also zwei Drittel der Studierenden, im Wintersemester 1917/18 sogar fast 71\%. Man vermag sich kaum vorzustellen, wie stark dies das gesamte Leben an der Universität beeinflusste. Ihr Gesicht hatte sich innerhalb weniger Tage vollständig gewandelt. Die jungen Männer, unter ihnen auch die zahlreichen Verbindungsstudenten, die zuvor 
immer das Bild der Universität geprägt hatten, fehlten nun; ebenso ihre ausländischen Kommilitonen. Frauen und nicht wehrfähige Männer saßen jetzt in fast leeren Hörsälen. Unter sie mischten sich bald zahlreiche verwundete Soldaten und auch immer mehr dauerhaft Kriegsbeschädigte.

Als der Krieg nicht das allgemein erwartete schnelle Ende fand, wurden über Jahre hinweg kaum noch reguläre Studienabschlüsse erworben. Infolgedessen staute sich eine immer größere Zahl inaktiver Studierender an. Als die Soldaten schließlich an die Universität zurückkehrten, stellte ihre Rückkehr eine noch größere Herausforderung dar, als vorher ihr Ausbleiben: Mit Ende des Krieges versechsfachte sich innerhalb nur weniger Semester die Zahl der in Göttingen anwesenden Studierenden.

So schwerwiegend diese enormen Schwankungen auch waren, so wenig können sie doch über die Realität des Krieges innerhalb der Institution Universität aussagen. Als die Soldaten und Kriegsfreiwilligen die Stadt verlassen hatten, ergab sich für ihre noch in Göttingen verbliebenen Kommilitonen die große Schwierigkeit, ihre Anwesenheit hier rechtfertigen zu müssen. Ein junger Mann in der Provinz, weit von den Fronten des Krieges entfernt und noch dazu ohne Uniform, stellte automatisch etwas Unnormales dar. Dies galt besonders in einer Epoche, in der auch zu Friedenszeiten Männlichkeit und Militär einen enormen Stellenwert besaßen. Gerade unter den Verbindungsstudenten waren dies die alles dominierenden Faktoren. Die Ursachen dafür, dass ein junger Mann nicht eingezogen wurde, konnten vielfältig sein; die Möglichkeiten, diesen Makel auf anderen Gebieten zu kompensieren, waren es nicht. Eine willkommene Gelegenheit bot hierfür die schnell um sich greifende und staatlich geförderte Furcht vor Spionen und Saboteuren. Im Rahmen eines aus heutiger Perspektive teilweise grotesk anmutenden Aktionismus vereinigten sich der dringende Wunsch der Daheimgebliebenen, etwas tun zu können mit einer seit langem bestehenden massiven Ausländerfeindlichkeit. Auch Studierende waren hieran beteiligt. Sie konnten nun ungestraft gegen ihre ausländischen Kommilitonen vorgehen, deren Gesellschaft ihnen nicht willkommen war.

Hiervon waren vor allem russische Staatsangehörige betroffen. Als die offene Jagd auf Spione und Saboteure beendet war, gelang es Teilen der Studentenschaft, den Krieg dafür zu nutzen, ihren Kampf gegen die Ausländerei auch in die Universität hineinzutragen. Der eigentliche Auslöser war dabei nebensächlich; man wollte keine Einzelfälle diskutieren. Vielmehr wollte die Vertretung der Göttinger Studentenschaft das durch den Krieg veränderte Klima nutzen, um grundsätzlich mit etwas aufzuräumen, das in ihren Augen ein schwerer Missstand war. Allerdings wurden ihre Hoffnungen enttäuscht, und sie mussten erkennen, dass sich bei ihren Professoren und den entscheidenden Instanzen der Universität das Klima nicht verändert hatte; hier stand man dem Studium von Ausländern nach wie vor positiv gegenüber und ließ diese auch weiterhin an Vorlesungen teilnehmen. Man nahm sogar einem Inhaftierten eine mündliche Prüfung ab. Auch bei 
der Mehrheit der Studierenden war der Rückhalt für die radikalen Forderungen der verbindungsstudentisch dominierten Vertretung der Studentenschaft offensichtlich nicht so groß, wie diese Glauben machen wollte.

Als die Vertretung der Studentenschaft dies erkannte, wandte sie sich an die Presse. Diese nahm das Thema zwar wenig sachlich, aber sehr bereitwillig auf und brachte damit die Universität in eine schwere Verlegenheit. Die sich im Folgenden entspinnende Zeitungsaffäre verzerrte das Bild der Universität in der Öffentlichkeit. Die Versuche sachlicher Gegendarstellungen blieben weitgehend wirkungslos.

In Anbetracht der Tatsache, dass sowohl die männliche als auch die ausländische Konkurrenz weitgehend ausfiel, lag die Vermutung nahe, dass die Studentinnen, entsprechend ihres gestiegenen relativen Anteils an den Studierenden, durch den Krieg profitieren konnten. Auch die Zeitgenossen sahen dies so, aber die Universität bemühte sich, diesen Eindruck nicht entstehen zu lassen. Anhand der Vergabe von Assistentenstellen wurde deutlich, dass Frauen nur so weit in vormals ausschließlich Männern vorbehaltene Bereiche eindringen konnten, wie die Besitzstände von Kriegsteilnehmern gewahrt blieben. Studentinnen wurden meist nur als Ersatz angestellt. Die Universität vermied es vollständig, den Eindruck zu erwecken, dass ein Soldat in seiner Abwesenheit aus seiner angestammten Position verdrängt wurde. Ganz ohne Wirkung auf die Stellung der Studentinnen innerhalb der Universität blieb der Krieg jedoch nicht: Frauen promovierten nun häufiger und erlangten erste, wenn auch vertretungsweise Anstellungen als Assistentinnen. Auch wenn sie durch die Rückkehr ihrer Kommilitonen aus dem Kriegsdienst zunächst wieder zurückgedrängt wurden, waren doch erste Schritte in Richtung einer Gleichstellung der Geschlechter unternommen worden, die nicht wieder rückgängig gemacht werden konnten.

Das Vorlesungsangebot für die in Göttingen verbliebenen Studierenden stand dem zu Friedenszeiten zumindest quantitativ kaum nach. Es fielen meist nur Veranstaltungen der jüngeren Privatdozenten aus. Diese Ausfälle waren angesichts der geringen Studierendenzahlen zu verschmerzen. Auch inhaltlich änderte sich durch den Krieg wenig an den angebotenen Themen. Kriegsrelevante oder rüstungstechnische Themen gab es im Lehrplan der Universität nicht. Dies wurde durch eine aktive Zensur der Militärbehörden gewährleistet.

Eine andere Art von Veranstaltungen forderte die Dozenten der Göttinger Universität allerdings mehr: Schnell hatte man erkannt, dass die herkömmlichen Vorlesungen den Bedürfnissen derer, die aus dem Krieg zurückkehrten, nicht gerecht werden konnten. Mangelnde Vorbildung der Notabiturienten, lange Studienpausen der Studenten und nicht zuletzt das an der Front Erlebte machten es dringend notwendig, sie erst wieder an wissenschaftliches Denken und Arbeiten heranzuführen. Dies musste noch dazu in einem recht engen Zeitrahmen geschehen, denn die enormen Studierendenzahlen belasteten die Universität so stark, dass schnell wieder Abschlüsse gemacht werden mussten. Deutschlandweit war die Universität Göttingen führend bei der Einrichtung von Ergänzungskursen für 
Kriegsteilnehmer. Das Kultusministerium schaltete sich erst deutlich später in die Diskussion ein und verordnete mehrere Zwischensemester. Interessant bei allen Hilfsangeboten ist außerdem, dass die Betroffenen selbst, nämlich die studentischen Kriegsteilnehmer, zwar durchaus eigene und konkrete Vorstellungen in diesen Fragen hatten, aber niemand den Dialog mit ihnen suchte.

Kontakte zu den Studenten im Feld bestanden auf anderen Ebenen. Für die Studierenden im Kriegsdienst blieb ihr studentisches Leben weiterhin als Bezugssystem bestehen. Die Zugehörigkeit zu einer studentischen Verbindung blieb stets von großer Bedeutung, und die Infrastruktur der Verbindungszeitungen ermöglichte es, den Kontakt zu anderen Studierenden zu wahren und sogar Treffen an der Front zu organisieren. Die Universität musste solche Strukturen erst aufbauen, um ihre Angehörigen an der Front zu erreichen, bemühte sich dann aber, durch den jährlichen Versand der so genannten Weihnachtsgaben, den Kontakt zu wahren und Verbundenheit zu demonstrieren, auch wenn man sich bewusst war, dass man nicht wirklich helfen konnte. Man bemühte sich zu zeigen, dass die Universität den Studenten im Kriegsdienst auch weiterhin als Angehörigen der Universität betrachtete. Engere Kontakte zwischen einzelnen Professoren und ihren Schülern blieben allerdings die Ausnahme.

In der Universität selbst kam während des Krieges vieles zum Erliegen. Unbedingte Sparsamkeit war das oberste Gebot, und beinahe alle Institutsdirektoren akzeptierten die massiven finanziellen Einschnitte als selbstverständlich. Mit den regulären Etats konnten sie vor Kriegsbeginn gerade den alltäglichen Unterhalt ihrer Institute bestreiten. Alles, was hierüber hinausging, musste gesondert beantragt werden. Auf diese Weise konnte bis zum Sommer des Jahres 1914 ein konstanter Ausbau der Institute betrieben werden. Je nach Fach waren dafür mehr oder weniger hohe Sonderzahlungen erforderlich. Mit Kriegsbeginn wurde dieser Mechanismus jäh unterbrochen. Die Universität signalisierte ihren Professoren frühzeitig, dass sie sich einzuschränken hatten und diese stellten keine Anträge mehr. Daher musste das Kuratorium auch nur sehr wenige Anträge ablehnen. Besonders in den schnell voranschreitenden Fächern der Naturwissenschaften musste dies jedoch de facto einen Rückschritt bedeuten. Jeglicher Fortschritt oder Ausbau der Institute kam während des Krieges vollständig zum Erliegen. Die Direktoren verstanden diese Einsparungen jedoch auch als ihren Beitrag zum Krieg.

Auch die Inanspruchnahme von Drittmitteln nichtstaatlicher Einrichtungen war nicht mehr möglich. Dies jedoch nicht etwa, weil sich diese kriegsbedingt zurückgezogen hätten, sondern weil das Kultusministerium während des Krieges als Geldgeber vollständig ausfiel. Großprojekte, wie der Neubau des mathematischen Instituts oder der Erwerb eines landwirtschaftlichen Versuchsgutes, ruhten für die Dauer des Krieges, da von ministerieller Seite aus nicht mehr die geringsten vertraglichen Zusagen gemacht werden konnten. Dass solche Großprojekte trotzdem nicht endgültig scheiterten, ist nur der Beharrlichkeit, dem Organisati- 
onstalent und der Entschlossenheit von Persönlichkeiten wie Felix Klein zu verdanken.

Ein ähnliches Schicksal drohte auch den ehrgeizigen Plänen Ludwig Prandtls und wiederum Felix Kleins zur Errichtung eines modernen aerodynamischen Forschungsinstituts. Allerdings unterschieden sich Prandtls Forschungen in einem sehr wesentlichen Punkt von der Arbeit eines landwirtschaftlichen Versuchsguts: Sie waren für Militärbehörden und Rüstungsindustrie von größtem Interesse. Es wurde deutlich, mit wie viel Geschick und Engagement die Protagonisten Prandtl, Klein, von Böttinger und die Göttinger Vereinigung es seit der Berufung Prandtls nach Göttingen immer wieder schafften, Schritt für Schritt eine innovative Forschungseinrichtung aufzubauen. Trotzdem kam das Projekt mit Ausbruch des Krieges zunächst zum Erliegen. Erst an diesem Punkt begann sich die Geschichte der Modellversuchsanstalt von der vergleichbarer Projekte, wie dem Neubau des mathematischen Instituts, zu unterscheiden. Die Wissenschaftler entschlossen sich, die Militärs für ihre Arbeit zu interessieren.

Diese Idee war als solche nicht neu, und auch andere Wissenschaftler boten sich an, ihre Arbeiten dem Militär zur Verfügung zu stellen. Im Falle Ludwig Prandtls trafen jedoch verschiedene Faktoren zusammen, die bewirkten, dass in diesem konkreten Fall die Militärbehörden das Angebot annahmen: Die noch sehr junge Luftfahrt benötigte dringend fundierte wissenschaftliche Grundlagen, um sie als effiziente Waffe nutzbar machen zu können. Außerdem handelte es sich bei Prandtls Modellversuchsanstalt nicht um ein herkömmliches Universitätsinstitut. So war es für die Militärbehörden möglich, Geheimhaltung und Kontrolle zu gewährleisten. Die finanziellen Mittel, die dann nach Göttingen flossen, stellten alles Vergleichbare aus Kriegs- und auch Friedenszeiten in den Schatten. Aber nicht nur auf finanziellem Gebiet ragt die Modellversuchsanstalt im Vergleich zur Universität heraus. Gerade hinsichtlich des Personals könnte der Kontrast zwischen Prandtls Möglichkeiten und den Beschränkungen für die Universitätsinstitute nicht größer sein. In gewisser Weise profitierte Prandtl sogar von der Not seiner Kollegen: Diese mussten hoch qualifizierte junge Wissenschaftler aufgrund ihrer Militärpflicht ziehen lassen, die Prandtl dann für sich reklamierte. In der Modellversuchsanstalt konnte Militärdienst und Kriegshilfsdienst geleistet werden. Prandtls eigene Arbeiten traten während des Krieges weitgehend in den Hintergrund, da sein neues Institut vollständig durch Rüstungsaufträge ausgelastet war. Dies stellte für Prandtl aber kein Problem dar. Er leistete entsprechend seiner Qualifikation bereitwillig Kriegsdienst und wurde dafür mit der Erfüllung seines großen Traums - einer hochmodernen Forschungseinrichtung - entlohnt.

Die Bereitschaft, auf wissenschaftlichem Gebiet die eigene Arbeit in den Dienst von Staat und Krieg zu stellen, war durchaus nicht ungewöhnlich, sie stellte vielmehr den Normalfall dar. Allerdings wurde diese Bereitschaft von staatlicher Seite fast nicht angenommen. Für die naturwissenschaftlichen Fächer an der Göttinger Universität existieren lediglich im agrikulturchemischen Institut 
Beweise für kriegsrelevante Arbeiten. Hier wurden in begrenztem Umfang Versuche mit Düngemitteln vorgenommen. Generell ist festzustellen, dass es innerhalb der Georg-August-Universität keine Rüstungsforschung gegeben hat. Es bestand sogar ein gewisses $\mathrm{Maß}$ an Unmut unter den Dozenten darüber, dass ihnen die Möglichkeit verwehrt wurde, ihr Wissen und ihre Qualifikation einzubringen. Gelegentliche Klagen über den Einsatz von Naturwissenschaftlern im regulären Frontdienst sind als Warnung vor einer Verschwendung von Ressourcen zu verstehen. Ausnahmen, wie die Arbeit an der drahtlosen Telegraphie durch Max Born während seines Militärdienstes, oder Adolf Windaus Kontakte zur chemischen Industrie im Kontext des Kriegshilfsdienstes, bedurften stets starker Eigeninitiative.

Auch wenn der rein quantitative Verlust, den das Göttinger Kollegium zu verkraften hatte, verglichen mit den Verhältnissen bei den Studierenden keine ähnlich großen Ausmaße annahm, zeigte der Krieg doch deutliche Auswirkungen auf das Innere der Gruppe der Professoren: Es gab Streit und Missstimmungen. Von einem entschieden unpolitischen Denken und Handeln oder dem Rückzug in die wissenschaftliche Askese naturwissenschaftlicher Dozenten kann keine Rede sein; die verwendeten Ausdrucksformen waren nur andere, als die der Kollegen anderer Fächer. Ein zuvor alltäglicher Vorgang, wie die Erstellung einer Vorschlagsliste für die Neubesetzung eines Lehrstuhls, konnte nun zu einem Punkt werden, an dem sich Konflikte entzündeten. Wie auch im Falle der mündlichen Prüfung des inhaftierten kanadischen Studenten Bell oder der Teilnahme ausländischer Studierender an einem Vortrag Albert Einsteins, bewies der Vorgang der Benennung eines Nachfolgers für Professor Eduard Riecke, welche Brisanz zur Zeit des Ersten Weltkrieges in der Frage des Umgangs mit Ausländern lag. Die Nennung eines holländischen Wissenschaftlers in einem Berufungsvorgang wurde angesichts dieser Problematik zu einem Stellvertreterkonflikt aufgewertet. Die Offenheit gegenüber ausländischen Wissenschaftlern und Studierenden war einer der wenigen Punkte, die Göttinger Naturwissenschaftler auch während des Krieges offensiv verteidigten, sei es in diesem Berufungsvorgang oder in den Zeitungen.

Differierende Meinungen und auch Meinungsäußerungen stellten kein grundsätzliches Problem innerhalb der Universität dar. Dieses Recht gestanden sich die Dozenten untereinander durchaus zu, sei es im Rahmen des so genannten Krieges der Geister oder im Privaten. Um so empfindlicher reagierte man, wenn im Rahmen solcher Meinungsäußerungen der Eindruck entstand, als würde die Institution Universität als Ganzes politisch Stellung beziehen. Dies war der Fall, als Theodor Simon in seiner Funktion als Rektor für die Erklärung gegen die Reichstagsmebrheit warb und als Leonard Nelson innerhalb einer Veranstaltung auf die Neutralität Belgiens zu sprechen kam. Auch unpopuläre Ansichten, wie der Pazifismus Heinrich Rausch von Traubenbergs, wurden geduldet, solange sie nicht in offizieller Funktion geäußert wurden.

Wie außergewöhnlich diese besondere Art von Toleranz in ihrer Zeit war, hat deutlich ein Blick auf die Stadt Göttingen gezeigt. Innerhalb der Universität gab es 
mit Edward Schröder und Heinrich Alfred Schmid nur wenige Personen, die die genannten Grundsätze nicht akzeptieren konnten. Außerhalb der Universität genügten schon deutlich kleinere Vergehen oder auch nur Gerüchte, um sich dauerhaft der Bespitzelung durch Polizei und Mitbürger auszusetzen. Man kann sich leicht vorstellen, dass es für Leonard Nelson weitreichende Konsequenzen nach sich gezogen hätte, wäre er gegenüber Polizei- oder Militärbehörden mit dem gleichen Ton aufgetreten, den er gegenüber den Fakultätsgremien anschlug. Dies führt zu der Frage, wie das so entstandene Gesamtbild zu bewerten ist. Die Vorgänge um Leonard Nelson, Heinrich Rausch von Traubenberg und Theodor Simon müssen in einem größeren Kontext gesehen werden, nämlich in dem identischen Kontext, in dem auch die Affäre um die Teilnahme feindlicher Ausländer an der Mathematischen Gesellschaft David Hilberts oder das hohe Maß finanzieller Disziplin der Institute stehen. Auf den ersten Blick scheint es so, als habe die Universität weitgehend unberührt durch den Ersten Weltkrieg weiter existiert und weiter funktioniert, wenn auch mit weniger Studierenden und weniger finanziellen Mitteln. Dies entspricht auch genau dem Bild, welches die Universität und ihre Angehörigen bewusst vermitteln wollten. Zumindest für die in dieser Arbeit untersuchten naturwissenschaftlichen Fächer lässt sich jedoch feststellen, dass die Universität tatsächlich durch den Ersten Weltkrieg berührt wurde.

Zur Gewährleistung des Funktionierens der Institution Universität wurde ein großer Aufwand betrieben; der zur Aufrechterhaltung des positiven Bildes der Universität in der Öffentlichkeit betriebene Aufwand stand diesem allerdings in nichts nach. Dies verstand man als Pflicht in der Situation des Krieges. Spätestens seitdem der Konflikt mit der Vertretung der Studentenschaft an die Öffentlichkeit gedrungen war und gezeigt hatte, wie schnell ein Skandal entstehen konnte, versuchte man, neuerliche Zeitungsaffären unbedingt zu vermeiden. Man war zutiefst darauf bedacht, zu verhindern, dass das Bild einer Universität als Unruheherd entstand, in der Feinde Deutschlands studierten und über Themen wie die Verletzung der belgischen Neutralität diskutierten. Es ist unwahrscheinlich, dass sich die philosophische Fakultät Nelsons Provokationen zu Friedenszeiten hätte gefallen lassen. Während des Krieges scheute man aber die Gefahr einer offenen Auseinandersetzung und nahm ihn sogar gegenüber den Militärbehörden in Schutz.

Bedeutet das Auftreten Nelsons und die Denunziation Rausch von Traubenbergs nun aber, dass das Funktionieren der Institution Universität nur eine mühsam aufrechterhaltene Fassade war? Gewiss nicht. Die Korporation Universität blieb intakt und ihre Bestandteile stets miteinander verbunden. Man bemühte sich ehrlich, den im Kriegsdienst befindlichen Studierenden zu zeigen, dass man sie auch weiterhin als Teil der Universität betrachtete und sich ihnen verbunden fühlte. Bereits während des Krieges entwarf und erprobte man Maßnahmen, um sie nach ihrer Rückkehr wieder zu integrieren. Den Betrieb der Institute und Seminare erhielt man unter Schwierigkeiten und Einschränkungen ohne Unterbrechung aufrecht, ohne über die Situation zu klagen. Wirkliche Rüstungsforschung 
gab es innerhalb der Naturwissenschaften an der Universität Göttingen nicht, aber alle Teile der Korporation Universität verrichteten in ihren Augen kriegswichtige Arbeit, indem sie das reibungslose Funktionieren ihrer Institution gewährleisteten.

Die Universität selbst überstand auf diese Weise eine schwere Krisensituation weitgehend unbeschadet. Sie war Teil ihrer Zeit und damit nahm sie auch am Ersten Weltkrieg teil. Die Menschen, die als Studierende, Dozenten oder im Rahmen der Verwaltung Teil der Korporation Universität waren, erfuhren hier ein ganz eigenes Kriegserlebnis, das sie prägte und das sie mit in die kommenden Krisensituationen nahmen. Gerade die, die der Generation angehörten, die den Ersten Weltkrieg als Studierende erlebte, stellten als Hochschulabsolventen eine Elite dar und prägten die Zeit der Weimarer Republik und des Nationalsozialismus mit. 


\section{Literatur und Quellen}

\section{Ungedruckte Quellen}

Universitätsarchiv Göttingen (UAG.)

Bestand Kuratorium (Kur.)

UAG.Kur.0548: Durchführung des Gesetzes zur Wiederherstellung des Berufsbeamtentums.

UAG.Kur.0609: Verleihung des deutschen Nationalpreises anstelle des Nobelpreises.

UAG.Kur.1388: Etat und Mittelbewilligungen für die Sammlung mathematischer Instrumente und Modelle bzw. das Mathematische Institut.

UAG.Kur.1396: Etat und Mittelbewilligungen für das MathematischPhysikalische Seminar.

UAG.Kur.1449: Etat und Mittelbewilligungen für die mathematische Abteilung des Physikalischen Instituts sowie für das 2. Physikalische Institut.

UAG.Kur.1456: Besetzung und Verwaltung der Assistentenstellen der Abteilung für Technische Physik des Physikalischen Instituts bzw. des Instituts für Angewandte Mechanik. 
UAG.Kur.1458: Etat und Mittelbewilligungen für die Abteilung für Angewandte Elektrizität des Physikalischen Instituts bzw. das Institut für Angewandte Elektrizität.

UAG.Kur.1470: Besetzung und Verwaltung der Assistentenstellen des Geophysikalischen Instituts.

UAG.Kur.1499: Organisation, Verwaltung, Etat und Mittelbewilligungen des Pharmazeutisch-Chemischen Instituts sowie Besetzung und Verwaltung der Assistentenstellen.

UAG.Kur.1505: Errichtung einer Anstalt zur Untersuchung von Nahrungs- und Genussmitteln.

UAG.Kur.1514: Einrichtung einer Photochemischen Abteilung im PhysikalischChemischen Institut sowie Mittelbewilligungen.

UAG.Kur.1516: Etat und Mittelbewilligungen für das Institut für anorganische Chemie bzw. das Institut für Allgemeine Metallkunde.

UAG.Kur.1522: Besetzung und Verwaltung der Assistentenstellen am Mineralogisch-Petrographischen Institut.

UAG.Kur.1538: Besetzung und Verwaltung der Assistentenstellen am Geologisch-Paläontologischen Institut.

UAG.Kur.1551: Besetzung und Verwaltung der Assistentenstellen des Geographischen Seminars.

UAG.Kur.1553: Mittelbewilligungen für Exkursionen des Geographischen Seminars.

UAG.Kur.1564: Etat und Mittelbewilligungen für das Zoologisch-Zootomische Institut und die Ethnographische Sammlung.

UAG.Kur.1579: Etat und Mittelbewilligungen für den Botanischen Garten bzw. die Botanischen Anstalten.

UAG.Kur.1594: Besetzung und Verwaltung der Assistentenstellen beim Pflanzenphysiologischen Institut.

UAG.Kur.1656: Versuchsgut und Tierzuchtinstitut.

UAG.Kur.1679: Finanzierung des Agrikulturchemischen Instituts.

UAG.Kur.2262: Einführung von Zwischensemestern für Kriegsteilnehmer.

UAG.Kur.2408: Planung eines Neubaus für das Mathematische Institut.

UAG.Kur.3247: Abhaltung von Sonderkursen für die aus der Kriegsgefangenschaft heimgekehrten Studenten.

UAG.Kur.3388: Verhältnisse der zum Heeresdienst einberufenen Reichs- und Staatsbeamten. Generalia.

UAG.Kur.3407: Studierende; Ausschüsse.

UAG.Kur.3439: Verhältnisse der zum Heeresdienst einberufenen Reichs- und Staatsbeamten. Specialia. 
UAG.Kur.3441-3448: Mobilmachung und Krieg 1914.

UAG.Kur.3452: Vaterländischer Kriegshilfsdienst.

UAG.Kur.3569: Gründung eines Vereins für Luftschifffahrt in Göttingen.

UAG.Kur.4090: Vorlesungsverzeichnisse. Verzeichnisse der angekündigten Vorlesungen nebst Angaben der Zuhörerzahl; Bd. II: 1908-1919.

UAG.Kur.4092-4093: Beurlaubung jüdischer Professoren.

UAG.Kur.4095: Professoren: Bereitstellen von Gehaltsteilen für vaterländische Zwecke.

UAG.Kur.4101: Erfassung der promovierten Ausländer.

UAG.Kur.4117: Berichterstattung über die abgeschlossenen Promotionen.

UAG.Kur.5537: Besetzung und Verwaltung der Assistentenstellen am Allgemeinen Chemischen Laboratorium.

UAG.Kur.5538: Besetzung und Verwaltung der Assistentenstellen am Allgemeinen Chemischen Laboratorium.

UAG.Kur.5544: Etat und Mittelbewilligungen für das Chemische Institut (Allgemeines Chemisches Laboratorium).

UAG.Kur.5999-6000: Prof. Dr. Hermann Theodor Simon.

UAG.Kur.6019: O. Prof. Dr. Ehrenberg.

UAG.Kur.6263: Prof. Dr. Wolkenhauer.

UAG.Kur.6279: Prof. Dr. Bestelmeyer.

UAG.Kur.6290: Prof. Dr. Siegfried Simon.

UAG.Kur.6299: Dr. Joh. Sielisch.

UAG.Kur.6305: Priv.-Doz. Dr. Wedekind.

UAG.Kur.6307: Prof. Freudenberg.

UAG.Kur.6317: Prof. Dr. Frh. Rausch von Traubenberg.

UAG.Kur.6320: Prof. Dr. Madelung.

UAG.Kur.6323: Dr. Behrens.

UAG.Kur.6329: Dr. Henseler.

UAG.Kur.6330: Dr. Gerlach.

UAG.Kur.6333: Dr. Sagawe.

UAG.Kur.7331: Besetzung und Verwaltung der Assistentenstellen an der Sternwarte.

UAG.Kur.7459-7460: Besetzung und Verwaltung der Assistentenstellen der Abteilung für Geophysik (Geophysikalisches Institut).

UAG.Kur.7464: Etat und Mittelbewilligungen für das physikalische Institut.

UAG.Kur.7465: Organisation und Finanzierung der Modellversuchsanstalt für Aerodynamik. 
UAG.Kur.7466: Besetzung und Verwaltung der Assistentenstellen der Abteilung für Experimentelle Physik sowie des Instituts für Angewandte Elektrizität am Physikalischen Institut.

UAG.Kur.7467: Besetzung und Verwaltung der Assistentenstellen der Abteilung für Experimentelle Physik sowie des Instituts für Angewandte Elektrizität am Physikalischen Institut.

UAG.Kur.7469: Etat und Mittelbewilligungen für die Abteilung für Experimentalphysik des Physikalischen Instituts.

UAG.Kur.7470: Angliederung der Radioelektrischen Versuchsanstalt für Marine und Heer an die Abteilung für Angewandte Elektrizität und ihr Betrieb.

UAG.Kur.7471: Besetzung und Verwaltung der Assistentenstellen der Abteilung für Mathematische (bzw. Theoretische) Physik am Physikalischen Institut.

UAG.Kur.7472: Etat und Mittelbewilligungen für die Abteilung für Geophysik des Physikalischen Instituts bzw. das Institut für Geophysik.

UAG.Kur.7515: Etat und Mittelbewilligungen für das MineralogischPetrographische Institut.

UAG.Kur.7554: Besetzung und Verwaltung der Assistentenstellen am Mathematischen Institut (Sammlung mathematischer Instrumente und Modelle).

UAG.Kur.7555: Besetzung und Verwaltung der Assistentenstellen am Mathematisch-Physikalischen Seminar bzw. des Mathematischen Instituts.

UAG.Kur.7578: Errichtung und Betrieb des Physikalisch-Chemischen Instituts sowie Mittelbewilligungen.

UAG.Kur.7581: Besetzung und Verwaltung der Assistentenstelle am Institut für Anorganische Chemie.

UAG.Kur.7651: Besetzung und Verwaltung der Assistentenstellen des Geologisch-Paläontologischen Instituts.

UAG.Kur.7653: Etat und Mittelbewilligungen für das GeologischPaläontologische Institut.

UAG.Kur.7659: Etat und Mittelbewilligungen für das Geographische Seminar.

UAG.Kur.7679: Besetzung und Verwaltung der Assistentenstelle am Botanischen Garten.

UAG.Kur.7749: Etat und Mittelbewilligungen für das Versuchsfeld des Landwirtschaftlichen Instituts.

UAG.Kur.7750: Etat und Mittelbewilligungen für das Versuchsfeld des Landwirtschaftlichen Instituts.

UAG.Kur.7756: Etat und Mittelbewilligungen für das Landwirtschaftliche Institut.

UAG.Kur.7757: Etat und Mittelbewilligungen für das Landwirtschaftliche Institut.

UAG.Kur.7758: Besetzung und Verwaltung der Assistentenstelle am Agrikulturchemischen Institut. 
UAG.Kur.7761: Besetzung und Verwaltung der Assistentenstellen am Allgemeinen Chemischen Laboratorium.

UAG.Kur.9689: Errichtung eines Forschungsinstituts für Aerodynamik und Hydrodynamik.

UAG.Kur.9824: Bewilligungen pp.

Bestand Kuratorium Personalakten (Kur.PA.)

UAG.Kur.PA.Courant, Richard: Personalakte Prof. Dr. Richard Courant.

UAG.Kur.PA.Hertz, Paul: Personalakte Prof. Dr. Paul Hertz.

UAG.Kur.PA.Kötz, Arthur: Personalakte Prof. Dr. Arthur Kötz.

UAG.Kur.PA.Peter, Albert: Personalakte Prof. Dr. Albert Peter.

UAG.Kur.PA.Pohl, Robert: Personalakte Prof. Dr. Robert Pohl.

UAG.Kur.PA.Prandtl, Ludwig: Personalakte Prof. Dr. Ludwig Prandtl.

UAG.Kur.PA.Reich, Max: Personalakte Prof. Dr. Max Reich.

UAG.Kur.PA.Salfeld, Hans: Personalakte Priv.-Doz. Dr. Hans Salfeld.

UAG.Kur.PA.Stille, Hans: Personalakte Prof. Dr. Hans Stille.

Bestand Sekretariat (Sek.)

UAG.Sek.21.1: Förderung der Flugwissenschaft.

UAG.Sek.38.1: Krieg 1914.

UAG.Sek.38.2: Krieg 1914/18. Ruhr, Oberschlesien u.s.w.

UAG.Sek.38.3: Vaterländischer Hilfsdienst.

UAG.Sek.38.4: Bekanntmachungen des Generalkommandos btr. Materialien.

UAG.Sek.38.5: Krieg, Revolution, Aufrufe btr. Freicorps u.s.w.

UAG.Sek.38.6: Kriegsnachrichten, Sammelstelle.

UAG.Sek.38.8: Herstellung einer Weihnachtsgabe für die Angehörigen der Universität im Felde.

UAG.Sek.39.5: Bekanntmachungen von Tübingen, Theodor Simon 1917.

UAG.Sek.411.4: Einrichtung von Zwischensemestern für Kriegsteilnehmer.

UAG.Sek.412.g.3: Ergänzungskurse für Kriegsteilnehmer.

UAG.Sek.412.h: Ergänzungskurse für Kriegsteilnehmer.

UAG.Sek.412.i: Studium kriegsgefangener Studenten in der Schweiz.

UAG.Sek.543.3: Neubauten der Universität und Erweiterungsbauten.

UAG.Sek.558.6: Studium der Ausländer. Generalia.

UAG.Sek.598.8: Disziplin-Bestrafungen. Rechtspflege-Ausschuss.

UAG.Sek.683: Nachrichten über die studentischen Corps während des Ersten Weltkrieges. 
UAG.Sek.691: Verzeichnis der Chargierten und Einzelmitglieder der Studentenverbindungen.

Bestand Philosophische Fakultät (Phil.Fak.)

UAG.Phil.Fak.II.1c: Decanats-Berichte 1904-1922.

UAG.Phil.Fak.II.33.b: Ergänzungs- und Ferienkurse.

UAG.Phil.Fak.II.36.c: Docenten-Generalia Iib 1913-1917.

UAG.Phil.Fak.II.96: Betrifft den 1. Weltkrieg.

UAG.Phil.Fak.II.Prom.Spec.: [Diverse Promotionsvorgänge].

UAG.Phil.Fak.III.34: Promotionsbuch der historisch-philologischen Abteilung bzw. der Philosophischen Fakultät von 1.7.1910 bis 1933.

UAG.Phil.Fak.III.Protokollbuch Senat-Konzil 1912-1933: Protokollbuch SenatKonzil 1912-1933.

UAG.Phil.Fak.Prom.E.II.7: Promotionsvorgang Gerhard Engel.

UAG.Phil.PA.Nelson: Personalakte Dr. Leonard Nelson.

Bestand Mathematisch-Naturwissenschaftliche Fakultät (Math.Nat.)

UAG.Math.Nat.Prüf.Pers.Nöther: Personalakte Dr. Emmy Nöther.

Handschriftenabteilung der Niedersächsischen Staats- und

Universitätsbibliothek Göttingen (SUB.Gött.HSD.)

SUB.Gött.HSD.Cod.Ms.E.Ehlers.114: Karl Berger (Schüler Ehlers, Landesschulinspektor) (Ostfront im Ersten Weltkrieg) an Ernst Ehlers.

SUB.Gött.HSD.Cod.Ms.E.Ehlers.137: Richard Bielert (Schüler von Ehlers) (Magdeburg/Westfront im Ersten Weltkrieg) an Ernst Ehlers.

SUB.Gött.HSD.Cod.Ms.E.Ehlers.373: Domeier (Schüler von Ehlers) (Feldpost im Ersten Weltkrieg) an Ernst Ehlers.

SUB.Gött.HSD.Cod.Ms.E.Ehlers.392: Hans Duncker (Bad Lobenstein/ Bremen/Westfront im Ersten Weltkrieg) an Ernst Ehlers.

SUB.Gött.HSD.Cod.Ms.J.Hartmann.32: Anstellung von Assistenten an der Sternwarte Göttingen.

SUB.Gött.HSD.Cod.Ms.D.Hilbert.144: Ernst Hellinger (Mathematiker) [Westfront im Ersten Weltkrieg] an David Hilbert.

SUB.Gött.HSD.Cod.Ms.D.Hilbert.195: Maximilian Krafft (Mathematiker) [Westfront im Ersten Weltkrieg] an David Hilbert.

SUB.Gött.HSD.Cod.Ms.D.Hilbert.207: Alfred Landé (Theoretische Physik) (Ostfront im Ersten Weltkrieg/Ohio) an David Hilbert. 
SUB.Gött.HSD.Cod.Ms.D.Hilbert.406: William Threlfall (Schüler Hilberts) und dessen Mutter Helene Threlfall (Dresden/Rudka) an David Hilbert.

SUB.Gött.HSD.Cod.Ms.D.Hilbert.438: Adolf Windaus (Chemiker, 1876-1959) (Göttingen) an David Hilbert.

SUB.Gött.HSD.Cod.Ms.D.Hilbert.457 Nr.13: David Hilbert an Carl Runge (Mathematiker, 1856-1927) (Göttingen).

SUB.Gött.HSD.Cod.Ms.F.Klein.1.A.1-5: Tätigkeit von Felix Klein als Mitglied des Preußischen Herrenhauses.

SUB.Gött.HSD.Cod.Ms.F.Klein.3.A: Wiederanknüpfung an internationale Wissenschaftsbeziehungen nach dem Ersten Weltkrieg.

SUB.Gött.HSD.Cod.Ms.F.Klein.3.I: Zusammenarbeit mit Henry T. Von Böttinger für die Göttinger Vereinigung zur Förderung der Angewandten Physik und Mathematik.

SUB.Gött.HSD.Cod.Ms.F.Klein.8.75-76: Wilhelm Behrens (Munsterlager/ Ostfront im Ersten Weltkrieg) an Felix Klein.

SUB.Gött.HSD.Cod.Ms.F.Klein.8.206: Karl Brandi (Frontstellung im Ersten Weltkrieg) an Felix Klein.

SUB.Gött.HSD.Cod.Ms.K.Schwarzschild.22: Teilnahme Schwarzschilds am Ersten Weltkrieg.

Historisches Archiv der Deutschen Forschungsanstalt für

Luft- und Raumfahrt Göttingen (DLR.GOAR.)

DLR.GOAR.2623: Gründung und Entwicklung der Aerodynamischen Versuchsanstalt und des Instituts für Angewandte Mechanik.

DLR.GOAR.2633: Planung des Neubaus der Modellversuchsanstalt.

DLR.GOAR.106: Korrespondenz der Aerodynamischen Versuchsanstalt mit verschiedenen Auftraggebern.

DLR.GOAR.1239: Untersuchungsberichte der Modellversuchsanstalt für verschiedene Auftraggeber.

DLR.GOAR.1298: Korrespondenz der Aerodynamischen Modellversuchsanstalt mit verschiedenen Firmen zur Erlangung von Friedensaufträgen nach dm Waffenstillstand von 1918.

DLR.GOAR.1353: Korrespondenz der Aerodynamischen Versuchsanstalt mit der Flugzeugmeisterei Berlin-Adlershof zur Ausführung von Modellversuchen.

DLR.GOAR.1356: Zeugnisse und Stellenausschreibungen für studentische Mitarbeiter der Aerodynamischen Versuchsanstalt. 
DLR.GOAR.1359: Personalangelegenheiten der Aerodynamischen Versuchsanstalt.

DLR.GOAR.1360: Beantwortung von wissenschaftlichen und personellen Anfragen durch die Aerodynamische Versuchsanstalt.

DLR.GOAR.2632: Planung des Instituts für Aero- und Hydrodynamik in Göttingen.

DLR.GOAR.2634: Errichtung des Neubaus der Modellversuchsanstalt.

DLR.GOAR.2635: Errichtung des Neubaus der Modellversuchsanstalt.

DLR.GOAR.2636: Freistellung des Personals der Aerodynamischen Versuchsanstalt.

DLR.GOAR.2637: Finanzierung und Verwaltung der Aerodynamischen Versuchsanstalt.

DLR.GOAR.2639: Neubau und Verwaltung der Aerodynamischen Versuchsanstalt.

DLR.GOAR.2641: Freistellung des Personals der Aerodynamischen Versuchsanstalt.

DLR.GOAR.2647: Korrespondenz der Aerodynamischen Versuchsanstalt (Ludwig Prandtl) mit verschiedenen Behörden, Firmen und Privatpersonen A-M (1917-1918)

DLR.GOAR.2654.1-2: Korrespondenz der Aerodynamischen Versuchsanstalt (Ludwig Prandtl) mit A. Beldimann, Staatssekretär des Reichsmarineamts und anderen Behörden, Firmen und Wissenschaftlern.

DLR.GOAR.2661: Gründung der Modellversuchsanstalt in Göttingen.

DLR.GOAR.3664: Korrespondenz von Ludwig Prandtl mit verschiedenen Wissenschaftlern.

Stadtarchiv Göttingen (St.A.Gö.)

Kriegsgefangenenlager (KGL)

St.A.Gö.KGL43 Nr.40: Vlamenschule und akademische Kurse.

St.A.Gö.KGL44 Nr.41: Studien-Baracke - Wissenschaftliche Arbeiten.

Polizei Direktion (Pol.Dir.)

St.A.Gö.Pol.Dir.31a,6: Landesverräterische Umtriebe von ausländischen Personen.

St.A.Gö.Pol.Dir.159,3: Spionageverdächtige Personen, Pazifisten usw.

St.A.Gö.Pol.Dir.163,3: Verhängung geheimer Postkontrolle und Auskunft über Personen.

St.A.Gö.Pol.Dir.164,1: Mobilmachung Spec. 
St.A.Gö.Pol.Dir.164,3: Mobilmachung Spec.

St.A.Gö.Pol.Dir.164,4: Briefsperre Gen.

St.A.Gö.Pol.Dir.164,5: Anmeldung der Militärpersonen.

St.A.Gö.Pol.Dir.164,6: Bürgerwehr.

St.A.Gö.Pol.Dir.164,7: Vorgänge betreffend den Zivilschutz und Einrichtung einer Bürgerwehr.

St.A.Gö.Pol.Dir.164,8: Überwachung der Presse.

St.A.Gö.Pol.Dir.164,19: Verkauf von Schriften und Veranstaltung von Sammlungen.

St.A.Gö.Pol.Dir.164,20: Kriegswohlfahrtspflege.

St.A.Gö.Pol.Dir.165,1: Ausländer.

St.A.Gö.Pol.Dir.165,2: Die in Schutzhaft genommenen Japaner.

St.A.Gö.Pol.Dir.165,3: Kriegsgefangenenlager.

\section{Gedruckte Quellen}

o.N.: Academische Mobilmachung. Göttingen. In: Burschenschaftliche Blätter, Nr. 10 vom 15.08.1914.

o.N.: Der Krieg. In: Deutsche Korpszeitung (Academische Monatshefte), Nr. 376 vom 15.08.1914.

o.N.: Die Deutsche Burschenschaft im Felde. In: Burschenschaftliche Blätter, Nr. 10 vom 15.08.1914.

o.N.: Brunsviga-Göttingen. In: Burschenschaftliche Blätter, Nr. 1 vom 01.10.1914.

o.N.: Vor und in Namur. In: Burschenschaftliche Blätter, Nr. 1 vom 01.10.1914.

o.N.: Vom belgischen Kriegsschauplatze. In: Burschenschaftliche Blätter, Nr. 1 vom 01.10.1914.

o.N.: Von den Kämpfen in Lothringen. In: Burschenschaftliche Blätter, Nr. 6 vom 15.12.1914.

o.N.: Aus Feldpostbriefen der Normannia-Leipzig. In: Burschenschaftliche Blätter, Nr. 1 vom 01.04.1915.

o.N.: Die Zerschießung der Kathedrale von Ypern. In: Burschenschaftliche Blätter, Nr. 10 vom 15.02.1915.

o.N.: Aus den Feldpostbriefen von Leipziger Normannen. In: Burschenschaftliche Blätter, Nr. 3 vom 01.11.1916.

Bierbaum, Otto Erich: Kriegsrecht im Feindesland. In: Burschenschaftliche Blätter, Nr. 3 vom 01.11.1914.

Doring, Toni: Landwehr. In: Burschenschaftliche Blätter, Nr. 7 vom 01.01.1917. 
Dunkers, Hans: Die Einrichtung von Wiederholungskursen für die studentischen Feldzugsteilnehmer nach dem Kriege. In: Burschenschaftliche Blätter, Nr. 5 vom 01.06.1915.

Gerrath: Die ersten Tage des Waffenstillstands. In: Burschenschaftliche Blätter, Nr. 7 vom 18.01.1918.

Goldmann: Vor dem Sturm. In: Burschenschaftliche Blätter, Nr. 2 vom 01.05.1918.

Königliche Gesellschaft der Wissenschaften zu Göttingen (Hrsg.): Nachrichten von der Königlichen Gesellschaft der Wissenschaften zu Göttingen. Geschäftliche Mitteilungen aus dem Jahre 1919. Berlin 1919.

Riebesell, F.: Die Hochschulbildung der Kriegsteilnehmer. In: Burschenschaftliche Blätter, Nr. 5 vom 01.12.1915.

Runge, Carl: Mathematik und Bildung. Festrede im Namen der Georg-AugustUniversität zur Jahrfeier der Universität am 9. Juni 1915. Göttingen 1915.

Schneider, Paul: Von den Karpathenkämpfen. In: Burschenschaftliche Blätter, Nr. 6 vom 15.06.1915.

Schröder, M.: Im Kampf mit Gestank und Schmutz. In: Burschenschaftliche Blätter, Nr. 6 vom 15.06.1915.

Simon, Hermann Theodor: Leben und Wissenschaft, Wissenschaft und Leben. Rektoratsrede zur Jahresfeier der Georgia Augusta am 26. Juni 1918. Leipzig 1918.

Staatshaushaltsplan [Preußen]: für das Rechnungsjahr. Berlin 1909-1919. (Jeweils im Voraus für ein Rechnungsjahr. 1910 bis 1920.)

Stelzner, Edgar: Das Studium der Kriegsteilnehmer. In: Burschenschaftliche Blätter, Nr. 4 vom 15.05.1917.

Universität Göttingen (Hrsg.): Alt-Göttinger Stammbuch. Die Georgia Augusta ihren Angehörigen im Felde. Weihnachten 1916. Göttingen 1916.

Universität Göttingen (Hrsg.): Amtliches Verzeichnis des Personals und der Studierenden der königl. Georg-August-Universität zu Göttingen. Göttingen 1910 bis 1920. Jeweils für ein Semester. Vom Sommersemester 1910 bis Wintersemester 1919/20.)

Universität Göttingen (Hrsg.): Chronik der Georg-August-Universität für die Rechnungsjahre 1916-1920. (=Sonderabdruck aus den Mitteilungen des Universitätsbundes Göttingen, Jhrg. 4, Heft 2). Göttingen [1921].

Universität Göttingen (Hrsg.): Chronik der Georg-August-Universität zu Göttingen für das Rechnungsjahr. Göttingen 1911 bis 1916. Jeweils für ein Rechnungsjahr. Von 1910 bis 1915.)

Universität Göttingen (Hrsg.): Dem Andenken ihrer im Weltkriege Gefallenen. Gewidmet zum 1. März 1925 von der Georg-August-Universität Göttingen. München 1925. 
Universität Göttingen (Hrsg.): Stimmen aus zwei Jahrhunderten der Georgia Augusta. Weihnachtsgabe 1917 für ihre Angehörigen im Felde. Göttingen 1917.

Universität Göttingen (Hrsg.): Verzeichnis der Vorlesungen auf der GeorgAugust-Universität zu Göttingen. Göttingen 1910 bis 1920. (Jeweils für ein Semester. Vom Sommersemester 1910 bis Wintersemester 1919/20.)

Universität Göttingen (Hrsg.): Weihnachten 1915. Die Georgia Augusta ihren Angehörigen im Felde. Göttingen 1915.

\section{Literaturverzeichnis}

Anderhub, Andreas: Das Antoniterkreuz in Eisen. Zur Geschichte der Universität Gießen während des Ersten Weltkrieges. Gießen 1979.

Ash, Mitchell G.: Wissenschaft - Krieg - Modernität: Einführende Bemerkungen. In: Berichte zur Wissenschaftsgeschichte, 19. Jg. (1996), H. 1, S. 69-75.

Baumgart, Peter (Hrsg.): Bildungspolitik in Preußen zur Zeit des Kaiserreichs. Stuttgart 1980. (= Schriftenreihe, herausgegeben von der Arbeitsgemeinschaft zur Preußischen Geschichte e.V.)

Baumgarten, Marita: Die Geistes- und Naturwissenschaften an der Universität Göttingen 1866-1914: Die Universität unter preußischer Führung. In: Strobel, Karl (Hrsg.): Die deutsche Universität im 20. Jahrhundert: die Entwicklung einer Institution zwischen Tradition, Autonomie, historischen und sozialen Rahmenbedingungen. Beiträge eines universitäts- und bildungsgeschichtlichen Kolloquiums am 15. und 16. Januar 1993 in München. München 1993. (=Abhandlungen zum Studenten- und Hochschulwesen; 5 Veröffentlichungen des Historischen Corpsmuseum München; Bd. 1) S. 30-68.

Baumgarten, Marita: Professoren und Universitäten im 19. Jahrhundert. Zur Sozialgeschichte deutscher Geistes- und Naturwissenschaftler. Göttingen 1997.

Beckett, Ian F. W.: The Great War 1914-1918. Harlow u.a. 2001. (= Modern wars in perspective)

Bessel, Richard: Mobilization and Demobilization in Germany, 1916-1919. In: Horne, John N. (Hrsg.): State, society an mobilization in Europe during the First World War. Cambridge 1997. (=Studies in the social and cultural history of modern warfare; 3) S. 212-222.

Betz, Albert: Geschichte der Aerodynamischen Versuchsanstalt Göttingen e.V. in der Max-Planck-Gesellschaft zur Förderung der Wissenschaften in Göttingen. In: Jahrbuch der Max-Planck Gesellschaft zur Förderung der Wissenschaften e.V. , Jg. 1961, S. 3-15. 
Bias-Engels, Sigrid: Zwischen Wandervogel und Wissenschaft: zur Geschichte von Jugendbewegung und Studentenschaft 1896-1920. Köln 1988. (= Edition Archiv der Deutschen Jugendbewegung; 4)

Bihl, Wolfdieter (Hrsg.): Deutsche Quellen zur Geschichte des Ersten Weltkriegs. Darmstadt 1991.

Bockstaele, Paul: The Mathematical and the Exact Sciences. In: Rüegg, Walter (Hrsg.): A History of the University in Europe. Volume III: Universities in the nineteenth and early twentieth Centuries (1800-1945). Cambridge 2004. S. 493-518.

Böhme, K. (Hrsg.): Aufrufe und Reden deutscher Professoren im Ersten Weltkrieg. Stuttgart 1975.

Bonner, Thomas Neville: American Doctors and German Universities. A Chapter in International Intellectual Relations 1870-1914. Lincoln 1963.

Born, Max: Mein Leben. München 1975.

Bourne, Randolph S. (Hrsg.): War and the intellectuals: essays; 1915-1919. New York 1964 1964. (= Harper Torchbooks; 3043 American Perspectives)

Brandi, Karl: Die Universität im Kriege. In: Saathoff, Albrecht (Hrsg.): Göttinger Kriegsgedenkbuch 1914-1918. Göttingen 1935. S. 145-152.

Brocke, Bernhard vom (Hrsg.): Wissenschaftsgeschichte und Wissenschaftspolitik im Industriezeitalter: Das ,System Althoff in historischer Perspektive. Hildesheim 1991. (= Geschichte von Bildung und Wissenschaft: Reihe B, Sammelwerke; 5. Edition Bildung und Wissenschaft)

Brocke, Bernhard vom: Hochschul- und Wissenschaftspolitik in Preußen und im Deutschen Kaiserreich. 1882-1907: das „System Althoff“ . In: Baumgart, Peter (Hrsg.): Bildungspolitik in Preußen zur Zeit des Kaiserreichs. Stuttgart 1980. (=Schriftenreihe, herausgegeben von der Arbeitsgemeinschaft zur Preußischen Geschichte e.V.) S. 9-118.

Brocke, Bernhard vom: „Wissenschaft und Militarismus“. Der Aufruf der 93 „An die Kulturwelt!“" und der Zusammenbruch der internationalen Gelehrtenwelt im Ersten Weltkrieg. In: Calder, William M. (Hrsg.): Wilamowitz nach 50 Jahren. Festschrift Ulrich von Wilamowitz-Möllendorf. Darmstadt 1985. S. 649719.

Bruch, Rüdiger vom: Die deutsche Hochschule in der historischen Forschung. In: Goldschmidt, Dietrich; Teichler, Ulrich; Webler, Wolff-Dietrich (Hrsg.): Forschungsgegenstand Hochschule. Überblick und Trendbericht. Frankfurt a.M. 1984. (=Campus Forschung Band 403. Schwerpunktreihe Hochschule und Beruf) S. 1-51.

Bruendel, Steffen: Volksgemeinschaft oder Volksstaat: die „Ideen von 1914“ und die Neuordnung Deutschlands im Ersten Weltkrieg. Berlin 2003. 
Burchardt, Lothar: Naturwissenschaftliche Universitätslehrer im Kaiserreich. In: Schwabe, Klaus (Hrsg.): Deutsche Hochschullehrer als Elite: 1815-1945. Boppard am Rhein 1988. (=Deutsche Führungsschichten in der Neuzeit; 17. Büdinger Forschungen zur Sozialgeschichte, 1983) S. 151-214.

Burchardt, Lothar: Die Kaiser-Wilhelm-Gesellschaft im Ersten Weltkrieg (19141918). In: Vierhaus, Rudolf; Brocke, Bernhard vom (Hrsg.): Forschung im Spannungsfeld von Politik und Gesellschaft. Geschichte und Struktur der Kaiser-Wilhelm-/Max-Planck-Gesellschaft. Aus Anlaß ihres 75jährigen Bestehens. Stuttgart 1990. S. 163-196.

Busch, Alexander: Die Geschichte des Privat-Dozenten. Eine soziologische Studie zur großbetrieblichen Entwicklung der deutschen Universitäten. Stuttgart 1959. (= Göttinger Abhandlungen zur Soziologie unter Einschluß ihrer Grenzgebiete; 5)

Calder, William M. (Hrsg.): Wilamowitz nach 50 Jahren. Festschrift Ulrich von Wilamowitz-Möllendorf. Darmstadt 1985.

Charle, Christophe: Patterns. In: Rüegg, Walter (Hrsg.): A History of the University in Europe. Volume III: Universities in the nineteenth and early twentieth Centuries (1800-1945). Cambridge 2004. S. 33-74.

Chickering, Roger: Imperial Germany and the Great War, 1914-1918. Cambridge 1998. (= New Approaches to European History)

Craig, John E.: Higher Education and Social Mobility in Germany. In: Jarausch, Konrad H. (Hrsg.): The Transformation of Higher Learning 1860-1930. Expansion, Diversification, Social Opening, and Professionalization in England, Germany, Russia, and the United States. Stuttgart 1983. S. 219-244.

Crawford, Elisabeth: Internationalism in Science as a casualty of the First World War: Relations between German and allied scientists as reflected in nominations for the Nobel Prizes in physics and chemistry. In: Social Science Information [Great Britain], 27(2). Jg. (1988), S. 163-201.

Deist, Wilhelm: Militär und Innenpolitik im Weltkrieg 1914-1918. Beteiligt: Deist, Wilhelm Matthias, Erich ; Meier-Welcker, Hans ; Bracher, Karl Dietrich Düsseldorf 1970.

Deist, Wilhelm: The German army, the authorian nation-state and total war. In: Horne, John N. (Hrsg.): State, society an mobilization in Europe during the First World War. Cambridge 1997. (=Studies in the social and cultural history of modern warfare; 3) S. 160-172.

Dinghaus, Angela (Hrsg.): Frauenwelten. Biographisch-historische Skizzen aus Niedersachsen. Hildesheim 1993.

Dolderer, Winfried: Deutscher Imperialismus und belgischer Nationalitätenkonflikt. Die Rezeption der Flamenfrage in der deutschen Öffentlichkeit und deutsch-flämische Kontakte 1890-1920. Melsungen 1989. (= Kasseler Forschungen zur Zeitgeschichte; 7) 
Dülffer, Jost: Disposition zum Krieg im wilhelminischen Deutschland. In: Dülffer, Jost; Holl, Karl (Hrsg.): Bereit zum Krieg: Kriegsmentalität im wilhelminischen Deutschland 1890-1914. Beiträge zur historischen Friedensforschung. Göttingen 1986. S. 9-98.

Dülffer, Jost; Holl, Karl (Hrsg.): Bereit zum Krieg: Kriegsmentalität im wilhelminischen Deutschland 1890-1914. Beiträge zur historischen Friedensforschung. Göttingen 1986.

Ebel, Wilhelm: Catalogus Professorum Gottingensium. Göttingen 1962.

Flasch, Kurt: Die geistige Mobilmachung: die deutschen Intellektuellen und der Erste Weltkrieg. Ein Versuch. Berlin 2000.

Franke, Holger: Leonard Nelson. Ein biographischer Beitrag unter besonderer Berücksichtigung seiner rechts- und staatspolitischen Arbeiten. Ammersbek bei Hamburg 1997.

Geinitz, Christian: Kriegsfurcht und Kampfbereitschaft: das Augusterlebnis in Freiburg. Eine Studie zum Kriegsbeginn 1914. Essen 1998. (= Schriften der Bibliothek für Zeitgeschichte; N.F. 7)

Gevers, Lieve; Vos, Louis: Student Movements. In: Rüegg, Walter (Hrsg.): A History of the University in Europe. Volume III: Universities in the nineteenth and early twentieth Centuries (1800-1945). Cambridge 2004. S. 269362.

Geyer, Michael: Deutsche Rüstungspolitik 1860-1980. Frankfurt a.M. 1984.

Goldschmidt, Dietrich; Teichler, Ulrich; Webler, Wolff-Dietrich (Hrsg.): Forschungsgegenstand Hochschule. Überblick und Trendbericht. Frankfurt a.M. 1984. (= Campus Forschung Band 403. Schwerpunktreihe Hochschule und Beruf)

Grüner, Walter: Die Universität Jena während des Weltkrieges und der Revolution bis zum Sommer 1920. Ein Beitrag zur allgemeinen Geschichte der Universität. Jena 1934.

Gundelach, Ernst: Die Verfassung der Göttinger Universität in drei Jahrhunderten. Göttingen 1955.

Gundler, Bettina: Technische Bildung, Hochschule, Staat und Wirtschaft: Entwicklungslinien des Technischen Hochschulwesens 1914-1930. Das Beispiel der TH Braunschweig. Hildesheim 1991. (= Veröffentlichungen der Technischen Universität Carolo-Wilhelmina zu Braunschweig; 3)

Hammerstein, Notker: Epilogue: Universities and War in the twentieth Century. In: Rüegg, Walter (Hrsg.): A History of the University in Europe. Volume III: Universities in the nineteenth and early twentieth Centuries (1800-1945). Cambridge 2004. S. 637-672.

Harrison, Brian (Hrsg.): The History of the University of Oxford. Volume VIII. The Twentieth Century. Oxford 1994. 
Harwood, Jonathan: Mandarine oder Aussenseiter? Selbstverständnis Deutscher Naturwissenschaftler (1900-1933). In: Schriewer, Jürgen; Keiner, Edwin; Charle, Christophe (Hrsg.): Sozialer Raum und akademische Kulturen. Studien zur europäischen Hochschul- und Wissenschaftsgeschichte im 19.und 20. Jahrhundert. Frankfurt u.a. 1993. (=Komparatistische Bibliothek; 3) S. 183-212.

Hentschel, Klaus; Tobies, Renate: Brieftagebuch zwischen Max Planck, Carl Runge, Bernhard Karsten und Adolf Leopold. Berlin 1999. (= Berliner Beiträge zur Naturwissenschaft und der Technik; 24)

Hirschfeld, Gerhard (Hrsg.): „Keiner fühlt sich hier mehr als Mensch ...“: Erlebnis und Wirkung des Ersten Weltkriegs. Essen 1993. (= Schriften der Bibliothek für Zeitgeschichte; N.F. 1)

Hirschfeld, Gerhard (Hrsg.): Kriegserfahrungen. Studien zur Sozial- und Mentalitätsgeschichte des Ersten Weltkriegs. Essen 1997. (= Schriften der Bibliothek für Zeitgeschichte; N.F. 5)

Hirschfeld, Gerhard; Krumeich, Gerd: Die Geschichtsschreibung zum Ersten Weltkrieg. In: Hirschfeld, Gerhard, Krumeich, Gerd, Renz, Irina (Hrsg.): Enzyklopädie Erster Weltkrieg. Paderborn u.a. 2003. S. 304-315.

Hirschfeld, Gerhard, Krumeich, Gerd, Renz, Irina (Hrsg.): Enzyklopädie Erster Weltkrieg. Paderborn u.a. 2003.

Horne, John N. (Hrsg.): State, society an mobilization in Europe during the First World War. Cambridge 1997. (= Studies in the social and cultural history of modern warfare; 3)

Horne, John N.; Kramer, Alan: German atrocities 1914: a history of denial. New Haven u.a. 2001.

Howarth, Janet: Women. In: Harrison, Brian (Hrsg.): The History of the University of Oxford. Volume VIII. The Twentieth Century. Oxford 1994. S. 345375.

Hubatsch, Walter (Hrsg.): Grundriß zur deutschen Verwaltungsgeschichte. 18151945. Reihe A: Preußen. Marburg/Lahn 1978.

Hunger, Ulrich; Wellenreuther, Herrmann (Hrsg.): Spezialinventar zur Geschichte der Mathematik und Naturwissenschaften an der Universität Göttingen von 1880-1933. Ein Führer zu den archivalischen Quellen. Göttingen 2002. (= Schriften des Universitätsarchivs Göttingen Bd. 1)

Hüppauf, Bernd: Schlachtenmythen und die Konstruktion des „Neuen Menschen“. In: Hirschfeld, Gerhard (Hrsg.): „Keiner fühlt sich hier mehr als Mensch ...“: Erlebnis und Wirkung des Ersten Weltkriegs. Essen 1993. (=Schriften der Bibliothek für Zeitgeschichte; N.F. 1) S. 43-84.

Hüppauf, Bernd: Langemarck-Mythos. In: Hirschfeld, Gerhard, Krumeich, Gerd, Renz, Irina (Hrsg.): Enzyklopädie Erster Weltkrieg. Paderborn u.a. 2003. S. 671-672. 
Jansen, Christian: Professoren und Politik. Politisches Denken und Handeln der Heidelberger Hochschullehrer 1914-1935. Göttingen 1992.

Jarausch, Konrad H. (Hrsg.): The Transformation of Higher Learning 1860-1930.

Expansion, Diversification, Social Opening, and Professionalization in England, Germany, Russia, and the United States. Stuttgart 1983.

Jarausch, Konrad H.: Students, Society, and Politics in Imperial Germany. The Rise of Academic Illiberalism. Princeton 1982.

Jarausch, Konrad H.: Higher Education and Social Change: Some Comparative Perspectives. In: Jarausch, Konrad H. (Hrsg.): The Transformation of Higher Learning 1860-1930. Expansion, Diversification, Social Opening, and Professionalization in England, Germany, Russia, and the United States. Stuttgart 1983. S. 9-36.

Jarausch, Konrad H.: Deutsche Studenten. 1800-1970. Frankfurt a.M. 1984. (= Neue Historische Bibliothek, Edition Suhrkamp 1258, Neue Folge 258)

Jarausch, Konrad H.: Graduation and Careers. In: Rüegg, Walter (Hrsg.): A

History of the University in Europe. Volume III: Universities in the nineteenth and early twentieth Centuries (1800-1945). Cambridge 2004. S. 363392.

Jeserich, Kurt G. A.; Pohl, Hans; Unruh, Georg-Christoph von (Hrsg.): Deutsche Verwaltungsgeschichte. Bd. 3: Das Deutsche Reich bis zum Ende der Monarchie. Suttgart 1984.

Klinge, Matti: Teachers. In: Rüegg, Walter (Hrsg.): A History of the University in Europe. Volume III: Universities in the nineteenth and early twentieth Centuries (1800-1945). Cambridge 2004. S. 123-162.

Kocka, Jürgen: Klassengesellschaft im Krieg: deutsche Sozialgeschichte 19141918. Göttingen 1978. (= Kritische Studien zur Geschichtswissenschaft; 8)

Kohnle, Armin; Engehausen, Frank (Hrsg.): Zwischen Wissenschaft und Politik. Studien zur deutschen Universitätsgeschichte. Festschrift für Eike Wolgast zum 65. Geburtstag. Stuttgart 2001.

Kramer, Alan: Franktireur. In: Hirschfeld, Gerhard, Krumeich, Gerd, Renz, Irina (Hrsg.): Enzyklopädie Erster Weltkrieg. Paderborn u.a. 2003. S. 500-501.

Kruse, Wolfgang (Hrsg.): Eine Welt von Feinden: Der Große Krieg 1914-1918. Frankfurt 1997.

Leikola, Anto: Biology and the Earth Sciences. In: Rüegg, Walter (Hrsg.): A History of the University in Europe. Volume III: Universities in the nineteenth and early twentieth Centuries (1800-1945). Cambridge 2004. S. 519542.

Lenoir, Timothy: Politik im Tempel der Wissenschaft. Forschung und Machtausübung im deutschen Kaiserreich. Frankfurt a.M. 1992. (= Edition Pandorra: 2) 
Liermann, Hans: Die Friedrich-Alexander-Universität Erlangen 1910-1920. Neustadt a.d. Aisch 1977. (=Schriften des Zentralinstituts für Fränkische Landeskunde und allgemeine Regionalforschung an der Universität ErlangenNürnberg; 16)

Lipp, Anne: Meinungslenkung im Krieg: Kriegserfahrungen deutscher Soldaten und ihre Deutung 1914-1918. Göttingen 2003. (= Kritische Studien zur Geschichtswissenschaft; 159)

Lundgreen, Peter: Differentiation in German Higher Education. In: Jarausch, Konrad H. (Hrsg.): The Transformation of Higher Learning 1860-1930. Expansion, Diversification, Social Opening, and Professionalization in England, Germany, Russia, and the United States. Stuttgart 1983. S. 149-179.

Mai, Gunther: Das Ende des Kaiserreichs: Politik und Kriegführung im Ersten Weltkrieg. München 1997. (= Deutsche Geschichte der neuesten Zeit vom 19. Jahrhundert bis zur Gegenwart; 10)

Manegold, Karl Heinz: Felix Klein als Wissenschaftsorganisator. Ein Beitrag zum Verhältnis von Naturwissenschaft und Technik im 19. Jahrhundert. In: Technikgeschichte, 35. Jg. (1968), H. 3, S. 177-204.

Manegold, Karl Heinz: Universität, Technische Hochschule und Industrie. Ein Beitrag zur Emanzipation der Technik im 19. Jahrhundert unter besonderer Berücksichtigung der Bestrebungen Felix Kleins. Berlin 1970.

Martinez, Dieter: Der Gaskrieg 1914/18: Entwicklung, Herstellung und Einsatz chemischer Kampfstoffe. Das Zusammenwirken von militärischer Führung, Wissenschaft und Industrie. Bonn 1996.

Maurer, Trude: Der Krieg als Chance? Frauen im Streben nach Gleichberechtigung an deutschen Universitäten 1914-1918. In: Schwinges, Rainer C. (Hrsg.): Jahrbuch für Universitätsgeschichte. Bd. 6 (2003); Universität im Mittelalter. Stuttgart 2003. S. 107-138.

Maurer, Trude: Weder Kombattanten noch Kommilitonen. „Feindliche Ausländer“ in einer deutschen Universitätsstadt während des Ersten Weltkriegs. In: Jahrbuch für Universitätsgeschichte, Jg. 2005, H. 8, S. 211-235.

Mc Clelland, Charles E.: Professionalization and Higher Education in Germany. In: Jarausch, Konrad H. (Hrsg.): The Transformation of Higher Learning 1860-1930. Expansion, Diversification, Social Opening, and Professionalization in England, Germany, Russia, and the United States. Stuttgart 1983. S. 306-320.

Meinhardt, Günther: Die Universität Göttingen. Ihre Entwicklung und Geschichte von 1734-1974. Göttingen 1977.

Messerschmidt, Manfred: Waffenentwicklung - Normsetzungen für den Krieg. In: Berichte zur Wissenschaftsgeschichte, 19. Jg. (1996), H. 1, S. 119-130.

Michalka, Wolfgang (Hrsg.): Der Erste Weltkrieg: Wirkung, Wahrnehmung, Analyse. München 1994. (= Serie Piper; 1927) 
Mirwald, Christa: Ausländer in Göttingen - von 1914 bis heute. Kriegsgefangene des Lagers Ebertal. In: Schmeling, Hans-Georg (Hrsg.): 100 Jahre Göttingen und sein Museum : Texte u. Materialien zur Ausstellung im Städt. Museum u. im Alten Rathaus 1. Oktober 1989 - 7. Januar 1990. Göttingen 1989. S. 88117.

Mommsen, Hans (Hrsg.): Der Erste Weltkrieg und die europäische Nachkriegsordnung: sozialer Wandel und Formveränderung der Politik. Köln u.a. 2000. (= Industrielle Welt; 60)

Mommsen, Wolfgang J. (Hrsg.): Kultur und Krieg: Die Rolle der Intellektuellen, Kuenstler und Schriftsteller im Ersten Weltkrieg. München 1966. (= Schriften des Historischen Kollegs: Kolloquien; 34)

Mommsen, Wolfgang J.: German artists, writers and intellectuals and the meaning of war 1914-1918. In: Horne, John N. (Hrsg.): State, society an mobilization in Europe during the First World War. Cambridge 1997. (=Studies in the social and cultural history of modern warfare; 3) S. 21-38.

Moraw, Peter: Kleine Geschichte der Universität Gießen 1607-1982. Gießen 1982.

Müller, Sven Oliver: Die Nation als Waffe und Vorstellung: Nationalismus in Deutschland und Großbritannien im Ersten Weltkrieg. Göttingen 2002. (= Kritische Studien zur Geschichtswissenschaft; 158)

Neitzel, Sönke: Kriegsausbruch: Deutschlands Weg in die Katastrophe 19001914. München 2002. (= Deutsche Geschichte im 20. Jahrhundert)

Overmans, Rüdiger: Kriegsverluste. In: Hirschfeld, Gerhard, Krumeich, Gerd, Renz, Irina (Hrsg.): Enzyklopädie Erster Weltkrieg. Paderborn u.a. 2003. S. 664-665.

Paine, Norton: Die Siedlung Ebertal. In: Göttinger Jahrbuch, Jg. 1983, H. 31, S. 183-216.

Paletschek, Sylvia: Tübinger Hochschullehrer im Ersten Weltkrieg: Kriegserfahrungen an der „Heimatfront“ Universität und im Feld. In: Hirschfeld, Gerhard (Hrsg.): Kriegserfahrungen. Studien zur Sozial- und Mentalitätsgeschichte des Ersten Weltkriegs. Essen 1997. (=Schriften der Bibliothek für Zeitgeschichte; N.F. 5) S. 83-106.

Paletschek, Sylvia: Die permanente Erfindung einer Tradition. Die Universität Tübingen im Kaiserreich und in der Weimarer Republik. Stuttgart 2001.

Pöhlmann, Markus: Kriegsgeschichte und Geschichtspolitik: der Erste Weltkrieg: die amtliche deutsche Militärgeschichtsschreibung 1914-1956. Paderborn u.a. 2002.

Pöppinghege, Rainer: Das Kriegsgefangenenlager Ebertal als Zentrum flämischer Propaganda im Ersten Weltkrieg. In: Göttinger Jahrbuch, Jg. 2003, H. 51, S. 49-60. 
Raithel, Thomas: Das „Wunder“" der inneren Einheit: Studien zur deutschen und französischen Öffentlichkeit bei Beginn des Ersten Weltkriegs. Bonn 1996. (= Pariser Historische Studien; 45)

Rasch, Manfred: Wissenschaft und Militär. Die Kaiser-Wilhelm-Stiftung für kriegstechnische Wissenschaft. In: Militärgeschichtliche Mitteilungen, Jg. 1991, H. 1, S. 73-120.

Reichert, Folker: Wissenschaft und „Heimatfront“. Heidelberger Hochschullehrer im Ersten Weltkrieg. In: Kohnle, Armin; Engehausen, Frank (Hrsg.): Zwischen Wissenschaft und Politik. Studien zur deutschen Universitätsgeschichte. Festschrift für Eike Wolgast zum 65. Geburtstag. Stuttgart 2001. S. 494-520.

Ringer, Fritz: The decline of the German mandarins: the German academic community 1890-1933. Cambridge 1969.

Ringer, Fritz: Die Gelehrten: der Niedergang der deutschen Mandarine 18901933. Stuttgart 1983.

Ringer, Fritz: Das gesellschaftliche Profil der deutschen Hochschullehrerschaft 1871-1933. In: Schwabe, Klaus (Hrsg.): Deutsche Hochschullehrer als Elite: 1815-1945. Boppard am Rhein 1988. (=Deutsche Führungsschichten in der Neuzeit; 17. Büdinger Forschungen zur Sozialgeschichte, 1983) S. 93-104.

Roland, Alex: Science and War. In: Osiris (Second Series), Jg. 1985, H. 1, S. $247-$ 272.

Rotta, Julius C.: Dokumente zur Geschichte der Aerodynamischen Versuchsanstalt in Göttingen 1907-1925. Köln 1990. (= Mitteilungen der deutschen Forschungsanstalt für Luft- und Raumfahrt; DLR Mitteilungen 90-05)

Rotta, Julius C.: Die Aerodynamische Versuchsanstalt in Göttingen: Ein Werk Ludwig Prandtls. Ihre Geschichte von den Anfängen bis 1925. Göttingen 1990.

Rüegg, Walter (Hrsg.): A History of the University in Europe. Volume III: Universities in the nineteenth and early twentieth Centuries (1800-1945). Cambridge 2004.

Rudy, Willis: Total War and twienth-century higher learning: universities of the western world in the first and second world wars. Rutherford u.a. 1991.

Saathoff, Albrecht (Hrsg.): Göttinger Kriegsgedenkbuch 1914-1918. Göttingen 1935.

Salewski, Michael: Der Erste Weltkrieg. Paderborn 2003.

Schade, Peter: Nachrichtenpolitik und Meinungssteuerung im Kaiserreich: dargestellt an den deutschen Kriegsideologie und Propaganda für die Massen im Ersten Weltkrieg 1914-1918. Hannover, Diss. 1998 Als Manuskript gedruckt.

Schmeling, Hans-Georg (Hrsg.): 100 Jahre Göttingen und sein Museum : Texte u. Materialien zur Ausstellung im Städt. Museum u. im Alten Rathaus 1. Oktober 1989 - 7. Januar 1990. Göttingen 1989. 
Schriewer, Jürgen; Keiner, Edwin; Charle, Christophe (Hrsg.): Sozialer Raum und akademische Kulturen. Studien zur europäischen Hochschul- und Wissenschaftsgeschichte im 19.und 20. Jahrhundert. Frankfurt u.a. 1993. (= Komparatistische Bibliothek; 3)

Schubert-Weller, Christoph: „Kein schönrer Tod ...“: die Militarisierung der männlichen Jugend und ihr Einsatz im Ersten Weltkrieg 1890-1918. Weinheim 1998. (= Materialien zur historischen Jugendforschung)

Schubring, Gert: Mathematik und Naturwissenschaften zwischen SpezialschulStruktur und Forschungs-Imperativ. In: Schwinges, Rainer C. (Hrsg.): Humboldt International. Der Export des deutschen Universitätsmodells im 19. und 20. Jahrhundert. Basel 2001. (=Veröffentlichungen der Gesellschaft für Universitäts- und Wissenschaftsgeschichte; 3) S. 403-443.

Schwabe, Klaus (Hrsg.): Wissenschaft und Kriegsmoral: die deutschen Hochschullehrer und die politischen Grundfragen des 1. Weltkriegs. Göttingen u.a. 1969.

Schwabe, Klaus (Hrsg.): Deutsche Hochschullehrer als Elite: 1815-1945. Boppard am Rhein 1988. (= Deutsche Führungsschichten in der Neuzeit; 17. Büdinger Forschungen zur Sozialgeschichte, 1983)

Schwinges, Rainer C. (Hrsg.): Humboldt International. Der Export des deutschen Universitätsmodells im 19. und 20. Jahrhundert. Basel 2001. (= Veröffentlichungen der Gesellschaft für Universitäts- und Wissenschaftsgeschichte; 3)

Schwinges, Rainer C. (Hrsg.): Jahrbuch für Universitätsgeschichte. Bd. 6 (2003); Universität im Mittelalter. Stuttgart 2003.

Selle, Götz von: Die Georg-August Universität. 1737-1937. Göttingen 1937.

Selle, Götz von: Die Universität Göttingen: Wesen und Geschichte. Göttingen 1953.

Siebe, Daniela: Ausländische Studenten in Gießen (1900-1949). Akzeptanz, Umwerbung und Ausgrenzung. Gießen 2000.

Sieg, Ulrich: Jüdische Intellektuelle im Ersten Weltkrieg: Kriegserfahrungen, weltanschauliche Debatten und kulturelle Neuentwürfe. Berlin 2001.

Ssymank, Paul; Schulze, Friedrich: Das deutsche Studententum von den aeltesten Zeiten bis zur Gegenwart. München 1932.

Stange, Carl: Das Gefangenen-Lager in Göttingen. Göttingen 1916.

Stibbe, Matthew: German anglophobia and the Great War 1914-1918. Cambridge 2001. (= Studies in the social and cultural history of modern warfare; 11) 
Strobel, Karl (Hrsg.): Die deutsche Universität im 20. Jahrhundert: die Entwicklung einer Institution zwischen Tradition, Autonomie, historischen und sozialen Rahmenbedingungen. Beiträge eines universitäts- und bildungsgeschichtlichen Kolloquiums am 15. und 16. Januar 1993 in München. München 1993. (= Abhandlungen zum Studenten- und Hochschulwesen; 5 Veröffentlichungen des Historischen Corpsmuseum München; Bd. 1)

Studier, Manfred: Der Corpsstudent als Idealbild der Wilhelminischen Ära: Untersuchungen zum Zeitgeist 1888 bis 1914. Schernfeld 1990.

Szöllösi-Janze, Margit: Fritz Haber 1868-1934. Eine Biographie. München 1998.

Thadden, Rudolf von; Trittel, Günther (Hrsg.): Göttingen. Geschichte einer Universitätsstadt. Bd. 3. Von der preußischen Mittelstadt zur südniedersächsischen Großstadt 1866-1989. Göttingen 1999.

Thoß, Bruno; Volkmann, Hans-Erich (Hrsg.): Erster Weltkrieg - Zweiter Weltkrieg : ein Vergleich ; Krieg, Kriegserlebnis, Kriegserfahrung in Deutschland / im Auftr. des Militärgeschichtlichen Forschungsamtes. Paderborn u.a. 2002.

Titze, Hartmut: Enrollment Expansion and Academic Overcrowding in Germany. In: Jarausch, Konrad H. (Hrsg.): The Transformation of Higher Learning 1860-1930. Expansion, Diversification, Social Opening, and Professionalization in England, Germany, Russia, and the United States. Stuttgart 1983. S. 57-88.

Tobies, Renate: Felix Klein. Leipzig 1981. (= Biographien hervorragender Naturwissenschaftler, Techniker und Mediziner; 50)

Tobies, Renate: Wissenschaftliche Schwerpunktbildung: Der Ausbau Göttingens zum Zentrum der Mathematik und Naturwissenschaften. In: Brocke, Bernhard vom (Hrsg.): Wissenschaftsgeschichte und Wissenschaftspolitik im Industriezeitalter: Das ,System Althoff in historischer Perspektive. Hildesheim 1991. (=Geschichte von Bildung und Wissenschaft: Reihe B, Sammelwerke; 5. Edition Bildung und Wissenschaft) S. 87-108.

Tollmien, Cordula: Luftfahrtforschung. Die Aerodynamische Versuchsanstalt in Göttingen. In: Tschimer, Martina; Göbel, Heinz-Werner (Hrsg.): Wissenschaft im Krieg - Krieg in der Wissenschaft. Ein Symposium an der PhilippsUniversität Marburg. 50 Jahre nach Beginn des II. Weltkriegs. Marburg 1990. (=Schriftenreihe des Arbeitskreises Marburger Wissenschaftler für Friedens und Abrüstungsforschung (AMW) und der Interdiziplinären Arbeitsgruppe Friedens- und Abrüstungsforschung an der Philipps-Universität Marburg; 15) S. 51-81.

Tollmien, Cordula: ,Sind wir doch der Meinung, daß ein weiblicher Kopf nur ganz ausnahmsweise in der Mathematik schöpferisch sein kann...' Emmy Noether 1882-1935. In: Göttinger Jahrbuch, Jg. 1990, H. 38, S. 153-219. 
Tollmien, Cordula: „Die wissenschaftliche Höhe der deutschen Universitäten würde durch die fortschreitende Verweiblichung zweifellos sinken." Die Mathematikerin Emmy Noether (1882-1935). In: Dinghaus, Angela (Hrsg.): Frauenwelten. Biographisch-historische Skizzen aus Niedersachsen. Hildesheim 1993. S. 268-283.

Tollmien, Cordula: Der „Krieg der Geister“ in der Provinz - das Beispiel der Universität Göttingen 1914-1919. In: Göttinger Jahrbuch, Jg. 1993, H. 41, S. $137-210$.

Tollmien, Cordula: Die Universität Göttingen im Kaiserreich. In: Thadden, Rudolf von; Trittel, Günther (Hrsg.): Göttingen. Geschichte einer Universitätsstadt. Bd. 3. Von der preußischen Mittelstadt zur südniedersächsischen Großstadt 1866-1989. Göttingen 1999. S. 357-393.

Tooley, Hunt: The western front : battle ground and home front in the First World War. Basingstoke u.a. 2003. (= European history in perspective)

Trischler, Helmuth: Luft- und Raumfahrtforschung in Deutschland 1900-1970. Politische Geschichte einer Wissenschaft. Frankfurt a.M. 1992. (= Studien zur Geschichte der deutschen Großforschungseinrichtungen; 4)

Trischler, Helmuth: Die neue Räumlichkeit des Krieges: Wissenschaft und Technik im Ersten Weltkrieg. In: Berichte zur Wissenschaftsgeschichte, 19. Jg. (1996), H. 1, S. 95-104.

Tschimer, Martina; Göbel, Heinz-Werner (Hrsg.): Wissenschaft im Krieg - Krieg in der Wissenschaft. Ein Symposium an der Philipps-Universität Marburg. 50 Jahre nach Beginn des II. Weltkriegs. Marburg 1990. (= Schriftenreihe des Arbeitskreises Marburger Wissenschaftler für Friedens und Abrüstungsforschung (AMW) und der Interdiziplinären Arbeitsgruppe Friedens- und Abrüstungsforschung an der Philipps-Universität Marburg; 15)

Ullmann, Hans-Peter: Kriegswirtschaft. In: Hirschfeld, Gerhard, Krumeich, Gerd, Renz, Irina (Hrsg.): Enzyklopädie Erster Weltkrieg. Paderborn u.a. 2003. S. 220-232.

Ulrich, Bernd: Die Augenzeugen: deutsche Feldpostbriefe in Kriegs- und Nachkriegszeit. Essen 1997. (= Schriften der Bibliothek für Zeitgeschichte; N.F. 8)

Ulrich, Bernd; Vogel, Jakob; Ziemann, Benjamin (Hrsg.): Untertan in Uniform. Militär und Militarismus im Kaiserreich 1871-1914. Quellen und Dokumente. Frankfurt a.M. 2001.

Ulrich, Bernd; Ziemann, Benjamin (Hrsg.): Frontalltag im Ersten Weltkrieg. Wahn und Wirklichkeit. Quellen und Dokumente. Frankfurt a.M. 1994.

Ulrich, Bernd (Hrsg.): Krieg im Frieden: die umkämpfte Erinnerung an den Ersten Weltkrieg; Quellen und Dokumente. Frankfurt a.M. 1997.

Ungern-Sternberg, Jürgen von: Wissenschaftler. In: Hirschfeld, Gerhard, Krumeich, Gerd, Renz, Irina (Hrsg.): Enzyklopädie Erster Weltkrieg. Paderborn u.a. 2003. S. 169-176. 
Ungern-Sternberg, Jürgen von; Ungern-Sternberg, Wolfgang von: Der Aufruf „An die Kulturwelt!“: Das Manifest der 93 und die Anfänge der Kriegspropaganda im Ersten Weltkrieg; mit einer Dokumentation. Stuttgart 1996. (= Historische Mitteilungen: Beiheft 18)

Verhey, Jeffrey: Der „Geist von 1914“ und die Erfindung der Volksgemeinschaft. Aus dem Engl. von Jürgen Bauer. Hamburg 2000.

Vierhaus, Rudolf; Brocke, Bernhard vom (Hrsg.): Forschung im Spannungsfeld von Politik und Gesellschaft. Geschichte und Struktur der Kaiser-Wilhelm/Max-Planck-Gesellschaft. Aus Anlaß ihres 75jährigen Bestehens. Stuttgart 1990.

Weber, Thomas: Studenten. In: Hirschfeld, Gerhard, Krumeich, Gerd, Renz, Irina (Hrsg.): Enzyklopädie Erster Weltkrieg. Paderborn u.a. 2003. S. 910-912.

Welch, David: Germany, propaganda and total war 1914-1918: the sins of omission. London 2000.

Wettmann, Andrea: Heimatfront Universität. Preußische Hochschulpolitik und die Universität Marburg im Ersten Weltkrieg. Köln 2000. (= Abhandlungen zum Studenten- und Hochschulwesen; 9)

Winter, J. M.: Oxford and the First World War. In: Harrison, Brian (Hrsg.): The History of the University of Oxford. Volume VIII. The Twentieth Century. Oxford 1994. S. 3-25.

Wüst, Walter: Sie zähmten den Sturm. Zur Geschichte der AVA, einem Forschungszentrum der Deutschen Forschungsanstalt für Luft- und Raumfart (DLR) in Göttingen. Göttingen 1991. 
$\mathrm{D}$ er Erste Weltkrieg wirkte auf vielen unterschiedlichen Ebenen auf die Institution Universität ein. Mit Beginn des Wintersemesters 1914/15 hatten sich in Göttingen wie an allen europäischen Hochschulen die Hörsäle geleert. Die wenigen Studierenden, die nicht als Kriegsfreiwillige angenommen worden waren, jagten nun gemeinsam mit der Bevölkerung Spione, wozu sie auch ihre ausländischen Kommilitonen zählten.

Die Institute der aufstrebenden naturwissenschaftlichen Fächer mussten mit massiven wirtschaftlichen und personellen Schwierigkeiten kämpfen. Sie konnten keineswegs vom militärischen Interesse an naturwissenschaftlicher Forschung profitieren, da die Militärbehörden sich bewusst nur außeruniversitärer Forschungseinrichtungen, wie der Modellversuchsanstalt Ludwig Prandtls, bedienten.

Göttinger Professoren nahmen am schnell aufflammenden internationalen Propagandakrieg teil. Zeitgleich kam es im Innern der Universität zu mit großem Ernst geführten Auseinandersetzungen. Angesichts dieser Rahmenbedingungen überrascht es, dass es den Professoren der Georgia Augusta weitgehend gelang, das Bild einer funktionierenden Universität zu wahren. 